University of Louisville

ThinkIR: The University of Louisville's Institutional Repository

Electronic Theses and Dissertations

$12-2011$

\title{
Comparative evaluation of conventional soldier pile/lagging retention systems versus soil nailing retention systems.
}

Abdul Amir Al-Helu 1966-

University of Louisville

Follow this and additional works at: https://ir.library.louisville.edu/etd

Part of the Civil and Environmental Engineering Commons

\section{Recommended Citation}

Al-Helu, Abdul Amir 1966-, "Comparative evaluation of conventional soldier pile/lagging retention systems versus soil nailing retention systems." (2011). Electronic Theses and Dissertations. Paper 30.

https://doi.org/10.18297/etd/30

This Doctoral Dissertation is brought to you for free and open access by ThinkIR: The University of Louisville's Institutional Repository. It has been accepted for inclusion in Electronic Theses and Dissertations by an authorized administrator of ThinkIR: The University of Louisville's Institutional Repository. This title appears here courtesy of the author, who has retained all other copyrights. For more information, please contact thinkir@louisville.edu. 


\title{
COMPARATIVE EVALUATION OF CONVENTIONAL SOLDIER PILE/LAGGING RETENTION SYSTEMS VERSUS SOIL NAILING RETENTION SYSTEMS
}

\author{
By \\ Abdul Amir Al-Helu \\ A Dissertation \\ Submitted to the Faculty of the \\ Graduate School of the University of Louisville \\ In Partial Fulfillment of the requirements \\ For the Degree of \\ Doctor of Philosophy \\ Department of \\ Civil and Environmental Engineering \\ University of Louisville \\ Louisville, Kentucky
}

December, 2011 
Copyright 2011 by Abdul Amir Al-Helu

All rights reserved 


\title{
COMPARATIVE EVALUATION OF CONVENTIONAL SOLDIER
}

\section{PILE/LAGGING RETENTION SYSTEMS VERSUS SOIL NAILING RETENTION SYSTEMS}

\author{
By \\ Abdul Amir Al-Helu
}

A Dissertation Approved on

September 28, 2011

By the following Dissertation Committee:

\begin{tabular}{c}
\hline $\begin{array}{c}\text { Dr. D. Joseph Hagerty } \\
\text { Dissertation Director }\end{array}$ \\
\hline Dr. Ibrahim N. Imam \\
\hline Dr. C. Robert Ullrich \\
\hline Dr. James C. Watters
\end{tabular}

Dr. James C. Watters

Dr. Terence Á. Weigel 


\section{DEDICATION}

This dissertation is dedicated to my mother Maliha Al-Helu who passed away before seeing me graduate as she wished. 


\section{ACKNOWLEDGEMENTS}

I would like to thank Dr. Hagerty for his guidance and enthusiasm throughout this study. Thank you to the other members of this committee, Dr. Ullrich, Dr. Weigel, Dr. Watters, and Dr. Imam. Many thanks go to Mr. Richard Chilton who helped me very much to estimate job pricing, including materials and labor costs for both retention methods and for his encouragement to finish the $\mathrm{PhD}$ program.

I would like to thank my family and my brothers for their encouragement. 


\begin{abstract}
COMPARATIVE EVALUATION OF CONVENTIONAL SOLDIER

PILE/LAGGING RETENTION SYSTEMS VERSUS SOIL NAILING

RETENTION SYSTEMS

ABDUL AMIR AL-HELU

$9 / 28 / 2011$
\end{abstract}

An investigation was made into the relative costs of excavation retention by two systems: conventional soldier pile-wale-tieback support, and support by soil nailing. The investigation included design of excavation supports by the two aforementioned systems for fifteen actual excavations, the majority of which were accomplished in the Louisville, Kentucky area. The design was optimized to arrive at minimum cost solutions. In all cases, the soil nailing system was much less costly than the conventional system. Several factors appeared to make soil nailing more economical than conventional retention systems, if deformations and settlement of soil nailing systems can be tolerated: lower cost for construction materials; quicker mobilization of installation equipment; faster construction time; smaller construction space requirements; and less need for heavy equipment. 


\section{TABLE OF CONTENTS}

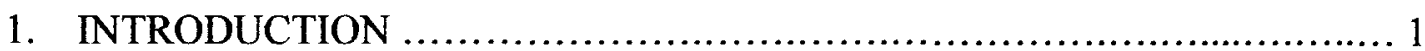

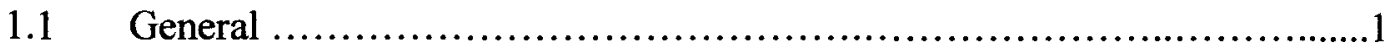

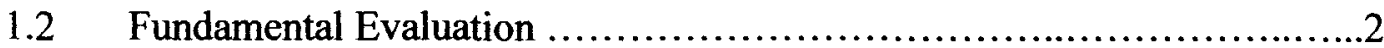

$1.3 \quad$ Conventional Retention Systems.................................... 2

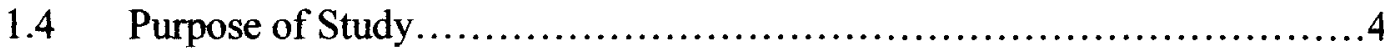

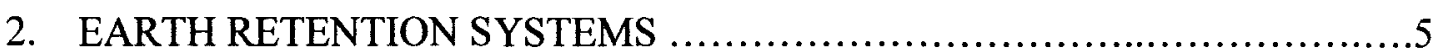

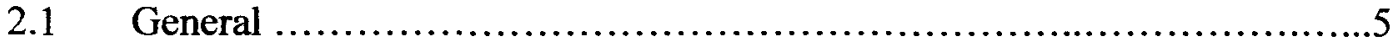

$2.2 \quad$ Soldier Piles and Lagging...............................................6

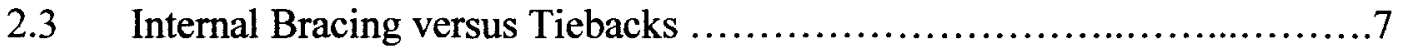

2.4 Conventional Tied Systems versus Soil Nailing ..........................8

2.4.1 Installation of Conventional Systems................................ 10

2.4.2 Installation of Soil Nails ...........................................16

2.4.3 Advantages of Conventional Systems .............................20

2.4.4 Disadvantages of Conventional Systems...............................20

2.4.5 Advantages of Soil Nailing Systems .......................................21

2.4.6 Disadvantages of Soil Nailing Systems...............................22

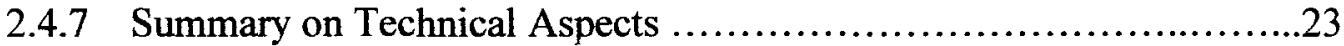

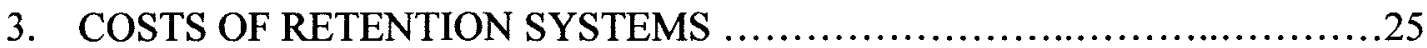

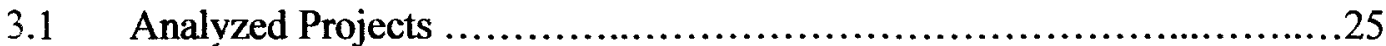




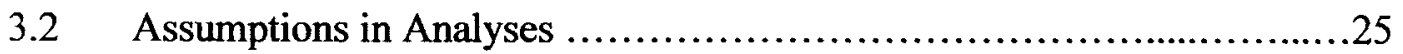

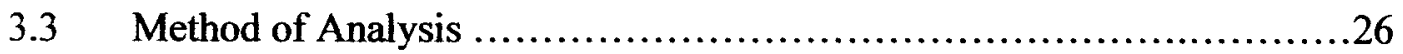

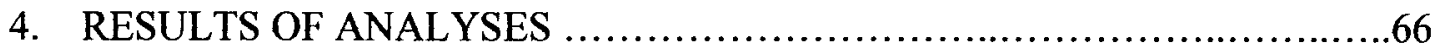

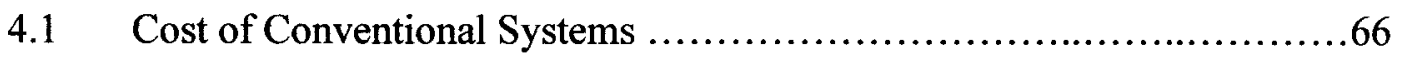

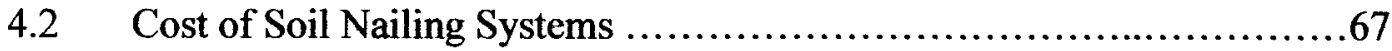

4.3 Factors Causing Differences in Cost ...................................69

4.3.1 Construction Management Approach ................................69

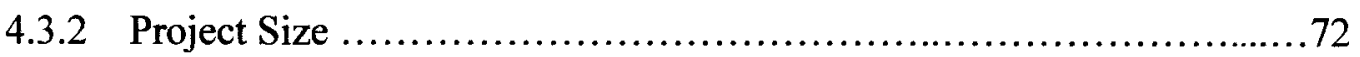

4.3.3 Project Location .................................................. 91

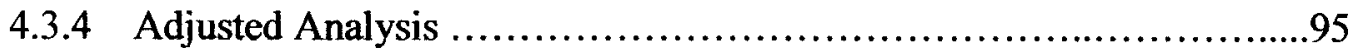

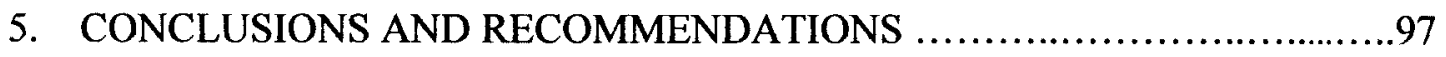

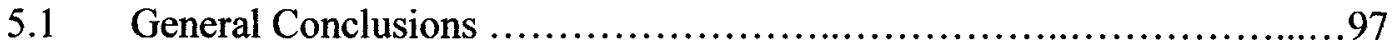

$5.2 \quad$ Factors Affecting Cost..................................................98

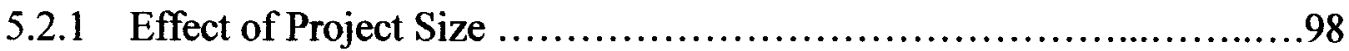

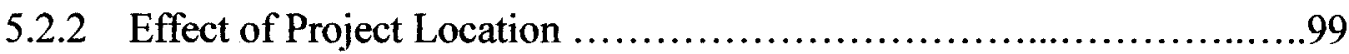

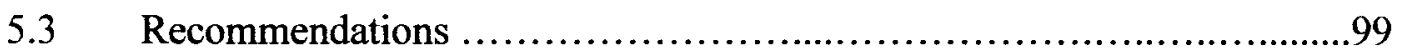

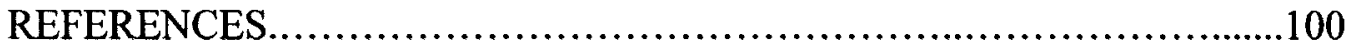

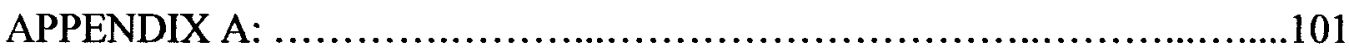

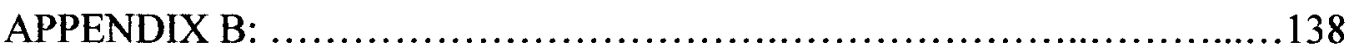

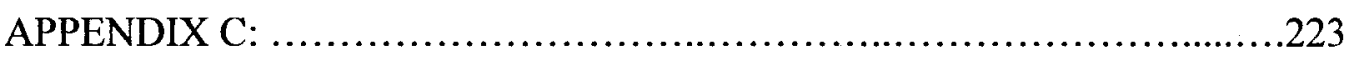

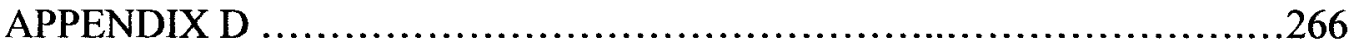

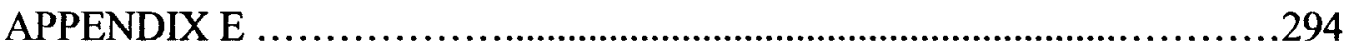

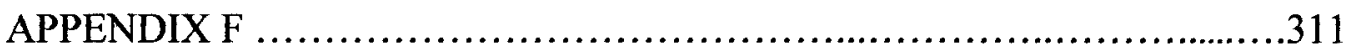

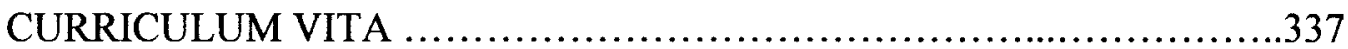

vii 


\section{LIST OF FIGURES}

Figure 1 Typical Wood Lagging Wall....................................12

Figure 2 Tieback through Soldier Pile Detail............................... 13

Figure 3 Tieback with Common Wale Detail............................... 13

Figure 4 Lagging Stud Detail .............................................. 14

Figure 5 Typical Soil Nail Wall Construction Sequence........................18

Figure 6 Tieback Bonded Length and Free Length............................27

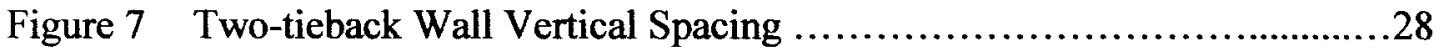

Figure 8 Three-tieback Wall Vertical Spacing .................................29

Figure 9 Four-tieback Wall Vertical Spacing .............................29

Figure 10 Step 1 of Retention System Design Process part A

(all dimensions in feet)............................................. 31

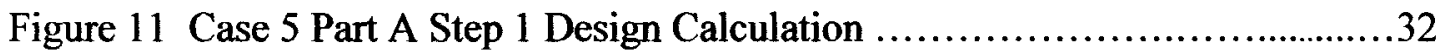

Figure 12 Step 2 of Retention System Design Process part A

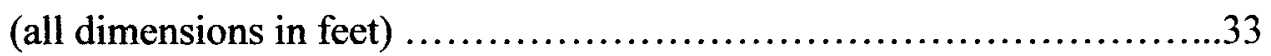

Figure 13 Case 5 part A step 2 design calculation ............................. 34

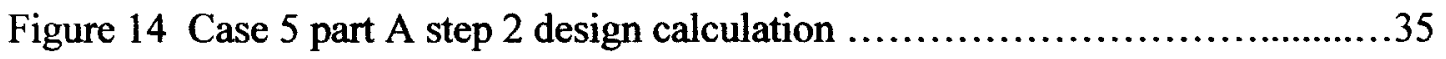

Figure 15 Step 3 of Retention System Design Process part A

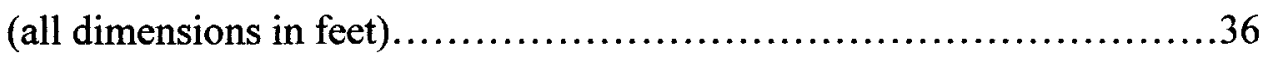

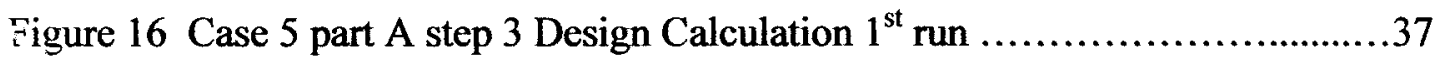


Figure 17 Case 5 part A step 3 Design Calculation $2^{\text {nd }}$ run .38

Figure 18 Step 4 of Retention System Design Process part A

(all dimensions in feet)

Figure 19 Case 5 part A step 4 Design Calculation

Figure 20 Step 1 of Retention System Design Process part B

(all dimensions in feet) 41

Figure 21 Case 5 part B step 1 Design Calculation 42

Figure 22 Step 2 of Retention System Design Process part B

(all dimensions in feet)

Figure 23 Case 5 part B step 2 Design Calculation.............................44

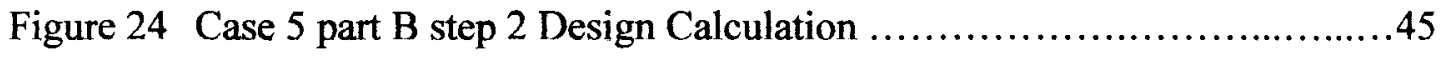

Figure 25 Step 3 Final Stage of Design Process part B (all dimensions in feet).....46

Figure 26 Case 5 part B step 3 Design Calculation ..............................47

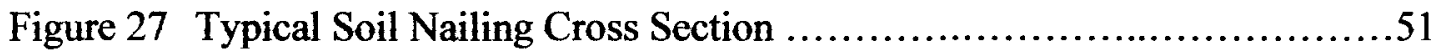

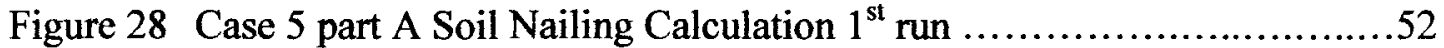

Figure 29 Case 5 part A Soil Nailing Calculation $2^{\text {nd }}$ run.........................54

Figure 30 Case 5 part A Soil Nailing Calculation $3^{\text {rd }}$ run .......................56

Figure 31 Case 5 part A Final Soil Nail Section (all dimensions in feet).............58

Figure 32 Case 5 part B Soil Nailing Calculation ...............................59

Figure 33 Case 5 Part B Final Soil Nail Section (all dimensions in feet)...........61

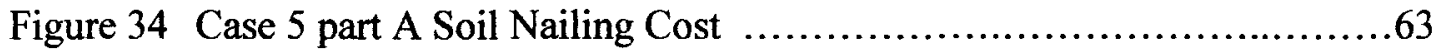

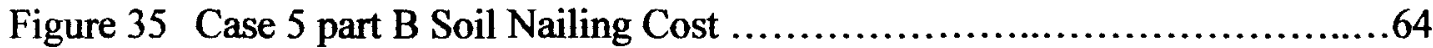

Figure 36 Total Cost Comparison, Conventional and Soil Nailing Systems. ..........68 
Figure 37 Unit Cost Comparison, Conventional Systems and

Soil Nailing Systems ...........................................68

Figure 38 Cost Ratio (Soil Nailing / Conventional)...........................69

Figure 39A Total Cost of Conventional Systems and Soil Nailing Systems versus

Retained Area

Figure 39B Total Cost of Conventional Systems and Soil Nailing Systems versus

Retained Area without case $15(71,820 \mathrm{sq} \mathrm{ft}) \ldots \ldots \ldots \ldots \ldots \ldots \ldots \ldots \ldots . \ldots \ldots$

Figure 40A Unit Cost of Conventional Systems and Soil Nailing Systems versus

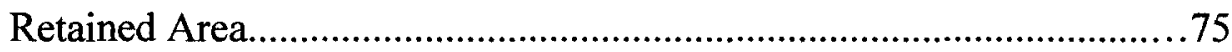

Figure 40B Unit Cost of Conventional Systems and Soil Nailing Systems versus

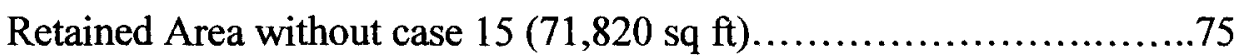

Figure 41A Unit Cost of Steel Pile and Tiebacks versus Retained Area ...............76

Figure 41B Unit Cost of Steel Pile and Tiebacks versus Retained Area without

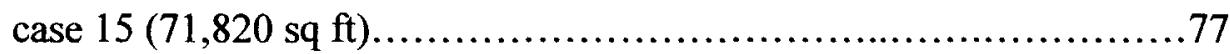

Figure 42A Cost of Nail, Plate, Nut and Shotcrete versus Retained Area .............77

Figure 42B Unit Cost of Nail, Plate, Nut and Shotcrete versus Retained Area

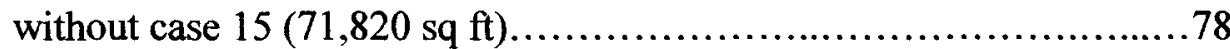

Figure 43A Total Cost of Conventional Systems and Soil Nailing Systems

versus Depth of Cut (depth of retained excavation)...................79

Figure 43B Total Cost of Conventional Systems and Soil Nailing Systems

versus Depth of Cut (depth of retained excavation) without case $15 \ldots . . .80$

Figure 44A Unit Cost of Conventional Systems and Soil Nailing Systems

versus Depth of Cut (depth of retained excavation). 
Figure 44B Unit Cost of Conventional Systems and Soil Nailing Systems versus

Depth of Cut (depth of retained excavation) without case 15................81

Figure 45A Unit Cost of Tiebacks versus Depth of Cut (depth of retained excavation)

Figure 45B Unit Cost of Tiebacks versus Depth of Cut (depth of retained

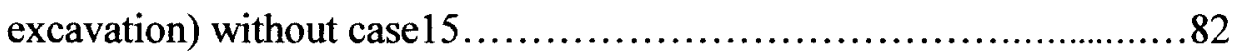

Figure 46 Unit Cost (\$/Linear foot) of Conventional and Soil Nailing versus Depth of Cut (depth of retained excavation) ..............................83

Figure 47 Unit Cost (Case 3) for Each Conventional System Component .............85

Figure 48 (Case 3) Unit Cost for Each Soil Nailing System Component ..............85

Figure 49 Unit Cost (Case 7) for Each Conventional System Component.............86

Figure 50 (Case 7) Unit Cost for Each Soil Nailing System Component ..............86

Figure 51 Unit Cost (Case 13) for Each Conventional System Component............87

Figure 52 (Case 13) Unit Cost for Each Soil Nailing System Component............87

Figure 53 Unit Cost (Case 14) for Each Conventional System Component ..........88

Figure 54 (Case 14) Unit Cost for Each Soil Nailing System Component ............88

Figure 55A Unit Cost of Conventional Systems and Soil Nailing Systems versus

Retained area in Louisville, KY ...................................92

Figure 55B Unit Cost of Conventional Systems and Soil Nailing Systems versus

Retained area in Louisville, KY without case $15(17,820 \mathrm{sq} \mathrm{ft}) \ldots \ldots \ldots \ldots . .92$

Figure 56 Unit Cost of Conventional Systems and Soil Nailing Systems versus Retained area Outside of Louisville, KY .............................93

Figure 57 Total Cost of Conventional System with Location versus Retained

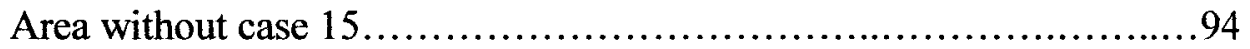


Figure 58 Total Cost of Soil Nailing System with Location versus Retained

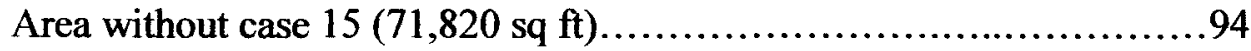

Figure 59 Unit Cost of Conventional System with Location versus Depth of Cut (depth of retained excavation) ..................................95

Figure 60 Unit Cost of Soil Nailing System with Location versus Depth of

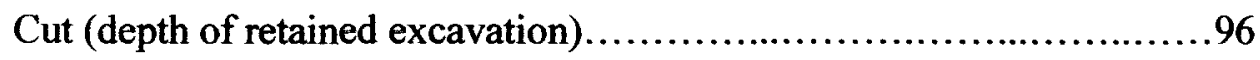




\section{LIST OF TABLES}

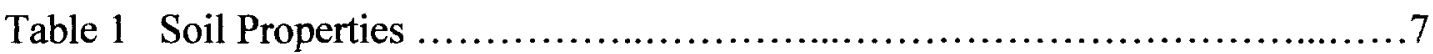

Table 2 Case 5 Conventional System Materials Takeoff ...........................48

Table 3 Case 5 Conventional System Materials and Operation Cost ..................49

Table 4 Case 5 Soil Nailing Materials Takeoff part A and part B..................62

Table 5 Case 5 Soil Nailing Materials takeoff ..................................62

Table 6 Case 5 part A, and part B Soil Nailing Cost ............................65

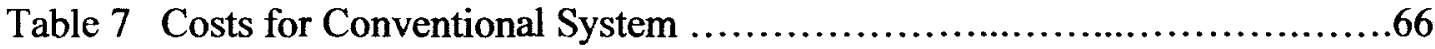

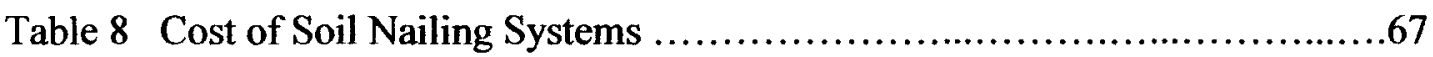

Table 9 Unit Cost $\$ /$ Linear Foot versus Depth of Cut (depth of retained excavation) for Conventional and Soil Nailing ...................................84

Table 10 Conventional System Unit Cost for Components and Operations, $\$ /$ sqft...90

Table 11 Soil Nailing System Unit Cost for Components and Operations, $\$ /$ sqft......91 


\section{LIST OF ILLUSTRATIONS}

Illustration 1 Tieback through Common Wale........................... 14

Illustration 2 Wood Lagging Detail....................................... 15

Illustration 3 Tieback through Steel Pile................................... 15

Illustration 4 New Construction in Excavated Area...........................16 


\section{CHAPTER I}

\section{INTRODUCTION}

\subsection{General}

Deep excavations are becoming increasingly common for the construction of buildings, road tunnels, mass rapid transit systems and other facilities at densely builtup areas within city and suburban areas. Soil or rock excavation can be considered as deep excavation if the excavation is typically more than 14 feet deep. Such works could affect nearby structures and the foundations of those structures because of ground movement associated with stress changes. Deep excavation dictates careful design and planning especially when constructed in urban areas. Retaining and support system selection in deep excavation can have significant impact on time, cost and performance of the completed excavation and construction project. Hence, there is a need for design and execution of cost-effective systems for retention of deep excavations. The Author, in this research, will make a comparison of costs for fifteen cases on the basis of design and installation of a conventional (H-pile and lagging) retention system versus design and installation of a soil nailing system. The hypothesis is that soil nailing is more economical for earth retention in excavations than is conventional H-pile, lagging, wales and tiebacks, for the situations examined in this study. 


\subsection{Fundamental Evaluation}

A consideration of fundamental soil-structure interaction would indicate that the soil nailing system would be cheaper than the conventional retaining system for conditions encountered on typical projects, because the soil nailing system is a passive system that uses the in situ soil as part of the retaining system. The soil is allowed to move sufficiently to mobilize the shearing resistance of the soil mass. Then, the resistance to further movement offered by the soil shear strength combines with the soil nail system support to hold the mass of soil in place. The installed system will start working to hold the soil against further movement using the effects of the nails, shotcrete and wire mesh in conjunction with the soil internal resistance. In contrast, the conventional system is built as an active pressure system with stiff members that push against the retained soil with the effects of the steel soldier piles, tiebacks, and steel wales. The key consideration is that the soil nailing system allows a certain amount of movement of the retained soil mass, and that movement may not be acceptable on some projects. If that movement is not acceptable under project conditions, the conventional system will be required and may be more costly than the soil nailing system. The analysis in the following sections will show a cost comparison for 15 actual projects. First, an explanation of retaining system characteristics is given.

\subsection{Conventional Retention Systems}

The most popular retaining systems for deep excavations can be classified as soldier piles and lagging walls, sheet piling walls, soil mix walls, and diaphragm 
walls. The lateral force members for these retaining systems can be of different types: soil tiebacks; rock anchors; internal struts and braces. All conventional systems have similar characteristics in that they include some sort of vertical membrane (lagging boards between vertical soldier piles, interlocked sheet piles; or overlapping piles or drilled shafts) held in place by components that provide resistance to lateral earthpressure forces (tie-backs drilled into soil behind the membrane; anchors drilled and secured in rock behind and below the membrane, or horizontal struts bearing on horizontal wales arranged to spread load from struts to membrane). In rare circumstances (not to be treated in this research) vertical piles or drilled shafts are embedded below the excavation bottom and extend as cantilevers up to the top of the excavation. In all of these systems, some part of the membrane is installed before excavation is begun. Components used to resist lateral earth-pressure forces are installed soon after the membrane is in place (tie-backs or anchors) or are installed as excavation proceeds (wales and struts). By far the most common retention system is soldier piles with horizontal wooden lagging retained by soil tie backs. Appendix A contains sketches illustrating various conventional retention systems.

In contrast to conventional retention systems, soil nailing involves installation of tensile members into the soil behind the outer edges of an excavation without a membrane that extends from top to bottom of the excavation. Shallow excavations are made, and then tensile members are installed at a shallow angle to the horizontal through the exposed short sides of the excavation. Vertical sheets of drainage fabric are placed against the soil face to provide outlets for any water that would collect under the cover to be placed over the soil face. After the tensile members are in place, 
some sort of reinforcing system is placed over the exposed soil face and a relatively thin coating of gunite or shotcrete is sprayed over the reinforcing bars. Then, a plate is placed over the exposed end of each tensile element, and secured in place with a lock nut threaded on the end of the tensile member. After all the exposed soil is covered in this fashion, the excavation is deepened; the increments of excavation depth are kept uniform from top to bottom of the excavation. Soil nailing thus is a "top down" construction method. Soil nailing has become very popular for retention of deep excavations, and has been claimed to be more economic than conventional retention systems.

\section{$1.4 \quad$ Purpose of study}

The purpose of this study is to make a cost comparison between two retention systems and examine which of these two systems is the more economic; the first system is the most commonly used conventional system, soldier piles (H-pile sections), wood lagging, and tieback anchors. The other system is the soil nailing system, with low-strength steel tendons as tensile anchors, welded wire mesh to act as

reinforcing between tensile members to hold the face of the wall, and shotcrete to cover the face of the wall. 


\section{CHAPTER 2}

\section{EARTH RETENTION SYSTEMS}

\subsection{General}

Excavation with vertical sides requires lateral support, to prevent sidewall collapse and to reduce lateral movement and settlement of the surrounding ground. Retention systems also are evaluated against the tendency for base failure and bottom heave in soft clays.

The settlement and lateral movement depend on

1- Soil properties

2- General procedure of excavation

3- Adequacy of the bracing

4- Workmanship

The settlement near an open cut can be reduced only if the inward movement of the sheeting and the bottom heave can be substantially reduced. Experience shows that using a heavy and stiff section of soldier piles or sheet piles usually is not sufficient to limit lateral movements and settlements (Clough and O'Rourke, 1990). If soil stiffness and strength are low, lateral supports or anchors must be spaced closely to reduce the magnitude of the lateral movement of a wall. In other words, movements can be substantially reduced by installing layers of struts or anchors relatively close in vertical spacing. The most important variable, however, that 
determines the amount of movement is not the stiffness of the wall sections, or the stiffness of the lateral force members, or the vertical spacing of bracing, but the properties of the surrounding soil. The combination of the four parameters listed above has driven practice to the use of soldier pile and lagging systems restrained by soil tie-backs/anchors. Such systems have been chosen for analysis in this research.

In this study, the Author provides an economic comparison between two types of retention systems: soldier pile (H-pile) and wood lagging, restrained by soil anchors (conventional method), versus the soil nailing retention method. The Author studied fifteen cases for which he already had designed a conventional retention system (and that had been installed) and used a present cost analysis to compare costs

for design and construction of those systems, to the costs associated with design and installation of soil nailing systems for those fifteen cases. Soil strata in most of the fifteen cases are layers of sandy clay and sandy silt soils. Soil properties are listed in Table 1 on the next page for each case. For context, the deepest cut in this study was 42 feet.

\subsection{Soldier Piles and Lagging}

The most common system for retaining open excavations in the United States is the use of soldier piles and lagging; the components of such a system include soldier piles, wooden lagging boards, lateral load-spreader beams (wales) and tiebacks. Soldier piles are driven or predrilled at intervals along the edges of the excavation. If a predrilled approach is used, holes are drilled, grout is placed and $\mathrm{H}$ - 
piles are installed in the hole. Soldier piles and wood lagging systems have been used commonly for many years,

Table 1. Soil Properties

\begin{tabular}{|c|c|c|c|c|c|c|c|c|c|c|c|c|c|}
\hline & $\begin{array}{c}\text { 1st } \\
\text { Layer }\end{array}$ & $\begin{array}{c}\text { Soin } \\
\text { unit } \\
\text { weight }\end{array}$ & $\begin{array}{c}\text { Friction } \\
\text { angle }\end{array}$ & Conesion & $\begin{array}{c}\text { 2nd } \\
\text { Layer }\end{array}$ & $\begin{array}{c}\text { Soll } \\
\text { writ } \\
\text { weight }\end{array}$ & $\begin{array}{c}\text { Friction } \\
\text { angle }\end{array}$ & Conesion & $\begin{array}{c}\text { 3rd } \\
\text { Layer }\end{array}$ & $\begin{array}{c}\text { Soil unit } \\
\text { waight }\end{array}$ & $\begin{array}{c}\text { Friction } \\
\text { angle }\end{array}$ & $\begin{array}{c}\text { Depth fo hard } \\
\text { panesion below } \\
\text { excavation } \\
\text { level }\end{array}$ \\
\hline Case 1 & 8.5 & 120 & 25 & 700 & 15 & 125 & 30 & 1500 & & & & & 60 \\
\hline Case 2 & 15 & 110 & 20 & 500 & 20 & 120 & 30 & 1000 & & & & & 50 \\
\hline Case 3 & 20 & 125 & 30 & 550 & & & & & & & & & 35 \\
\hline Case 4 & 8 & 120 & 25 & 650 & 10 & 125 & 30 & 1100 & 25 & 130 & 35 & 1600 & 40 \\
\hline Case 5 & 11.5 & 115 & 30 & 500 & 10 & 120 & 30 & 1000 & 20 & 125 & 25 & 1500 & 35 \\
\hline Case 6 & 11 & 120 & 20 & 600 & 16 & 125 & 25 & 1500 & 18 & 130 & 30 & 1700 & 35 \\
\hline Case 7 & 13 & 110 & 20 & 750 & 20 & 125 & 30 & 1100 & & & & & 12 \\
\hline Case 8 & 15 & 30 & 115 & 800 & 28 & 120 & 28 & 1500 & & & & & 29 \\
\hline Case 9 & 17 & 115 & 28 & 550 & 19 & 130 & 33 & 1200 & & & & & 23 \\
\hline Case 10 & 22 & 120 & 30 & 1000 & 18 & 125 & 33 & 1600 & & & & & 15 \\
\hline Case 11 & 18 & 125 & 30 & 1100 & & & & & & & & & 32 \\
\hline Case 12 & 21 & 120 & 28 & 550 & 25 & 125 & 32 & 1300 & & & & & 24 \\
\hline Case 13 & 15 & 115 & 20 & 1100 & & & & & & & & & 40 \\
\hline Case 14 & 13 & 110 & 28 & 500 & 17 & 120 & 30 & 1100 & & & & & 28 \\
\hline Case 15 & 10 & 110 & 20 & 550 & 13 & 120 & 30 & 1000 & 19 & 125 & 30 & 1500 & 20 \\
\hline
\end{tabular}

thereby providing a vibration-free installation. As the excavation in front of the wall proceeds, wood lagging is installed between the soldier piles in lifts. Tieback anchors are installed and stressed to provide lateral restraint as needed. Some type of lateral load-spreader is used to distribute the concentrated load from the anchor to the soldier piles.

\subsection{Internal Bracing versus Tiebacks}

In the case of internal bracing systems, the lateral earth pressure is transferred between opposing walls through compressive struts. Rakes resting on a foundation mat or rock offer another internal bracing alternative. Usually, the struts are either pipe or I- beam sections and usually are preloaded to provide a very stiff system. 
Installation of the bracing struts is carried out by excavating soil locally around the strut and only continuing the general excavation when preloading is complete. The struts rest on a series of wale beams that distribute the strut load to the wall. Pre-

loading ensures a rigid contact between interacting members and is accomplished by inserting a hydraulic jack on each side of an individual strut between the wale beam and a special jacking plate welded to the strut. Internal bracing makes sense in narrow excavations and in cases where tieback installation is not practicable. The struts can bend excessively under their own weight if the excavation spacing is very large. A clear benefit of using struts is that no openings are required in the wall membrane for tieback installation. In contrast to internally braced systems, using tieback retention systems will give a clear, open excavation that facilitates construction within the retention system. In addition, if any lateral movement occurs in the retained wall, the movement could be eliminated by increasing load in the adjacent tieback.

\subsection{Conventional Tied Systems versus Soil Nailing Systems}

A principal difference between these systems lies in the character of the tensile elements used to resist lateral soil-pressure forces. Soil nails are usually shorter than tie-backs, with much lower design loads than tieback anchors. In length, soil nails usually are between 70 percent and 100 percent of the wall height. Grouted tieback anchors are usually longer than soil nails; tiebacks are usually 100 percent to 125 percent of the wall height in length. Sometimes, tieback anchors are much longer to reach rock or soil with sufficient strength to support the design load. 
Soil nails are usually installed at closer spacing than are tiebacks. Nails may be installed to support an area of approximately 20 to 30 square feet per nail, while tiebacks may be installed to support an area of approximately 120 square feet per tie. Tiebacks are active support members; they push on the retained soil harder than the earth and surcharge pressures would push on the wall. Soil nails are passive support members. They provide their support as the soil mass begins to strain to mobilize resistance to shear. Soil nailing cannot be used in sandy soils or soils that cannot stand in a vertical cut of 4 to 6 feet without support until wire mesh and shotcrete are installed.

Soil nails and tieback anchors typically have similar corrosion protection details. Every tieback anchor is usually proof tested or performance tested. Most soil nails are not tested. Usually a small percentage of the nails are tested or nonproduction nails are tested. Soil nail tendons are usually Grade 60 or 75 thread bar tendons. Tieback tendons are usually either thread bar tendons (Grade 160) or multistrand tendons (Grade 270). A soil nail wall does not have soldier piles (H-piles). Shotcrete and nails are the sole support. There may be a second or permanent facing of shotcrete or even a precast facing attached to the nails. Tied back walls often use soldier beams, lagging, and tiebacks with a precast or cast-in-place concrete permanent facing when required.

Construction experience suggests that soil nail walls become economical when the retained soils have a little cohesion and when it may be expensive to install soldier piles. Uncontrolled ground water can preclude the use of soil nails and 
conventional retaining systems; dewatering may be required to permit use of either of these systems.

\subsubsection{Installation of Conventional Systems}

The membrane components of the conventional system under study in this research are $\mathrm{H}$-piles and wood lagging. The $\mathrm{H}$-pile sections usually are 10BP42 or 12BP53 sections installed at 8 to 10 feet center-to-center around the perimeter of the excavation. The timber lagging is 3-inch-thick to 4 -inch-thick rough-cut boards. Bridging between $\mathrm{H}$-piles and anchors is accomplished with horizontal wales consisting of double C-section channels. A drilled and grouted tieback is the most common anchor. Usually the wood lagging in the upper 8 feet of the retained wall, or down to the first row of tiebacks, will be installed behind the soldier pile flanges to accomplish a fast installation. The lagging at larger depths of the wall will be installed on the front face of the piles by welding studs and plates to the piles to hold the wood lagging. Welding will slow the work in the lower parts of the excavations; therefore, the installation cost of the wood lagging for the upper 8 feet is lower than the cost at lower elevations.

To install the kind of system analyzed in this research, the first thing done is to predrill or drive the steel beam (soldier pile) into the ground on a base line around the excavation perimeter down to the required depth (depth of the excavation plus the required depth below the bottom as needed for stability according to the design calculations). Then the excavation is advanced down to a depth of 4 to 6 feet, or down to the upper tieback elevation, depending on the type of the soil [Can the soil 
maintain a vertical face without support until lagging (wood, steel, concrete, etc,) is installed?]. When excavation level reaches a tieback elevation, the process of tieback installation starts.

The tieback installation starts with drilling a hole 4 inches to 6 inches in diameter at an angle of about 20 to 30 degrees below the horizontal plane as deep as the design requires. The depth of tieback installation depends on the soil (strength) properties, and the design load. Then, a hollow high-tensile-strength threaded steel reinforcing bar (175 ksi) is inserted into the hole and grout is injected through the center of the rebar. The grouted part of the rebar is called the bonded zone and the upper part of the rebar (not grouted) is called a free zone. The bonded zone must be behind the failure zone in the soil to make the system stable. The failure zone is assumed to extend up from the bottom of the H-piles at a steep angle to the horizontal; the angle depends on the shearing resistance of the soil. A stability analysis must be done to ensure that the mass of soil retained by the piles, lagging and tiebacks will not fail along a shearing surface that extends below the bottom of the excavation in a global shear failure.

Depending on the design, a wale(s) may be installed, or the tieback can be installed through the steel $\mathrm{H}$-pile. If a wale design has been used, then a steel wedge will be welded to each steel $\mathrm{H}$-pile at an angle that is the same as the tieback angle. Then, the wale will be mounted on these wedges and the tieback will go through the wale usually between two channel section. The tieback will be secured through a steel plate and held with nuts against the plate that, in turn, bears against the wale. The tieback then is stressed with hydraulic jacks to provide a pre-stressed lateral 
resistance. This sequence is shown in Fig. 1. Also, Fig 2 shows the arrangement for a tieback installed through a steel H-pile. Details of the connections are shown in Fig. 3 and Fig. 4. Each tieback will be proof tested to 120 percent of the design load per the Prestressed Testing Institute recommendations. Illustrations 1 through 4 show typical scenes from a project where a conventional retention system was installed.

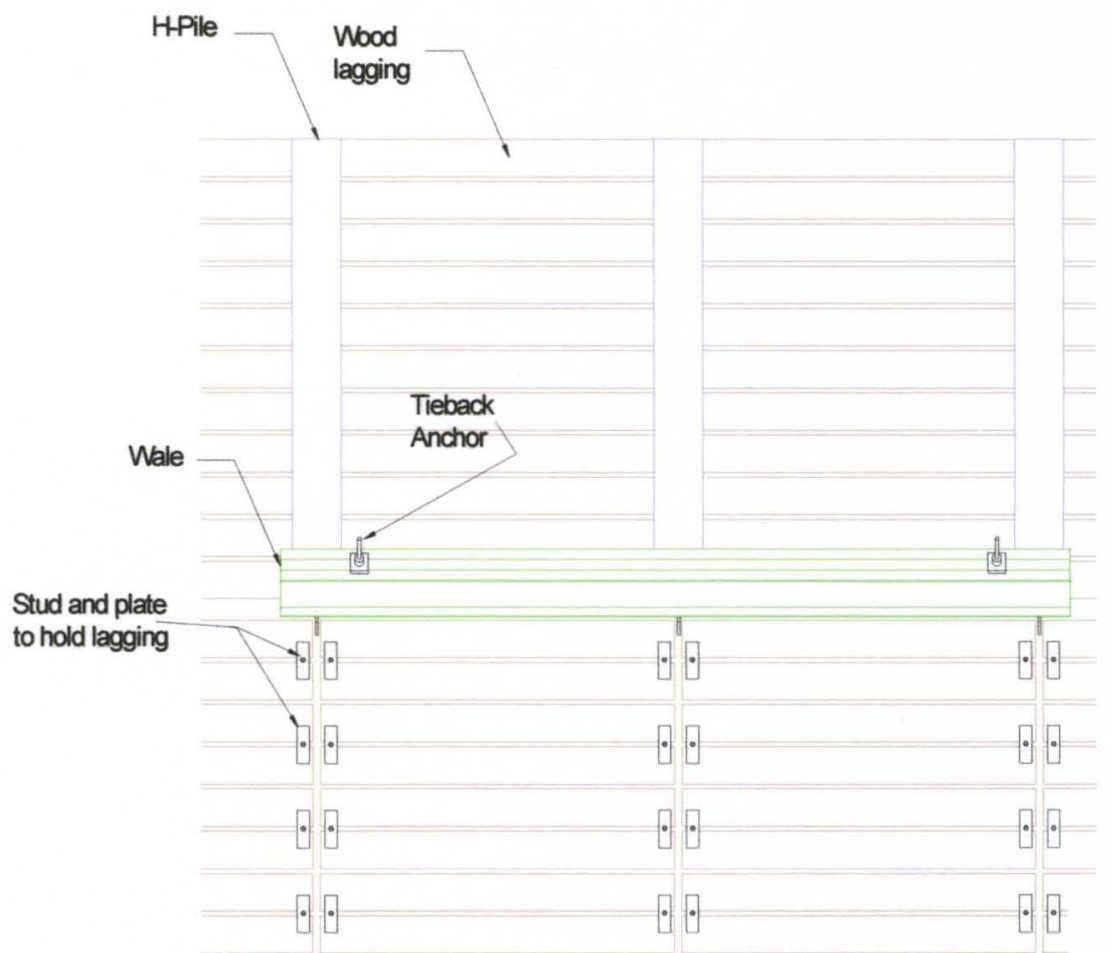

Figure 1. Typical Wood Lagging Wall 


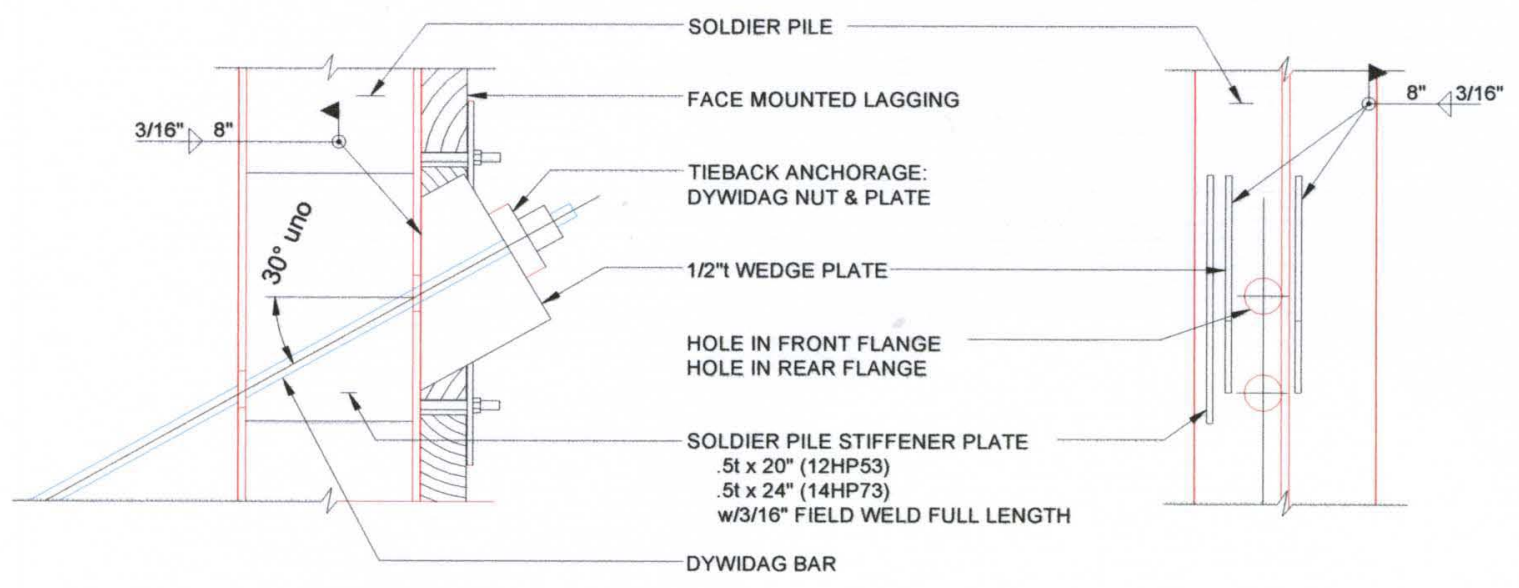

Figure 2. Tieback through Soldier Pile Detail

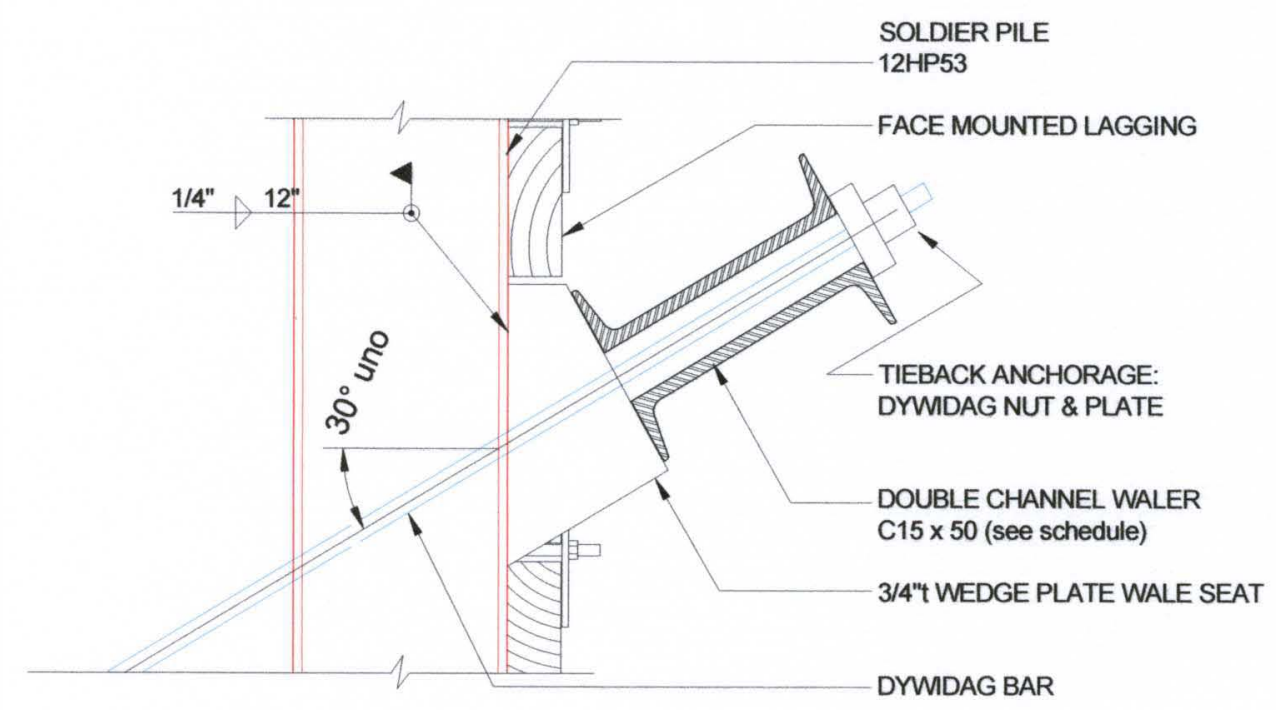

Figure 3. Tieback with Common Wale Detail 


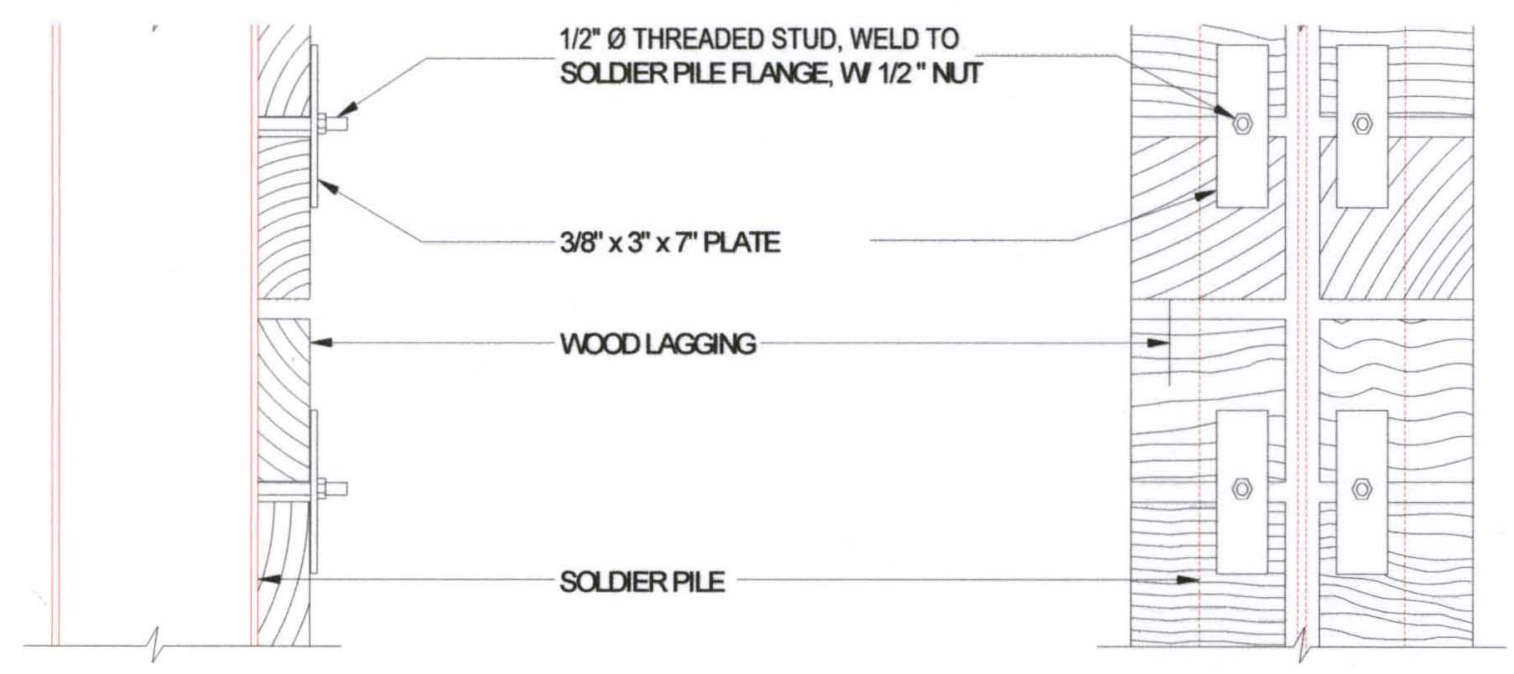

Figure 4. Lagging Stud Detail

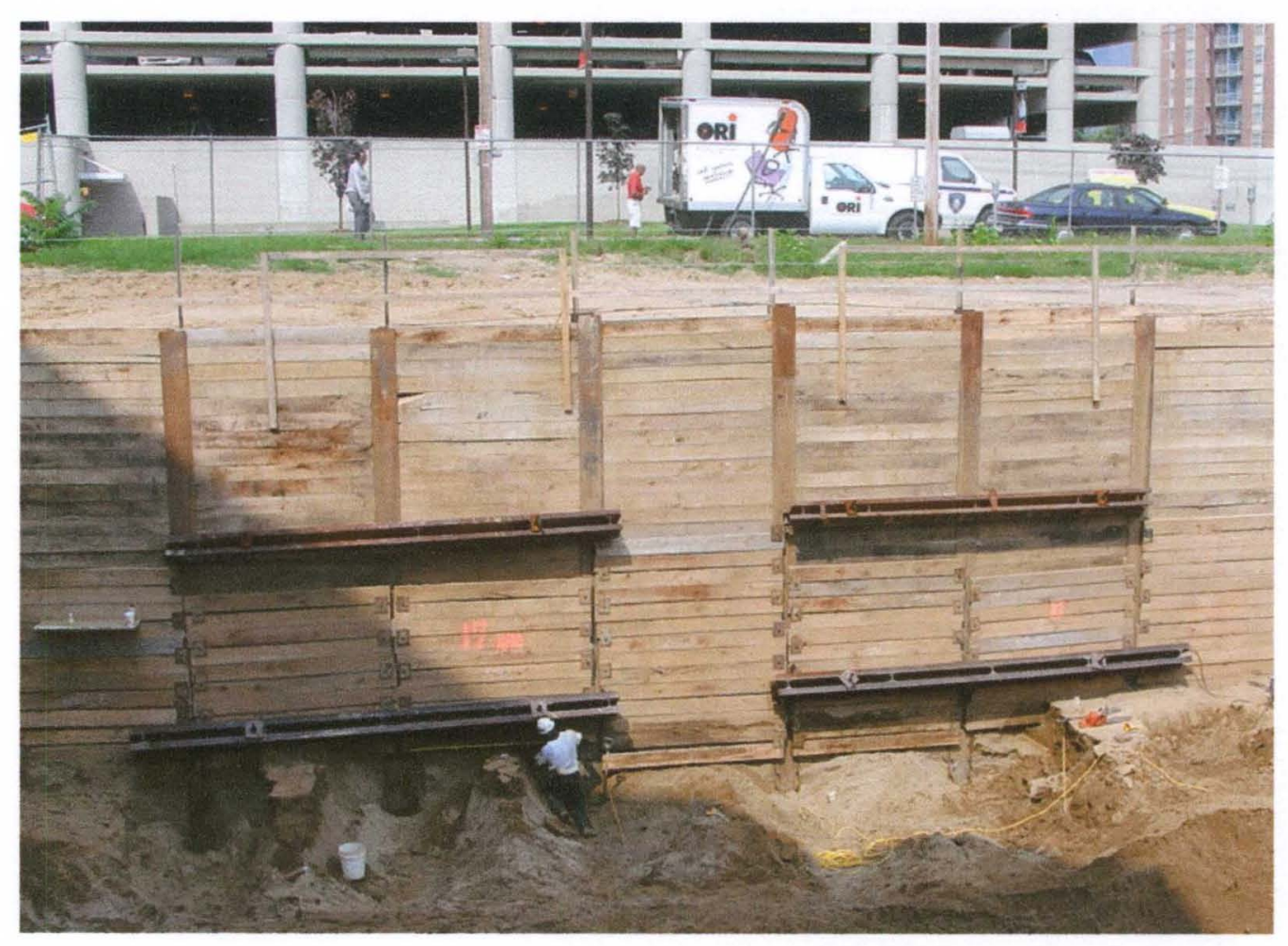

Illustration 1. Tieback through Common Wale (courtesy of RAM Engineering) 


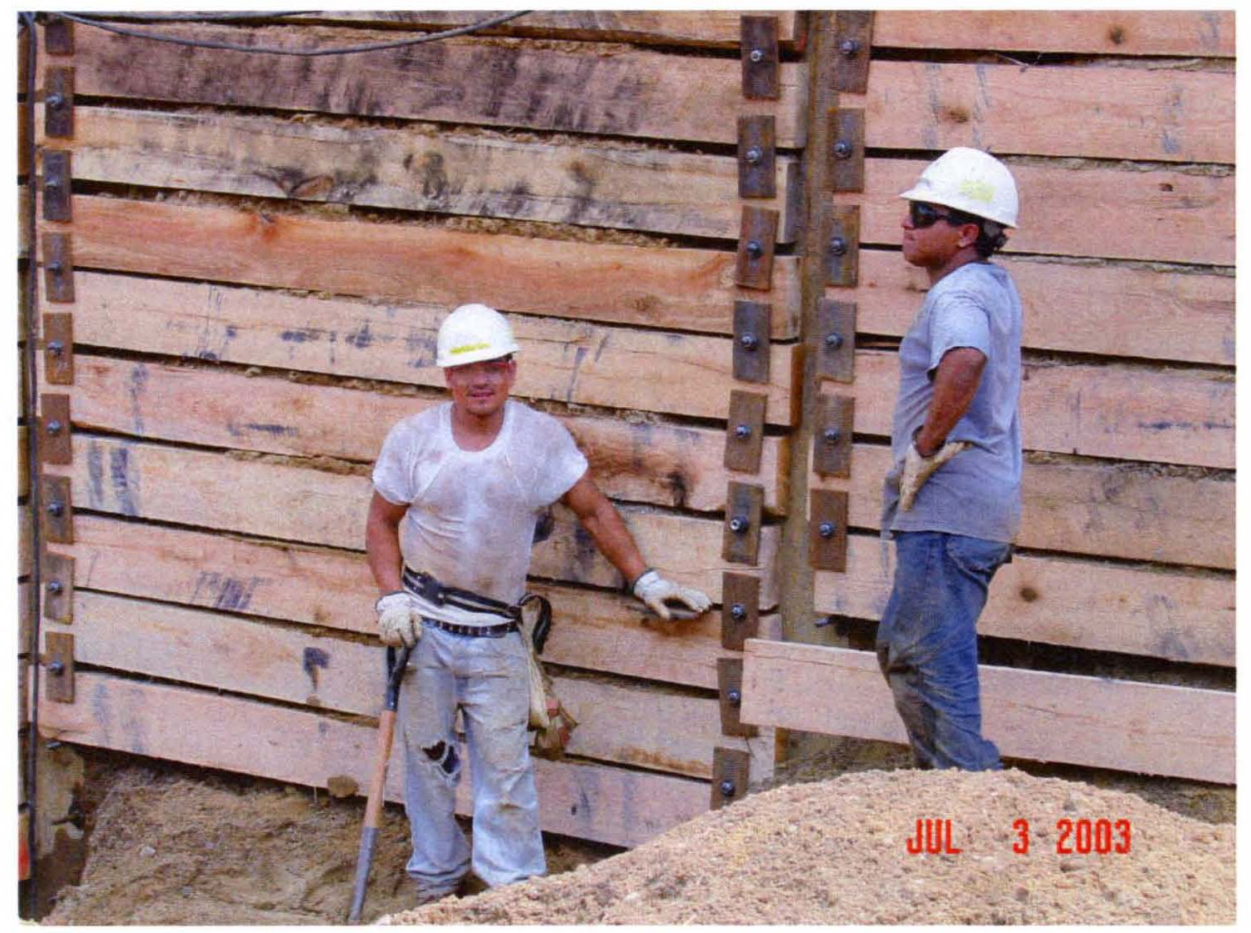

Illustration 2. Wood Lagging Detail (courtesy of RAM Engineering)

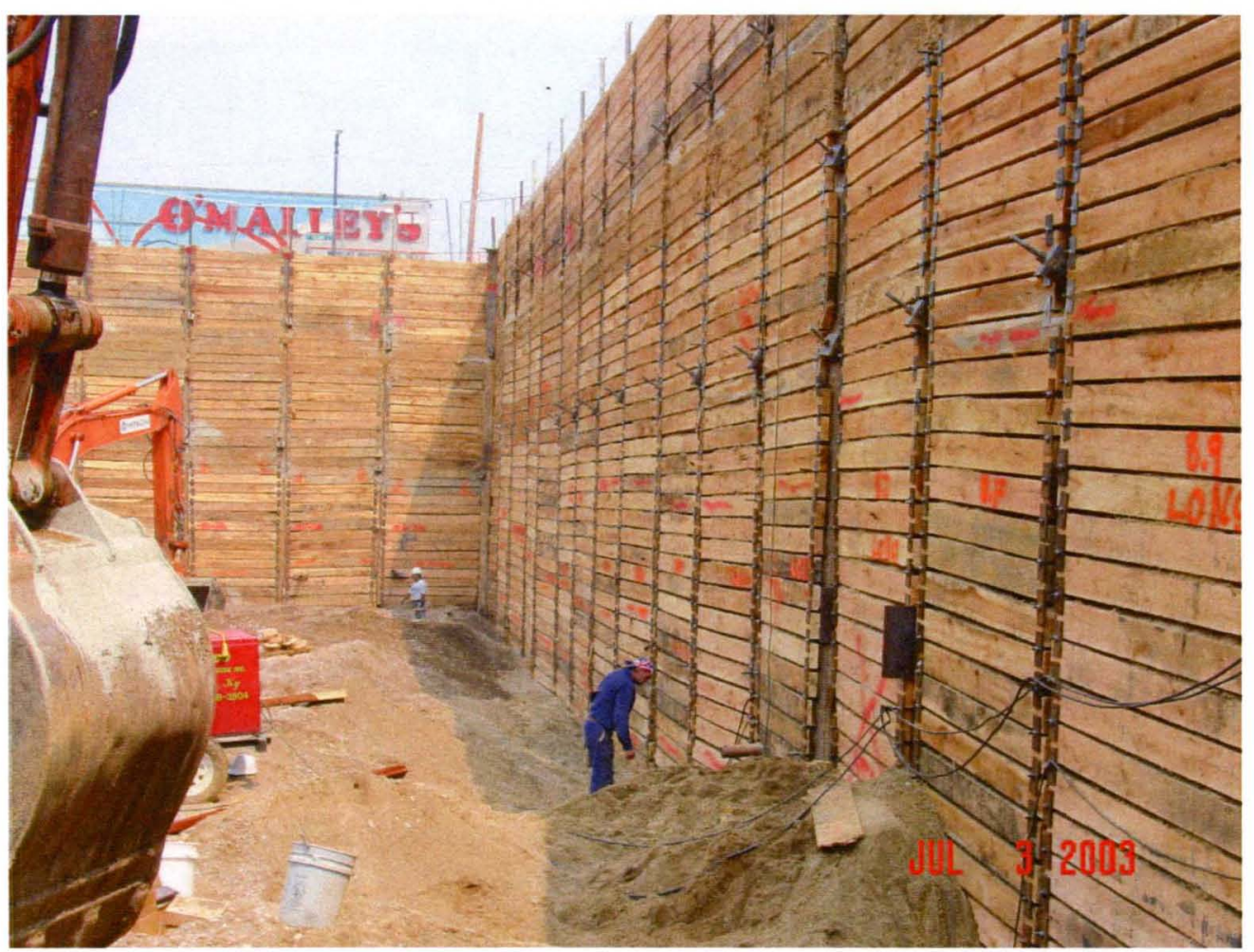

Illustration 3 Tieback through Steel Pile (courtesy of RAM Engineering) 


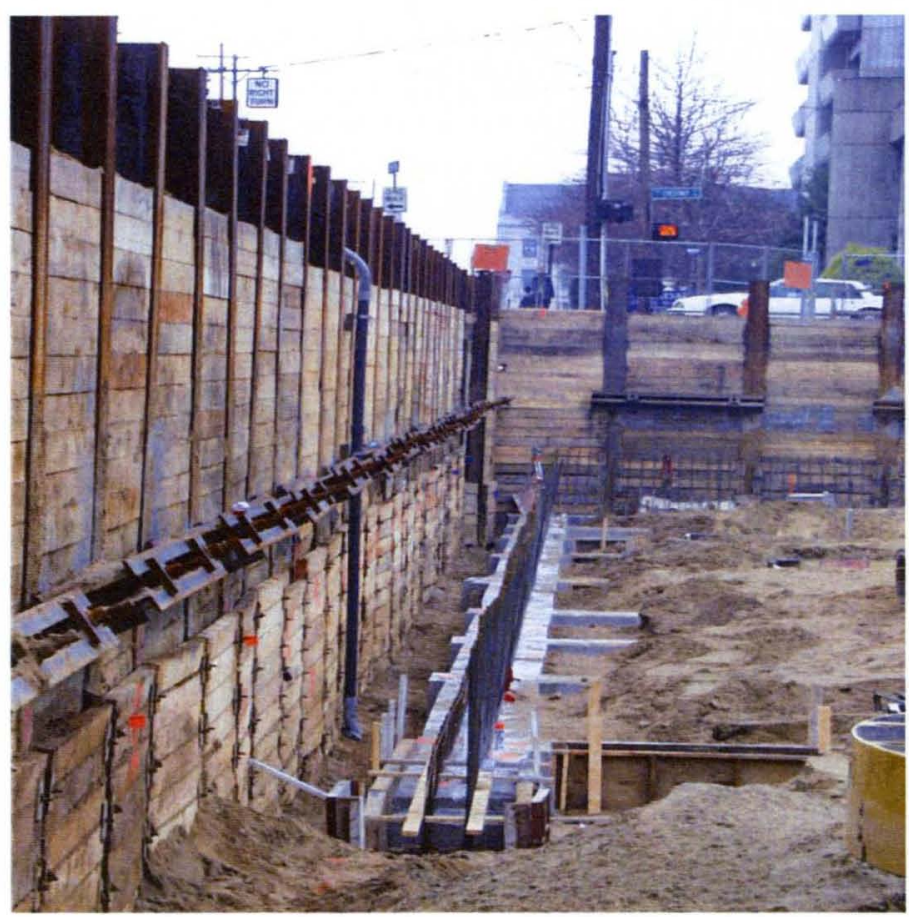

Illustration 4 New Construction in Excavated Area (courtesy of RAM Engineering)

\subsubsection{Installation of Soil Nails.}

Soil nailing is an in-situ soil reinforcement technique, which has been used during the last 28 years, mainly in France and Germany, to retain excavations or stabilize slopes. The fundamental concept of soil nailing consists of placing in the ground passive inclusions, closely spaced, to increase the overall shear strength of the in-situ soil, to restrain its displacements and limit its lateral expansion during and after excavation (Lazarte et al., 2003).

The typical sequence of construction for a soil nail wall using solid steel nail bars as assumed for study in this research is described below and shown schematically in Figure 5. 


\section{Step 1. Excavation:}

Initial excavation is carried out to a depth for which the face of the excavation has the ability to remain unsupported for a short period, typically on the order of 24 to 48 hours. The depth of the excavation lift is usually between 3 and 6 feet and reaches slightly below the elevation where nails will be installed. The width of the excavated platform or bench must be sufficient to provide access to the installation equipment.

\section{Step 2. Drilling Nail Holes:}

Nail holes are drilled to a specified length, diameter, inclination, and horizontal spacing from the excavated platform. Nails can be driven, but for this research, the more common technique of drilling nail holes has been assumed. 


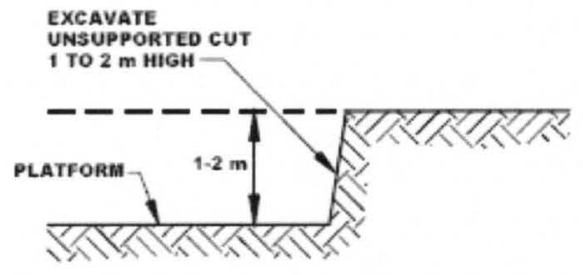

STEP 1. EXCAVATE SMALL CUT

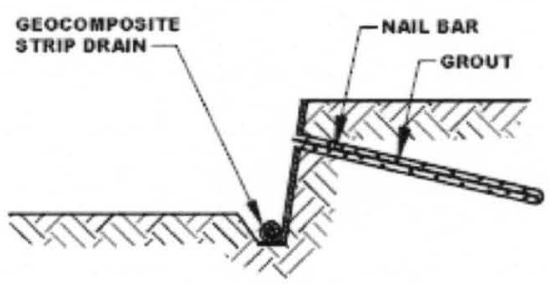

STEP 3. INSTALL AND GROUT NAIL (INCLUDES STRIP DRAIN INSTALLATION)

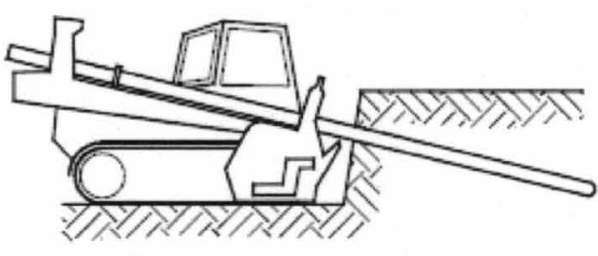

STEP 2. DRILL NAIL HOLE

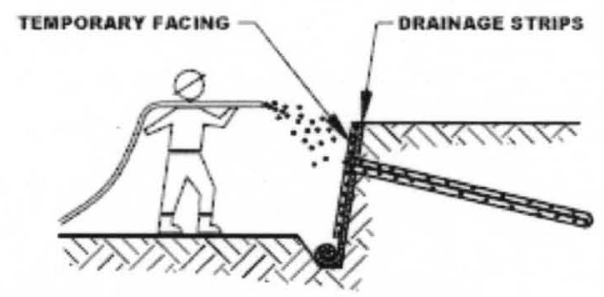

STEP 4. PLACE TEMPORARY FACING (INCLUDES SHOTCRETE, REINFORCEMENT,

BEARING PLATE, HEX NUT, AND WASHERS INSTALLATION)

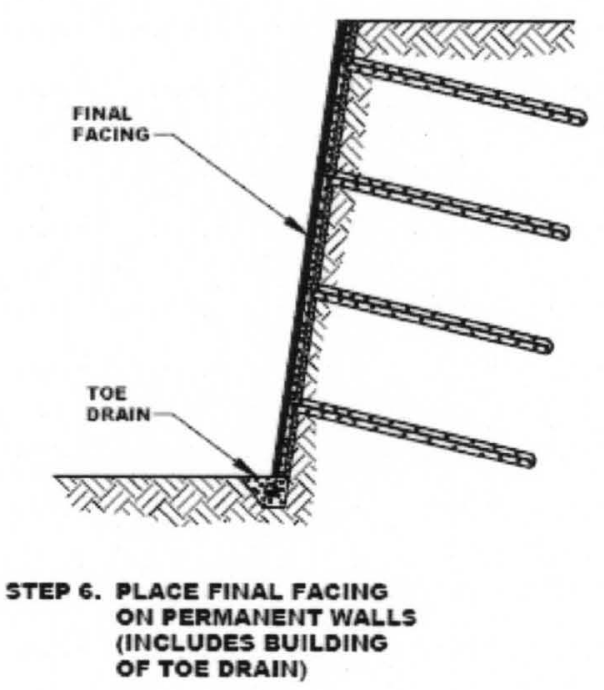

Figure 5. Typical Soil Nail Wall Construction Sequence.

Modified after Porterfield et al. (1994). 


\section{Step 3. Nail Installation and Grouting:}

Nail bars are placed in the pre-drilled holes. The bars are most commonly solid, although hollow steel nails can be used and have seen increased usage. Centralizers are placed around the nails prior to insertion to help maintain alignment within the hole and allow sufficient protective grout coverage over the nail bar. A grout pipe (tremie) is also inserted in the drill hole at this time. When corrosion protection requirements are high, corrugated plastic sheathing can be used to provide an additional level of corrosion protection. The drill hole then is filled with cement grout through the tremie pipe. The grout is commonly placed under gravity or low pressure. Prior to Step 4 (facing placement), geocomposite drainage strips are installed on the excavation face approximately midway between each set of adjacent nails. The drainage strips then are unrolled to the next wall lift. The drainage strips extend to the bottom of the excavation where collected water is conveyed via a toe drain away from the soil nail wall.

\section{Step 4. Construction of Temporary Shotcrete Facing:}

A temporary facing system then is constructed to support the open-cut soil section before the next lift of soil is excavated. The most typical temporary facing consists of a lightly reinforced shotcrete layer commonly containing $6 \times 6$ welded wire mesh (WWM), which is placed at approximately the middle of the facing thickness. Following appropriate curing time for the temporary facing, a steel bearing plate is placed over the nail head protruding from the drill hole. A hexagonal nut and washers are installed to secure the nail head against the bearing plate. The hexagonal nut is 
tightened to a required minimum torque after the temporary facing has sufficiently cured. Curing usually requires a minimum of 24 hours.

\subsubsection{Advantages of Conventional Systems}

The conventional methods of retention have some advantage over the soil nailing methods, such as:

1. The lateral deformation of the retained wall is less than the deformation of a soil nailing wall; this deformation is on the order of 0.08 percent to 0.1 percent of the height of the wall compared to 0.2 percent to 0.4 percent of the height of the wall in soil nailing systems (Stocker and Riedinger, 1990).

2. Conventional systems are more commonly used, so more workers will be knowledgeable about conventional systems and can perform this type of retention work with little training.

3. Conventional systems require fewer anchors and that means they are faster to install (less drilling time).

\subsubsection{Disadvantage of Conventional Systems}

1. This system requires heavy construction equipment and extra cost for mobilization and demobilization of such equipment.

2. Conventional systems require a larger easement for tieback installation, because tiebacks are drilled deep in the ground and adjacent underground utilities or underground structures may be in the way, or adjacent property 
owner(s) may not give permission to install tiebacks under these properties. Soil nails are more plentiful, but typically are shorter than tiebacks.

3. A conventional system is not sufficiently flexible to adapt to complex job geometry.

4. Conventional systems typically consist of components that are expensive (long complex tiebacks, long H-piles, wales) compared to the costs of soil nailing components.

5. The mode of failure is sudden without large prior deformations that signal impending failure.

6. After installation, conventional systems are difficult to change to conform to different design parameters.

\subsubsection{Advantages of Soil Nailing Systems (Stocker and Riedinger, 1990)}

1. The components of these systems are relatively low cost compared to components of conventional retaining systems.

2. Soil nailing systems can be adapted easily to different site conditions and soil profiles.

3. Soil nailing systems can be modified easily in order to change or optimize the initial design during construction.

4. The resultant soil nail structure has greater flexibility than conventional systems and the capacity to withstand larger total and differential settlements.

5. The failure mode is less dangerous (a soil nailing system does not collapse suddenly without large deformation). 
6. Right-of-way (easements) requirements are less than for conventional systems, as the nails typically are shorter than the tieback anchors.

7. Installation of soil nails involves smaller equipment and causes little environmental disturbance.

8. The bottom of the wall is placed at the bottom of the excavation with no need for the embedment required for stability of soldier piles.

\subsubsection{Disadvantages of Soil Nailing Systems}

1. Soil nailing cannot be used in loose granular soil or very soft fine-grained soil that cannot sustain a vertical cut 3 to 6 feet high without support until shotcrete is placed.

2. Reliable drainage systems are difficult to construct because the elements of the drainage system are flexible sheets of fabric placed against exposed soil with little security against movement or blockage.

3. Soil nailing systems exhibit larger lateral deformations and consequent settlement behind excavation faces than do anchored tieback walls $(0.2$ percent of excavation height for granular soils and 0.4 percent of excavation height for fine-grained soils).

4. Aesthetically, the shortcrete face of a nailed system is not satisfying. Additional measures have to be taken to cover the shotcrete with surface treatments. 
5. Soil nailing in very low shear strength soil may require a very high soil nail density.

6. Soil nailing in sensitive soils and expansive soils for permanent long-term applications is not recommended.

\subsubsection{Summary on Technical Aspects}

The design of a soil nailing system involves selection of the size, type, and spacing of the nails. It also includes selection of a facing and an appropriate drainage system. The design criteria of the nailed soil system include:

1. Stability with respect to the potential failure of the soil, the inclusions (excessive tension or bending), and their interaction with the soil (pullout failure or plastic flow of the soil between the inclusions).

2. Stability with respect to the nail-facing connection for a facing system with only modest strength.

3. Tolerable displacements with respect to expected structure performance.

4. Environmental and architectural aspects.

Soil nailing design requires an evaluation and analysis for every step during which soil nails are installed. The design procedure requires obtaining a factor of safety for each lift by finding maximum tension and maximum shear force on a slip surface. When the excavation is advanced, the analysis for wall stability must be repeated again, for each lift. Therefore, use of a computer program for design is recommended, especially when the wall is inclined, the soil has several layers of different properties, and the ground surface is not horizontal. Several computer 
programs are available, such as the SNAIL PROGRAM by the California Department of Transportation, Division of New Technology, Materials and Research, Office of Geotechnical Engineering User's Manual (not dated), and Nail M15 by Dr. S. Bang, South Dakota School of Mines and Technology, User's Manual, (obtained by personal contact). The Author used the Nail M15 Program for design of the systems included in this research, because of experience with excellent analytical results, verified with hand calculations, over a span of several years. 


\section{CHAPTER 3}

\section{COSTS OF RETENTION SYSTEMS}

\subsection{Analyzed Projects}

Fifteen retention system projects were selected for analysis; those systems have been designed and constructed, using conventional retention systems. Eleven systems were built around the Louisville, Kentucky area; four of these projects were done outside of Louisville. Therefore, the mobilization and demobilization costs were considered, and an out-of-state allowance was included in accounting for the total cost. These projects were analyzed using present worth and current cost approaches for both conventional retention and soil nailing, and several cost comparison studies were done. Appendix $\mathrm{B}$ contains design results of conventional systems and Appendix $\mathrm{C}$ contains design results for soil nailing systems. Material takeoff calculations are given in Appendix D. Costs for conventional systems are given in detail in Appendix E and costs for soil nailing systems are given in detail in Appendix F.

\subsection{Assumptions in Analyses}

All conditions on the analyzed sites were assumed to be the same when designing and constructing both systems, conventional and soil nailing, using current 
dollar cost for all components. Actual cost figures were available for the conventional systems that had been built, but those costs were calculated again using current unit costs for material, equipment rental and labor.

\subsection{Method Of Analysis}

To show the steps that have been followed to arrive at the final design for each case, the design steps for case 5 have been selected for illustration as an example, and the other fourteen cases will follow the same procedure. The rationale given in the following paragraphs allows development of a conceptual model of a typical conventional wall.

From experience and PTI recommendations, the length of the bonded zone should not exceed 30 feet, because tiebacks would not get any extra bonded strength even if their length exceeds 30 feet; the tiebacks would fail in tension rather than pull out.

To determine how long the free length will be, two methods are available to define the failure zone or the slip surface: the first method is to draw a line from the bottom of the wall (toe) to the surface with an outer angle of $(45+\phi / 2)$; where $\phi$ is the angle of internal friction. This line was moved 5 feet into the retained soil. This line defines the boundary between the soil that will move with the wall and the soil that will remain stable, and is taken to be the boundary between the free length and the bonded length. The other method is to draw a logarithmic spiral slip surface based on the soil properties to choose the most critical line that defines the boundary between the moving soil and the soil that will remain stable. By experience, the first method will 
give a line located farther from the wall and, thus, more conservative, as shown in Fig. 6 on the next page.

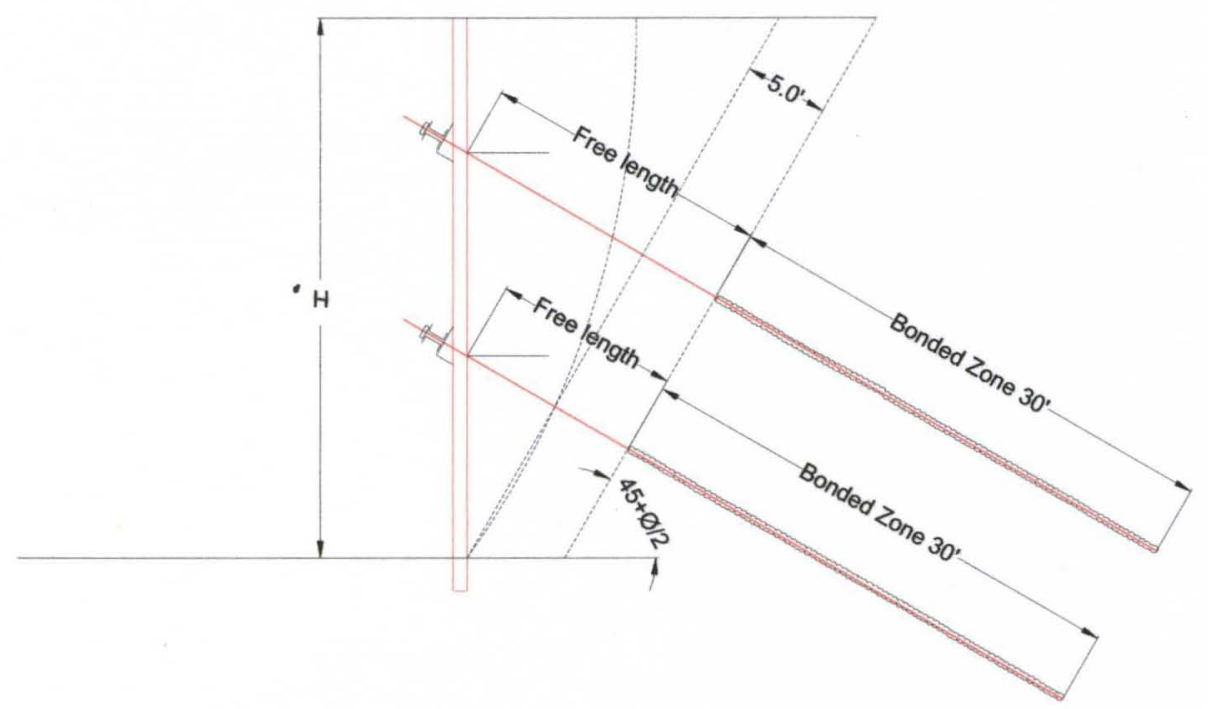

Figure 6. Tieback Bonded Length and Free Length

The total length of tieback is the summation of the bonded length, free length and 5 feet of tie tail, that extends beyond the wall.

To determine tieback vertical spacing, an empirical approach is used. From experience it is known that if the project requires a single tieback, the best tieback location is about $(0.35$ to 0.4$)$ of the wall height, $\mathrm{H}$. from the top of the wall, but not more than 10 feet. At any greater spacing, a heavy soldier pile section will be required for the initial cantilever stage during construction. Also, a bench two feet deep will be required below the tieback location to allow tieback installation, therefore even if the top cantilever section of the wall is 10 feet, the total height to be supported is 12 feet. If the project requires installation of two tiebacks, the location of the upper tieback will be about ( 0.275 to 0.3$)$ of the total wall height from top of 
the wall, and lower tieback location will be about $(0.3$ to 0.4$)$ of the total wall height up from the bottom of the wall. These values have been determined from experience. The designer must check the load on the tieback for the situation during construction just before lower tieback installation to check tieback design load, soldier pile section modulus, and soldier pile embedment in the ground to determine the requirements at this intermediate stage, versus the completed stage, for the configuration as shown in Fig. 7 below.

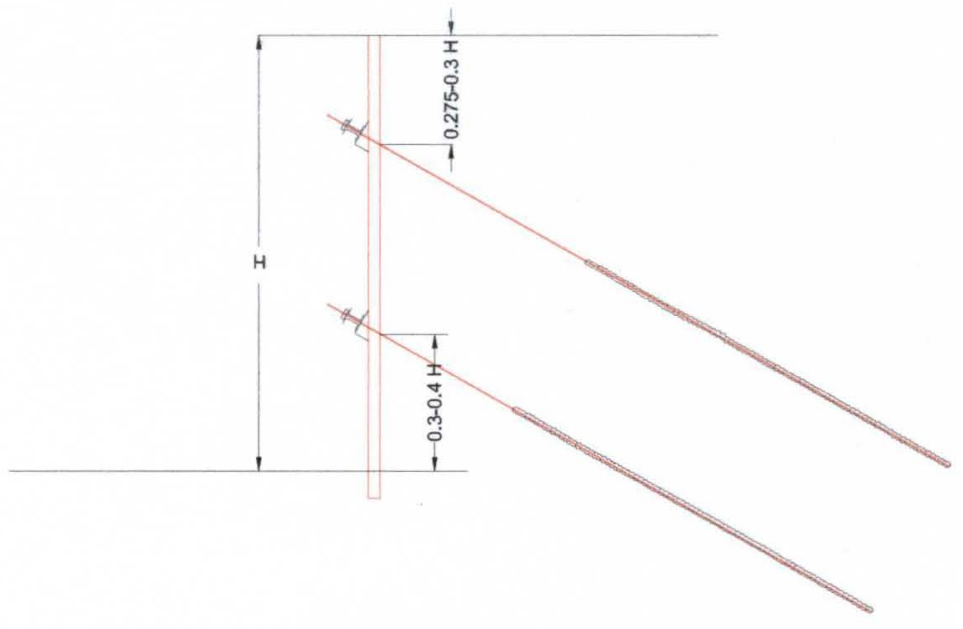

Figure 7. Two-tieback Wall Vertical Spacing

When project design requires installation of three tiebacks, the upper tieback location will be about $(0.2$ to 0.25$) \mathrm{H}$ from the top of the wall, with the same spacing for the lower tieback from the bottom of the wall, and the remaining length between upper and lower tiebacks will be divided into two equal segments for midpoint tieback location, as shown in Fig. 8. 


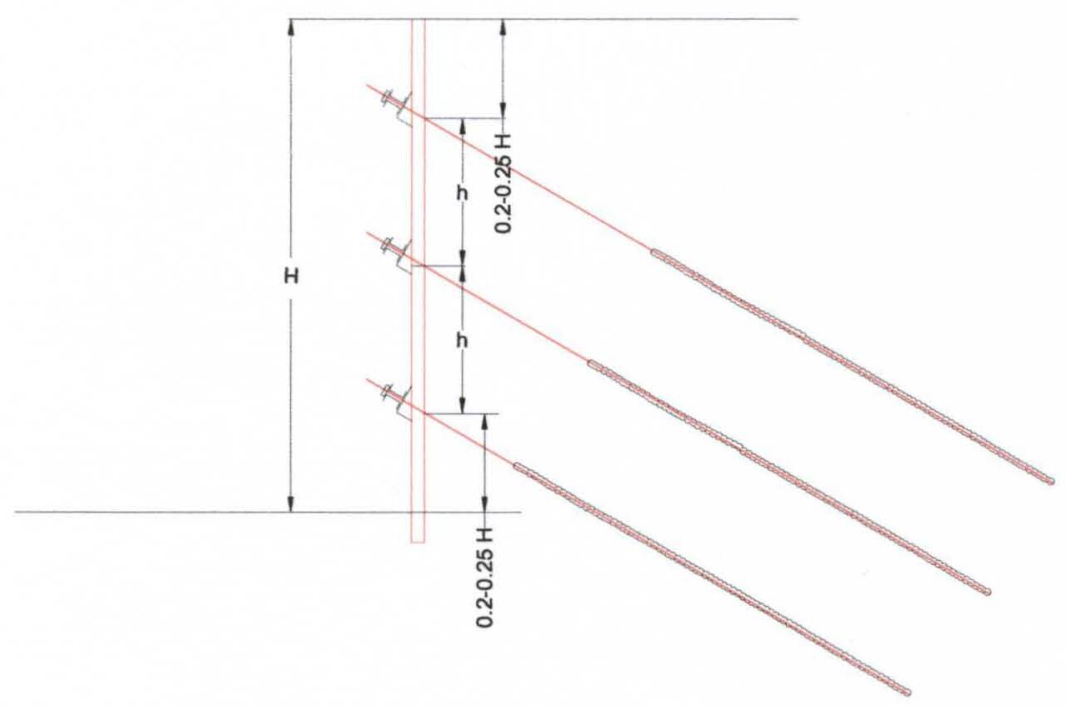

Figure 8. Three-tieback Wall Vertical Spacing

When projects design requires installation of four tiebacks, upper tieback location will be at $(0.175$ to 0.2$) \mathrm{H}$ and the lower tieback will be the same distance from the bottom of the excavation, and then the spacing between upper and lower tiebacks will be divided into three equal segments for location of the two remaining tiebacks, as shown in Fig. 9.

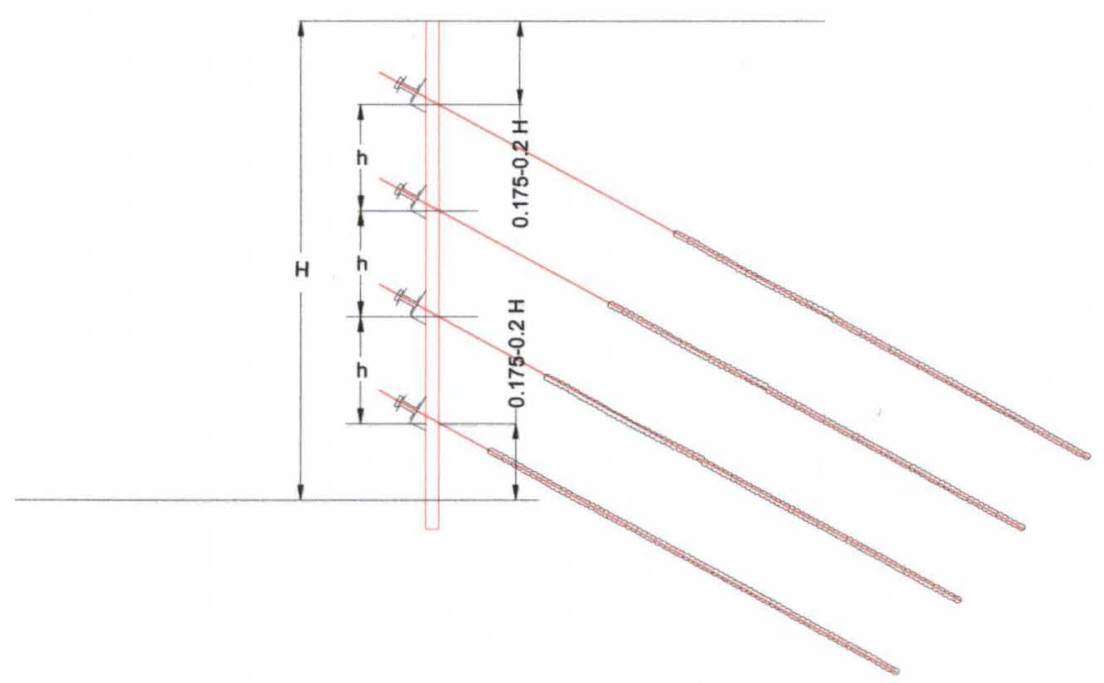

Figure 9. Four-tieback Wall Vertical Spacing 
To determine the required soldier pile section, the designer calculates the maximum moment in the pile at all construction stages and at the final stage, and then calculates the section modulus ( $\mathrm{Sx}$ ) required to limit bending stress in the pile to the appropriate code value. Then, the designer chooses the available steel section that will provide at least that section modulus.

An evaluation for tieback design load needs to be conducted to get an economical design; high tensile strength steel rebar with a diameter of 1-1/4 inch will hold up to 100 kips of design load and 120 kips of the proof load, which experience has shown the author to be adequate for all depths of excavation considered in this study. Therefore, author tried to use 1-1/4 inch-diameter rebar for tiebacks and not to go to $1-3 / 8$ inch-diameter rebar, because the larger rebar will entail higher steel cost and installation cost.

If the design requires a tieback for each bay (soldier pile to soldier pile), then an evaluation needs to be conducted to find which method will be more economic; to install the tieback through pile penetration or to install the tieback through the wale. Usually, if the selected soldier pile has adequate section modulus remaining after cutting a hole through pile flanges to install a tie back through the pile, then this method will be more economical than using a wale.

If the tieback capacity is sufficient to hold more than one bay load (1-1/2 or 2 bays) then using a wale will be the more economic design rather than penetrating each soldier pile for a tieback, because the cost of tiebacks is much higher than the cost of wales. 
To illustrate fully these design steps, the situation of Case 5 will be described, where the required walls are 37.5 feet high (Part A) and 26 feet high (Part B).

\section{CASE 5 PART A 37.5 FT WALL DESIGN STEPS:}

Step 1: Assume that steel soldier piles will be driven on a base line to a depth of 2 feet below the bottom of the excavation. Then, the excavation will be advanced to a depth about 18 inches to 2 feet below the first tie location. Run design calculation as a cantilever wall to size the system components, as shown on the following page.

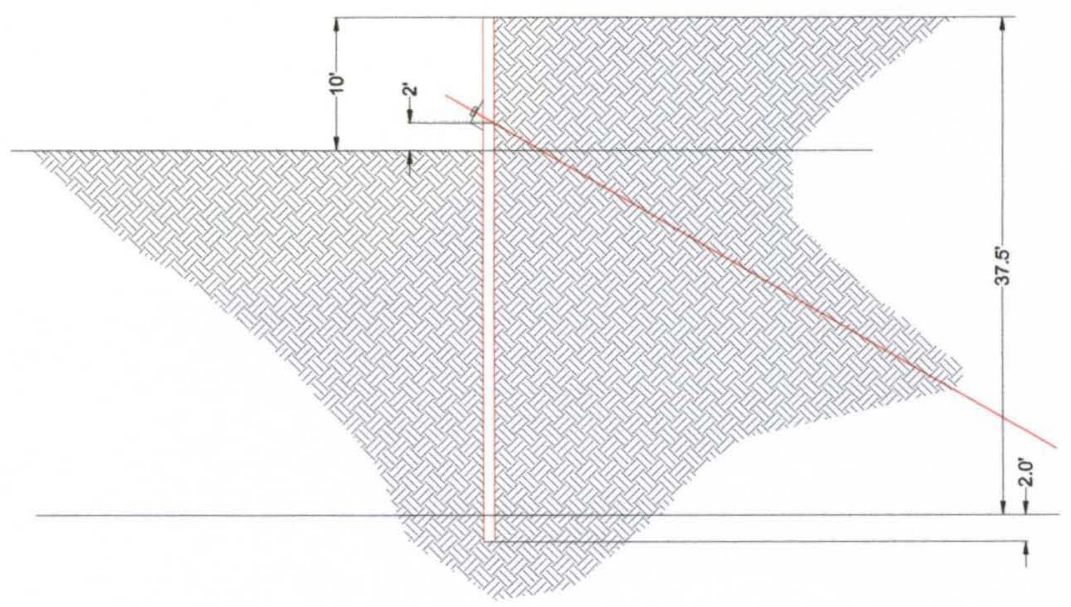

Figure 10. Step 1 of Retention System Design Process part A (all dimensions in feet) 
CASE 5 PART A STEP 1

\begin{tabular}{|cc|}
\hline$H$ & 10 \\
SCH. & 300 \\
SPACING & 8.5 \\
$\mathrm{Ka} 1=$ & 0.33 \\
$\mathrm{Ka}=$ & 0.33 \\
$\mathrm{KP}$ & 3 \\
GAMMA 1 & 120 \\
GAMMA SUB. 2 & 120 \\
(BEAM WIDTH) b & 1 \\
\hline
\end{tabular}

TRY DIFF, YALUE OF D TO MAKE THIS EQ. $=0$

ASSUME $d=\quad 16.2$ ZERO SHEAR POINT

$D=1.2 \times d=\quad 19.44 \quad F T$

total length $=29.44 \quad \mathrm{FT}$

use total length $=30 \quad$ FT

$\begin{array}{lll}\text { P1 } & 8415.00 \\ \text { P2 } & 16830.00 \\ \text { P3 } & 34834.54 \\ \text { P4 } & 140502.60\end{array}$

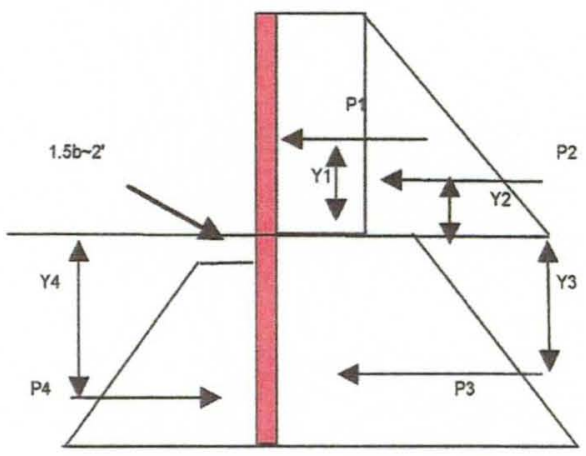

$Y_{1} \quad 5.000$

$\begin{array}{ll}Y 2 & 3.333 \\ Y 3 & 9.332\end{array}$

$\begin{array}{ll}\mathrm{Y}_{4} & 10.885\end{array}$

SEM. OF F $x=0$

$3+P q 2-P 4$ SHOULD $=0$

SUM. OF Fx $=-80423.064$ this value should $=0$

also satisfy sum. of moment $=0$

8415.00

8415.00
16830.00

P3 34834.54

P4 140502.60

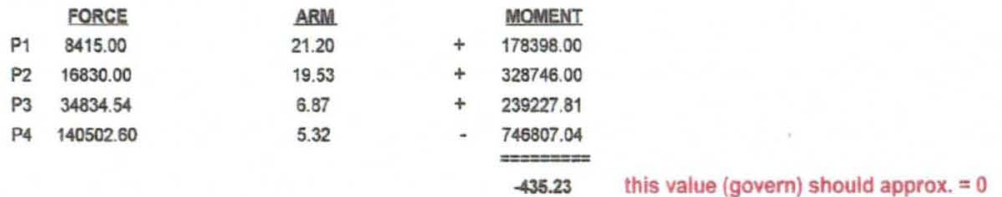

find zero shear point

$x=8.755$

$\begin{array}{ll}P 1 & 8415.00 \\ P 2 & 16830.00 \\ P\end{array}$

P $3, x \quad 14953.95$

$\begin{array}{ll}P 4, x & 40176.01\end{array}$

$\mathrm{P} 1+\mathrm{P} 2+\mathrm{P} 3, \mathrm{x}-\mathrm{P} 4, \mathrm{x}=$

2294

try diff. value of $x$ to make this value close to zero

find Max Moment At $\mathrm{X}=$

8.75

ft

$\begin{array}{cccc}\frac{\text { FORCE }}{8415.00} & \text { ARM } & & \text { MOMENT } \\ 16830.00 & 13.755 & + & 115748.325 \\ 14953.95 & 12.088 & + & 203446.650 \\ 40176.01 & 4.831 & + & 72237.397 \\ & 5.983 & - & 240370.549 \\ & & & ==== \pm== \\ & & & 151061.82\end{array}$

Max. Moment $=151.06 \quad k-f t$

$S x=48.99$ in^ $3 \mathrm{Gr}-50$

Figure 11. Case 5 Part A Step 1 Design Calculation 
Step 2: In the construction process, the field personnel will drill and install the first tieback, and then advance the excavation to about 18 inches to 2 feet below the second tieback location. Run a design calculation with the first tieback in place, to size the retention system, as shown in the following three figures.

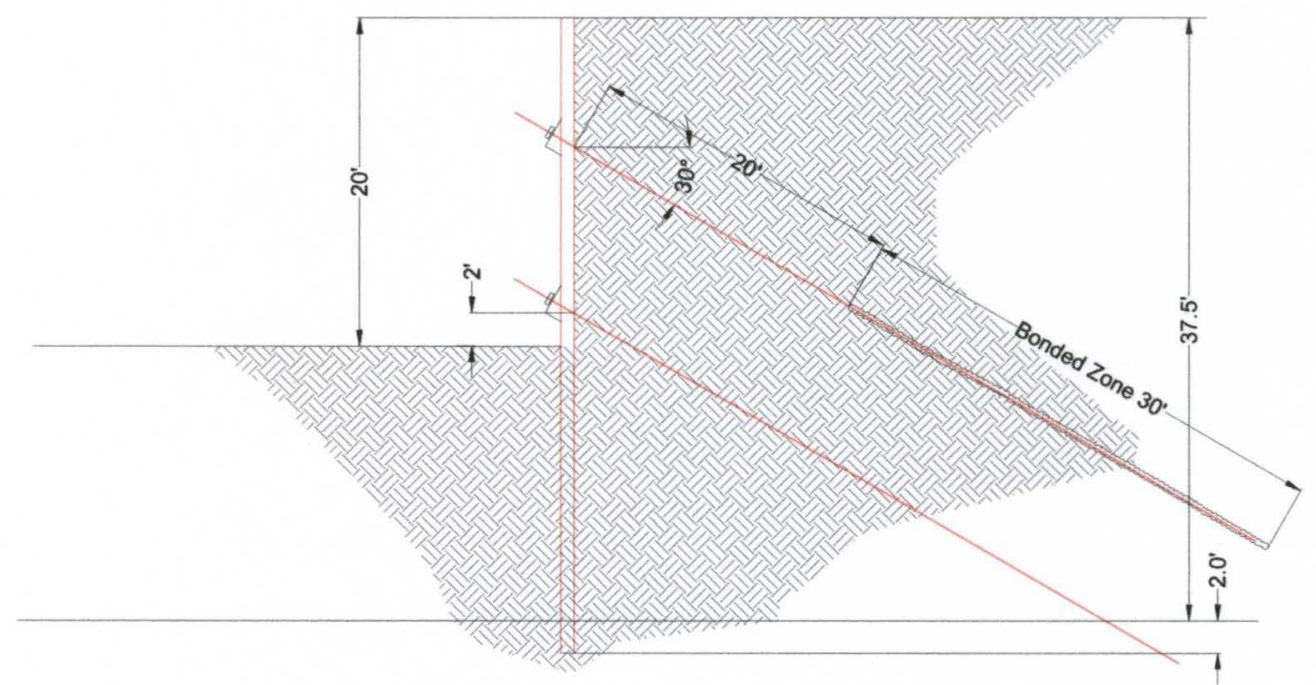

Figure 12. Step 2 of Retention System Design Process part A (all dimensions in feet) 


\section{CASE 5 PART A STEP 2}

FORCE

6732

\begin{tabular}{|rcl|}
\hline DEPTH OF EXCA & 20.75 & FT \\
FRICTION- PHEE & 30 & DEGREE \\
SOIL UNIT WEIGHT & 120 & \#IC.F \\
SURCHARGE Scu & 300 & PSF \\
PILES SPACE s & 8.5 & FT \\
PILE FLANGE b & 1 & FT \\
PILE EFF. FACTOR & 3 & \\
Ka & 0.33 & \\
Kp & 3 & \\
TIE LOCATION & 8 & FT \\
TE ANGLE X $=$ & 30 & DEGREE \\
Pb FACTOR $=$ & 22 & \\
LLLOWABLE STRESS $=$ & 37 & KSI \\
\hline COS X= & 0.8660 & \\
Pb $=$ & 456.5 & PSF \\
Pq $=$ & 99 & PSF \\
LENGTH OFupper triangle & 4.15 & FT \\
LENGTH OF rectangle & 12.45 & FT
\end{tabular}

8051.51875
14938.9625

10729.125

33370.15

8051.51875

16813.656

4585.086

616.50072

\begin{tabular}{|lcl|}
\hline PILE PENETR. D $=$ & 5.58 & FT \\
\hline PAS.PRESSUP1 $=$ & 6026.4 & PSF \\
ACT.PRESSUP1 $=$ & 821.7 & PSF \\
ACT.PRESSUP2 $=$ & 220.968 & PSF \\
DIST.FROM DRE- & 12.75 & FT \\
DGE LINE TO TIE & & \\
\hline
\end{tabular}

try diff.value of $D$

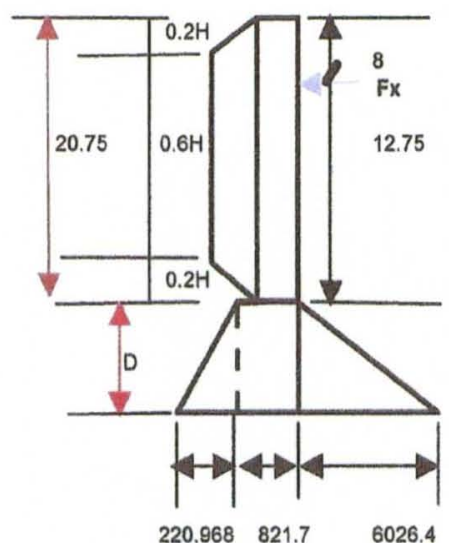

$\begin{array}{cc}\text { ARM } & \\ 4 & + \\ 5.2195 & + \\ 1.925 & + \\ 6.375 & - \\ 4.3 & - \\ 9.9695 & - \\ 16.4328 & + \\ 15.54 & + \\ 16.4328 & - \\ & -\end{array}$

MOMENT

26928

28757.50281

68398.17188

143491.645

80269.61618

276295.4463

71252.23644

10130,83303

TOTAL MOMENT@TIE LOCATION= $463.3 \quad$ (THIS VALUE SHOULD APPROX.$=0$ )

the (D)should be= $6.70 \quad$ FT

$\begin{array}{ccc}\text { USE D } & 18.00 & \text { FT } \\ F . S= & 3.23 & \text { HENCE }\end{array}$

OK

TOTALLENGTHED+H= $38.75 \quad \mathrm{FT}$

Figure 13. Case 5 part A step 2 design calculation 


\begin{tabular}{|c|c|c|}
\hline \multirow[b]{2}{*}{$\mathrm{Fl}=$} & \multicolumn{2}{|c|}{$\begin{array}{l}\text { TO FIND TIEBACK FORCE } \\
\text { MAKE SUM. FOR Fx }=0\end{array}$} \\
\hline & 17461.125 & + \\
\hline$F 2=$ & 16103.0375 & + \\
\hline $\mathrm{F} 3=$ & 48309.1125 & + \\
\hline $\mathrm{F} 4=$ & 4585.086 & + \\
\hline $\mathrm{F} 5=$ & 16813.656 & - \\
\hline $\mathrm{F} 6=$ & 616.50072 & + \\
\hline FX/ONE BAY= & 70.26 & KIP \\
\hline FX/ONE FT= & 8.27 & KIP/FT \\
\hline$F x / B A Y=$ & 70.26 & KIP \\
\hline TIE FORCE/1 BAY= & 81.13 & KIP \\
\hline PROOFTEST LOAD= & 97.36 & KIP \\
\hline & FIND MAX. & MENT \\
\hline
\end{tabular}

1 @TIEBACK LOCATION =

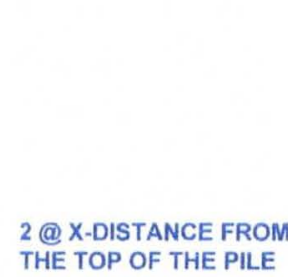

THE TOP OF THE PILE

\section{ARM \\ 5.2195}

1.925

\section{8051.5187}

14938.9625

FIND $X$ WHEN SUM.OF FX $=0$

$X=16.58553 \mathrm{FT}$ \begin{tabular}{c} 
FORCE \\
\hline 13956.72 \\
70261.21 \\
8051.52 \\
48252.96
\end{tabular}

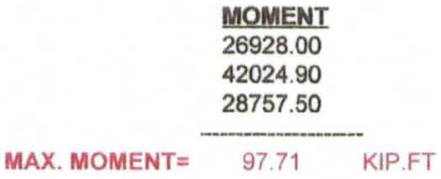

(ZERO SHEAR POINT)

$\begin{array}{ccc} & \text { ARM } & \text { MOMENT } \\ & 8.2927648 & 115739.82 \\ & 8.5855296 & 603229.66 \\ & 13.80503 & 111151.45 \\ & 6.2177648 & 300025.58 \\ \text { MAX. MOMENT }= & 76.31 & \text { KIP.FT } \\ \text { USE MAX. MOMENT }= & 97.71 & \text { KIP.FT } \\ \text { MOD. SECTION }= & 31.69 & \text { CUB. IN (Gr-50) }\end{array}$

Figure 14. Case 5 part A step 2 design calculation (cont.) 
Step 3: In the construction process, the field crew will drill and install the second tieback, and then advance the excavation to about 18 inches to 2 feet below the third tieback location. Run a design calculation with two tiebacks in place to size the retention system.

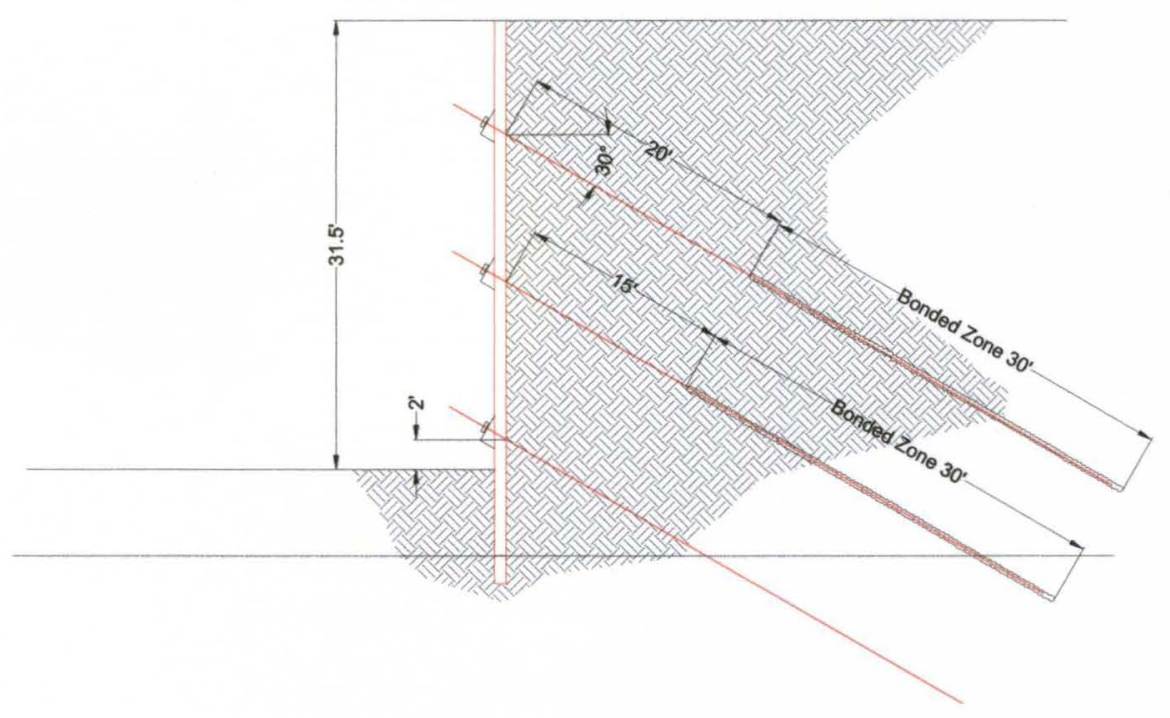

Figure 15. Step 3 of Retention System Design Process part A (all dimensions in feet) 


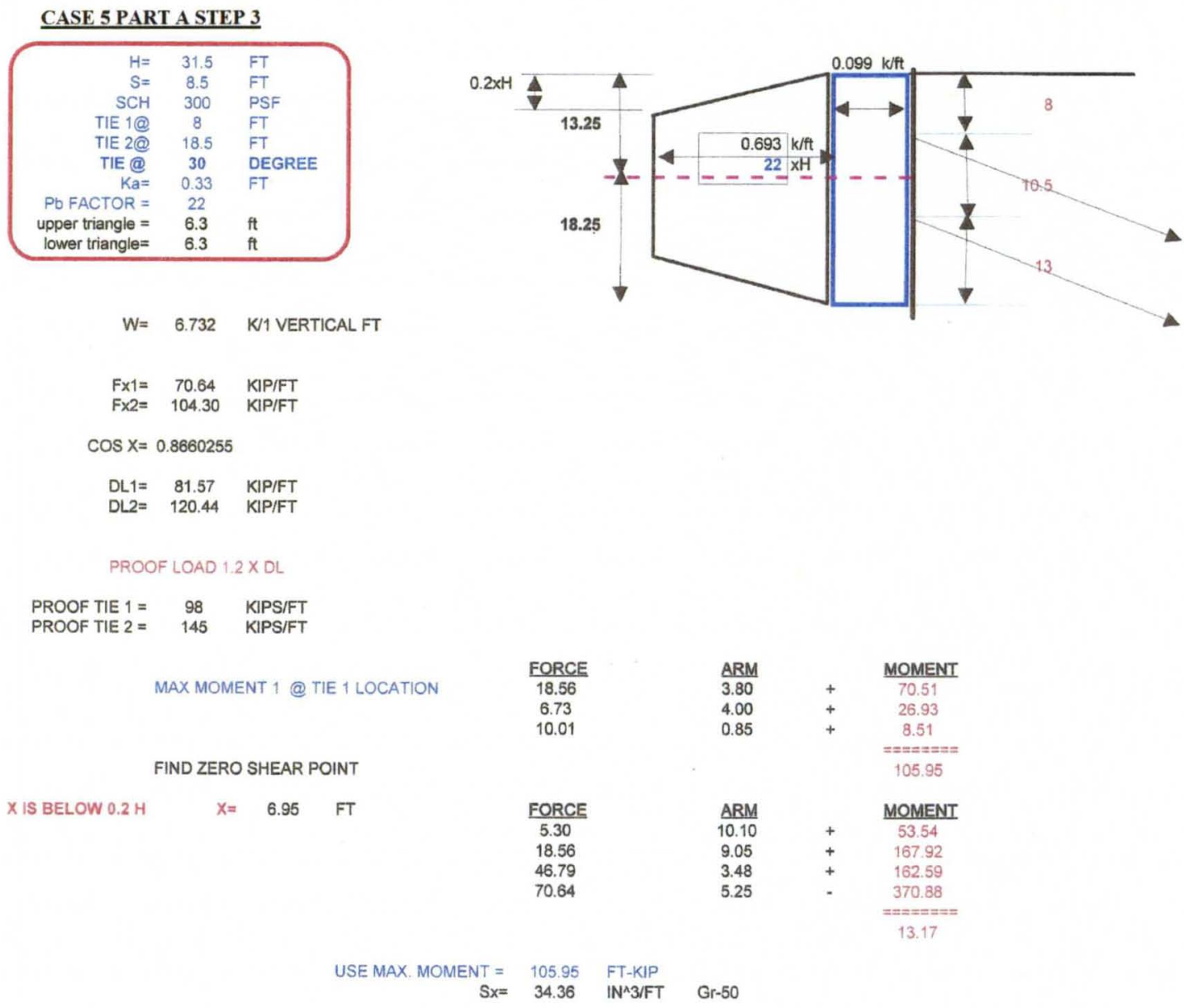

Figure 16. Case 5.part A step 3 Design Calculation $1^{\text {st }}$ run

The resultant design is not acceptable, because the second tieback design load will exceed 80 percent of the ultimate allowable load for (11/4-inch-diameter) reinforcing bar per PTI recommendations. If (1 3/8-inch-diameter) rebar were used that will increase the cost of tiebacks; therefore, redesign the system to keep the load in the second tiebacks around 100 kips (the proof load will be about 120 kips, or 120 percent of the design load). To do so, rerun the design calculation. Assume the surcharge load during construction will be limited to about 50 pounds per square foot rather than 300 pounds per square foot until the proof load test was performed, and 
assume the tieback load will be locked at 75 percent of the design load. On the final stage design, use the normal surcharge of 300 pounds per square foot.

CASE 5 PART A STEP 3 TO KEEP 2 NA TIE ABOUT 100 KIPS TO USE 1.25 INCH REBAR

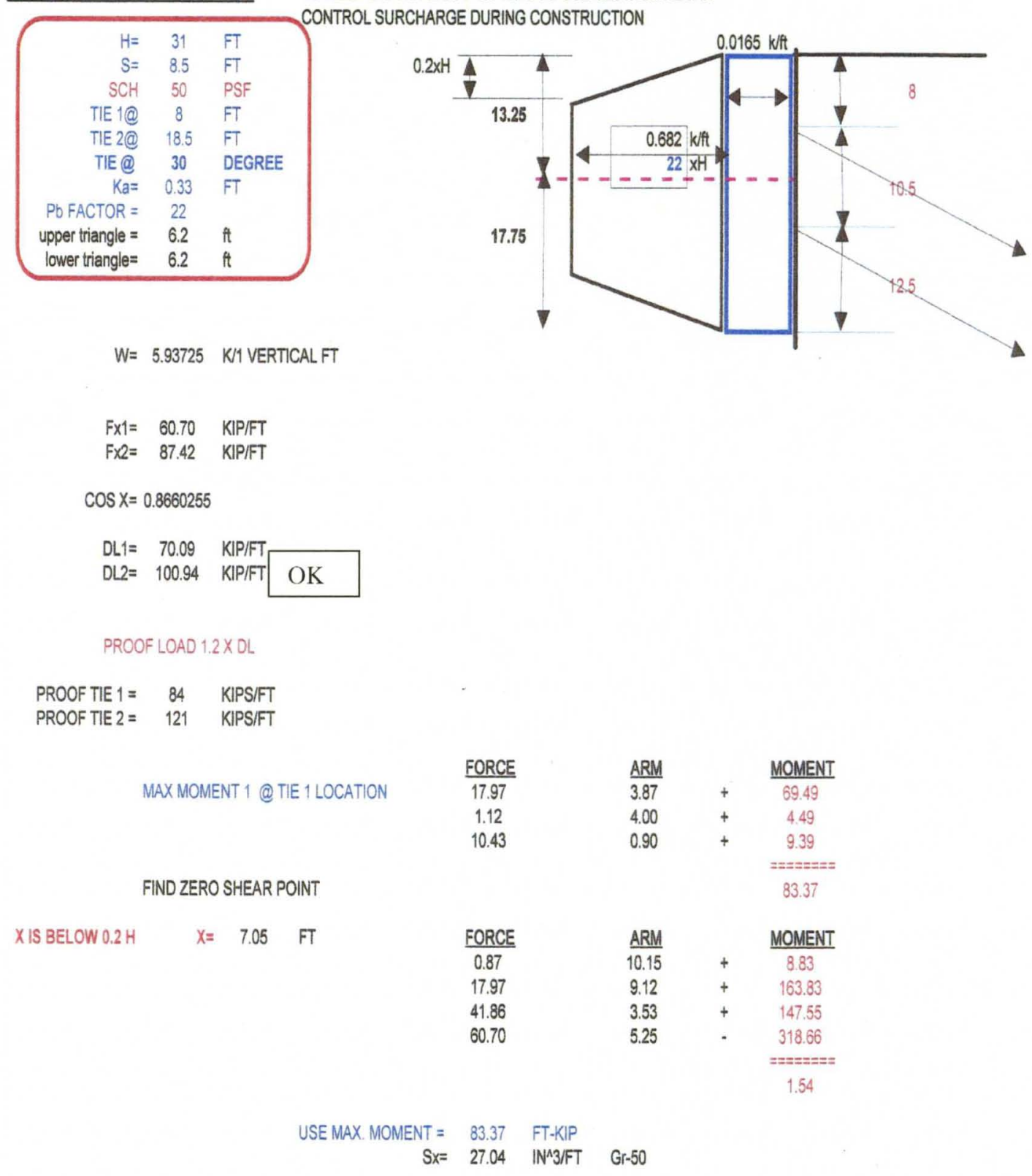

Figure 17. Case 5 part A step 3 Design Calculation $2^{\text {nd }}$ run 
Step 4: Field crew will drill and install the third tieback, and then advance the excavation to the planned bottom elevation as the final stage. Run a design calculation for the final stage and use the design that will satisfy the final stage condition and conditions during construction.

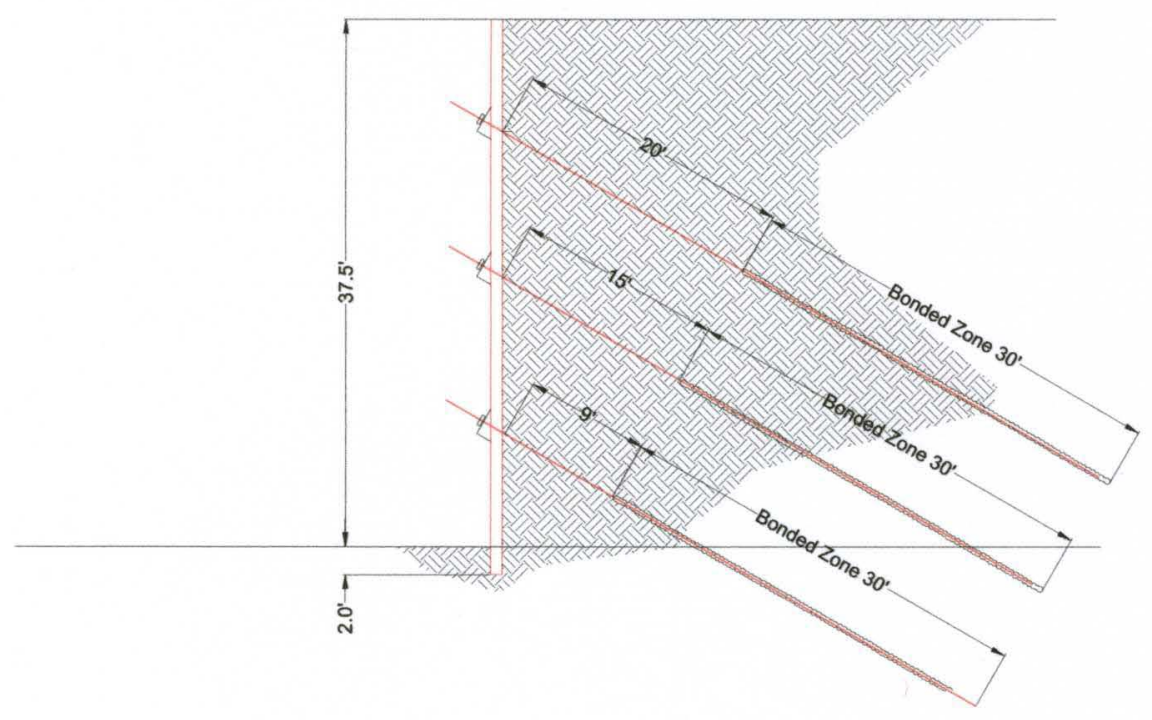

Figure 18. Step 4 of Retention System Design Process part A (all dimensions in feet) 


\section{CASE 5 PART A STEP 4 (FINAL)}

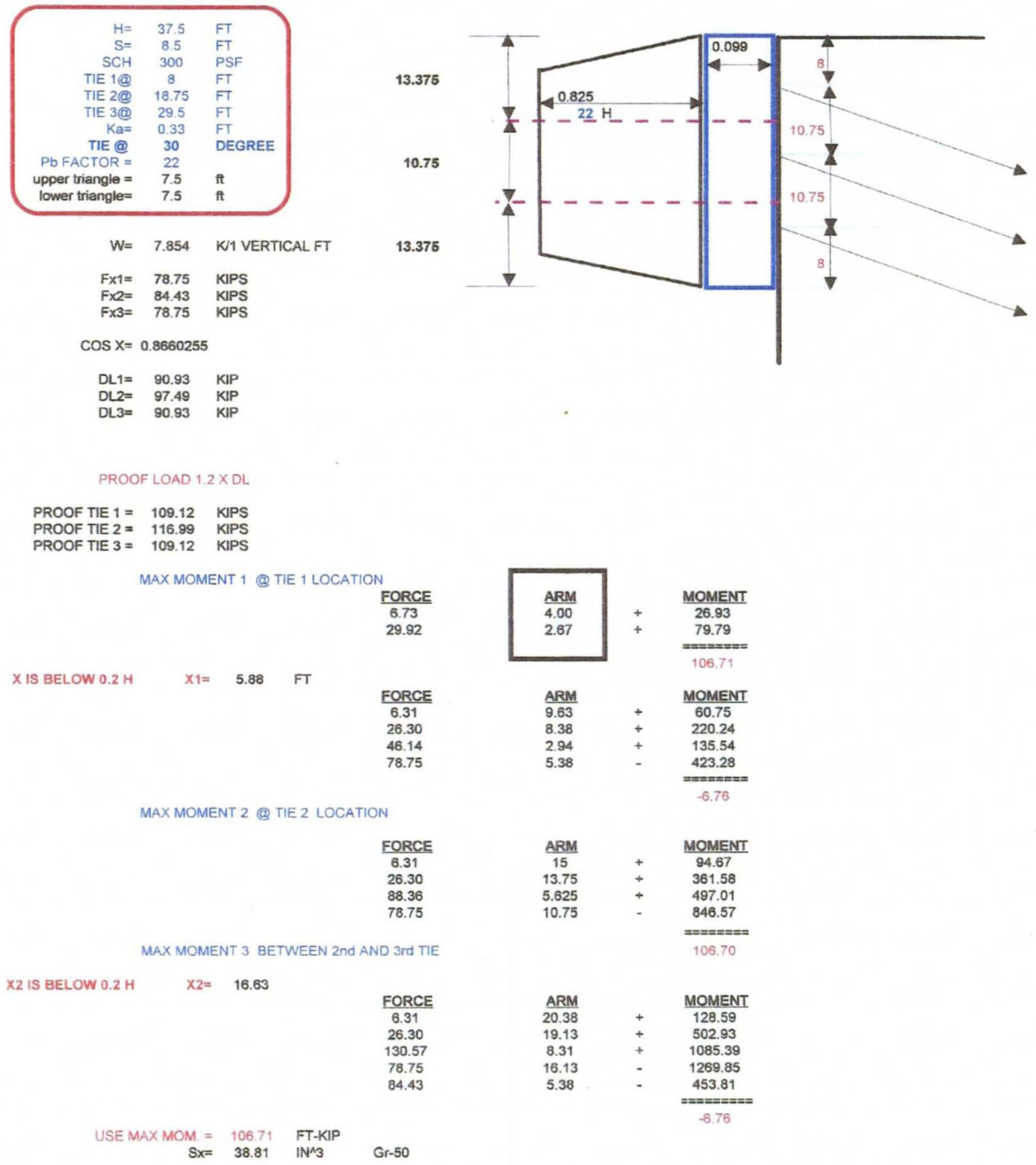

Figure 19. Case 5 part A step 4 Design Calculation 
For case 5 part B with 26 feet depth, the same steps will be followed.

Step 1: Assume steel soldier piles will be driven on a base line to the designed depth ( 2 feet below bottom of excavation), and then the excavation will be advanced to a depth about 18 inches to 2 feet below the first tie location. Run a design calculation for a cantilever wall to size the system components.

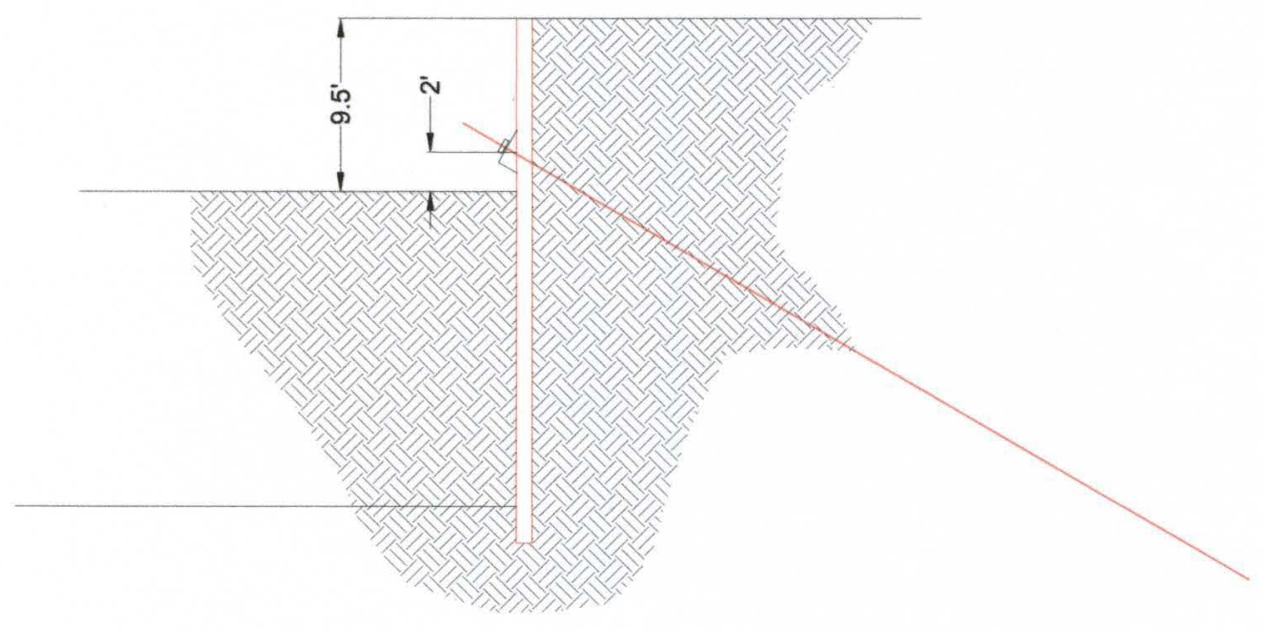

Figure 20. Step 1 of Retention System Design Process part B (all dimensions in feet) 


\section{CASE 5 PART B STEP 1}

Input Data
\begin{tabular}{|cc|}
\hline $\mathrm{H}$ & 9.5 \\
SCH. & 300 \\
SPACING & 8.5 \\
$\mathrm{Ka} 1=$ & 0.33 \\
$\mathrm{Ka2}=$ & 0.33 \\
Kp & 3 \\
GAMMA 1 & 120 \\
GAMMA SUB. 2 & 120 \\
(BEAM WIDTH) b & 0.83 \\
\hline
\end{tabular}

TRY DIFF. VALUE OF D TO MAKE THIS EQ. $=0$

ASSUME $d=\quad 16.63 \quad$ ZERO SHEAR POINT

$\mathrm{D}=1.2 \times \mathrm{d}=$

19.96 FT

total length $=$

29.46 FT

use total length $=30 \quad$ FT

$P 1$
$P 2$
$P 3$
$P 4$
$Y 1$
$Y 2$
$Y 3$
$Y 4$

7994.25

15189.08

29212.76

123258.08

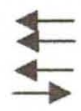

$\begin{array}{ll}Y_{1} & 4.750 \\ Y_{2} & 3.167\end{array}$

$\begin{array}{ll}Y 1 & 3.167 \\ Y 3 & 9.635\end{array}$

SEM. OF FX $=0$

$\mathrm{P} 1+\mathrm{P} 2+\mathrm{P} 3+\mathrm{Pq2}-\mathrm{P} 4 \mathrm{SHOULD}=0$

SUM. OF FX $=-70861.9952$ this value should $=0$

also satisfy sum. of moment $=0$

P1 7994.25

P2 15189.08

P3 29212.76

P4 123258.08

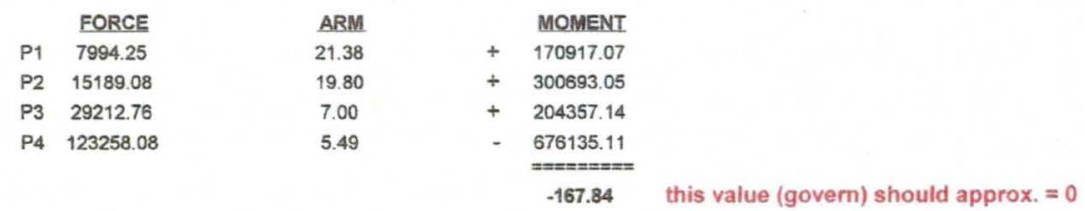

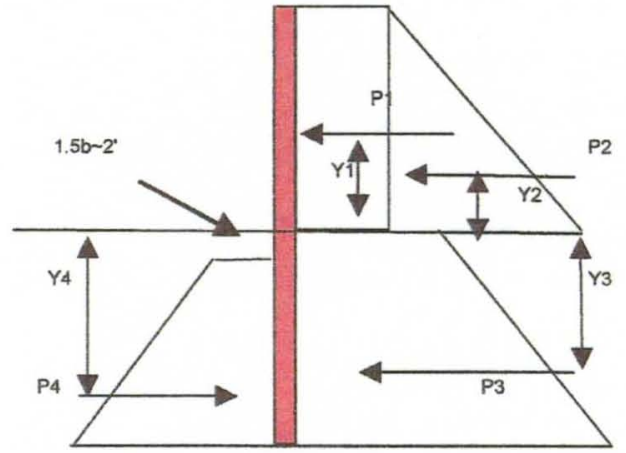

this value (govern) should approx. $=0$

find zero shear point

$\begin{array}{ccc} & X= & \\ & & \\ P 1 & 7994.25 \\ \text { P2 } & 15189.08 \\ \text { P3, } & 12424.10 \\ \text { P4, } & 35609.48\end{array}$

$1+\mathrm{P} 2+\mathrm{P} 3, \mathrm{x}-\mathrm{P} 4, \mathrm{x}=$

try diff. value of $x$ to make this value close to zero

id Max Moment At $\mathrm{X}=$

$\mathrm{ft}$

$\begin{array}{cc} & \text { EORCE } \\ \text { P1 } & 7994.25 \\ \text { P2 } & 15189.08 \\ \text { P3,x } & 12424.10 \\ \text { P4,X } & 35609.48\end{array}$

$\begin{array}{ccc}\text { ARM } & & \text { MOMENT } \\ 13.750 & + & 109920.938 \\ 12.167 & + & 184800.413 \\ 4.992 & + & 62018.465 \\ 6.101 & + & 217248.581 \\ & & ========== \\ & & 139491.23\end{array}$

Max. Moment $=139.49 \quad k-f t$

$S x=45.24$ in ${ }^{\wedge} 3 \mathrm{Gr}-50$

Figure 21. Case 5 part B step 1 Design Calculation 
Step 2: The field crew will drill and install the first tieback, and then advance the excavation to a depth about 18 inches to 2 feet below the second tieback location. Run a design calculation with a single tieback in place to size the retention system.

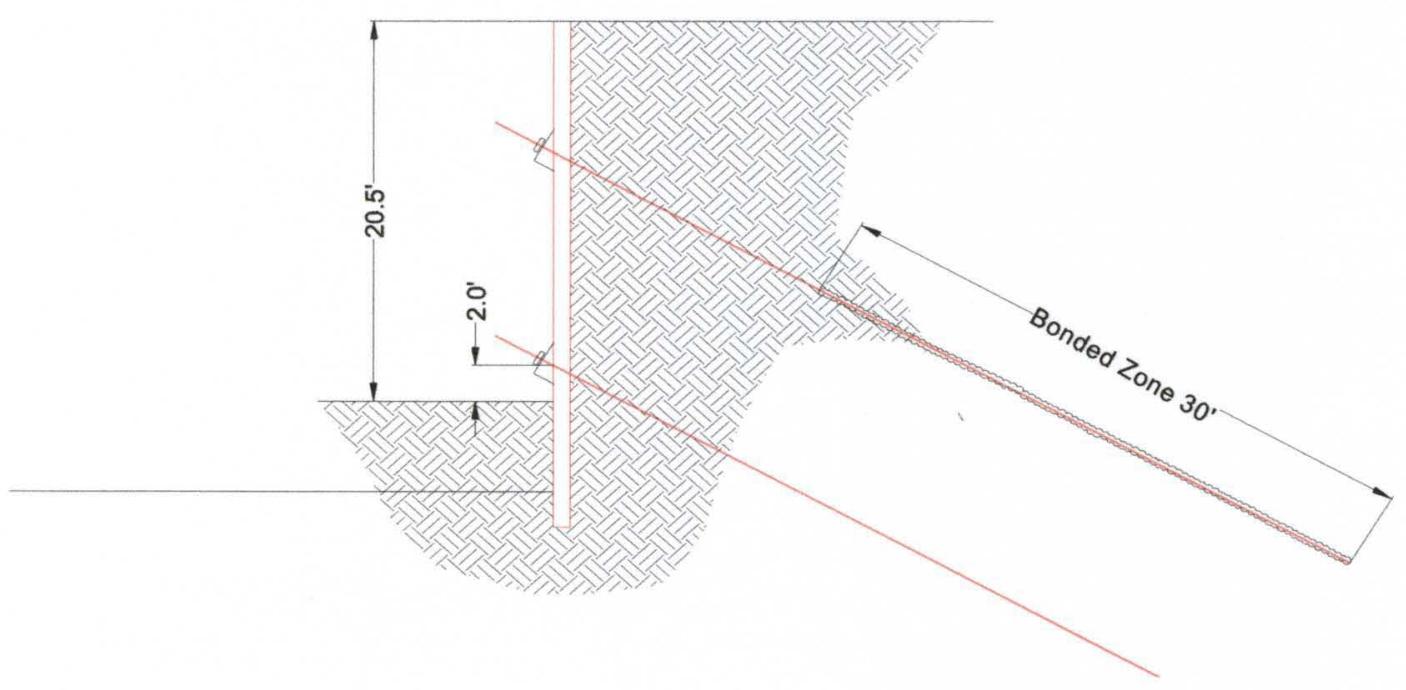

Figure 22. Step 2 of Retention System Design Process part B (all dimensions in feet) 

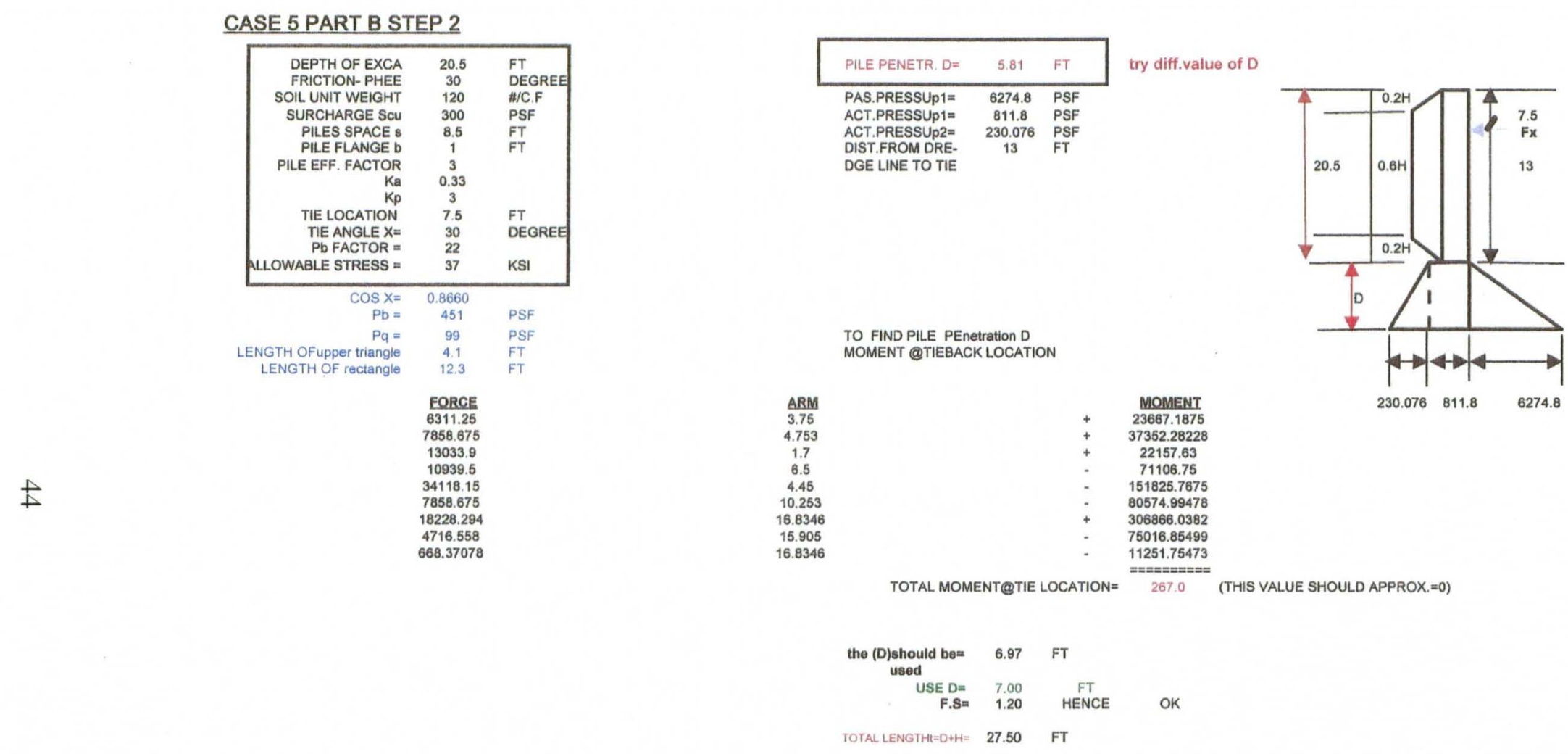

Figure 23. Case 5 part B step 2 Design Calculation 
TO FIND TIEBACK FORCE

MAKE SUM. FOR FX $=0$

$\begin{array}{lcc} & \text { MAKE SUM. FOR FX=0 } \\ \text { FI= } & 17250.75 & + \\ \text { F2 }= & 15717.35 & + \\ \text { F3 }= & 47152.05 & + \\ \text { F4 }= & 4716.558 & + \\ \text { F5 }= & 18228.294 & - \\ \text { F6 }= & 668.37078 & +\end{array}$

FXIONE BAY $=67.28 \quad$ KIP

FXIONE FT $=7.91 \quad$ KIP/FT

$F X / B A Y=67.28 \quad \mathrm{KIP}$

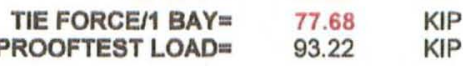

FIND MAX. MOMENT

1 @TIEBACK LOCATION =

2 @ X-DISTANCE FROM
THE TOP OF THE PILE

FORCE

6311.25

7858.675

$\frac{\text { ARM }}{3.75}$

3.75

4.753
1.7

MOMENT

23667.19

FIND $X$ WHEN SUM.OF FX $=0$

(ZERO SHEAR POINT)

$X=16.071756 \mathrm{FT}$

\section{FORCE}

13524.38

67276.78

7858.68

$$
\begin{gathered}
\text { ARM } \\
8.0358781 \\
8.5717561 \\
13.324756
\end{gathered}
$$

13.324756
5.9858781

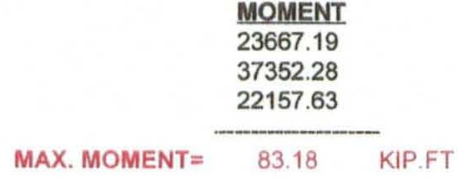

88.57

KIPFT

USE MAX. MOMENT = MOD. SECTION =

88.57 KIP.FT

28.73 CUB. IN (Gr-50)

Figure 24. Case 5 part B step 2 Design Calculation (cont.)

MOMENT

108680.29

104714.93

104714.93

274714.25 
Step 3: The field crew will drill and install the second tieback, and then advance the excavation to the planned bottom elevation as the final stage. Run a design calculation for the final stage, and then use the design that will satisfy the final stage conditions and conditions during construction.

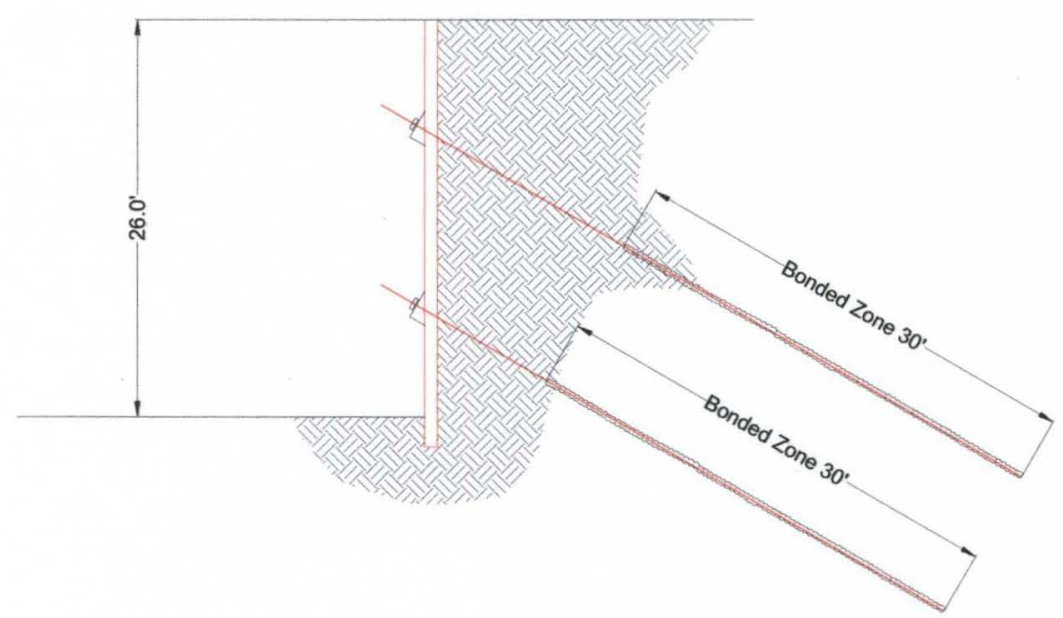

Figure 25. Step 3 Final Stage of Design Process part B (all dimensions in feet) 


\section{CASE 5 PART B STEP 3 (FINAL)}

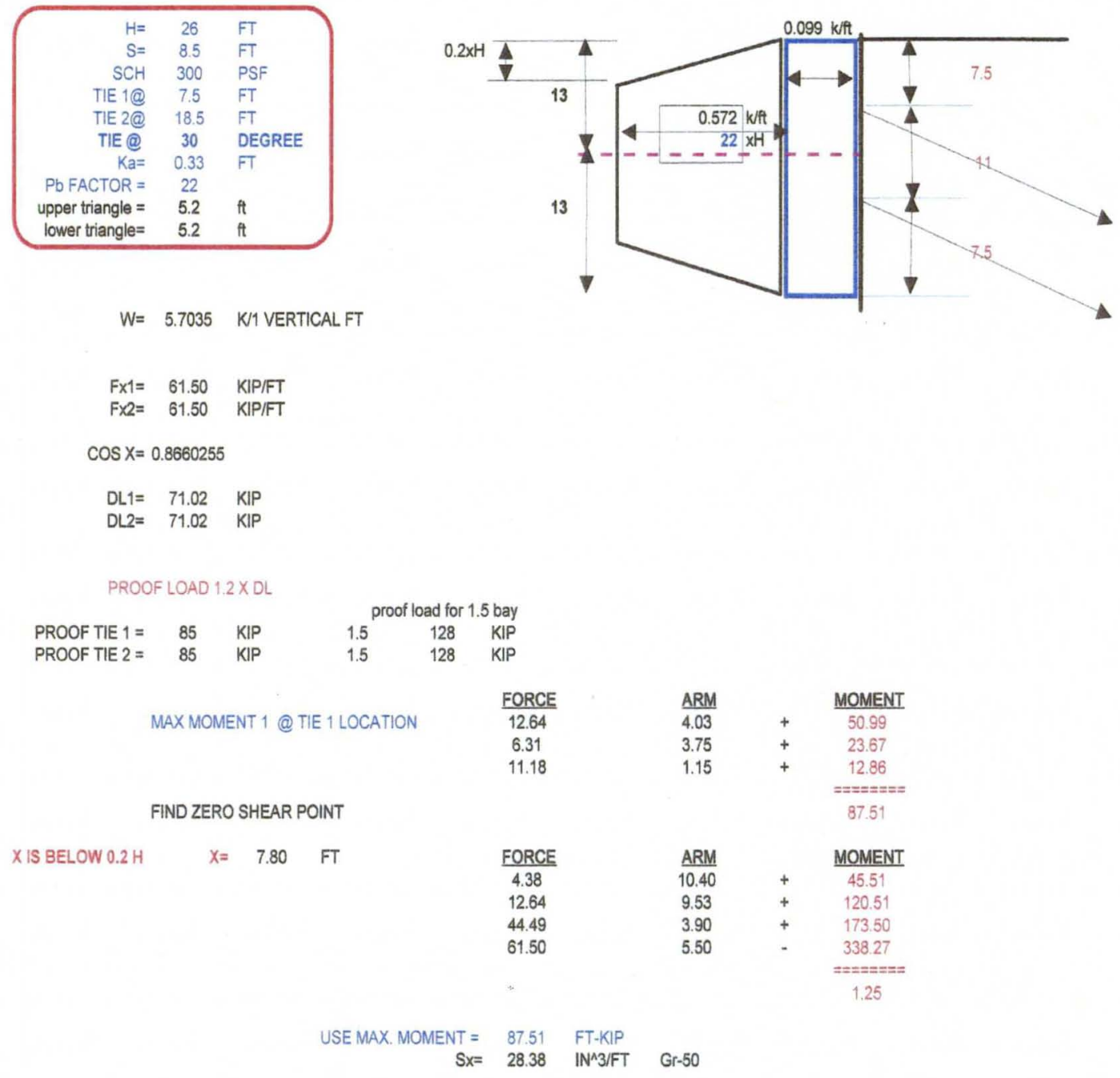

Figure 26. Case 5 part B step 3 Design Calculation 
The next step will be the take off for all the components that are required.

Table 2. Case 5 Conventional System Materials Takeoff

\begin{tabular}{|c|c|c|c|c|c|c|c|c|}
\hline \multicolumn{9}{|c|}{ CONVENTIONAL SYSTEM MATERIALS TAKEOFF } \\
\hline \multirow[t]{2}{*}{$\mathrm{AREA}=$} & 24,318 & $\mathrm{Sq} \mathbf{f t}$ & & & FT & Each & Total ft & $\begin{array}{c}\text { Total steel } \\
\text { pounds }\end{array}$ \\
\hline & & & & $\begin{array}{c}\text { HP } \\
12 X 53\end{array}$ & 30 & 42 & $1,260.0$ & \\
\hline \multirow[t]{3}{*}{ TIE BACK } & 190 & Each & $\begin{array}{l}1.25^{\prime \prime} \\
\text { rebar }\end{array}$ & & & & & \\
\hline & & & & & & & & \\
\hline & & & & pound & & $===$ & $=====$ & $=======$ \\
\hline WALES & 3 & Each & $10 \mathrm{ft}$ & 53 & & 42 & $1,260.0$ & $66,780.0$ \\
\hline \multirow[t]{2}{*}{ WALES } & 30 & Each & $20 \mathrm{ft}$ & & & & & \\
\hline & & & & & & & & \\
\hline \multirow[t]{10}{*}{$\begin{array}{r}12 \times 53 \\
\text { Beam } \\
\text { Penetration } \\
\end{array}$} & 130 & Each & & HP $10 \times 42$ & 10 & 1 & 10 & \\
\hline & & & & HP $10 \times 42$ & 25 & 2 & 50 & \\
\hline & & & & HP $10 \times 42$ & 33 & 1 & 33 & \\
\hline & & & & HP $10 \times 42$ & 28 & 46 & 1288 & \\
\hline & & & & HP $10 \times 42$ & 20 & 1 & 20 & \\
\hline & & & & HP $10 \times 42$ & 6.5 & 1 & 6.5 & \\
\hline & & & & pound & & $====$ & $=====$ & \\
\hline & & & & 42 & & 52.00 & $1,407.5$ & $59,115.0$ \\
\hline & & & & & & & & $=======$ \\
\hline & & & & & & & & $125,895.00$ \\
\hline
\end{tabular}

Area is the total retained area in square feet.

Pile length is the total length of the soldier piles, in feet.

Total pounds are the weight of the soldier piles in pounds.

Soldier piles used in this case are steel piles $10 \times 42$ and steel piles $12 \times 53$.

Wales are the double c-section steel channels through which tiebacks are inserted and which rest on soldier piles. The length of wale is determined by the support condition (if the wale is used to hold one bay (soldier pile to soldier pile) or used to hold two bays (three consecutive soldier piles)). 
Beam penetration is the operation of punching a hole through both flanges of the soldier piles to install tiebacks through soldier piles.

Then the next step is to calculate the cost of the project as follows:

Table 3. Case 5 Conventional System Materials and Operation Cost

\begin{tabular}{|c|c|c|c|c|c|}
\hline & rate $\$$ & per & unit & rate $x$ unit & $\$ / \mathrm{sft}$ \\
\hline driving in earth & 10.00 & $\mathrm{ft}$ & $2,667.50$ & $26,675.00$ & 1.10 \\
\hline steel cost beam & 0.52 & $\mathrm{Ib}$ & $125,895.0$ & $65,465.40$ & 2.69 \\
\hline wale $10^{\prime}$ long & 450.00 & ea. & 3 & $1,350.00$ & 0.06 \\
\hline wale $20^{\prime}$ long & 550.00 & ea. & 30 & $16,500.00$ & 0.68 \\
\hline wale $10^{\prime}$ uninstall & 200.00 & ea. & 3 & 600.00 & 0.02 \\
\hline wale $20^{\prime}$ uninstall & 250.00 & ea. & 30 & $7,500.00$ & 0.31 \\
\hline tieback cost & $1,100.00$ & ea. & 190 & $209,000.00$ & 8.59 \\
\hline pent. throu. 10" beam & 100.00 & ea. & 0 & 0.00 & 0.00 \\
\hline pent. throu. 12 " beam & 125.00 & ea. & 130 & $16,250.00$ & 0.67 \\
\hline $\begin{array}{l}\text { wood lagging down } \\
\text { to } 1 \text { st tie }\end{array}$ & 4.10 & $\mathrm{sft}$ & $6,309.0$ & $25,866.90$ & 1.06 \\
\hline wood lagging below & 6.76 & sft & $18,009.0$ & $121,740.84$ & 5.01 \\
\hline $\begin{array}{l}\text { mob/demob + shop } \\
\mathrm{dwg}\end{array}$ & 1.00 & ea. & $10,000.00$ & $10,000.00$ & 0.41 \\
\hline OTA & 100.00 & $\mathrm{M} / \mathrm{DAY}$ & 0 & 0.00 & 0.00 \\
\hline set pile in hole & 5.00 & $\$ / \mathrm{ft}$ & $2,667.50$ & 13.337 .50 & 0.55 \\
\hline & & & & $====-==$ & $=======$ \\
\hline & & & & $514,285.64$ & 21.15 \\
\hline Area $=$ & 24,318 & sft & Cost $=$ & 21.15 & $\$ / \mathrm{sft}$ \\
\hline
\end{tabular}

Then the same procedure will be followed to calculate the cost for the soil nailing system. Experience and research have developed typical parameters for soil nailing that allow development of a conceptual model of a typical soil nailing wall.

Usually the soil nailing wall is inclined about 5 degrees from the vertical plane, toward the retained soil. The first nail row will be about 2 feet from the top of the wall. Vertical and horizontal spacing will be on the order of 4 to 6 feet each. Uppermost nail length is about 80 to 100 percent of the wall height, $\mathrm{H}$, while lowest 
nail length is about 60 to 80 percent of the wall height and the length of nails between uppermost and lowest will be linearly proportioned between those two lengths. Nail steel rebar is usually No. 8 low strength ( $75 \mathrm{ksi})$; the nails are inserted in a drilled hole four inches in diameter and grouted with low pressure. The holes are installed at an angle of about 20 degrees from the horizontal plane.

The desired safety factor for sliding through the (bottom of the excavation) is 1.5 as a minimum, and 2.0 for deep-seated rotation (global failure). Permanent retention of the soil face between nails is accomplished by installing No. 4 steel rebar horizontally and vertically as a wale or spreader mat behind a nail plate. A drainage blanket will be installed between nails vertically from the top of the wall toward the bottom of excavation. Fig. 27 shows a typical section through a soil nailing wall. Soil nailing design parameters that could be changed to get the optimal design are: steel nail parameters (length, size, strength), drilled-hole diameters, vertical and horizontal spacing of nails, and nail inclination angle from horizontal plane. Also, surcharge load can be changed during design of intermediate stages in construction if it could be controlled. 


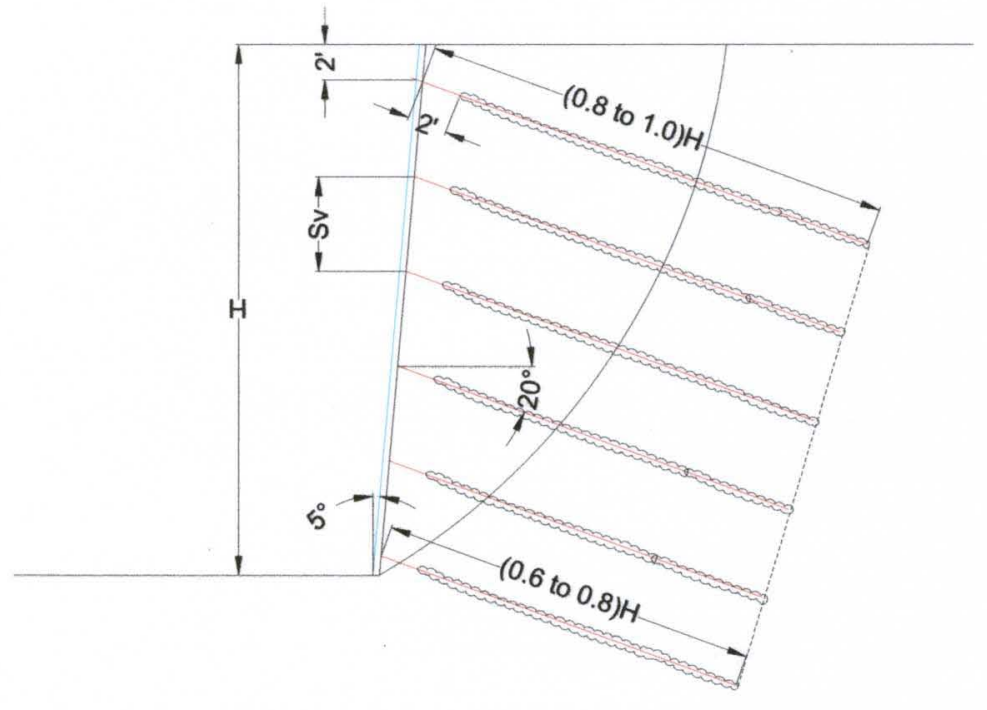

Figure 27. Typical Soil Nailing Cross Section

\section{Case 5 soil nailing design procedure:}

Step 1: Run design calculation for part A, with a wall height of 37.5 feet, and try different nail patterns (patterns commonly used are spacing vertically and horizontally between 4 feet by 4 feet and 6 feet by 6 feet. In this case, a pattern of 6 feet by 6 feet will be used and the length of the upper nail was assumed to be $25 \mathrm{ft}$ and the lower nail length was assumed to be $20 \mathrm{ft}$, based on experience. 


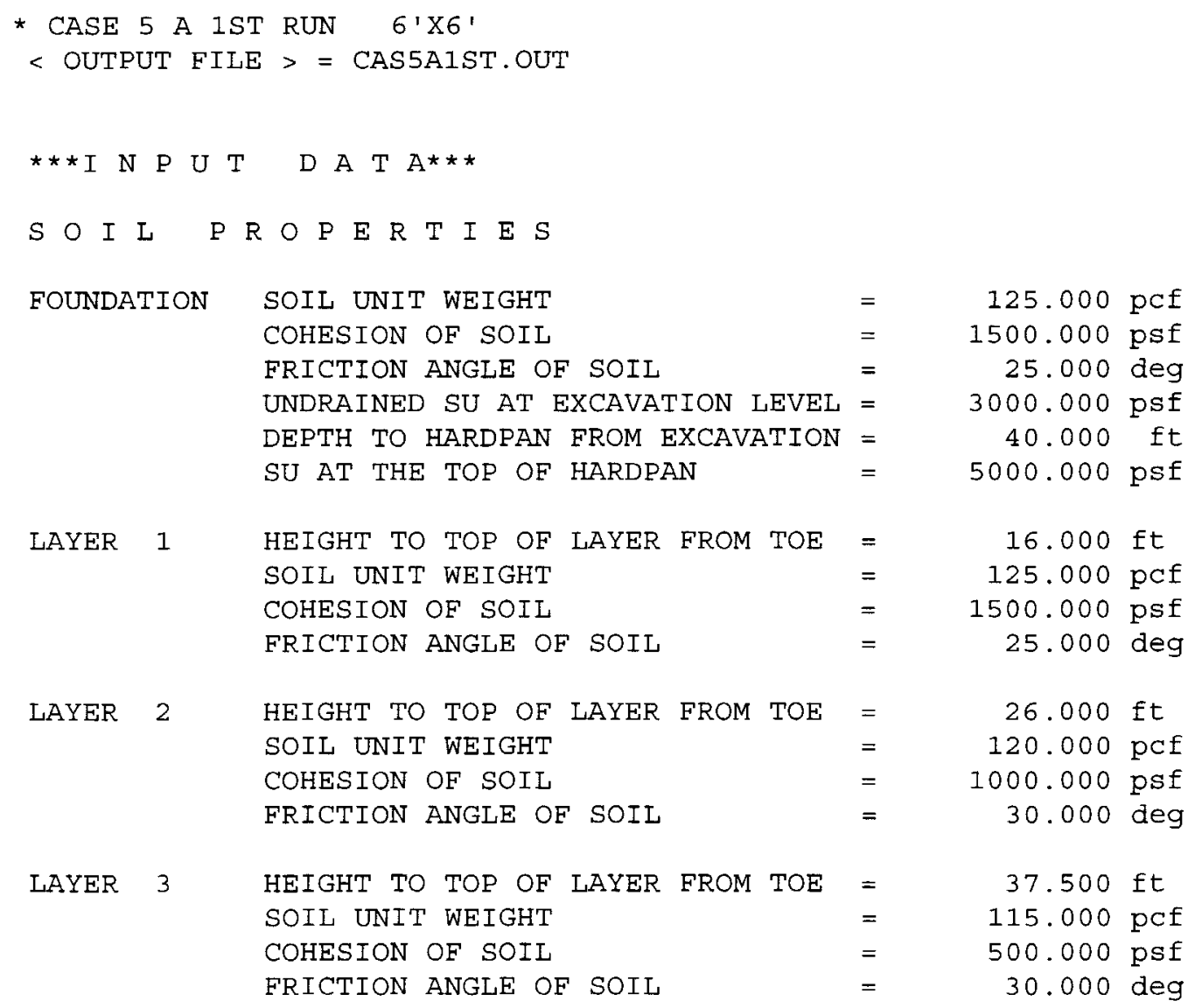

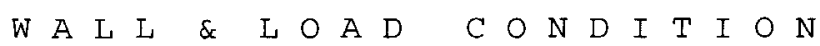

$\begin{array}{llr}\text { WALL INCLINATION ANGLE } & = & 5.000 \mathrm{deg} \\ \text { SURCHARGE LOAD } & = & 300.000 \mathrm{psf} \\ \text { HOR. ACCELERATION COEFF. } & = & .000\end{array}$

$N$ A I L P R O P E R T I E S

$\begin{array}{llr}\text { CROSS SECTIONAL AREA OF NAIL } & = & .790 \mathrm{si} \\ \text { GROUT DIAMETER } & = & 4.000 \mathrm{in} \\ \text { YIELD STRENGTH OF NAIL } & = & 60.000 \mathrm{ksi} \\ \text { NAIL INCLINATION ANGLE } & = & 20.000 \mathrm{deg} \\ \text { NAIL SKEW ANGLE AT SURFACE } & = & .000 \mathrm{deg} \\ \text { DEPTH TO UPPERMOST NAIL } & = & 2.000 \mathrm{ft} \\ \text { VER. SPACING OF NAIL } & = & 6.000 \mathrm{ft} \\ \text { HOR. SPACING OF NAIL } & = & 6.000 \mathrm{ft} \\ \text { TOTAL LENGTH OF UPPERMOST NAIL } & = & 25.000 \mathrm{ft} \\ \text { TOTAL LENGTH OF LOWERMOST NAIL } & = & 20.000 \mathrm{ft} \\ \text { TOTAL UNBONDED LENGTH OF NAIL } & = & 2.000 \mathrm{ft}\end{array}$

Figure 28. Case 5 part A Soil Nailing Calculation $1^{\text {st }}$ run 


\begin{tabular}{|c|c|c|c|c|c|c|c|c|}
\hline$I=$ & 2 & $A=$ & .133 & F.S. $=$ & 4.495 & $\mathrm{~T}=$ & 11184.2900 & $1 b / f$ \\
\hline$I=$ & 3 & $A=$ & .200 & F.S. $=$ & 2.813 & $\mathrm{~T}=$ & 15993.8400 & $I b / f$ \\
\hline$I=$ & 4 & $A=$ & .267 & F.S. $=$ & 2.215 & $\mathrm{~T}=$ & 18200.2800 & $1 \mathrm{~b} /$ \\
\hline$I=$ & 5 & $A=$ & .333 & F.S. $=$ & 1.910 & $\mathrm{~T}=$ & 18989.5800 & $1 \mathrm{~b} /$ \\
\hline$I=$ & 6 & $A=$ & .400 & F.S. $=$ & 1.731 & $\mathrm{~T}=$ & 18868.8800 & $1 \mathrm{~b} /$ \\
\hline$I=$ & 7 & $A=$ & .467 & F.S. $=$ & 1.615 & $\mathrm{~T}=$ & 18113.5700 & $1 \mathrm{~b} /$ \\
\hline$I=$ & 8 & $A=$ & .533 & F.S. $=$ & 1.539 & $T=$ & 16945.2800 & $1 \mathrm{~b} /$ \\
\hline$I=$ & 9 & $A=$ & .600 & F.S. $=$ & 1.492 & $T=$ & 15501.8300 & $1 \mathrm{~b} /$ \\
\hline$I=$ & 10 & $A=$ & .667 & F.S. $=$ & 1.461 & $\mathrm{~T}=$ & 13892.5600 & $1 \mathrm{~b} /$ \\
\hline$I=$ & 11 & $A=$ & .733 & F.S. $=$ & 1.447 & $\mathrm{~T}=$ & 12168.1600 & $1 \mathrm{~b} /$ \\
\hline$I=$ & 12 & $A=$ & .800 & F.S. $=$ & 1.444 & $\mathrm{~T}=$ & 10400.0600 & $1 \mathrm{~b} /$ \\
\hline$I=$ & 13 & $A=$ & .867 & F.S. $=$ & 1.458 & $\mathrm{~T}=$ & 8694.9650 & 1b/ \\
\hline$I=$ & 14 & $A=$ & .933 & F.S. = & 1.487 & $\mathrm{~T}=$ & 7359.0290 & $1 \mathrm{~b} /$ \\
\hline$I=$ & 15 & $A=$ & 1.000 & F.S. $=$ & 1.518 & $\mathrm{~T}=$ & 6300.6500 & $1 \mathrm{~b} /$ \\
\hline$I=$ & 16 & $A=$ & 1.067 & F.S. $=$ & 1.551 & $T=$ & 5532.0060 & $1 \mathrm{~b} /$ \\
\hline$I=$ & 17 & $A=$ & 1.133 & F.S. $=$ & 1.585 & $\mathrm{~T}=$ & 4815.3470 & $1 \mathrm{~b} /$ \\
\hline$I=$ & 18 & $A=$ & 1.200 & F.S. $=$ & 1.625 & $\mathrm{~T}=$ & 4349.9400 & $1 \mathrm{~b} /$ \\
\hline$I=$ & 19 & $A=$ & 1.267 & F.S. $=$ & 1.664 & $\mathrm{~T}=$ & 3979.5310 & $1 \mathrm{~b} /$ \\
\hline $\mathrm{I}=$ & 20 & $A=$ & 1.333 & F.S. $=$ & 1.703 & $\mathrm{~T}=$ & 3635.9900 & $\mathrm{Ib} /$ \\
\hline$I=$ & 21 & $\mathrm{~A}=$ & 1.400 & F.S. $=$ & 1.742 & $\mathrm{~T}=$ & 3317.1270 & $\mathrm{Ib} /$ \\
\hline$I=$ & 22 & $A=$ & 1.467 & F.S. $=$ & 1.783 & $\mathrm{~T}=$ & 3021.0720 & $1 \mathrm{~b} /$ \\
\hline$I=$ & 23 & $A=$ & 1.533 & F.S. $=$ & 1.824 & $\mathrm{~T}=$ & 2746.1790 & $1 \mathrm{~b} /$ \\
\hline$I=$ & 24 & $A=$ & 1.600 & F.S. $=$ & 1.867 & $\mathrm{~T}=$ & 2490.9690 & $1 \mathrm{~b} /$ \\
\hline$I=$ & 25 & $A=$ & 1.667 & F.S. $=$ & 1.911 & $T=$ & 2324.8800 & $1 \mathrm{~b} / \mathrm{s}$ \\
\hline$I=$ & 26 & $A=$ & 1.733 & F.S. $=$ & 1.957 & $\mathrm{~T}=$ & 2225.7320 & $1 \mathrm{~b} /$ \\
\hline$I=$ & 27 & $A=$ & 1.800 & F.S. $=$ & 2.004 & $\mathrm{~T}=$ & 2133.0070 & $\mathrm{Ib} /$ \\
\hline$I=$ & 28 & $\mathrm{~A}=$ & 1.867 & F.S. $=$ & 2.051 & $\mathrm{~T}=$ & 2046.2080 & $1 \mathrm{~b} /$ \\
\hline$I=$ & 29 & $A=$ & 1.933 & F.S. $=$ & 2.100 & $\mathrm{~T}=$ & 1964.8910 & $1 \mathrm{~b} /$ \\
\hline$I=$ & 30 & $A=$ & 2.000 & F.S. $=$ & 2.148 & $\mathrm{~T}=$ & 1888.6440 & $1 \mathrm{~b} /$ \\
\hline
\end{tabular}

$\mathrm{H} / \mathrm{LT}=1.500 \quad \mathrm{H} / \mathrm{LB}=1.875$

NO. OF NAILS (INCLUDING THE LOWERMOST) $=6$

* F.S. AGAINST SLIDING THROUGH TOE $=1.44$ NOT GOOD $<\mathbf{1 . 5}$

$\star \star$ F.S. AGAINST DEEP SEATED ROTATION $=4.32$

1 TH NAIL FORCE $=$

2 TH NAIL FORCE =

3 TH NAIL FORCE =

4 TH NAIL FORCE =

5 TH NAIL FORCE =

6 TH NAIL FORCE =

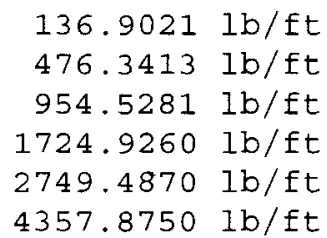

Figure 28. Case 5 part A Soil Nailing Calculation $1^{\text {st }}$ run (cont.) 
Step 2: Rerun design calculation and change the nail properties; the upper nail length will be $30 \mathrm{ft}$ and the lower nail length will be $20 \mathrm{ft}$, but keep the nail pattern as $6 \mathrm{ft}$ by 6ft. Results are shown in Fig. 29.

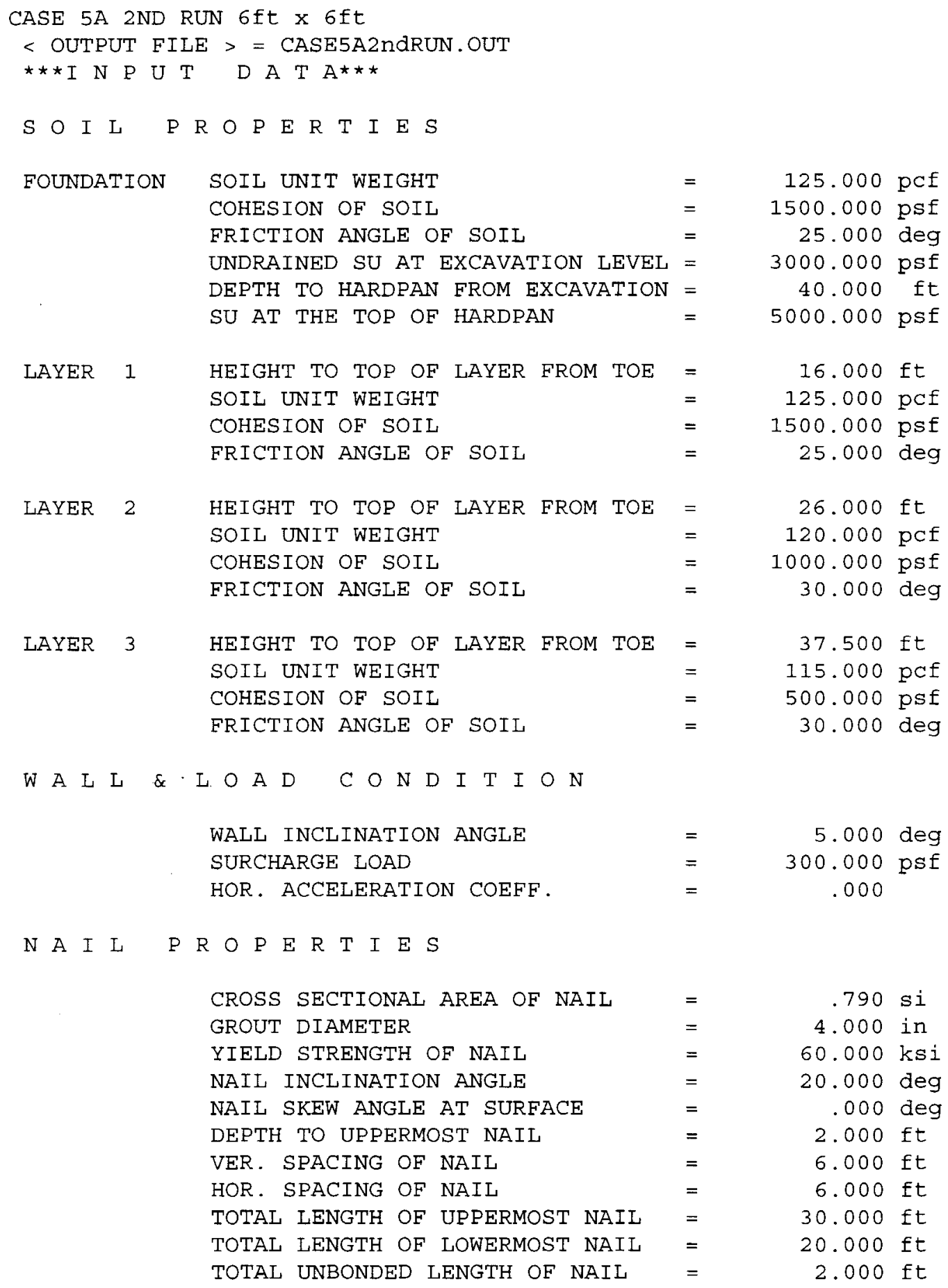

Figure 29. Case 5 part A Soil Nailing Calculation $2^{\text {nd }}$ run 


\begin{tabular}{|c|c|c|c|c|c|c|c|c|}
\hline$I=$ & 2 & $A=$ & .133 & F.S. $=$ & 4.437 & $\mathrm{~T}=$ & 12660.2600 & $1 b / f t$ \\
\hline$I=$ & 3 & $A=$ & .200 & F.S. $=$ & 2.826 & $T=$ & 17933.9200 & $1 b / f t$ \\
\hline$I=$ & 4 & $A=$ & .267 & F.S. $=$ & 2.248 & $\mathrm{~T}=$ & 20408.6800 & $1 \mathrm{~b} / \mathrm{ft}$ \\
\hline$I=$ & 5 & $A=$ & .333 & F.S. $=$ & 1.949 & $\mathrm{~T}=$ & 21413.1600 & $1 \mathrm{~b} / \mathrm{ft}$ \\
\hline$I=$ & 6 & $A=$ & .400 & F.S. $=$ & 1.773 & $\mathrm{~T}=$ & 21463.4100 & $1 b / f t$ \\
\hline$I=$ & 7 & $A=$ & .467 & F.S. $=$ & 1.661 & $\mathrm{~T}=$ & 20819.1600 & $1 b / f t$ \\
\hline$I=$ & 8 & $A=$ & .533 & F.S. $=$ & 1.588 & $\mathrm{~T}=$ & 19762.9300 & $1 \mathrm{~b} / \mathrm{ft}$ \\
\hline$I=$ & 9 & $A=$ & .600 & $F \cdot S .=$ & 1.541 & $\mathrm{~T}=$ & 18412.4800 & $1 b / f t$ \\
\hline$I=$ & 10 & $A=$ & .667 & F.S. $=$ & 1.513 & $\mathrm{~T}=$ & 16870.5300 & $1 \mathrm{~b} / \mathrm{ft}$ \\
\hline$I=$ & 11 & $A=$ & .733 & F.S. $=$ & 1.497 & $\mathrm{~T}=$ & 15221.9900 & $1 b / f t$ \\
\hline$I=$ & 12 & $A=$ & .800 & F.S. $=$ & 1.494 & $\mathrm{~T}=$ & 13501.0600 & $1 b / f t$ \\
\hline$I=$ & 13 & $A=$ & .867 & F.S. $=$ & 1.500 & $\mathrm{~T}=$ & 11764.9500 & $1 \mathrm{~b} / \mathrm{ft}$ \\
\hline$I=$ & 14 & $A=$ & .933 & F.S. $=$ & 1.511 & $\mathrm{~T}=$ & 10039.9700 & $1 b / f t$ \\
\hline$I=$ & 15 & $A=$ & 1.000 & F.S. $=$ & 1.527 & $\mathrm{~T}=$ & 8253.2720 & $1 b / f t$ \\
\hline$I=$ & 16 & $A=$ & 1.067 & F.S. $=$ & 1.561 & $\mathrm{~T}=$ & 6749.6450 & $1 \mathrm{~b} / \mathrm{ft}$ \\
\hline$I=$ & 17 & $A=$ & 1.133 & F.S. $=$ & 1.602 & $\mathrm{~T}=$ & 5671.0580 & $I b / f t$ \\
\hline $\mathrm{I}=$ & 18 & $A=$ & 1.200 & F.S. $=$ & 1.646 & $\mathrm{~T}=$ & 4969.5170 & $1 \mathrm{~b} / \mathrm{ft}$ \\
\hline$I=$ & 19 & $A=$ & 1.267 & F.S. $=$ & 1.689 & $\mathrm{~T}=$ & 4324.7430 & $1 b / f t$ \\
\hline$I=$ & 20 & $A=$ & 1.333 & F.S. $=$ & 1.736 & $\mathrm{~T}=$ & 3876.8120 & $1 \mathrm{~b} / \mathrm{ft}$ \\
\hline$I=$ & 21 & $A=$ & 1.400 & F.S. $=$ & 1.783 & $\mathrm{~T}=$ & 3547.9620 & $\mathrm{Ib} / \mathrm{ft}$ \\
\hline$I=$ & 22 & $A=$ & 1.467 & F.S. $=$ & 1.828 & $\mathrm{~T}=$ & 3245.5210 & $1 b / f t$ \\
\hline$I=$ & 23 & $A=$ & 1.533 & F.S. $=$ & 1.874 & $\mathrm{~T}=$ & 2966.6840 & $1 b / f t$ \\
\hline$I=$ & 24 & $A=$ & 1.600 & F.S. $=$ & 1.919 & $\mathrm{~T}=$ & 2709.1320 & $1 \mathrm{~b} / \mathrm{ft}$ \\
\hline$I=$ & 25 & $A=$ & 1.667 & F.S. $=$ & 1.965 & $\mathrm{~T}=$ & 2470.9180 & $1 b / f t$ \\
\hline$I=$ & 26 & $A=$ & 1.733 & F.S. $=$ & 2.010 & $\mathrm{~T}=$ & 2250.3700 & $1 b / f t$ \\
\hline$I=$ & 27 & $A=$ & 1.800 & F.S. $=$ & 2.057 & $\mathrm{~T}=$ & 2086.4750 & $1 b / f t$ \\
\hline$I=$ & 28 & $A=$ & 1.867 & F.S. $=$ & 2.106 & $\mathrm{~T}=$ & 2001.4090 & $1 \mathrm{~b} / \mathrm{ft}$ \\
\hline$I=$ & 29 & $A=$ & 1.933 & F.S. $=$ & 2.155 & $\mathrm{~T}=$ & 1921.9540 & $1 \mathrm{~b} / \mathrm{ft}$ \\
\hline$I=$ & 30 & $A=$ & 2.000 & F.S. $=$ & 2.205 & $\mathrm{~T}=$ & 1847.6220 & $1 \mathrm{~b} / \mathrm{ft}$ \\
\hline
\end{tabular}

$\mathrm{H} / \mathrm{LT}=1.250 \quad \mathrm{H} / \mathrm{LB}=1.875$

NO. OF NAILS (INCLUDING THE LOWERMOST) $=6$

* F.S. AGAINST SLIDING THROUGH TOE $=1.49$ still< 1.5

**F.S. AGAINST DEEP SEATED ROTATION $=4.32$

1 TH NAIL FORCE =

2 TH NAIL FORCE =

3 TH NAIL FORCE =

4 TH NAIL FORCE =

5 TH NAIL FORCE =

$6 \mathrm{TH}$ NAIL FORCE =

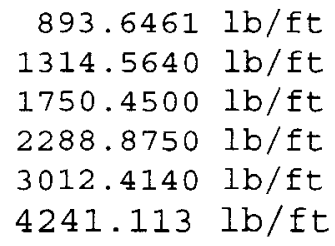

Figure 29. Case 5 part A Soil Nailing Calculation $2^{\text {nd }}$ run (cont.) 
Step 3: Rerun design calculation to get the factor of safety for sliding through toe equal to 1.5 or greater. Change nail pattern to 5.5 feet by 5 feet and keep upper nail length $30 \mathrm{ft}$ and lower nail $20 \mathrm{ft}$.

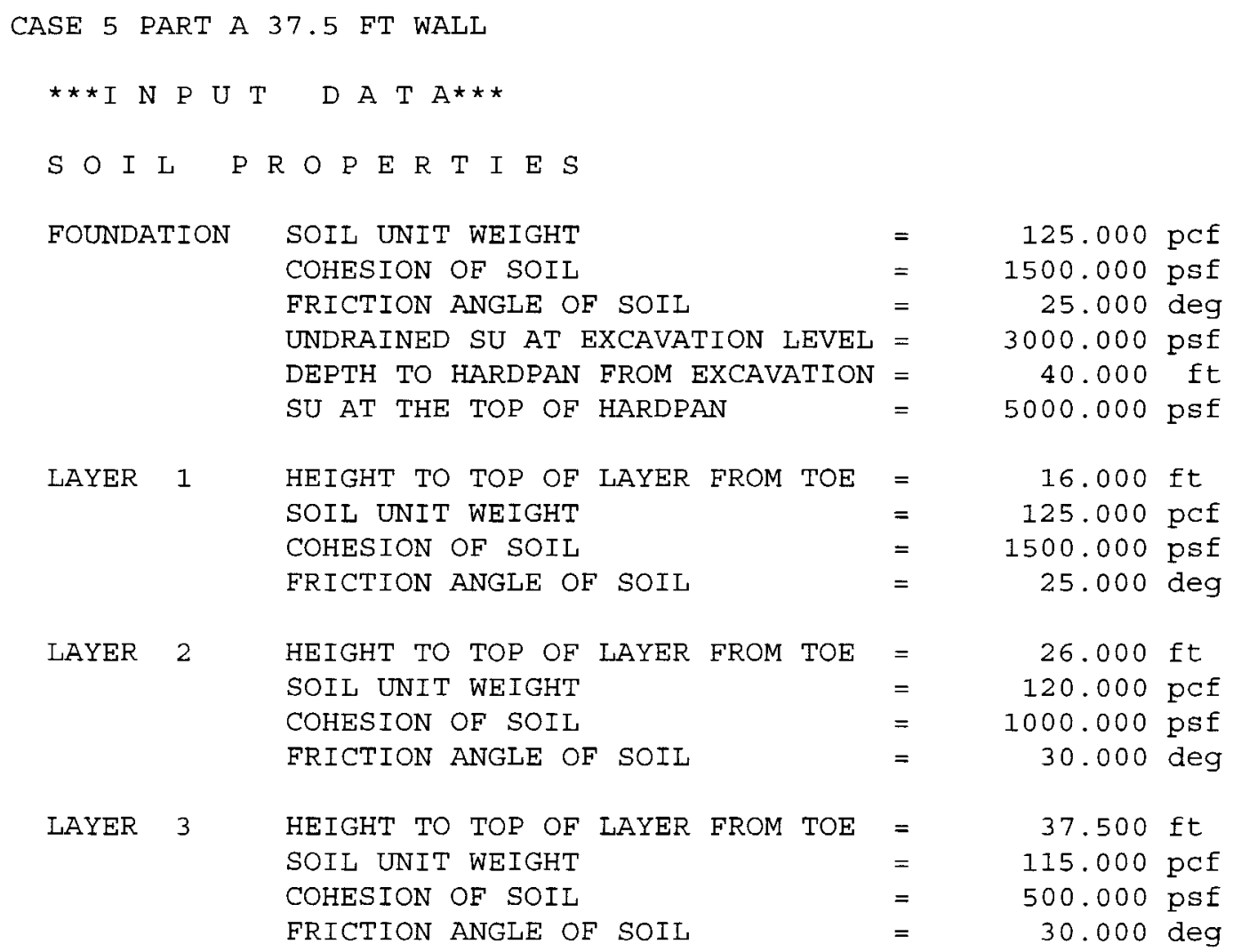

W A L L \& L O A D $\quad$ C O N D I T I O N

$\begin{array}{llr}\text { WALL INCLINATION ANGLE } & = & 5.000 \text { deg } \\ \text { SURCHARGE LOAD } & = & 300.000 \mathrm{psf} \\ \text { HOR. ACCELERATION COEFF. } & = & .000\end{array}$

$N$ A I L $\quad P$ R O $P$ E

$\begin{array}{llr}\text { CROSS SECTIONAL AREA OF NAIL } & = & .790 \mathrm{si} \\ \text { GROUT DIAMETER } & = & 4.000 \mathrm{in} \\ \text { YIELD STRENGTH OF NAIL } & = & 60.000 \mathrm{ksi} \\ \text { NAIL INCLINATION ANGLE } & = & 20.000 \mathrm{deg} \\ \text { NAIL SKEW ANGLE AT SURFACE } & = & .000 \mathrm{deg} \\ \text { DEPTH TO UPPERMOST NAIL } & = & 2.000 \mathrm{ft} \\ \text { VER. SPACING OF NAIL } & = & 5.500 \mathrm{ft} \\ \text { HOR. SPACING OF NAIL } & = & 5.000 \mathrm{ft} \\ \text { TOTAL LENGTH OF UPPERMOST NAIL } & = & 30.000 \mathrm{ft} \\ \text { TOTAL LENGTH OF LOWERMOST NAIL } & = & 25.000 \mathrm{ft} \\ \text { TOTAL UNBONDED LENGTH OF NAIL } & = & 2.000 \mathrm{ft}\end{array}$

Figure 30. Case 5 part A Soil Nailing Calculation $3^{\text {rd }}$ run 


\begin{tabular}{|c|c|c|c|c|c|c|c|c|}
\hline$I=$ & 2 & $A=$ & .133 & $\mathrm{~F} \cdot \mathrm{S} .=$ & 4.102 & $T=$ & 22879.6900 & $1 \mathrm{~b} / \mathrm{f}$ \\
\hline$I=$ & 3 & $A=$ & .200 & F.S. $=$ & 2.896 & $\mathrm{~T}=$ & 29925.6400 & $1 \mathrm{~b} / \mathrm{f}$ \\
\hline$I=$ & 4 & $A=$ & .267 & F.S. $=$ & 2.421 & $\mathrm{~T}=$ & 33272.0000 & $1 \mathrm{~b} / \mathrm{f}$ \\
\hline$I=$ & 5 & $A=$ & .333 & F.S. $=$ & 2.166 & $\mathrm{~T}=$ & 34650.8500 & $1 b / f$ \\
\hline$I=$ & 6 & $A=$ & .400 & F.S. $=$ & 2.007 & $T=$ & 34955.6000 & $1 b / f$ \\
\hline$I=$ & 7 & $A=$ & .467 & F.S. = & 1.903 & $\mathrm{~T}=$ & 34417.8600 & $1 b / f$ \\
\hline$I=$ & 8 & $A=$ & .533 & F.S. $=$ & 1.835 & $T=$ & 33306.4300 & $I b / f$ \\
\hline$I=$ & 9 & $A=$ & .600 & F.S. $=$ & 1.787 & $\mathrm{~T}=$ & 31881.5700 & $1 \mathrm{~b} / \mathrm{f}$ \\
\hline$I=$ & 10 & $A=$ & .667 & F.S. $=$ & 1.756 & $\mathrm{~T}=$ & 30204.3800 & $1 b / f$ \\
\hline$I=$ & 11 & $A=$ & .733 & F.S. $=$ & 1.738 & $\mathrm{~T}=$ & 28361.3900 & $1 \mathrm{~b} / \mathrm{f}$ \\
\hline$I=$ & 12 & $A=$ & .800 & F.S. $=$ & 1.729 & $\mathrm{~T}=$ & 26433.6400 & $1 b / f$ \\
\hline$I=$ & 13 & $A=$ & .867 & $\mathrm{~F} \cdot \mathrm{S} .=$ & 1.729 & $\mathrm{~T}=$ & 24424.6300 & $1 b / f$ \\
\hline$I=$ & 14 & $A=$ & .933 & F.S. $=$ & 1.736 & $\mathrm{~T}=$ & 22403.3800 & $1 b / f$ \\
\hline$I=$ & 15 & $A=$ & 1.000 & F.S. $=$ & 1.746 & $\mathrm{~T}=$ & 20322.9200 & $1 \mathrm{~b} / \mathrm{f}$ \\
\hline$I=$ & 16 & $A=$ & 1.067 & $\mathrm{~F} \cdot \mathrm{S} .=$ & 1.777 & $\mathrm{~T}=$ & 18370.5800 & $1 b / f$ \\
\hline$I=$ & 17 & $A=$ & 1.133 & $\mathrm{~F} \cdot \mathrm{S} .=$ & 1.815 & $\mathrm{~T}=$ & 16731.5800 & $1 b / f$ \\
\hline$I=$ & 18 & $A=$ & 1.200 & F.S. $=$ & 1.851 & $\mathrm{~T}=$ & 15343.4200 & $1 b / f$ \\
\hline$I=$ & 19 & $A=$ & 1.267 & F.S. = & 1.889 & $T=$ & 14258.7000 & $1 \mathrm{~b} / \mathrm{f}$ \\
\hline$I=$ & 20 & $A=$ & 1.333 & F.S. $=$ & 1.929 & $\mathrm{~T}=$ & 13332.1200 & $1 b / f$ \\
\hline$I=$ & 21 & $A=$ & 1.400 & F.S. $=$ & I. 967 & $\mathrm{~T}=$ & 12469.8500 & $1 b / f$ \\
\hline$I=$ & 22 & $A=$ & 1.467 & $\mathrm{~F} \cdot \mathrm{S} .=$ & 2.007 & $\mathrm{~T}=$ & 11722.2600 & $1 b / f$ \\
\hline$I=$ & 23 & $A=$ & 1.533 & F.S. $=$ & 2.049 & $\mathrm{~T}=$ & 11189.4900 & $1 b / f$ \\
\hline$I=$ & 24 & $A=$ & 1.600 & F.S. = & 2.092 & $\mathrm{~T}=$ & 10690.9700 & $1 b / f$ \\
\hline$I=$ & 25 & $A=$ & 1.667 & F.S. $=$ & 2.134 & $\mathrm{~T}=$ & 10223.0400 & $1 b / f$ \\
\hline$I=$ & 26 & $A=$ & 1.733 & F.S. $=$ & 2.177 & $\mathrm{~T}=$ & 9782.7750 & $I b / f$ \\
\hline$I=$ & 27 & $A=$ & 1.800 & F.S. $=$ & 2.220 & $\mathrm{~T}=$ & 9367.7940 & $1 b / f$ \\
\hline$I=$ & 28 & $A=$ & 1.867 & F.S. $=$ & 2.264 & $T=$ & 8976.1250 & $1 b / f$ \\
\hline$I=$ & 29 & $A=$ & 1.933 & F.S. $=$ & 2.308 & $\mathrm{~T}=$ & 8606.0970 & $1 b / f$ \\
\hline$I=$ & 30 & $A=$ & 2.000 & F.S. $=$ & 2.353 & $\mathrm{~T}=$ & 8256.2400 & $1 b / f$ \\
\hline
\end{tabular}

$\mathrm{H} / \mathrm{LT}=1.250 \mathrm{H} / \mathrm{LB}=1.500$

NO. OF NAILS (INCLUDING THE LOWERMOST) = 7

**.S. AGAINST SLIDING THROUGH TOE $=1.73$ good $>1.5$

**F.S. AGAINST DEEP SEATED ROTATION $=4.32$

1 TH NAIL FORCE =

2 TH NAIL FORCE =

3 TH NAIL FORCE =

$4 \mathrm{TH}$ NAIL FORCE = $5 \mathrm{TH}$ NAIL FORCE = $6 \mathrm{TH}$ NAIL FORCE = $7 \mathrm{TH}$ NAIL FORCE = $\begin{array}{rl}958.8588 & \mathrm{lb} / \mathrm{ft} \\ 1616.2710 & \mathrm{lb} / \mathrm{ft} \\ 2323.0820 & \mathrm{lb} / \mathrm{ft} \\ 3266.6650 & \mathrm{lb} / \mathrm{ft} \\ 4331.3090 & \mathrm{lb} / \mathrm{ft} \\ 5805.6800 & \mathrm{lb} / \mathrm{ft} \\ 8131.7790 & \mathrm{lb} / \mathrm{ft}\end{array}$

Figure 30. Case 5 part A Soil Nailing Calculation $3^{\text {rd }}$ run (cont.) 


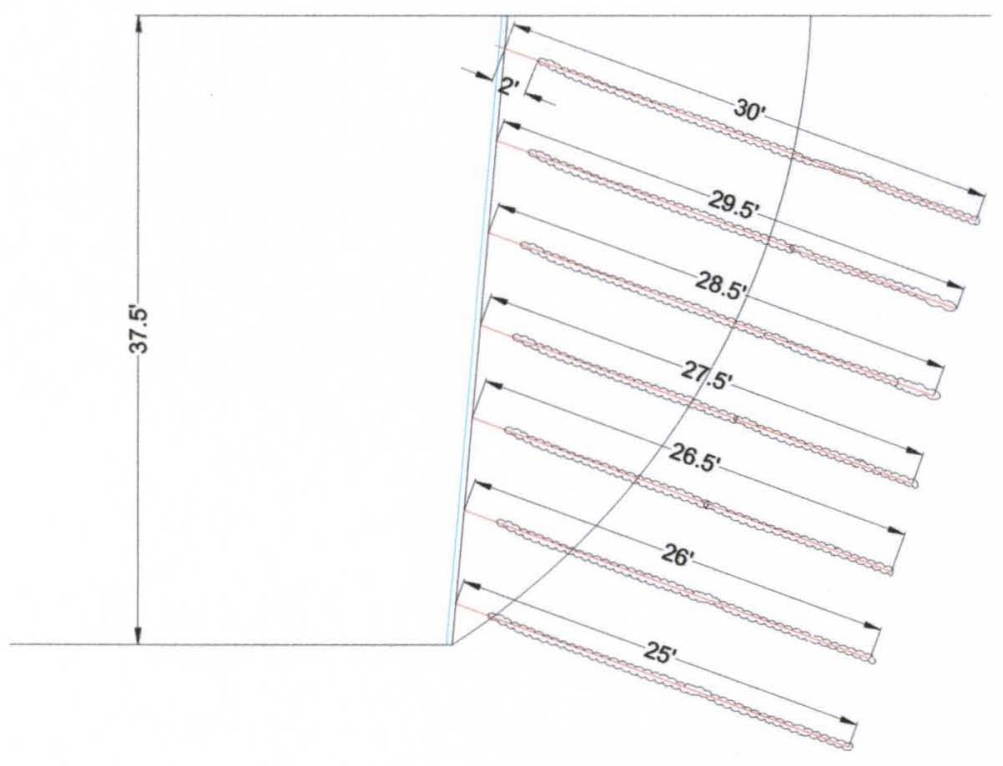

Figure 31. Case 5 part A Final Soil Nail Section (all dimensions in feet)

Follow same steps for part B, with a wall height of 26 feet, and get the final design as shown on the following pages. 


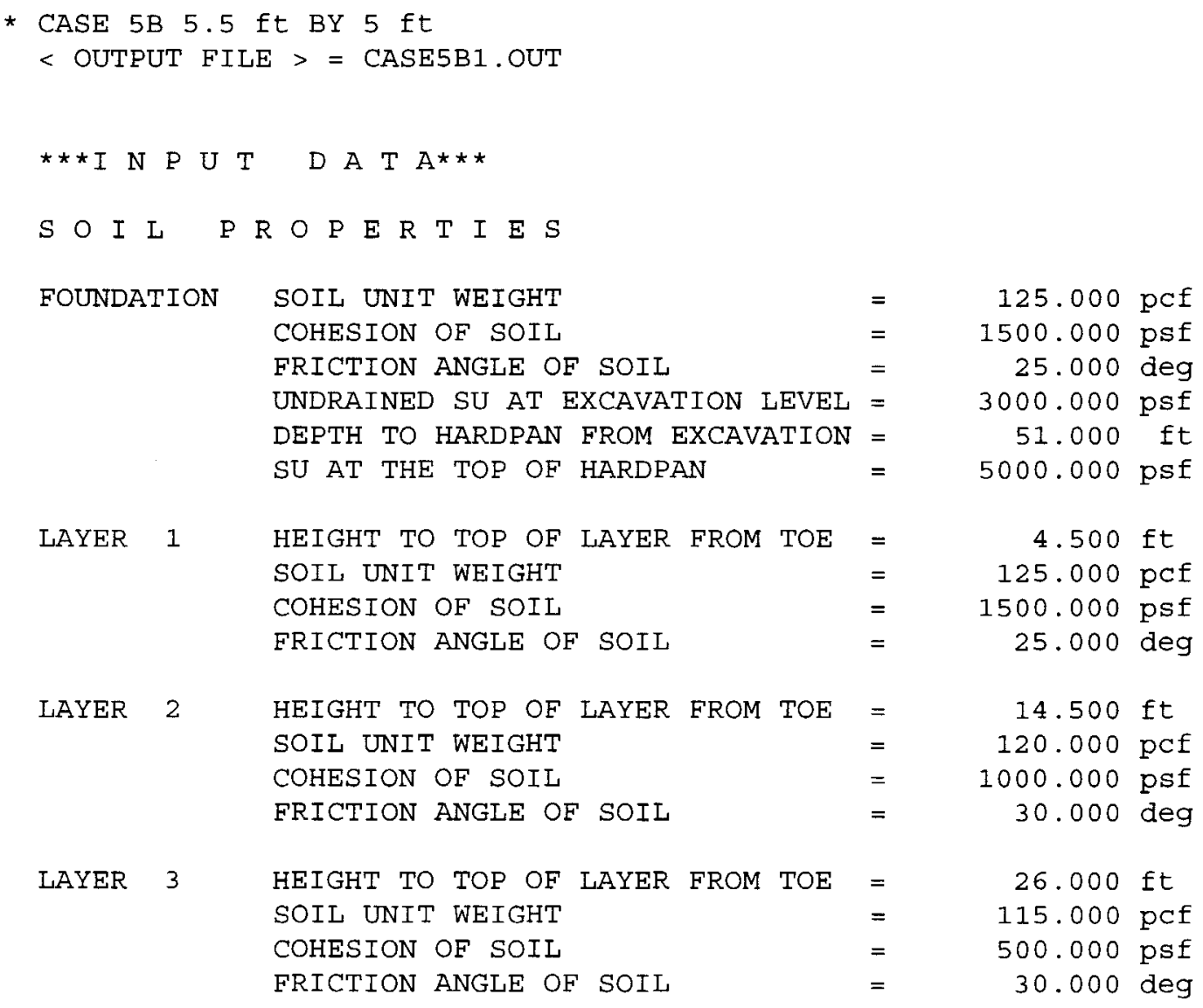

W A L L \& L $O A D$ D $\quad \mathrm{C} O \mathrm{~N}$ D

$\begin{array}{llr}\text { WALL INCLINATION ANGLE } & = & 5.000 \text { deg } \\ \text { SURCHARGE LOAD } & = & 300.000 \text { psf } \\ \text { HOR. ACCELERATION COEFF. } & = & .000\end{array}$

$N A I L \quad P R O F E R T I E S$

$\begin{array}{llr}\text { CROSS SECTIONAL AREA OF NAIL } & = & .790 \mathrm{si} \\ \text { GROUT DIAMETER } & = & 4.000 \mathrm{in} \\ \text { YIELD STRENGTH OF NAIL } & = & 60.000 \mathrm{ksi} \\ \text { NAIL INCLINATION ANGLE } & = & 20.000 \mathrm{deg} \\ \text { NAIL SKEW ANGLE AT SURFACE } & = & .000 \mathrm{deg} \\ \text { DEPTH TO UPPERMOST NAIL } & = & 2.000 \mathrm{ft} \\ \text { VER. SPACING OF NAIL } & = & 5.500 \mathrm{ft} \\ \text { HOR. SPACING OF NAIL } & = & 5.000 \mathrm{ft} \\ \text { TOTAL LENGTH OF UPPERMOST NAIL } & = & 20.000 \mathrm{ft} \\ \text { TOTAL LENGTH OF LOWERMOST NAIL } & = & 15.000 \mathrm{ft} \\ \text { TOTAL UNBONDED LENGTH OF NAIL } & = & 2.000 \mathrm{ft}\end{array}$

Figure 32. Case 5 part B Soil Nailing Calculation 


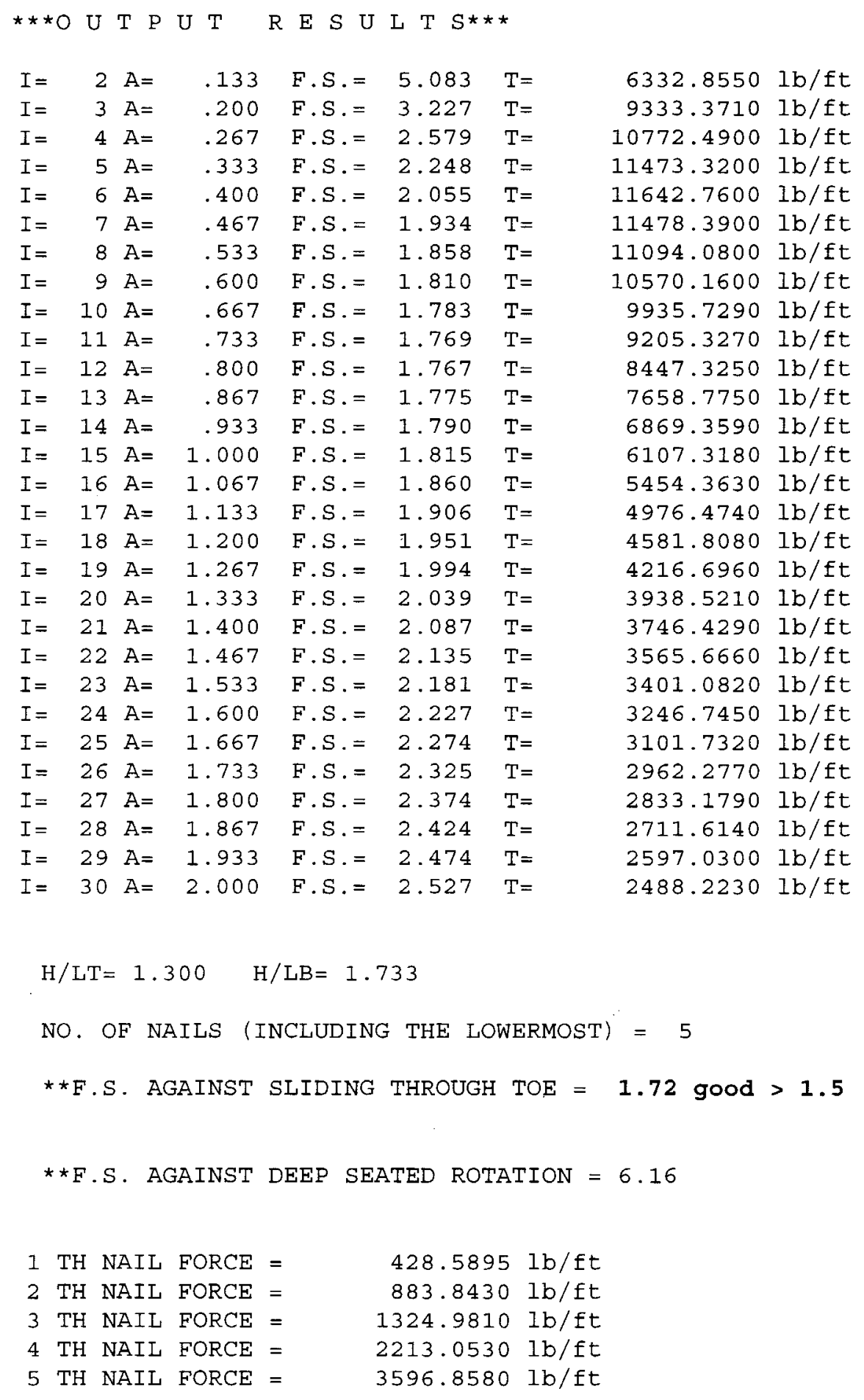

Figure 32. Case 5 part B Soil Nailing Calculation (cont.) 


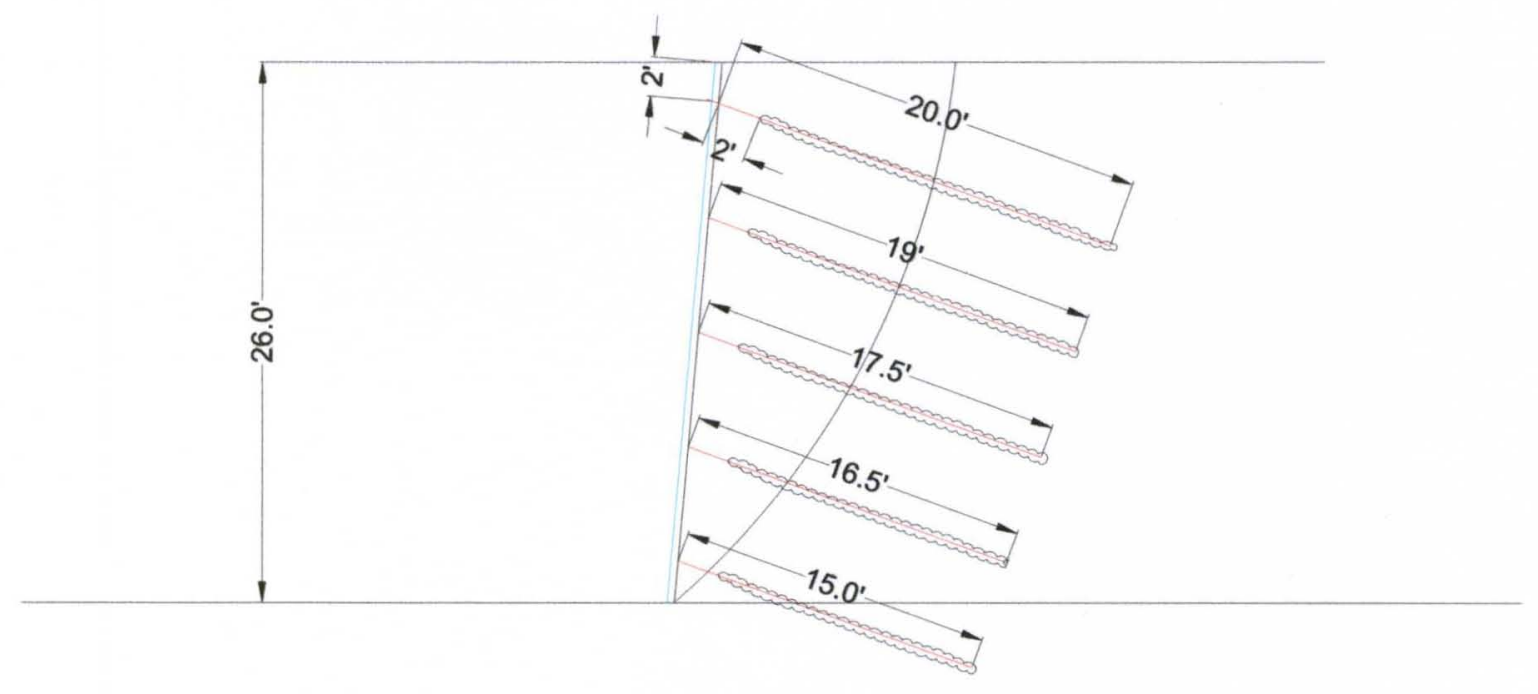

Figure 33. Case 5 Part B Final Soil Nail Section (all dimensions in feet)

By experience, it is very practical to keep the same pattern for soil nailing even if there are two different excavation levels to keep commonality in the job site and avoiding any worker mistakes.

The next step is materials take off as shown in Table 4 and Table 5. 
Table 4. Case 5 Soil Nailing Materials Takeoff part A and part B

\begin{tabular}{|c|c|c|c|c|}
\hline part A & & Quantity & $\begin{array}{l}\text { Unit } \\
\text { Length }\end{array}$ & $\begin{array}{l}\text { Total } \\
\text { Length } \\
\end{array}$ \\
\hline \multirow[t]{9}{*}{ \#8 rebar } & $1 \mathrm{st}$ & 79 & 30.00 & 2,370 \\
\hline & 2 nd & 78 & 29.50 & 2,301 \\
\hline & $3 \mathrm{rd}$ & 77 & 28.50 & 2,195 \\
\hline & 4 th & 76 & 27.50 & 2,090 \\
\hline & 5 th & 75 & 26.50 & 1,988 \\
\hline & 6 th & 73 & 26.00 & 1,898 \\
\hline & 7 th & 71 & 25.00 & 1,775 \\
\hline & & $=======$ & & $=======$ \\
\hline & & 529 & & $14,616.00$ \\
\hline part B & & Quantity & $\begin{array}{c}\text { Unit } \\
\text { Length }\end{array}$ & $\begin{array}{c}\text { Total } \\
\text { Length } \\
\end{array}$ \\
\hline \multirow[t]{7}{*}{ \#8 rebar } & $1 \mathrm{st}$ & 80 & 20.00 & 1,600 \\
\hline & $2 \mathrm{nd}$ & 79 & 19.00 & 1,501 \\
\hline & $3 \mathrm{rd}$ & 78 & 17.50 & 1,365 \\
\hline & 4 th & 76 & 16.50 & 1,254 \\
\hline & 5 th & 75 & 15.00 & 1,125 \\
\hline & & $=======$ & & $======$ \\
\hline & & 388 & & $6,845.00$ \\
\hline \#4 wales & 18,412 & $\mathrm{ft}$ & & \\
\hline $\begin{array}{r}6 \times 6 \text { wire } \\
\text { mesh } \\
\end{array}$ & 24,318 & $\mathrm{sqft}$ & & \\
\hline $22^{\prime \prime}$ gunnite & 24,318 & sqft & 297.22 & cy \\
\hline no. of nails & 917 & & & \\
\hline
\end{tabular}

Table 5. Case 5 Soil Nailing Materials takeoff

\begin{tabular}{|r|c|l|}
\hline SOLL NA ILING & & \\
\hline total linear ft of nails drill & 21,461 & $\mathrm{ft}$ \\
\hline \# 8 total linear ft of nails steel & 21,461 & $\mathrm{ft}$ \\
\hline no. of soil nails & 917 & each \\
\hline no. of soil nails plates \& nuts & 917 & each \\
\hline$\# 4$ wales & 18,412 & $\mathrm{lft}$ \\
\hline 6x6 wire mesh & $24,318.00$ & sqft \\
\hline shotcrete or gunnite 2,2" & $24,318.00$ & sqft \\
\hline layout & 40 & $\mathrm{man} / \mathrm{day}$ \\
\hline & & \\
\hline
\end{tabular}

Then the next step is to calculate the soil nailing cost, as shown in Figs. 34 and 35. 


\section{$\underline{\text { Case } 5 \text { Part A Soil Nailing Cost }}$}

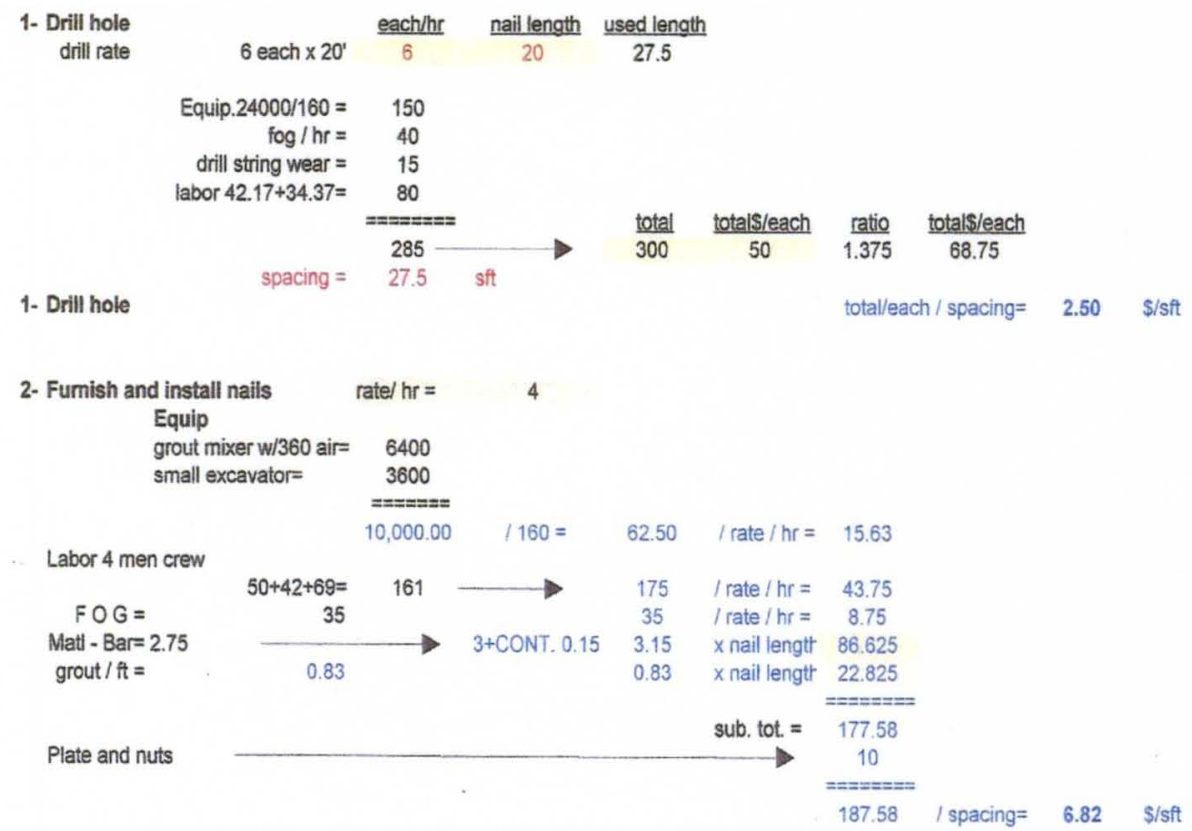

3- Place $6 \times 6$ mesh w/ miradrain

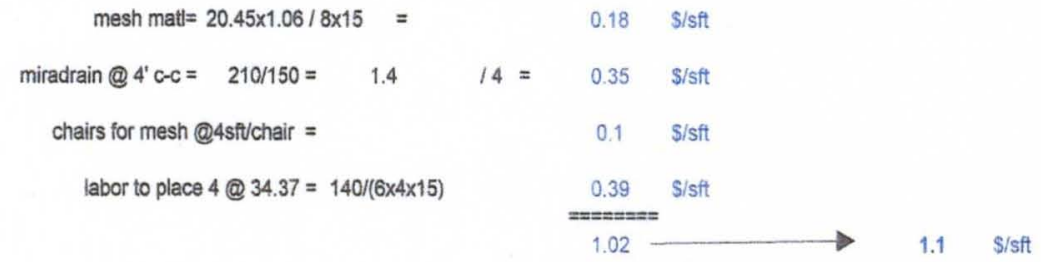

contin. walers @ dbl \#4 and 4'

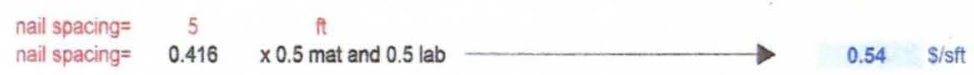

4- Shotcrete

$82.5 \times 1.06+75 /$ cy sub/place

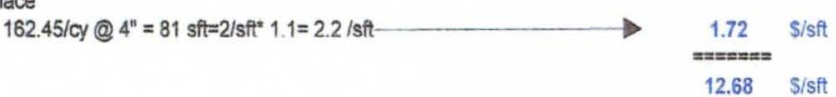

5- over-all supervision @ 750 sfviday $75 \times 8 / 750=0.8$

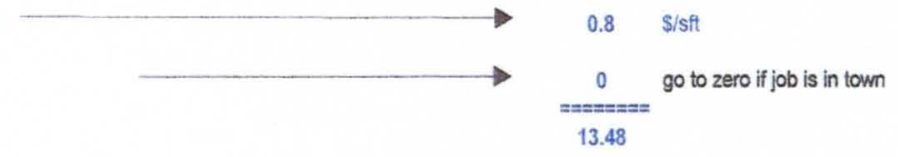

6- OTA 6 men $\times 100 /$ day $/ 750: \quad 0.8$

7- MOB AND DEMOB+ SHOP DRAWING $(2500+2500+5000) / 27000$

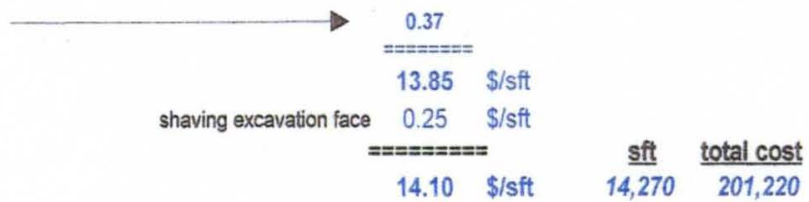

Figure 34 Case 5 part A Soil Nailing Cost 


\section{Case 5 Part B Soil Nailing Cost}

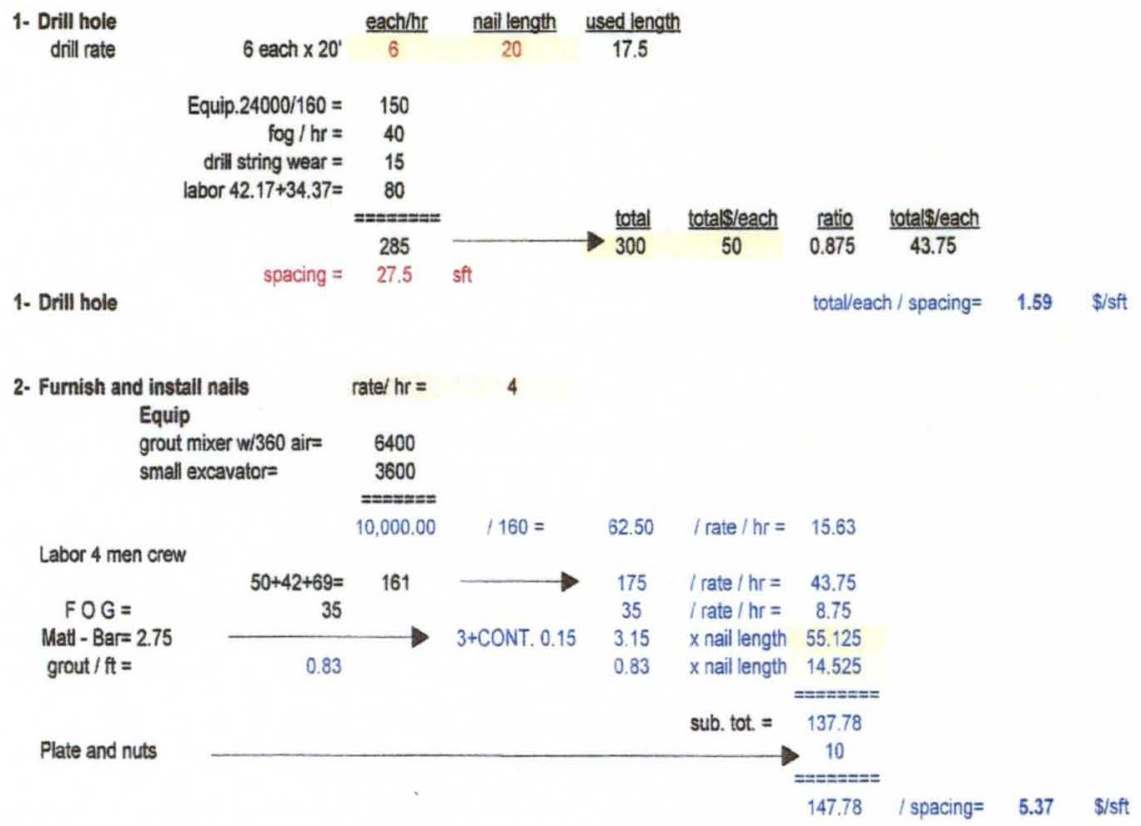

3. Place $6 \times 6$ mesh wi miradrain

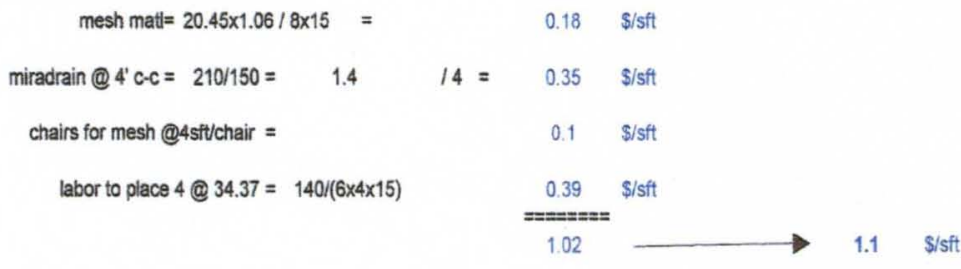

contin. wailers @ $\mathrm{dbl} \# 4$ and $4^{\prime}$

nail spacing $=$

nail spacing $=0.416 \times 0.5$ mat and $0.5 \mathrm{lab} \longrightarrow 0.54 \mathrm{~S} / \mathrm{st}$

4 Shotcrete

$82.5 \times 1.06+75 /$ cy sub/place

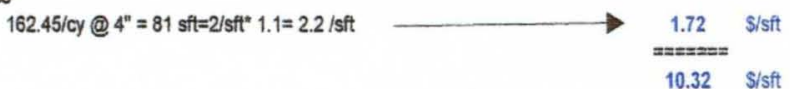

5- over-all supervision @ 750 sftday $75 \times 8 / 750=0.8$

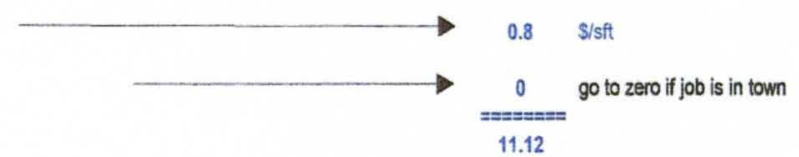

6- OTA 6 men $\times 100 /$ day $/ 750 \mathrm{sft} \quad 0.8$

11.12

7. MOB AND DEMOB+ SHOP DRAWING $(2500+2500+5000) / 27000$

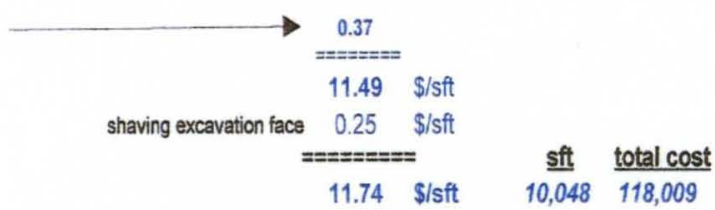

Figure 35. Case 5 part B Soil Nailing Cost 
Next, calculate the total cost and unit cost for the project part A and part B together.

Table 6. Case 5 part A, and part B Soil Nailing Cost

\begin{tabular}{|c|c|c|c|}
\hline & Soil Nailing Area Sqft & Unit cost \$/sqft & Total Cost \$ \\
\hline Part A & 14,270 & 14.1 & 201,220 \\
\hline Part B & 10,048 & 11.74 & 118,009 \\
\hline Total A+B & 24,318 & 13.13 & 319,229 \\
\hline
\end{tabular}




\section{CHAPTER 4}

\section{RESULTS OF ANALYSES}

Several cost comparison studies were done for both systems; total cost versus total cost; unit cost versus unit cost, and soil nailing cost as a percentage of conventional system cost, for all fifteen projects.

\subsection{Cost of Conventional Systems}

Table 7 below shows total cost, total square footage and the unit cost in dollars per square foot, of the conventional systems for the fifteen projects

Table 7. Costs for Conventional System

\begin{tabular}{|c|c|c|c|}
\hline CASE NO. & Total cost \$ & Area Sq ft & Unit cost \$/Sq ft \\
\hline CASE 1 & 254,352 & 12,560 & 20.25 \\
\hline CASE 2 & 519,479 & 22,400 & 23.19 \\
\hline CASE 3 & 49,445 & 1,875 & 26.37 \\
\hline CASE 4 & 188,197 & 8,940 & 21.05 \\
\hline CASE 5 & 514,285 & 24,318 & 21.15 \\
\hline CASE 6 & 567,366 & 24,933 & 22.76 \\
\hline CASE 7 & 69,567 & 3,020 & 23.04 \\
\hline CASE 8 & 294,056 & 13,234 & 22.22 \\
\hline CASE 9 & 179,376 & 8,514 & 21.07 \\
\hline CASE 10 & 235,262 & 11,940 & 19.70 \\
\hline CASE 11 & 138,127 & 6,218 & 22.21 \\
\hline CASE 12 & 325,384 & 14,710 & 22.12 \\
\hline CASE 13 & 68,565 & 2,765 & 24.80 \\
\hline CASE 14 & 95,346 & 4,100 & 23.26 \\
\hline CASE 15 & $1,833,996$ & 71,820 & 25.54 \\
\hline
\end{tabular}




\subsection{Cost of Soil Nailing Systems}

Table 8 below shows total cost, total square footage, and unit cost in dollars per square foot of the soil nailing systems for the fifteen projects; the table also shows the soil nailing cost as a percentage of the conventional system cost.

Table 8. Cost of Soil Nailing Systems

\begin{tabular}{|c|c|c|c|c|}
\hline $\begin{array}{c}\text { CASE } \\
\text { NO. }\end{array}$ & Total Cost, $\$$ & Area, Sqft & Unit cost, $\mathbf{\$} \mathbf{\text { Sqft }}$ & $\begin{array}{c}\text { Cost ratio (Soil nailing } \\
\text { /Conventional) } \mathbf{1 0 0}\end{array}$ \\
\hline CASE 1 & 156,258 & 12,560 & 12.44 & $61.43 \%$ \\
\hline CASE 2 & 322,224 & 22,400 & 14.39 & $62.03 \%$ \\
\hline CASE 3 & 20,531 & 1,875 & 10.95 & $41.52 \%$ \\
\hline CASE 4 & 127,796 & 8,940 & 14.29 & $67.91 \%$ \\
\hline CASE 5 & 319,229 & 24,318 & 13.13 & $62.07 \%$ \\
\hline CASE 6 & 383,761 & 24,933 & 15.39 & $67.64 \%$ \\
\hline CASE 7 & 31,056 & 3,020 & 10.28 & $44.64 \%$ \\
\hline CASE 8 & 180,362 & 13,234 & 13.63 & $61.34 \%$ \\
\hline CASE 9 & 127,401 & 8,514 & 14.96 & $71.02 \%$ \\
\hline CASE 10 & 176,399 & 11,940 & 14.77 & $74.98 \%$ \\
\hline CASE 11 & 74,648 & 6,218 & 12.01 & $54.04 \%$ \\
\hline CASE 12 & 212,131 & 14,710 & 14.42 & $65.19 \%$ \\
\hline CASE 13 & 30,266 & 2,765 & 10.95 & $44.14 \%$ \\
\hline CASE 14 & 46,924 & 4,100 & 11.44 & $49.21 \%$ \\
\hline CASE 15 & $1,124,953$ & 71,820 & 15.66 & $61.34 \%$ \\
\hline
\end{tabular}

The results shown in Table 8 are shown graphically in Figures 36, 37, and 38. 


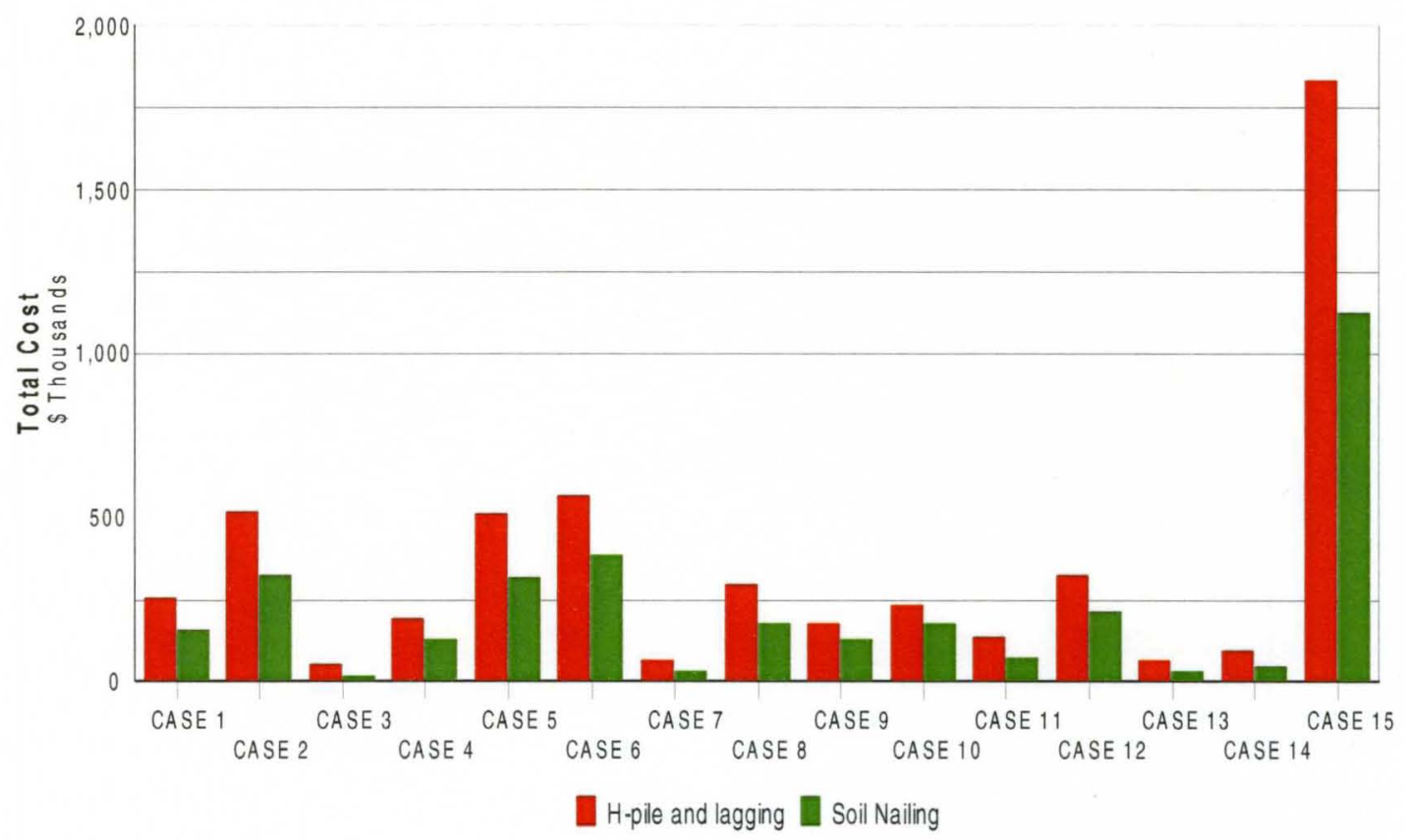

Figure 36. Total Cost Comparison, Conventional and Soil Nailing Systems

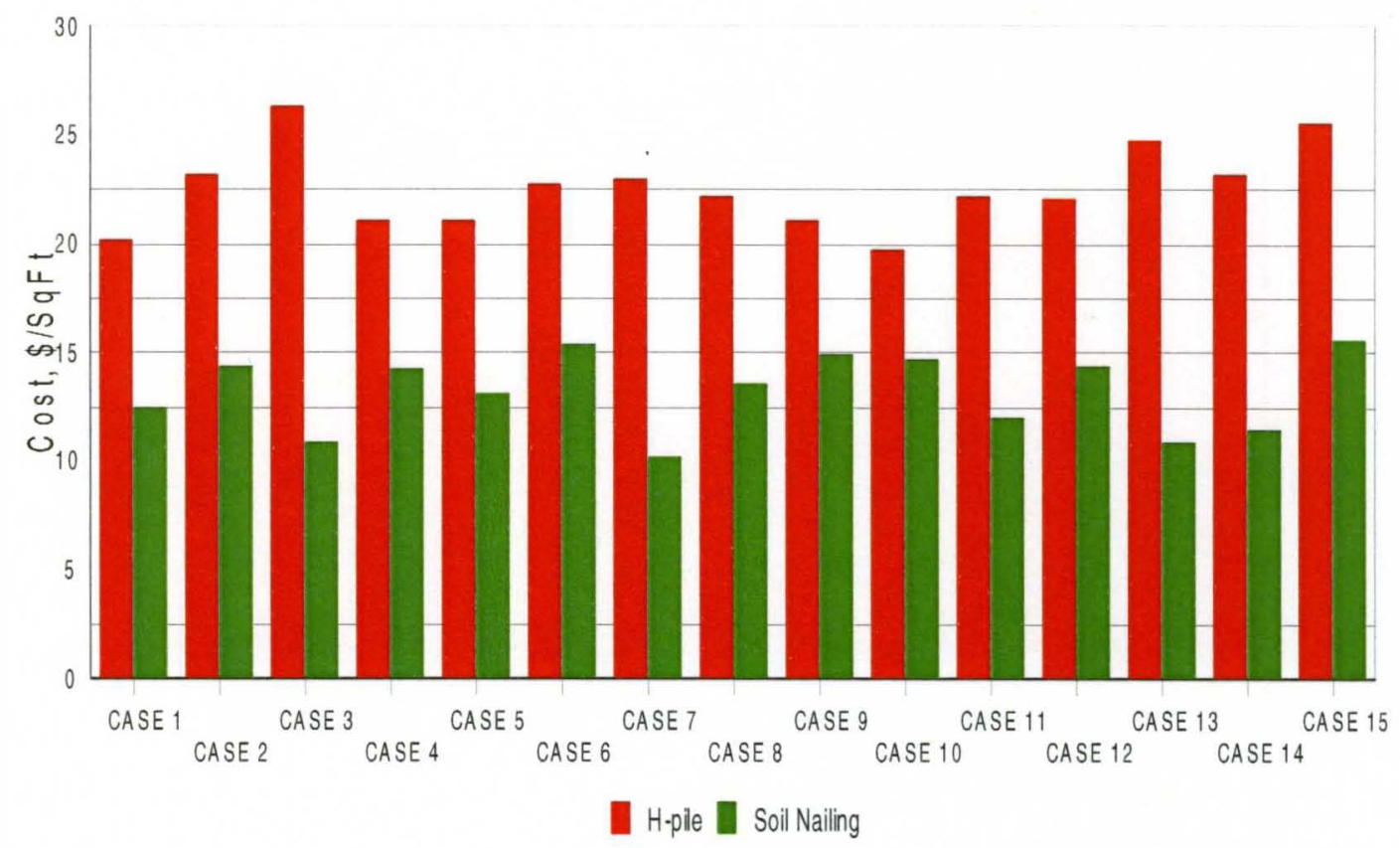

Figure 37. Unit Cost Comparison, Conventional Systems and Soil Nailing

Systems 


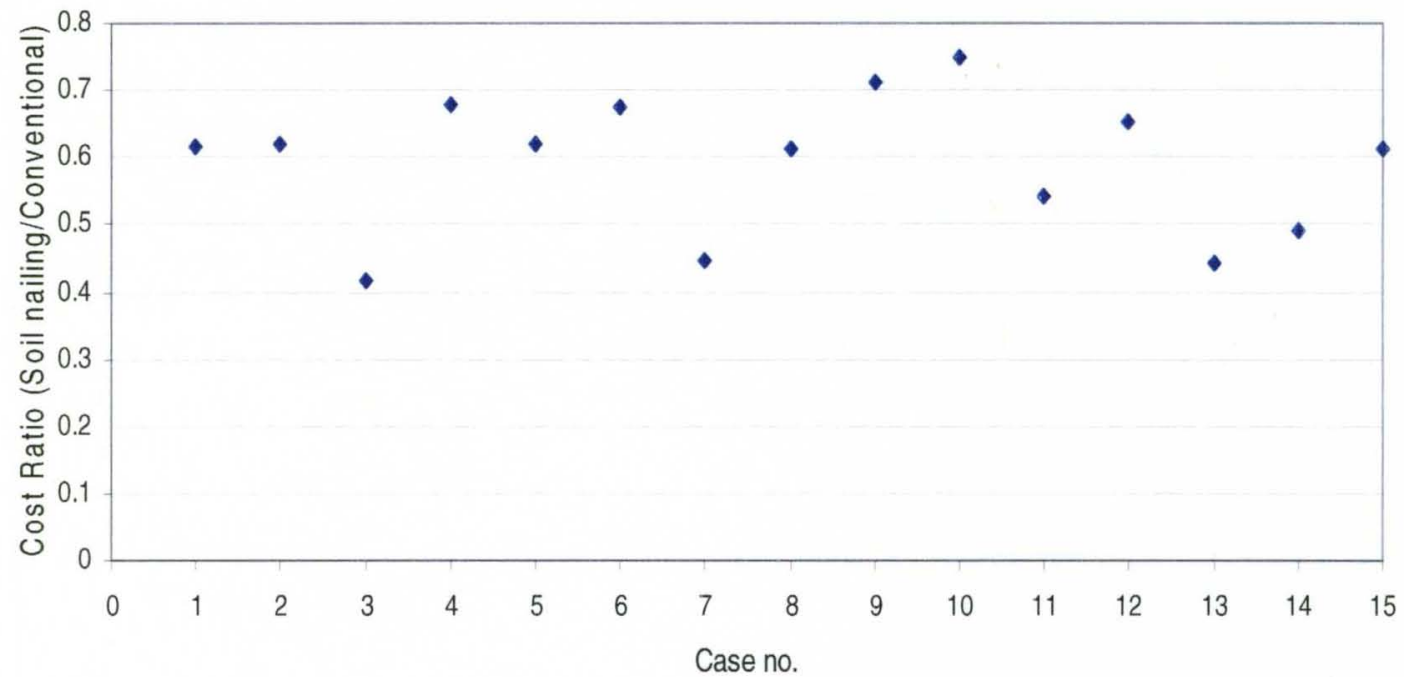

Figure 38. Cost Ratio (Soil Nailing / Conventional)

\subsection{Factors Causing Differences in Costs}

\subsubsection{Construction Management Approach}

To compare the cost of both retention systems (Conventional and Soil nailing), there are three simple categories of factors related to the construction process should be compared:

1- Material Cost

2- Labor Cost

3- Equipment Cost

Conventional system materials include steel piles, high tensile strength steel rebars or tendons, steel wales, wood lagging, and welded studs with plates to hold wood lagging boards in place. Soil nailing system materials include welded wire mesh, shotcrete, low tensile strength steel rebar for nails, and no. 4 steel rebars as 
wales. A comparison of the materials required to build both systems indicates that Soil Nailing materials are cheaper than conventional system materials. However, if a much larger quantity of cheaper materials were required for the soil nailing system than the quantity of more expensive materials involved in the conventional system, then the total costs of the two systems might be comparable or the soil nailing system might be more expensive. The analysis presented previously has used actual quantities of the various materials to get cost estimates that support the conclusion that material costs for soil nailing are lower than material costs for conventional retaining systems. This conclusion also is borne out by the data shown in Table 7 for conventional systems and Table 8 for soil nailing systems, showing material costs and costs for particular operations.

The second category of factors is the cost of labor to install both systems. Installing a conventional retention system requires driving steel piles in the ground with a vibratory hammer or predrilling holes and setting steel piles in those holes and then backfilling those holes with low strength concrete. Installing wood lagging behind steel pile flanges down to the first row of tiebacks, and after that drilling holes and installing tiebacks and then grouting the holes at high pressure are required for conventional systems. All tiebacks will be performance or proof tested to $120 \%$ of design load and locked at 75 percent of design load. When excavation advances below the first row of tiebacks, the installation of wood lagging requires welding studs on the steel pile flanges with plates to hold wood lagging boards; this procedure is labor-intensive and will slow the installation procedure. Some projects require wale installation which entails welding wedges on steel piles as seats for wales or the 
designer may choose to install tiebacks through the steel piles (which require cutting holes in both pile flanges and welding stiffener plates between the flanges to prevent local buckling. In contrast, soil nailing system installation requires drilling holes for nails that are more shallow/shorter than tieback holes and grouting at low-pressure, laying wire mesh on the face of excavated soil and placing no. 4 rebars to form a wale. After the wale is in place, 4 inches of shotcrete are sprayed on the soil face in two lifts. Installing a drainage system is required for both systems. By comparing the labor cost required to install both systems it is obvious that the soil nailing system requires less labor and less costly labor than the conventional system.

The third category of factors to consider is the equipment costs for both systems; the conventional system requires steel piles to be driven into the ground with a vibratory hammer or cutting predrilled vertical holes, using a drilling machine to drill inclined holes for tiebacks and then using a high-pressure pump to grout the inclined holes. Installing a conventional system requires using excavator to lower heavy wales to proper depth, and a welding machine to finish wale installation and weld studs for wood lagging boards.

Soil nailing will require small, light-weight equipment to install the system. A drilling machine will be needed to drive short nails or drill short holes for nails. A pump will be required to grout the annuli around the nails at low pressure, as well as a mixer for shotcrete and a pneumatic system to blow the shotcrete onto the face of the excavation.

By comparing these equipment needs, it is obvious that soil nailing system equipment will be cheaper both in capital cost and operating expenses. 
This study shows that the soil nailing system is cheaper than the conventional system. Therefore, a meaningful question will be asked, "Why is not Soil Nailing more widely used"? According to the construction management analysis, other factors influence the decision on which retention system should be used. Two factors determine what system to use:

1- Area of local practice: This description refers to how easily a local contractor can get project materials, hire labor and secure equipment by either purchase or rental, to install a retention system. Put another way, would it be necessary for a general contractor to rely on a specialist subcontractor to come into town and do the job?

2- Engineer's recommendations: The design engineer's state of knowledge and his experience with retention systems will influence what system is chosen. Engineers typically feel more comfortable with what they know and are slow to adopt new systems; contractors usually have to persuade engineers to adopt new methods or systems.

In analyzing the results of this research, two other inherent factors that could affect costs were investigated: project size; and project location.

\subsubsection{Project Size}

The overall variation in total system cost with size of retained area is shown in Figure 39 (Parts A and B), for conventional systems and soil nailing systems for linear fits to the generated data. Unit costs are shown in Figure 40 (Parts

A and B), for both systems as a function of retained soil area. Conventional systems 
ranged in unit cost between $\$ 19.70 /$ sqft and $\$ 26.37 /$ sqft, while soil nailing systems ranged between $\$ 10.28 / \mathrm{sqft}$ and $\$ 15.66 / \mathrm{sqft}$, for unit costs. The linear correlation shown is better than the correlation obtained through fitting a polynomial function to the data, and the resultant relation is simpler, so only the linear fit lines are shown. The correlation between project size and unit cost is not as significant as the correlation between total cost and project size, because the unit cost (total cost/project size) already includes the project size as a determinant. The unit cost of tiebacks is strongly related to the project size, even though the project size already was used to obtain the unit cost. The unit cost of steel piles is insensitive to project size because the length of steel piles is closely related to the depth of excavation, and thus is strongly related to project size. The unit costs of soil nailing system components are insensitive to project size because the unit cost already reflects the strong relation between number of components and project size. 


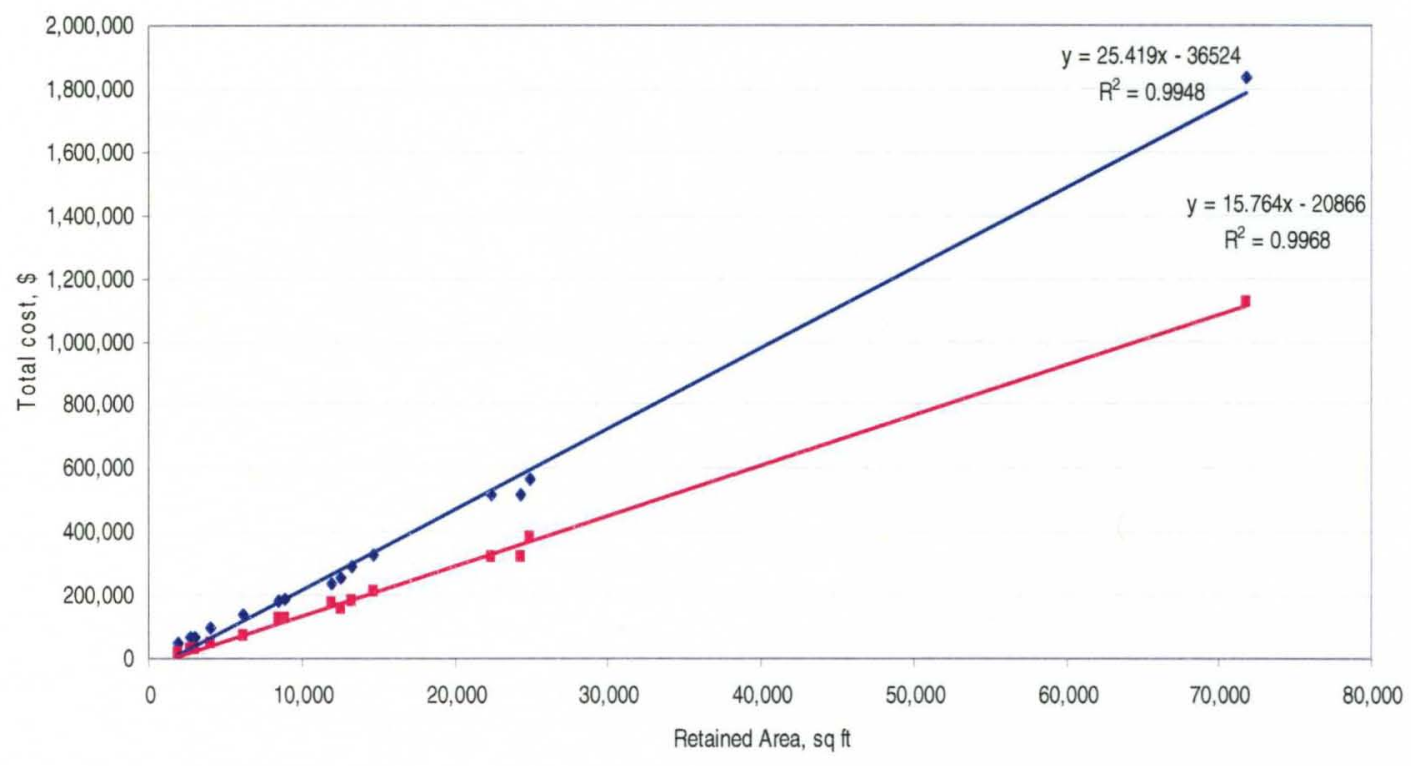

- Conventional " Soil Nailing — Linear (Conventional) — Linear (Soil Nailing)

Figure 39A. Total Cost of Conventional Systems and Soil Nailing Systems versus Retained Area

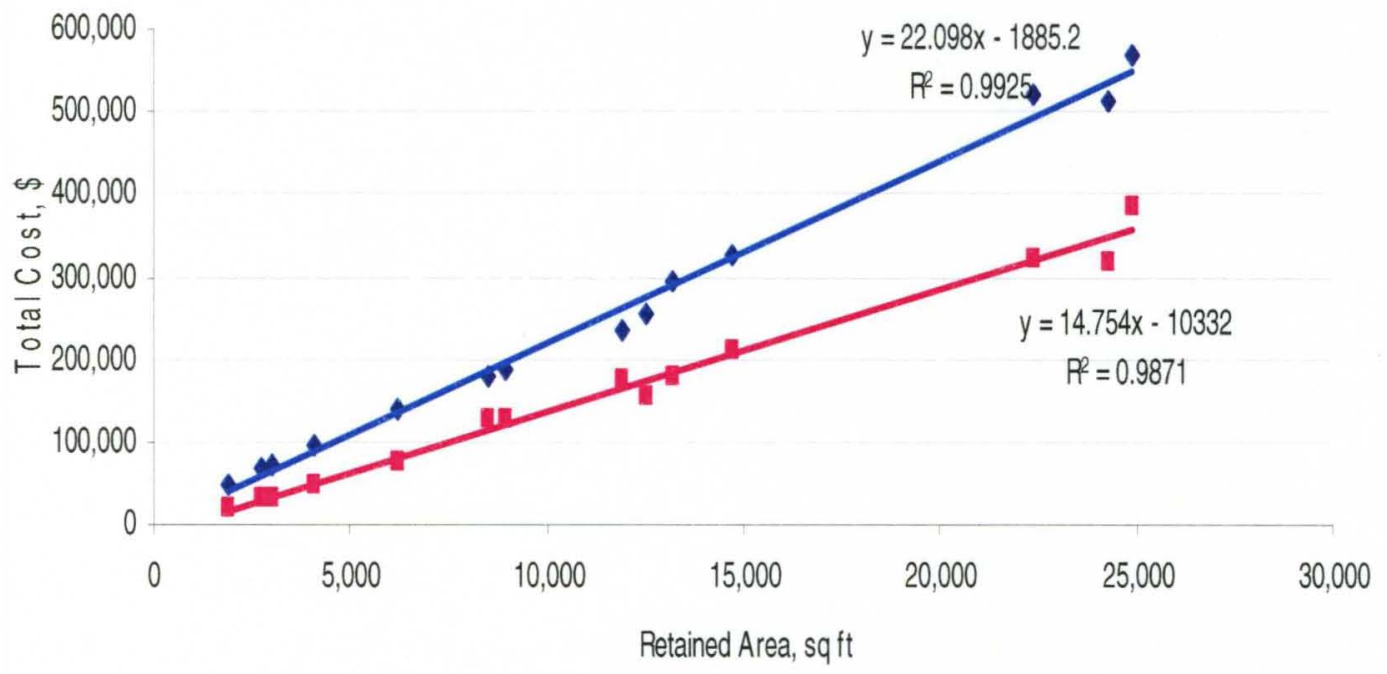

- Conventional I Soil Nailing —Linear (Conventional) —Linear (Soil Nailing)

Figure 39B. Total Cost of Conventional Systems and Soil Nailing Systems versus

Retained Area without case 15 (71,820 sq ft) 


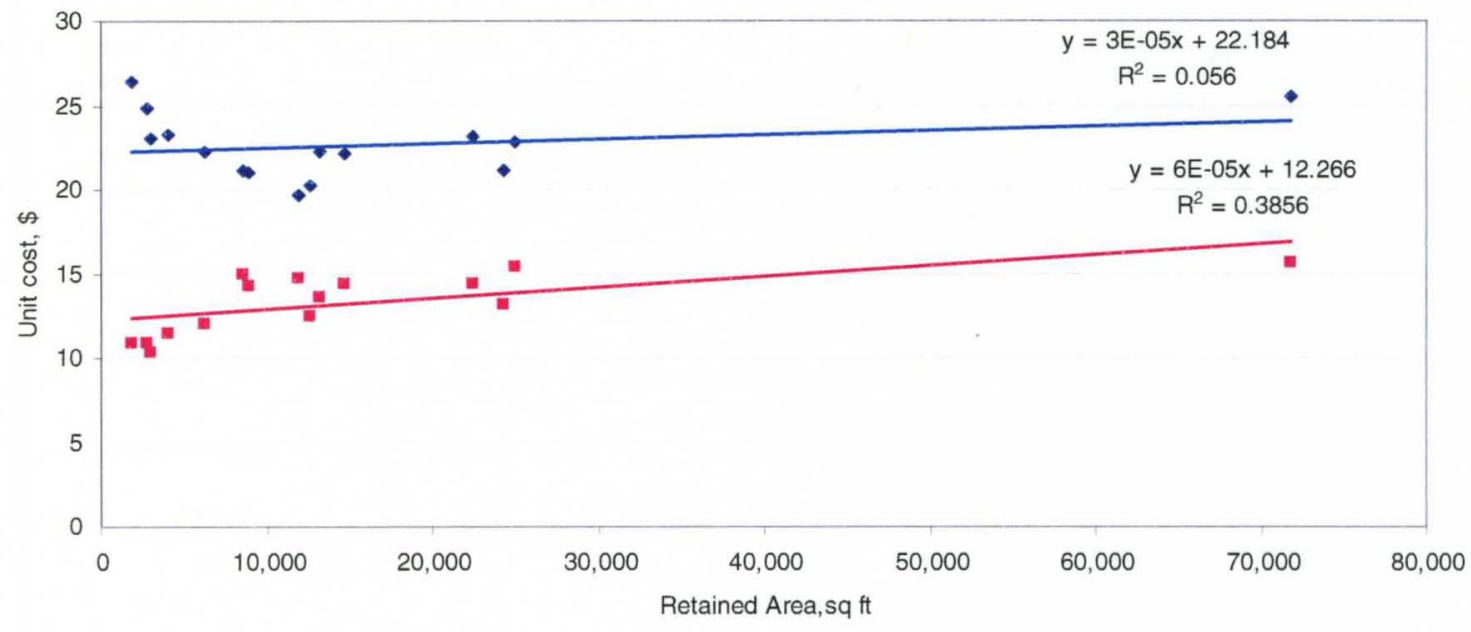

- Conventional = Soil nailing —_Linear (Conventional) __ Linear (Soil nailing)

Figure 40A. Unit Cost of Conventional Systems and Soil Nailing Systems versus

Retained Area

If case 15 is eliminated $(71,820 \mathrm{sq} \mathrm{ft})$ and Fig. $40 \mathrm{~A}$ is redrawn, a better fit to the generated data is obtained; see Fig. 40B.

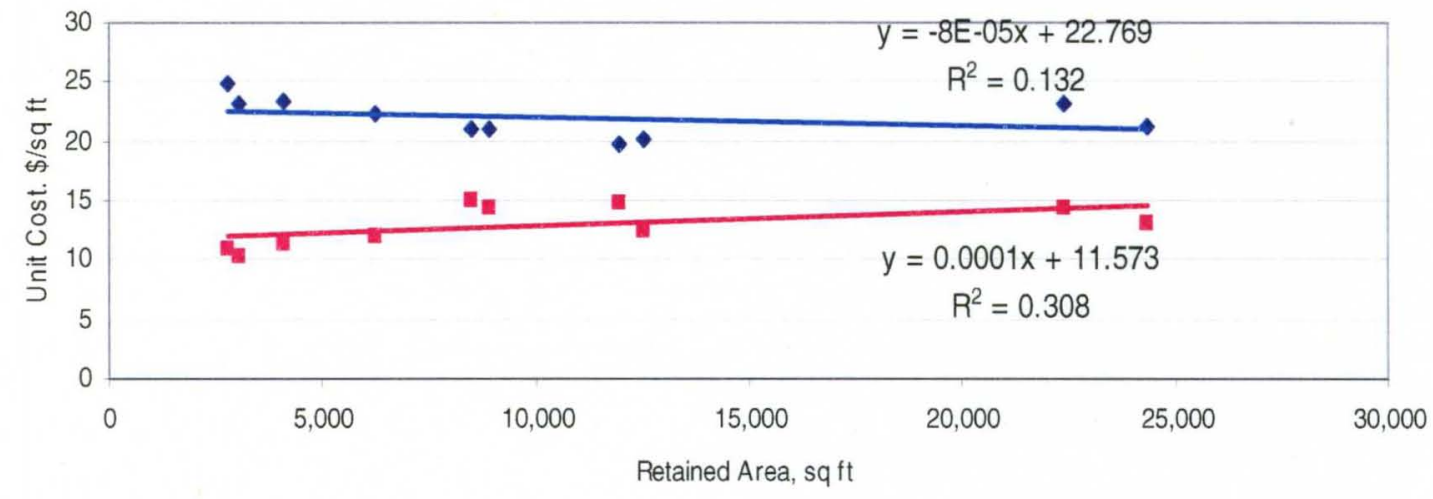

- Conventional @ Soil Nailing — Linear (Conventional) _ Linear (Soil Nailing)

Figure 40B. Unit Cost of Conventional Systems and Soil Nailing Systems versus

Retained Area without case 15 (71,820 sq ft) 
From Fig. 39B, linear equations were obtained to relate total cost to project size (where $\mathrm{X}$ is project size in square feet):

\section{A: Total Cost without case 15}

$\mathrm{Y} 1=22.098 \mathrm{X}-1,885.2$ Conventional

$(\mathrm{R})^{\wedge} 2=0.9925$

$\mathrm{Y} 2=14.75 \mathrm{X}-10,332$ Soil Nailing

$(\mathrm{R})^{\wedge} 2=0.9871$

Slope of line, $\mathrm{M} 1=22.098$ Conventional total cost

Slope of line, $\mathrm{M} 2=14.75$ Soil Nailing total cost

A comparison among slopes of the correlation lines shows that the conventional systems are more sensitive to the size of retained area than are the soil nailed systems.

Fig. 41 shows unit costs for steel beams and tiebacks as functions of retained area. Fig. 42 shows unit costs of (nail, plate and nut) and of shotcrete versus retained area.

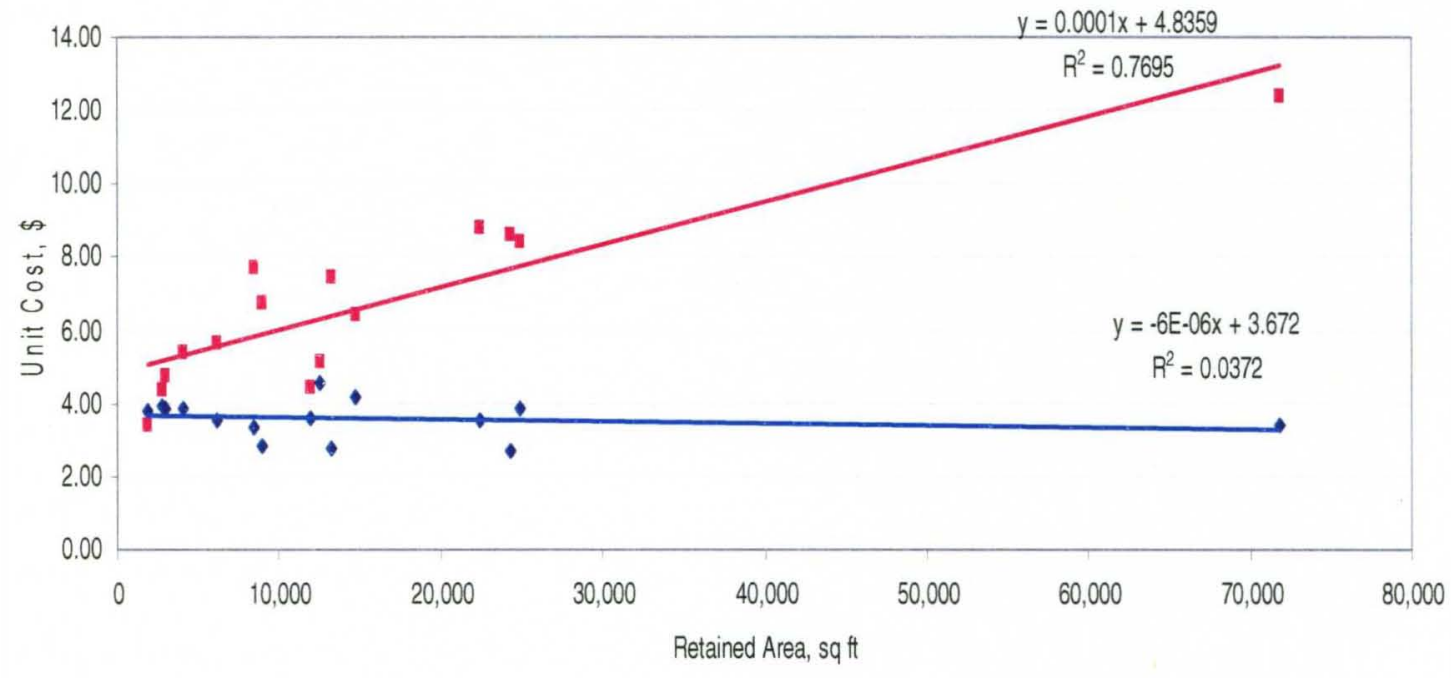

- Steel Pile Cost - Tieback Cost — Linear (Tieback Cost) — Linear (Steel Pile Cost)

Figure 41A. Unit Cost of Steel Pile and Tiebacks versus Retained Area 


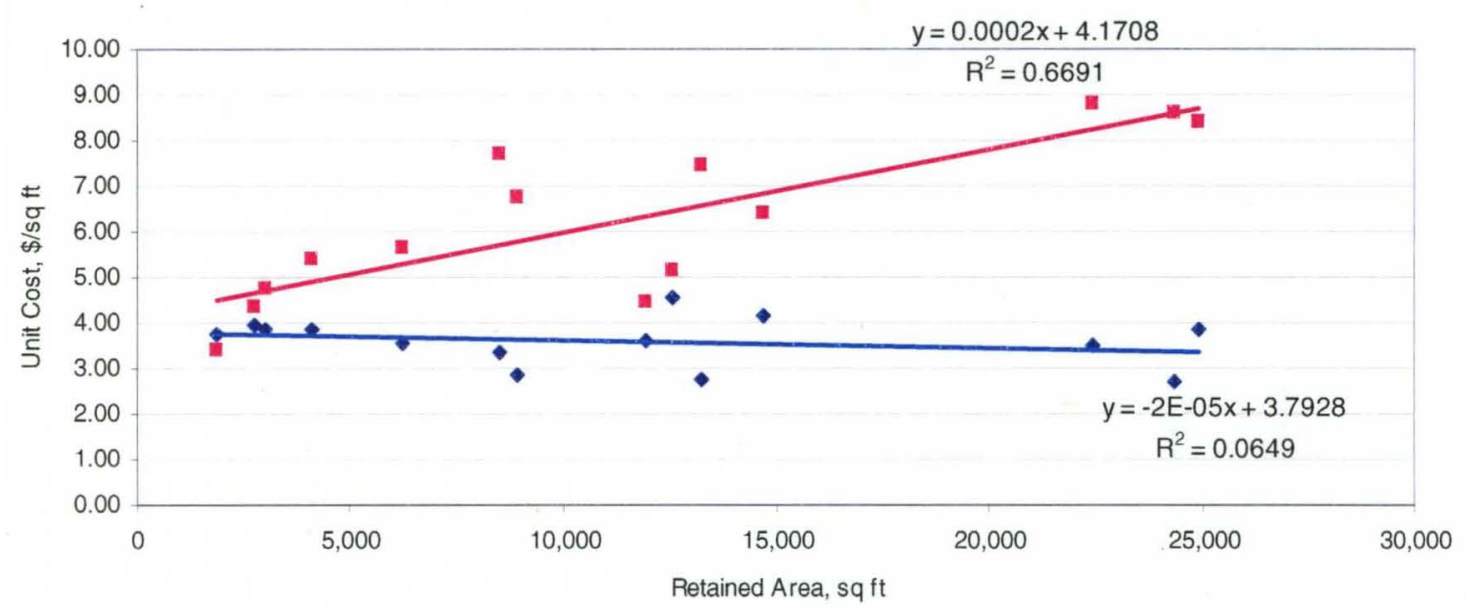

- Steel Pile Cost = Tieback Cost —Linear (Tieback Cost) — Linear (Steel Pile Cost)

Figure 41B. Unit Cost of Steel Pile and Tiebacks versus Retained Area without case $15(71,820 \mathrm{sq} \mathrm{ft})$

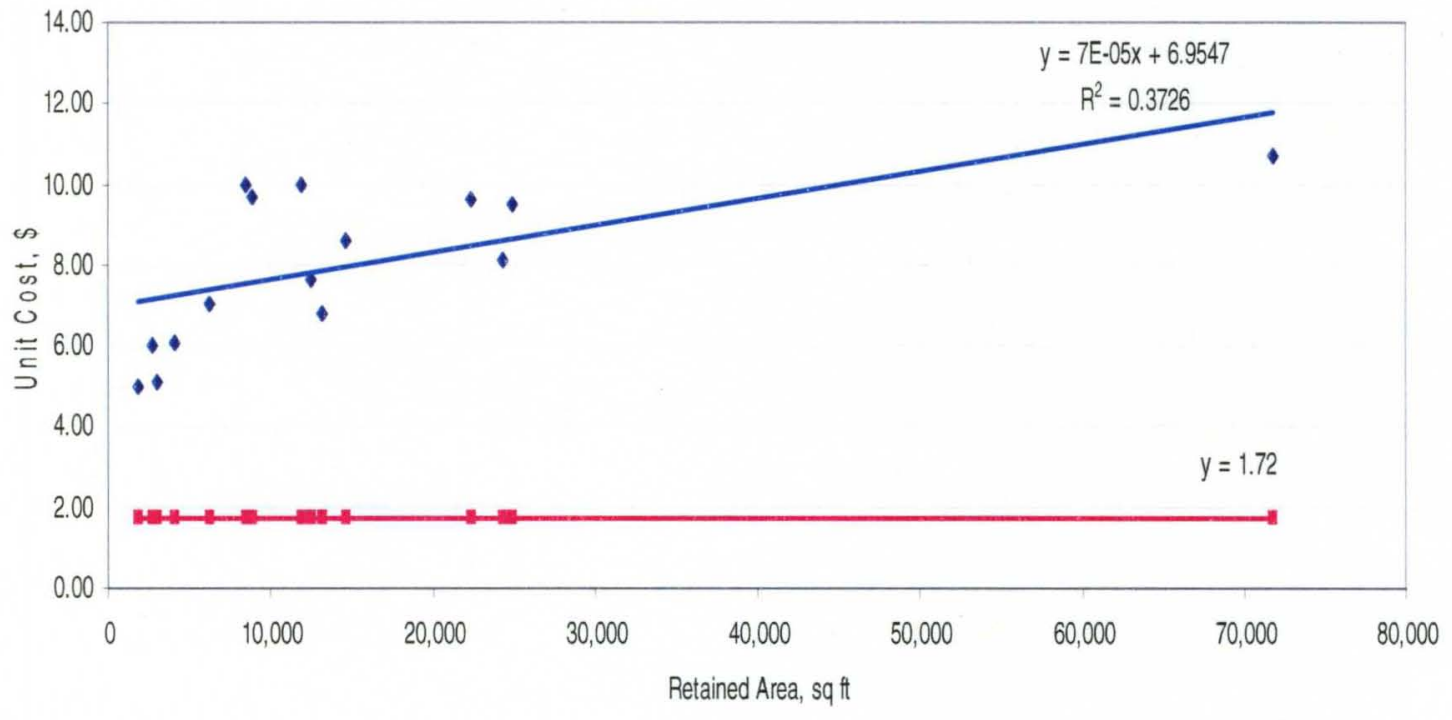

- Nail,Plate and Nut "Shotcrete — Linear ( Nail,Plate and Nut) — Linear (Shotcrete)

Figure 42A. Unit Cost of Nail, Plate, Nut and Shotcrete versus Retained Area 


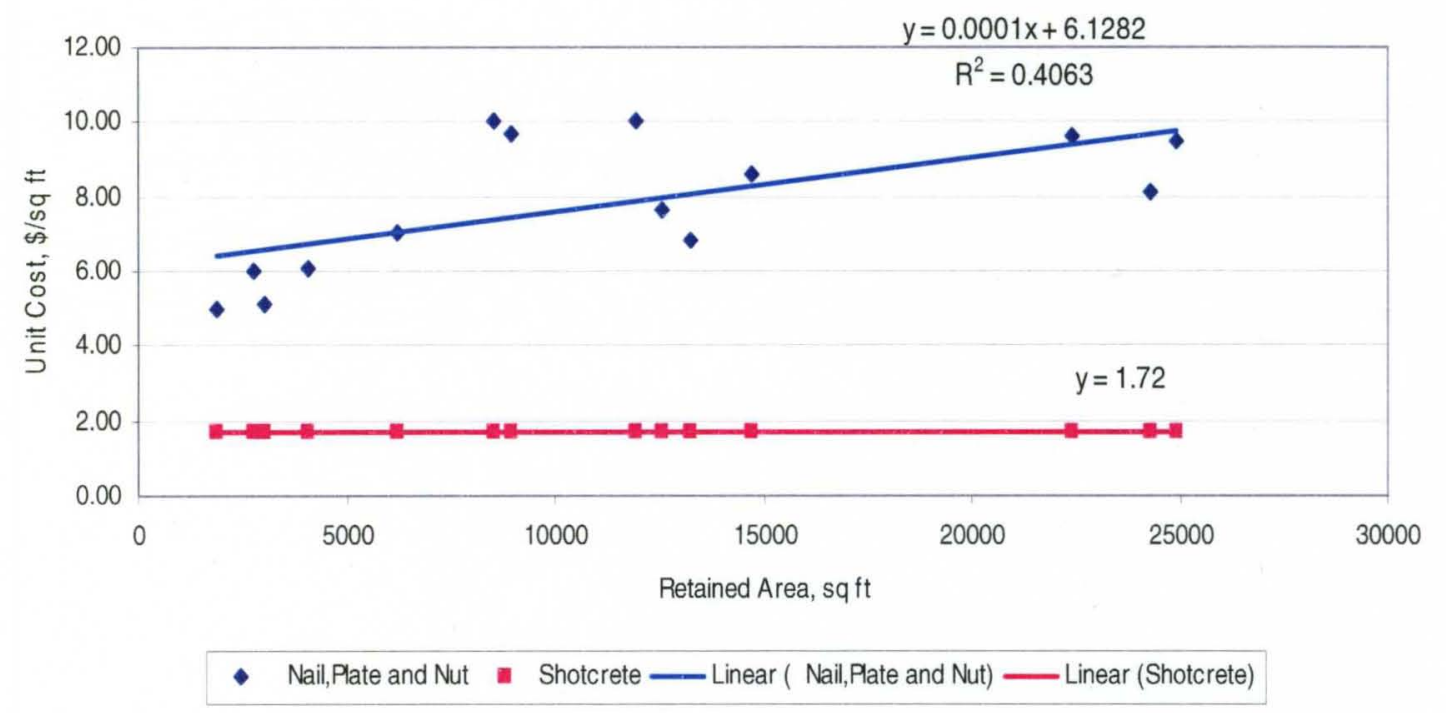

Figure 42B. Unit Cost of Nail, Plate, Nut and Shotcrete versus Retained Area without case $15(71,820 \mathrm{sq} \mathrm{ft})$

In Fig. 41B, the correlation without Case 15 data was not as good as the correlation for data from all cases, but in Fig. 42B, a slightly improved correlation was obtained by deleting the data from Case 15 .

From Figures 39B, 40B, 41B, and 42B a comparison among total cost, unit cost, cost of steel beams, and cost of tie backs for conventional systems can be made with costs of nails, nail drilling, nuts and shotcrete for soil nailing, for all the cases except Case 15 .

Conventional systems (In the following equations, $\mathrm{X}$ is project size)

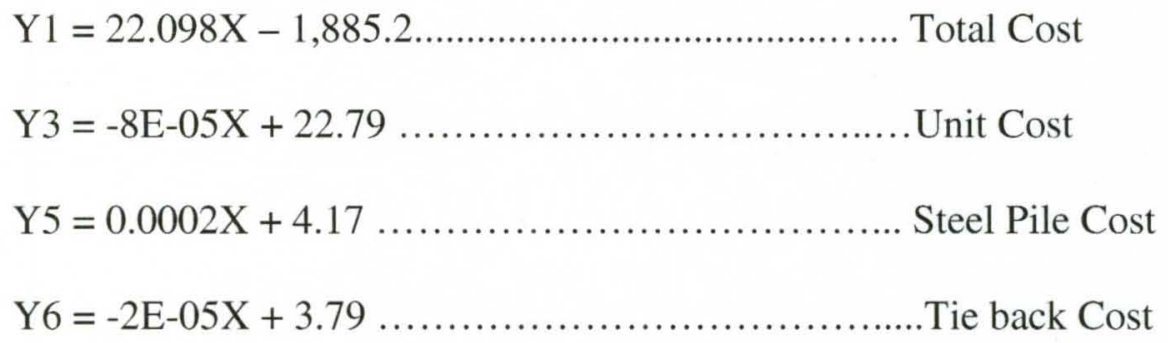


$\underline{\text { Soil Nailing Systems }}$

$\mathrm{Y} 2=14.75 \mathrm{X}-10,332 \ldots \ldots \ldots \ldots \ldots \ldots \ldots \ldots \ldots \ldots \ldots \ldots \ldots \ldots \ldots+$ Total Cost

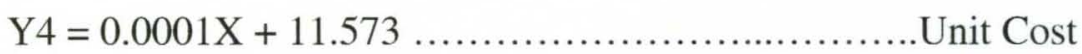

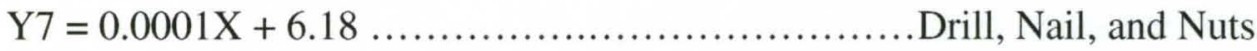

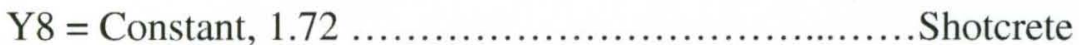

Fig. 43A shows total cost for both kinds of support systems versus depth of retained excavation, with results of a regression analysis based on a linear equation, and Fig. 43B shows data from all cases except Case 15, with linear regression analysis.

Figs. 44A and 44B show unit costs for the two retention systems versus depth of retained excavation, with results of a linear regression analysis in Fig. 44A and Fig. 44B (without Case 15).

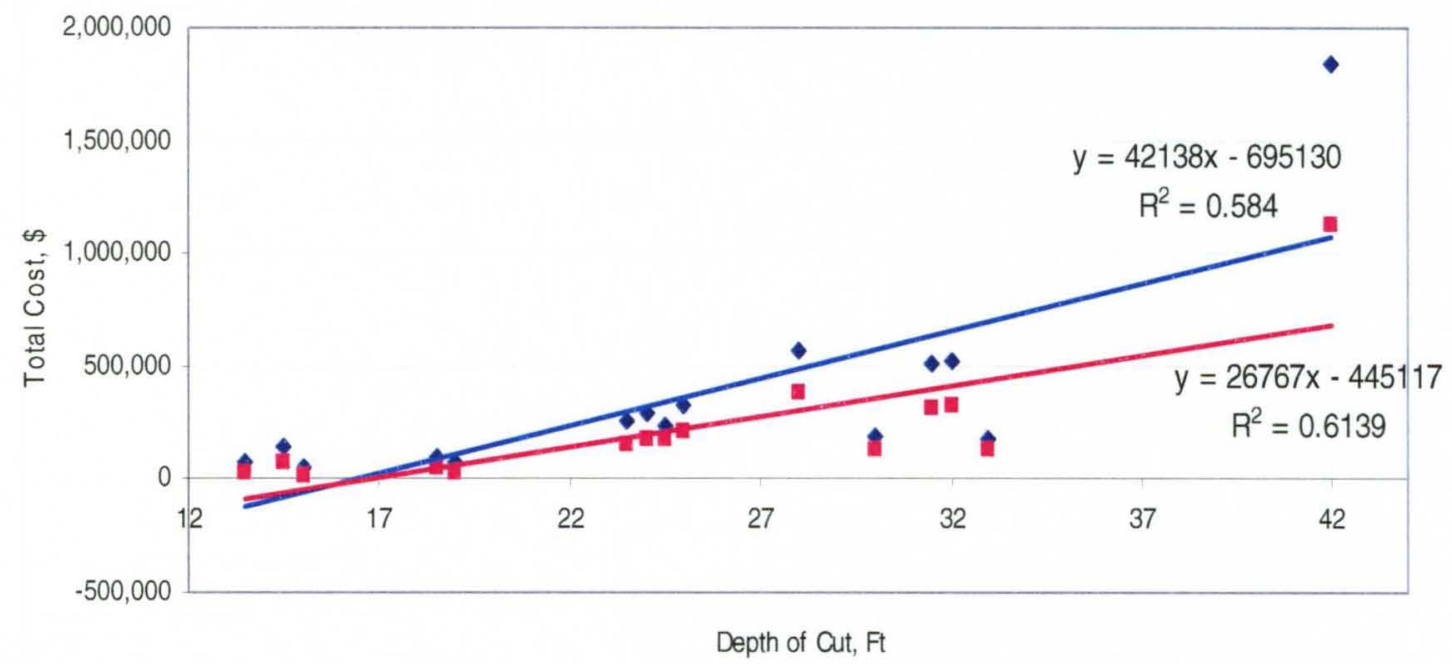

- Conventional a Soilnailing — Linear (Conventional) —_Linear (Soilnailing)

Figure 43A. Total Cost of Conventional Systems and Soil Nailing Systems versus Depth of Cut (depth of retained excavation) 


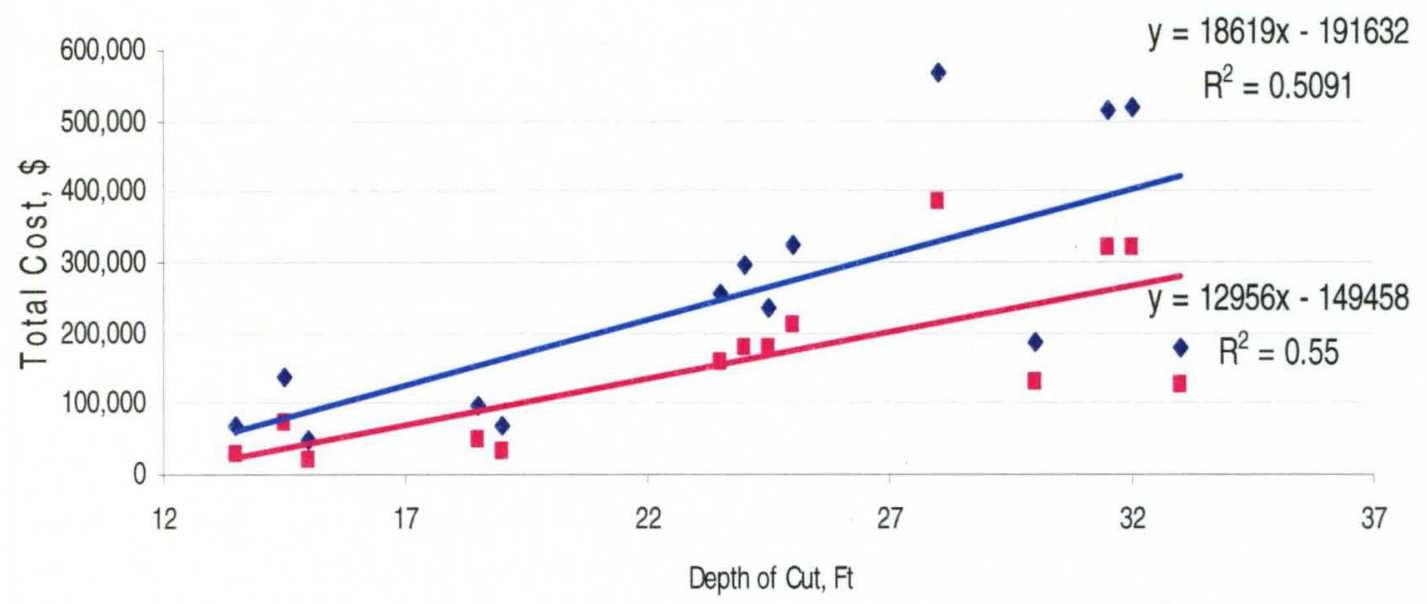

- Conventional n Soilnailing — Linear (Soilnailing) — Linear (Conventional)

Figure 43B. Total Cost of Conventional Systems and Soil Nailing Systems versus Depth of Cut (depth of retained excavation) without case 15

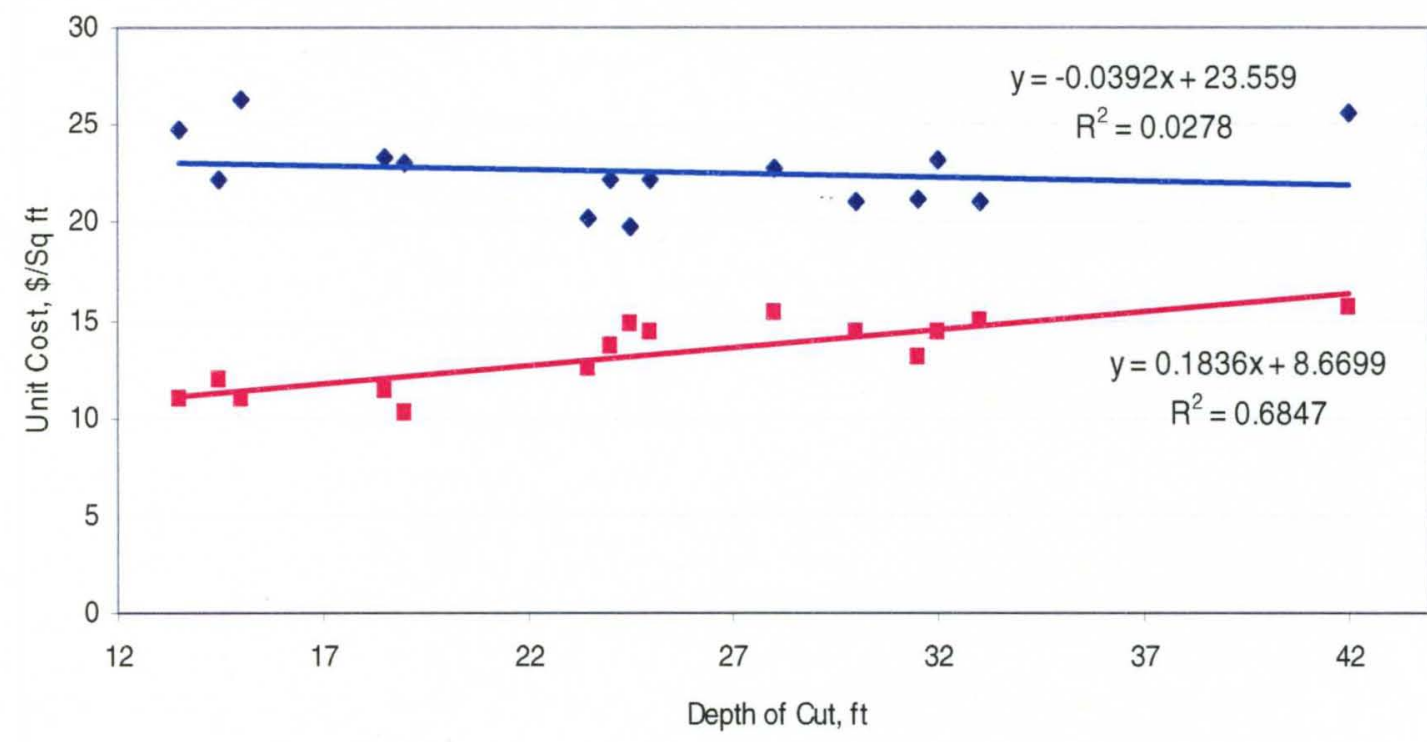

- Conventional a Soilnailing —Linear (Soilnailing) —Linear (Conventional)

Figure 44A. Unit Cost of Conventional Systems and Soil Nailing Systems versus Depth of Cut (depth of retained excavation) 


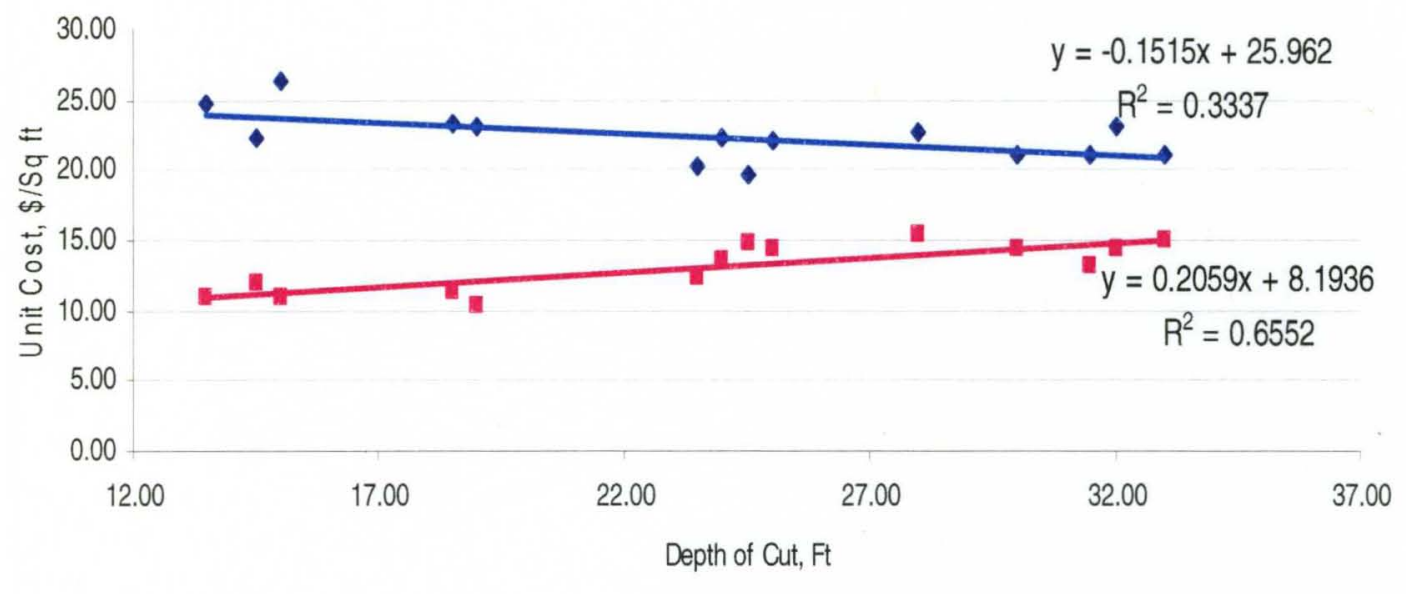

- Conventional = Soilnailing — Linear (Conventional) — Linear (Soilnailing)

Figure 44B. Unit Cost of Conventional Systems and Soil Nailing Systems versus Depth of Cut (depth of retained excavation) without case 15

Figs. 45A and 45B (without Case 15) show unit costs of tiebacks versus depth of excavation, with results of a linear regression analysis. A strong correlation is shown between cost of tiebacks and depth of cut because tieback length (and cost) is dependent on depth of cut. 


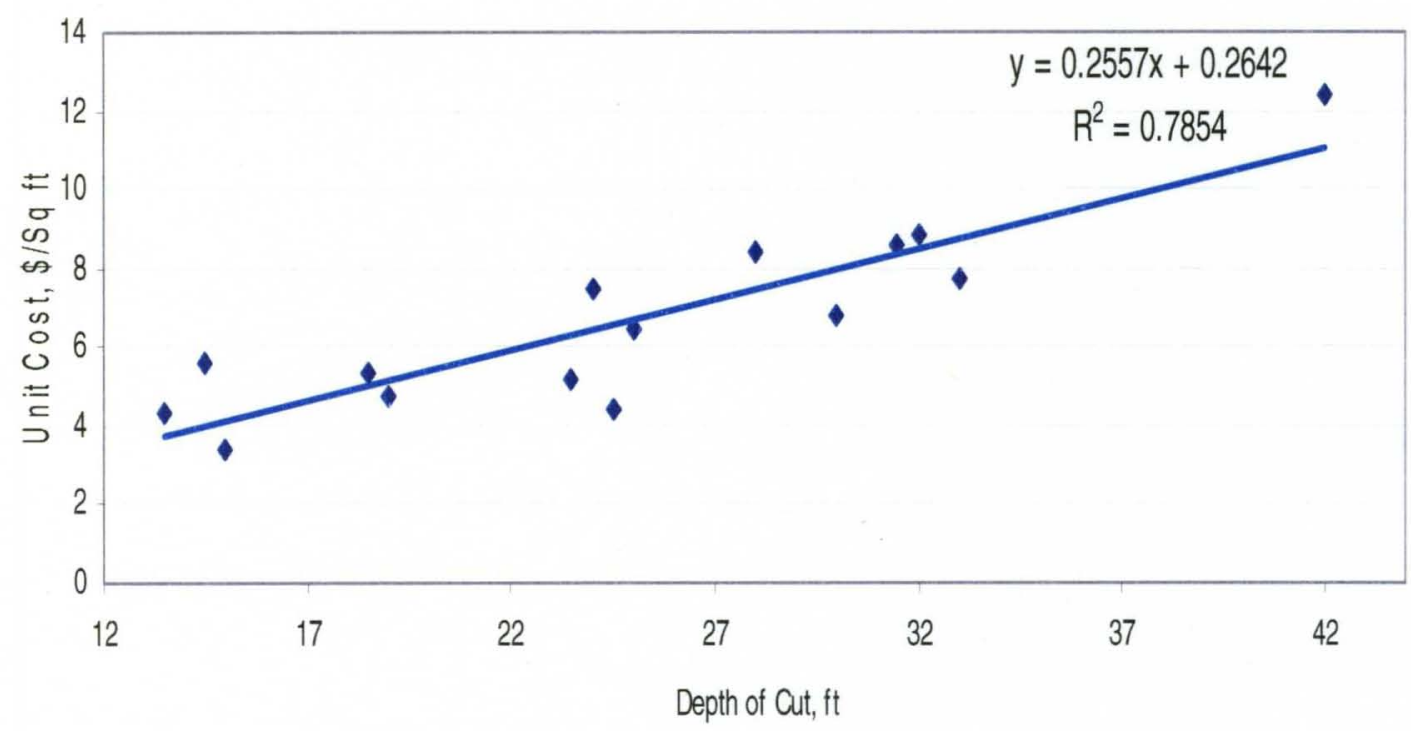

- Teback Cost — Linear (Tieback Cost)

Figure 45A. Unit Cost of Tiebacks versus Depth of Cut (depth of retained excavation)

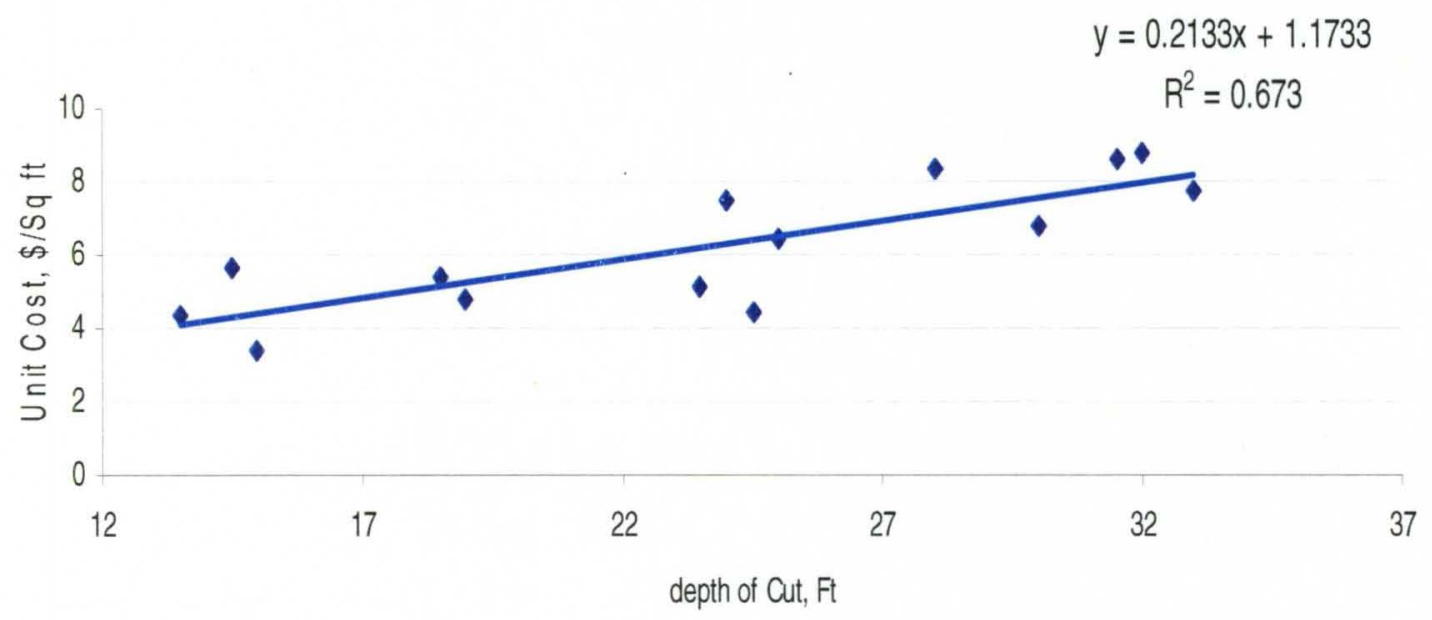

- tieback cost — Linear (tieback cost)

Figure 45B. Unit Cost of Tiebacks versus Depth of Cut (depth of retained excavation) without case 15 
Figure 46 shows unit cost per linear foot of excavation rather than per square foot of excavation versus depth of cut, for all the data from all fifteen cases.

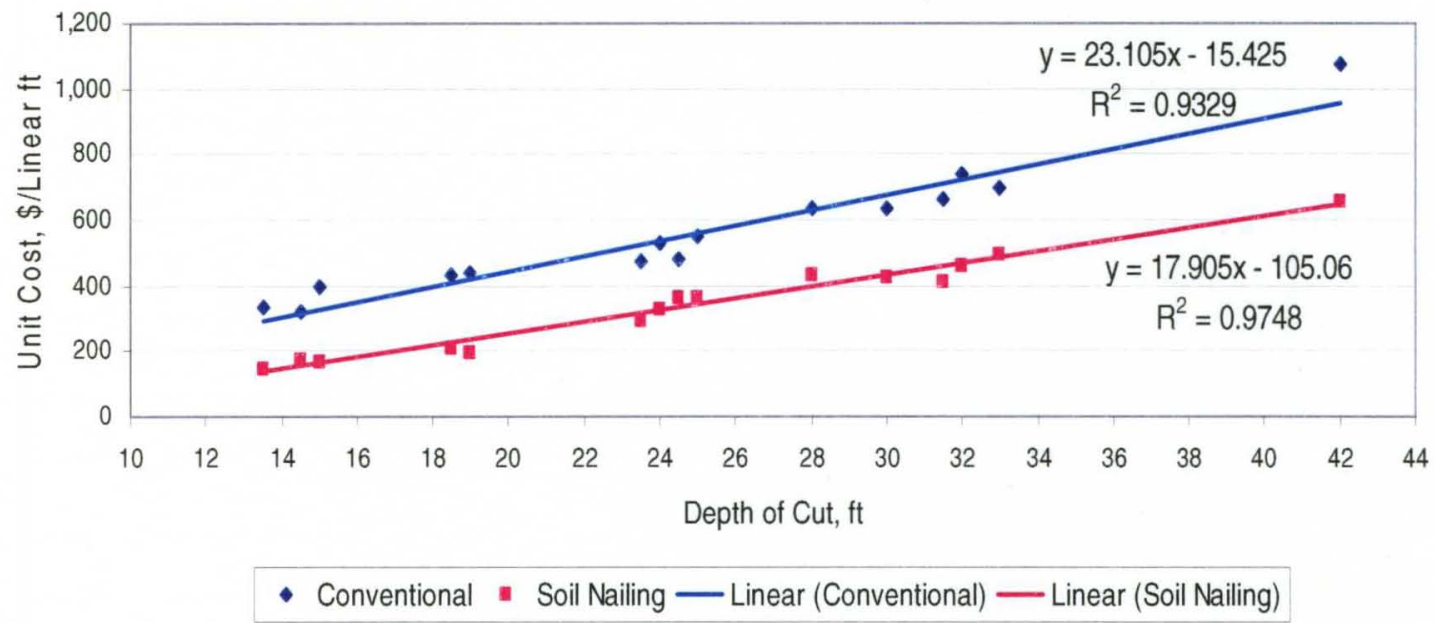

Figure 46. Unit Cost (\$/Linear foot) of Conventional and Soil Nailing versus Depth of Cut (depth of retained excavation)

Fig. 46 shows that depth of cut is a strong influence on unit cost, and that portraying unit cost per linear foot of excavation wall is a better way of representing unit cost than using cost per square foot of retained area, for both methods of retention. Table 9 shows the numerical data on which the foregoing Fig. 46 was based. 
Table 9. Unit Cost $\$ /$ Linear Foot versus Depth of Cut (depth of retained excavation) for Conventional and Soil Nailing

\begin{tabular}{|c|c|c|c|}
\hline CASE NO. & $\begin{array}{c}\text { Conventional } \\
\text { Unit Cost \$/L ft }\end{array}$ & $\begin{array}{c}\text { Soil Nailing } \\
\text { Unit Cost \$/L ft }\end{array}$ & $\begin{array}{c}\text { depth of } \\
\text { cut }(\mathbf{f t})\end{array}$ \\
\hline CASE 1 & 475.90 & 292.36 & 23.5 \\
\hline CASE 2 & 742.11 & 460.32 & 32 \\
\hline CASE 3 & 395.57 & 164.25 & 15 \\
\hline CASE 4 & 631.54 & 428.85 & 30 \\
\hline CASE 5 & 666.17 & 413.51 & 31.5 \\
\hline CASE 6 & 637.16 & 430.97 & 28 \\
\hline CASE 7 & 437.68 & 195.39 & 19 \\
\hline CASE 8 & 533.27 & 327.09 & 24 \\
\hline CASE 9 & 695.26 & 493.81 & 33 \\
\hline CASE 10 & 482.74 & 361.96 & 24.5 \\
\hline CASE 11 & 322.10 & 174.08 & 14.5 \\
\hline CASE 12 & 553.00 & 360.52 & 25 \\
\hline CASE 13 & 334.77 & 147.77 & 13.5 \\
\hline CASE 14 & 430.22 & 211.73 & 18.5 \\
\hline CASE 15 & $1,072.51$ & 657.87 & 42 \\
\hline
\end{tabular}

An analysis of the results of the cost compilation showed that the costs of soil nailing in cases numbers. $3,7,13$, and 14 were between 40 percent and 50 percent of the cost for conventional systems for those projects as shown in Figs. 47 through 54. Those four cases involved smaller excavations, and therefore, smaller areas of retained soil faces; the smaller retained areas made the unit costs of the conventional systems, in dollars per square feet, higher because the cost of mobilization and demobilization was divided by small areas. Material costs for the steel H-piles and for the tiebacks also were increased because of the small areas of the retained soil, as shown for case 3 in Figure 47, for case 7 in Figure 49, for case 13 in Figure 51, and for case 14 in Figure 53.

Comparable unit costs for soil nailing system components are shown in Figures 48, 50,52 , and 54 . 


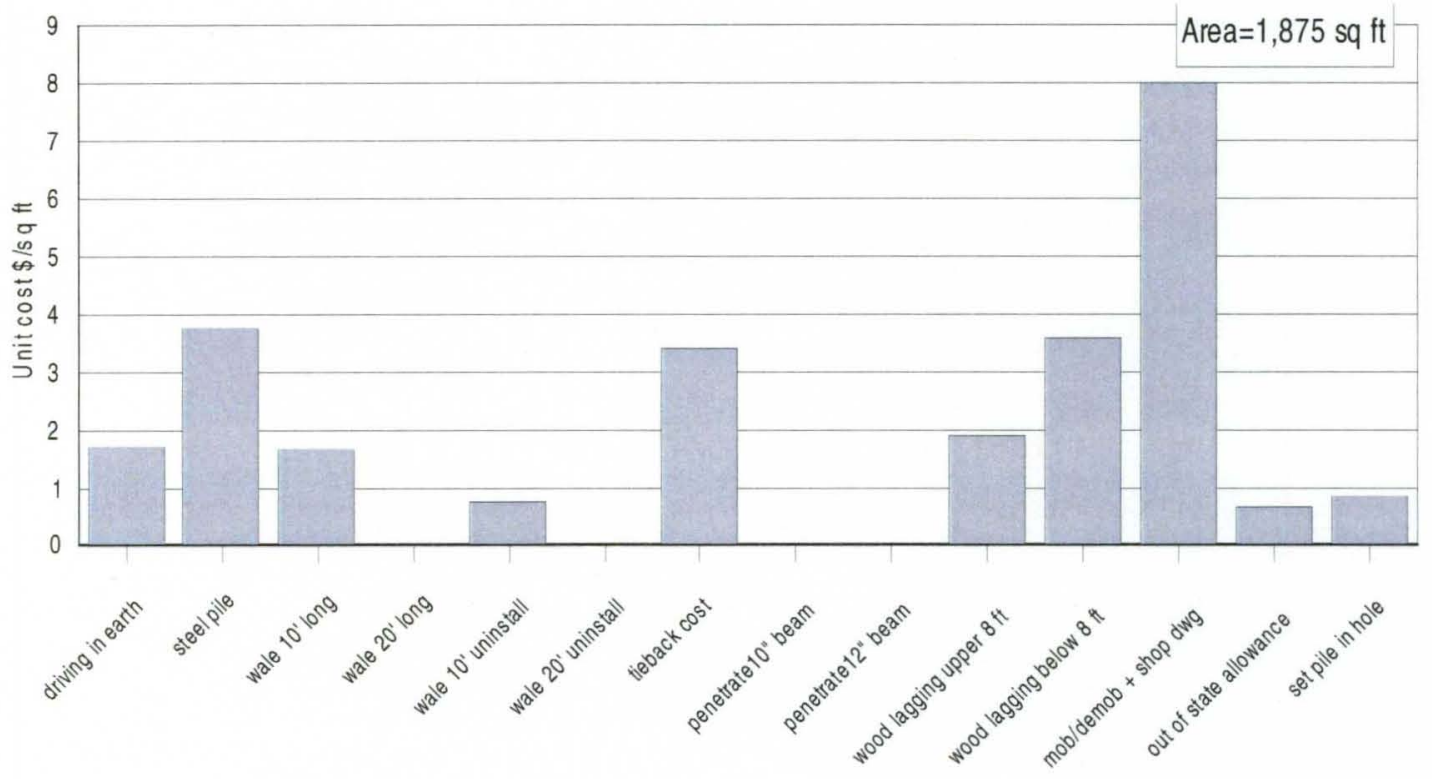

Figure 47. Unit Cost (Case 3) for Each Conventional System Component

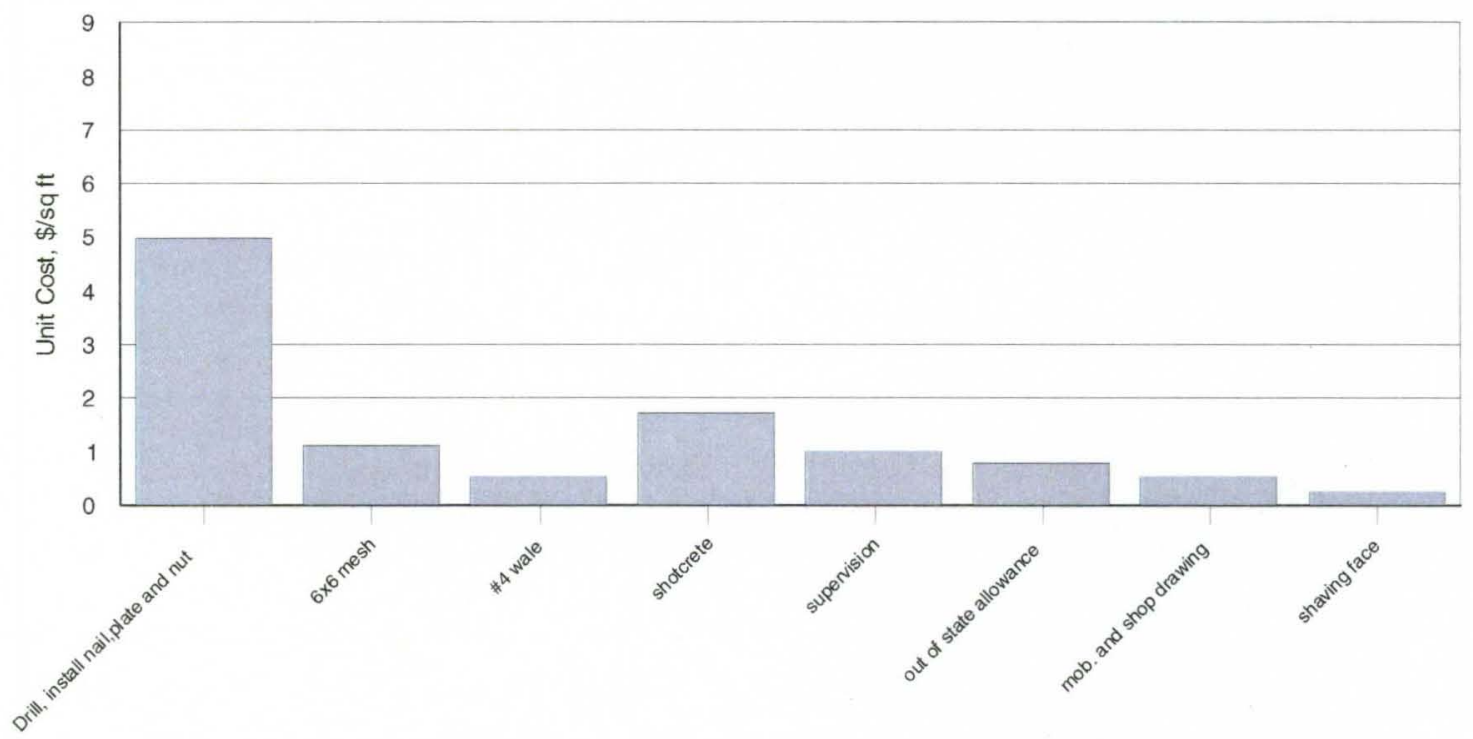

Figure 48. (Case 3) Unit Cost for Each Soil Nailing System Component 


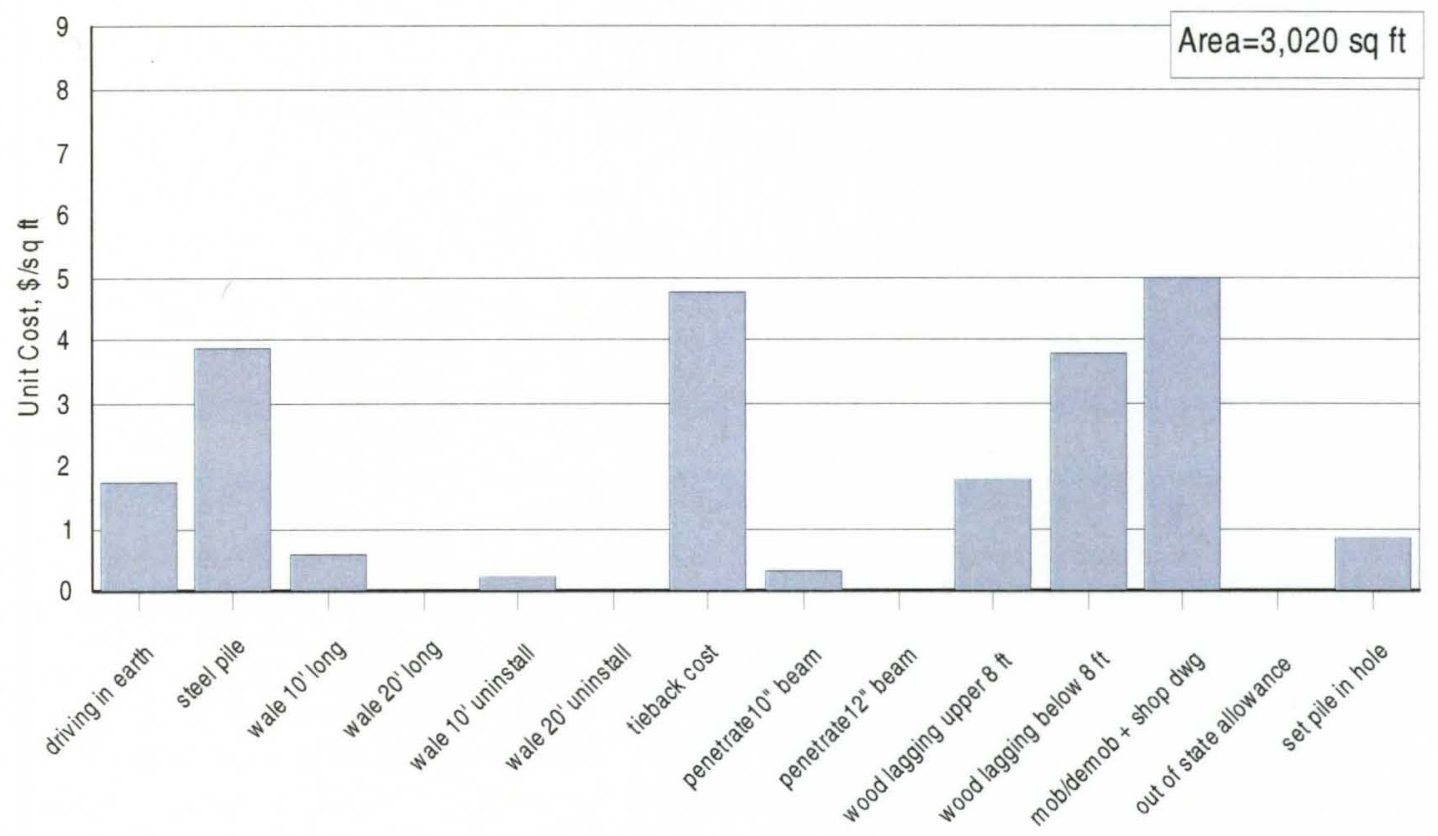

Figure 49. Unit Cost (Case 7) for Each Conventional System Component

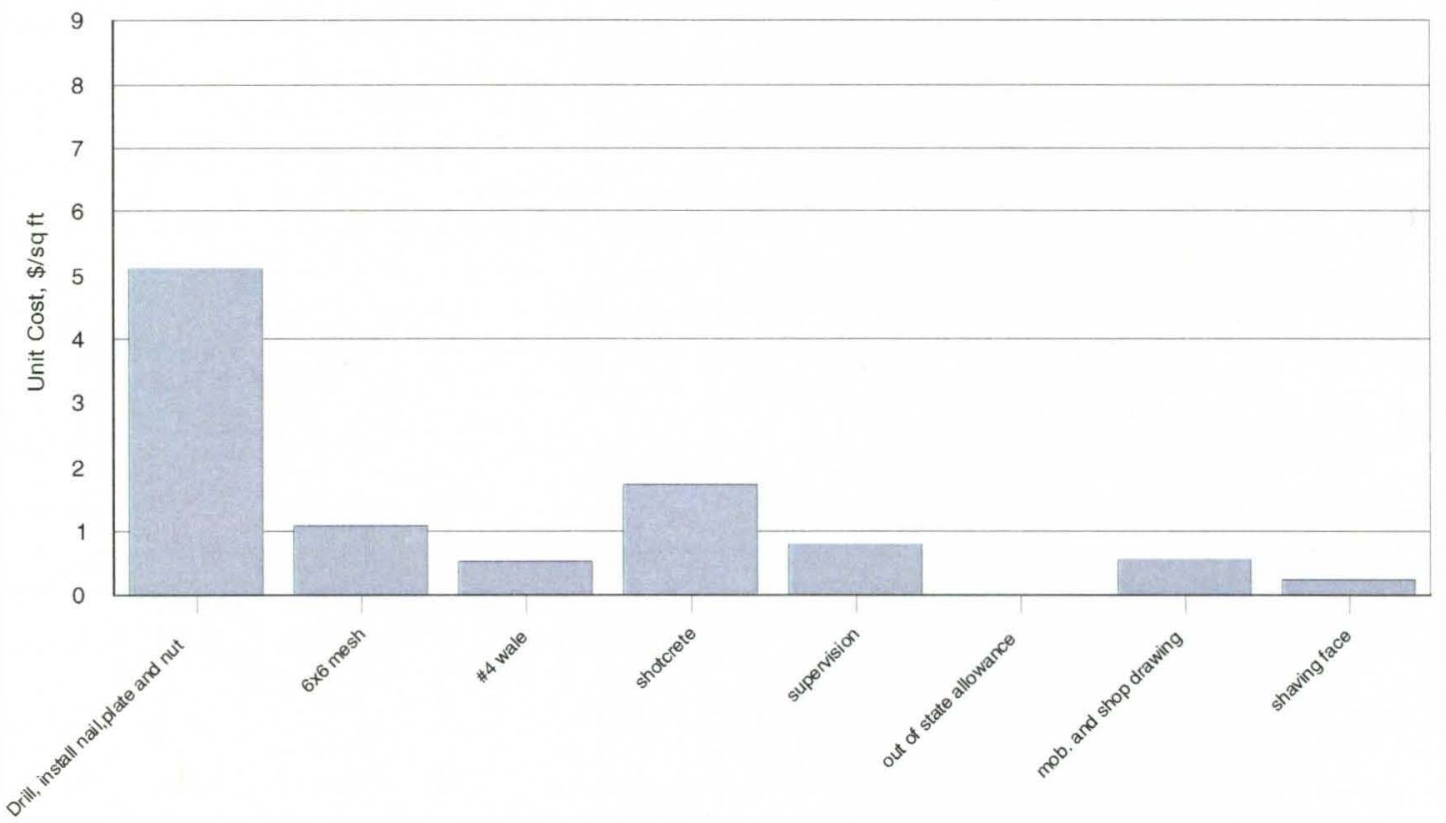

Figure 50. (Case 7) Unit Cost for Each Soil Nailing System Component 


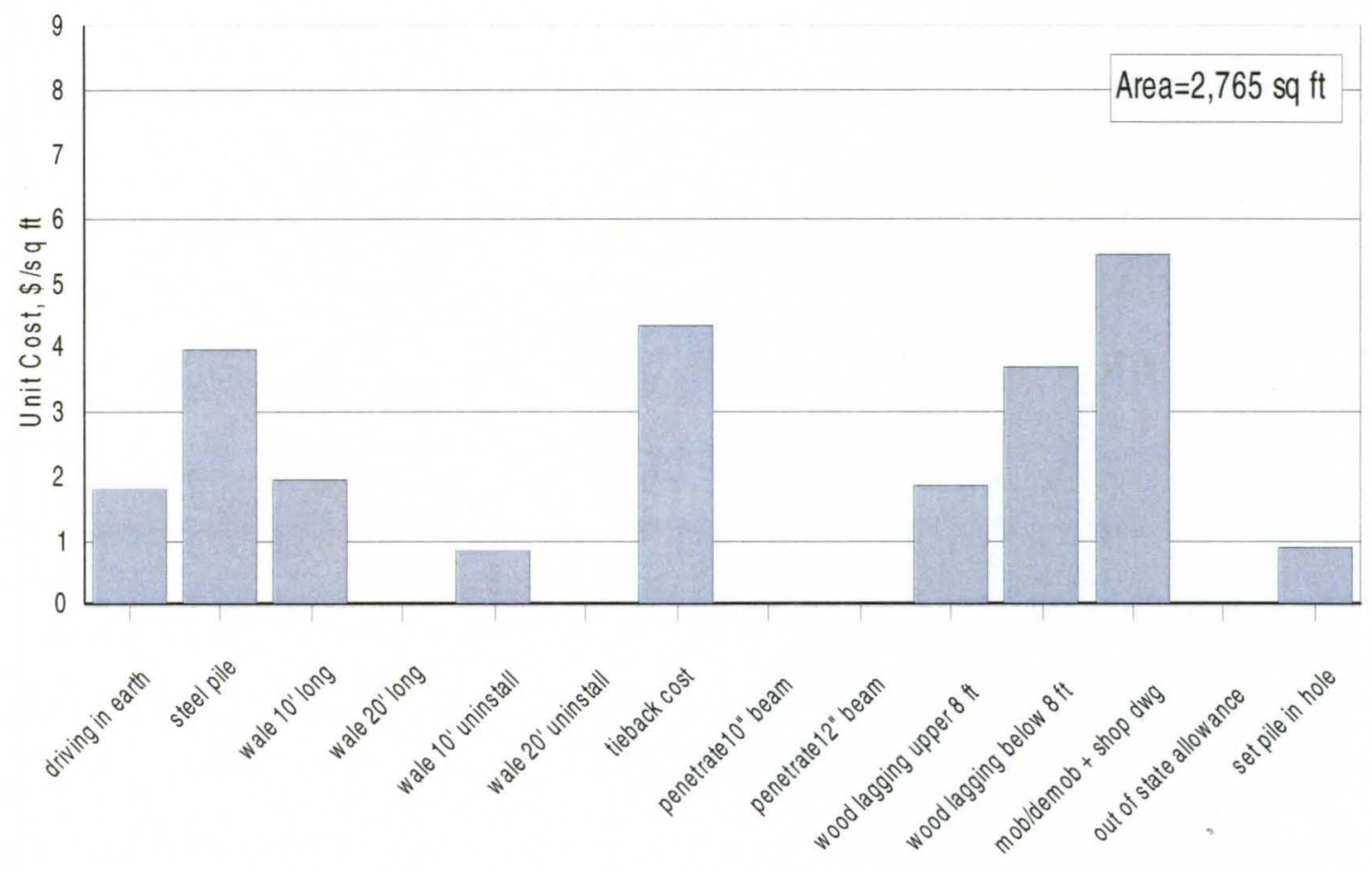

Figure 51. Unit Cost (Case 13) for Each Conventional System Component

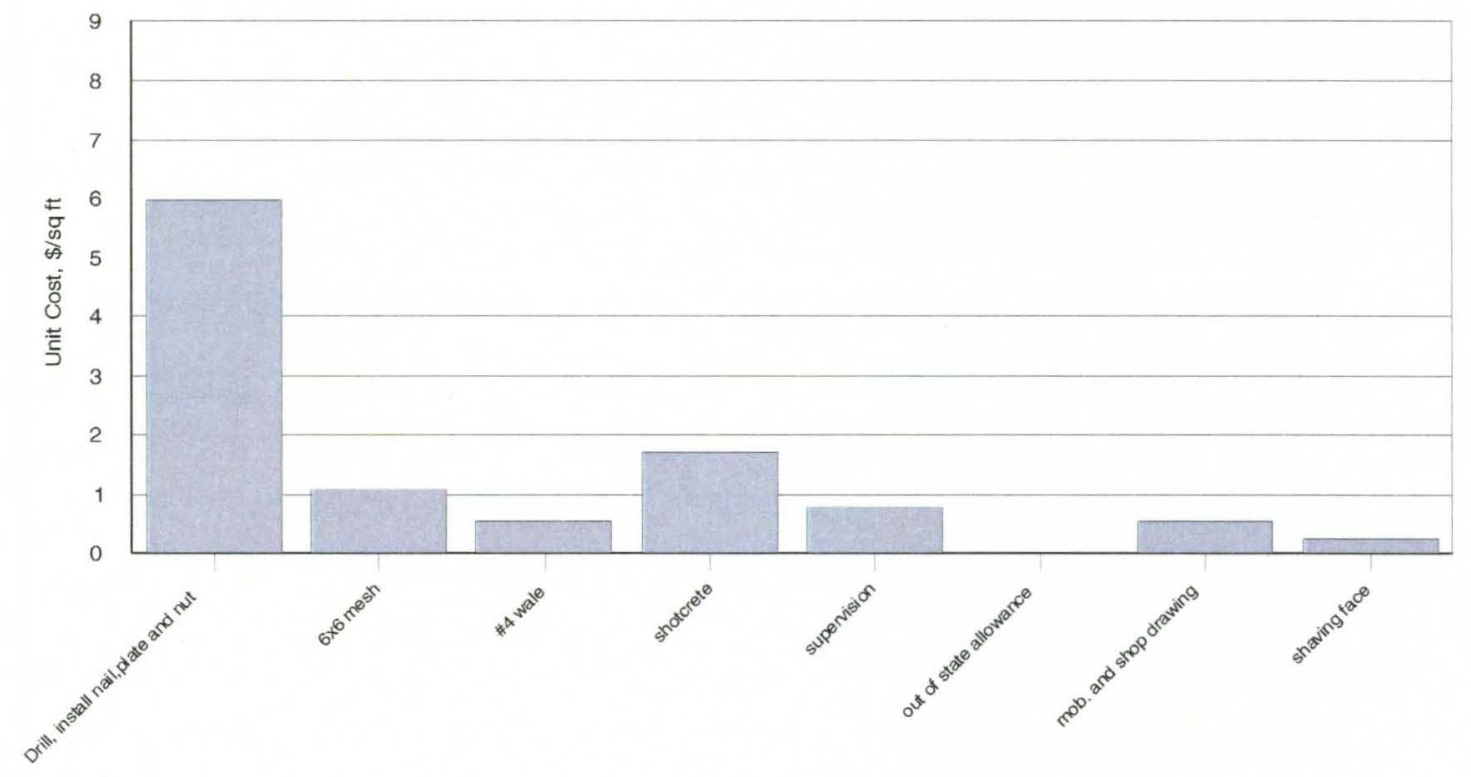

Figure 52. (Case 13) Unit Cost for Each Soil Nailing System Component 


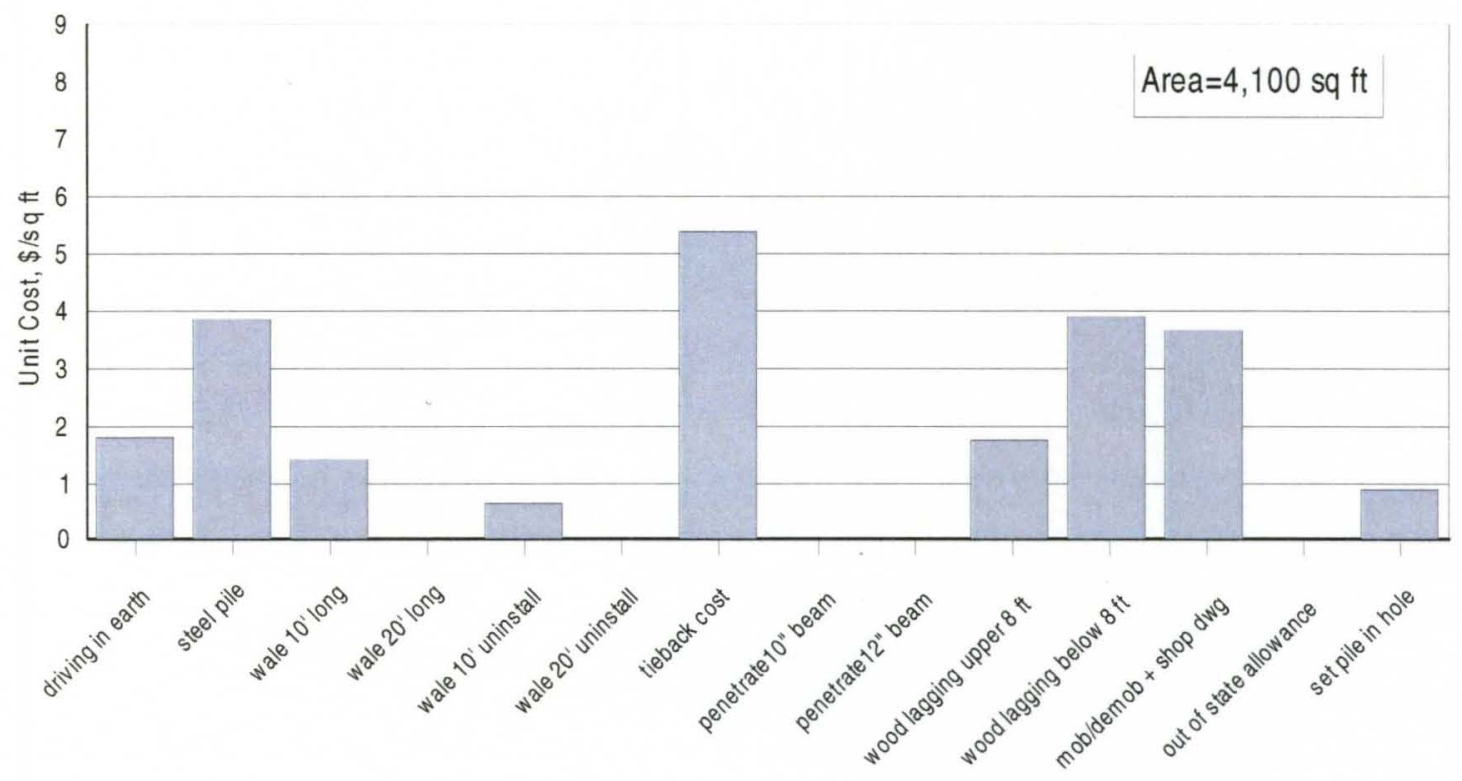

Figure 53. Unit Cost (Case 14) for Each Conventional System Component

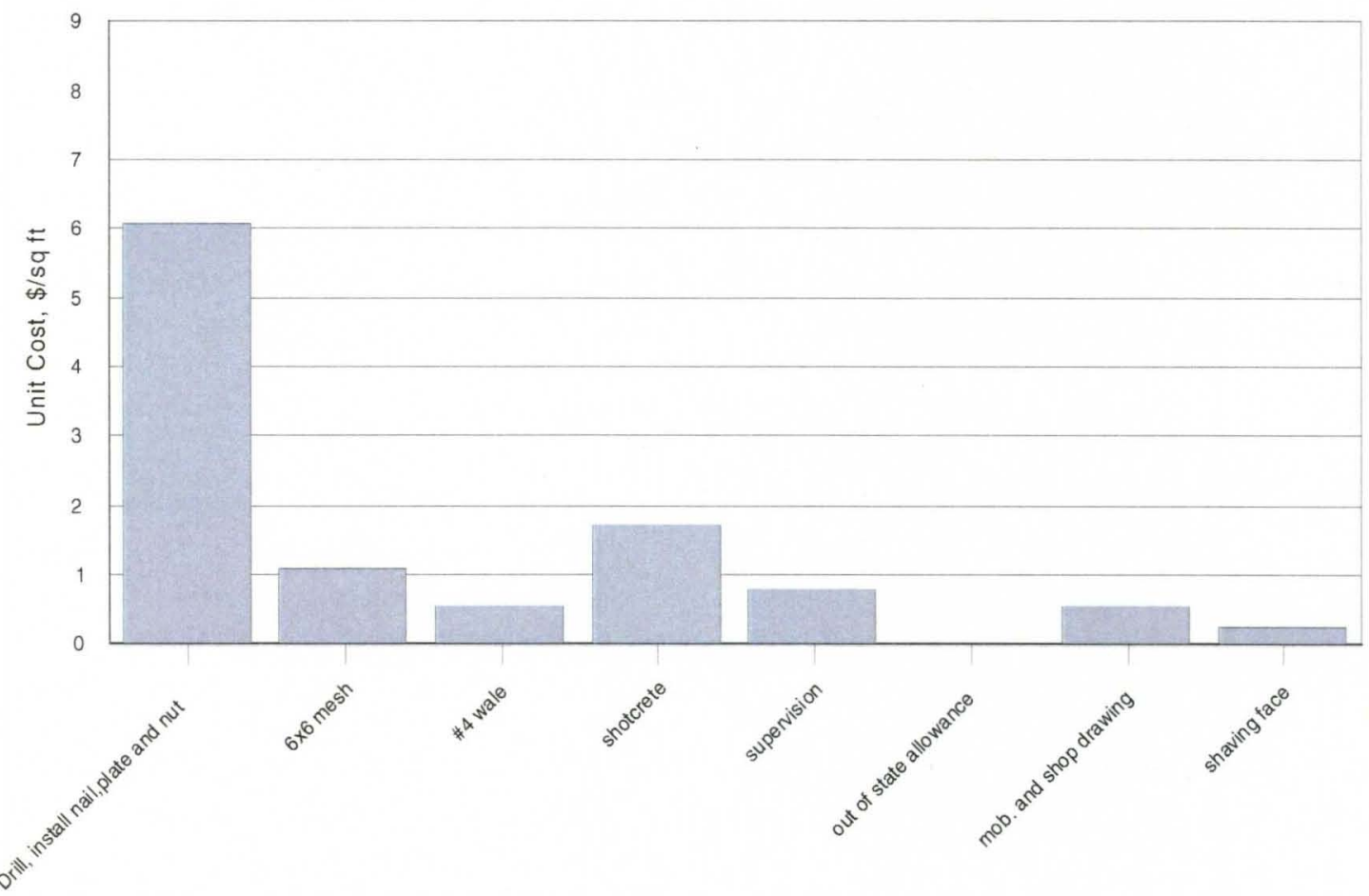

Figure 54. (Case 14) Unit Cost for Each Soil Nailing System Component 
By studying Table 10, on the next page, the Author found that the steel unit cost, tieback unit cost, and unit cost of the lagging below the upper 8 feet (that required welding studs on the soldier piles to hold lagging) are the most influential cost factors for the conventional retention system. Steel costs varied between $\$ 2.69 /$ sqft and $\$$ $4.57 / \mathrm{sqft}$ and tieback costs varied between $\$ 3.42 / \mathrm{sqft}$ and $\$ 12.38 / \mathrm{sqft}$. Unit costs for these two components are more variable than the unit costs of the rest of the retention system components. These variations depend on the project size (square footage) and the depth of the sheeted cut. When sheeted areas were small (2,000 to 4,000 square feet), the unit costs of steel and tiebacks increased, while the lagging unit cost did not vary significantly. Furthermore, when the required sheeted cut is deep and requires several layers of tiebacks, tieback unit costs will increase as in case 15 when the excavation required the deepest cut in this study (42 feet). 
Table 10. Conventional System Unit Cost for Components and Operations, \$/sqft

\begin{tabular}{|c|c|c|c|c|c|c|c|c|c|c|c|c|c|c|c|c|}
\hline & S/sqft & S/sqft & S/sqft & \$isqft & S/sqft & S/sqft & S/s qft & S/sqft & S/sqft & S/sqft & S/s qft & \$/s qft & S/sqft & $\$ / s q f t$ & S/sqft & \$/sqft \\
\hline & $\begin{array}{c}\text { Case } \\
1\end{array}$ & \begin{tabular}{|c|} 
Case \\
2 \\
\end{tabular} & \begin{tabular}{|c|} 
Case \\
3 \\
\end{tabular} & $\begin{array}{c}\text { Case } \\
4 \\
\end{array}$ & $\begin{array}{c}\text { Case } \\
5 \\
\end{array}$ & \begin{tabular}{|c|} 
Case \\
6 \\
\end{tabular} & \begin{tabular}{|c|} 
Case \\
7 \\
\end{tabular} & $\begin{array}{c}\text { Case } \\
8 \\
\end{array}$ & $\begin{array}{c}\text { Case } \\
9 \\
\end{array}$ & \begin{tabular}{|l|l|} 
Case \\
10
\end{tabular} & $\begin{array}{c}\text { Case } \\
11 \\
\end{array}$ & $\begin{array}{c}\text { Case } \\
12\end{array}$ & \begin{tabular}{|c|} 
Case \\
13 \\
\end{tabular} & $\begin{array}{c}\text { Case } \\
14 \\
\end{array}$ & \begin{tabular}{|c|} 
Case \\
15 \\
\end{tabular} & $\begin{array}{l}\text { Avg. } \\
=\end{array}$ \\
\hline $\begin{array}{l}\text { driving } \\
\text { in earth }\end{array}$ & 1.66 & 1.28 & 1.73 & 1.31 & 1.10 & 1.39 & 1.77 & 1.25 & 1.22 & 1.30 & 1.62 & 1.52 & 1.81 & 1.77 & 1.24 & 1.46 \\
\hline steel pile & 4.57 & 3.51 & 3.77 & 2.86 & 2.69 & 3.83 & 3.87 & 2.73 & 3.37 & 3.59 & 3.54 & 4.16 & 3.95 & 3.87 & 3.41 & 3.58 \\
\hline $\begin{array}{c}\text { wale } 10^{\prime} \\
\text { Iong }\end{array}$ & 1.07 & 1.61 & 1.68 & 0.10 & 0.06 & 0.00 & 0.60 & 0.68 & 0.00 & 1.73 & 1.81 & 1.38 & 1.95 & 1.43 & 0.00 & 0.94 \\
\hline $\begin{array}{c}\text { wale } 20^{\prime} \\
\text { Iong }\end{array}$ & 0.04 & 0.05 & 0.00 & 1.54 & 0.68 & 0.44 & 0.00 & 1.08 & 0.00 & 0.00 & 0.00 & 0.00 & 0.00 & 0.00 & 0.00 & 0.26 \\
\hline $\begin{array}{l}\text { Wale } 10^{\prime} \\
\text { uninstall }\end{array}$ & 0.48 & 0.71 & 0.75 & 0.04 & 0.02 & 0.00 & 0.26 & 0.30 & 0.00 & 0.77 & 0.80 & 0.61 & 0.87 & 0.63 & 0.00 & 0.42 \\
\hline $\begin{array}{l}\text { wale } 20^{\prime} \\
\text { uninstall }\end{array}$ & 0.02 & 0.02 & 0.00 & 0.70 & 0.31 & 0.20 & 0.00 & 0.49 & 0.00 & 0.00 & 0.00 & 0.00 & 0.00 & 0.00 & 0.00 & 0.12 \\
\hline $\begin{array}{c}\text { tieback } \\
\text { cost }\end{array}$ & 5.15 & 8.79 & 3.42 & 6.76 & 8.59 & 8.38 & 4.76 & 7.47 & 7.70 & 4.43 & 5.63 & 6.42 & 4.34 & 5.38 & 12.38 & 6.64 \\
\hline $\begin{array}{l}\text { penetrate } \\
10^{\prime \prime} \text { bea } \mathrm{m}\end{array}$ & 0.00 & 0.00 & 0.00 & 0.00 & 0.00 & 0.00 & 0.33 & 0.00 & 0.67 & 0.00 & 0.00 & 0.00 & 0.00 & 0.00 & 0.00 & 0.07 \\
\hline $\begin{array}{l}\text { penetrate } \\
12^{\prime \prime} \text { beam }\end{array}$ & 0.00 & 0.00 & 0.00 & 0.00 & 0.67 & 0.74 & 0.00 & 0.00 & 0.00 & 0.00 & 0.00 & 0.00 & 0.00 & 0.00 & 1.41 & 0.19 \\
\hline $\begin{array}{c}\text { Wood } \\
\text { lagging } \\
\text { upper } 8 \mathrm{ft}\end{array}$ & 1.75 & 0.96 & 1.91 & 1.21 & 1.06 & 1.23 & 1.80 & 1.31 & 1.57 & 1.23 & 1.81 & 1.60 & 1.87 & 1.74 & 0.74 & 1.45 \\
\hline $\begin{array}{c}\text { wood } \\
\text { lagging } \\
\text { below } 8 \mathrm{ft}\end{array}$ & 3.87 & 5.18 & 3.61 & 4.76 & 5.01 & 4.74 & 3.79 & 4.60 & 4.17 & 4.73 & 3.78 & 4.12 & 3.68 & 3.89 & 5.54 & 4.36 \\
\hline $\begin{array}{l}\text { mob/demob } \\
+ \text { shop dwg }\end{array}$ & 0.80 & 0.45 & 8.00 & 1.12 & 0.41 & 0.60 & 4.97 & 1.13 & 1.76 & 1.26 & 2.41 & 1.02 & 5.42 & 3.66 & 0.21 & 2.21 \\
\hline \begin{tabular}{|c|} 
out of \\
state \\
allowance
\end{tabular} & 0.00 & 0.00 & 0.64 & 0.00 & 0.00 & 0.51 & 0.00 & 0.54 & 0.00 & 0.00 & 0.00 & 0.53 & 0.00 & 0.00 & 0.00 & 0.15 \\
\hline \multirow[t]{2}{*}{\begin{tabular}{|l|l}
$\begin{array}{l}\text { set pile } \\
\text { in hole }\end{array}$ \\
\end{tabular}} & 0.83 & 0.64 & 0.86 & 0.65 & 0.55 & 0.70 & 0.89 & 0.62 & 0.61 & 0.65 & 0.81 & 0.76 & 0.90 & 0.89 & 0.62 & 0.73 \\
\hline & $===$ & $===$ & $===$ & $===$ & $===$ & $===$ & $===$ & $===$ & $===$ & $===$ & $===$ & $===$ & $===$ & $===$ & $===$ & $===$ \\
\hline $\begin{array}{c}\text { Unit cost } \\
\text { Total }=\end{array}$ & 20.25 & 23.19 & 26.37 & 21.05 & 21.15 & 22.76 & 23.04 & 22.22 & 21.07 & 19.70 & 22.21 & 22.12 & 24.80 & 23.26 & 25.54 & 22.58 \\
\hline
\end{tabular}

Table 11 shows the unit costs for the soil nailing system components; the most influential cost factors are the unit cost for nails and nail installation. Soil nail unit cost varied between $\$ 4.98 /$ sqft and $\$ 10.68$ / sqft. These unit costs are low when project size is small (2,000 to 4,000 square feet) as in cases $3,7,13$ and 14 . The unit cost for other soil nailing components did not vary with project size. 
Table 11. Soil Nailing System Unit Cost for Components and Operations, \$/sqft

\begin{tabular}{|c|c|c|c|c|c|c|c|c|c|c|c|c|c|c|c|c|}
\hline & \$/s qft & S/s qft & S/sqft & S/sqft & S/sqft & S/sqft & Sis qft & Sis qft & \$/s qft & S/sqft & S/sqft & S/sqft & S/sqft & \$/sqft & S/sqft & S/sqft \\
\hline & $\begin{array}{c}\text { Case } \\
1\end{array}$ & $\begin{array}{c}\text { Case } \\
2\end{array}$ & \begin{tabular}{|c|} 
Case \\
3
\end{tabular} & $\begin{array}{c}\text { Case } \\
4\end{array}$ & $\begin{array}{c}\text { Case } \\
5\end{array}$ & $\begin{array}{c}\text { Case } \\
6\end{array}$ & $\begin{array}{c}\text { Case } \\
7\end{array}$ & $\begin{array}{c}\text { Case } \\
8\end{array}$ & $\begin{array}{c}\text { Case } \\
9\end{array}$ & $\begin{array}{l}\text { Case } \\
10\end{array}$ & $\begin{array}{c}\text { Case } \\
11\end{array}$ & $\begin{array}{c}\text { Case } \\
12\end{array}$ & $\begin{array}{c}\text { Case } \\
13\end{array}$ & \begin{tabular}{|c|} 
Case \\
14
\end{tabular} & $\begin{array}{c}\text { Case } \\
15\end{array}$ & $\begin{array}{c}\text { Avg. } \\
=\end{array}$ \\
\hline $\begin{array}{r}\text { Drill and } \\
\text { install } \\
\text { nail,plate } \\
\text { and nut }\end{array}$ & 7.66 & 9.61 & 4.98 & 9.67 & 8.14 & 9.48 & 5.12 & 6.79 & 9.99 & 9.99 & 7.04 & 8.59 & $\begin{array}{c}5.9 \\
8\end{array}$ & 6.08 & 10.69 & 7.99 \\
\hline $\begin{array}{c}6 \times 6 \\
\text { mesh }\end{array}$ & 1.10 & 1.10 & 1.10 & 1.10 & 1.10 & 1.10 & 1.10 & 1.10 & 1.10 & 1.10 & 1.10 & 1.10 & 1.10 & 1.10 & 1.10 & 1.10 \\
\hline$\# 4$ wale & 0.54 & 0.54 & 0.54 & 0.54 & 0.54 & 0.54 & 0.54 & 0.54 & 0.54 & 0.54 & 0.54 & 0.54 & 0.54 & 0.54 & 0.54 & 0.54 \\
\hline shotcrete & 1.72 & 1.72 & 1.72 & 1.72 & 1.72 & 1.72 & 1.72 & 1.72 & 1.72 & 1.72 & 1.72 & 1.72 & 1.72 & 1.72 & 1.72 & 1.72 \\
\hline $\begin{array}{c}\text { Supervis- } \\
\text { ion }\end{array}$ & 0.80 & 0.80 & 1.00 & 0.80 & 0.80 & 0.80 & 0.80 & 0.80 & 0.80 & 0.80 & 0.80 & 0.80 & 0.80 & 0.80 & 0.80 & 0.81 \\
\hline $\begin{array}{c}\text { out of } \\
\text { state } \\
\text { allowance }\end{array}$ & 0.00 & 0.00 & 0.80 & 0.00 & 0.00 & 0.80 & 0.00 & 0.80 & 0.00 & 0.00 & 0.00 & 0.80 & 0.00 & 0.00 & 0.00 & 0.21 \\
\hline $\begin{array}{l}\text { mob. and } \\
\text { shop } \\
\text { drawing }\end{array}$ & 0.37 & 0.37 & 0.56 & 0.37 & 0.37 & 0.54 & 0.56 & 0.56 & 0.56 & 0.37 & 0.56 & 0.56 & 0.56 & 0.56 & 0.56 & 0.50 \\
\hline \multirow[t]{2}{*}{$\begin{array}{c}\begin{array}{c}\text { shaving } \\
\text { face }\end{array} \\
\end{array}$} & 0.25 & 0.25 & 0.25 & 0.25 & 0.25 & 0.25 & 0.25 & 0.25 & 0.25 & 0.25 & 0.25 & 0.25 & 0.25 & 0.25 & 0.25 & 0.25 \\
\hline & $===$ & $===$ & $===$ & $===$ & $===$ & $===$ & $===$ & $===$ & $===$ & $===$ & $===$ & $===$ & $===$ & $===$ & $===$ & $==$ \\
\hline $\begin{array}{l}\text { Unit cost } \\
\text { Total = }\end{array}$ & 12.44 & 14.39 & 10.95 & 14.45 & 12.92 & 15.23 & 10.09 & 12.56 & 14.96 & 14.77 & 12.01 & 14.36 & 10.95 & 11.05 & 15.66 & 13.12 \\
\hline
\end{tabular}

\subsubsection{Project Location}

Comparison of costs for projects done in Louisville, Kentucky with costs for projects done outside the Louisville area did not reveal a significant difference between the two locations of projects. Figures 55A and 55B (without Case 15) show unit costs for projects constructed in the Louisville, Kentucky area. Figure 56 shows unit costs for projects constructed outside of Louisville, for both conventional and soil nailing systems. 


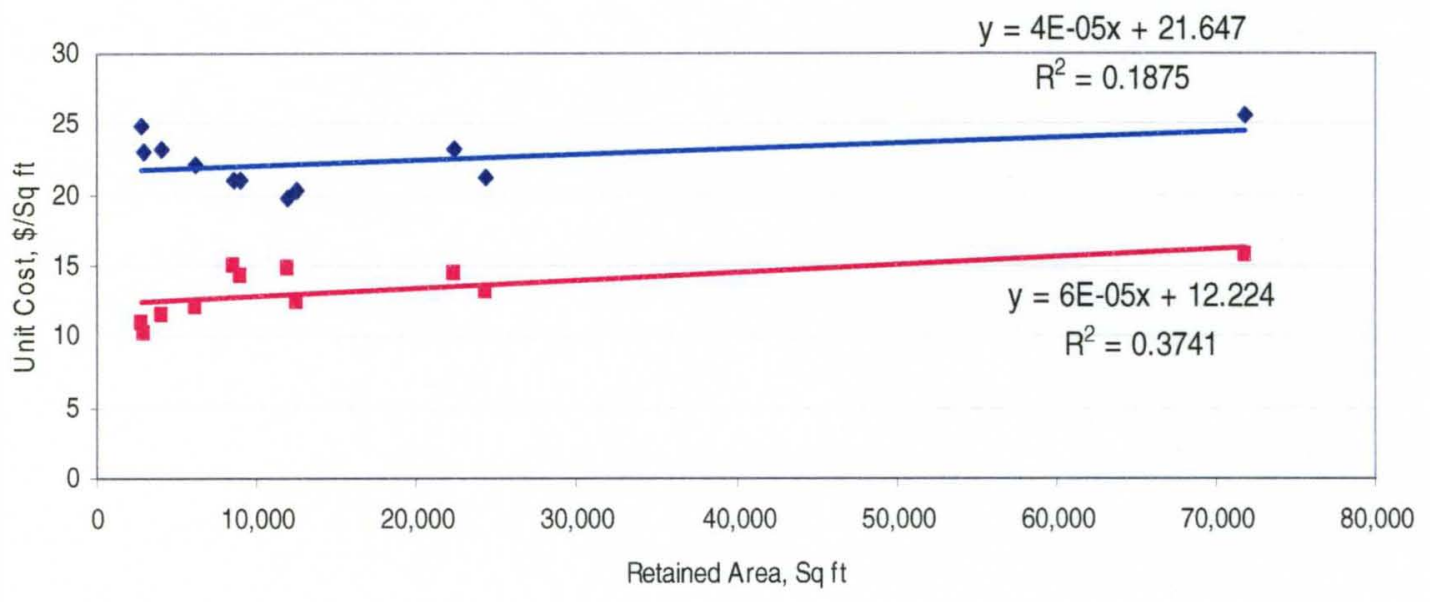

- Conventional a Soil Nailing _ Linear (Conventional) _ Linear (Soil Nailing)

Figure 55A. Unit Cost of Conventional Systems and Soil Nailing Systems versus

Retained area in Louisville, KY

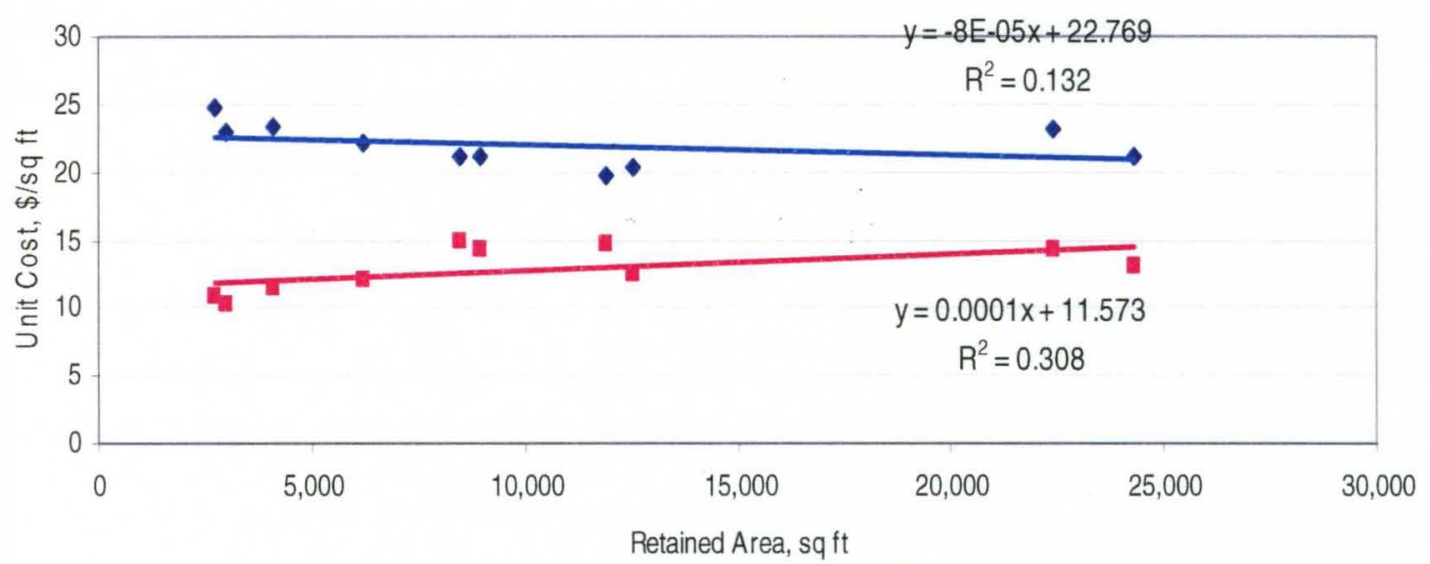

- Conventional n Soil Nailing — Linear (Conventional) —Linear (Soil Nailing)

Figure 55B. Unit Cost of Conventional Systems and Soil Nailing Systems versus

Retained area in Louisville, KY without case $15(17,820 \mathrm{sq} \mathrm{ft})$ 


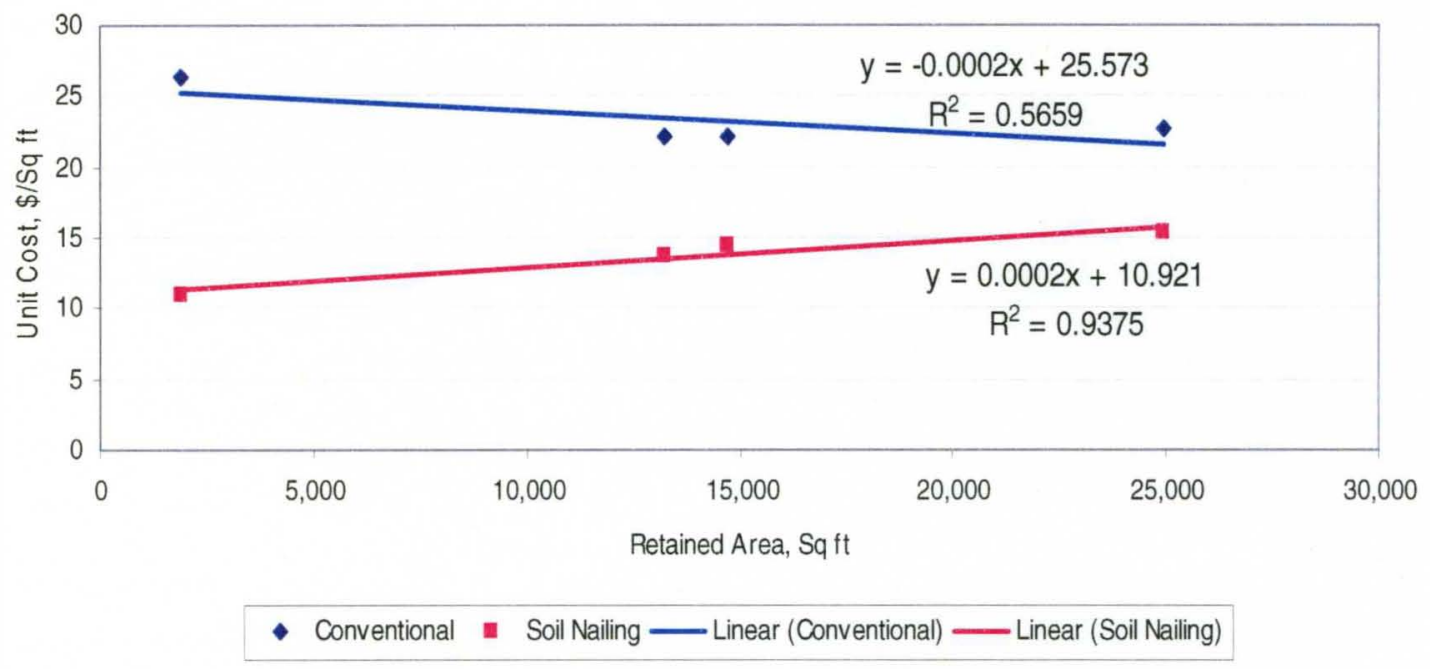

Figure 56. Unit Cost of Conventional Systems and Soil Nailing Systems versus Retained area Outside of Louisville, KY

By studying Figures 55B, and 56, the Author concluded that the unit cost of jobs for both conventional systems and soil nailing systems constructed in the Louisville, Kentucky area were in the same cost range as costs for projects constructed outside the Louisville area.

Figure 57 shows total cost for all projects except Case 15, differentiated by location, for conventional systems, and Figure 58 shows total cost for soil nailing systems differentiated by location, except for Case 15 . 


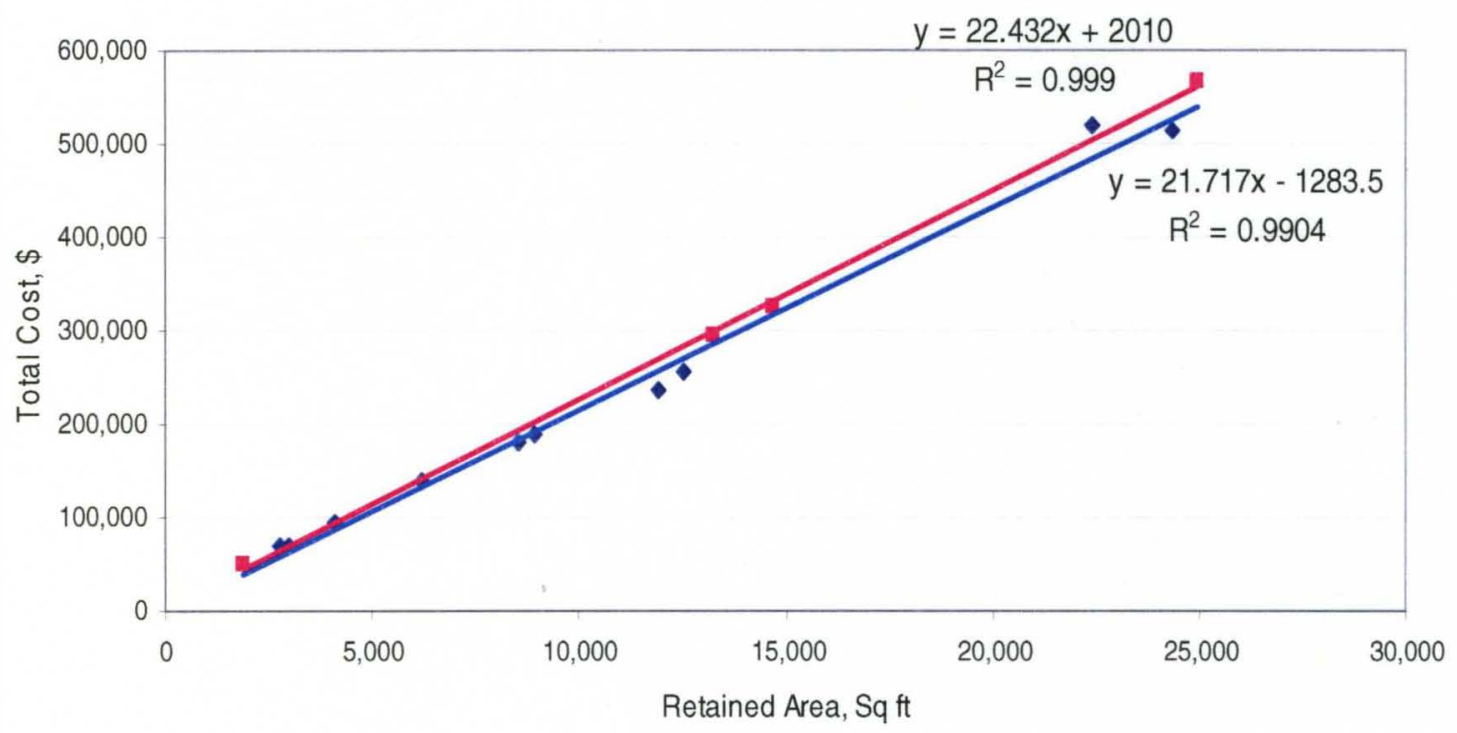

- In Louisville Out of Louisville _ Linear (In Louisville) _ Linear (Out of Louisville)

Figure 57. Total Cost of Conventional System with Location versus Retained Area without case 15

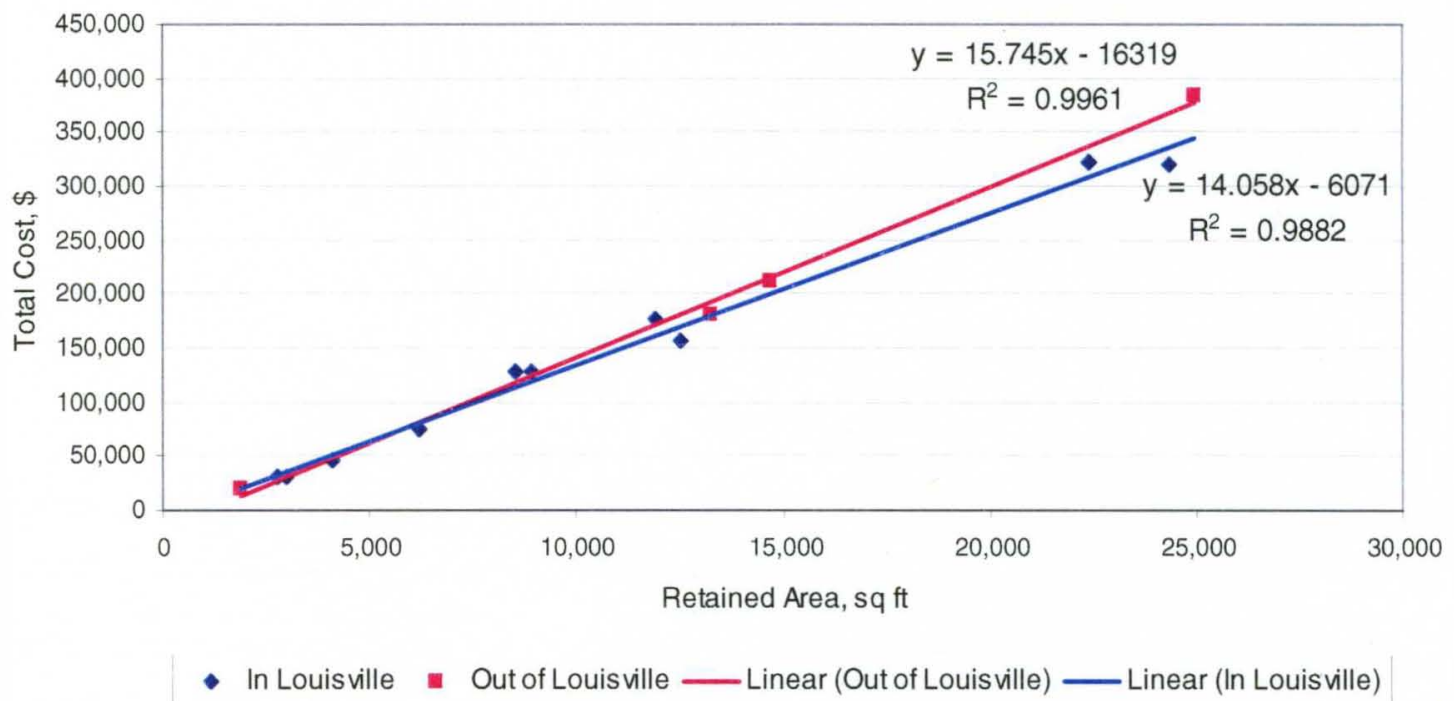

Figure 58. Total Cost of Soil Nailing System with Location versus Retained Area without case $15(71,820 \mathrm{sq} f \mathrm{ft})$ 


\subsubsection{Adjusted Analysis}

The most critical intrinsic factor affecting the cost of both systems was the job size. To make comparisons more meaningful, the Author divided total cost by project linear feet to produce the plot of unit cost versus size of project shown in Figure 59 for conventional systems. A similar procedure produced the plot of unit costs versus size of project for soil nailing systems shown in Figure 60 .

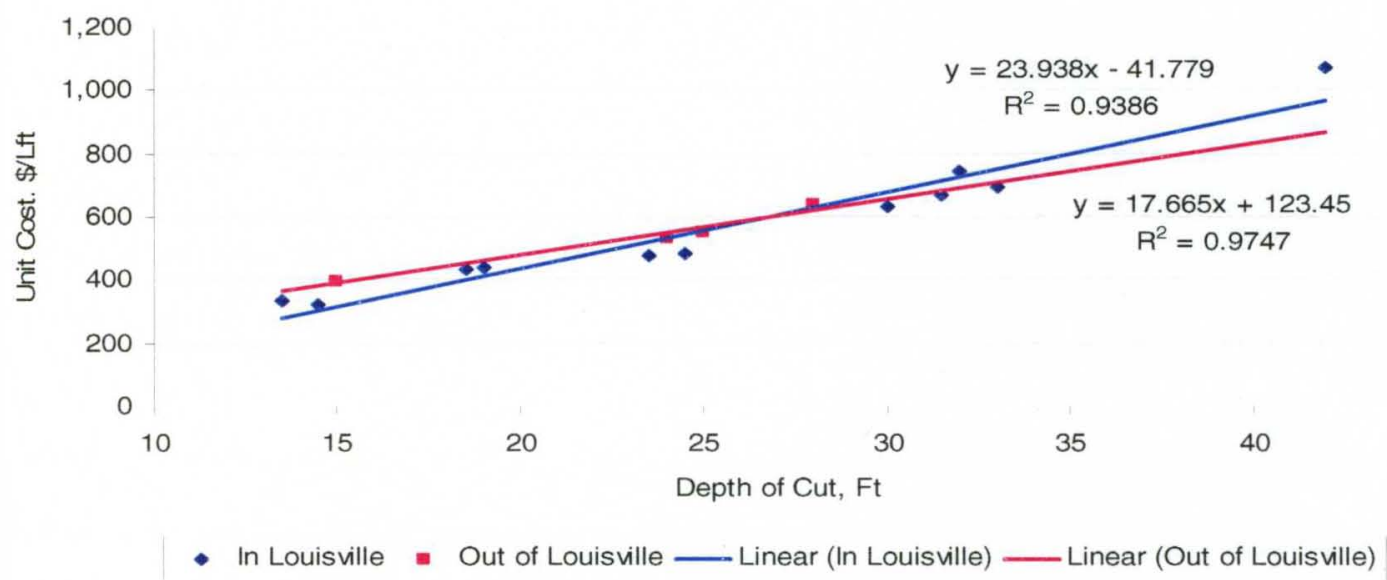

Figure 59. Unit Cost of Conventional System with Location versus Depth of Cut (depth of retained excavation) 


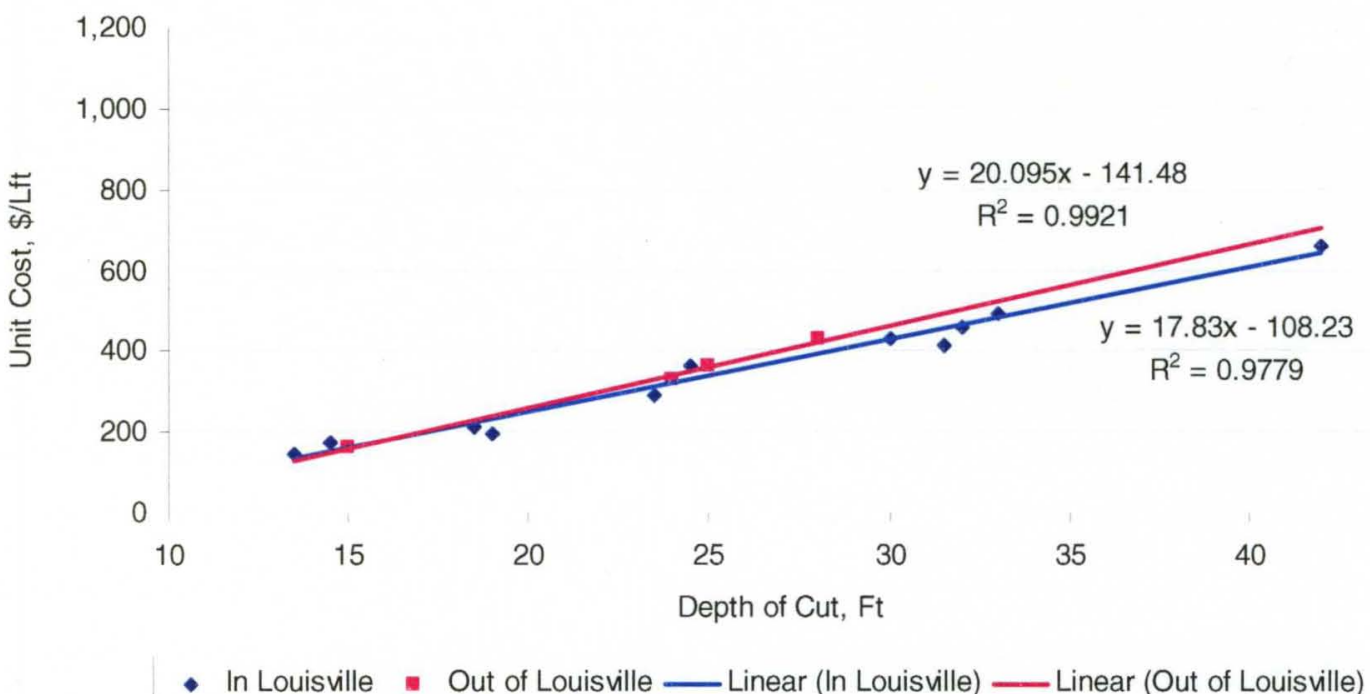

Figure 60. Unit Cost of Soil Nailing System with Location versus

Depth of Cut (depth of retained excavation)

Figures 59 and 60 show that the location will have less significance for the unit cost of both conventional and soil nailing systems than the project size. 


\section{CHAPTER 5}

\section{CONCLUSIONS AND RECOMMENDATIONS}

\subsection{General Conclusions}

Soil nailing can be used successfully and economically to retain deep excavations, provided the anticipated deformations and associated settlements are within acceptable limits as determined by project conditions.

Several factors are making soil nailing more economical than conventional retention systems, if the deformations and settlements of soil nailing systems can be tolerated: lower cost for materials; quicker mobilization; faster construction time; smaller construction space requirements; and less need for heavy equipment.

Soil nailing is advantageous in heterogeneous soils having boulders or rock mixed with softer soils, but that advantage is not necessarily related to project cost.

Soil nailing cannot be used in clayey soils of low strength, in poorly draining soils, in soils that cannot support a temporary vertical cut, and in soil profiles favoring deep-seated sliding surfaces.

In general, this research indicated that, if soil nailing can meet deformation and settlement criteria, soil nailing will be more economical than conventional retention systems for excavations up to 42 feet deep, for the conditions that existed in the fifteen project sites examined in this study. This conclusion supports the hypothesis stated at the beginning of this dissertation. 


\subsection{Factors Affecting Cost}

Comparing cost between Conventional and Soil Nailing retention systems, three categories of factors need to be compared: Material, Labor, and Equipment costs. Conventional system material will cost more than soil nailing material. Labor cost to install a conventional system is higher than labor cost for a soil nailing system, a conventional system requires buying or renting heavier and more expensive equipment to install the system, compared with light and less expensive equipment for a soil nailing system. In other words, for most cases, soil nailing systems will be cheaper than conventional systems. However, there are other factors affecting which system will be used in a project: Area of local practice (option for local contractors to get project materials, labor, and equipment), and Engineer's recommendation and experience with retention system, which will influence what system is chosen.

Two intrinsic factors were investigated in comparing the costs for soil nailing systems and conventional systems: project size; and project location, but the project size was the dominant factor, while project location mattered little.

\subsubsection{Effect of Project size}

If the project has a small square footage of sheeted area, the cost of the Conventional system will be increased primarily because of the unit costs for steel $\mathrm{H}$ piles and wales, steel tieback, and unit mobilization and demobilization costs. For projects that have a large square footage of sheeted area (more than 6,500 square feet), the average cost of soil nailing is about two-thirds of the cost of Conventional systems if all other conditions were the same. 


\subsubsection{Effect of Project Location}

According to the data in this study, the location of the project did not have a significant effect on cost.

\subsection{Recommendations}

The Author recommends that more studies be conducted for situations and conditions not covered herein, such as a cost comparison study of both systems versus depth of cut, with data from cuts more than 42 feet deep. Also, more data should be gathered from cities other than Louisville, Kentucky, especially cities such as Chicago, Boston, New York, and San Francisco. 


\section{REFERENCES}

Clough, G. W. and Thomas D. O'Rourke (1990). "Construction Induced Movements of Insitu Walls," Geotechnical Special Publication, No. 25, Design and Performance of Earth Retaining Structures, ASCE, New York, 18-21

Lazarte, C. A., Elias, V., Espinoza, D., and Sabatini, P. J. (2003). Soil Nailing Walls, Geotechnical Engineering Circular No. 7, Report No. 7, Report No. FHWA0IF-03-017 Federal Highway Administration, Washington, D. C., 7-16

PTI Post-Tensioning Institution (1996). Recommendations for Prestressed Rock and Soil Anchors $3^{\text {rd }}$ Edition

Porterfield, J. A., Cotton, D. M., and Byrne, R. J. (1994). "Soil Nailing Field Inspectors Manual, Project Demonstration 103," Publication No. FWHA-SA-93068, Federal Highway Administration, Washington, D.C., 7-9

Stocker, M. and Riedinger, G., (1990). "The Bearing Behavior of Nailed Retaining Structures," Geotechnical Special Publication, No. 25, Design and Performance of Earth Retaining Structures, ASCE, New York, .612-628 
Appendix A: Sketches of Systems 


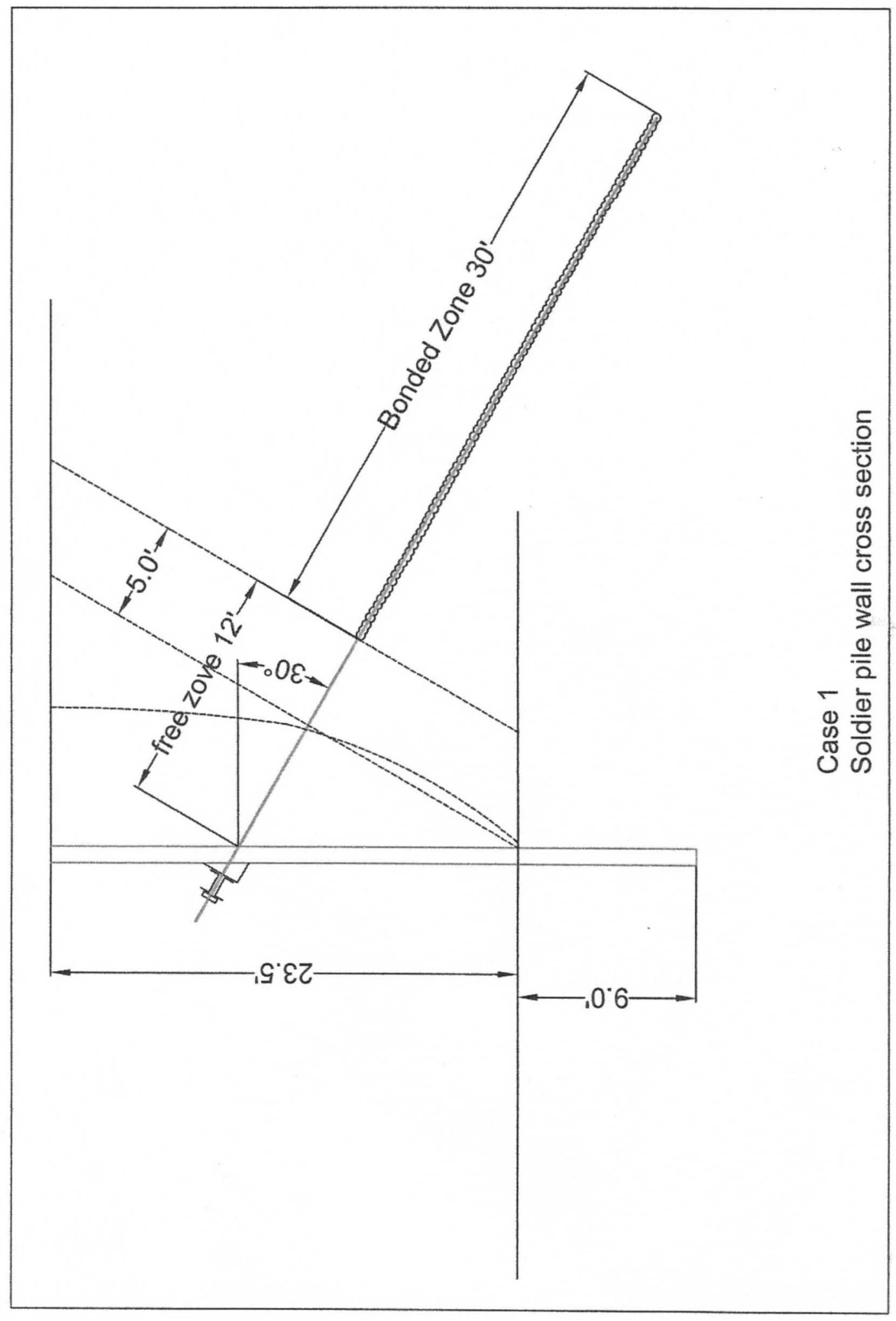




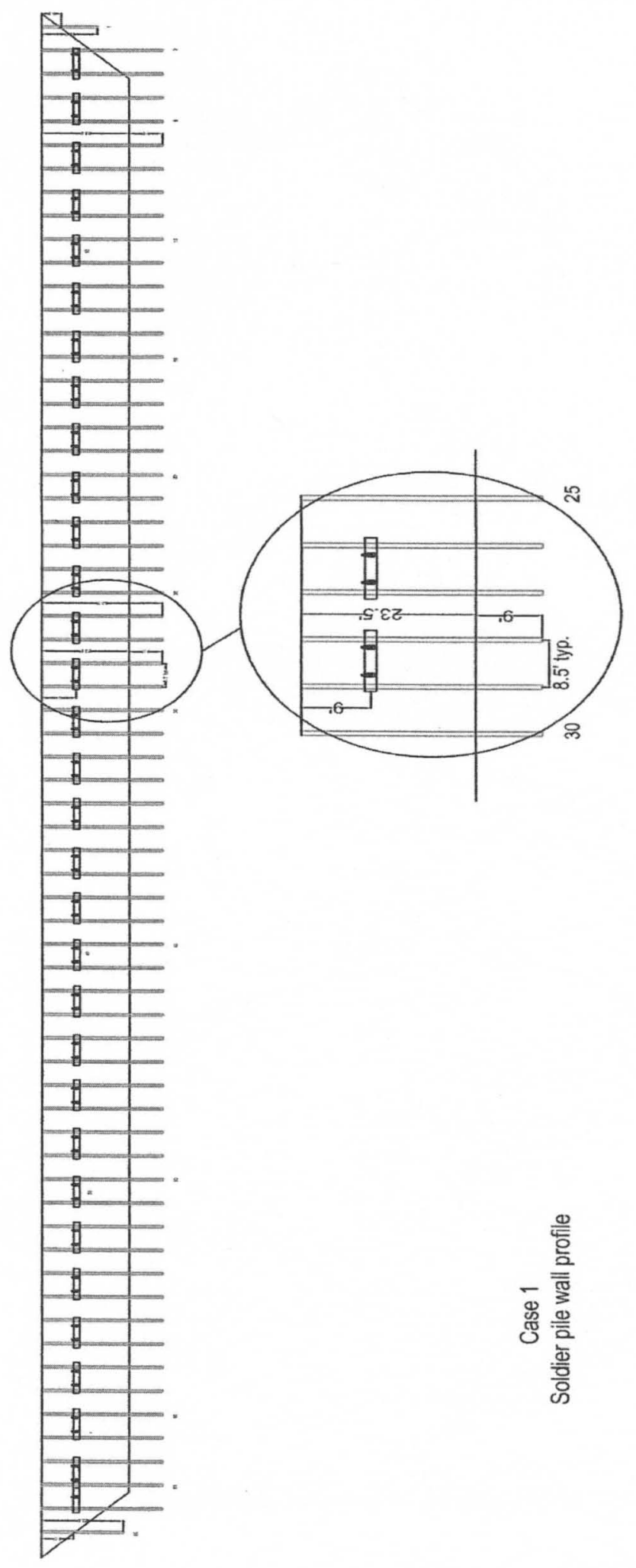




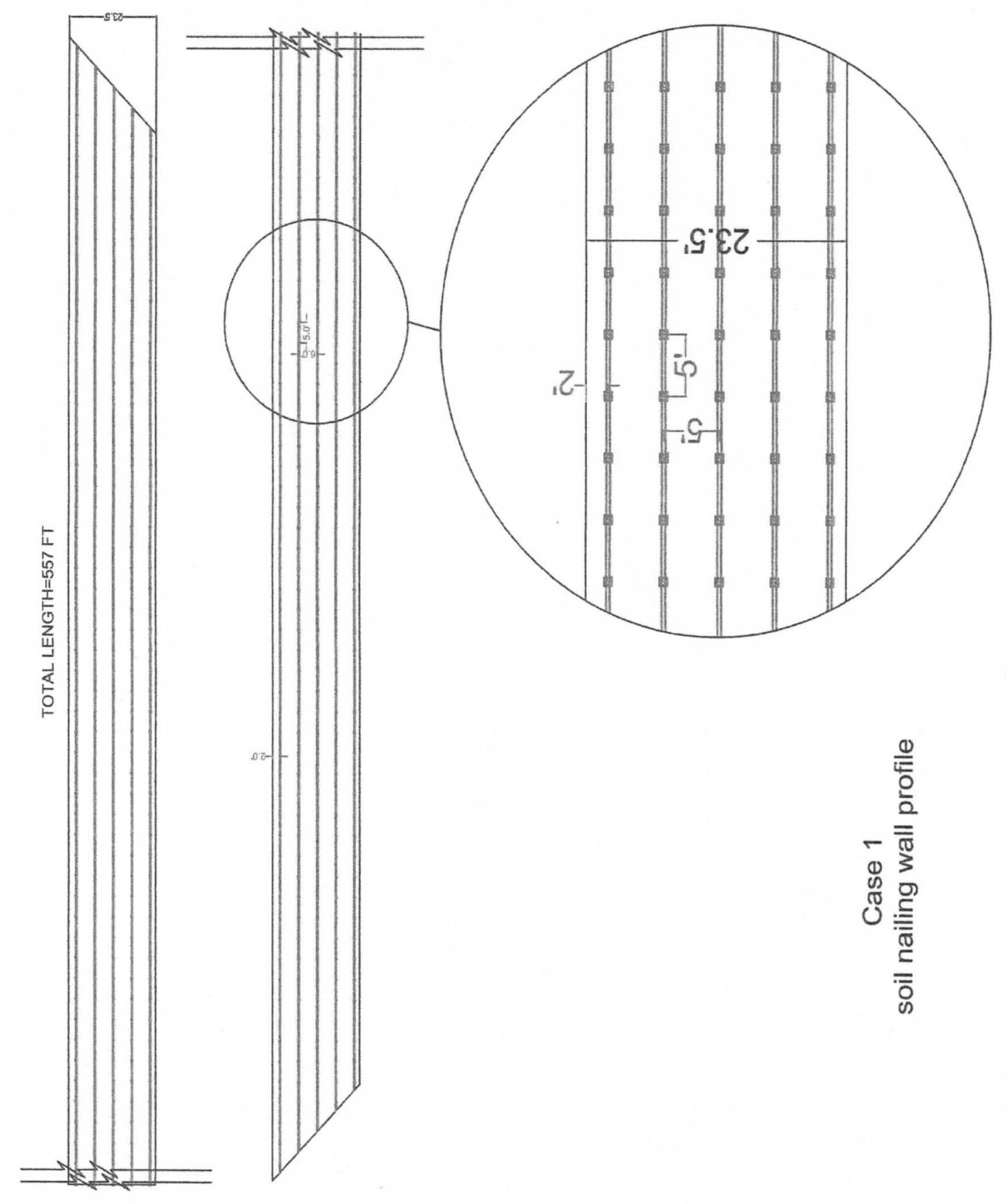




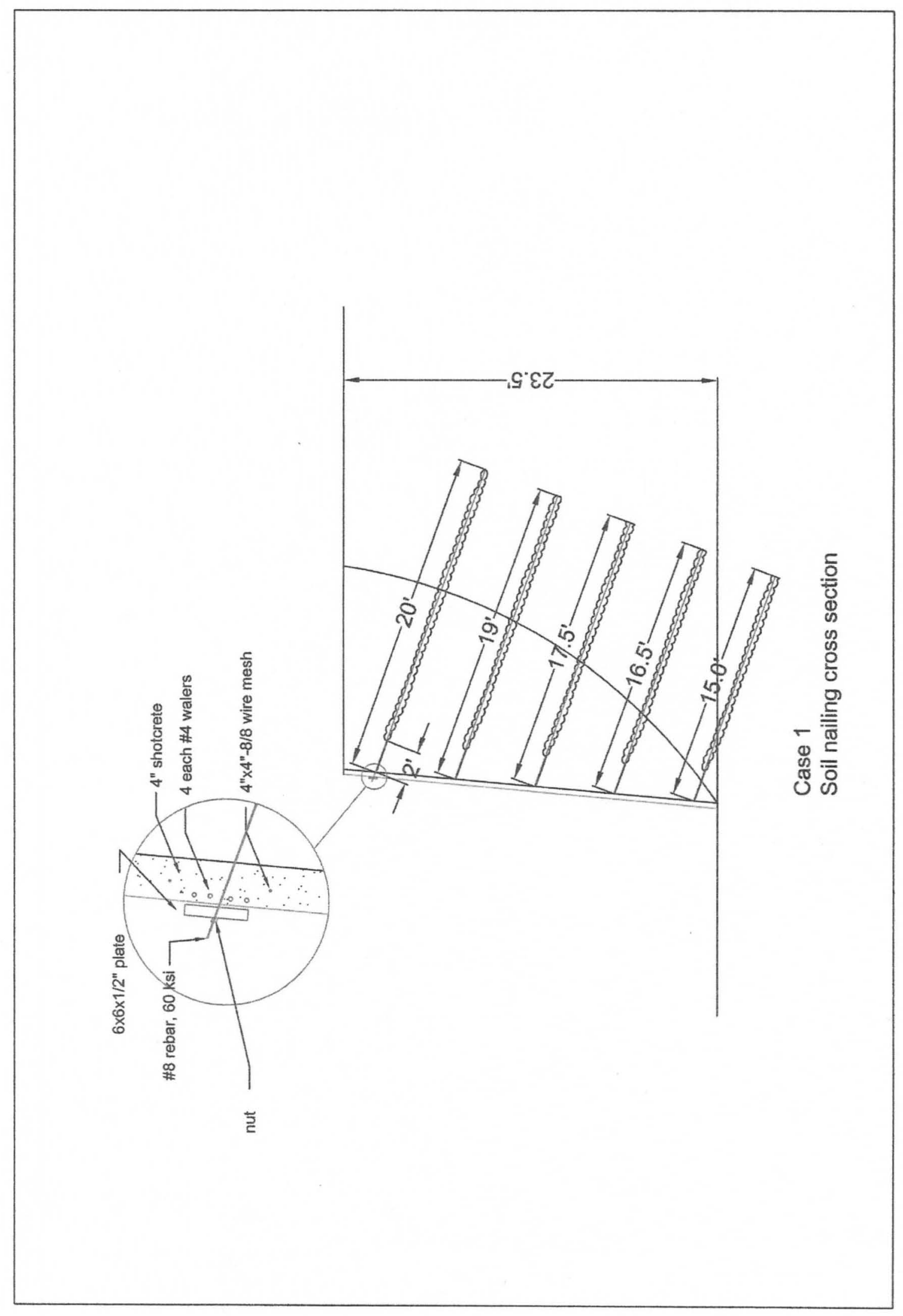




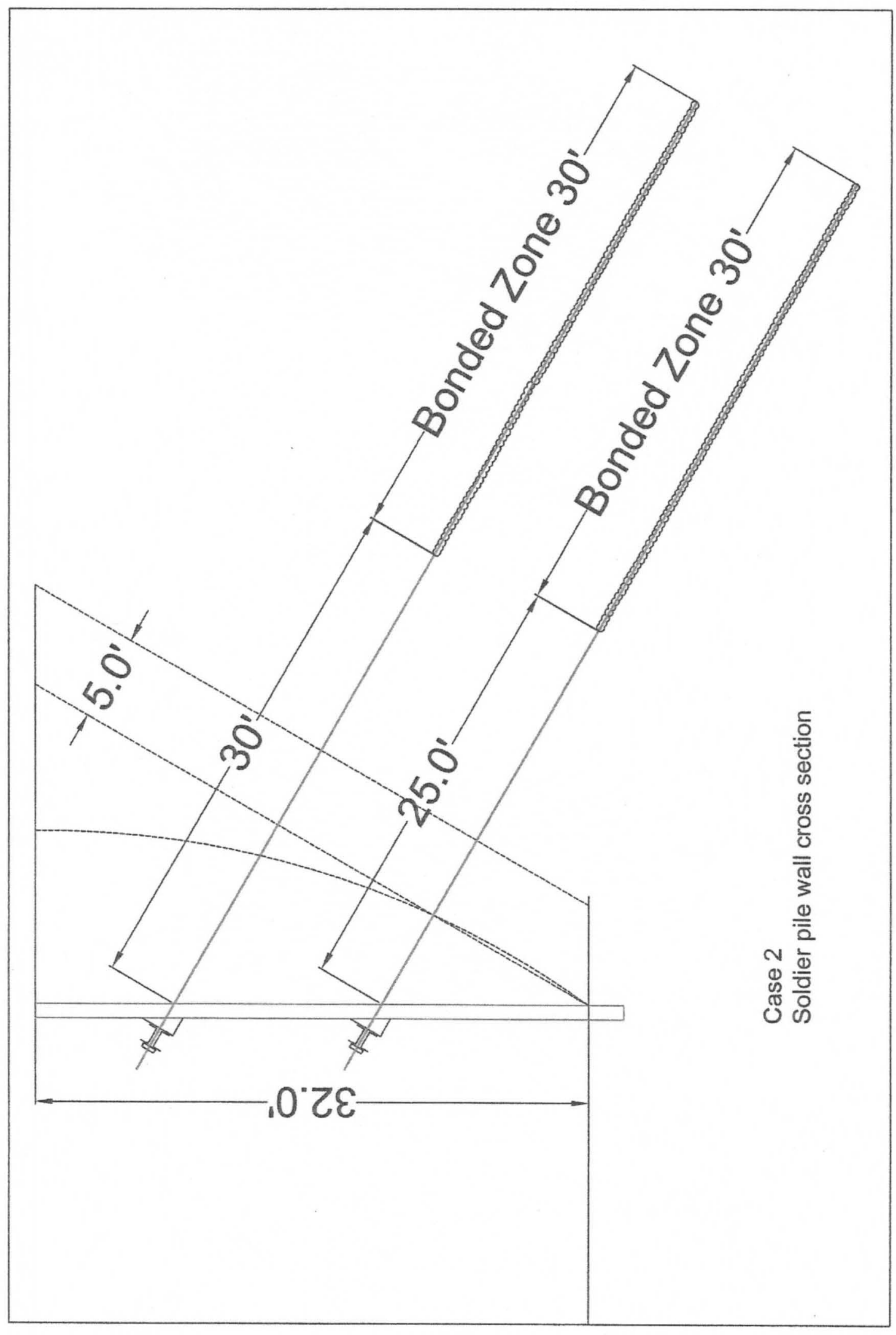




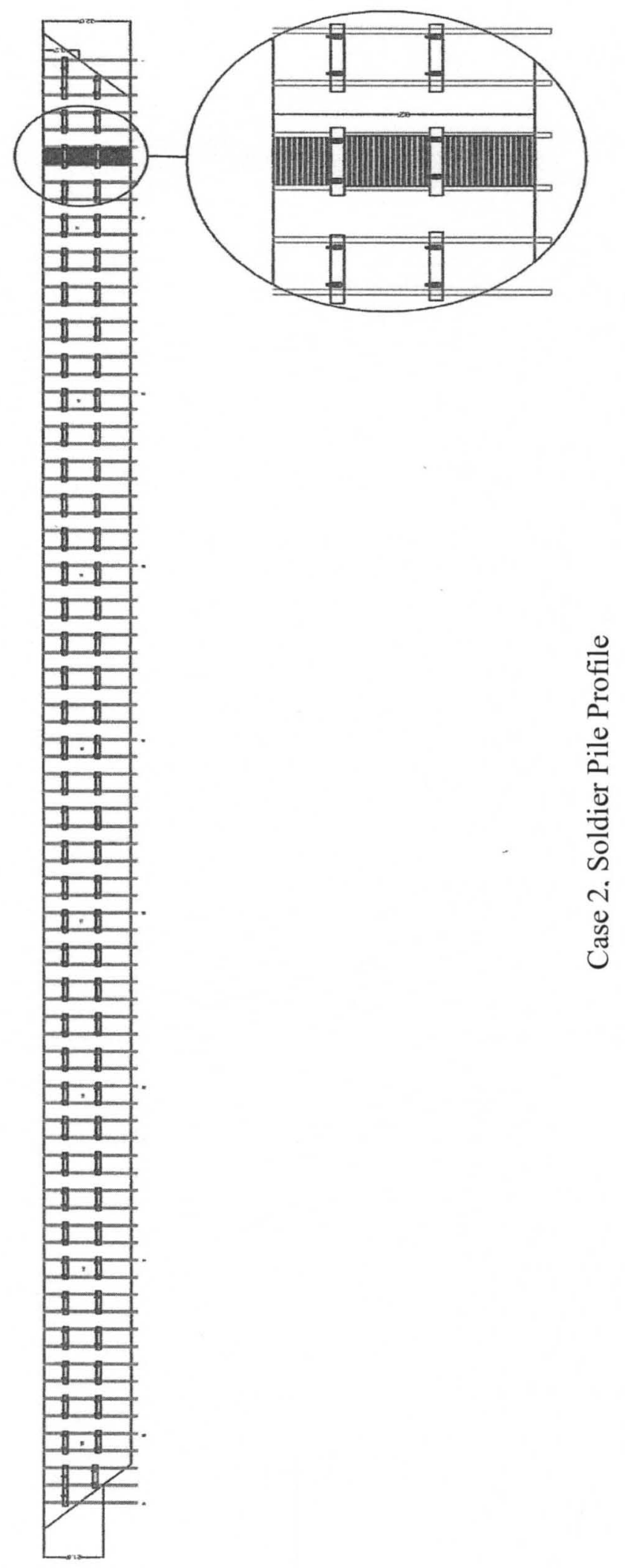




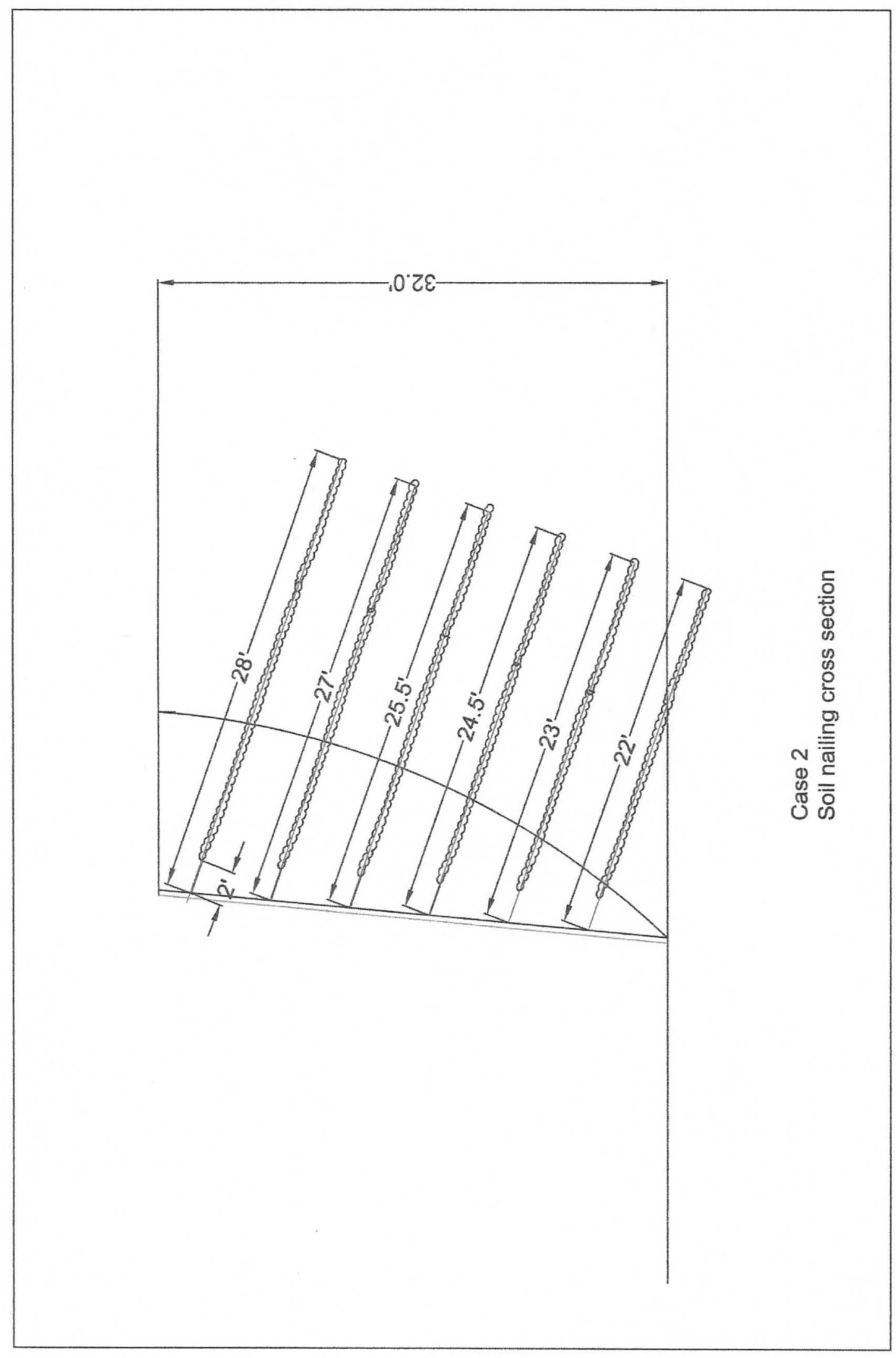



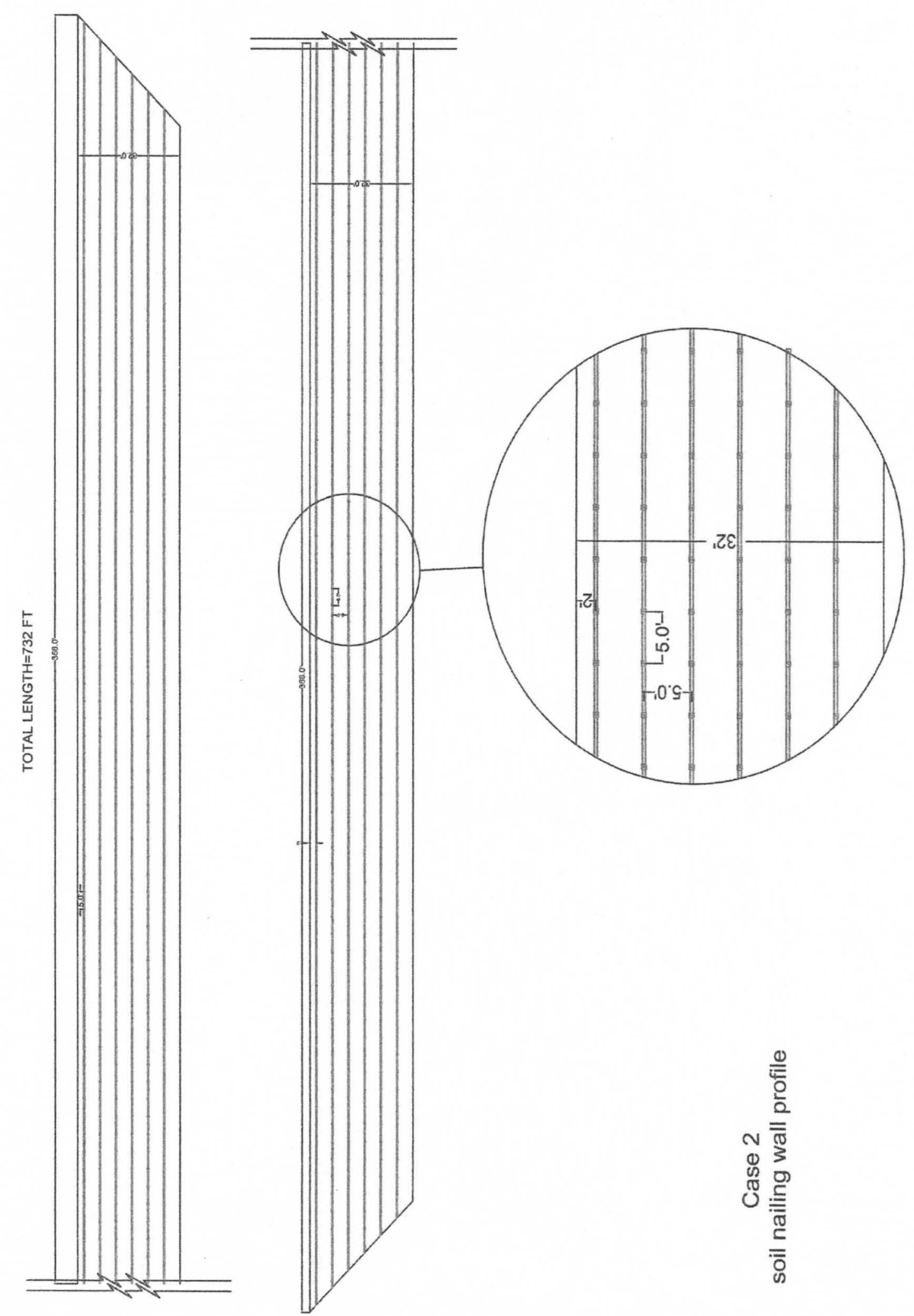


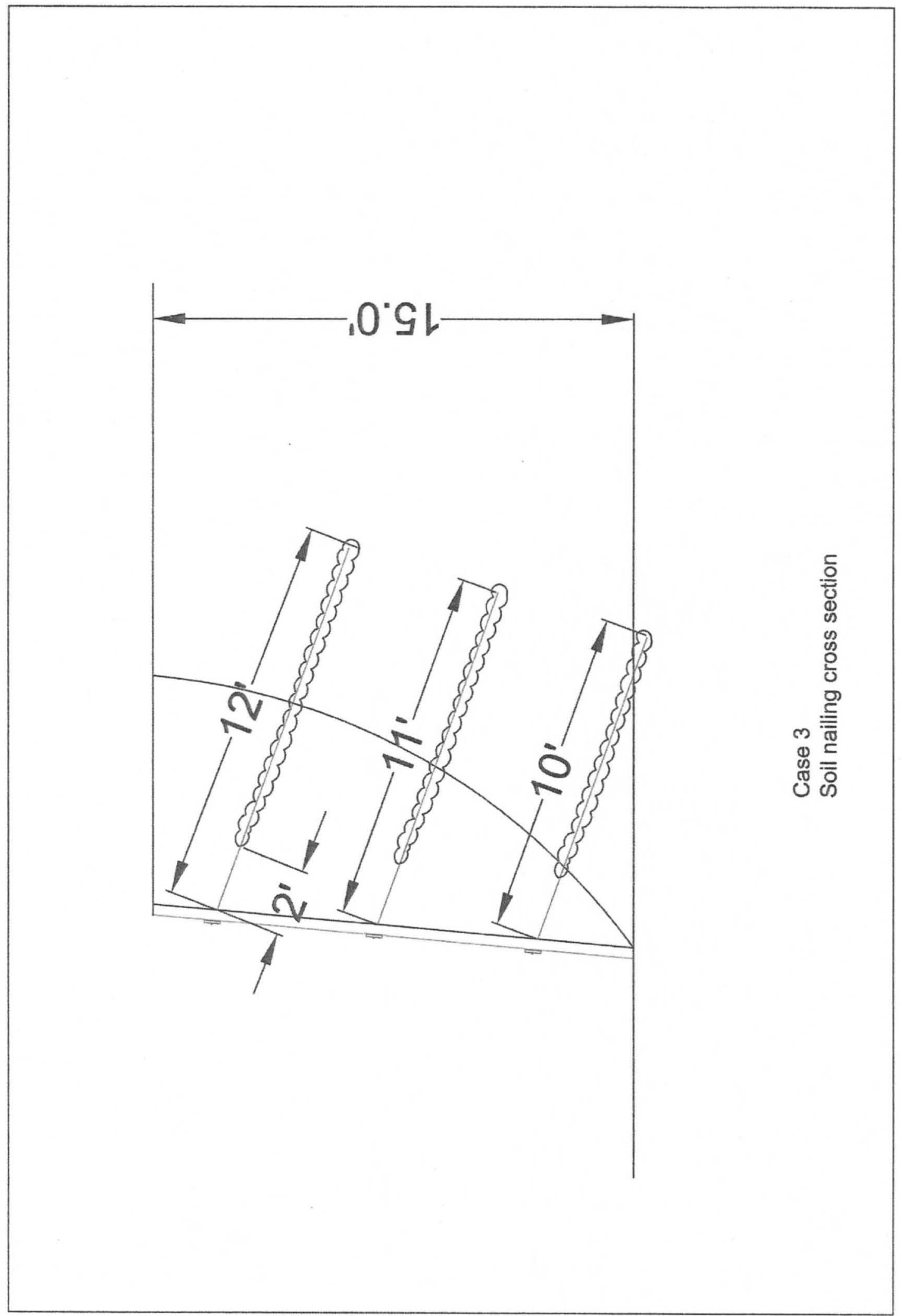




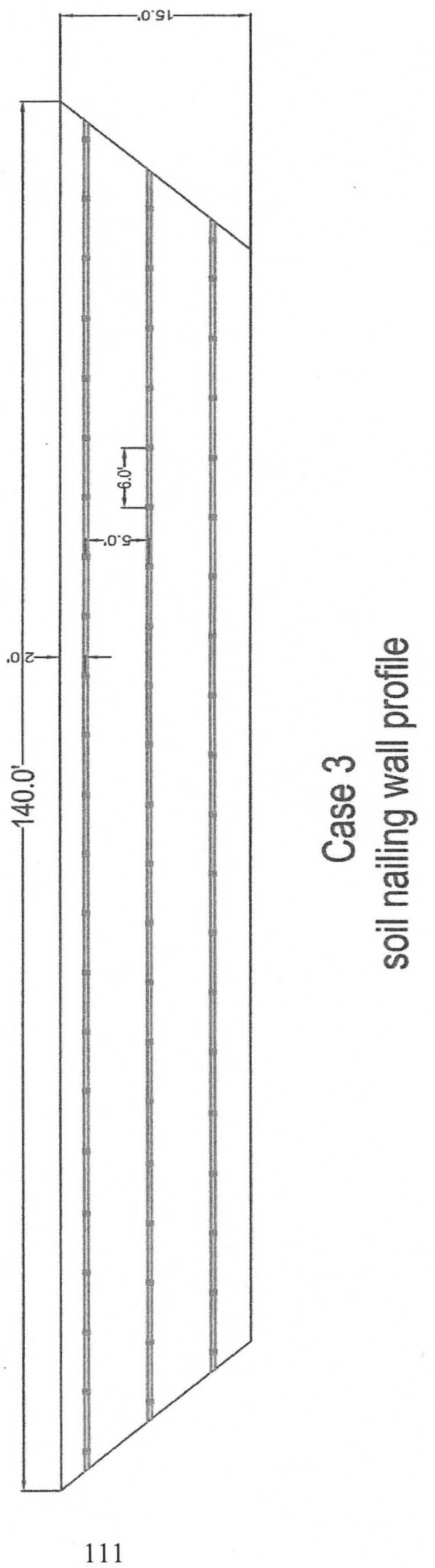




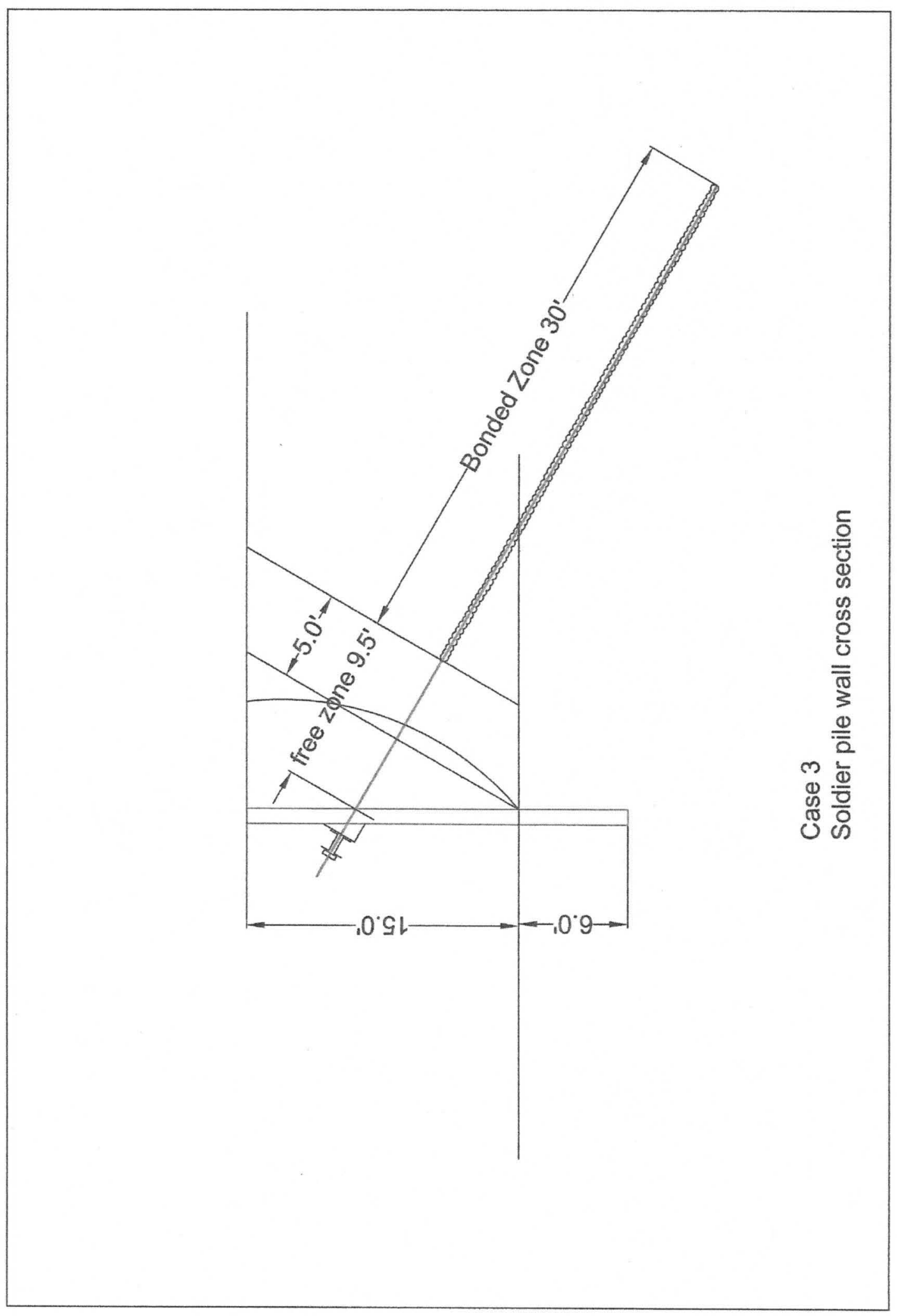




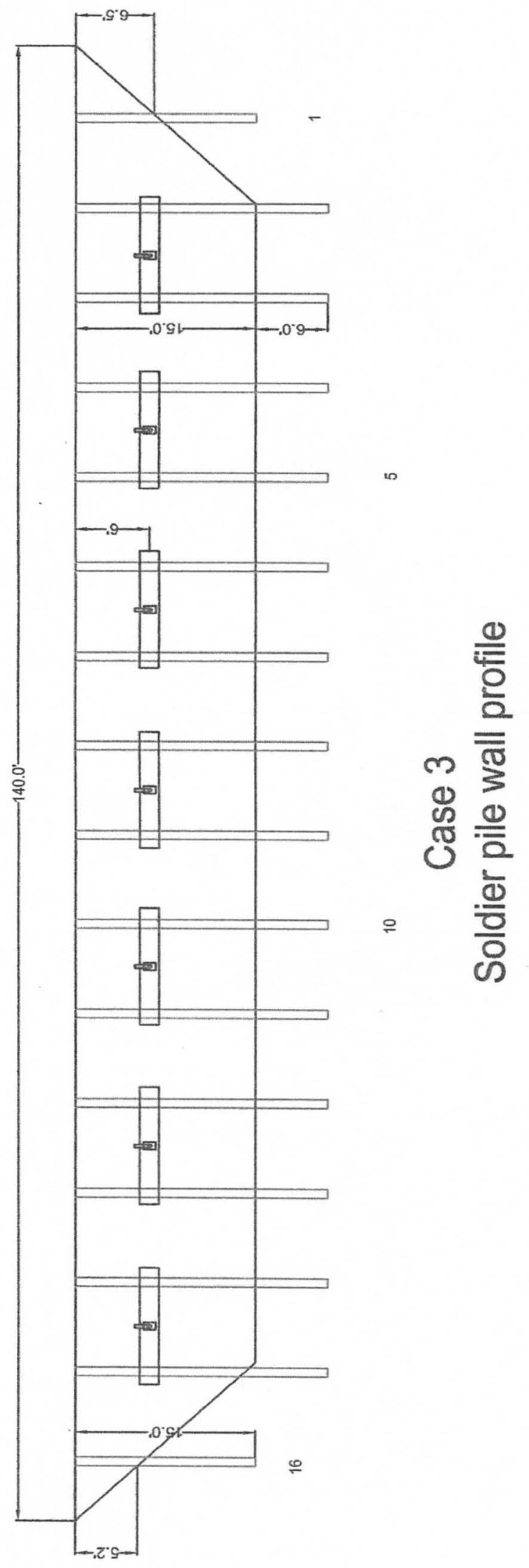




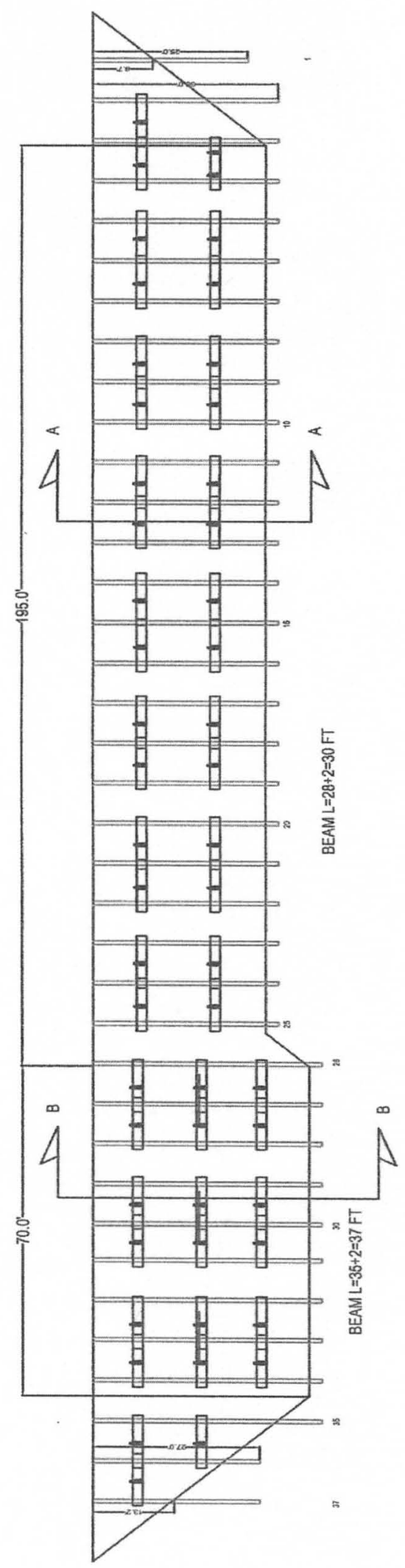

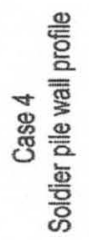




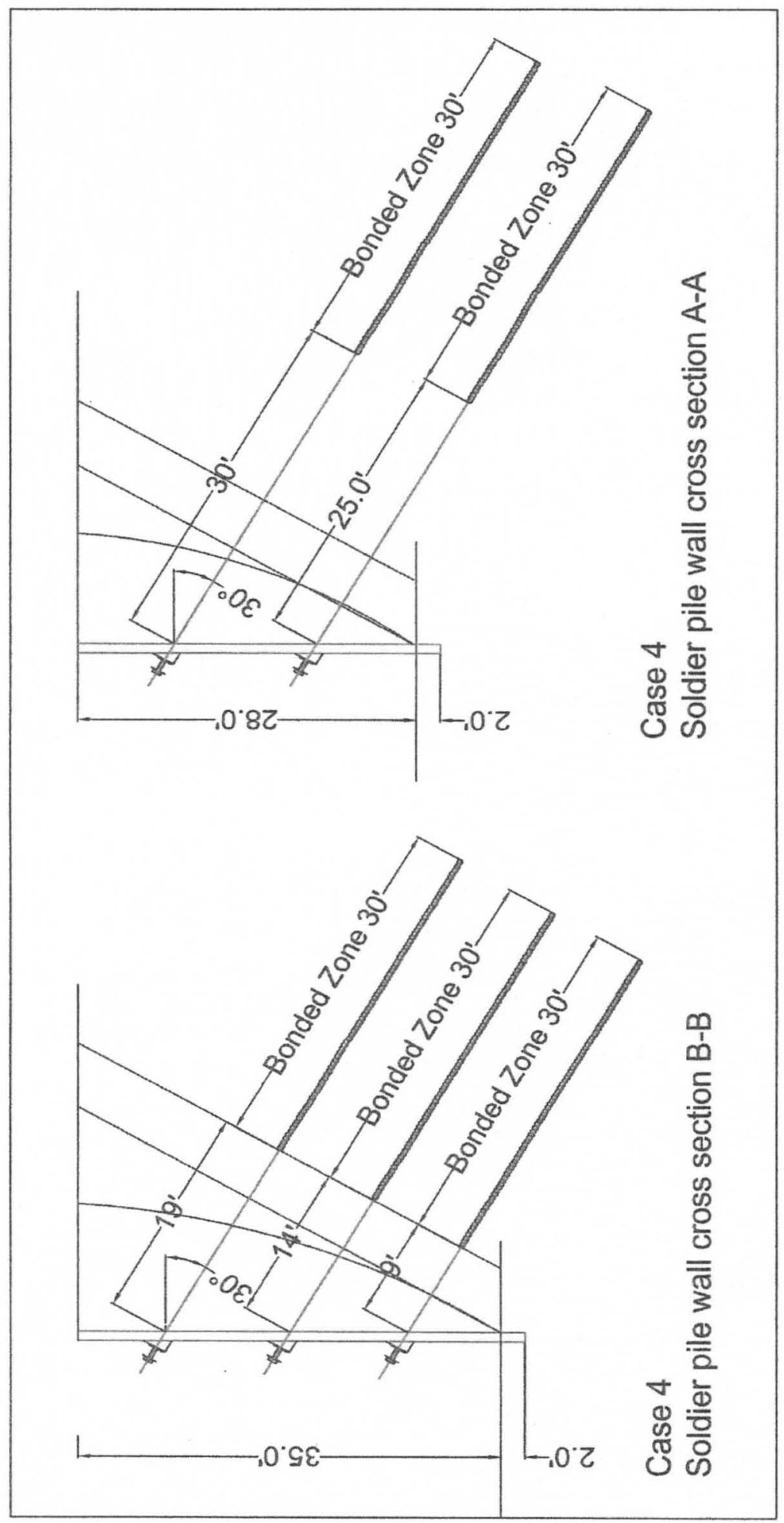




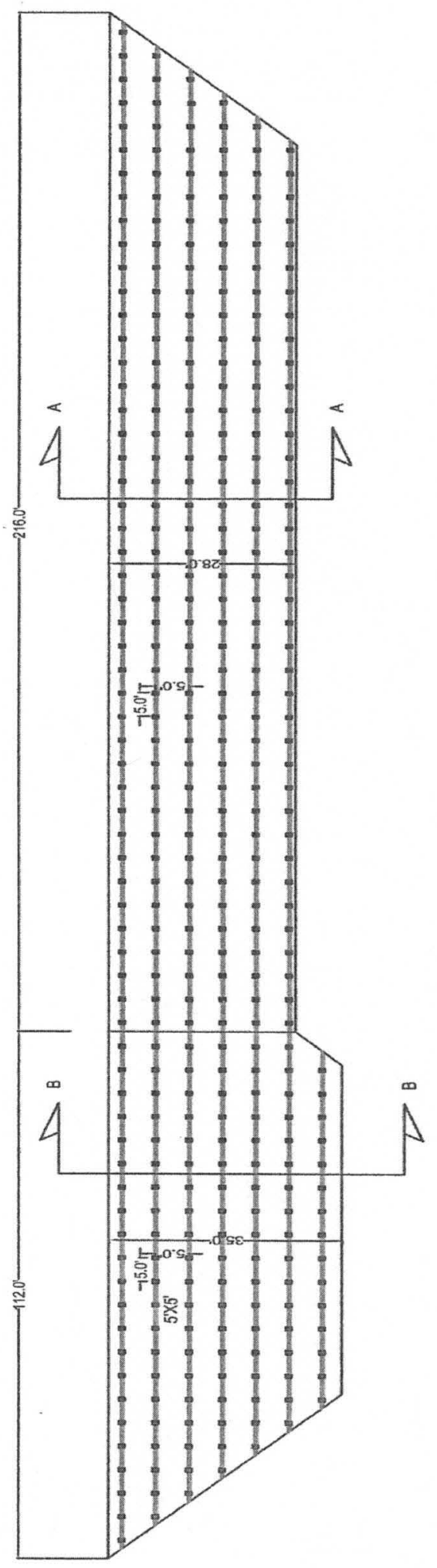

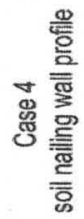

116 


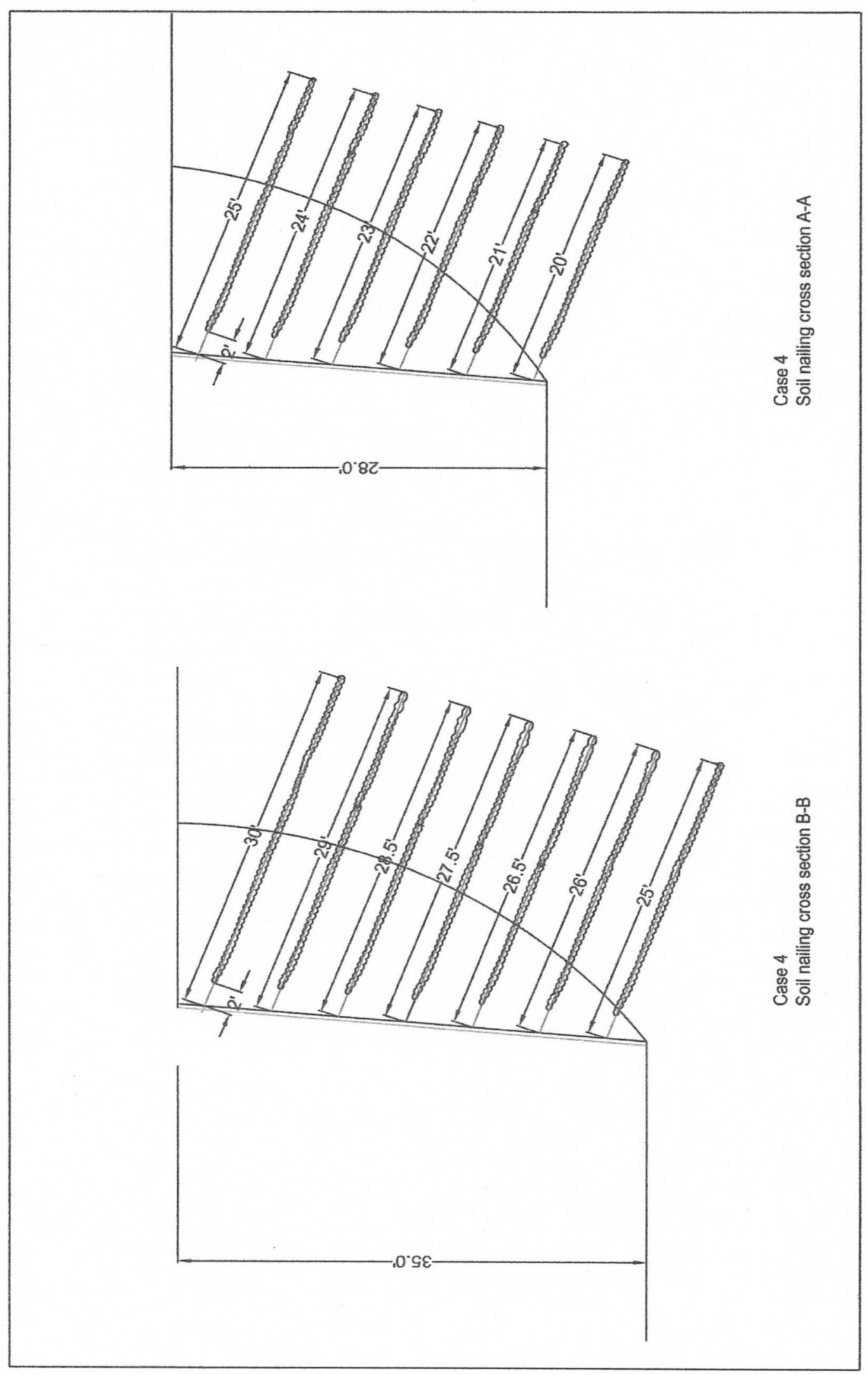




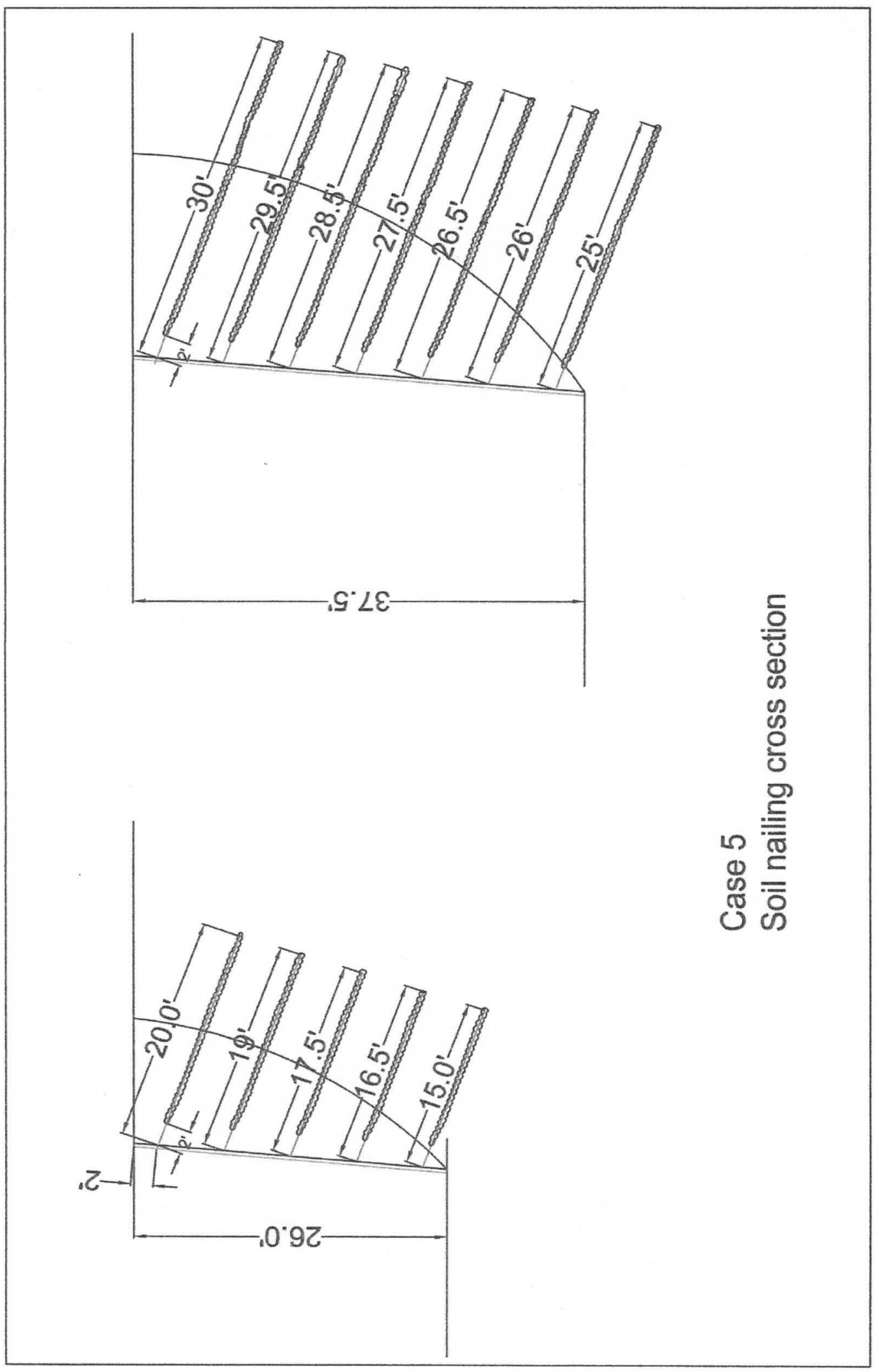



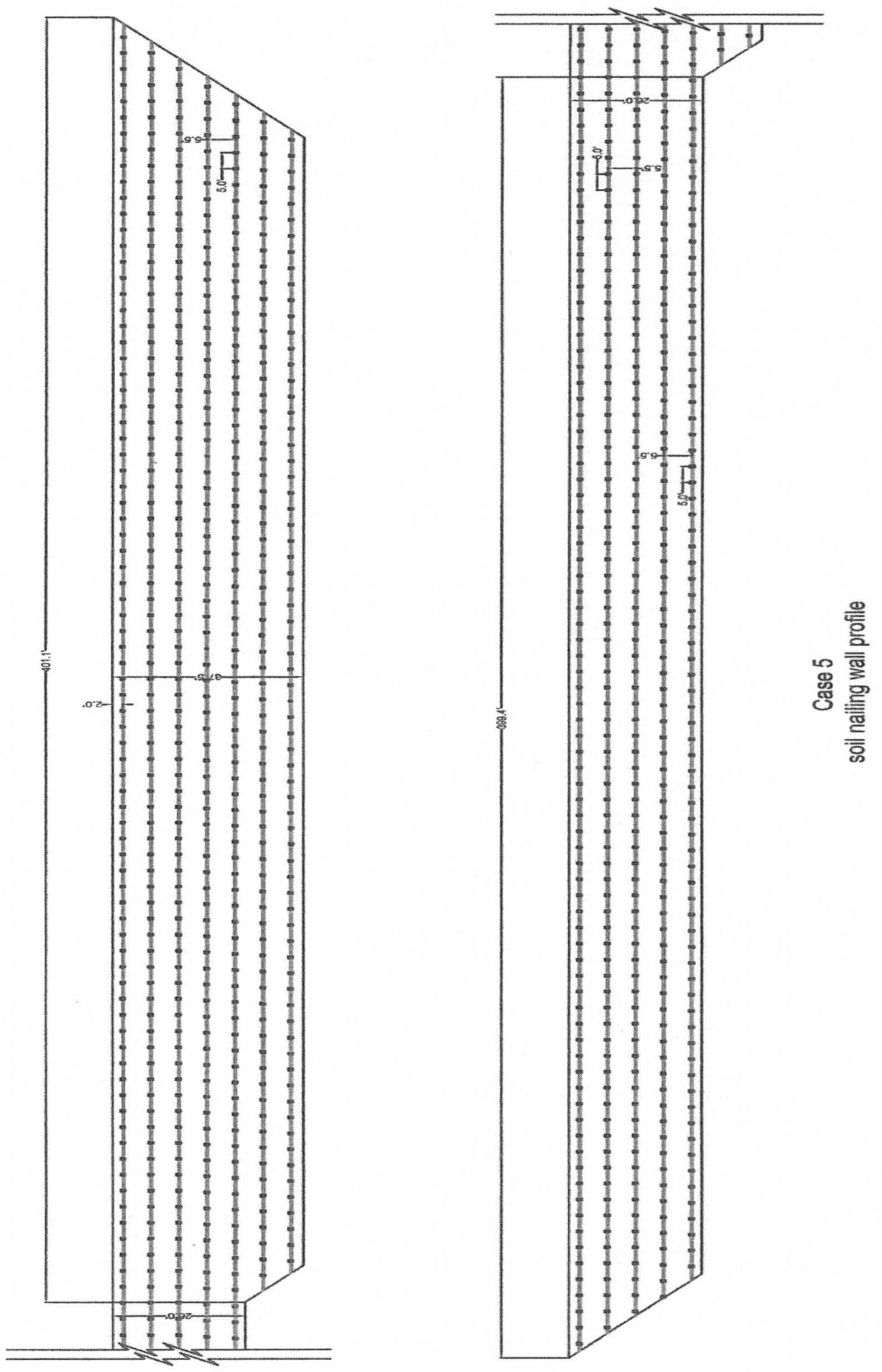


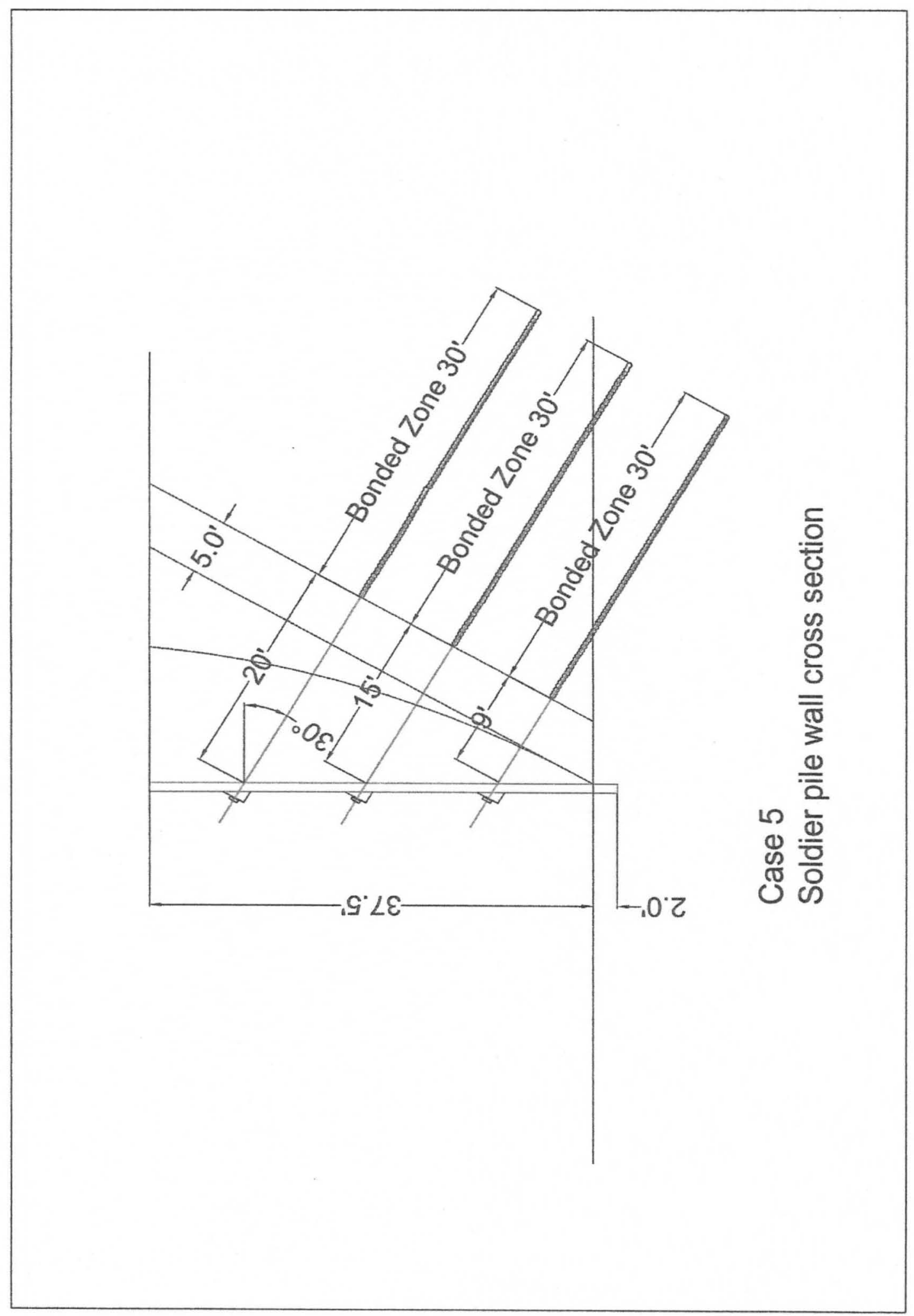




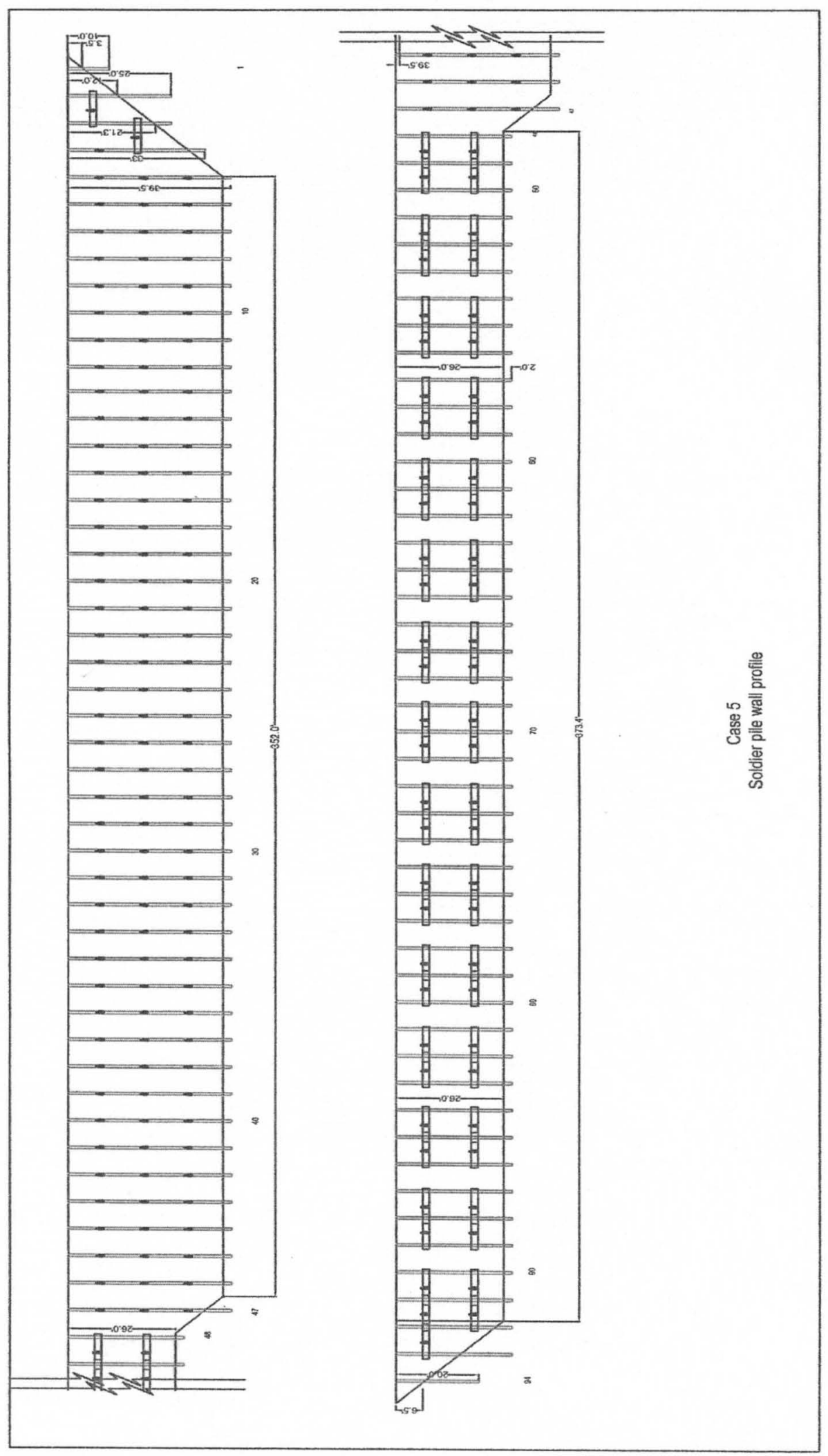



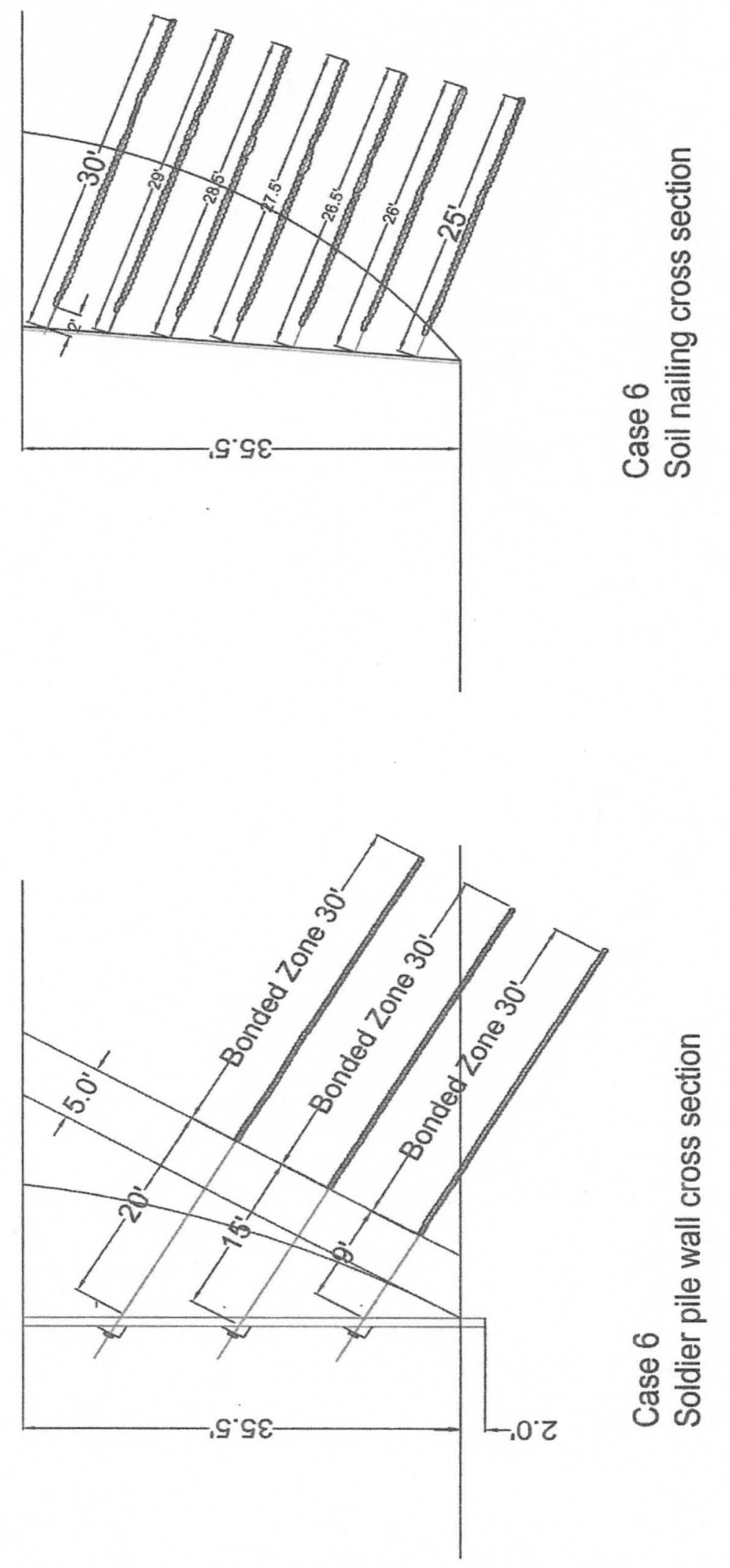


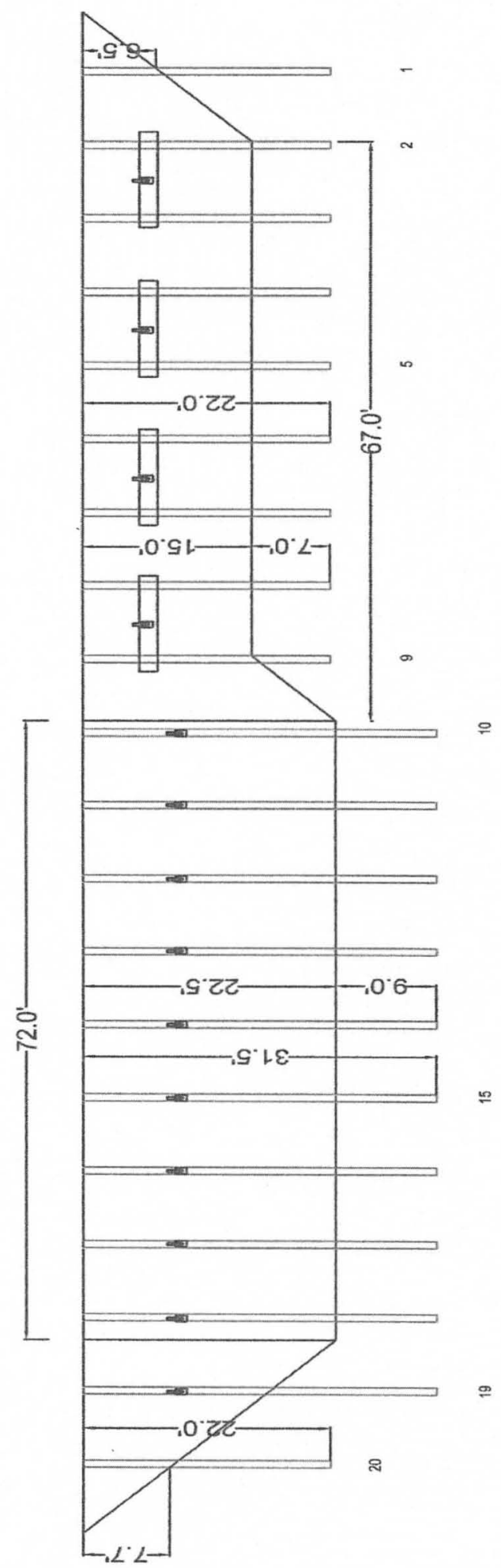

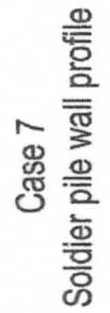



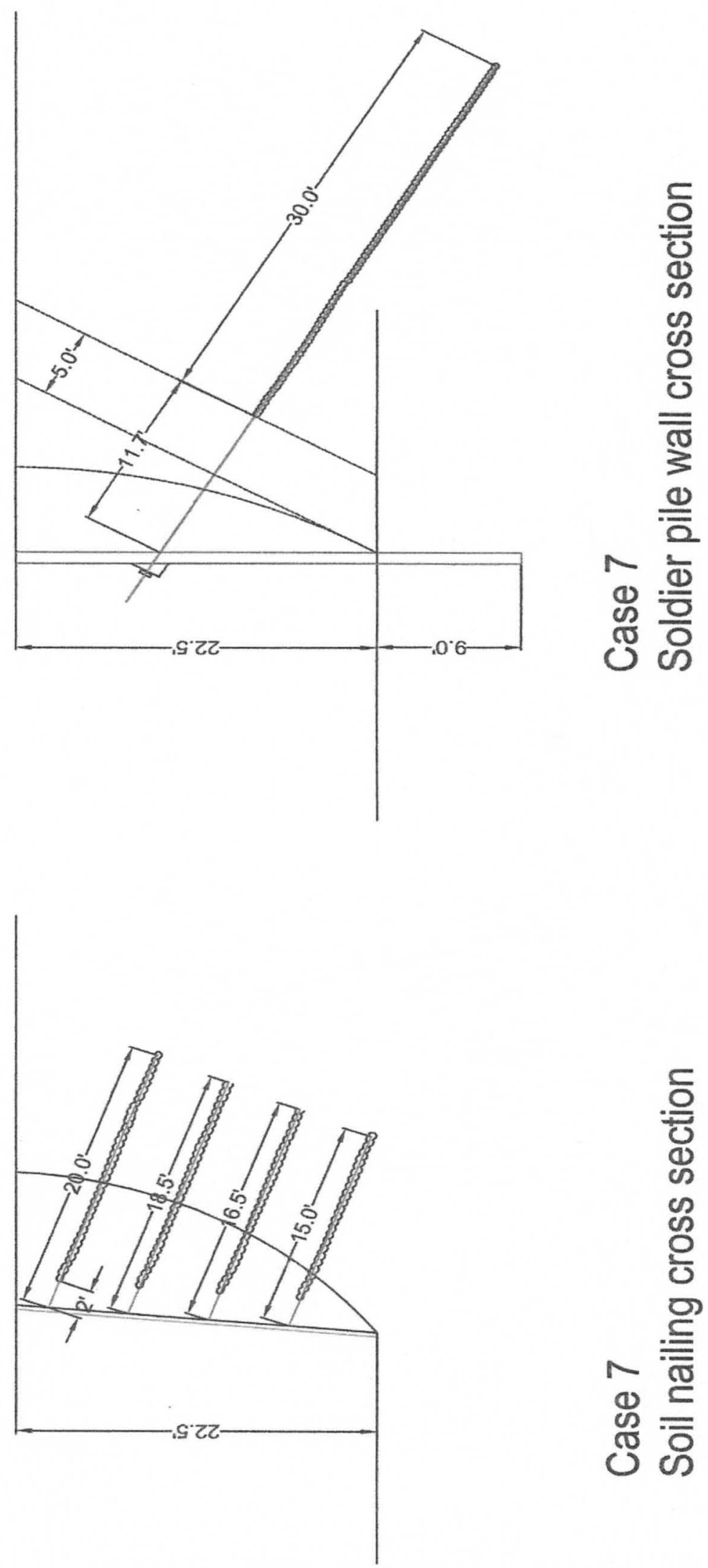


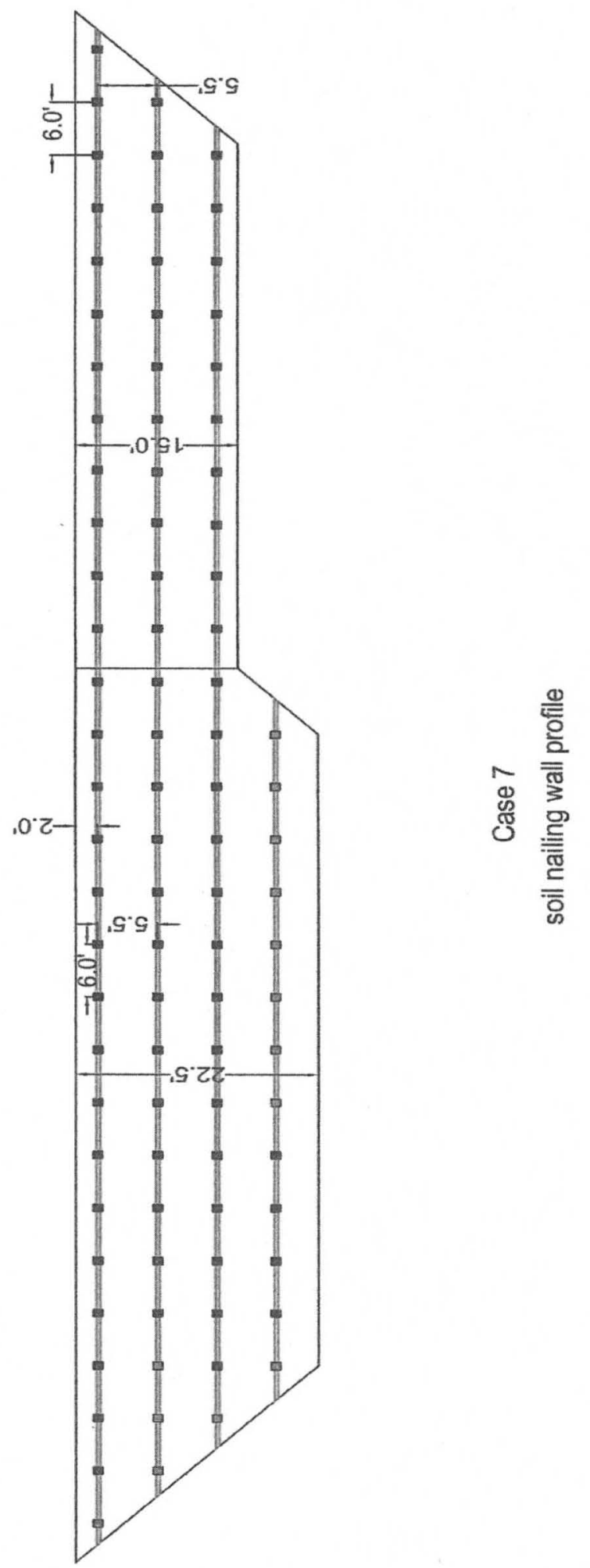



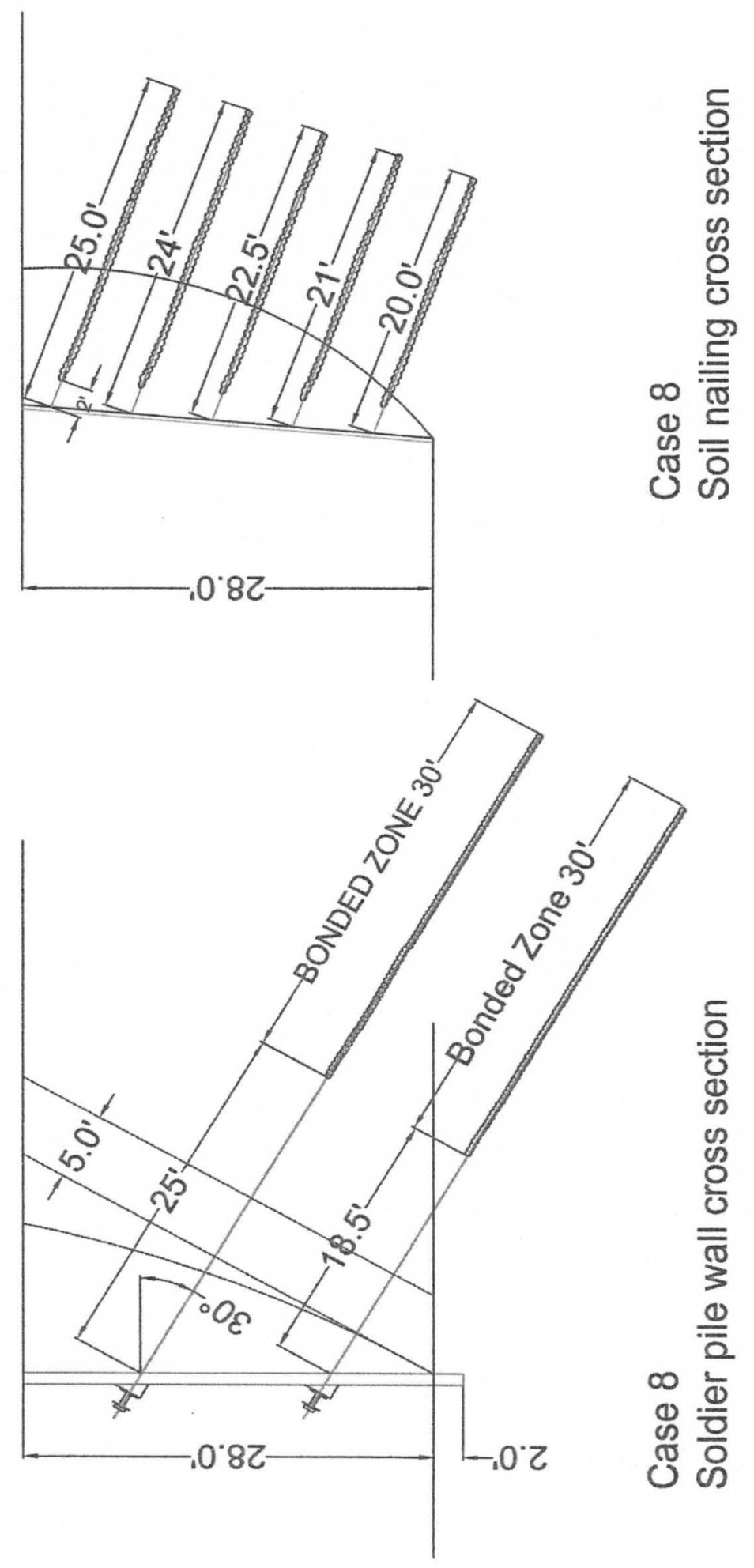

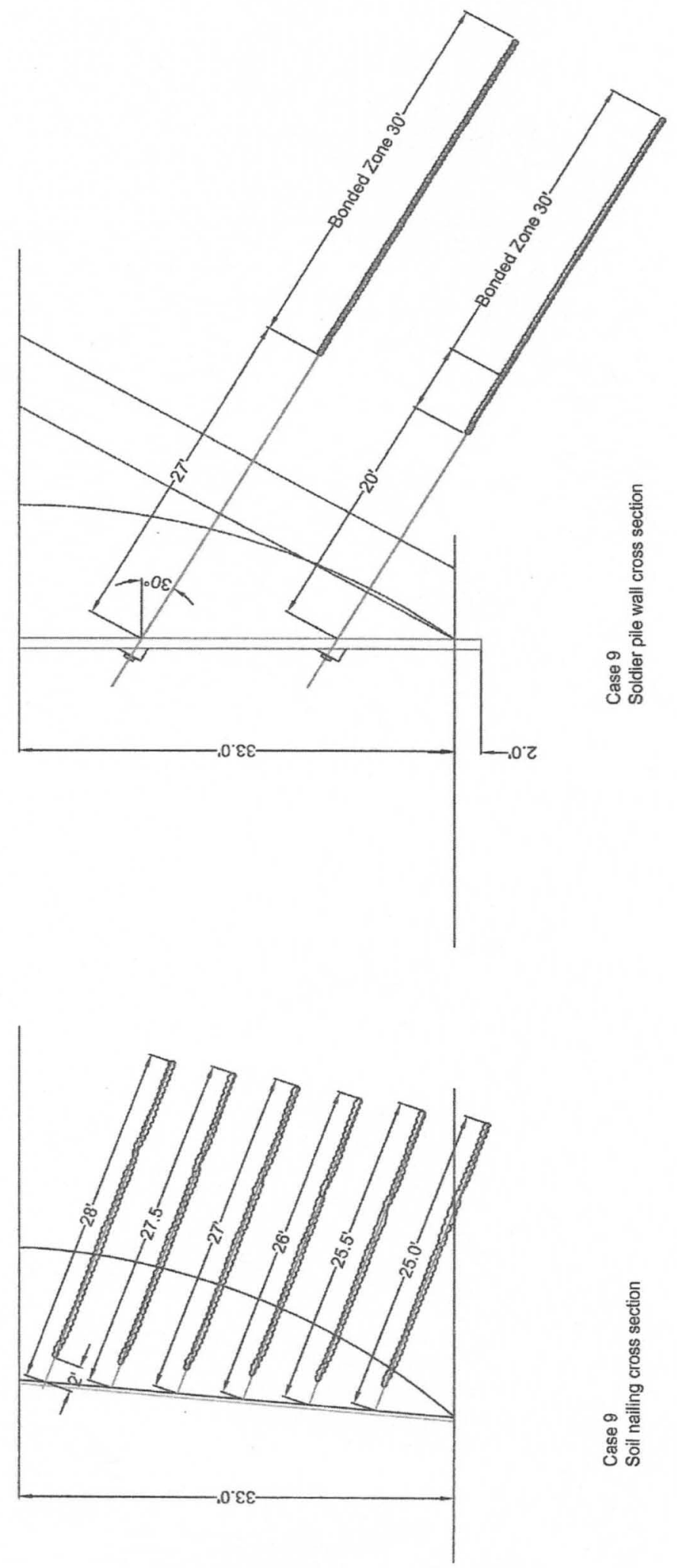

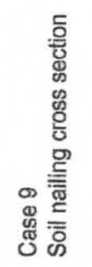




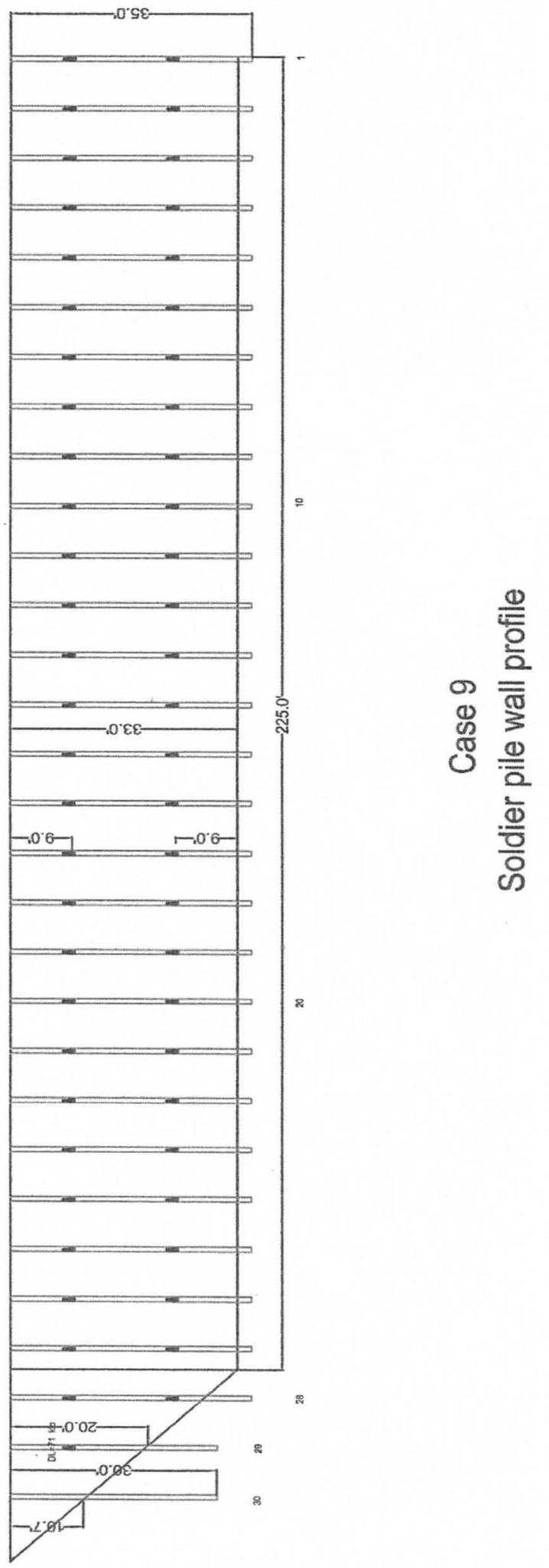




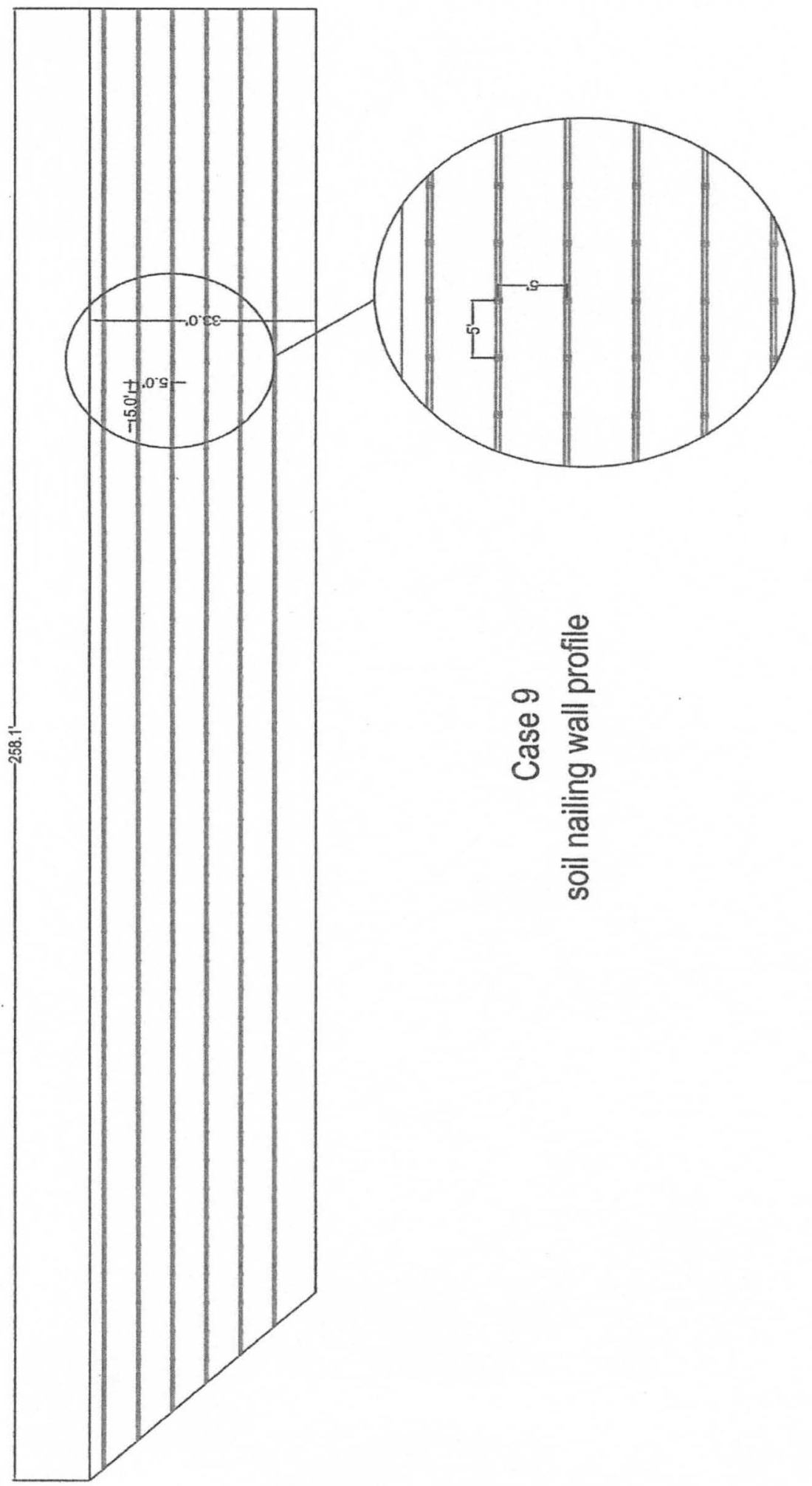




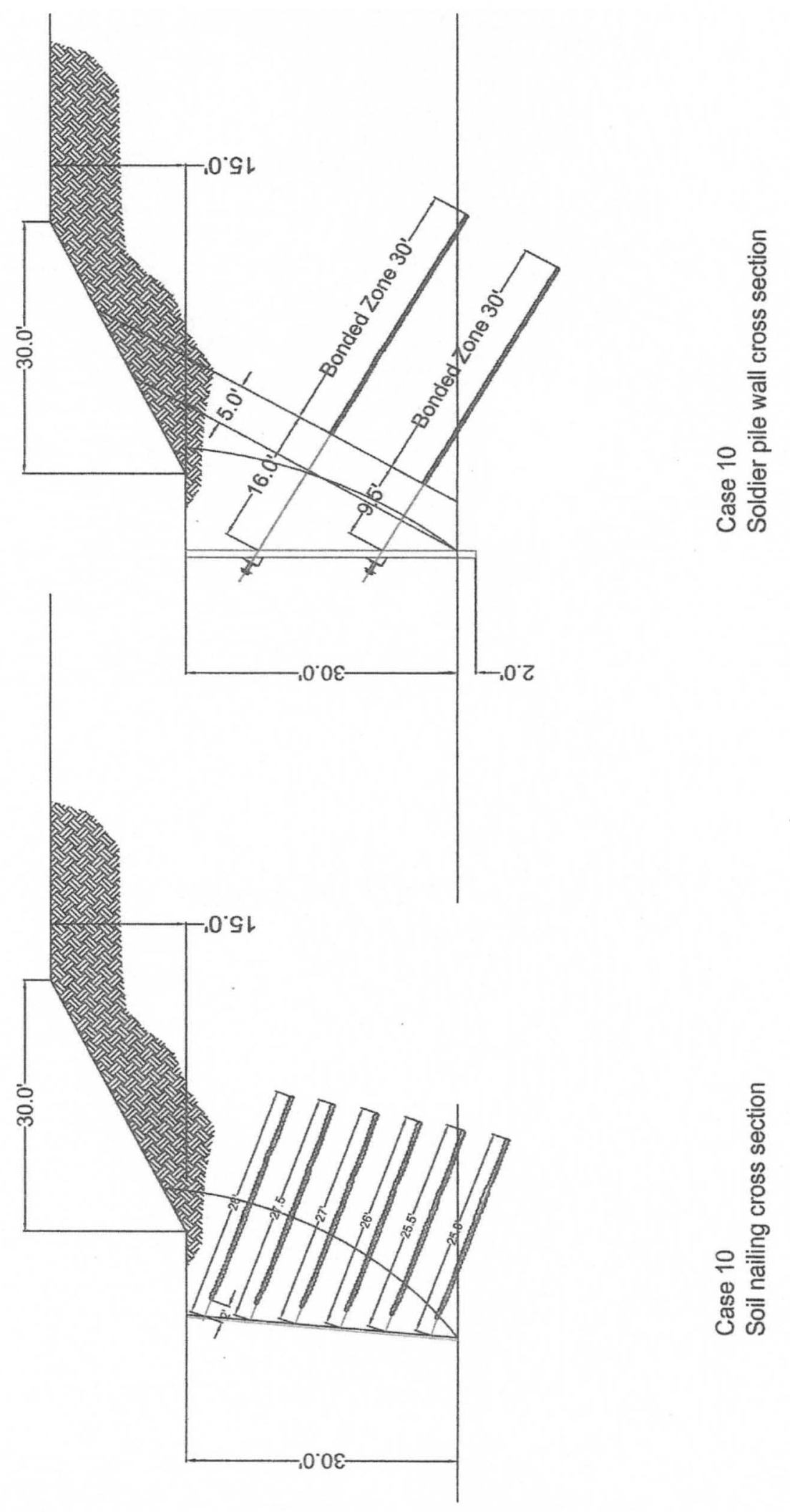



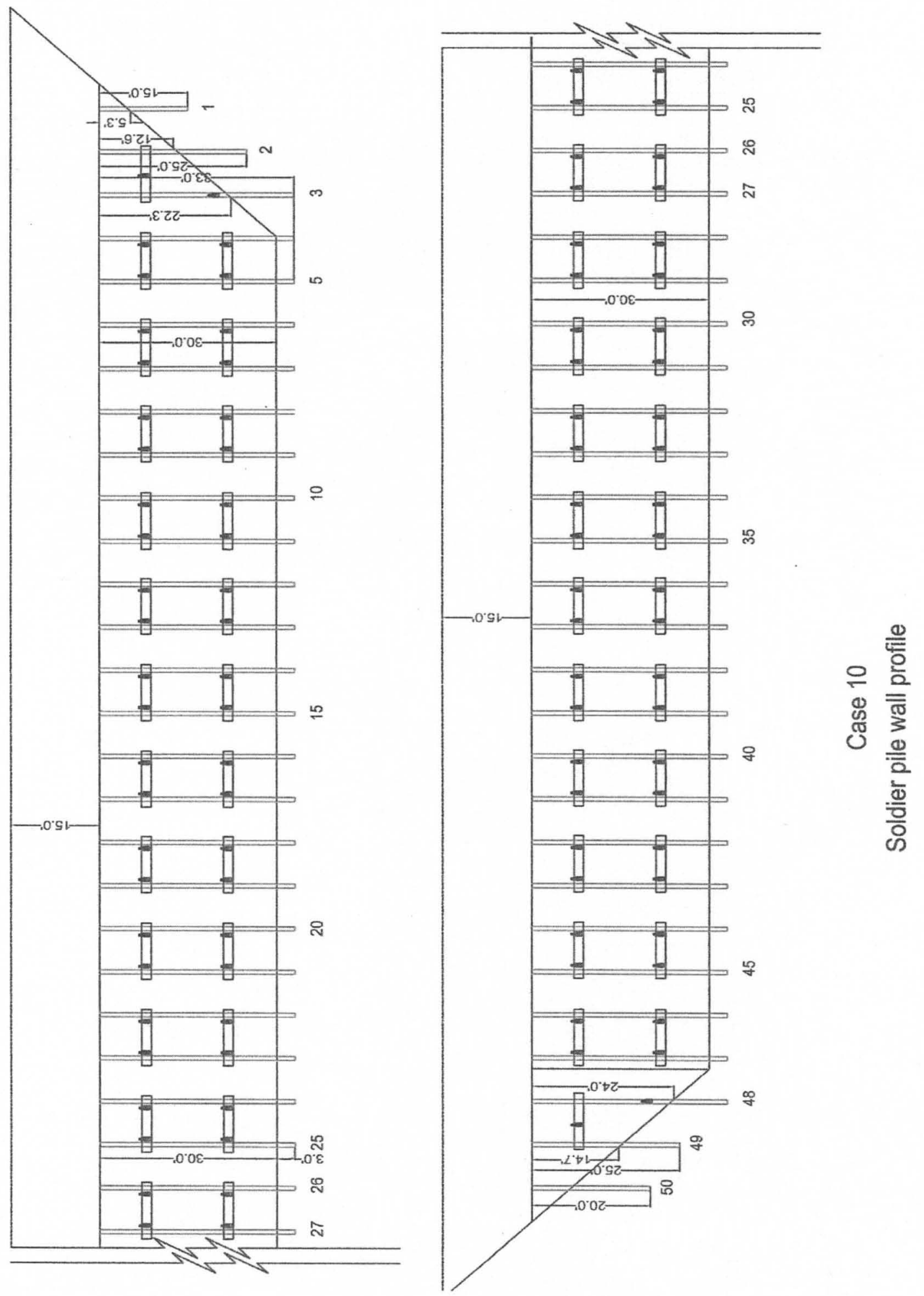

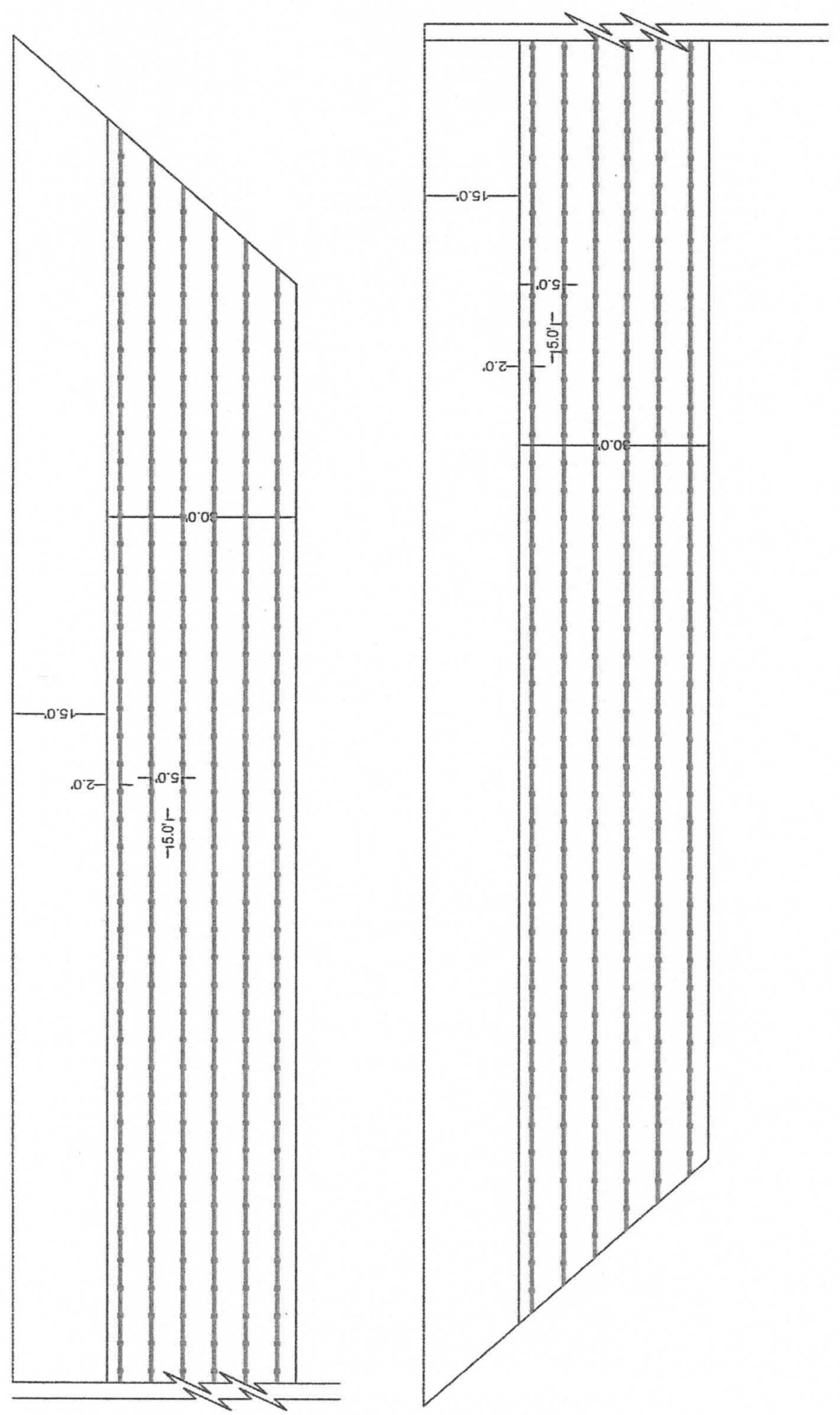

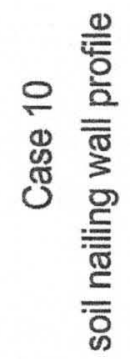



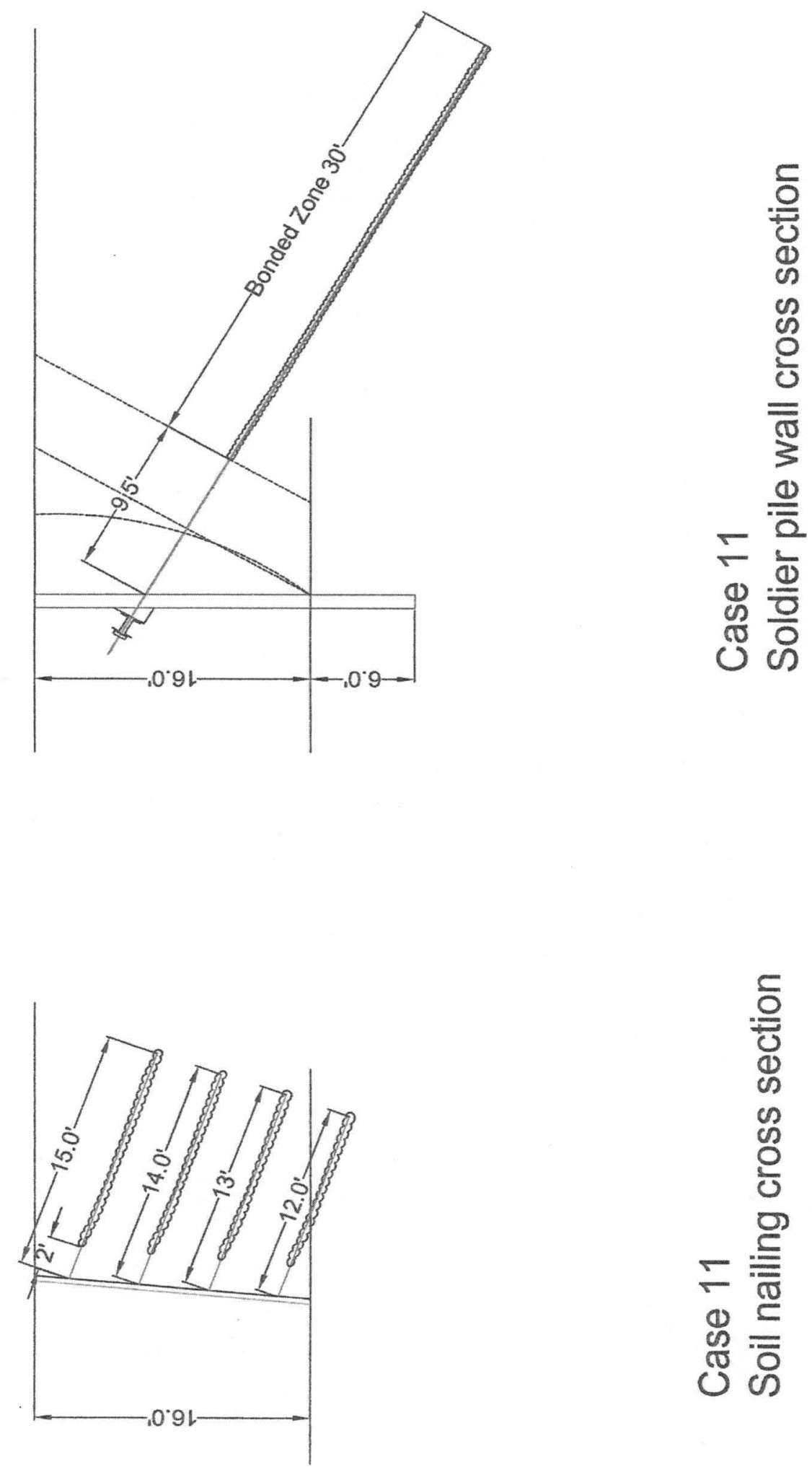


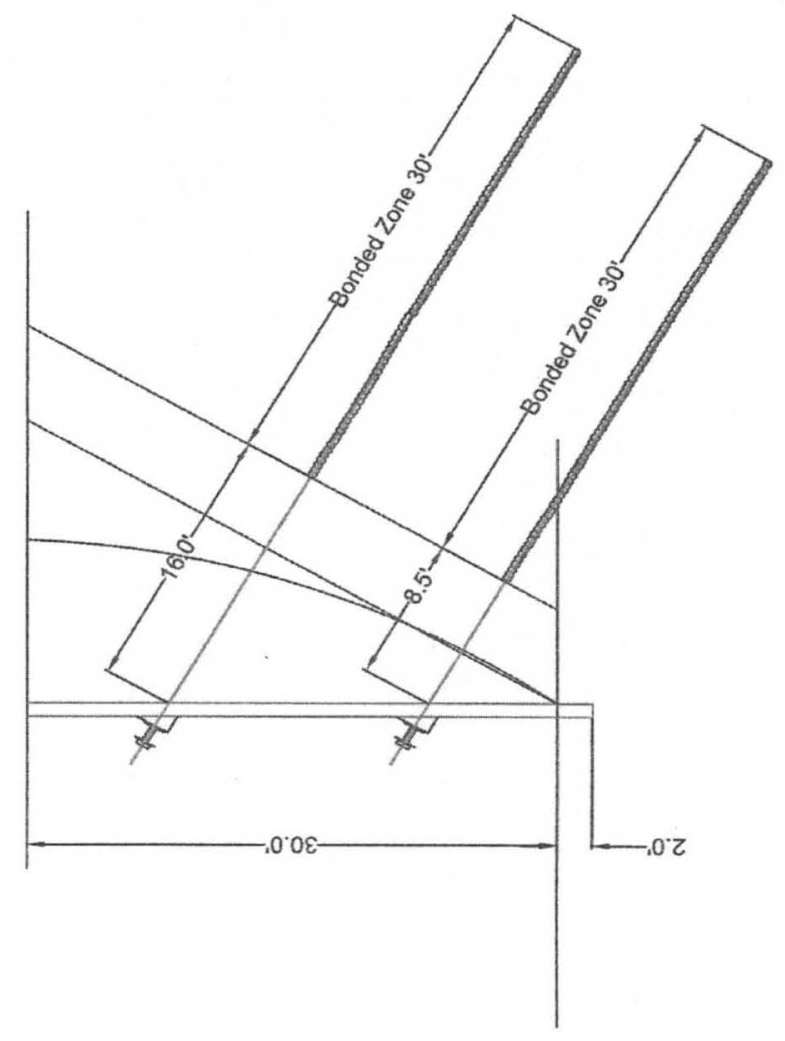

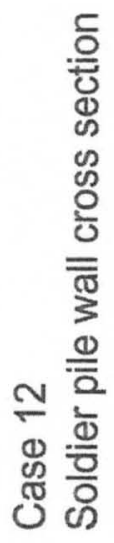

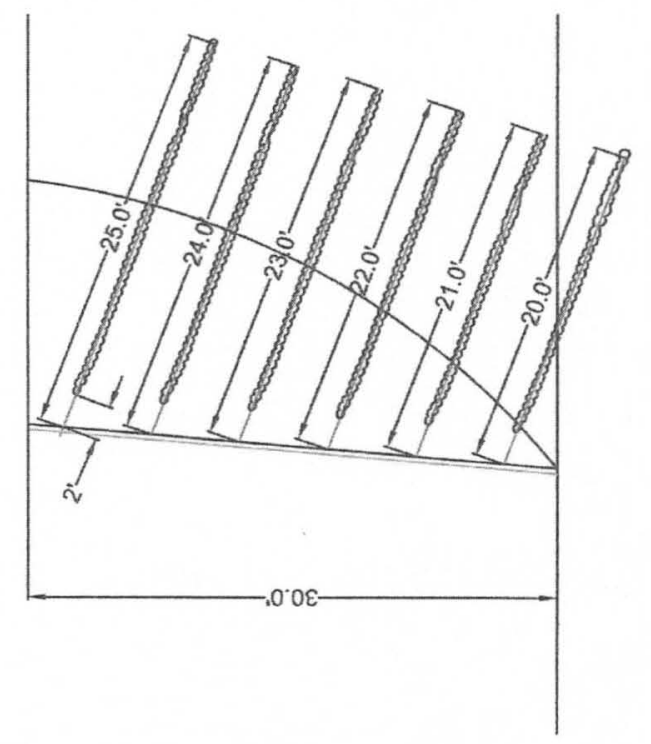

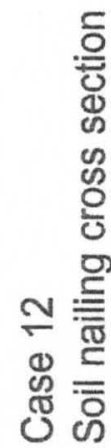



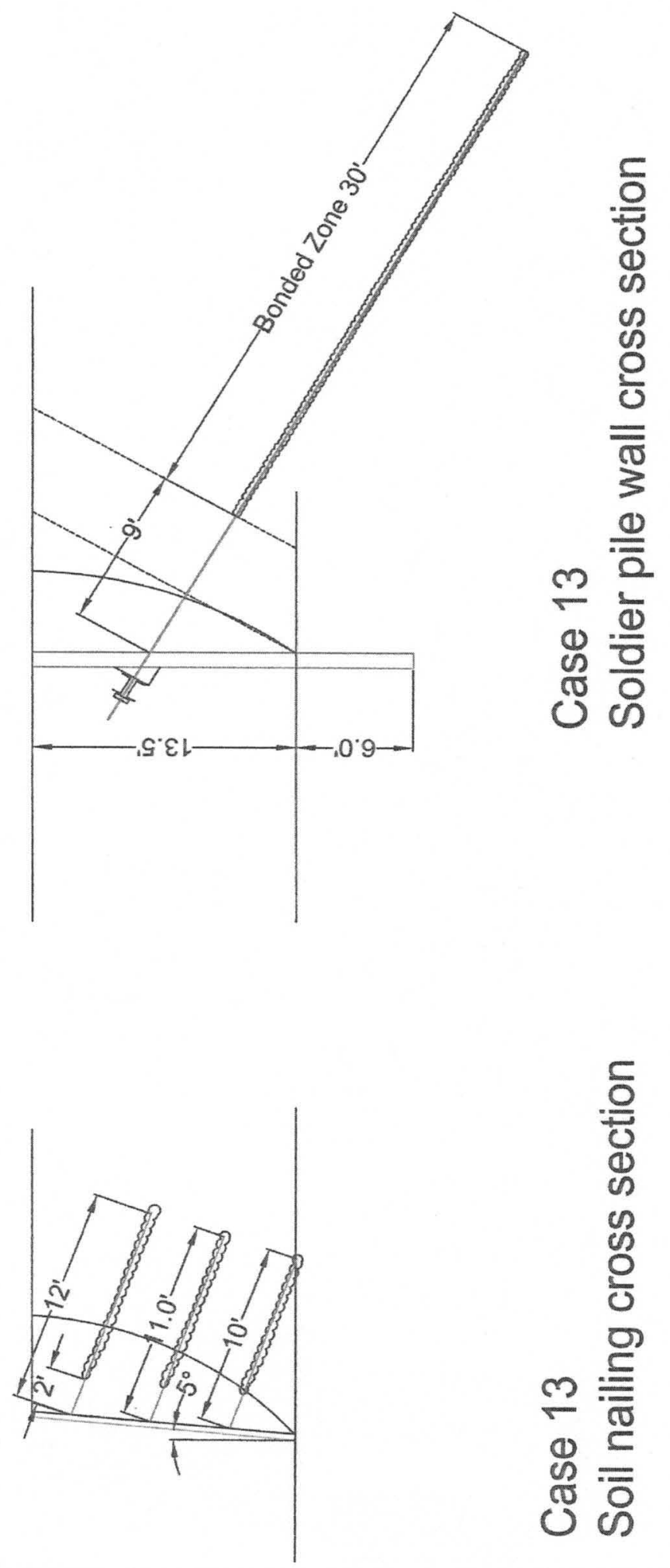


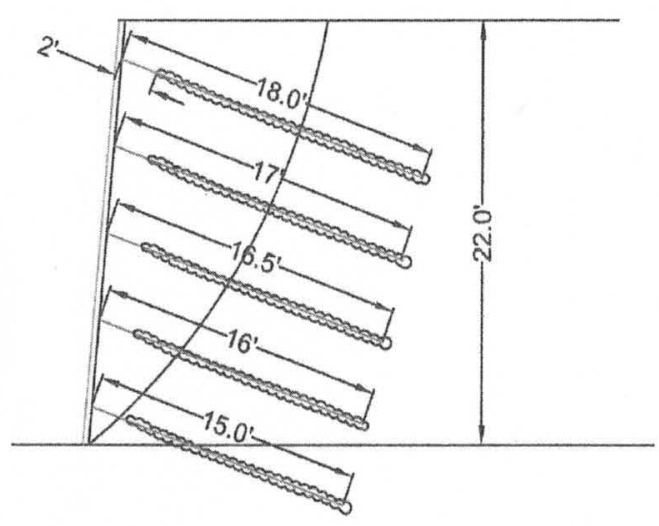

Case 14

Soil nailing cross section

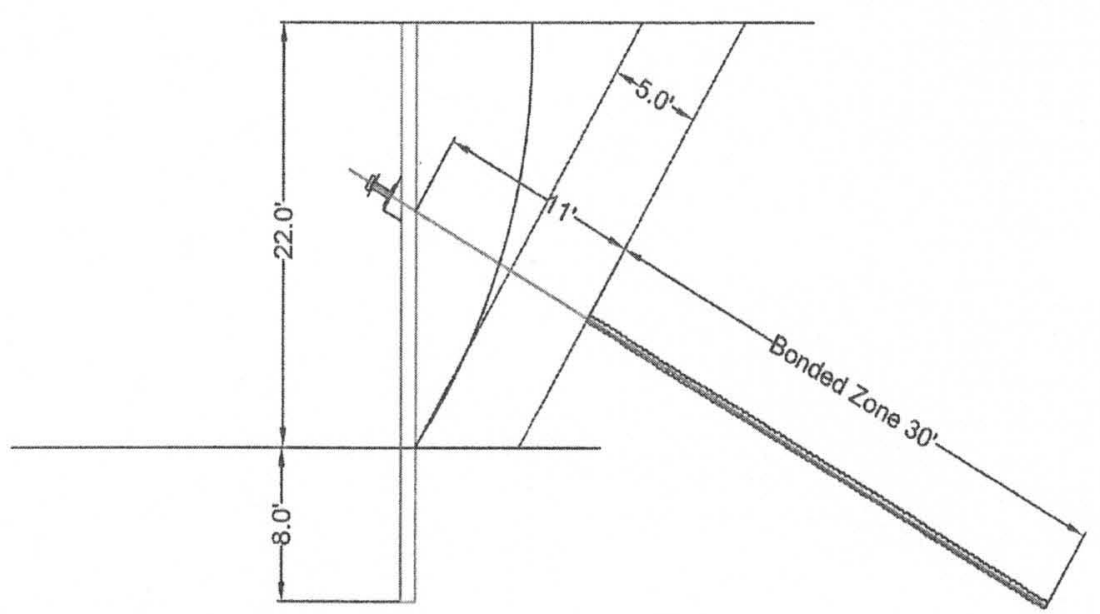

Case 14

Soldier pile wall cross section 


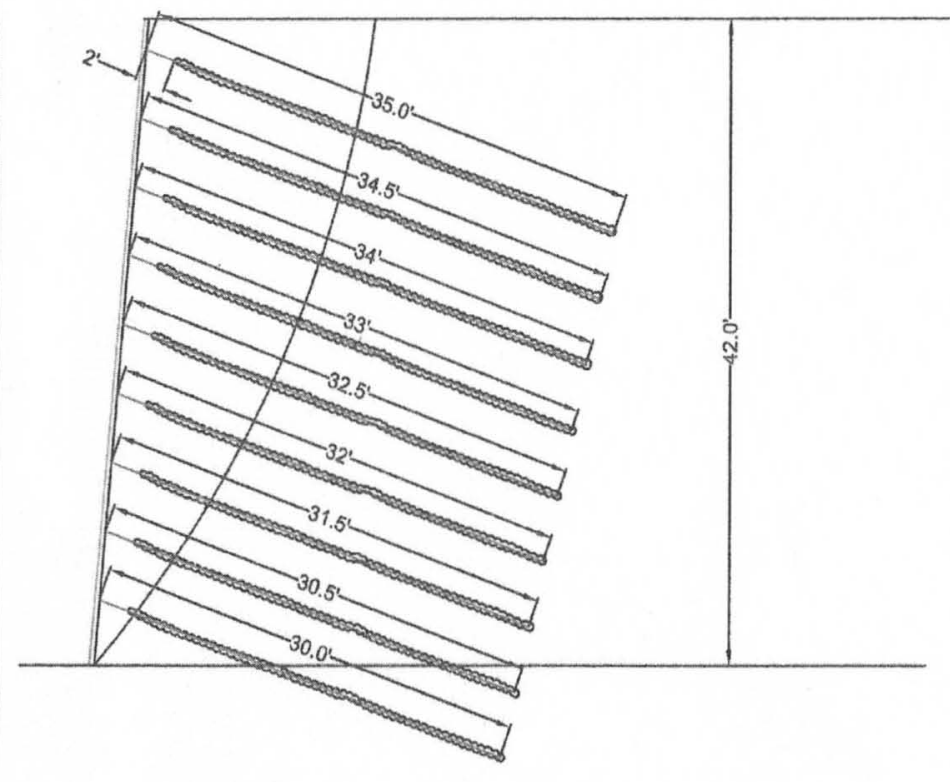

Case 15

Soil nailing cross section

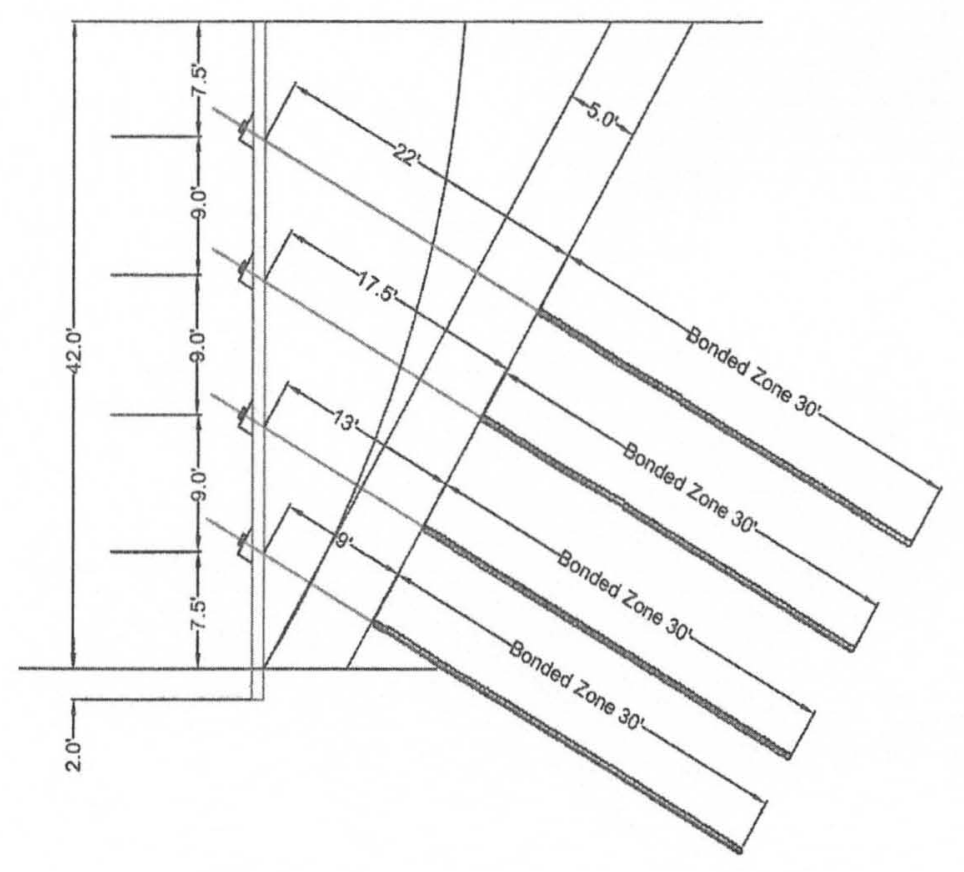

Case 15

Soldier pile wall cross section 
Appendix B: Conventional System Design 

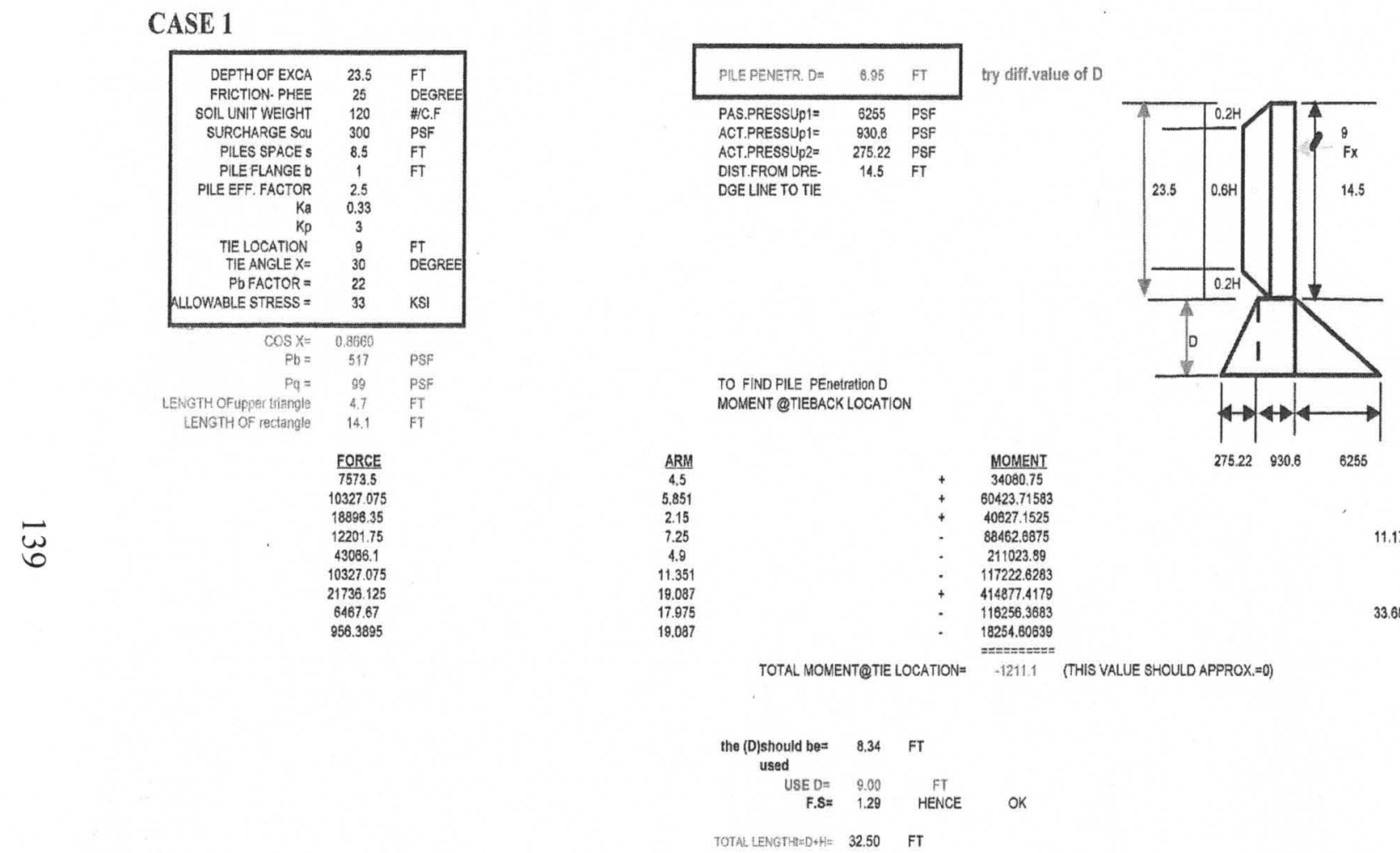

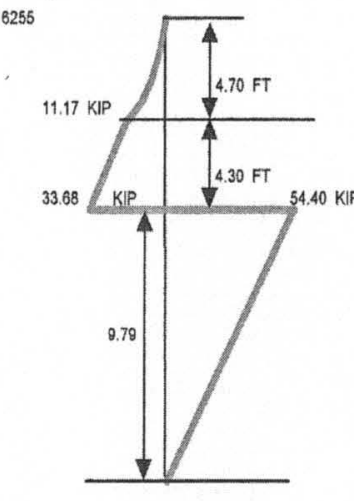

SHEAR DIAGRAM

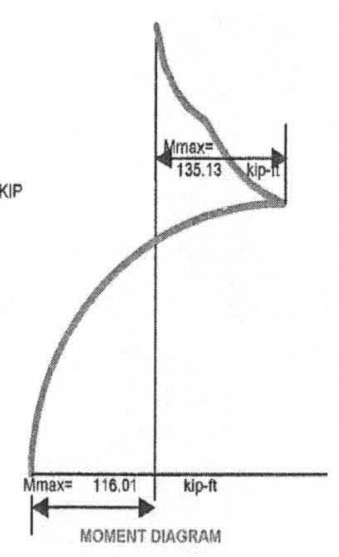




\section{CASE 1}

\begin{tabular}{|rcl|}
\hline DEPTH OF EXCA & 23.5 & FT \\
FRICTION-PHEE & 25 & DEGREE \\
SOIL UNIT WEIGHT & 120 & \#IC.F \\
SURCHARGE Scu & 300 & PSF \\
PILES SPACE s & 8.5 & FT \\
PILE FLANGE b & 1 & FT \\
PILE EFF. FACTOR & 2.5 & \\
Ka & 0.33 & \\
Kp & 3 & \\
TIE LOCATION & 9 & FT \\
TIE ANGLE X $=$ & 30 & DEGREE \\
Pb FACTOR $=$ & 22 & KSI \\
ALLOWABLE STRESS $=$ & 33 & \\
COS X $=$ & 0.8660 & \\
Pb $=$ & 517 & PSF \\
Pq $=$ & 99 & PSF \\
LENGTH OFupper triangle & 4.7 & FT \\
LENGTH OF rectangle & 14.1 & FT
\end{tabular}

$\frac{\text { FORCE }}{7573.5}$

7573.5
10327.075

10327.075
18896.35

18896.35
12201.75

12201.75

43066.1

10327.075

21736.125

6467.67

956.3895 try diff.value of $D$

\begin{tabular}{|lcl|}
\hline PILE PENETR. D= & 6.95 & FT \\
\hline PAS.PRESSUP1= & 6255 & PSF \\
ACT.PRESSUP1 $=$ & 930.6 & PSF \\
ACT.PRESSUP2= & 275.22 & PSF \\
DIST.FROM DRE- & 14.5 & FT \\
DGE LINE TO TIE & & \\
\hline
\end{tabular}

TO FIND PILE PEnetration D

MOMENT @TIEBACK LOCATION

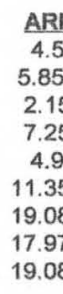

5.85

2.15

2.15
7.25
4.9

1.351

9.087

17.975

19.087

TOTAL MOMENT@TIE LOCATION= $\begin{gathered}18254.60639 \\ == \pm=== \\ -1211.1\end{gathered}$

(THIS VALUE SHOULD APPROX. $=0$ )
the (D)should be= $8.34 \quad \mathrm{FT}$
used
$\begin{array}{lll}\mathrm{SE} D= & 9.00 & \mathrm{FT} \\ \mathrm{F} . \mathrm{S}= & 1.29 & \text { HENCE }\end{array}$
TOTAL LENGTHI $=D+H=32.50 \quad F T$

HENCE OK

\subsection{5}

0423.71583

40627.1525

88462.6875

211023.89

117222.6283

414877.4179

116256.3683 


\begin{tabular}{ccc} 
& \multicolumn{2}{c}{ TO FIND TIEBACK FORC } \\
MAKE SUM. FOR FX=0 \\
$F=$ & 19775.25 & + \\
$F 2=$ & 20654.15 & + \\
$F 3=$ & 61962.45 & + \\
$F 4=$ & 6467.67 & + \\
$F 5=$ & 21736.125 & + \\
$F 6=$ & 956.3895 & + \\
FX/ONE BAY $=$ & 88.08 & $\mathrm{KIP}$ \\
FX/ONE FT $=$ & 10.36 & $\mathrm{KIP} / F T$ \\
& & \\
FXI BAY $=$ & 88.08 & $\mathrm{KIP}$ \\
TIE FORCE/ BAY $=$ & 101.71 & $\mathrm{KIP}$ \\
PROOFTEST LOAD $=$ & 122.05 & $\mathrm{KIP}$
\end{tabular}

FIND MAX. MOMENT

1 OTIEBACK LOCATION =

$$
\begin{gathered}
\text { FORCE } \\
\frac{7573.5}{10327.075} \\
18896.35
\end{gathered}
$$

2@X-DISTANCE FROI HE TOP OF THE PILE

FIND $X$ WHEN SUM.OF $F X=0$

$X=18.794282 \mathrm{FT}$

\section{FORCE}

15815.39
88079.78

10327.08

61937.32

\section{ARM}

4.5
5.851
2.15

(ZERO SHEAR POINT)

\section{ARM}

9. 3971409

9.7942818
15.645282

7.0471409

MAX. MOMENT =

USE MAX, MOMENT MOD. SECTION =
$135.13 \quad$ KIP.FT

(Gr-50)
$116.01 \quad$ KIP.FT

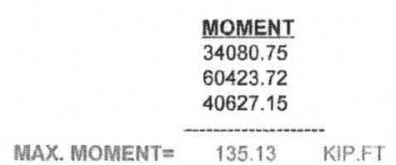

MOMENT

-148619.43
362678.23

161570.00

436481.03 
CASE 1

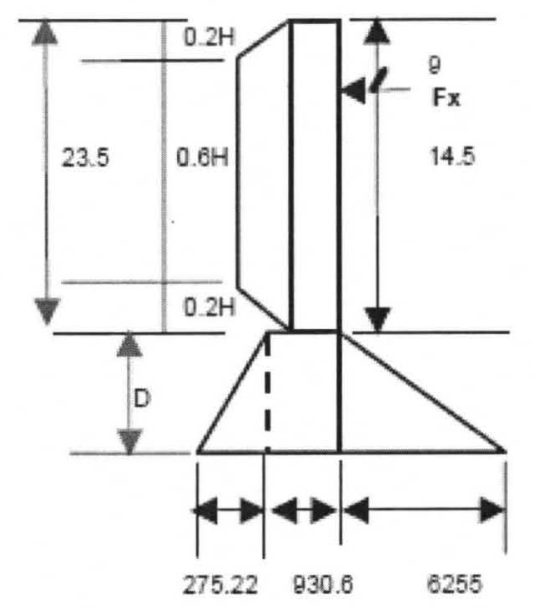

品

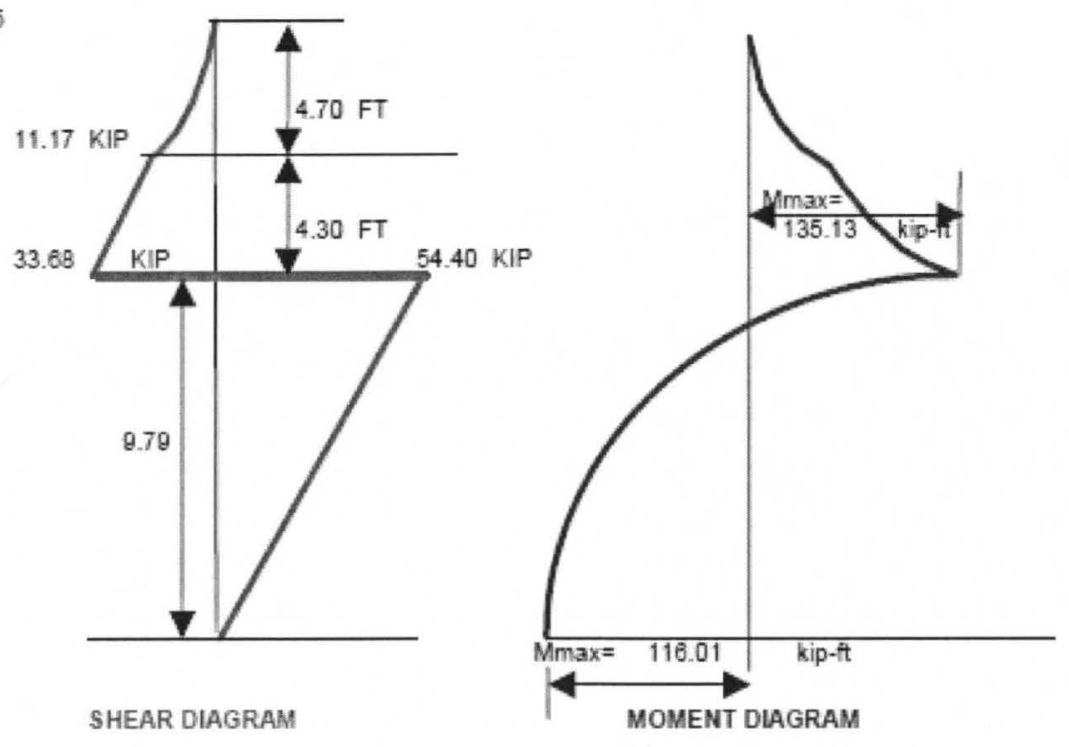


CASE 2

E

G

L

\begin{tabular}{|c|}
\hline DEPTH OF CUT H \\
SOIL UNIT WEIGHT \\
SOLD. PILE SPACE S \\
SURCHARGE LOAD \\
Ka \\
Kp \\
LOCATION OF 1ST TIE \\
LOCATION OF 2ND TIE \\
TIE ANGLE UPPER= \\
TIE ANGLE LOWER= \\
PDFACTOR
\end{tabular}

\begin{tabular}{ll}
32 & FT \\
115 & $\# / C . F T$. \\
8.5 & FT \\
300 & $\# / S . F T$ \\
0.33 & \\
3 & \\
9 & FT \\
23 & FT \\
30 & DEGREE \\
30 & DEGREE \\
22 & \\
\hline
\end{tabular}
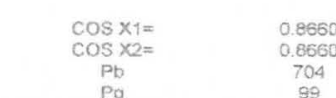

$\mathrm{PQ}$

LENGTH OF UPP.TRIA

LENGTH OF RECTANG

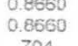

704
99
6.4
19.2

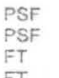

TO FIND THE VALUE OF THE FX1
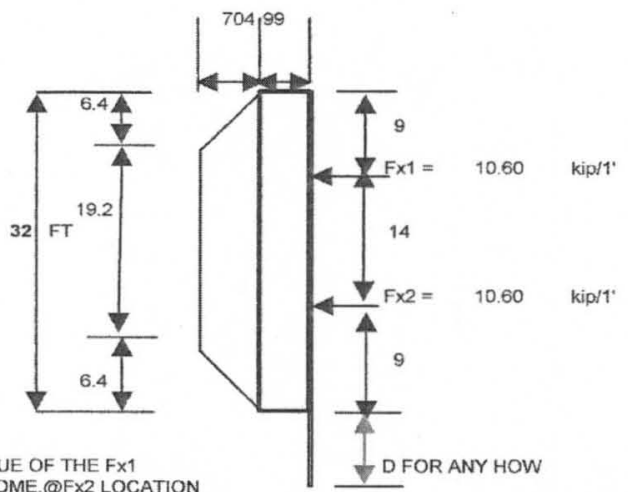

FOFCE

19354.50

19148.80
99334.40

$F \times 1=9005.40$

90059.20
7573.50

19148.80

15558.40

MAKE SUM. OF MOME.@FX2 LOCATION

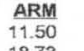

MOMENT
$11.50+22576.75$

$\begin{array}{ll}18.73 & +222576.75 \\ & +358720.85\end{array}$

8.30
14.00

4.50

4.73
1.30

$+824475.52$

$-1260828.80$

- 34080.75

- 90637.65

20225.92

Ex1 $=90059.2$

SUM OF MOMENT SHOUID

$-0.000000$

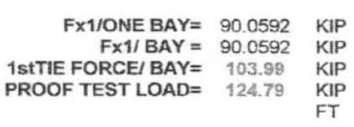

1stTIE FX1/ BAY $=90.0592 \quad \mathrm{KIP}$ 1stTIE FORCE $/ \mathrm{BAY}=103.98 \mathrm{KIP}$ $\begin{array}{ll}\text { PROOF TEST LOAD }=124.79 & \text { KIP } \\ \text { FT }\end{array}$

$\mathbf{F \times 2}=90059.2$

FX2/ONE BAY $=90.0592 \quad \mathrm{KIP}$ $\mathrm{F} \times 2 / \mathrm{BAY}=90.0592 \quad \mathrm{KIP}$ $\begin{array}{rlr}\text { TIE FORCE } / B A Y= & 103.99 & \mathrm{KIP} \\ \text { PROOF TSEST LOAD } & 124.79 & \mathrm{KIP}\end{array}$

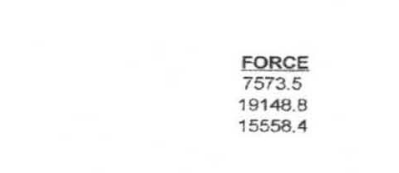

1-MXMOM.@1st tie= 144 94 KIP.FT

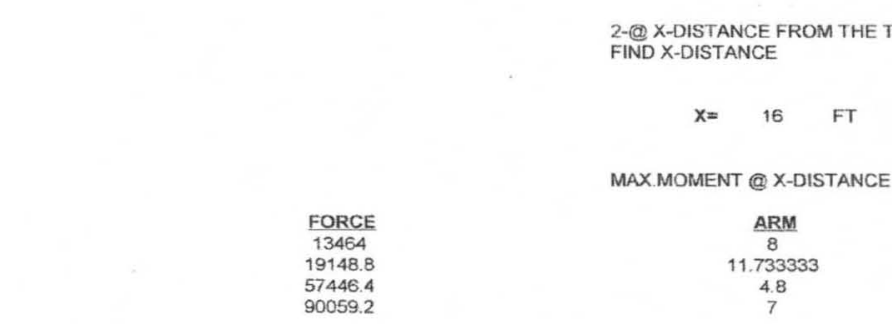

$\begin{array}{lll}\text { MAX.MOM@1stTIE LOCAT. }= & 144.94 & \text { KIP.FT } \\ \text { MAX.MOMENT@X-distanceE } & -22.28 & \text { KIP.FT }\end{array}$

USE MAX.MOM $=144.94 \quad$ KIP.FT

DESIGN SOLD. PILE

MOD.SEC. FOR THE PILE $=\mathbf{5 2 . 7 1}$ CU.IN Gr-50

USE HP $12 \times 53 \mathrm{Gr}-50 \mathrm{Sx}=66.8$

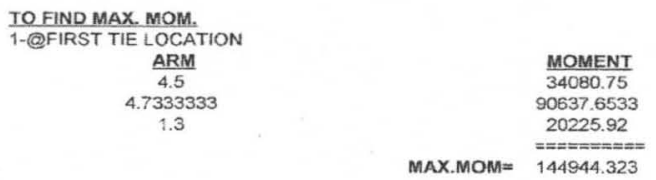

2-(C) X-DISTANCE FROM THE TOP OF THE PILE

TO FIND THE VALUE OF FX2 MAKE SUM. OF FX $=0$

MAX.MOM $=144944.323$

$X=16 \quad$ FT

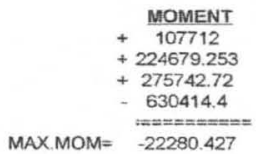

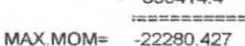



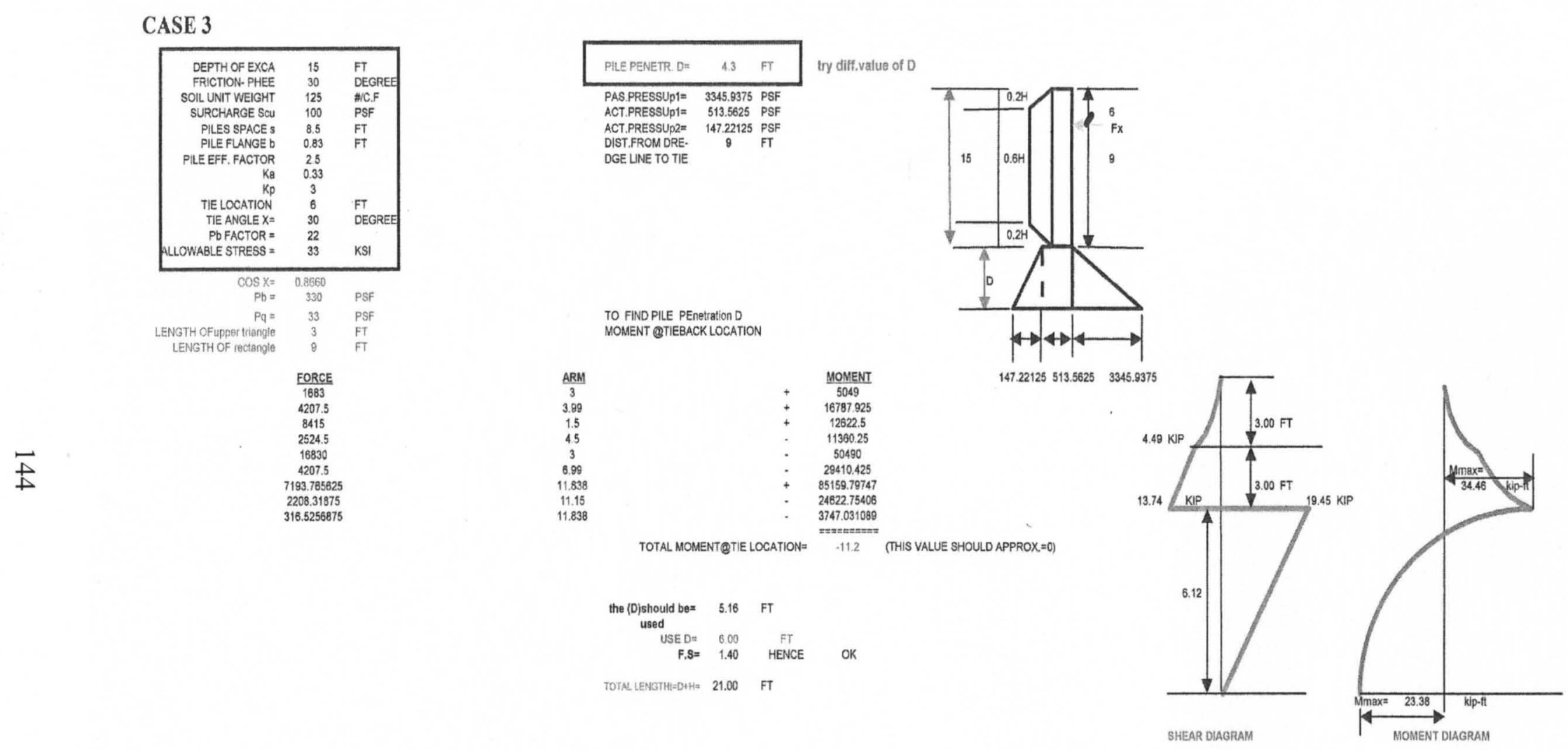


\section{CASE 3}

虫

\begin{tabular}{|c|c|c|}
\hline DEPTH OF EXCA & 15 & FT \\
\hline FRICTION-PHEE & 30 & DEGREE \\
\hline SOIL UNIT WEIGHT & 125 & $\# / C . F$ \\
\hline SURCHARGE ScU & 100 & PSF \\
\hline PILES SPACE $S$ & 8.5 & $\mathrm{FT}$ \\
\hline PILE FLANGE b & 0.83 & FT \\
\hline PILE EFF. FACTOR & 2.5 & \\
\hline & 0.33 & \\
\hline $\mathrm{Kp}$ & 3 & \\
\hline TIE LOCATION & 6 & \\
\hline TIE ANGLE $X=$ & 30 & DEGREE \\
\hline $\mathrm{Pb}$ FACTOR $=$ & 22 & \\
\hline ALLOWABLE STRESS = & 33 & KSI \\
\hline $\cos x=$ & 0.8660 & \\
\hline $\mathrm{Pb}=$ & 330 & PSF \\
\hline$P q=$ & 33 & PSF \\
\hline ENGTH OFupper triangle & 3 & FT \\
\hline LENGTH OF rectangle & 9 & FT \\
\hline & FORCE & \\
\hline & 1683 & \\
\hline & 4207.5 & \\
\hline & 8415 & \\
\hline & 2524.5 & \\
\hline & 16830 & \\
\hline & 4207.5 & \\
\hline & 7193.765625 & \\
\hline & 2208.31875 & \\
\hline & 316.5256875 & \\
\hline
\end{tabular}

try diff.value of $D$

\begin{tabular}{|ccc|}
\hline PILE PENETR. D= & 4.3 & FT \\
\hline PAS.PRESSUP1= & 3345.9375 & PSF \\
ACT.PRESSUP1 & 513.5625 & PSF \\
ACT.PRESSUP2= & 147.22125 & PSF \\
DIST.FROM DRE- & 9 & FT \\
DGE LINE TO TIE & & \\
\hline
\end{tabular}

TO FIND PILE PEnetration D

MOMENT @TIEBACK LOCATION

$\begin{array}{ccc}\text { ARM } & & \text { MOMENT } \\ 3 & + & 5049 \\ 3.99 & + & 16787.925 \\ 1.5 & + & 12622.5 \\ 4.5 & - & 11360.25 \\ 3 & - & 50490 \\ 6.99 & - & 29410.425 \\ 11.838 & + & 85159.79747 \\ 11.15 & - & 24622.75406 \\ 11.838 & - & 3747.031089 \\ & & ===== \\ & \text { TOTAL MOMENT@TIE LOCATION }= & -11.2\end{array}$

(THIS VALUE SHOULD APPROX $=0$ )

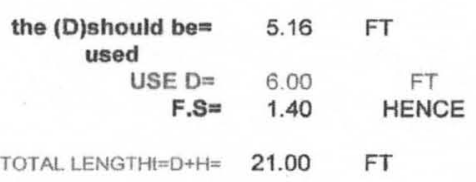

OK

12/05/201009:45:29 PM1case3.123 


\begin{tabular}{|c|c|c|}
\hline & \multicolumn{2}{|c|}{$\begin{array}{l}\text { TO FIND TIEBACK FORCE } \\
\text { MAKE SUM. FOR F } \mathrm{X}=0\end{array}$} \\
\hline $\mathrm{FI}=$ & & \\
\hline $\mathrm{F} 2=$ & 8415 & + \\
\hline $\mathrm{F} 3=$ & 25245 & + \\
\hline $\mathrm{F} 4=$ & 2208.31875 & + \\
\hline $\mathrm{F} 5=$ & 7193.765625 & - \\
\hline $\mathrm{F} 6=$ & 316.5256875 & + \\
\hline $\mathrm{FX} / \mathrm{ONE} B A \mathrm{Y}=$ & 33.20 & KIP \\
\hline $\mathrm{F} / \mathrm{ONE} \mathrm{FT}=$ & 3.91 & KIP/FT \\
\hline & & \\
\hline TIE FORCE/2 BAYs= & 76.67 & KIP \\
\hline PROOFTEST LOAD $=$ & 92.00 & KIP \\
\hline
\end{tabular}

1 @TIEBACK LOCATION =

FORCE

1683

8415 $2 @$ X-DISTANCE FROM
THE TOP OF THE PILE

FIND $X$ WHEN SUM.OF $F X=0$

(ZERO SHEAR POINT) $-6 \quad \mathrm{FT}$

\section{FORCE \\ 3400.55
33198.58}

4207.50

\section{ARM}

1.5

\section{ARM}

6.0615911

6.1231822

10.113182
4.5615911

23.38 KIP.FT

MAX. MOMENT $=$

USE MAX. MOMENT =

MOD. SECTION =
12.53 CUB. IN (Gr-50)

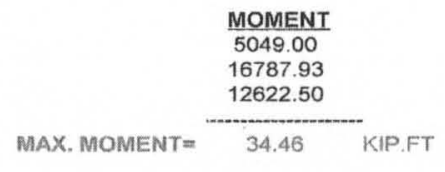

MOMENT

20612.76
203280.95

42551.21
116733.52 
CASE 3

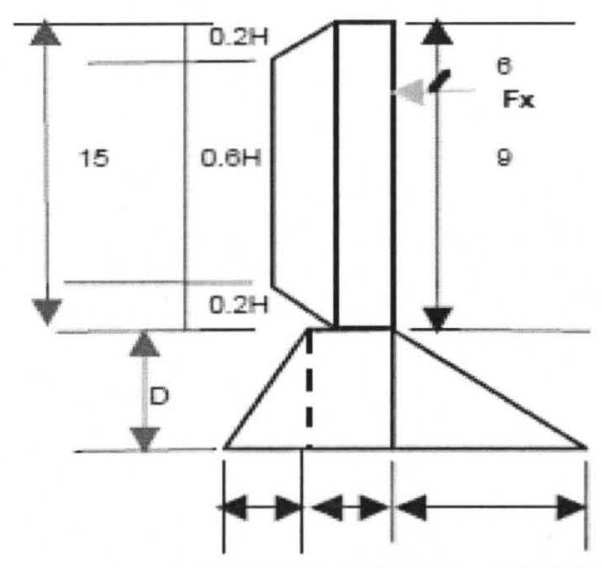

$147.22125 \quad 513.5625 \quad 3345.9375$

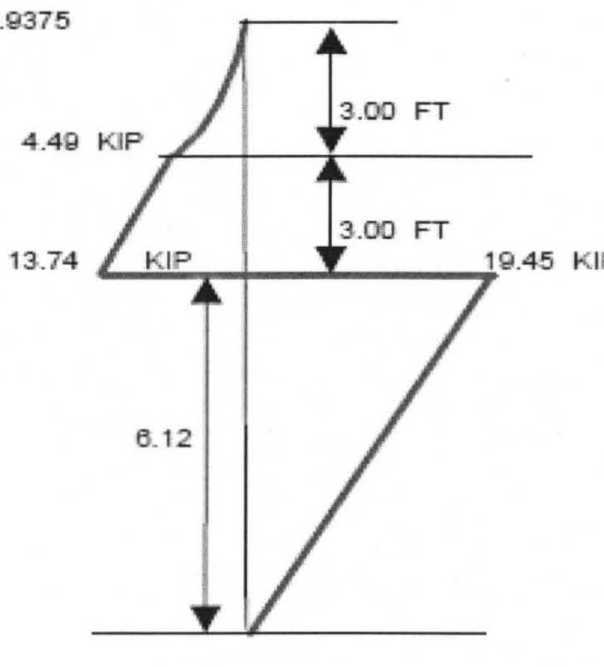

SHEAR DIAGRAM

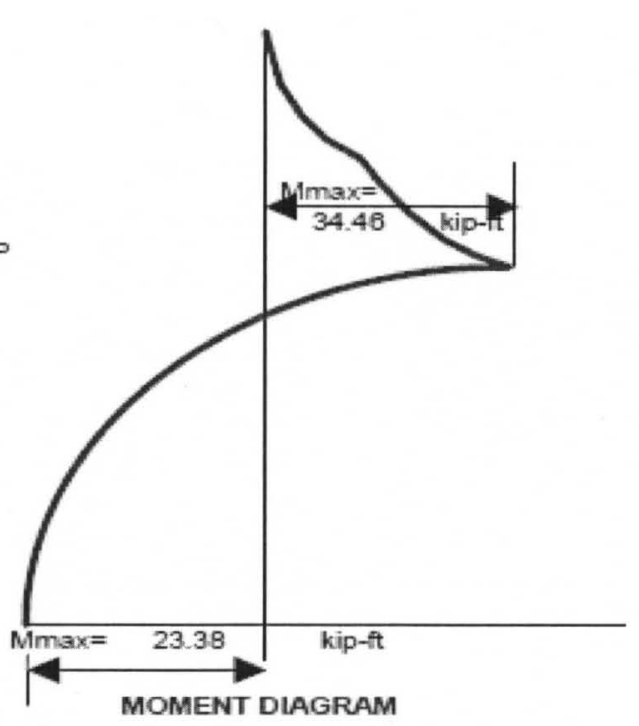




\section{CASE 4 PART A}

\begin{tabular}{|c|}
\hline DEPTH OF CUT H \\
SOIL UNIT WEIGHT \\
SOLD. PILE SPACE S \\
SURGHARGE LOAD \\
Ka \\
Kp \\
LOCATION OF 1 ST TIE \\
LOGATION OF $2 N D$ TIEE \\
TIE ANGLE UPPER= \\
TIE ANGLE LOWER= \\
PD FACTOR
\end{tabular}

\begin{tabular}{ll}
\hline 8 & FT \\
\#IC.FT. \\
5 & FT \\
0 & $\# I S . F T$ \\
33 & \\
& FT \\
& FT \\
& DEGREE \\
& DEGREE
\end{tabular}

\begin{tabular}{l}
30 \\
22 \\
\hline
\end{tabular}

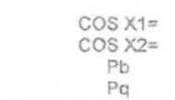

LENGTH OF UPP TRIA

LENGTH OF RECTANG

0.8660

0.8660
616

$\begin{array}{cc}82.5 & \text { PSF } \\ 5.6 & \text { FT }\end{array}$

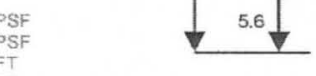

16.8 FT

TO FIND THE VALUE OF THE FX1

G $\quad H$

MAKE SUM OFLE OF THE FX1

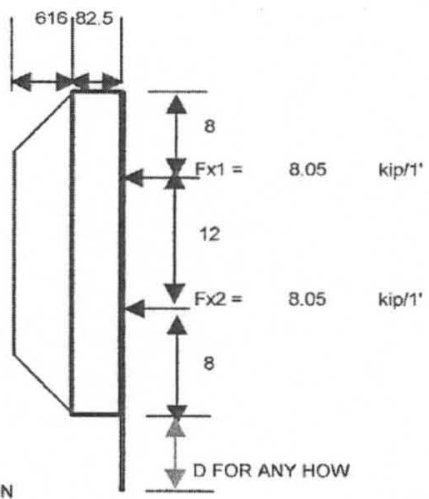

FOFCE

1466080

75398.40

75398.40
68460.70

5610.00

14660.80

12566.40

Fx1 $=\quad 68460.7$
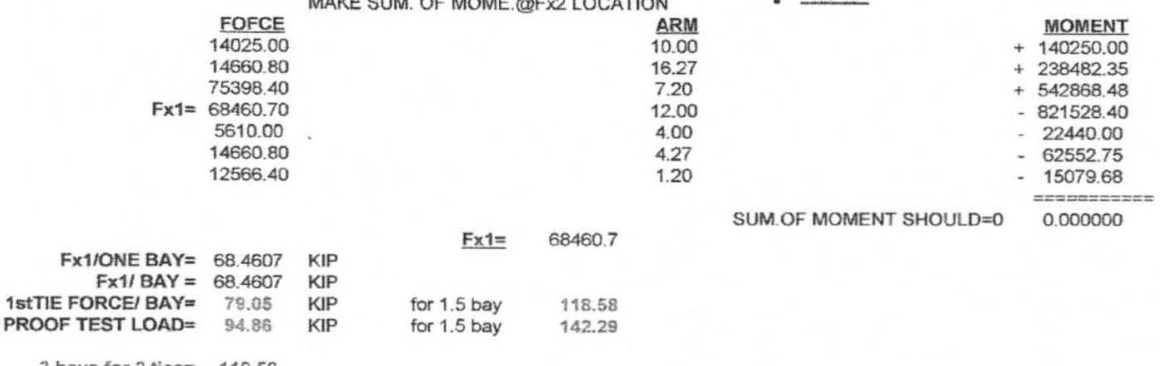

for 1.5 bay $\quad 118.58$

3 bays for 2 ties $=118.58$

TO FIND THE VALUE OF FX2

MAKE SUM. OF FX $=0$

$E \times 2=68460.7$

$\mathrm{KIP}$
$\mathrm{K}$

FX2 $\mathrm{BAY}=68.4607 \quad \mathrm{KIP}$

PROOF TSEST LOAD $=84.86 \quad \mathrm{KIP}$

for 1.5 bay $\quad 118.58$

3 bays for 2 ties $=118.58 \quad \mathrm{KIP}$

\section{TO FIND MAX. MOM.}

1-@FIRST TIE LOCATION

\section{FORCE \\ 5610
14660.8}

12566.4

ARM

4.2666667

1.2

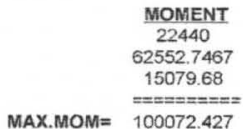

1-MXMOM.@1st tie $=100.07$ KIPF

2-@ X-DISTANCE FROM THE TOP OF THE PILE FIND X-DISTANCE

$X=14 \quad F T$

MAX.MOMENT @X-DISTANCE

FORCE
9817.5
14660.8
43982.4
68460.7

ARM

10.266657 
CASE 4 PART B

\begin{tabular}{|rcl|}
\hline $\mathrm{H}=$ & 35 & $\mathrm{FT}$ \\
$\mathrm{S}=$ & 8.5 & $\mathrm{FT}$ \\
$\mathrm{SCH}$ & 250 & $\mathrm{PSF}$ \\
TIE 1@ & 7.5 & $\mathrm{FT}$ \\
TIE 2@ & 17.5 & $\mathrm{FT}$ \\
TIE 3@ & 27.5 & $\mathrm{FT}$ \\
$\mathrm{Ka}=$ & 0.33 & $\mathrm{FT}$ \\
TIE @ & 30 & DEGREE \\
Pb FACTOR $=$ & 22 & \\
upper triangle $=$ & 7 & $\mathrm{ft}$ \\
lower triangle $=$ & 7 & $\mathrm{ft}$ \\
\hline
\end{tabular}

$W=7.24625 \quad K / 1$ VERTICAL FT

$\begin{array}{ll}F \times 1=67.67 & \text { KIPS } \\ F \times 2=72.46 & \text { KIPS }\end{array}$

$\mathrm{F} \times 3=67.67$ KIPS

$\cos x=0.8660255$

$\begin{array}{llll}\text { DL1 }= & 78.14 & \text { KIP } & 1.5 \times \mathrm{DL}= \\ \text { DL2 }= & 83.67 & \text { KIP } & 117.21 \\ \text { DL3 }=78.14 & \text { KIP } & 125.51 \\ & & & 117.21\end{array}$

PROOF LOAD $1.2 \times D L$

$\begin{array}{llll}\text { PROOF TIE 1 } & 93.77 & \text { KIPS } & 140.65 \\ \text { PROOF TIE 2 } & 100.41 & \text { KIPS } & 150.61 \\ \text { PROOF TIE }= & 93.77 & \text { KIPS } & 140.65\end{array}$

MAXMOMENT + @ TIE 1 LOCATION

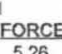

5.26

10

12.5
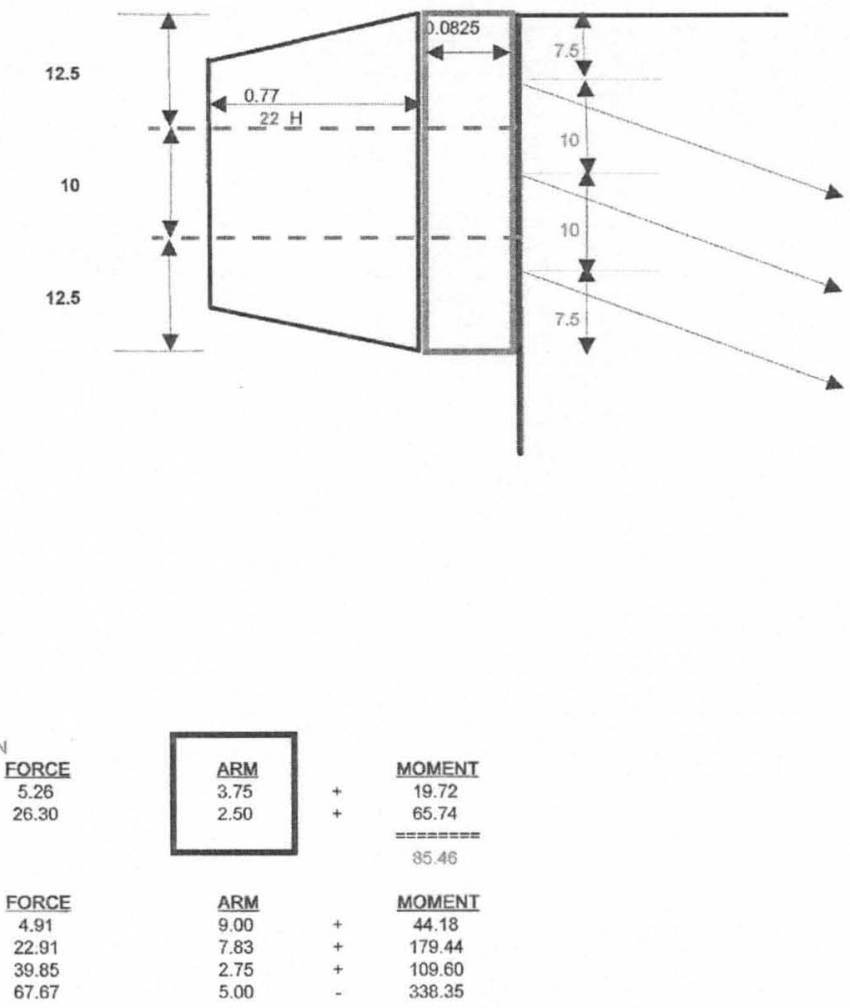

MAX MOMENT $2 @$ TIE 2 LOCATION

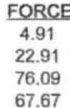

MAX MOMENT 3 BETWEEN 2nd AND 3rd TIE

$X 2$ IS BELOW $0.2 \mathrm{H} \quad \mathrm{X}_{2}=\quad 15.50$

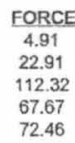

USE PAAX MOM. $=85.46 \quad$ FT-KIP

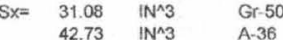

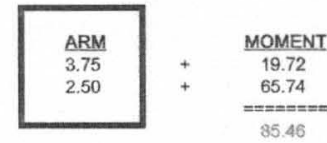

\begin{tabular}{llc} 
ARM & & MOMENT \\
\hline 9.00 & + & 44.18 \\
7.83 & + & 179.44 \\
2.75 & + & 109.60 \\
5.00 & - & 338.35 \\
& $======$ \\
& -5.13
\end{tabular}

$\begin{array}{ccc}\frac{}{\text { ARM }} & & \text { MOMENT } \\ 14 & + & 68.72 \\ 12.83 & + & 293.98 \\ 5.25 & + & 399.45 \\ 10 & - & 676.71 \\ & & =m==2= \\ & & 85.45\end{array}$

$\begin{array}{ccc}\text { ARM } & & \text { MOMENT } \\ 19.00 & + & 93.27 \\ 17.83 & + & 408.52 \\ 7.75 & + & 870.46 \\ 15.00 & - & 1015.06 \\ 5.00 & - & 362.31 \\ & & = \pm== \pm== \\ & & -5.13\end{array}$


CASE 5 PART A

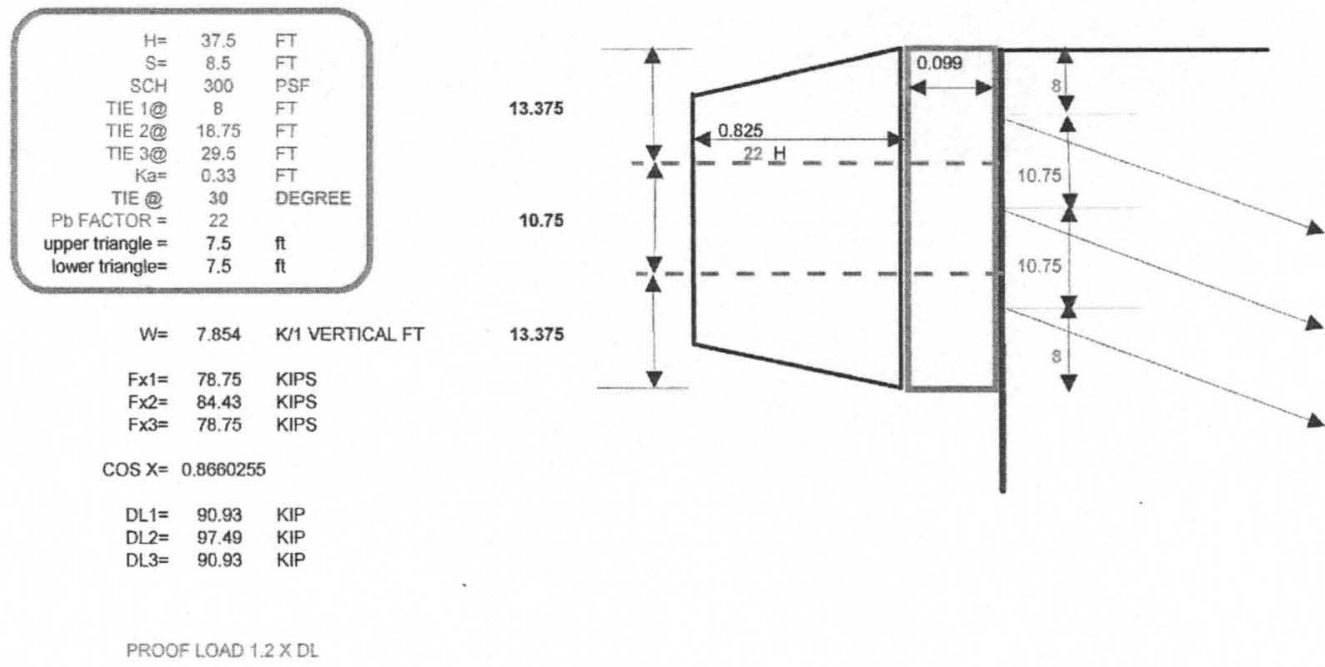

PROOF TIE $1=109.12 \quad \mathrm{KIPS}$

$\begin{array}{ll}\text { PROOF TIE 2 }=116.99 & \text { KIPS } \\ \text { PROOF TIE 3 }=109.12 & \text { KIPS }\end{array}$

MAXMOMENT $1 @$ TIE 1 LOCATION

FORCE
6.73
29.92

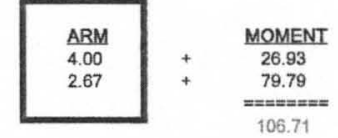

XIS BELOW $0.2 \mathrm{H} \quad \mathrm{X} 1=5.88 \quad \mathrm{FT}$
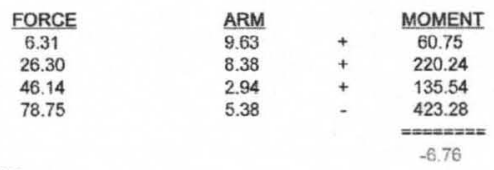

MAXMOMENT 2 @TIE 2 LOCATION

\begin{tabular}{c} 
FORCE \\
\hline 6.31 \\
26.30 \\
88.36 \\
78.75
\end{tabular}

$\begin{array}{ccc}\text { ARM } & & \text { MOMENT } \\ 15 & + & 94.67 \\ 13.75 & + & 361.58 \\ 5.625 & + & 497.01 \\ 10.75 & - & 846.57 \\ & & == \pm==10 \\ & & 106.70\end{array}$

X2 IS BELOW $0.2 \mathrm{H} \quad \mathrm{X} 2=\quad 16.63$

\begin{tabular}{cccc} 
FORCE & ARM & & MOMENT \\
\hline 6.31 & 20.38 & + & 128.59 \\
26.30 & 19.13 & + & 502.93 \\
130.57 & 8.31 & + & 1085.39 \\
78.75 & 16.13 & - & 1269.85 \\
84.43 & 5.38 & - & 453.81 \\
& & & $=====$ \\
& & & -6.76
\end{tabular}

$\begin{array}{rlll}\text { USE WAX MOM }= & 106.71 & \text { FT-KIP } & \\ \text { Sx }= & 38.81 & \text { IN^3 } & \text { Gr-50 } \\ & 53.36 & \mathrm{IN}^{\wedge} 3 & \text { A-36 }\end{array}$

use $12 \times 53$ to count for through beam penetration 
CASE 5 PART B

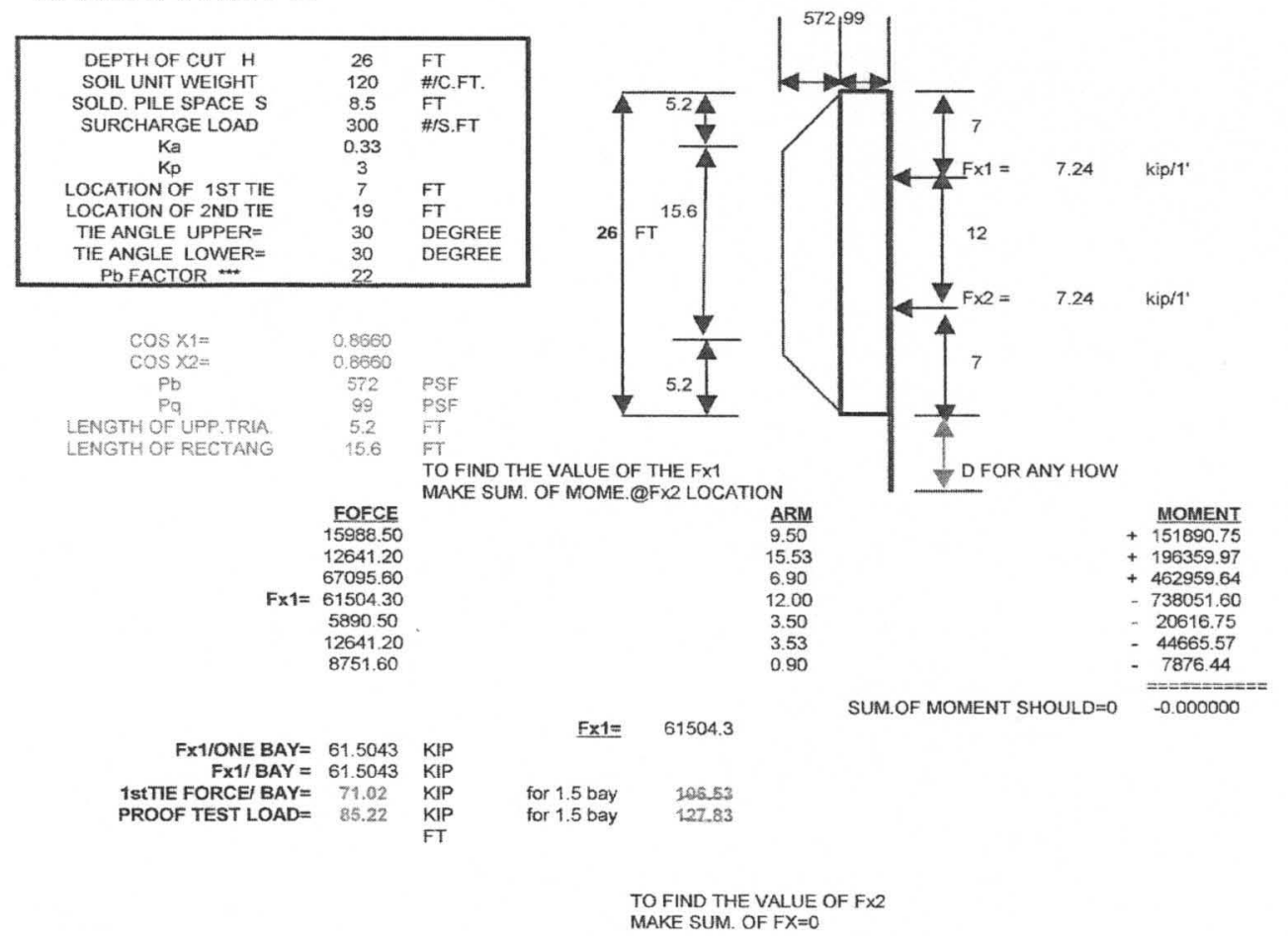

Fx2 $=61504.3$

$\begin{array}{rllll}\text { FX2/ONE BAY } & 61.5043 & \mathrm{KIP} & & \\ \text { FX2/ BAY }= & 61.5043 & \mathrm{KIP} & & \\ \text { TIE FORCE /BAY } & 71.02 & \mathrm{KIP} & \text { for } 1.5 \text { bay } & 106.53 \\ \text { PROOF TSEST LOAD }= & 85.22 & \mathrm{KIP} & \text { for } 1.5 \text { bay } & 127.83\end{array}$

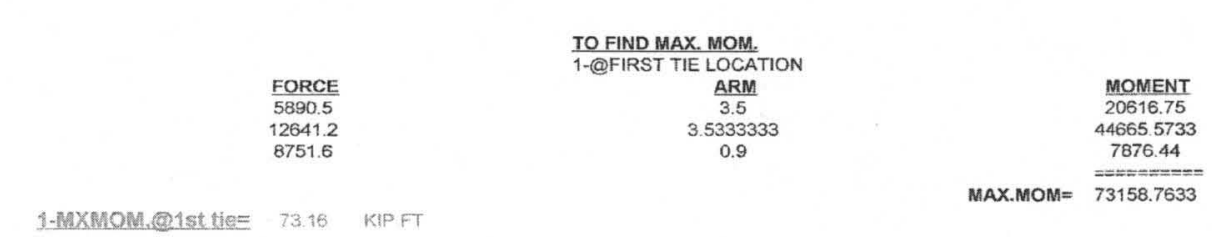
2-@ X-DISTANCE FROM THE TOP OF THE PILE
FIND X-DISTANCE

$X=13 \quad F T$

MAX.MOMENT @X-DISTANCE
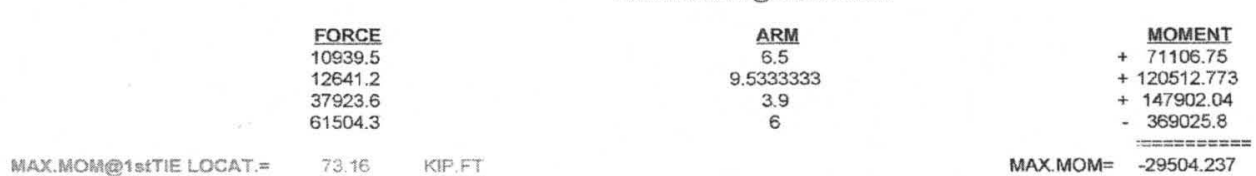

MAX.MOH@1sETIE LOCAT $=\quad 73.16 \quad$ KIF.FT

USE MAX.MOM $=73.16 \quad$ KIP.FT

DESIGN SOLD. PILE

MOD.SEC. FOR THE PILE $=26.60$ CU.IN Gr-50

USE HP $12 \times 53 \mathrm{Gr}-50 \mathrm{~S} x=66.8$ 


\section{CASE 6 PART A}

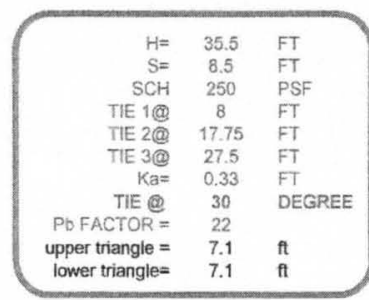

$W=7.33975 \quad$ KI1 VERTICAL FT

$\mathrm{Fx} 1=70.93 \mathrm{KIPS}$ $\begin{array}{ll}\mathrm{F} \times 2=71.56 & \mathrm{KIPS} \\ \mathrm{F} \times 3=70.93 & \mathrm{KIPS}\end{array}$

$\cos x=0.8660255$

$\begin{array}{llll}\text { DL1 }= & 81.91 & \text { KIP } & 122.86 \\ \text { DL2 } & 82.63 & \text { KIP } & 123.95 \\ \text { DL3 }= & 81.91 & \text { KIP } & 122.86\end{array}$

PROOF LOAD $1.2 \times D L$

PROOF THE $1=98.29 \quad \mathrm{KIPS}$ PROOF TIE 2 $=99.16 \quad$ KIPS PROOF TIE $3=98.29$ KIPS

147.43

148.74

MAXMOMENT 1 TIE 1 LOCATION FORCE 5.61
29.92

$X$ IS BELOW $0.2 \mathrm{H} \quad \mathrm{X} 1=5.78 \quad \mathrm{FT}$

$$
\begin{gathered}
\text { FORCE } \\
\hline 4.98 \\
23.57 \\
42.39 \\
70.93
\end{gathered}
$$

MAXMOMENT 2 (9) TIE 2 LOCATION

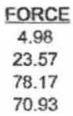

MAX MOMENT 3 BETWEEN 2nd AND 3rd TIE

$X_{2}$ IS BELOW $0.2 \mathrm{H} \quad \mathrm{X}_{2}=\quad 15.53$

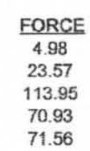

$$
\begin{array}{rlll}
\text { USE MAX MOM } & =102.23 & \text { FT-KIP } & \\
\text { Sx } & =37.17 & \text { IN^3 } & \text { Gr }-50 \\
& 51.11 & \mathbb{I N}^{\wedge} 3 & A-36
\end{array}
$$

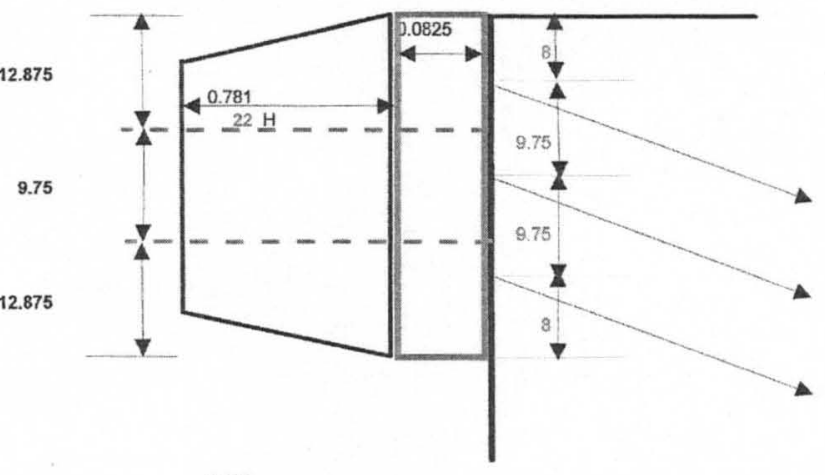

9.875

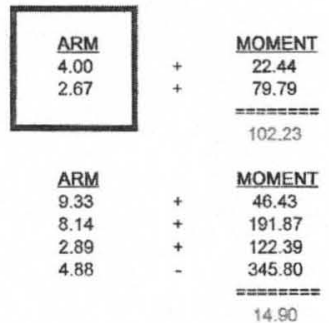

$$
\begin{array}{ccc}
\text { ARM } & & \text { MOMENT } \\
14.2 & + & 70.70 \\
13.02 & + & 306.76 \\
5.325 & + & 416.25 \\
9.75 & - & 691.59 \\
& & ==1===1 \\
& & 102.11
\end{array}
$$

$\begin{array}{ccc}\text { ARM } & & \text { MOMENT } \\ 19.08 & + & 94.97 \\ 17.89 & + & 421.65 \\ 7.76 & + & 884.53 \\ 14.63 & - & 1037.39 \\ 4.88 & - & 348.87 \\ & & == \pm= \pm=\pi \\ & & 14.90\end{array}$




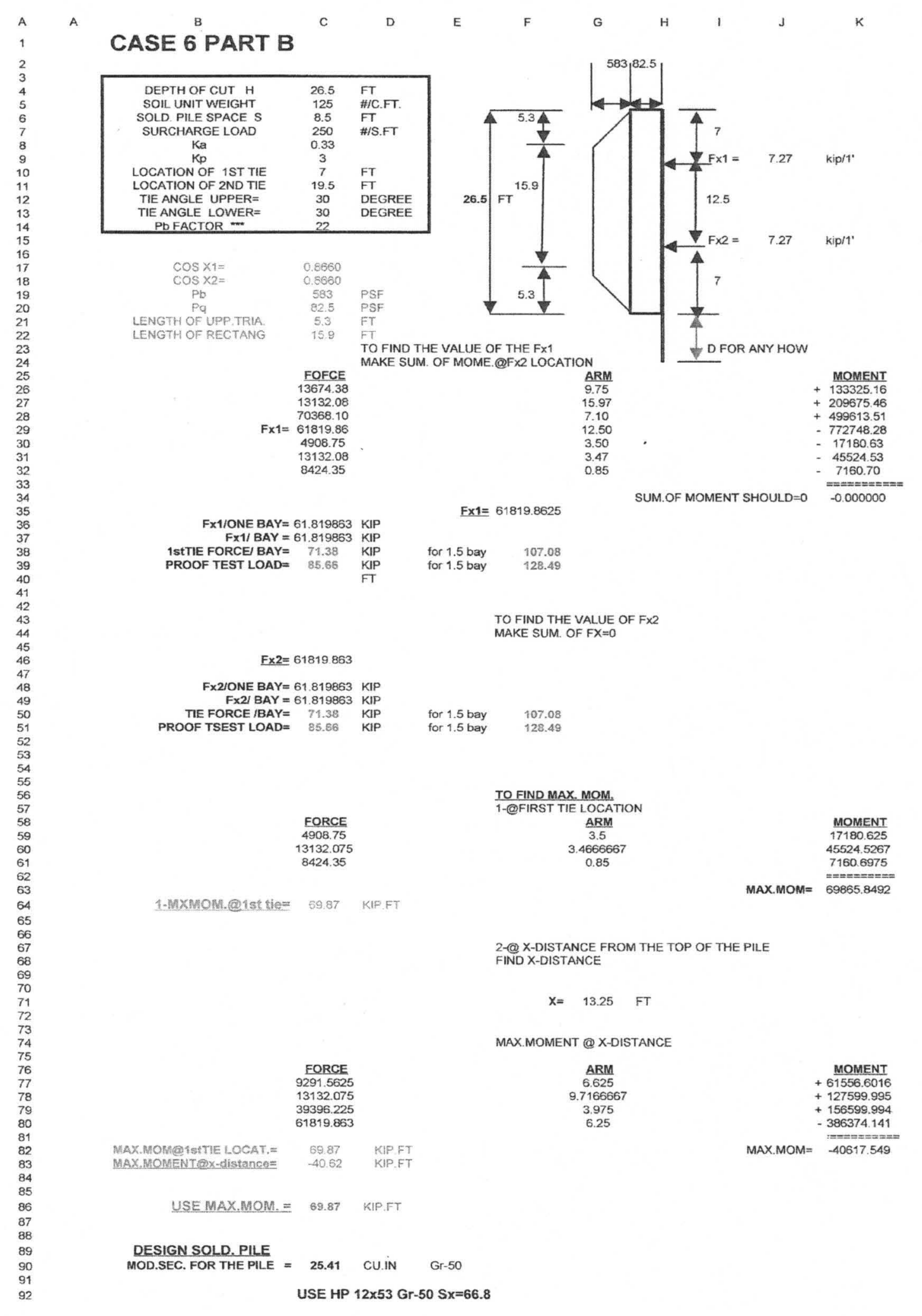



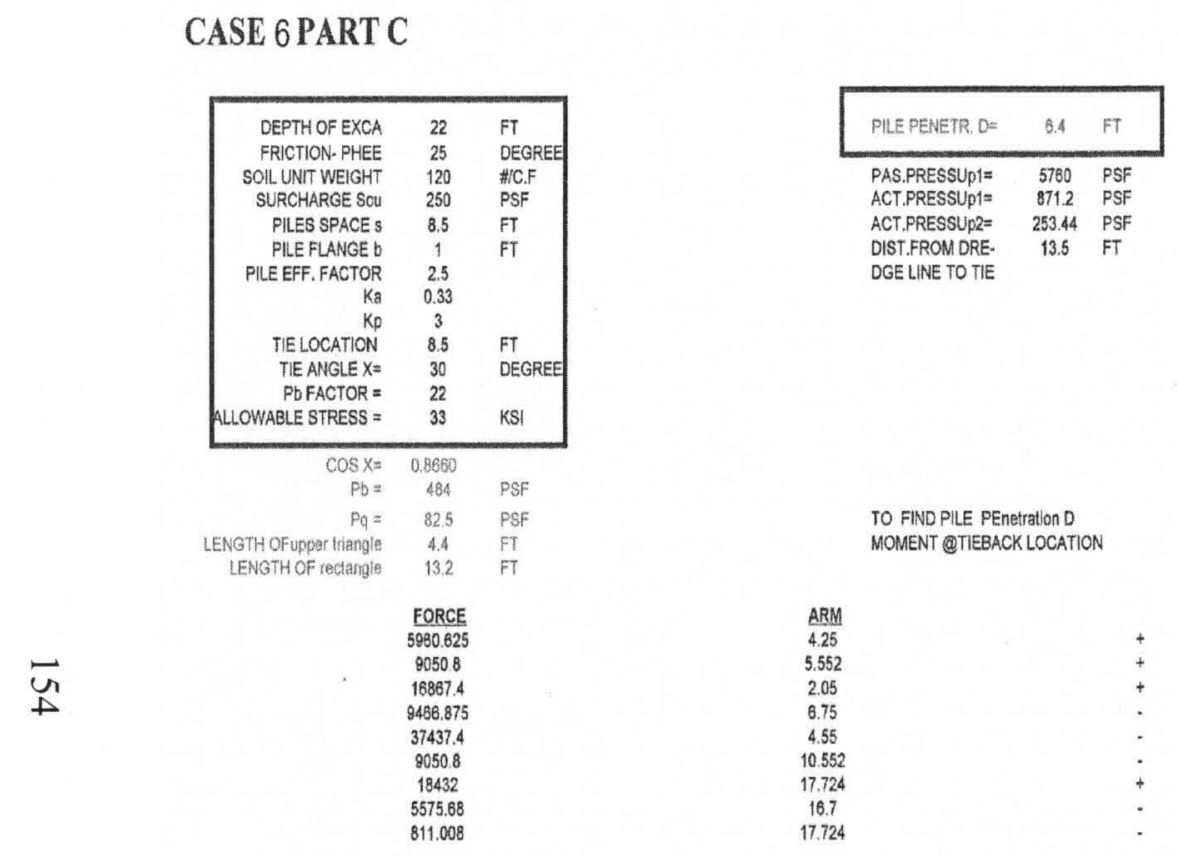

try diff.value of D
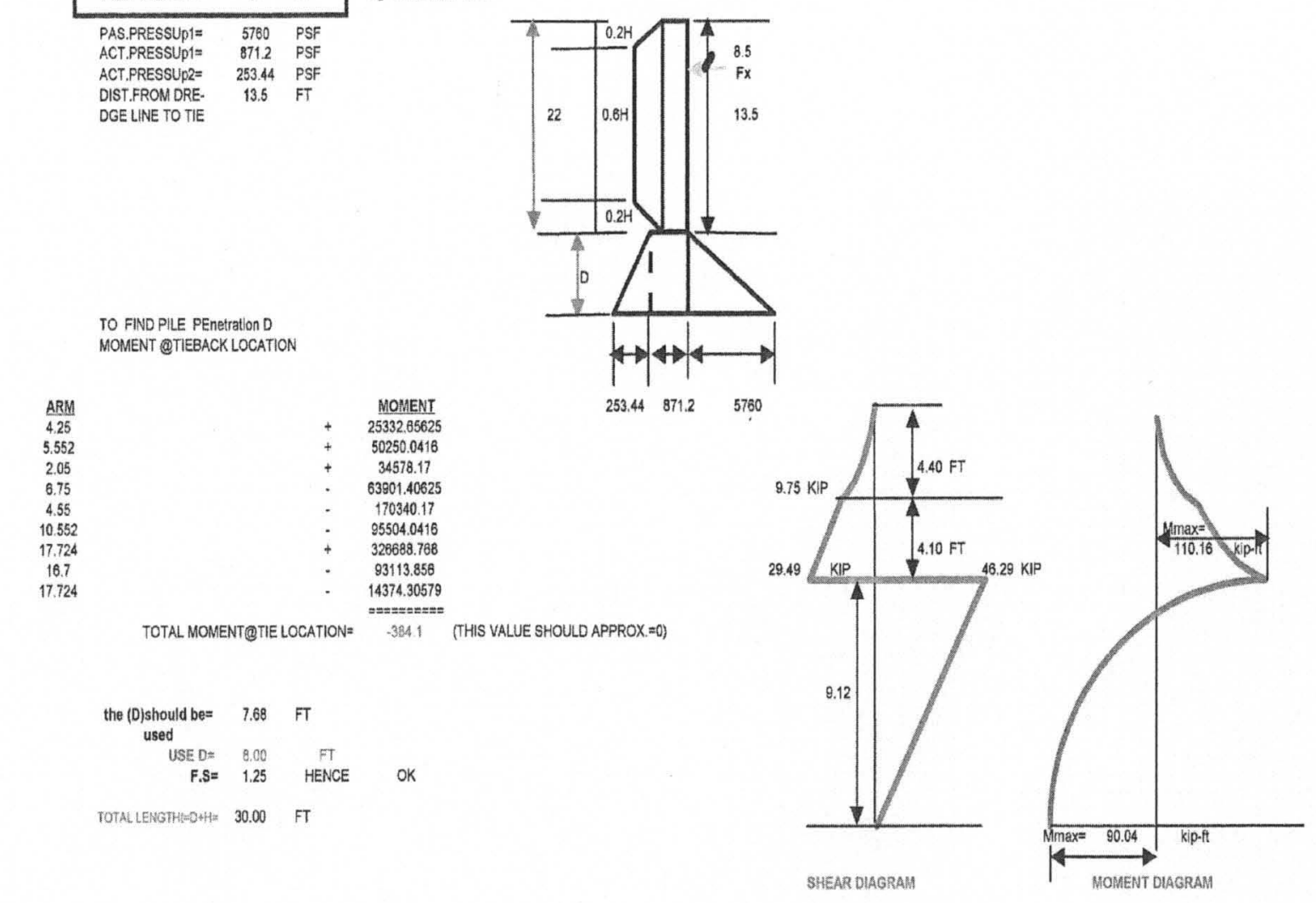


\section{CASE 6 PART C}

$\vec{u}$

\begin{tabular}{|c|c|c|}
\hline DEPTH OF EXCA & 22 & FT \\
\hline FRICTION-PHEE & 25 & DEGREE \\
\hline SOIL UNIT WEIGHT & 120 & $\# / C . F$ \\
\hline SURCHARGE SCU & 250 & PSF \\
\hline PILES SPACE S & 8.5 & FT \\
\hline PILE FLANGE b & 1 & FT \\
\hline PILE EFF. FACTOR & 2.5 & \\
\hline & 0.33 & \\
\hline$K p$ & 3 & \\
\hline TIE LOCATION & 8.5 & FT \\
\hline TIE ANGLE $X=$ & 30 & DEGREE \\
\hline $\mathrm{Pb}$ FACTOR $=$ & 22 & \\
\hline ALLOWABLE STRESS = & 33 & KSI \\
\hline $\begin{array}{r}\cos x= \\
P b=\end{array}$ & $\begin{array}{c}0.8660 \\
484\end{array}$ & PSF \\
\hline $\mathrm{Pq}=$ & 82.5 & PSF \\
\hline LENGTH OFupper triangle & 4.4 & FT \\
\hline LENGTH OF rectangle & 13.2 & FT \\
\hline & FORCE & \\
\hline & 5960.625 & \\
\hline & 9050.8 & \\
\hline & 16867.4 & \\
\hline & 9466.875 & \\
\hline & 37437.4 & \\
\hline & 9050.8 & \\
\hline & 18432 & \\
\hline & 5575.68 & \\
\hline & 811.008 & \\
\hline
\end{tabular}

\begin{tabular}{|ccl|}
\multicolumn{4}{c}{ try diff.value of D } \\
\hline PILE PENETR. D $=$ & 6.4 & FT \\
\hline PAS.PRESSUp1 $=$ & 5760 & PSF \\
ACT.PRESSUp1 $=$ & 871.2 & PSF \\
ACT.PRESSUp2= & 253.44 & PSF \\
DIST.FROM DRE- & 13.5 & FT \\
DGE LINE TO TIE & & \\
\hline
\end{tabular}

TO FIND PILE PEnetration D

MOMENT @TIEBACK LOCATION

$$
\begin{gathered}
\text { ARM } \\
4.25 \\
5.552 \\
2.05 \\
6.75 \\
4.55 \\
10.552 \\
17.724 \\
16.7
\end{gathered}
$$$$
17.724
$$

TOTAL MOMENT@TIE LOCATION=

$\begin{array}{lr}\text { OCATION }= & -384.1 \\ \text { (THIS VALUE SHOULD }\end{array}$

MOMENT
25332.65625
50250.0416
34578.17
63901.40625
170340.17
95504.0416
326688.768
93113.856
14374.30579
$====-$
-384.1

$\begin{array}{rrr}\begin{array}{c}\text { the (D)should be } \\ \text { used }\end{array} & 7.68 & \mathrm{FT} \\ \text { USE D }= & 8.00 & \text { FT } \\ \mathrm{F} . \mathrm{S}= & 1.25 & \text { HENCE } \\ & & \end{array}$

OK
12/05/201009:50:14 PM1CASE6PARTC.123 


\begin{tabular}{|c|c|c|}
\hline & \multicolumn{2}{|c|}{$\begin{array}{l}\text { TO FIND TIEBACK FORCE } \\
\text { MAKE SUM. FOR Fx }=0\end{array}$} \\
\hline $\mathrm{Fl}=$ & 15427.5 & \\
\hline $\mathrm{F} 2=$ & 18101.6 & \\
\hline $\mathrm{F} 3=$ & 54304.8 & + \\
\hline $\mathrm{F} 4=$ & 5575.68 & + \\
\hline $\mathrm{F} 5=$ & 18432 & - \\
\hline$F 6=$ & 811.008 & + \\
\hline FX/ONE BAY $=$ & 75.79 & \\
\hline FXIONE FT $=$ & 8.92 & KIP/FT \\
\hline $\mathrm{FX} / \mathrm{BAY}=$ & 75.79 & KIP \\
\hline TIE FORCE $/ 1$ BAY $=$ & 87.51 & KIP \\
\hline PROOFTEST LOAD = & 105.02 & KIP \\
\hline
\end{tabular}

1 @IIEBACK LOGATION =

$$
\begin{gathered}
\text { FORCE } \\
5960.625 \\
9050.8
\end{gathered}
$$$$
1887.4
$$
2 @ X-DISTANCE FROM
THE TOP OF THE PILE

$$
\text { FIND } X \text { WHEN SUM. OF } F X=0
$$$$
X=17.618896 \mathrm{FT}
$$

\section{$\frac{\text { FORCE }}{12355.25}$}

75788.59

9050.80

54382.54
ARM

8.8094479
9.1188958
14.670896
0.0094479

6.609447

MAX. MOMENT $=$

USE MAX. MOMENT
MOD. SECTION =
ARM

4.25
5.552
5

90.04 KIP.FT

110.16 KIP.F

40.06 CuB. IN (Gr-50)

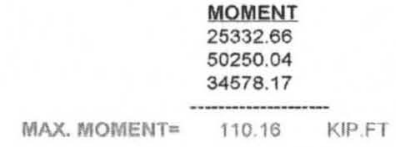

MOMENT

691108.24
132783.34

132783.34
358438.55 
CASE 6 PART C

$\vec{u}$
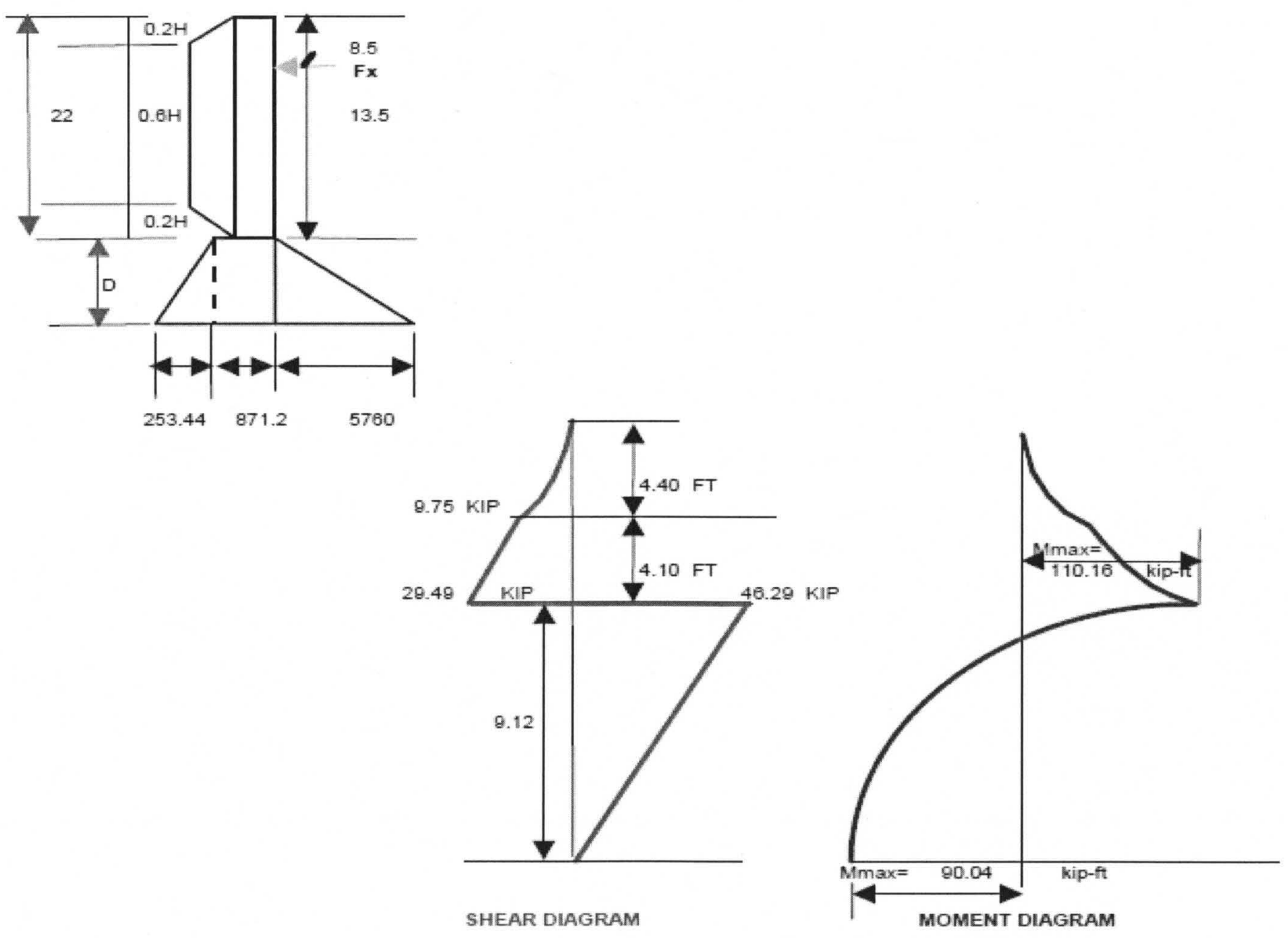


\section{CASE 7 PART A}

प్⿱

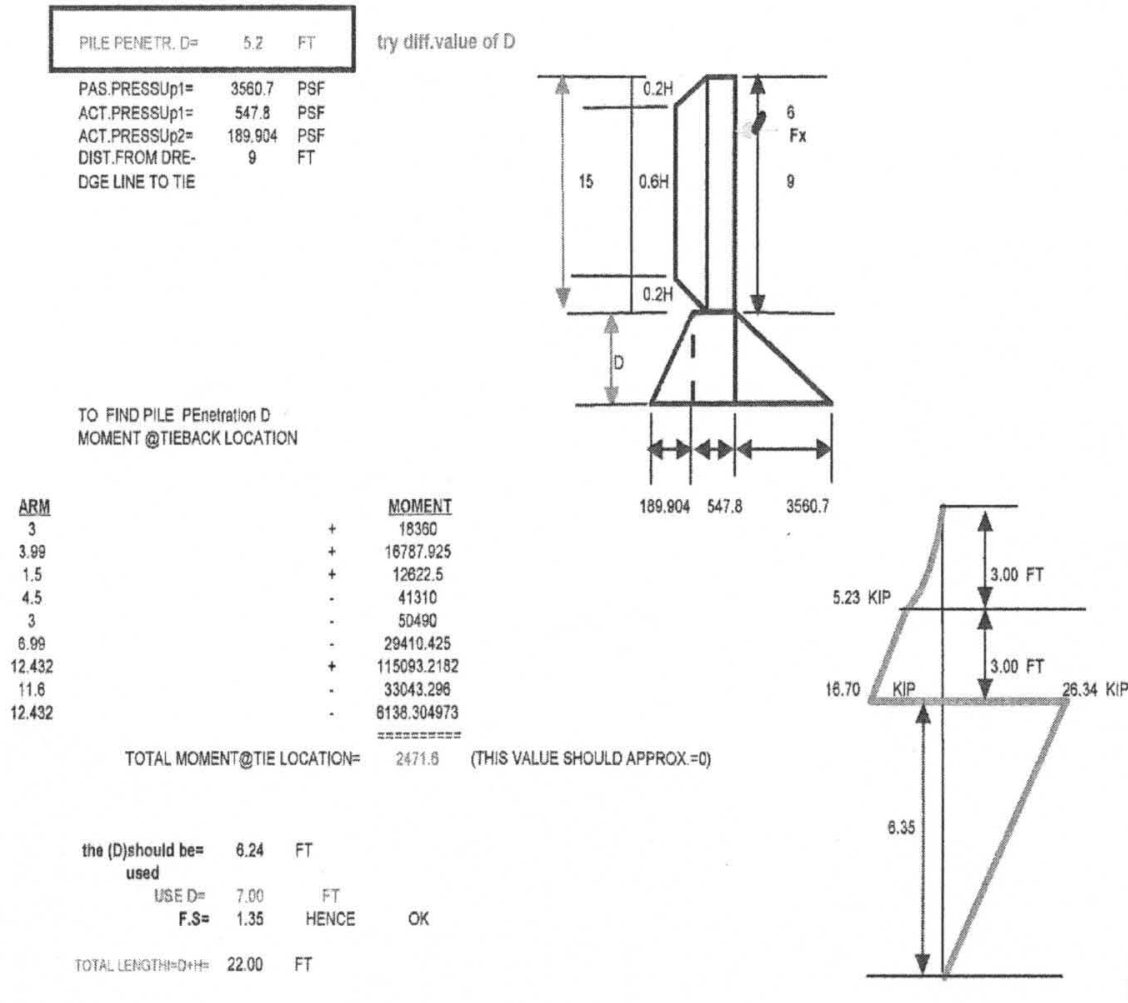

SHEAR DIAGRAM

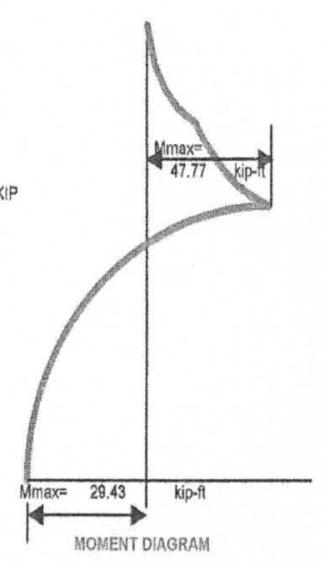




\section{CASE 7 PART A}

\begin{tabular}{|lcl|}
\multicolumn{3}{c}{ try diff.value of D } \\
\begin{tabular}{|lcl|}
\hline PILE PENETR. D $=$ & 5.2 & FT \\
\hline PAS.PRESSUP1 $=$ & 3560.7 & PSF \\
ACT.PRESSUp1 $=$ & 547.8 & PSF \\
ACT.PRESSUP2= & 189.904 & PSF \\
DIST.FROM DRE- & 9 & FT \\
DGE LINE TO TIE & & \\
\hline
\end{tabular}
\end{tabular}

TO FIND PILE PEnetration D

MOMENT @TIEBACK LOCATION

ARM
3
3.99
1.5
4.5
3
6.99
12.432
11.6
12.432

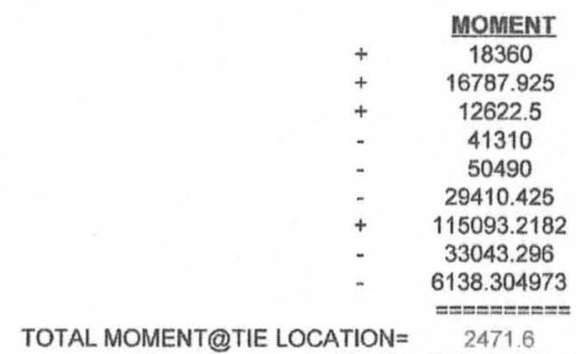

(THIS VALUE SHOULD APPROX. $=0$ ) used $\begin{aligned} \text { USE D } & =7.00 \quad \mathrm{FT} \\ \mathrm{F} . \mathrm{S} & =1.35 \quad \mathrm{HENCE}\end{aligned}$ ONCE

TOTAL LENGTHE $=0+H=22.00 \quad$ FT 


\begin{tabular}{|c|c|c|}
\hline & \multicolumn{2}{|c|}{$\begin{array}{l}\text { TO FIND TIEBACK FORCE } \\
\text { MAKE SUM. FOR F } \mathrm{F}=0\end{array}$} \\
\hline $\begin{array}{l}\mathrm{F}= \\
\mathrm{F} 2=\end{array}$ & $\begin{array}{l}15300 \\
8415\end{array}$ & $\stackrel{+}{+}$ \\
\hline $\begin{array}{l}\begin{array}{l}F= \\
F_{4}=\end{array}\end{array}$ & $\begin{array}{r}25245 \\
2848.56\end{array}$ & $t_{+}^{+} \quad r \quad l$ \\
\hline$F 5=$ & 9257.82 & \\
\hline & 493.7504 & \\
\hline $\begin{array}{l}\text { FXIONE BAY }= \\
\text { FXIONEFT }\end{array}$ & $\begin{array}{l}43.04 \\
5.06\end{array}$ & KIP \\
\hline 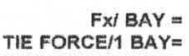 & $\begin{array}{l}43.04 \\
49.70\end{array}$ & $\begin{array}{l}\mathrm{K} \mid \mathrm{P} \\
\mathrm{K} \mid \mathrm{P}\end{array}$ \\
\hline ROOFTEST LOAD= & 59.64 & KIP \\
\hline $\begin{array}{l}\text { TIE FORCEI2 BAY= } \\
\text { ROOFTEST LOAD= }\end{array}$ & $\begin{array}{l}99.41 \\
119.29\end{array}$ & \\
\hline
\end{tabular}

FIND MAX. MOMENT

$1 @$ @IEBACK LOCATION = $\frac{\text { ARM }}{3}$

3.99
1.5

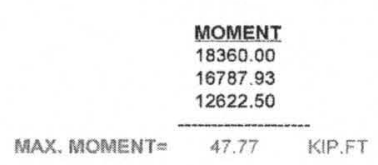

(ZERO SHEAR POINT

\section{ARM}

12600.53
43044.49

4207.50
6.1767308
6.3534615

10.343462
4.5767308

$29.43 \quad$ KIP.FT

47.77 KIP.FT
17.37 CUB. IN (Gr-50)

$\frac{\text { MOMENT }}{77830.09}$

273481.51

43520.11
122700.86

MAX. MOMENT $=$

USE MAX. MOMENT $=$ 


\section{CASE 7 PART A}

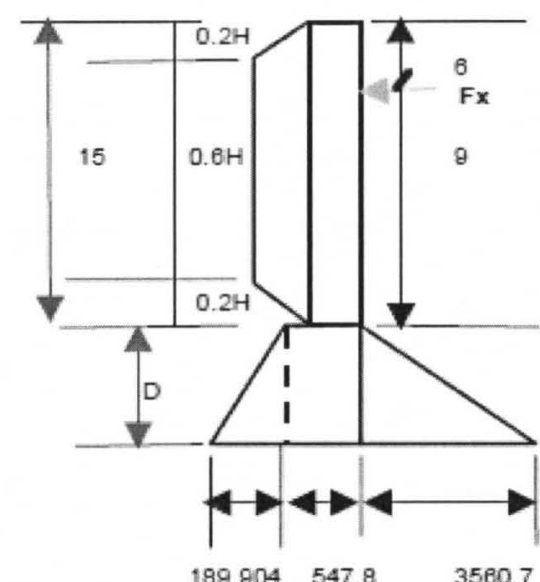

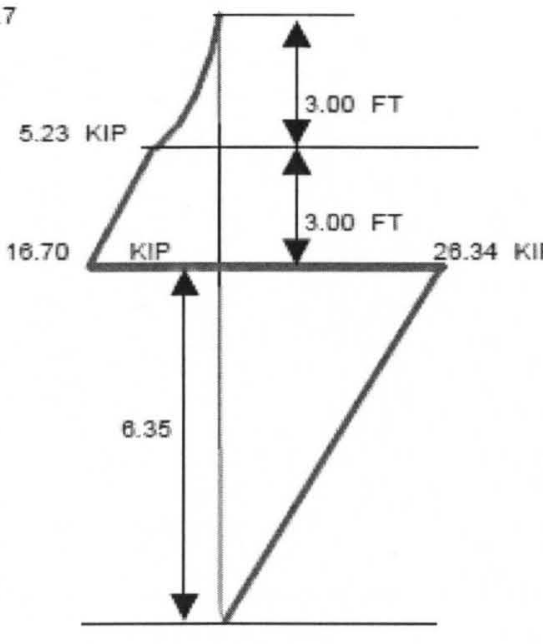

SHEAR DIAGRAM

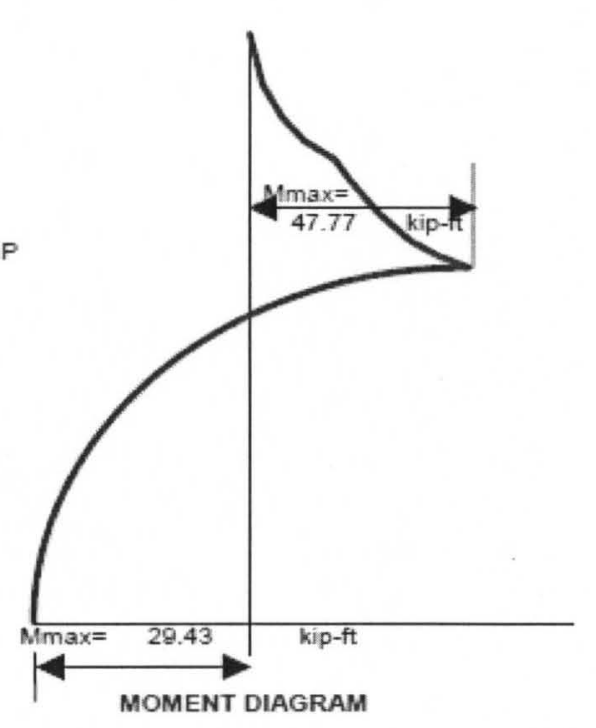



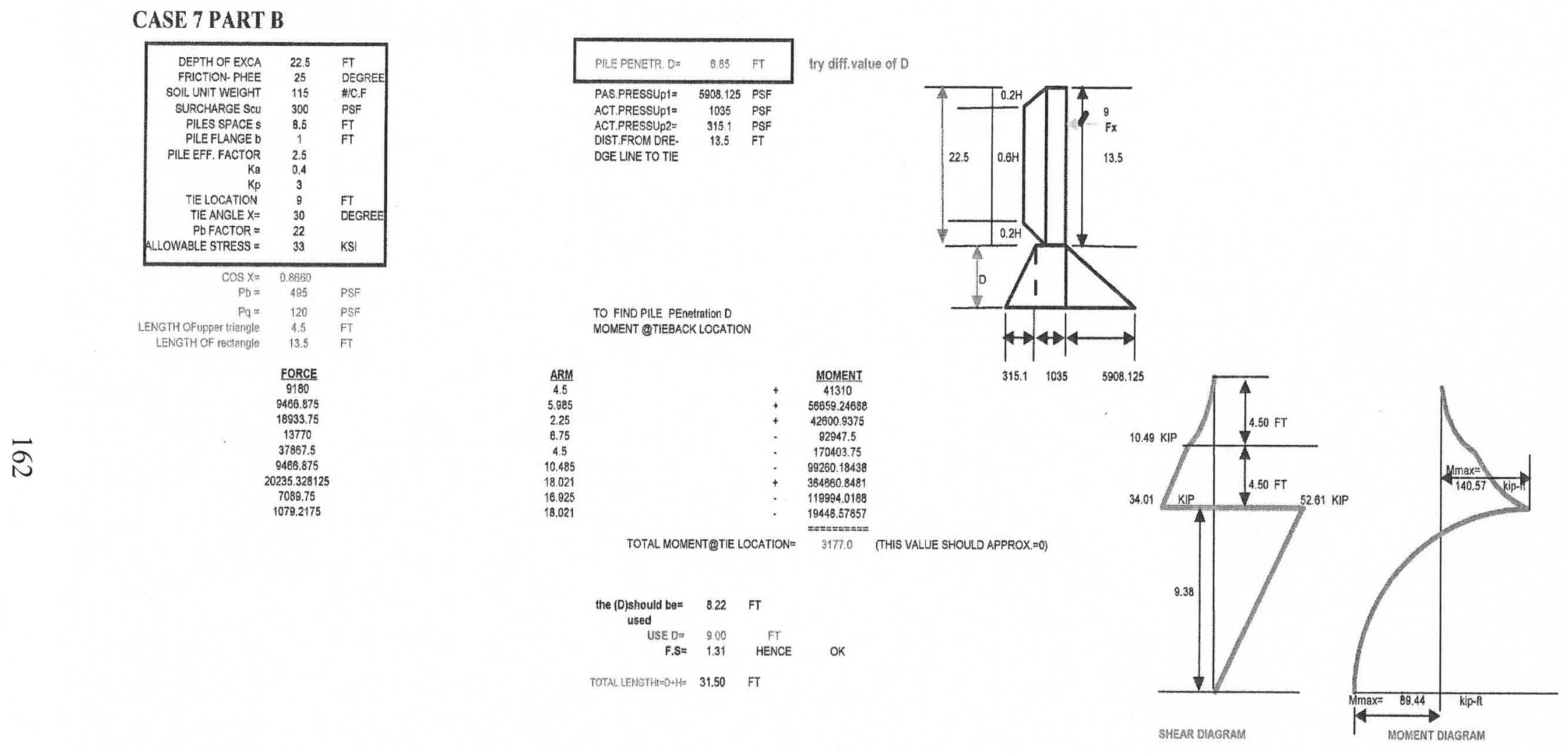


\section{CASE 7 PART B}

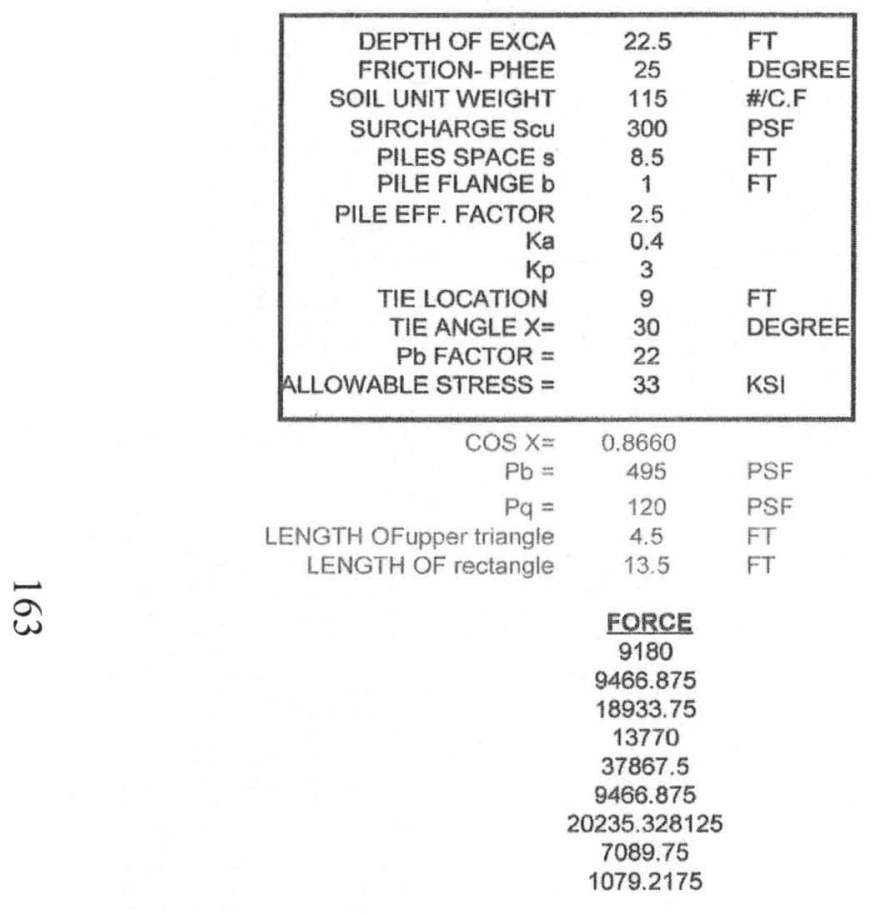

try diff.value of D

\begin{tabular}{|ccl|}
\hline PILE PENETR. D $=$ & 6.85 & FT \\
\hline PAS.PRESSUP1 $=$ & 5908.125 & PSF \\
ACT.PRESSUP1 $=$ & 1035 & PSF \\
ACT.PRESSUp2 $=$ & 315.1 & PSF \\
DIST.FROM DRE- & 13.5 & FT \\
DGE LINE TO TIE & & \\
\hline
\end{tabular}

TO FIND PILE PEnetration D

MOMENT @TIEBACK LOCATION

$\begin{array}{ccc}\text { ARM } & & \text { MOMENT } \\ 4.5 & + & 41310 \\ 5.985 & + & 56659.24688 \\ 2.25 & + & 42600.9375 \\ 6.75 & - & 92947.5 \\ 4.5 & - & 170403.75 \\ 10.485 & - & 99260.18438 \\ 18.021 & + & 364660.8481 \\ 16.925 & - & 119994.0188 \\ 18.021 & - & 19448.57857 \\ & & ===== \\ & \text { TOTAL MOMENT@TIE LOCATION }= & 3177.0\end{array}$

(THIS VALUE SHOULD APPROX. $=0$ )

\begin{tabular}{|c|c|c|}
\hline the $(D)$ should be= & 8.22 & FT \\
\hline USE $D=$ & 9.00 & FT \\
\hline$F \cdot S=$ & 1.31 & HENCE \\
\hline
\end{tabular}

12/05/201009:54:31 PM1case7 partB.123। 


\begin{tabular}{|c|c|c|}
\hline \multirow[b]{2}{*}{ Fl= } & \multicolumn{2}{|c|}{$\begin{array}{l}\text { TO FIND TIEBACK FORCE } \\
\text { MAKE SUM. FOR F } x=0\end{array}$} \\
\hline & & \\
\hline$F 2=$ & 18933.75 & \\
\hline$F 3=$ & 56801.25 & + \\
\hline $\mathrm{F} 4=$ & 7089.75 & + \\
\hline$F 5=$ & 20235.328125 & - \\
\hline$F G=$ & 1079.2175 & + \\
\hline FXIONE BAY $=$ & 86.62 & KIP \\
\hline $\mathrm{FX} / \mathrm{ONE} \mathrm{FT}=$ & 10.19 & KIP/FT \\
\hline & & KIP \\
\hline TIE FORCE $/ 1$ BAY & $\begin{array}{l}50.02 \\
100.02\end{array}$ & KIP \\
\hline PROOFTEST LOAD= & 120.02 & KIP \\
\hline
\end{tabular}

1 @TIEBACK LOCATION =

FT

$$
\begin{aligned}
& 9180 \\
& 9466.875 \\
& 18933.75
\end{aligned}
$$

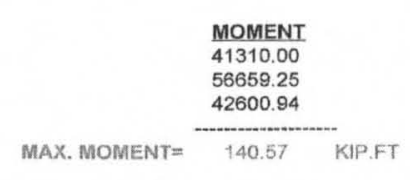

2 @ X-DISTANCE FROM
THE TOP OF THE PILE

FIND $X$ WHEN SUM. OF $F X=0$

$X=18.380777 \mathrm{FT}$

$$
\begin{gathered}
\text { FORCE } \\
\hline 18748.39 \\
86618.64 \\
9466.88 \\
58403.37
\end{gathered}
$$

9.1903887

9.1903887
9.3807775

15.365777

89.44 KIP.FT

MAX. MOMENT $=$

USE MAX. MOMENT=
MOD. SECTION =

140.57 KIP.FT
$\mathbf{5 1 . 1 2}$ CUB. IN (Gr-50) 


\section{CASE 7 PART B}

à

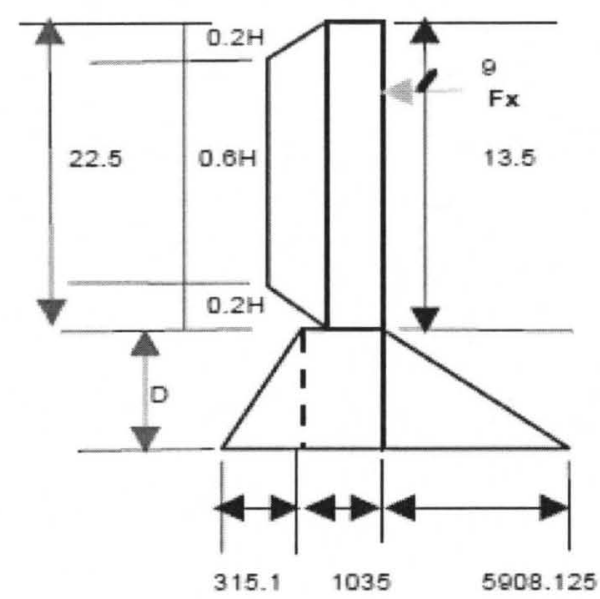

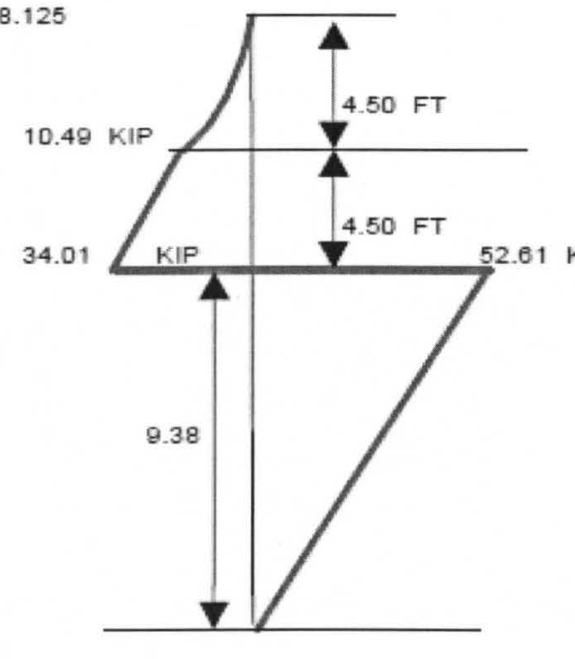

SHEAR DIAGRAM

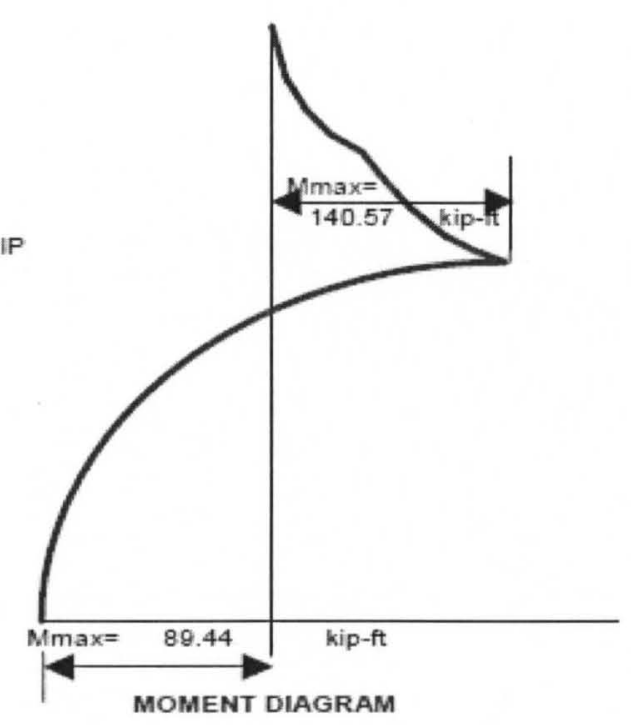



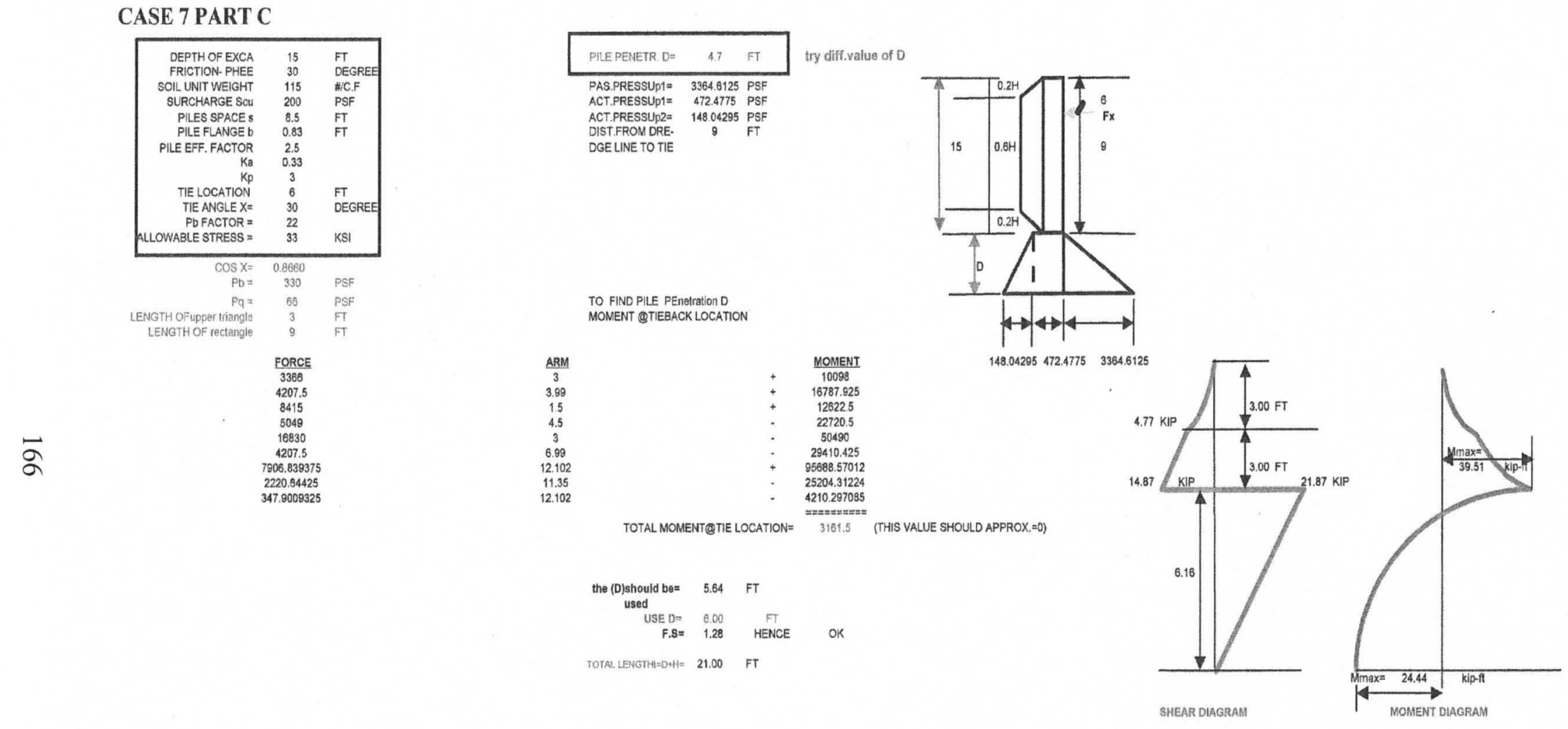


\section{CASE 7 PART C}

\begin{tabular}{|c|c|c|}
\hline DEPTH OF EXCA & 15 & FT \\
\hline FRICTION- PHEE & 30 & DEGREE \\
\hline SOIL UNIT WEIGHT & 115 & \#/C.F \\
\hline SURCHARGE SCL & 200 & PSF \\
\hline PILES SPACE $S$ & 8.5 & FT \\
\hline PILE FLANGE $\mathrm{b}$ & 0.83 & FT \\
\hline PILE EFF. FACTOR & 2.5 & \\
\hline & 0.33 & \\
\hline & 3 & \\
\hline TIE LOCATION & 6 & FT \\
\hline TIE ANGLE $X=$ & 30 & DEGREE \\
\hline $\mathrm{Pb} F A C T O R=$ & 22 & \\
\hline ALLOWABLE STRESS $=$ & 33 & KSI \\
\hline $\cos x=$ & 0.8660 & \\
\hline $\mathrm{Pb}=$ & 330 & PSF \\
\hline$P q=$ & 66 & PSF \\
\hline ENGTH OFupper triangle & 3 & FT \\
\hline LENGTH OF rectangle & 9 & FT \\
\hline & FORCE & \\
\hline & 3366 & \\
\hline & 4207.5 & \\
\hline & 8415 & \\
\hline & 5049 & \\
\hline & 16830 & \\
\hline & 4207.5 & \\
\hline & 7906.839375 & \\
\hline & 2220.64425 & \\
\hline & 347.9009325 & \\
\hline
\end{tabular}

try diff.value of D

\begin{tabular}{|lcl|}
\multicolumn{3}{c}{ try diff.value of D } \\
\hline PILE PENETR. D $=$ & 4.7 & FT \\
\hline PAS.PRESSUP1 $=$ & 3364.6125 & PSF \\
ACT.PRESSUP1 $=$ & 472.4775 & PSF \\
ACT.PRESSUP2 $=$ & 148.04295 & PSF \\
DIST.FROM DRE- & 9 & FT \\
DGE LINE TO TIE & & \\
\hline
\end{tabular}

TO FIND PILE PEnetration D

MOMENT @TIEBACK LOCATION

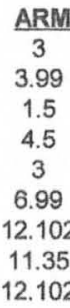

ARM

TOTALMOMENT@TIE LOCATION=

(THIS VALUE SHOULD APPROX. $=0$ )

\begin{tabular}{|c|c|c|}
\hline the (D)should be= & 5.64 & FT \\
\hline USE D= & 6.00 & FT \\
\hline$F . S=$ & 1.28 & HENCE \\
\hline rOTAL LENGTHt=D+H= & 21.00 & FT \\
\hline
\end{tabular}

12/05/201009:55:41 PM1case7 partC.123। 


\begin{tabular}{|c|c|c|}
\hline & $\begin{array}{l}\text { TO FIND TIEB } \\
\text { MAKE SUM. F }\end{array}$ & $\begin{array}{l}\text { ACK FORCE } \\
\text { OR FX }=0\end{array}$ \\
\hline $\mathrm{Fl}=$ & 8415 & + \\
\hline$F 2=$ & 8415 & + \\
\hline $\mathrm{F} 3=$ & 25245 & + \\
\hline$F_{4}=$ & 2220.64425 & + \\
\hline $\mathrm{F} 5=$ & 7906.839375 & - \\
\hline$F 6=$ & 347.9009325 & + \\
\hline$F X / O N E B A Y=$ & 36.74 & KIP \\
\hline FX/ONE FT= & 4.32 & KIPIFT \\
\hline$F x / B A Y=$ & 36.74 & KIP \\
\hline TIE FORCE/1 BAY= & 42.42 & KIP \\
\hline PROOFTEST LOAD= & 50.90 & KIP \\
\hline
\end{tabular}

1 @TIEBACK LOCATION =
ARM

3.99

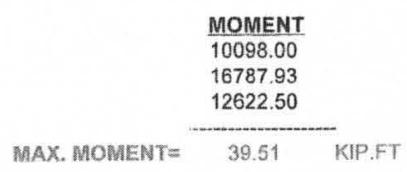

MAX. MOMENT $=$

2 @ X-DISTANCE FROM THE TOP OF THE PILE FIND $X$ WHEN SUM.OF $F \mathrm{X}=0$ $\mathrm{X}=12.164054 \mathrm{FT}$

\section{FORCE}

6824.03

36736.71

4207.50

$\begin{array}{ccl} & \text { ARM } & \\ & 6.082027 & \\ 6.164054 & \\ 10.154054 & \\ & 4.582027 & \\ & & \\ \text { MAX. MOMENT }= & 24.44 & \text { KIP.FT } \\ \text { USE MAX. MOMENT }= & 39.51 & \text { KIP.FT } \\ \text { MOD. SECTION }= & 14.37 & \text { CUB. IN (Gr-50) }\end{array}$

MOMENT

41503.96

42723.18

42723.18
117781.79 
CASE 7 PART C

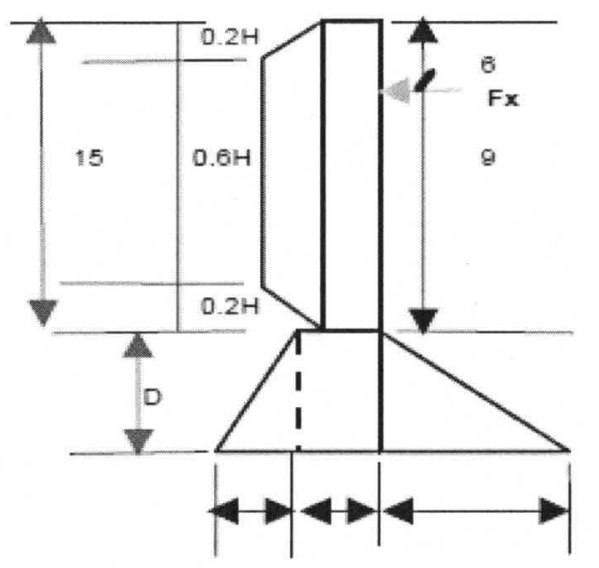

a

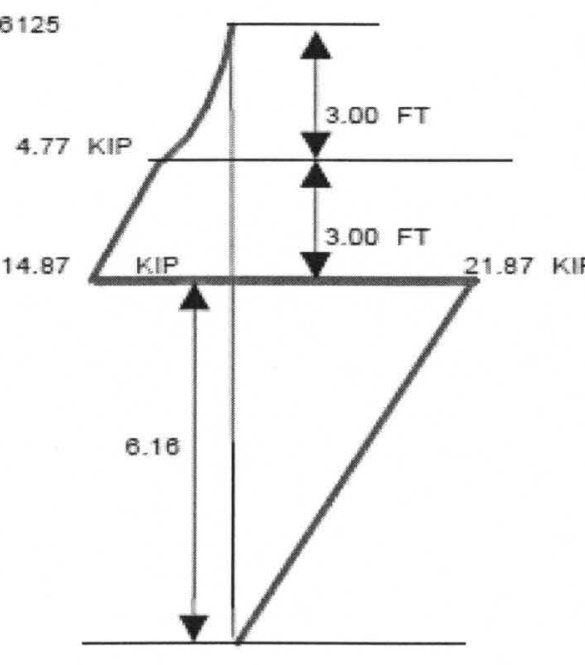

SHEAR DIAGRAM

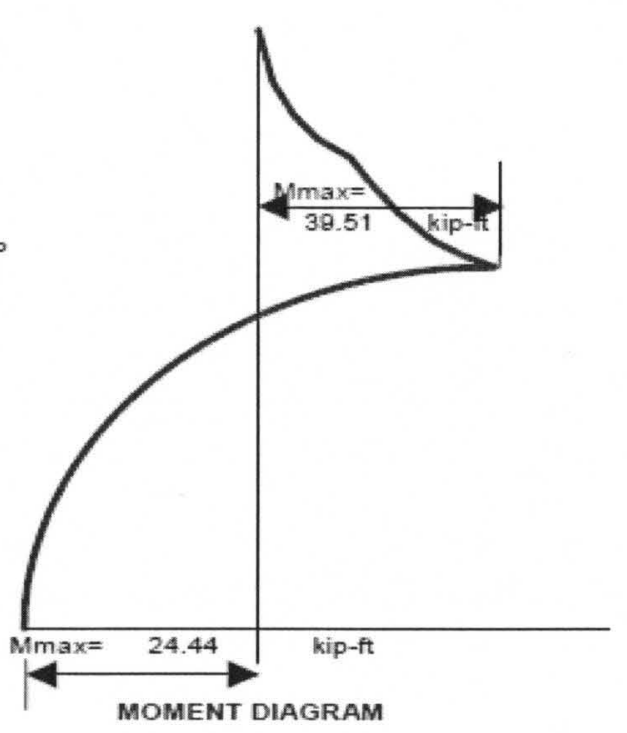


CASE 8 PART A

\begin{tabular}{|c|c|c|}
\hline DEPTH OF CUT $H$ & 28 & FT \\
\hline SOIL UNIT WEIGHT & 115 & $\# / \mathrm{C}$ \\
\hline SOLD. PILE SPACE $S$ & 8.5 & FT \\
\hline SURCHARGE LOAD & 200 & \#S \\
\hline $\mathrm{Ka}$ & 0.33 & \\
\hline$K_{p}$ & 3 & \\
\hline LOCATION OF IST TIE & 7 & FT \\
\hline LOCATION OF 2ND TIE & 21 & FT \\
\hline TIE ANGLE UPPER $=$ & 30 & DEC \\
\hline TIE ANGLE LOWER= & 30 & \\
\hline PbFACTOR & 22 & \\
\hline $\cos \times 1=$ & 0.8660 & \\
\hline $\cos \times 2=$ & 0.8660 & \\
\hline $\mathrm{Pb}$ & 616 & PS \\
\hline$P q$ & 56 & PSF \\
\hline LENGTH OF UPP TRIA. & 5.6 & FT \\
\hline LENGTH OF RECTANG & 16.8 & FT \\
\hline & & \\
\hline & FOFCE & \\
\hline & 11781.00 & \\
\hline & 14660.80 & \\
\hline & 80634.40 & \\
\hline$F \times 1=$ & 66497.20 & \\
\hline & 3927.00 & \\
\hline & 14660.80 & \\
\hline & 7330.40 & \\
\hline $\mathrm{F} \times 1 / \mathrm{ONE} \mathrm{BAY}=$ & 66.4972 & \\
\hline $\mathrm{F} \times 1 / \mathrm{BAY}=$ & 66.4972 & KIP \\
\hline 1stTIE FORCE BAY = & 76.78 & KIP \\
\hline PROOF TEST LOAD= & 92.14 & KIP \\
\hline
\end{tabular}

TO FIND THE VALUE OF FX2 MAKE SUM. OF FX $=0$

Ex2= 66497.2

FX2JONE BAY $=66.4972 \quad \mathrm{KIP}$ FX2l BAY $=66.4972 \quad \mathrm{KIP}$ $\begin{array}{rll}\text { TIE FORCE } / B A Y= & 76.78 & \mathrm{KIP} \\ \text { PROOF TSEST LOAD } & 92.14 & \mathrm{~K} ! \mathrm{P}\end{array}$
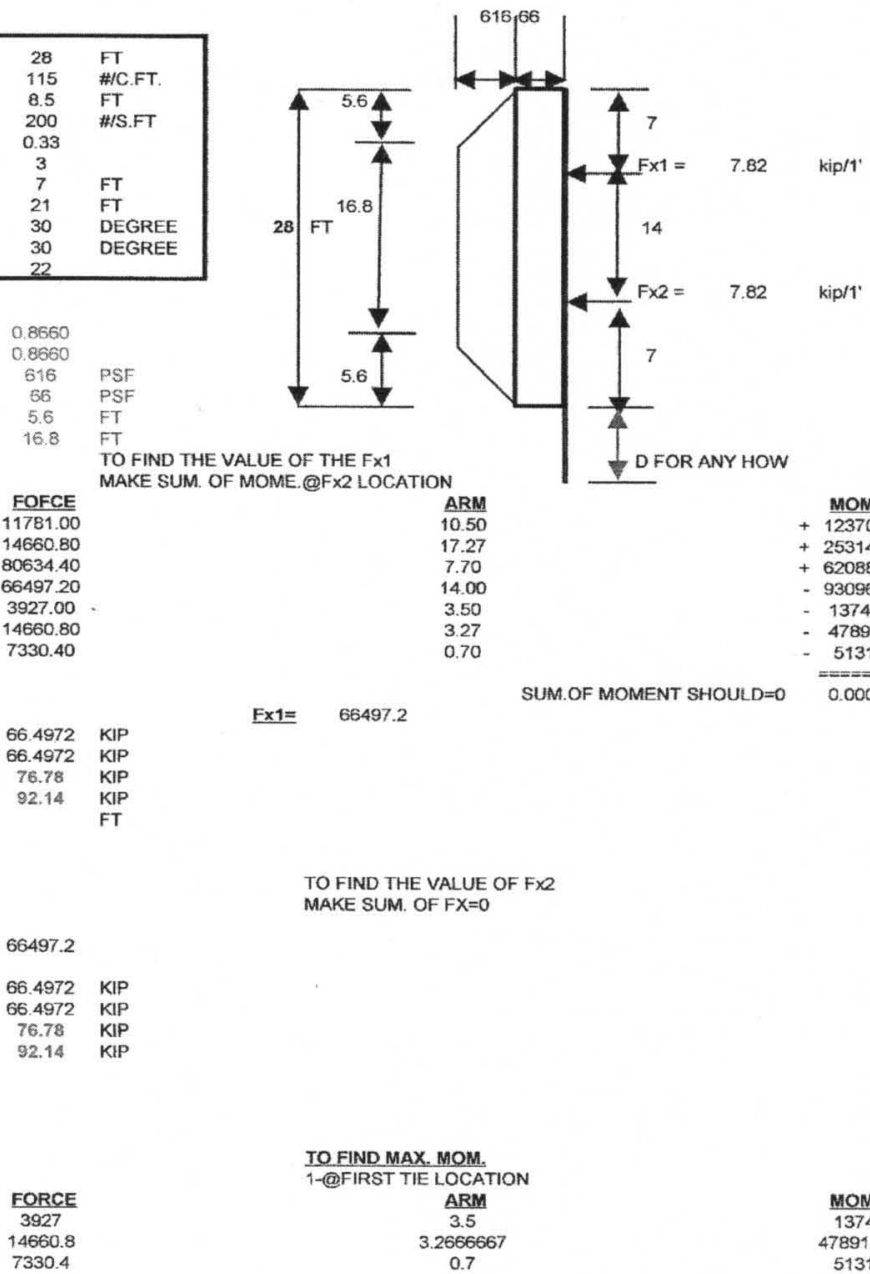

kip/1 EGREE FIND THE VALUE OF THE FX MKE SUM. OF MOME.@FX2 LOCATION

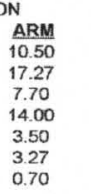

MOMENT

$+123700.50$

$+253143.15$

620884.88

930960.80

13744.50

47891.95

5131.28

SUM.OF MOMENT SHOULD $=0 \quad 0.000000$

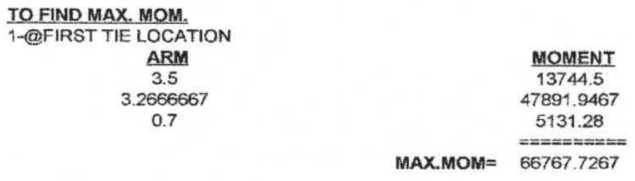

1-MXMOM.@1st tie= 66.77 KIP.FT

2-@ X-DISTANCE FROM THE TOP OF THE PILE FIND X-DISTANGE

$X=14 \quad F T$

MAX.MOMENT @ X-DISTANCE

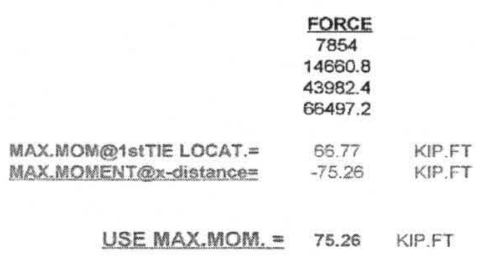

$\frac{\text { ARM }}{7}$
10.266667
4.2
7

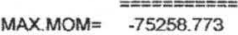

USE MAX.MOM. $\equiv 75.26 \quad$ KIP.FT

DESIGN SOLD. PILE

MOD.SEC. FOR THE PILE $=27.37 \quad$ CU.IN $\quad$ Gr 50 


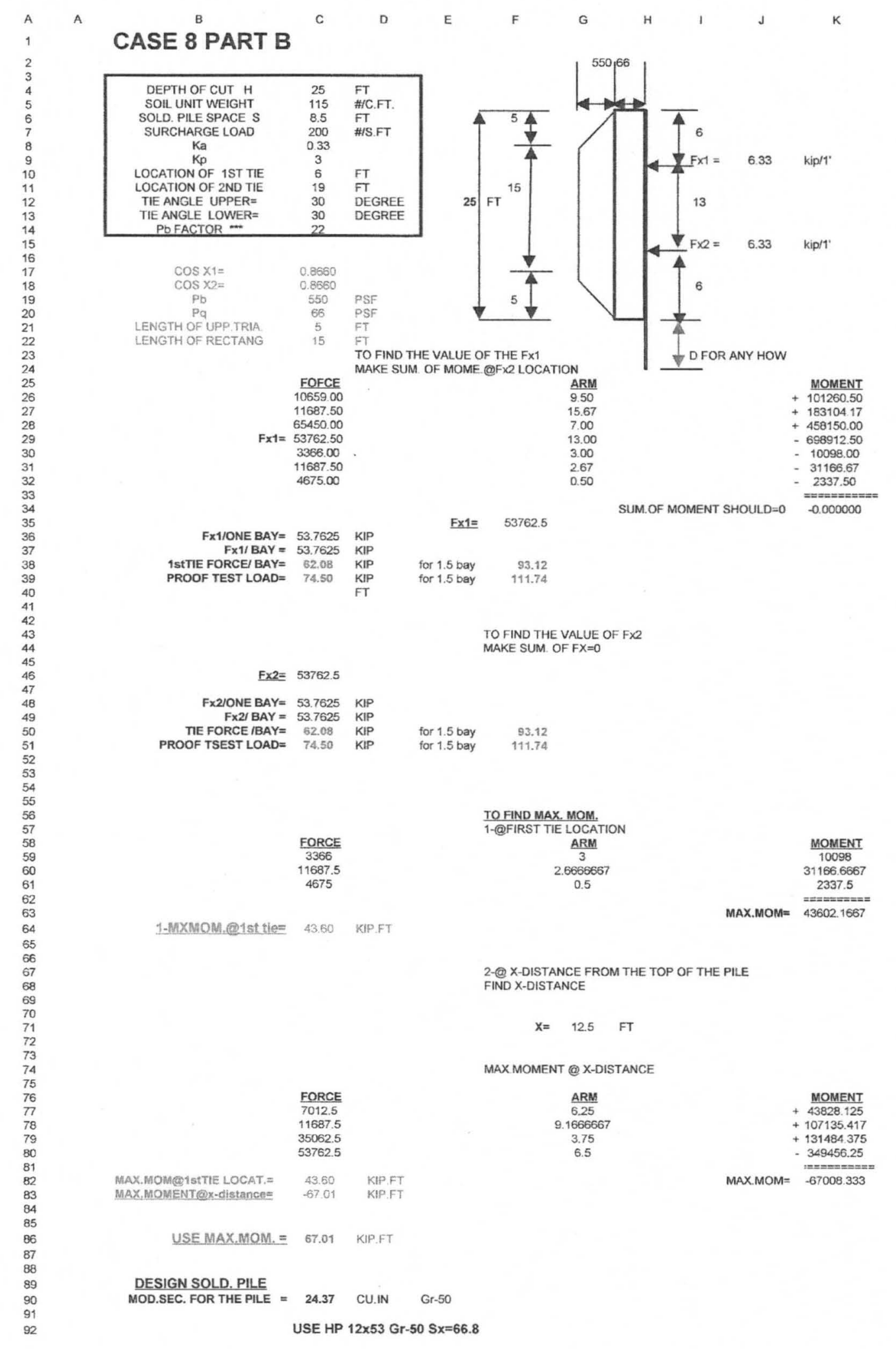



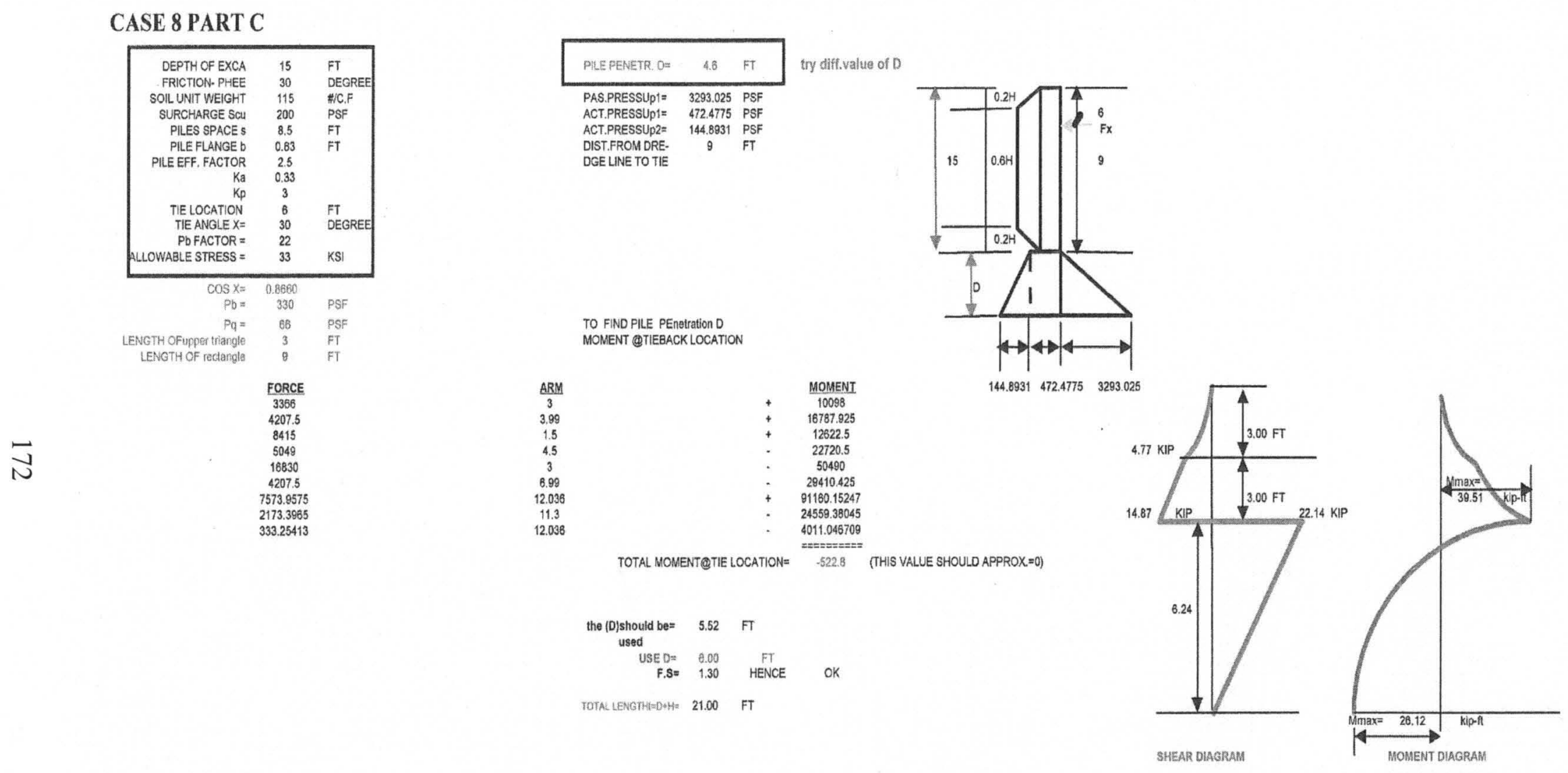


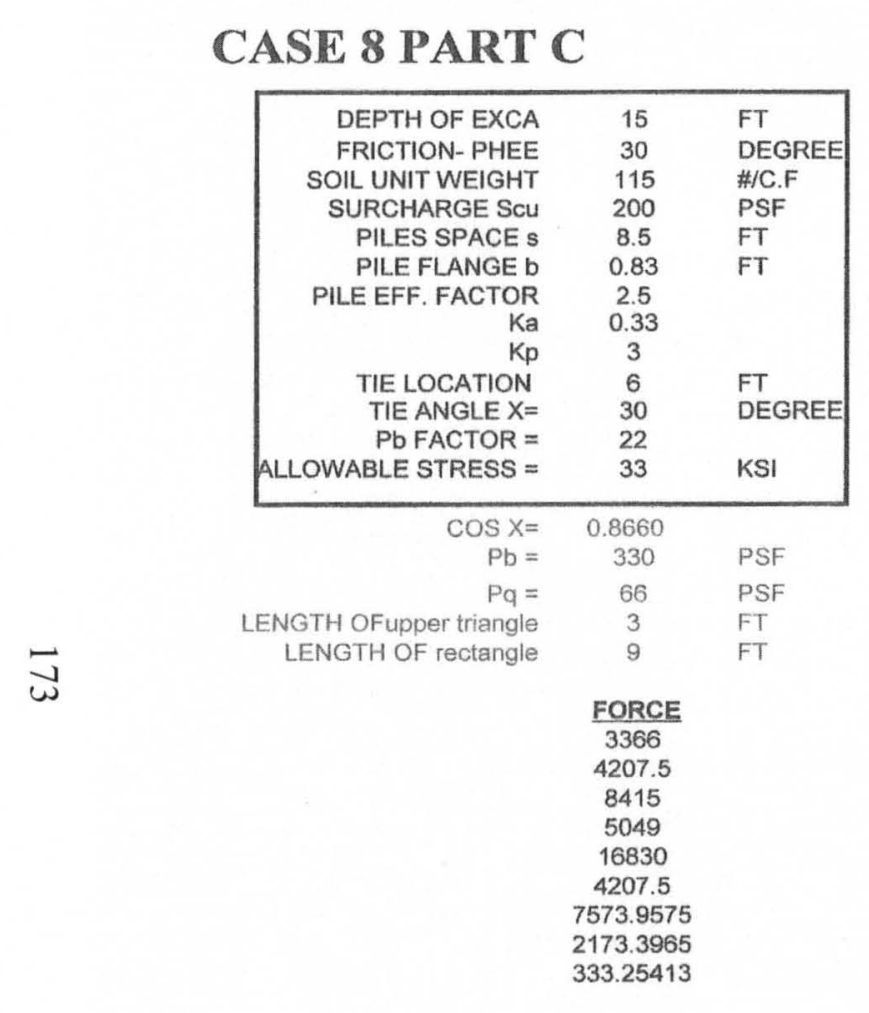

\section{CASE 8 PART C}

WEIGH STH OFupper triang

$$
8415
$$

EREE SF

DEGREE

C.F

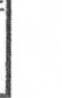

\begin{tabular}{|ccc|}
\multicolumn{4}{c}{ try diff.value of D } \\
\hline PILE PENETR. D $=$ & 4.6 & FT \\
\hline PAS.PRESSUp1 $=$ & 3293.025 & PSF \\
ACT.PRESSUP1= & 472.4775 & PSF \\
ACT.PRESSUp2= & 144.8931 & PSF \\
DIST.FROM DRE- & 9 & FT \\
DGE LINE TO TIE & & \\
\hline
\end{tabular}

INE TO TIE

-

\begin{abstract}
TO FIND PILE PEnetration D
\end{abstract}
MOMENT @TIEBACK LOCATION

$\begin{array}{ccc}\text { ARM } & & \text { MOMENT } \\ 3 & + & 10098 \\ 3.99 & + & 16787.925 \\ 1.5 & + & 12622.5 \\ 4.5 & - & 22720.5 \\ 3 & - & 50490 \\ 6.99 & - & 29410.425 \\ 12.036 & + & 91160.15247 \\ 11.3 & - & 24559.38045 \\ 12.036 & - & 4011.046709 \\ & & ==11=\pi=== \\ & \text { TOTAL MOMENT@TIE LOCATION }= & -522.8\end{array}$

(THIS VALUE SHOULD APPROX $=0$ )

\begin{tabular}{|c|c|c|}
\hline $\begin{array}{c}\text { the (D)should be= } \\
\text { used }\end{array}$ & 5.52 & FT \\
\hline $\begin{array}{r}\text { USE D }= \\
F . S=\end{array}$ & $\begin{array}{l}6.00 \\
1.30\end{array}$ & $\begin{array}{c}\text { FT } \\
\text { HENCE }\end{array}$ \\
\hline TOTAL LENGTHt $=\mathrm{D}+\mathrm{H}=$ & 21.00 & FT \\
\hline
\end{tabular}

12/05/201009:57:43 PM1case8 part c. 1231 


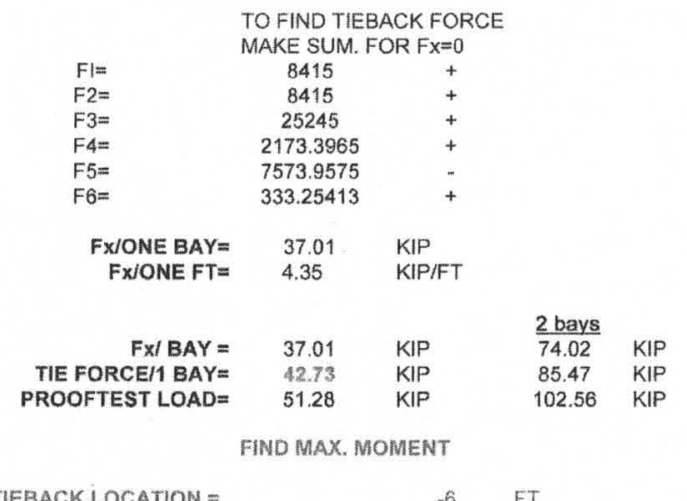

1 (PTIEBACK LOCATION =

$$
\begin{gathered}
\text { FORCE } \\
\hline 3366 \\
4207.5 \\
8415
\end{gathered}
$$

\section{ARM \\ 3.99 \\ 1.5}

(ZERO SHEAR POINT)
2 (@) X-DISTANCE FROM

THE TOP OF THE PILE

FIND $X$ WHEN SUM. OF F $\mathrm{X}=0$

$X=12.244561 \mathrm{FT}$

$$
\begin{gathered}
\text { FORCE } \\
\hline 6869.20 \\
37007.69 \\
4207.50 \\
25930.99
\end{gathered}
$$

ARM
$\begin{aligned} & \text { ARM } \\ & 6.2445612 \\ & 10.234561\end{aligned}$
4.6222806

4.6222806

MAX, MOMENT =

26.12 KIP.FT

USE MAX, MOMENT

MOD. SECTION =
39.51 KIP.FT

CUB.IN $(\mathrm{Gr}-50)$

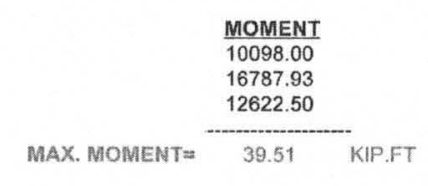

MOMENT

42105.16

231096.81
43061.92

119860.33

09/22/201012:09:16 AM1case8 part c.123 
CASE 8 PART C

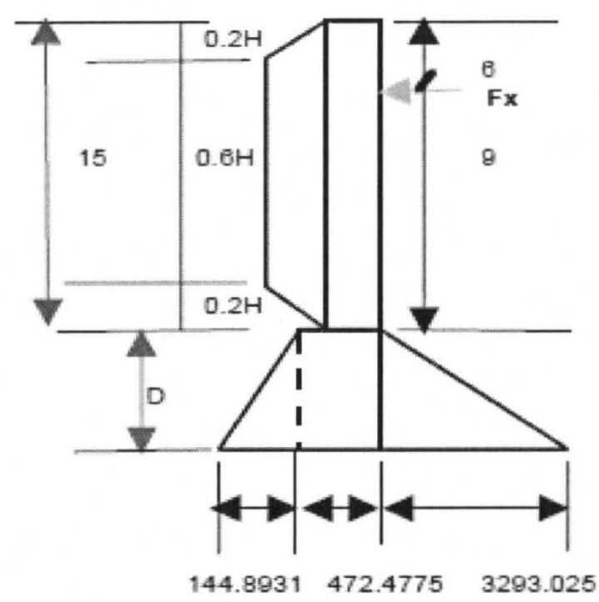

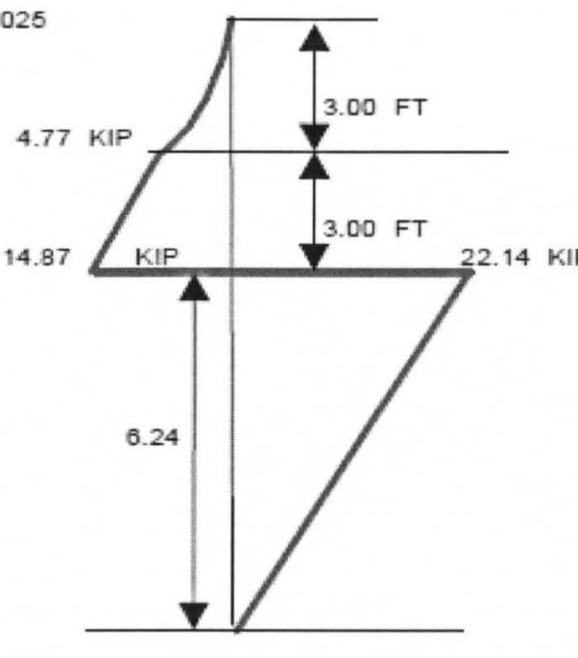

SHEAR DIAGRAM

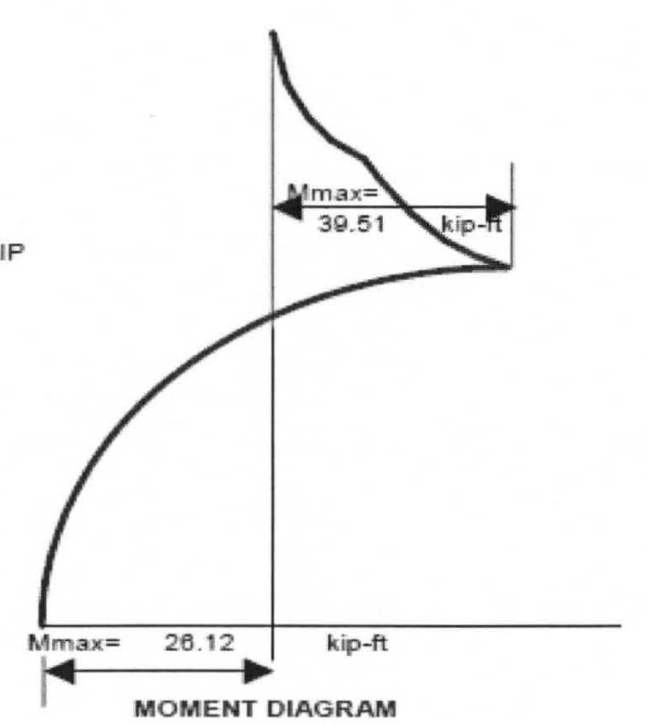




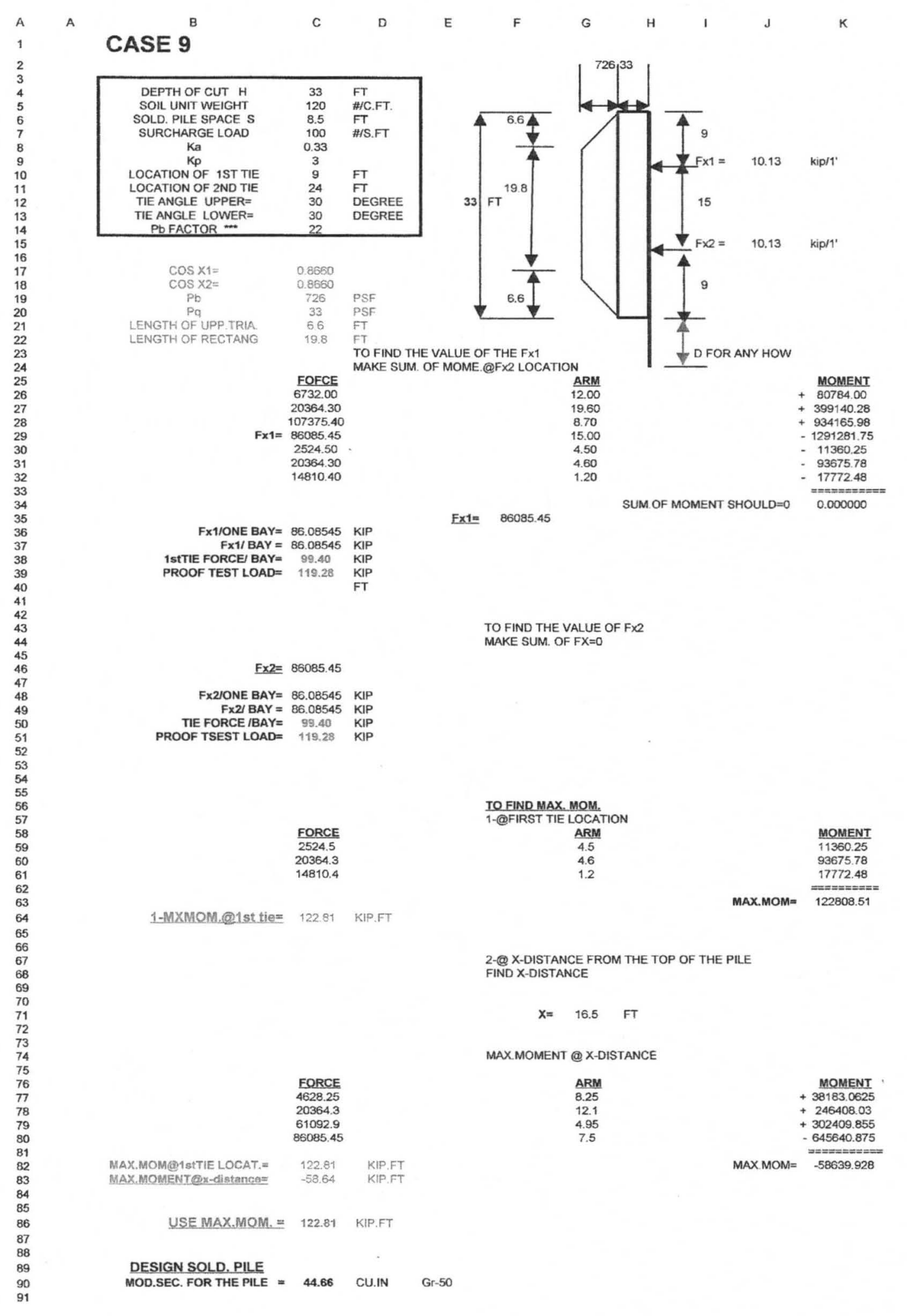



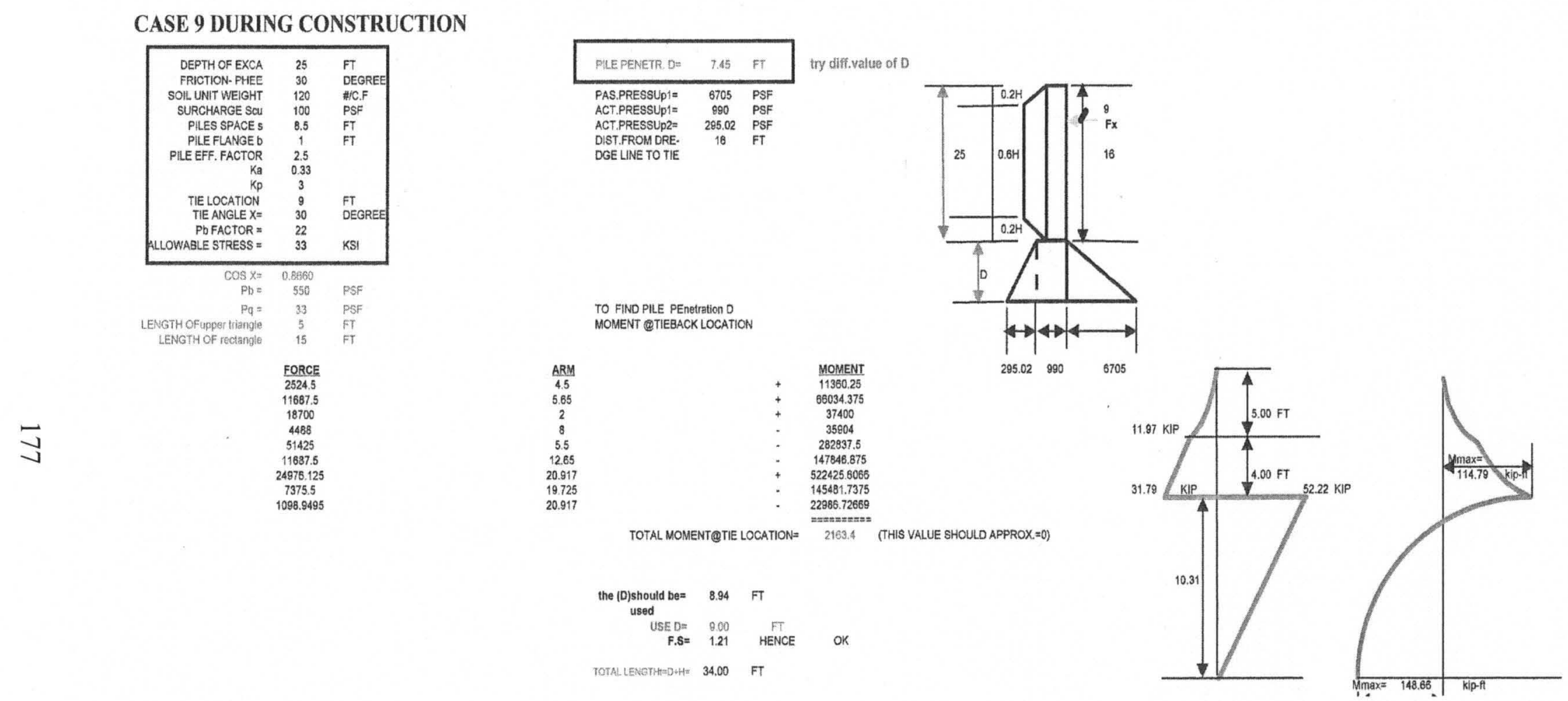


\section{CASE 9 DURING CONSTRUCTION}

\begin{tabular}{|c|c|c|}
\hline DEPTH OF EXCA & 25 & FT \\
\hline FRICTION-PHEE & 30 & DEGREE \\
\hline SOIL UNIT WEIGHT & 120 & \#/C.F \\
\hline SURCHARGE SCU & 100 & PSF \\
\hline PILES SPACE $\mathrm{S}$ & 8.5 & FT \\
\hline PILE FLANGE $b$ & 1 & FT \\
\hline PILE EFF. FACTOR & 2.5 & \\
\hline & 0.33 & \\
\hline $\mathrm{Kp}$ & 3 & \\
\hline TIE LOCATION & 9 & \\
\hline TIE ANGLE $X=$ & 30 & DEGREE \\
\hline $\mathrm{Pb} F A C T O R=$ & 22 & \\
\hline ALLOWABLE STRESS $=$ & 33 & KSI \\
\hline $\cos x=$ & 0.8660 & \\
\hline $\begin{array}{l}\mathrm{Pb}= \\
\mathrm{Pa}=\end{array}$ & 550 & PSF \\
\hline $\begin{aligned} & p q= \\
& \text { LENGTH OFupper triangle }\end{aligned}$ & $\begin{array}{c}33 \\
5\end{array}$ & $\begin{array}{l}\text { PSF } \\
\text { FT }\end{array}$ \\
\hline LENGTH OF rectangle & 15 & FT \\
\hline & FORCE & \\
\hline & 2524.5 & \\
\hline & 11687.5 & \\
\hline & 18700 & \\
\hline & 4488 & \\
\hline & 51425 & \\
\hline & 11687.5 & \\
\hline & 24976.125 & \\
\hline & 7375.5 & \\
\hline & 1098.9495 & \\
\hline
\end{tabular}

try diff.value of $D$

\begin{tabular}{|ccl|}
\hline PILE PENETR. D $=$ & 7.45 & FT \\
\hline PAS.PRESSUP1 $=$ & 6705 & PSF \\
ACT.PRESSUP1 $=$ & 990 & PSF \\
ACT.PRESSUp2 $=$ & 295.02 & PSF \\
DIST.FROM DRE- & 16 & FT \\
DGE LINE TO TIE & & \\
\hline
\end{tabular}

TO FIND PILE PEnetration D

MOMENT @TIEBACK LOCATION

$\begin{array}{ccc}\text { ARM } & & \text { MOMENT } \\ 4.5 & + & 11360.25 \\ 5.65 & + & 66034.375 \\ 2 & + & 37400 \\ 8 & - & 35904 \\ 5.5 & - & 282837.5 \\ 12.65 & - & 147846.875 \\ 20.917 & + & 522425.6066 \\ 19.725 & - & 145481.7375 \\ 20.917 & - & 22986.72669 \\ & & ===== \\ & \text { TOTAL MOMENT@TIE LOCATION }= & 2163.4\end{array}$

(THIS VALUE SHOULD APPROX. $=0$ )

\begin{tabular}{|c|c|c|c|}
\hline $\begin{array}{l}\text { the (D)shouid be= } \\
\text { used }\end{array}$ & 8.94 & $\mathrm{FT}$ & \\
\hline USE $D=$ & 9.00 & FT & \\
\hline F.S $=$ & 1.21 & HENCE & Or \\
\hline
\end{tabular}

12/05/201009:59:35 PM1case9 during construction. 123 


\begin{tabular}{|c|c|c|}
\hline & $\begin{array}{l}\text { TO FIND TIEE } \\
\text { MAKE SUM. }\end{array}$ & $\begin{array}{l}\text { ICK FORCE } \\
R \text { F } F=0\end{array}$ \\
\hline$F \mid=$ & 7012.5 & + \\
\hline $\mathrm{F} 2=$ & 23375 & + \\
\hline$F 3=$ & 70125 & + \\
\hline $\mathrm{F} 4=$ & 7375.5 & + \\
\hline$F 5=$ & 24976.125 & - \\
\hline$F 6=$ & 1098.9495 & + \\
\hline $\begin{array}{r}\mathrm{F} / \mathrm{ONE} \text { BAY }= \\
\mathrm{F} / \mathrm{ONE} \mathrm{FT}=\end{array}$ & $\begin{array}{l}84.01 \\
9.88\end{array}$ & $\begin{array}{l}\text { KIP } \\
\text { KIP/FT }\end{array}$ \\
\hline$F \times / B A Y=$ & 84.01 & KIP \\
\hline TIE FORCE/1 BAY= & 97.01 & KIP \\
\hline PROOFTEST LOAD $=$ & 116.41 & KIP \\
\hline
\end{tabular}

1 @TIEBACK LOCATION =

\begin{tabular}{c} 
FORCE \\
\hline 2524.5 \\
11687.5 \\
18700
\end{tabular}

2 @-DISTANCE FROM THE TOP OF THE PILE

FIND $X$ WHEN SUM. OF FX $=0$

$X=19.311538 \mathrm{FT}$

FORCE

84010.82

11687.50

MAX. MOMENT=
USE MAX. MOMENT=
MOD. SECTION =

ARM

9.6557688

10.311538
15.961538

7.1557688

$148.66 \quad$ KIP.FT

$148.66 \quad$ KIP.FT

54.06 CUB. IN (Gr-60)

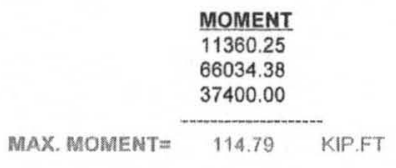

MOMENT

52304.20

186550.47

478767.00 


\section{CASE 9 DURING CONSTRUCTION}

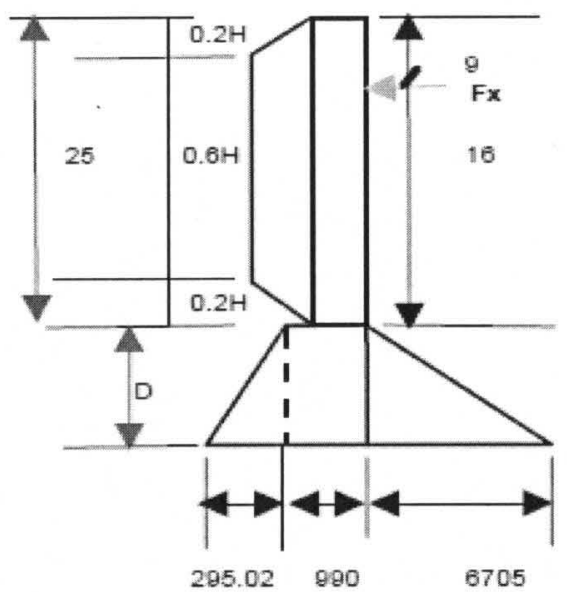

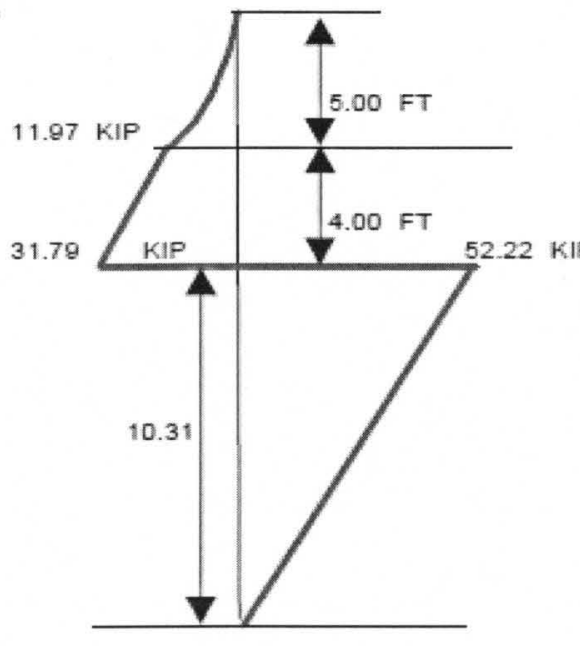

SHEAR DIAGRAM

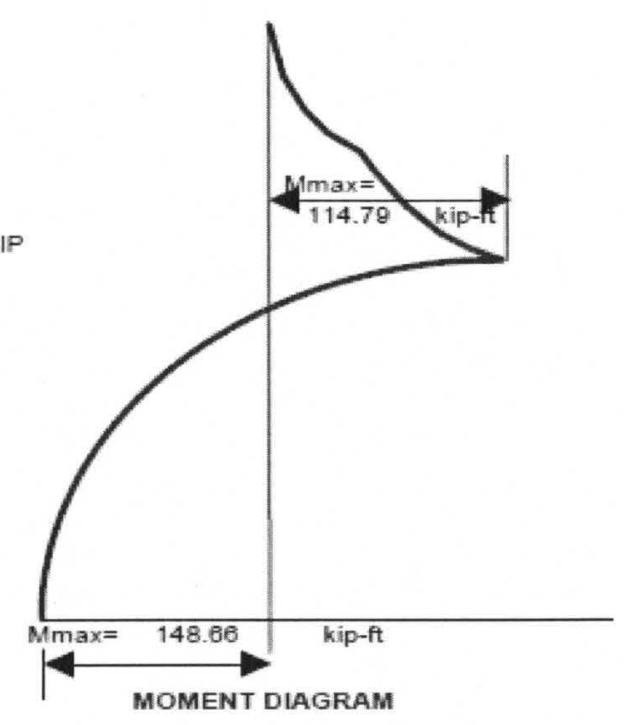




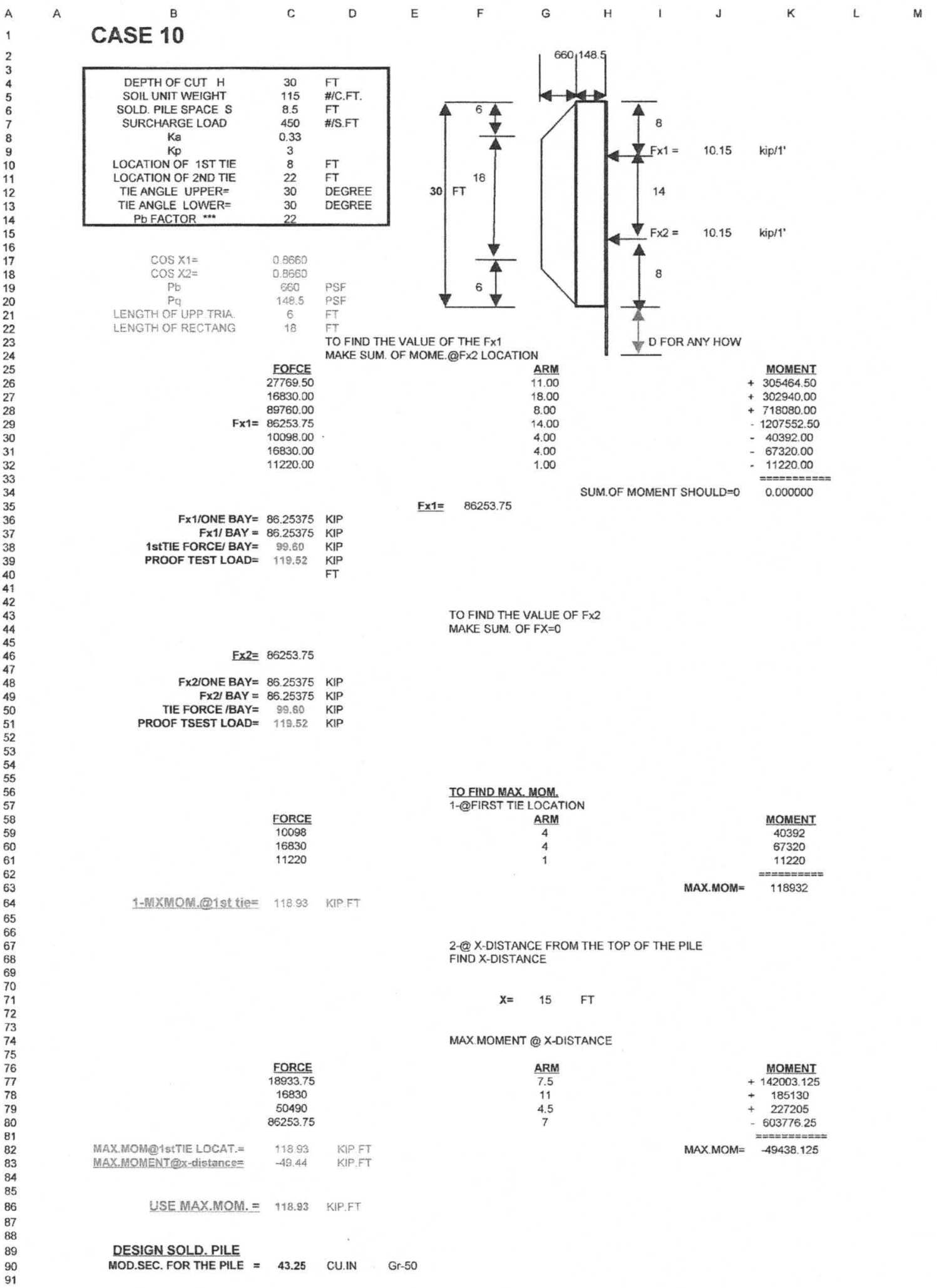




\section{CASE 10 DURING CONSTRUCTION}

\begin{tabular}{|rcl|}
\hline DEPTH OF EXCA & 23.5 & FT \\
FRICTION- PHEE & 30 & DEGREE \\
SOIL UNIT WEIGHT & 120 & H/C.F \\
SURCHARGE Scu & 450 & PSF \\
PILES SPACE S & 8.5 & FT \\
PILE FLANGE b & 1 & FT \\
PILE EFF. FACTOR & 2.5 & \\
Ka & 0.33 & \\
Kp & 3 & \\
TIE LOCATION & 8 & FT \\
TIE ANGLE X & 30 & DEGREE \\
Pb FACTOR $=$ & 22 & \\
ALLOWABLE STRESS $=$ & 33 & KSI \\
COS X $=$ & 0.8660 & \\
Pb $=$ & 517 & PSF \\
Pq $=$ & 148.5 & PSF \\
LENGTH OFupper triangle & 4.7 & FT \\
LENGTH OF rectangle & 14.1 & FT
\end{tabular}

\section{FORCE}

10098

10327.075

14501.85

19564.875

47460.6

10327.075

28084.5

7351.74

1235.718 try diff.value of D

\begin{tabular}{|ccl|}
\hline PILE PENETR. D $=$ & 7.9 & FT \\
\hline PAS.PRESSUP1 $=$ & 7110 & PSF \\
ACT.PRESSUP1= & 930.6 & PSF \\
ACT.PRESSUP2= & 312.84 & PSF \\
DIST.FROM DRE- & 15.5 & FT \\
DGE HINE TO TIE & &
\end{tabular}

DGE UINE TO TIE

TO FIND PILE PEnetration D

MOMENT @TIEBACK LOCATION

ARM

TOTAL MOMENT@TIE LOCATION $==== \pm== \pm==$

(THIS VALUE SHOULD APPROX. $=0$ )

\begin{tabular}{|c|c|c|}
\hline $\begin{array}{l}\text { the }(D) \text { should be= } \\
\text { used }\end{array}$ & 9.48 & FT \\
\hline USE $D=$ & 9.50 & FT \\
\hline$F . S=$ & 1.20 & HENCE \\
\hline
\end{tabular}

12/05/201010:02:00 PM1case10 during construction.123 


\begin{tabular}{|c|c|c|}
\hline & $\begin{array}{l}\text { TO FIND TIE } \\
\text { MAKE SUM. }\end{array}$ & $\begin{array}{l}\text { ACK FORC } \\
\text { OR F } x=0\end{array}$ \\
\hline $\mathrm{Fl}=$ & 29662.875 & + \\
\hline$F_{2}=$ & 20654.15 & + \\
\hline$F 3=$ & 61962.45 & + \\
\hline $\mathrm{F} 4=$ & 7351.74 & + \\
\hline$F 5=$ & 28084.5 & - \\
\hline $\mathrm{F} 6=$ & 1235.718 & + \\
\hline$F X / O N E B A Y=$ & 92.78 & KIP \\
\hline $\mathrm{Fx} / \mathrm{ONE} \mathrm{FT}=$ & 10.92 & KIP/FT \\
\hline$F X / B A Y=$ & 92.78 & KIP \\
\hline TIE FORCE/1 BAY= & 107.14 & KIP \\
\hline PROOFTEST LOAD $=$ & 128.56 & KIP \\
\hline
\end{tabular}

FIND MAX, MOMENT

1 @TEBACK LOCATION

$$
\begin{gathered}
\frac{\text { FORCE }}{10098} \\
10327.075 \\
14501.85
\end{gathered}
$$

@ X-DISTANCE FROM THE TOP OF THE PILE
ARM
4.85
1.65

(ZERO SHEAR POINT)

$X=18.227694 \mathrm{FT}$

\section{FORCE}

23007.91

92782.43

59447.45

ARM

9.113847

10.227694
15.078694

15.078694
6.763847

MAX. MOMENT $=$

181.45 KIP.FT

USE MAX. MOMENT =

MOD. SECTION =

65.98 CuB. IN $(\mathrm{Gr}-50)$

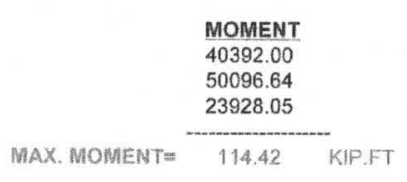

MOMENT

209690.54

948950.33

402093.46

09/22/201012:31:42 AM1case10 during construction.123 


\section{CASE 10 DURING CONSTRUCTION}

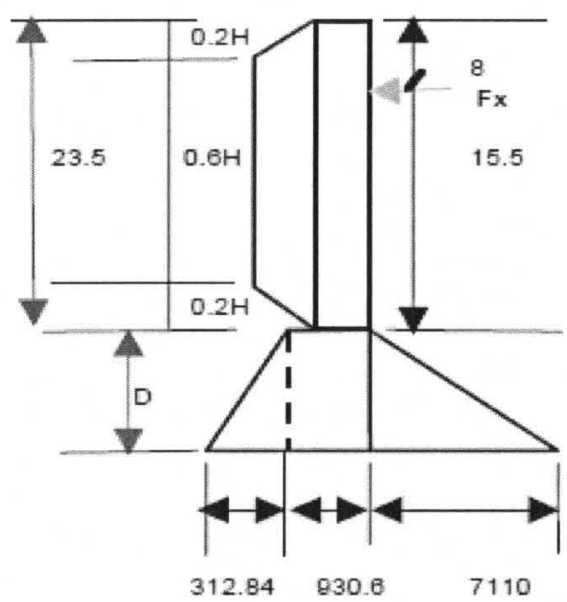

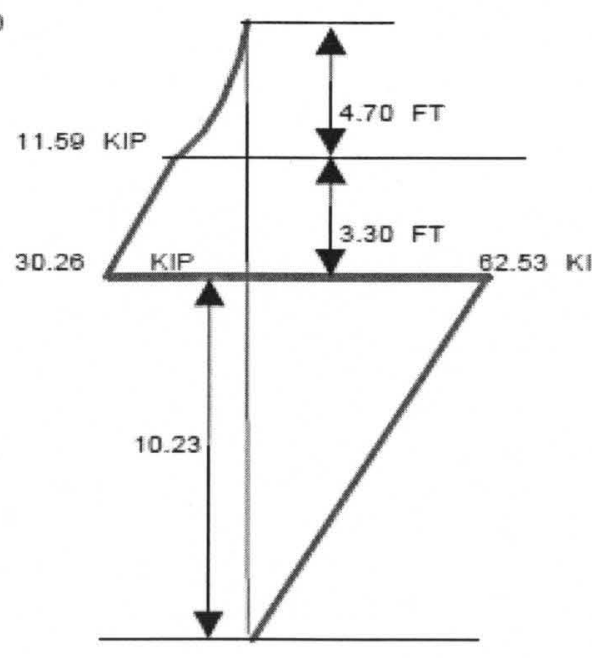

SHEAR DIAGRAM

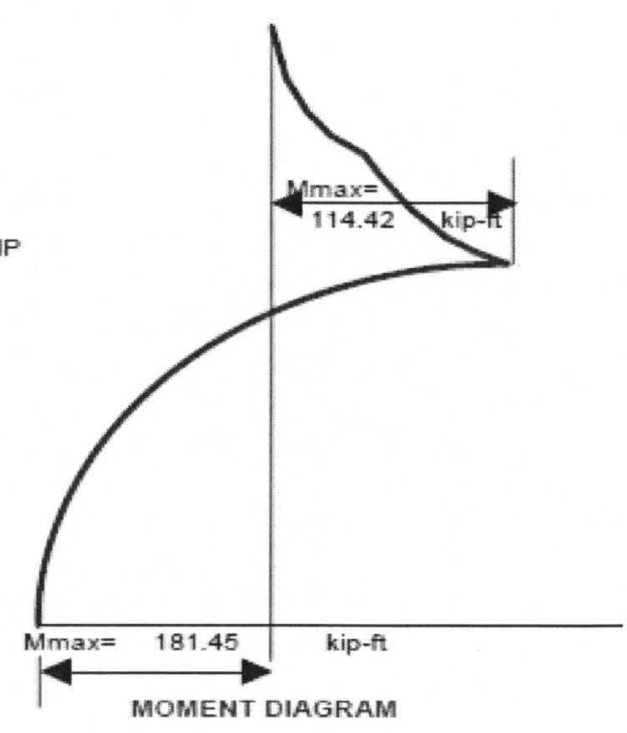



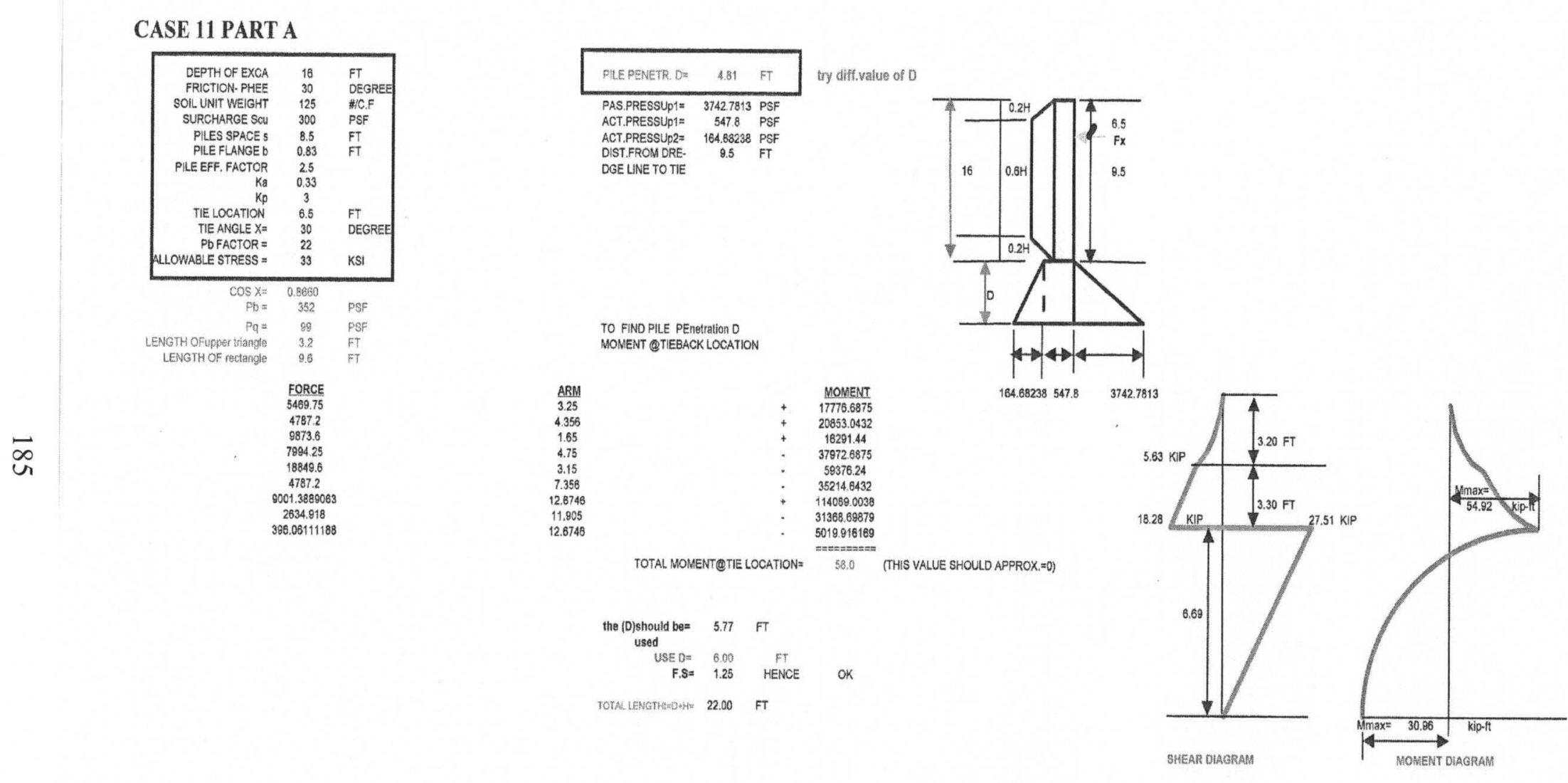


\section{CASE 11 PART A}

$\ddot{\infty}$

\begin{tabular}{|c|c|c|}
\hline $\begin{array}{l}\text { DEPTH OF EXCA } \\
\text { FRICTION- PHEE }\end{array}$ & $\begin{array}{l}16 \\
30\end{array}$ & $\begin{array}{l}\text { FT } \\
\text { DEGREE }\end{array}$ \\
\hline SOIL. UNIT WEIGHT & 125 & \#/C.F \\
\hline SURCHARGE Scu & 300 & PSF \\
\hline PILES SPACE $S$ & 8.5 & FT \\
\hline PILE FLANGE $\mathrm{b}$ & & \\
\hline PILE EFF. FACTOR & 2.5 & \\
\hline & 0.33 & \\
\hline & 3 & \\
\hline TIE LOCATION & 6.5 & \\
\hline TIE ANGLE $X=$ & 30 & DEGREE \\
\hline $\mathrm{Pb}$ FACTOR $=$ & 22 & \\
\hline ALLOWABLE STRESS = & 33 & KSI \\
\hline $\begin{aligned} \cos x & = \\
P b & =\end{aligned}$ & $\begin{array}{c}0.8660 \\
352\end{array}$ & PSF \\
\hline $\mathrm{Pq}=$ & 99 & PSF \\
\hline LENGTH OFupper triangle & 3.2 & FT \\
\hline LENGTH OF rectangle & 9.6 & FT \\
\hline & FORCE & \\
\hline & 5469.75 & \\
\hline & 4787.2 & \\
\hline & 9873.6 & \\
\hline & 7994.25 & \\
\hline & 18849.6 & \\
\hline & 4787.2 & \\
\hline & 9001.3889063 & \\
\hline & $\begin{array}{c}2634.918 \\
396.06111188\end{array}$ & \\
\hline
\end{tabular}

try diff.value of D

\begin{tabular}{|lcl|}
\multicolumn{3}{c}{ try diff.value of D } \\
\hline PILE PENETR. D $=$ & 4.81 & FT \\
\hline PAS.PRESSUP1 $=$ & 3742.7813 & PSF \\
ACT.PRESSUP1 $=$ & 547.8 & PSF \\
ACT.PRESSUP2 $=$ & 164.68238 & PSF \\
DIST.FROM DRE- & 9.5 & FT \\
DGE LINE TO TIE & & \\
\hline
\end{tabular}

TO FIND PILE PEnetration D

MOMENT @TIEBACK LOCATION

ARM
3.25
4.356
1.65
4.75
3.15
7.356
12.6746
11.905
12.6746

\section{MOMENT \\ 17776.6875 \\ 20853.0432 \\ 16291.44
37972.6875 \\ 59376.24 \\ 5937.24 \\ 114000.0038

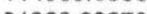 \\ 31368.69879
5019.916169}

TOTAL MOMENT@TIE LOCATION= 58.0

(THIS VALUE SHOULD APPROX $=0$ )

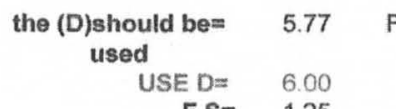

TOTAL LENGTHED+H $=22.00 \quad \mathrm{FT}$
FT
HENCE

12/05/201010:04:30 PM1case11 partA.123। 


\begin{tabular}{|c|c|c|c|}
\hline & \multicolumn{3}{|c|}{$\begin{array}{l}\text { TO FIND TIEBACK FORCE } \\
\text { MAKE SUM. FOR Fx=0 }\end{array}$} \\
\hline $\mathrm{Fl}=$ & & & \\
\hline$F 2=$ & 9574.4 & + & \\
\hline $\begin{array}{l}F 3= \\
F 4=\end{array}$ & $\begin{array}{l}28723.2 \\
264018\end{array}$ & & \\
\hline $\begin{array}{l}F 4= \\
F 5=\end{array}$ & 2634.918 & + & \\
\hline $\begin{array}{l}F== \\
F G=\end{array}$ & $\begin{array}{l}9001.38890633 \\
396.06111188\end{array}$ & + & \\
\hline $\begin{array}{l}\text { FXIONE BAY }= \\
\text { FXIONE FT }=\end{array}$ & $\begin{array}{l}45.79 \\
5.39\end{array}$ & $\begin{array}{l}\mathrm{KIP} \\
\mathrm{KIP/FT}\end{array}$ & \\
\hline $\mathrm{F} X / \mathrm{BAY}=$ & & $\mathrm{KPP}$ & $\begin{array}{l}1.5 \text { bay } \\
68.69\end{array}$ \\
\hline TIE FORCE $/ 1$ BAY $=$ & $\begin{array}{l}40.88 \\
52.88\end{array}$ & KIP & 79.31 \\
\hline PROOFTEST LOAD $=$ & 63.45 & KIP & 95.18 \\
\hline & FIND MAX. MO & MEENT & \\
\hline
\end{tabular}

1 @TIEBACK LOCATION =

$$
\begin{aligned}
& \text { FORCE } \\
& \hline 5469.75 \\
& 4787.2 \\
& 9873.6
\end{aligned}
$$

$\frac{\text { ARM }}{3.25}$

4.356

1.65

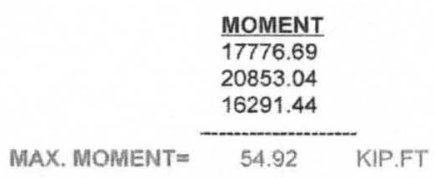

2 @ X-DISTANCE FROM THE TOP OF THE PILE

FIND $X$ WHEN SUM. OF $F X=0$

(ZERO SHEAR POINT)

$X=13.193789 \mathrm{FT}$

$$
\begin{array}{r}
\text { FORCE } \\
\hline 11102.57 \\
45791.19 \\
4787.20 \\
29901.42
\end{array}
$$

6.5968945

6.693789
11.049789

4.9968945

MAX. MOMENT =
USE MAX. MOMENT
MOD. SECTION =

30.96

KIP.FT
54.92 KIP.FT

19.97 CUB. IN (Gr-50) $\frac{\text { MOMENT }}{73242.51}$

73242.51
306516.57

52897.55

149414.23

09/22/201012:25:27 AM1case11 partA.123 
CASE 11 PART A

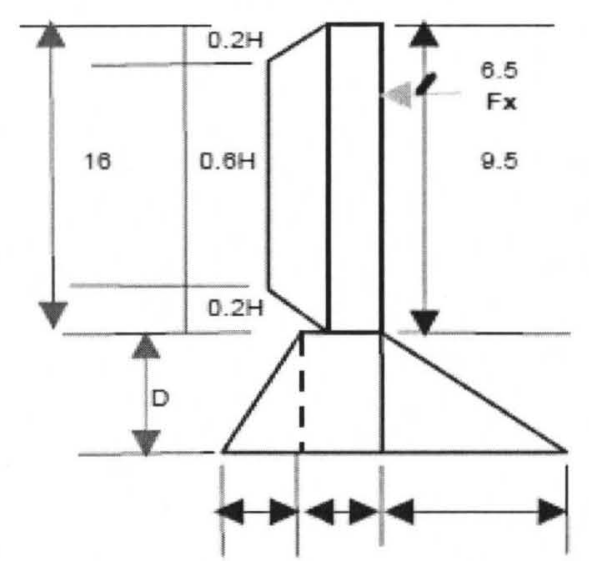

$\begin{array}{lll}164.68238 \quad 547.8 & 3742.7813\end{array}$

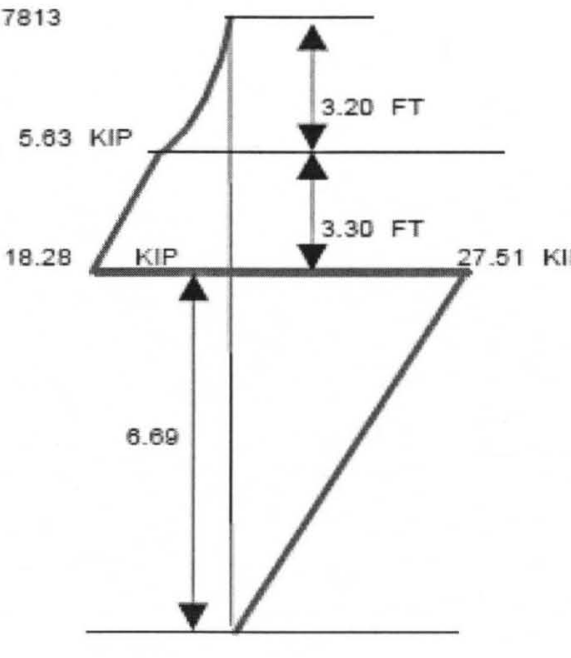

SHEAR DIAGRAM

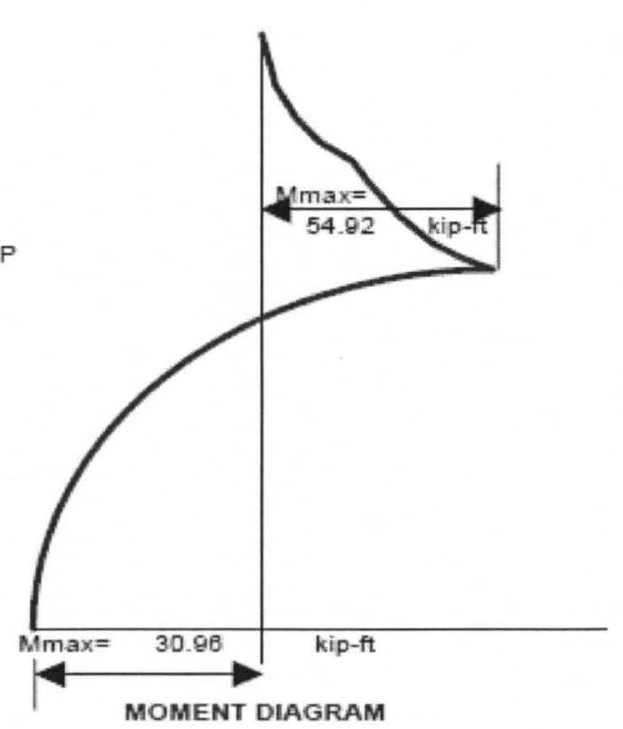



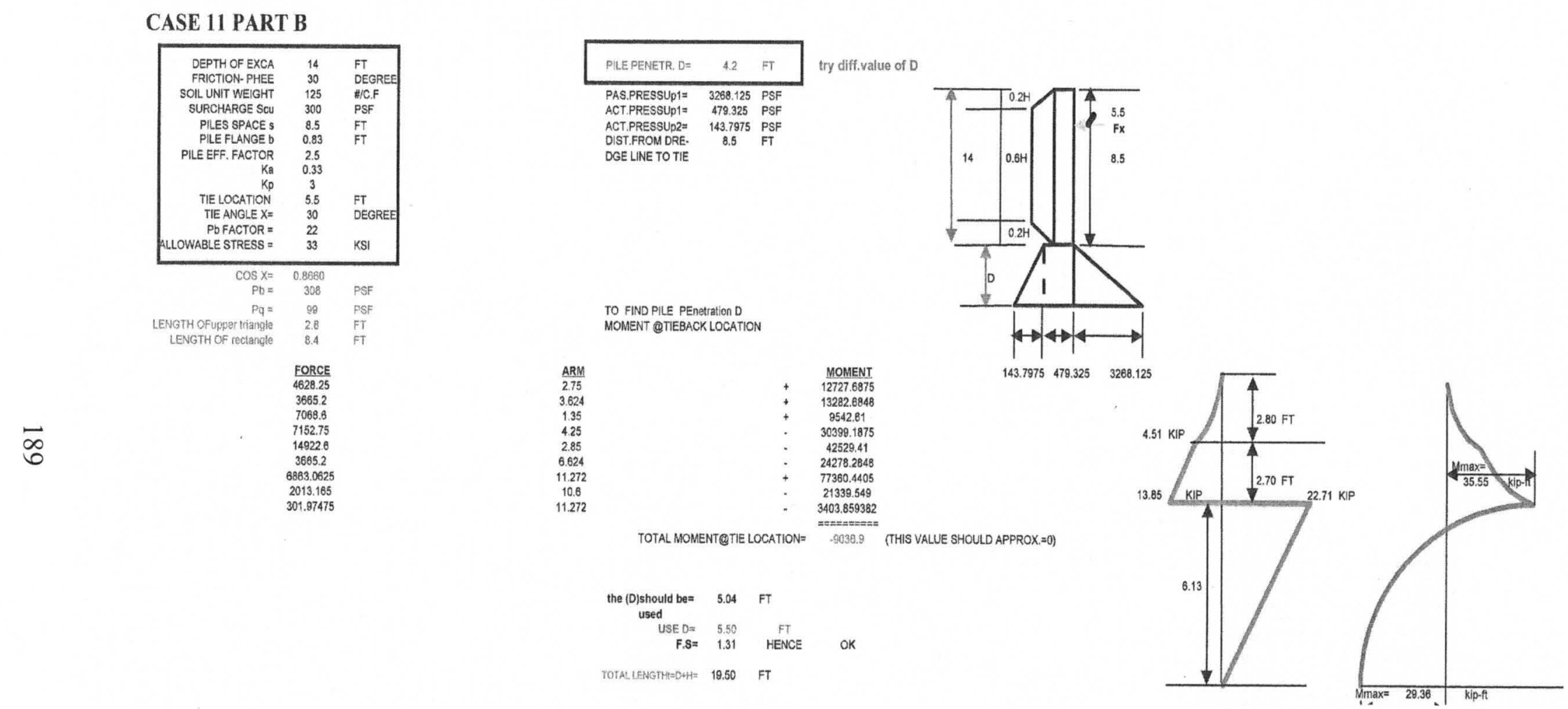


\section{CASE 11 PART B}

\begin{tabular}{|rcl|}
\hline DEPTH OF EXCA & 14 & FT \\
FRICTION- PHEE & 30 & DEGREE \\
SOIL UNIT WEIGHT & 125 & \#/C.F \\
SURCHARGE Scu & 300 & PSF \\
PILES SPACE s & 8.5 & FT \\
PILE FLANGE b & 0.83 & FT \\
PILE EFF. FACTOR & 2.5 & \\
Ka & 0.33 & \\
Kp & 3 & \\
TIE LOCATION & 5.5 & FT \\
TIE ANGLE X= & 30 & DEGREE \\
Pb FACTOR $=$ & 22 & \\
COS X $=$ & 0.8660 & \\
Pb $=$ & 308 & PSF \\
Pq $=$ & 99 & PSF \\
ALLOWABLE STRESS $=$ & 33 & KSI \\
LENGTH OFupper triangle & 2.8 & FT \\
LENGTH OF rectangle & 8.4 & FT \\
& FORCE & \\
& 4628.25 & \\
& 3665.2 & \\
& 7068.6 & \\
& 7152.75 & \\
& 14922.6 & \\
& 3665.2 & \\
& 6863.0625 & \\
& 2013.165 & \\
& 301.97475 & \\
& & \\
& & \\
&
\end{tabular}

try diff.value of $D$

\begin{tabular}{|c|c|c|}
\hline PILE PENETR. $D=$ & 4.2 & FT \\
\hline $\begin{array}{l}\text { PAS.PRESSUp1 = } \\
\text { ACT.PRESSUp1 }\end{array}$ & $\begin{array}{c}3268.125 \\
479.325\end{array}$ & $\begin{array}{l}\text { PSF } \\
\text { PSF }\end{array}$ \\
\hline $\begin{array}{l}\text { ACT.PRESSUP2= } \\
\text { DIST.FROM DRE- } \\
\text { DGE LINE TO TIE }\end{array}$ & $\begin{array}{c}143.7975 \\
8.5\end{array}$ & $\begin{array}{l}\text { PSF } \\
\text { FT }\end{array}$ \\
\hline
\end{tabular}

TO FIND PILE PEnetration D

MOMENT @TIEBACK LOCATION

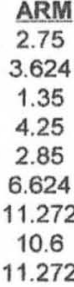

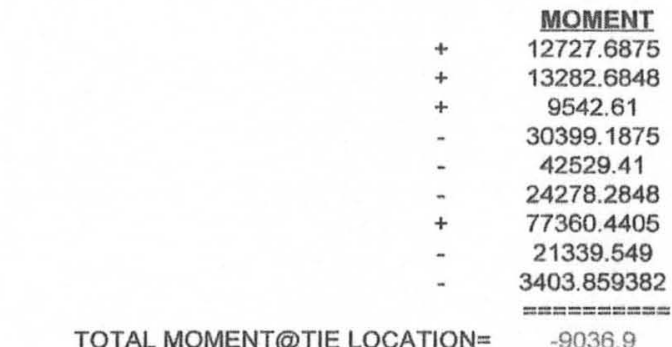

TOTAL MOMENT@TIE LOCATION=

(THIS VALUE SHOULD APPROX $=0$ )

\begin{tabular}{|c|c|c|}
\hline $\begin{array}{c}\text { the (D)should be= } \\
\text { used }\end{array}$ & 5.04 & FT \\
\hline USE $\mathrm{D}=$ & 5.50 & FT \\
\hline$F . S=$ & 1.31 & HENCE \\
\hline
\end{tabular}

12/05/201010:06:24 PM1case11 part B.123। 


\begin{tabular}{|c|c|c|}
\hline & \multicolumn{2}{|c|}{$\begin{array}{l}\text { TO FIND DTEBACK FORCE } \\
\text { MAKE SUM. FOR Fx=0 }\end{array}$} \\
\hline $\mathrm{Fl}=$ & 11781 & $\begin{array}{c}-1 \\
+\end{array}$ \\
\hline$F 2=$ & 7330.4 & + \\
\hline $\begin{array}{l}F 3= \\
F 4= \\
F 4=\end{array}$ & $\begin{array}{l}21991.2 \\
2013.165\end{array}$ & + \\
\hline & & \\
\hline & 301.97475 & + \\
\hline $\begin{array}{r}\text { FXIONE BAY }= \\
\text { FXIONE FT }\end{array}$ & $\begin{array}{l}36.55 \\
4.30\end{array}$ & $\begin{array}{l}\text { KIP } \\
\text { KIPIFT }\end{array}$ \\
\hline & & \\
\hline \multirow{3}{*}{$\begin{array}{r}F X / B A Y= \\
\text { TIE FORCE/1 BAY= } \\
\text { PROOFTEST LOAD }\end{array}$} & $\begin{array}{l}36.55 \\
42.21\end{array}$ & $\begin{array}{l}\mathrm{KIP} \\
\mathrm{KIP}\end{array}$ \\
\hline & 50.65 & KIP \\
\hline & FIND MAX. A & DMENT \\
\hline
\end{tabular}

$1 @$ @IIEBACK LOCATION =

$$
\begin{gathered}
\text { FORCE } \\
\hline 4628.25 \\
3665.2 \\
7068.6
\end{gathered}
$$

$x=11.625922 \mathrm{FT}$

$$
\begin{gathered}
\frac{\text { FORCE }}{9783.21} \\
36554.68 \\
3665.20 \\
23106.26
\end{gathered}
$$

\begin{tabular}{c} 
ARM \\
\hline 2.75 \\
3.624 \\
1.35
\end{tabular}

\section{ARM \\ 5.812961 \\ 6.125922
9.749922 \\ 4.412961}

$29.36 \quad$ KIP.FT

MAX. MOMENT $=$

USE MAX. MOMENT MOD. SECTION =
12.93 CUB. IN (Gr-50)

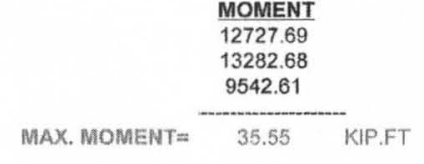

MOMENT

56869.44

35735.41

101967.04 


\section{CASE 11 PART B}

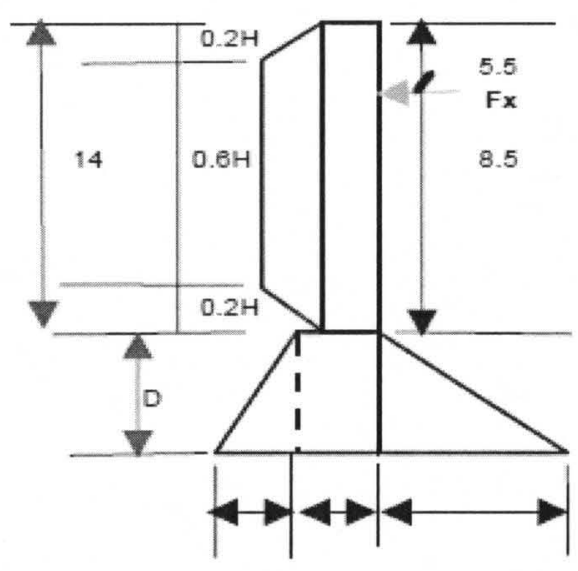

$143.7975 \quad 479.325 \quad 3268.125$

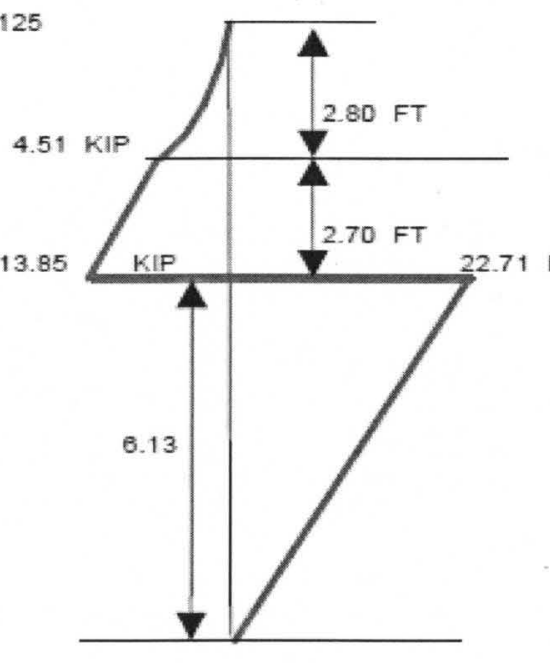

SHEAR DIAGRAM

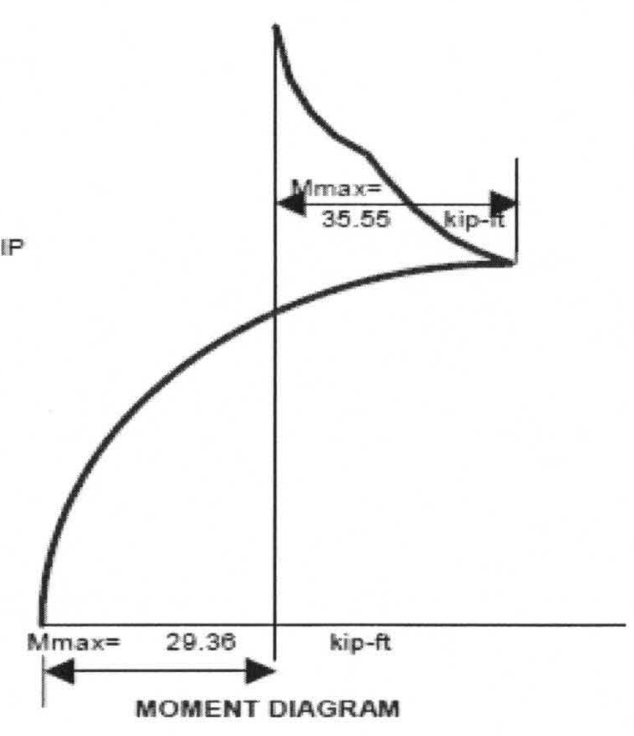




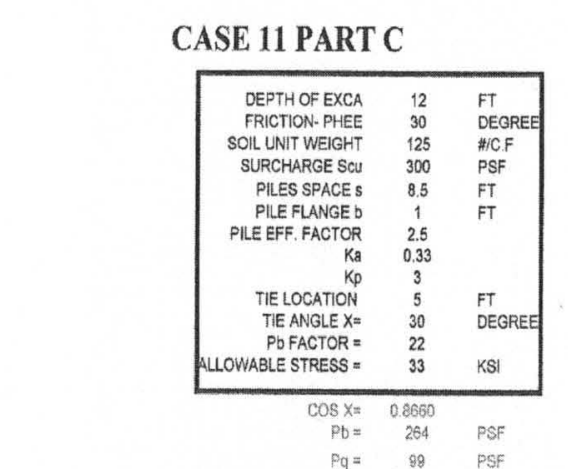

ఫ

$\begin{array}{lll} & \\ \text { LENGTH OF rectangle } & 2.4 & \text { FT } \\ & 7.2 & \text { FT }\end{array}$

。

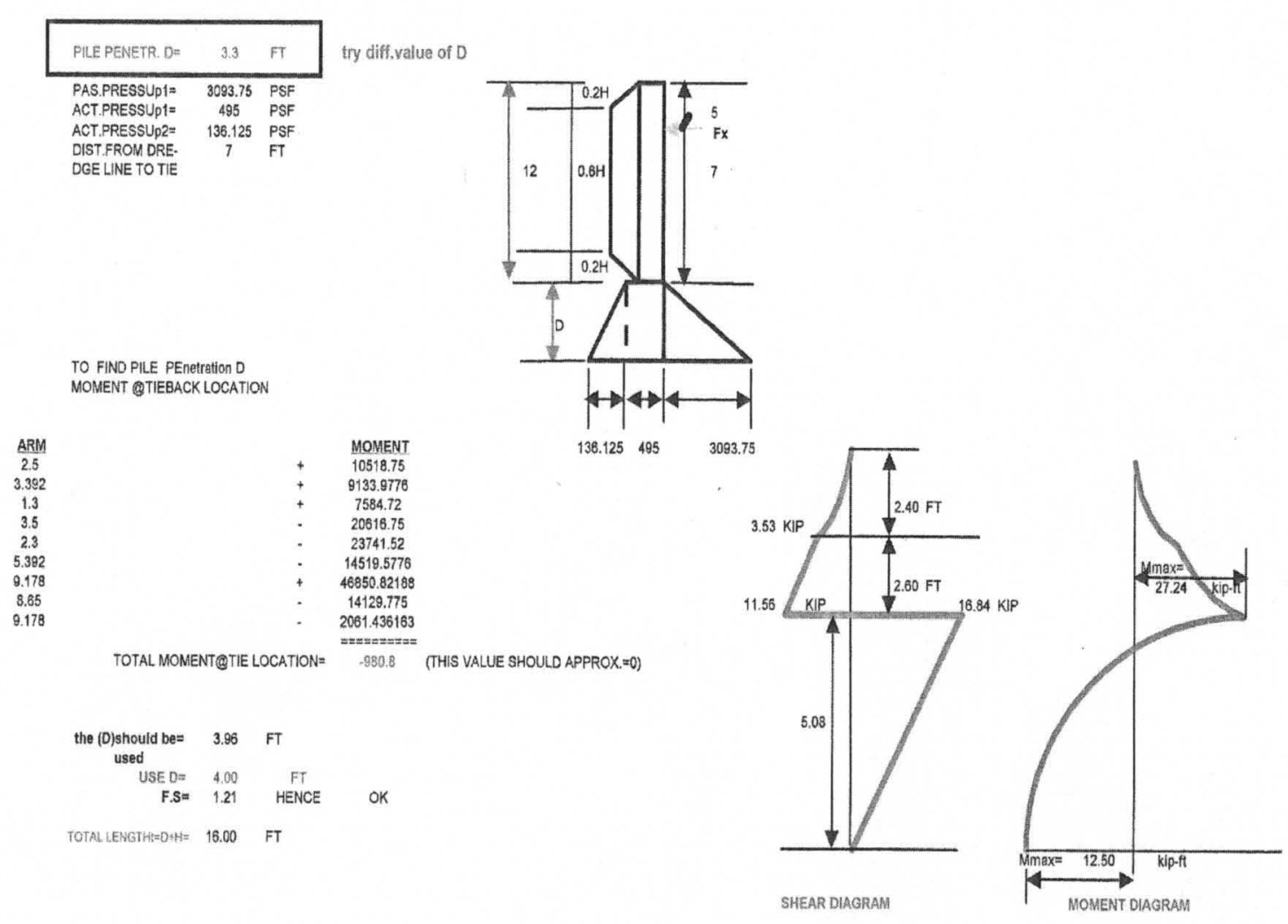




\section{CASE 11 PART C}

‡

\begin{tabular}{|rcl|}
\hline DEPTH OF EXCA & 12 & FT \\
FRICTION-PHEE & 30 & DEGREE \\
SOIL UNIT WEIGHT & 125 & \#IC.F \\
SURCHARGE Scu & 300 & PSF \\
PILES SPACE S & 8.5 & FT \\
PILE FLANGE b & 1 & FT \\
PILE EFF. FACTOR & 2.5 & \\
Ka & 0.33 & \\
Kp & 3 & \\
TIE LOCATION & 5 & FT \\
TIE ANGLE X= & 30 & DEGREE \\
Pb FACTOR $=$ & 22 & \\
ALLOWABLE STRESS $=$ & 33 & KSI \\
COS X $=$ & 0.8660 & \\
Pb $=$ & 264 & PSF \\
Pq $=$ & 99 & PSF \\
LENGTH OFupper triangle & 2.4 & FT \\
LENGTH OF rectangle & 7.2 & FT
\end{tabular}

\section{FORCE}

4207.5

2692.8

5834.4

5890.5

10322.4

2692.8

104.6875

1633.5

224.60625

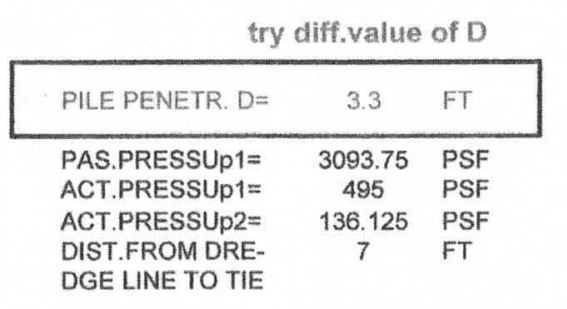

TO FIND PILE PEnetration D

MOMENT @TIEBACK LOCATION

$\begin{array}{ccc}\frac{}{\text { ARM }} 2.5 & + & \frac{\text { MOMENT }}{10518.75} \\ 3.392 & + & 9133.9776 \\ 1.3 & + & 7584.72 \\ 3.5 & - & 20616.75 \\ 2.3 & - & 23741.52 \\ 5.392 & - & 14519.5776 \\ 9.178 & + & 46850.82188 \\ 8.65 & - & 14129.775 \\ 9.178 & - & 2061.436163 \\ & & ====== \\ & \text { TOTAL MOMENT@TIE LOCATION }= & -980.8\end{array}$

(THIS VALUE SHOULD APPROX. $=0$ )

\begin{tabular}{|c|c|c|}
\hline $\begin{array}{c}\text { the (D)should be= } \\
\text { used }\end{array}$ & 3.96 & FT \\
\hline $\begin{array}{r}\text { USE D }= \\
\text { F.S }=\end{array}$ & $\begin{array}{l}4.00 \\
1.21\end{array}$ & $\begin{array}{c}\text { FT } \\
\text { HENCE }\end{array}$ \\
\hline TOTAL LENGTH $=D+H=$ & 16.00 & FT \\
\hline
\end{tabular}

12/05/201010:07:43 PM1case11 part C.123। 


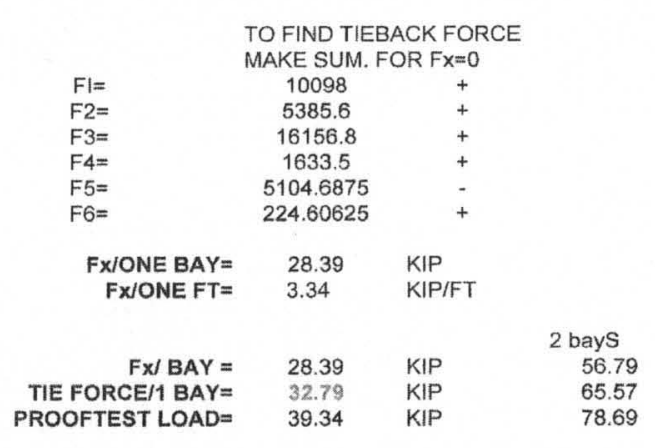

FIND MAX, MOMENT

1 (2)TIEBACK LOCATION =

\section{$\frac{\text { ARM }}{2.5}$}

3.392
1.3

4207.5
2692.8

2692.8
5834.4

W WHEN SUM.OF FX $=0$

$X=10.075067 \mathrm{FT}$

\section{FORCE}

8478.17
28393.82

2692.80

17222.85

$\begin{array}{ccl} & \text { ARM } & \\ & 5.0375334 & \\ & 5.0750668 & \\ & 8.4670668 \\ & 3.8375334 & \\ & & \\ \text { MAX. MOMENT }= & 12.50 & \text { KIP.FT } \\ \text { USE MAX. MONENT }= & 27.24 & \text { KIP.FT } \\ \text { MOD. SECTION }= & 9.90 & \text { CUB. IN (Gr-50) }\end{array}$

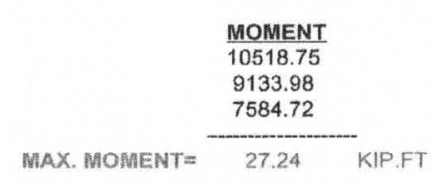

$\frac{\text { MOMENT }}{42709.06}$

144100.53

22800.12 
CASE 11 PART C

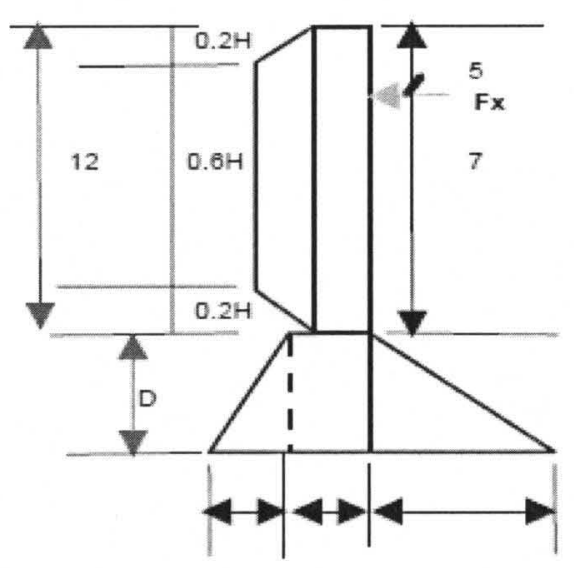

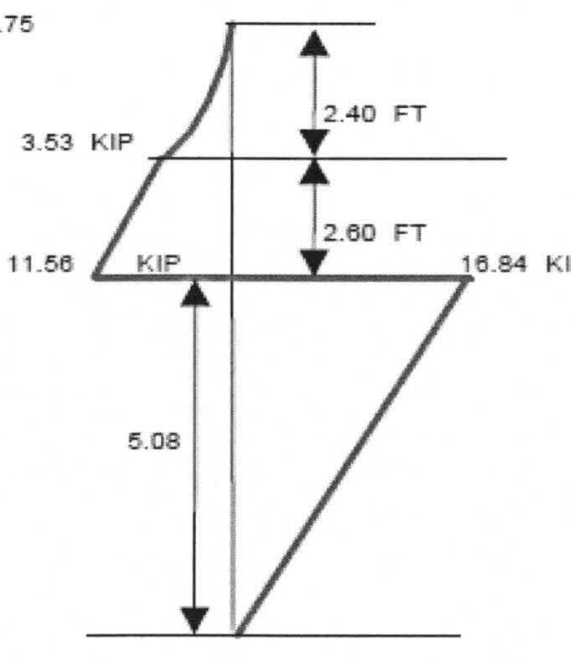

SHEAR DIAGRAM

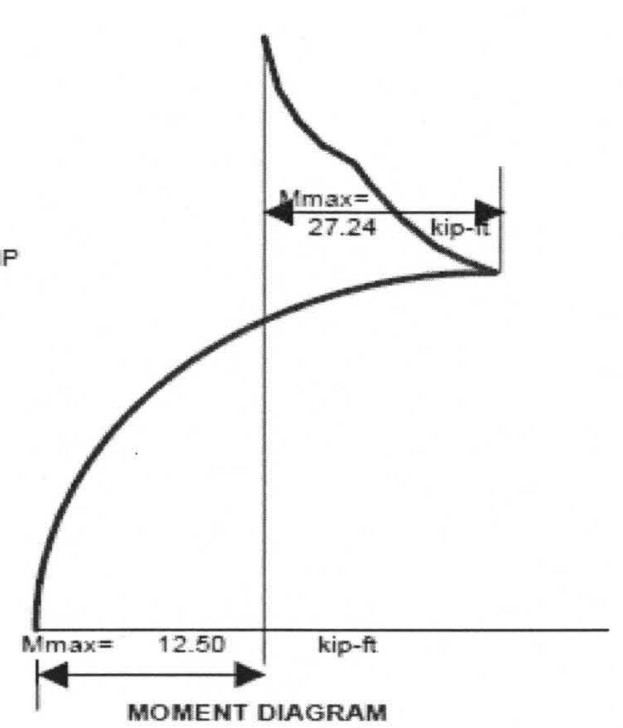




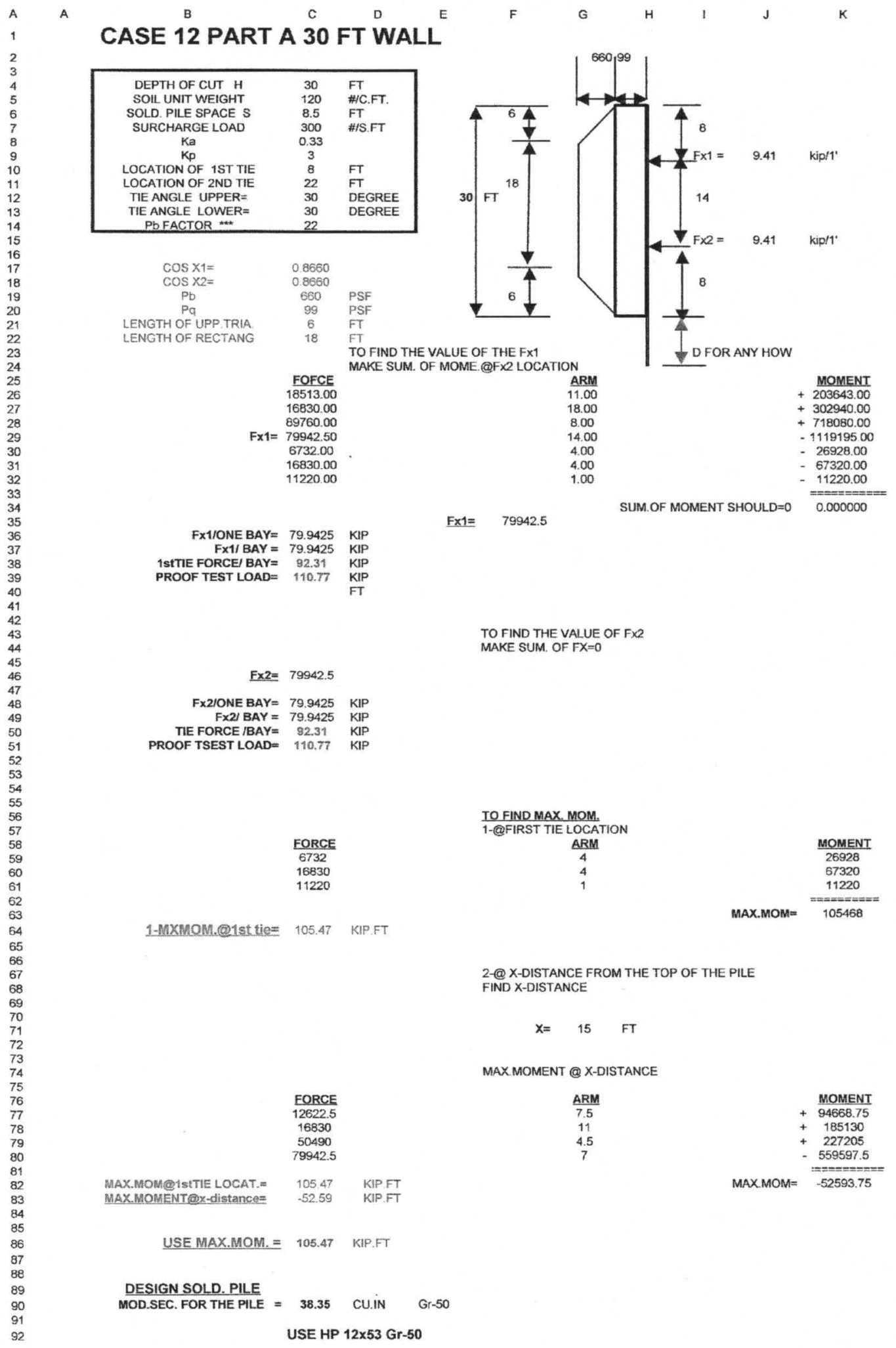



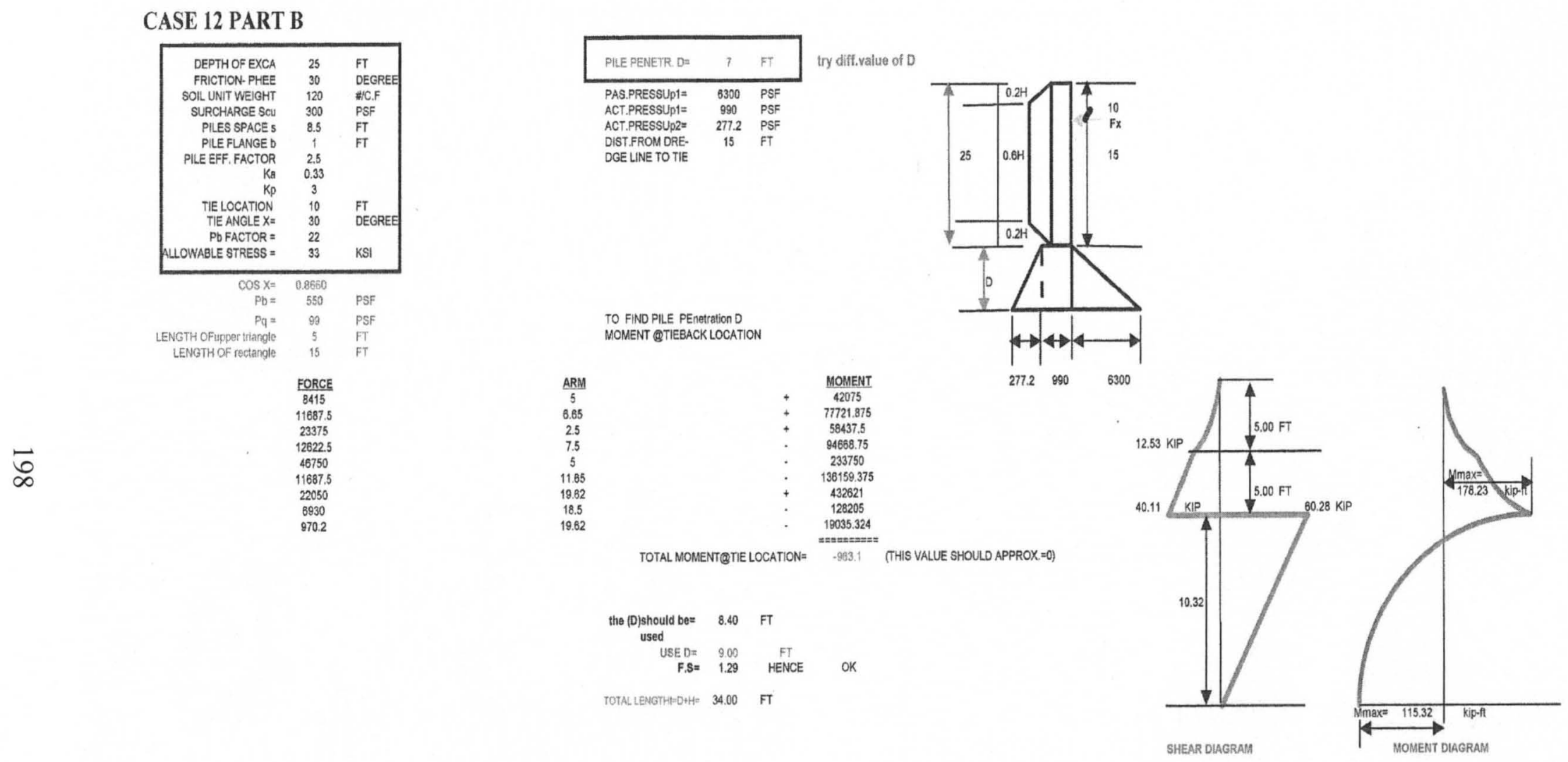


\section{CASE 12 PART B}

\begin{tabular}{|c|c|c|}
\hline DEPTH OF EXCA & $\begin{array}{l}25 \\
30\end{array}$ & FT \\
\hline FRICTION-PHEE & $\begin{array}{c}30 \\
120\end{array}$ & $\begin{array}{l}\text { DEGREE } \\
\# \text { C.F }\end{array}$ \\
\hline $\begin{array}{l}\text { SOIL UNIT WEIGHT } \\
\text { SURCHARGE SCU }\end{array}$ & 300 & $\begin{array}{l}\text { PSFF } \\
\text { PSF }\end{array}$ \\
\hline PILES SPACE $s$ & 8.5 & FT \\
\hline PILE FLANGE $b$ & 1 & FT \\
\hline PILE EFF. FACTOR & 2.5 & \\
\hline & 0.33 & \\
\hline $\mathrm{Kp}$ & 3 & \\
\hline TIE LOCATION & 10 & \\
\hline TIE ANGLE $X=$ & 30 & DEGREE \\
\hline $\mathrm{Pb} F A C T O R=$ & 22 & \\
\hline ALLOWABLE STRESS $=$ & 33 & KSI \\
\hline $\begin{aligned} \cos x & = \\
P b & =\end{aligned}$ & $\begin{array}{c}0.8660 \\
550\end{array}$ & \\
\hline $\begin{array}{l}P b= \\
P a=\end{array}$ & 550 & PSF \\
\hline $\begin{array}{l}\mathrm{Pq}= \\
\text { LENGTH OFupper triangle }\end{array}$ & $\begin{array}{c}99 \\
5\end{array}$ & $\begin{array}{l}\text { PSF } \\
\text { FT }\end{array}$ \\
\hline LENGTH OF rectangle & 15 & FT \\
\hline & FORCE & \\
\hline & 8415 & \\
\hline & 11687.5 & \\
\hline & 23375 & \\
\hline & 12622.5 & \\
\hline & 46750 & \\
\hline & 11687.5 & \\
\hline & 22050 & \\
\hline & 6930 & \\
\hline & 970.2 & \\
\hline
\end{tabular}

try diff.value of D

\begin{tabular}{lcl|}
\hline PILE PENETR. D $=$ & 7 & FT \\
\hline PAS.PRESSUp1 $=$ & 6300 & PSF \\
ACT.PRESSUp1= & 990 & PSF \\
ACT.PRESSUp2= & 277.2 & PSF \\
DIST.FROM DRE- & 15 & FT \\
DGE LINE TO TIE & & \\
& \\
& \\
& \\
TO FIND PILE PEnetration D \\
MOMENT @TIEBACK LOCATION
\end{tabular}

$\begin{array}{ccc}\text { ARM } & & \text { MOMENT } \\ 5 & + & 42075 \\ 6.65 & + & 77721.875 \\ 2.5 & + & 58437.5 \\ 7.5 & - & 94668.75 \\ 5 & - & 233750 \\ 11.65 & - & 136159.375 \\ 19.62 & + & 432621 \\ 18.5 & - & 128205 \\ 19.62 & - & 19035.324 \\ & \text { TOTAL MOMENT@TIE LOCATION }====== \\ & -963.1\end{array}$

(THIS VALUE SHOULD APPROX. $=0$ )

\begin{tabular}{|c|c|c|}
\hline $\begin{array}{l}\text { the (D)should be= } \\
\text { used }\end{array}$ & 8.40 & FT \\
\hline USE $\mathrm{D}=$ & 9.00 & FT \\
\hline F.S $=$ & 1.29 & HENCE \\
\hline
\end{tabular}

12/05/201010:08:51 PM1case12 part B.123। 


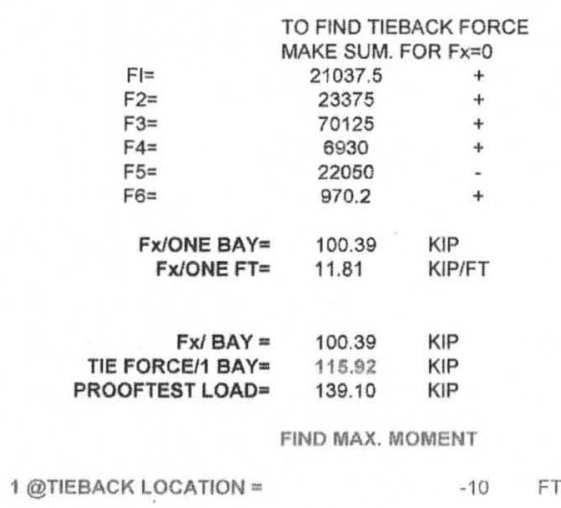

$\begin{array}{cc} & \text { FORCE } \\ 8415 \\ 1187.5 \\ \text { N } & 23375 \\ 8 & \end{array}$

\section{ARM \\ 6.65
2.5}

ZERO SHEAR POINT

2 X-DISTANCE FROM THE TOP OF THE PILE $X=20.31636 \mathrm{FT}$

$$
\begin{array}{r}
\text { FORCE } \\
17096.22 \\
100387.70 \\
11687.50 \\
71603.98
\end{array}
$$

ARM

10.15818

10.31636
16.96636

7.65818

115.32 KIP.FT

MAX. MOMENT $=$

USE MAX. MOMENT

178.23 KIP.FT

CUB. IN (Gr-50)

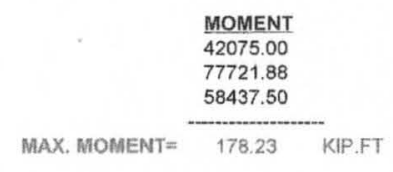

MOMENT

173666.45

1035635.65
198294.33

548356.19 


\section{CASE 12 PART B}
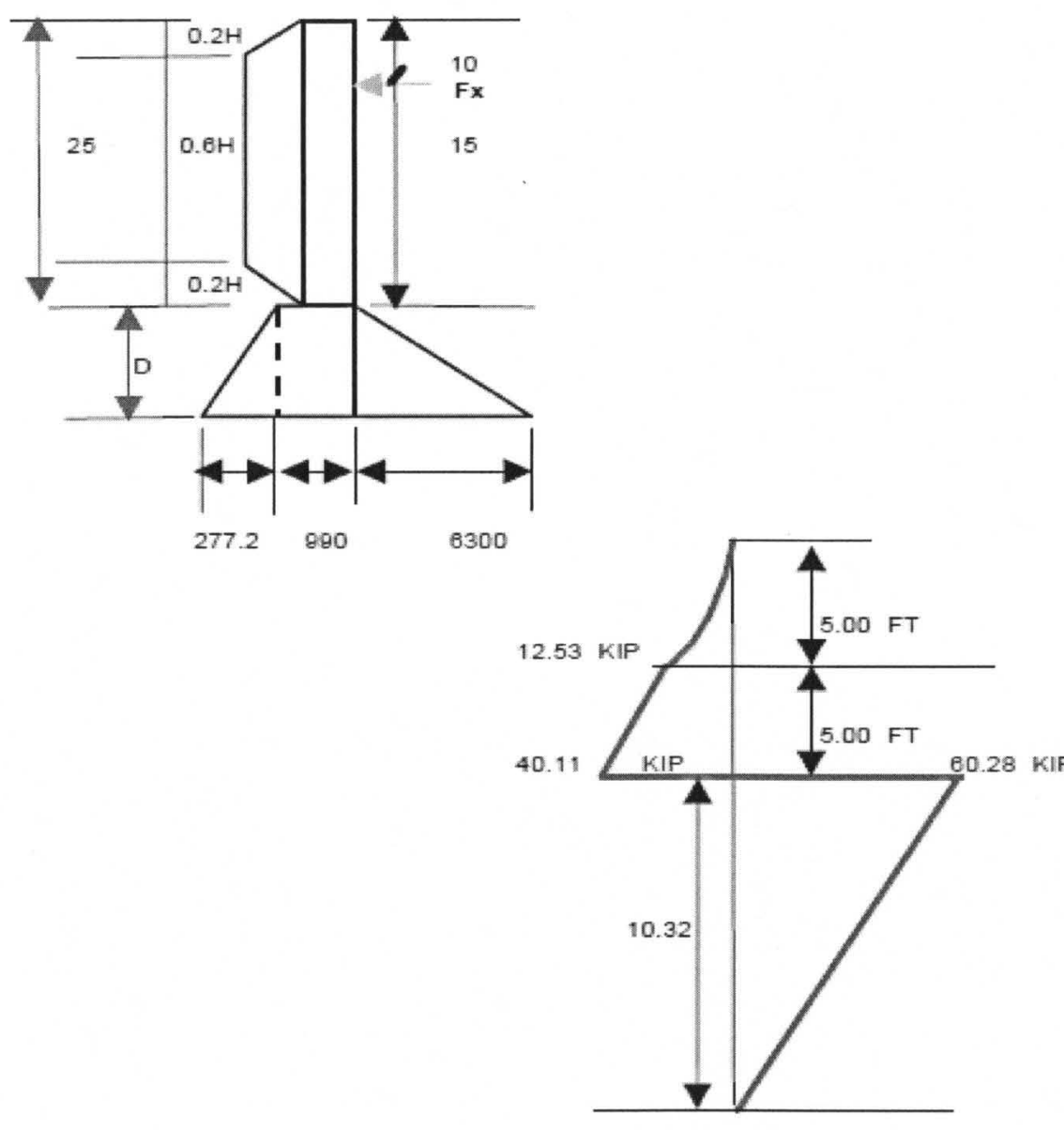

SHEAR DIAGRAM

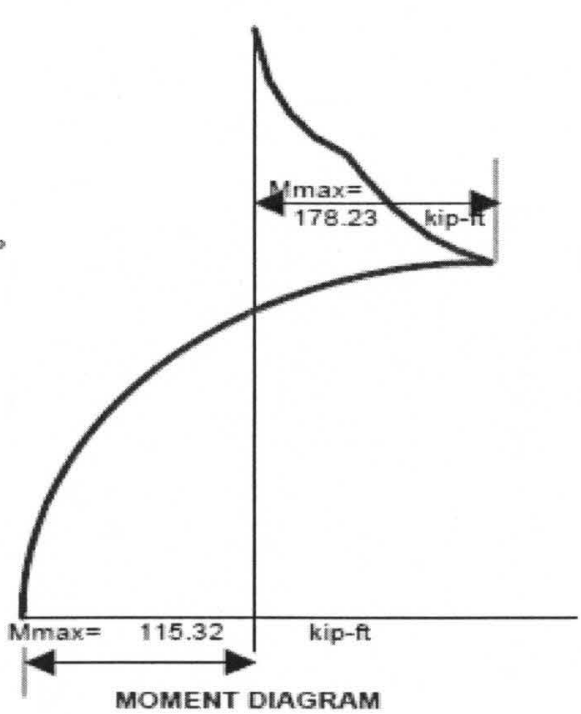



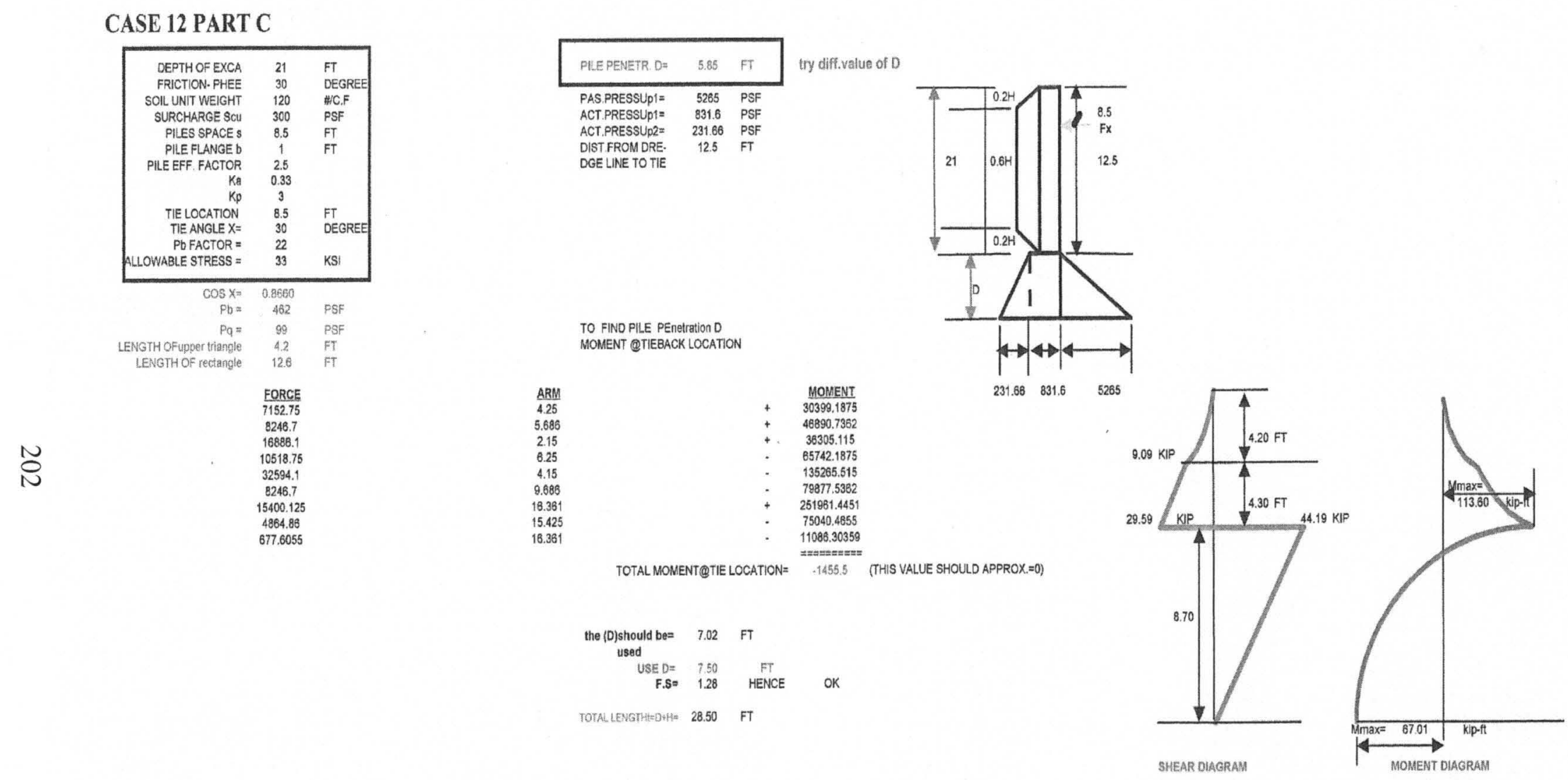


\section{CASE 12 PART C}

莒

\begin{tabular}{|c|c|c|}
\hline DEPTH OF EXCA & $\begin{array}{l}21 \\
30\end{array}$ & FT \\
\hline SOIL UNIT WEIGHT & $\begin{array}{c}30 \\
120\end{array}$ & $\begin{array}{l}\text { DEGREE } \\
\text { \#/C.F }\end{array}$ \\
\hline SURCHARGE Scu & 300 & PSF \\
\hline PILES SPACE $S$ & 8.5 & FT \\
\hline PILE FLANGE $\mathrm{b}$ & 1 & FT \\
\hline PILE EFF. FACTOR & 2.5 & \\
\hline & 0.33 & \\
\hline$K p$ & 3 & \\
\hline TIE LOCATION & 8.5 & \\
\hline TIE ANGLE $X=$ & 30 & DEGREE \\
\hline $\mathrm{Pb}$ FACTOR $=$ & 22 & \\
\hline ALLOWABLE STRESS = & 33 & KSI \\
\hline $\cos x=$ & 0.8660 & \\
\hline $\mathrm{Pb}=$ & 462 & PSF \\
\hline $\mathrm{Pq}=$ & 99 & PSF \\
\hline LENGTH OFupper triangle & 4.2 & FT \\
\hline LENGTH OF rectangle & 12.6 & FT \\
\hline & FORCE & \\
\hline & 7152.75 & \\
\hline & 8246.7 & \\
\hline & 16886.1 & \\
\hline & 10518.75 & \\
\hline & 32594.1 & \\
\hline & 8246.7 & \\
\hline & 15400.125 & \\
\hline & 4864.86 & \\
\hline & 677.6055 & \\
\hline
\end{tabular}

try diff.value of $D$

\begin{tabular}{|ccl|}
\hline PILE PENETR. D $=$ & 5.85 & FT \\
\hline PAS.PRESSUP1= & 5265 & PSF \\
ACT.PRESSUP1 $=$ & 831.6 & PSF \\
ACT.PRESSUP2 $=$ & 231.66 & PSF \\
DIST.FROM DRE- & 12.5 & FT \\
DGE LINE TO TIE & & \\
\hline
\end{tabular}

TO FIND PILE PEnetration D

MOMENT @TIEBACK LOCATION

$$
\begin{gathered}
\text { ARM } \\
\hline 4.25 \\
5.686 \\
2.15 \\
6.25 \\
4.15 \\
9.686 \\
16.361 \\
15.425 \\
16.361
\end{gathered}
$$

\section{MOMENT \\ 30399.1875 \\ 46890.7362 \\ 36305.115 \\ 65742.1875 \\ 135265.515 \\ 79877.5362 \\ 251961.4451 \\ 75040.4655 \\ 11086.30359}

TOTAL MOMENT@TIE LOCATION=

$-1455.5$

(THIS VALUE SHOULD APPROX $=0$ )

the (D)should be $=$
used

$\begin{array}{rlr}\text { USE D } & =7.50 & \\ \text { F.S } & =1.28 & \text { FT } \\ & & \text { HENCE }\end{array}$

TOTAL LENGTHt=D+H= $28.50 \quad \mathrm{FT}$

12/05/201010:09:56 PM1case12 part C. 1231 


\begin{tabular}{|c|c|c|}
\hline & MAKE SUM. & $O R F x=0$ \\
\hline $\mathrm{Fl}=$ & 17671.5 & + \\
\hline$F 2=$ & 16493.4 & + \\
\hline$F 3=$ & 49480.2 & + \\
\hline $\mathrm{F} 4=$ & 4864.86 & + \\
\hline$F 5=$ & 15400.125 & - \\
\hline$F 6=$ & 677.6055 & + \\
\hline $\mathrm{Fx} / \mathrm{ONE} \mathrm{BAY}=$ & 73.79 & KIP \\
\hline FX/ONE FT $=$ & 8.68 & KIP/FT \\
\hline & & KIP \\
\hline TIE FORCE $/ 1$ BAY $=$ & 85.20 & KIP \\
\hline PROOFTEST LOAD= & 102.24 & KIP \\
\hline
\end{tabular}

$1 @$ TIEBACK LOCATION =
$2 @$ X-DISTANCE FROM THE TOP OF THE PILE

\section{FIND $X$ WHEN SUM. OF F $x=0$}

$X=17.203343 \mathrm{FT}$

$\frac{\text { FORCE }}{14476.61}$

14476.61
73787.44

73787.44
8246.70

51064.13

$\begin{array}{ccll} & \text { ARM } & \\ & 8.6016714 & \\ & 8.7033429 & \\ & 14.389343 & \\ & 6.5016714 & \\ & & & \\ \text { MAX. MOMENT }= & 67.01 & \text { KIP.FT } \\ \text { USE MAX. MOMENT }= & 113.60 & \text { KIP.FT } \\ \text { MOD. SECTION }= & 41.31 & \text { CUB. IN (Gr-50) }\end{array}$

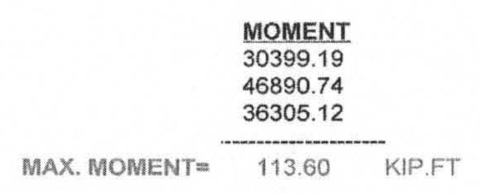

\begin{tabular}{l} 
MOMENT \\
\hline 124523.07 \\
642197.39 \\
118664.59 \\
332002.18
\end{tabular}

09/22/201012:17:28 AM1case12 part C.123) 
CASE 12 PART C

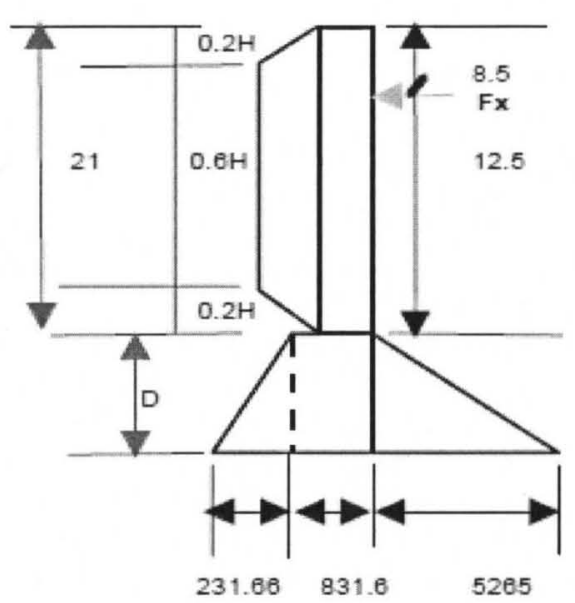

苔

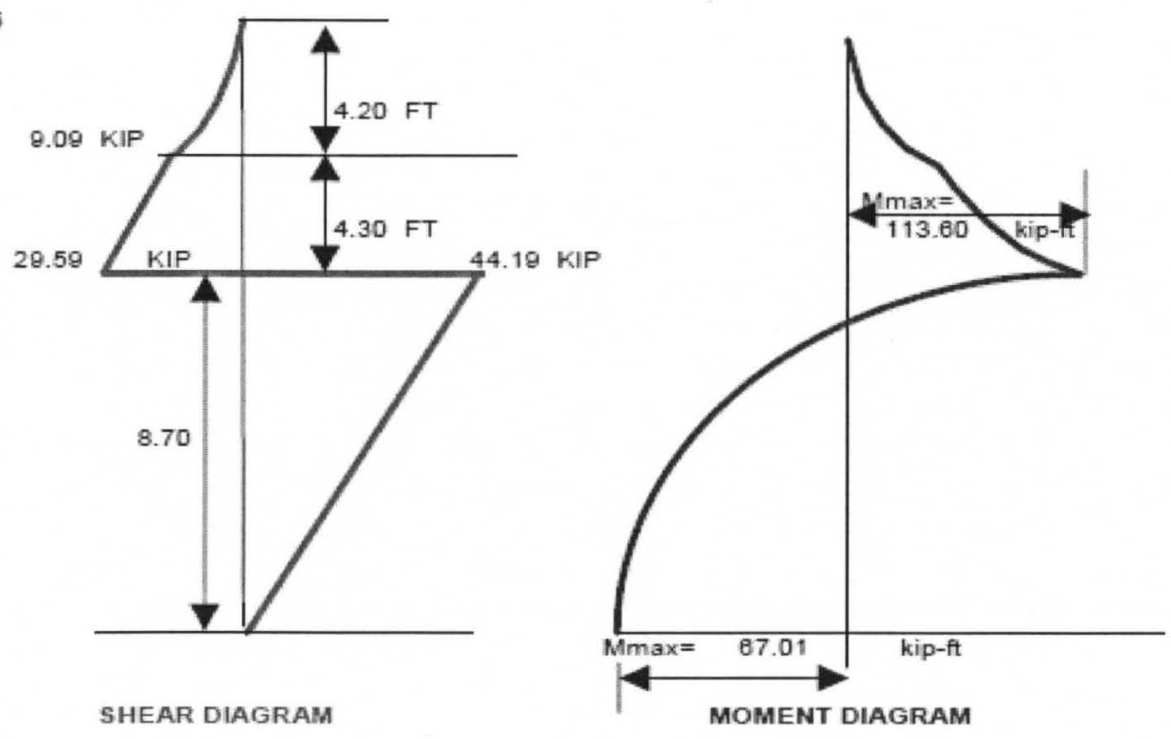




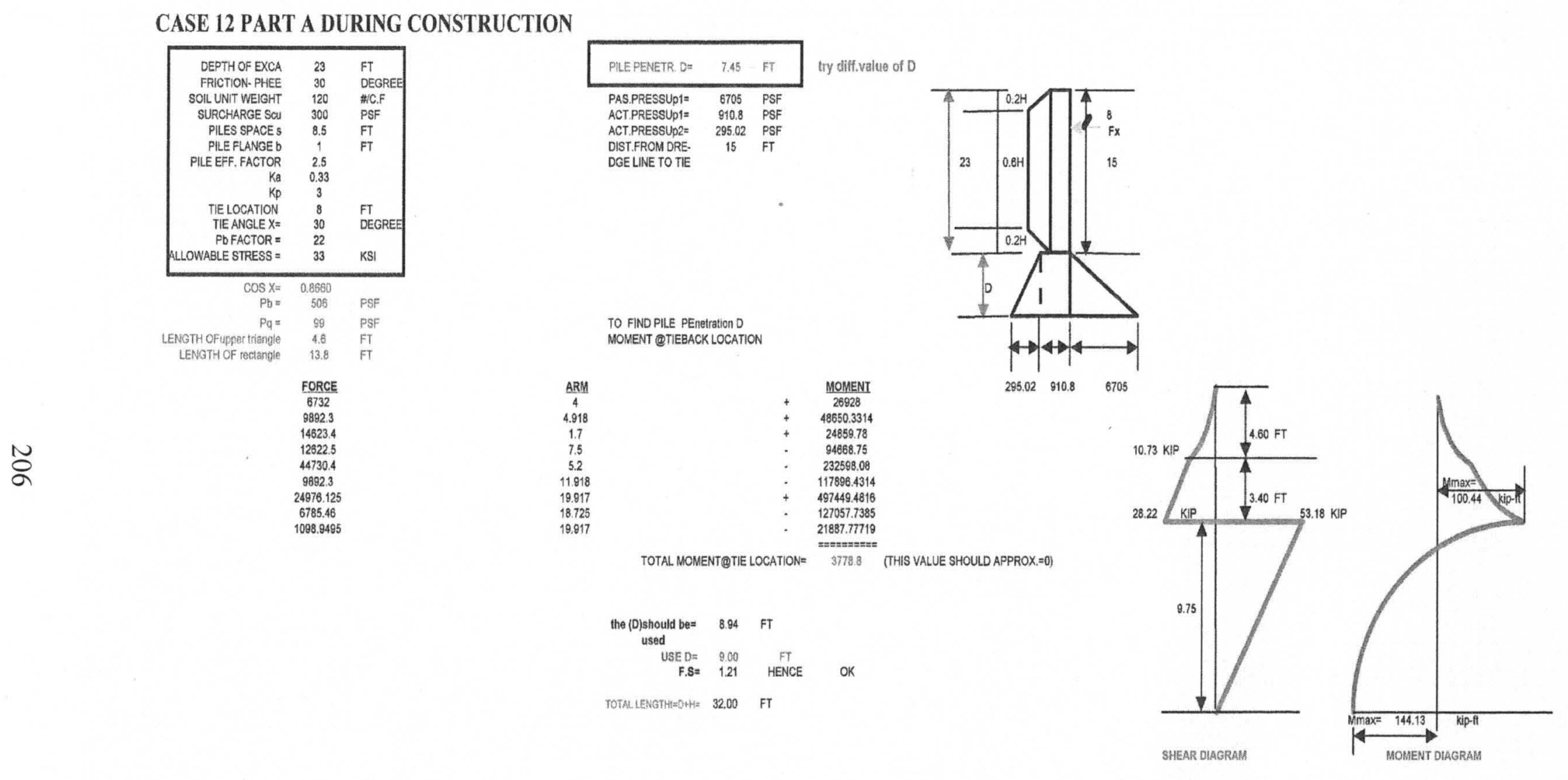


CASE 12 PART A DURING CONSTRUCTION

try diff.value of $D$

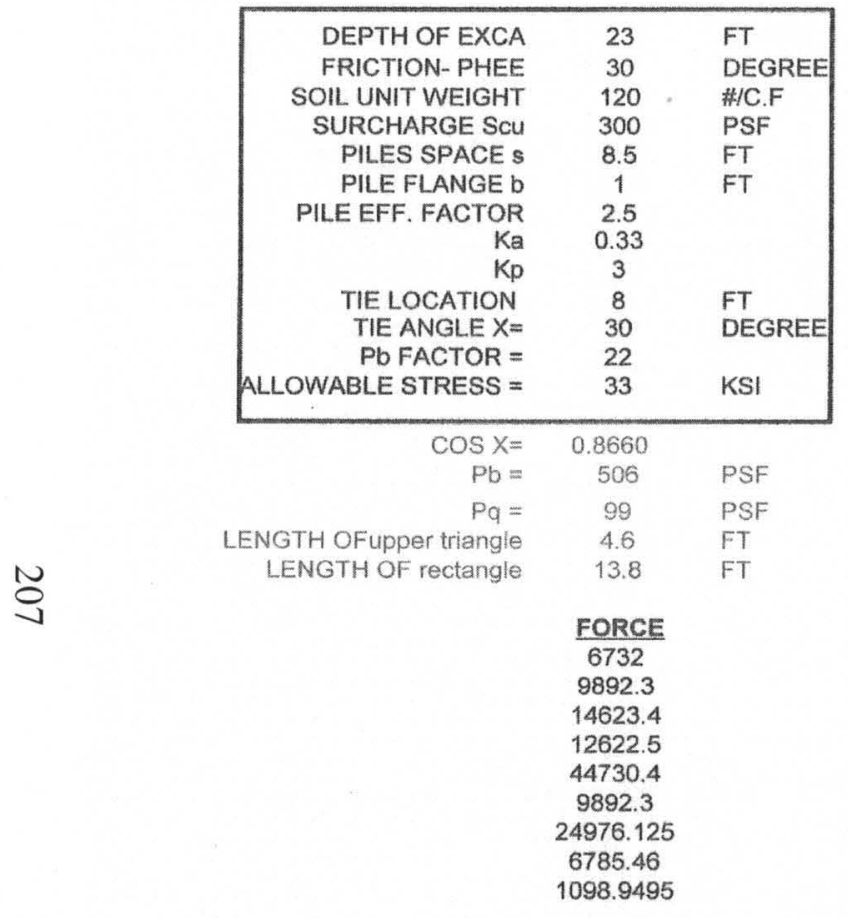

\begin{tabular}{|ccl|}
\hline & \multicolumn{3}{c}{ PILE PENETR. D $=$} & 7.45 & FT \\
\hline PAS.PRESSUP1 $=$ & 6705 & PSF \\
ACT.PRESSUP1 $=$ & 910.8 & PSF \\
ACT.PRESSUP2= & 295.02 & PSF \\
DIST.FROM DRE- & 15 & FT \\
DGE LINE TO TIE & & \\
\hline
\end{tabular}

TO FIND PILE PEnetration D

MOMENT @TIEBACK LOCATION

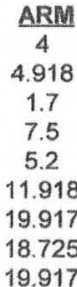

\begin{tabular}{cc} 
& MOMENT \\
+ & 26928 \\
+ & 48650.3314 \\
+ & 24859.78 \\
- & 94668.75 \\
- & 232598.08 \\
- & 117896.4314 \\
+ & 497449.4816 \\
- & 127057.7385 \\
- & 21887.77719 \\
\hline
\end{tabular}

TOTAL MOMENT@TIE LOCATION= 


\begin{tabular}{|c|c|c|}
\hline & \multicolumn{2}{|c|}{$\begin{array}{l}\text { TO FIND TIEBACK FORCE } \\
\text { MAKE SUM. FOR F } x=0\end{array}$} \\
\hline $\mathrm{FI}=$ & 19354.5 & + \\
\hline$F_{2}=$ & 19784.6 & + \\
\hline $\mathrm{F} 3=$ & 59353.8 & + \\
\hline $\mathrm{F} 4=$ & 6785.46 & + \\
\hline $\mathrm{F} 5=$ & 24976.125 & - \\
\hline $\mathrm{F} 6=$ & 1098.9495 & + \\
\hline FXIONE BAY $=$ & 81.40 & KIP \\
\hline FXIONE FT $=$ & 9.58 & KIP/FT \\
\hline$F \mathrm{~F} / \mathrm{BAY}=$ & 81.40 & KIP \\
\hline TIE FORCE/1 BAY= & 93.99 & KIP \\
\hline PROOFTEST LOAD = & 112.79 & $\mathrm{KIP}$ \\
\hline & & \\
\hline
\end{tabular}

1 @TIEBACK LOCATION =

$-8$
2 (2) X-DISTANCE FROM THE TOP OF THE PILE $\stackrel{\infty}{\infty}$

FORCE

6732

14623.4
FIND $X$ WHEN SUM.OF $F X=0$

$X=17.752744 \mathrm{FT}$

\section{ARM}

4
4.918
1.7

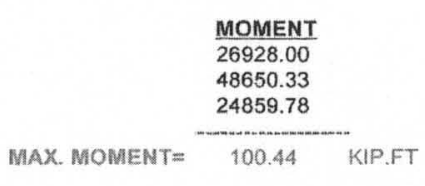

MOMENT

793884.89

145127.40

8.8763719
9.7527437

14.670744

6.5763719

81401.18

9892.30
56569.95

144.13 KIP.FT

MAX. MOMENT=

USE MAX. MOMENT:

MOD. SECTION =

144.13 KIP.FT

52.41 CUB. IN (Gr-50) 


\section{CASE 12 PART A DURING CONSTRUCTION}

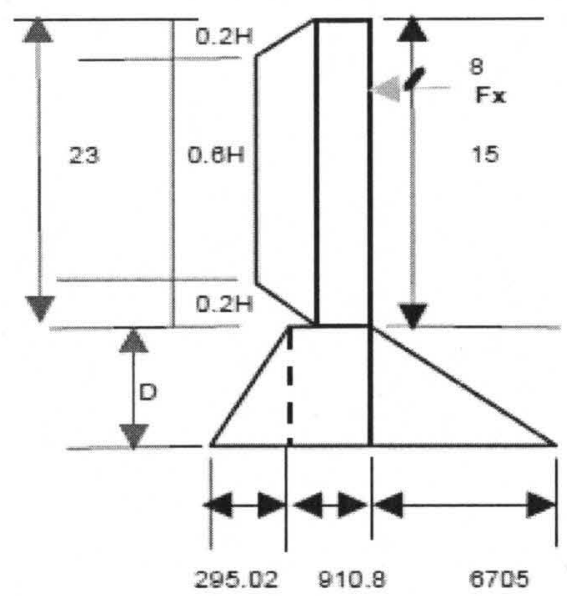

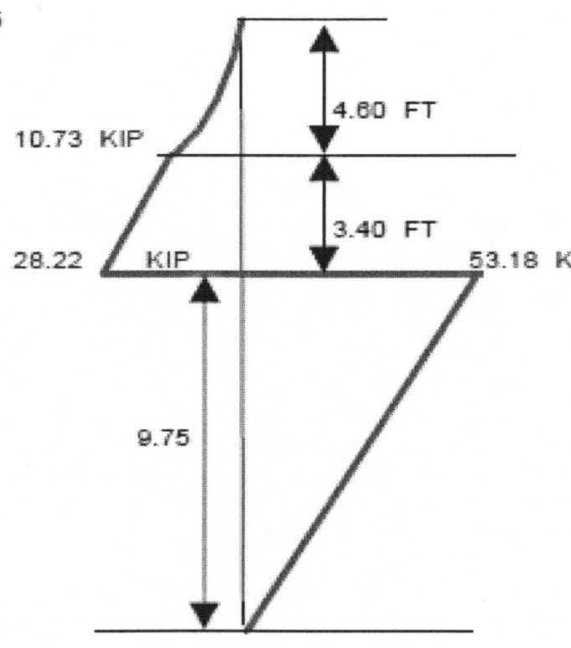

SHEAR DIAGRAM

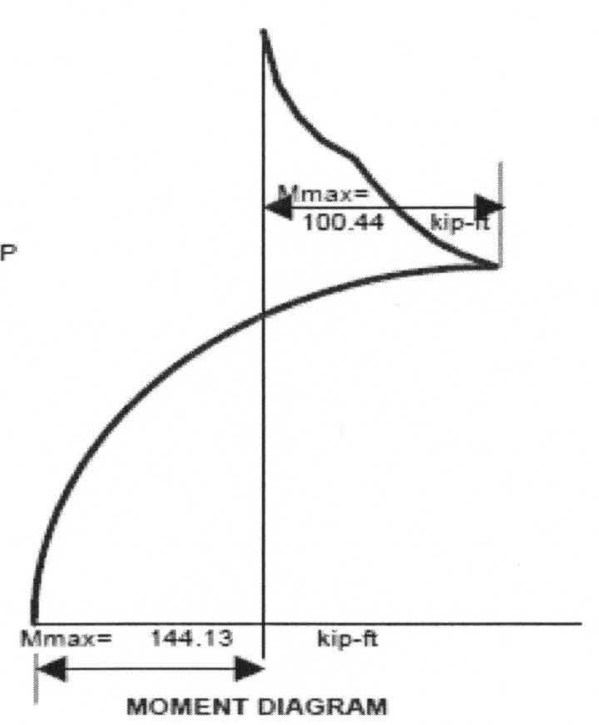



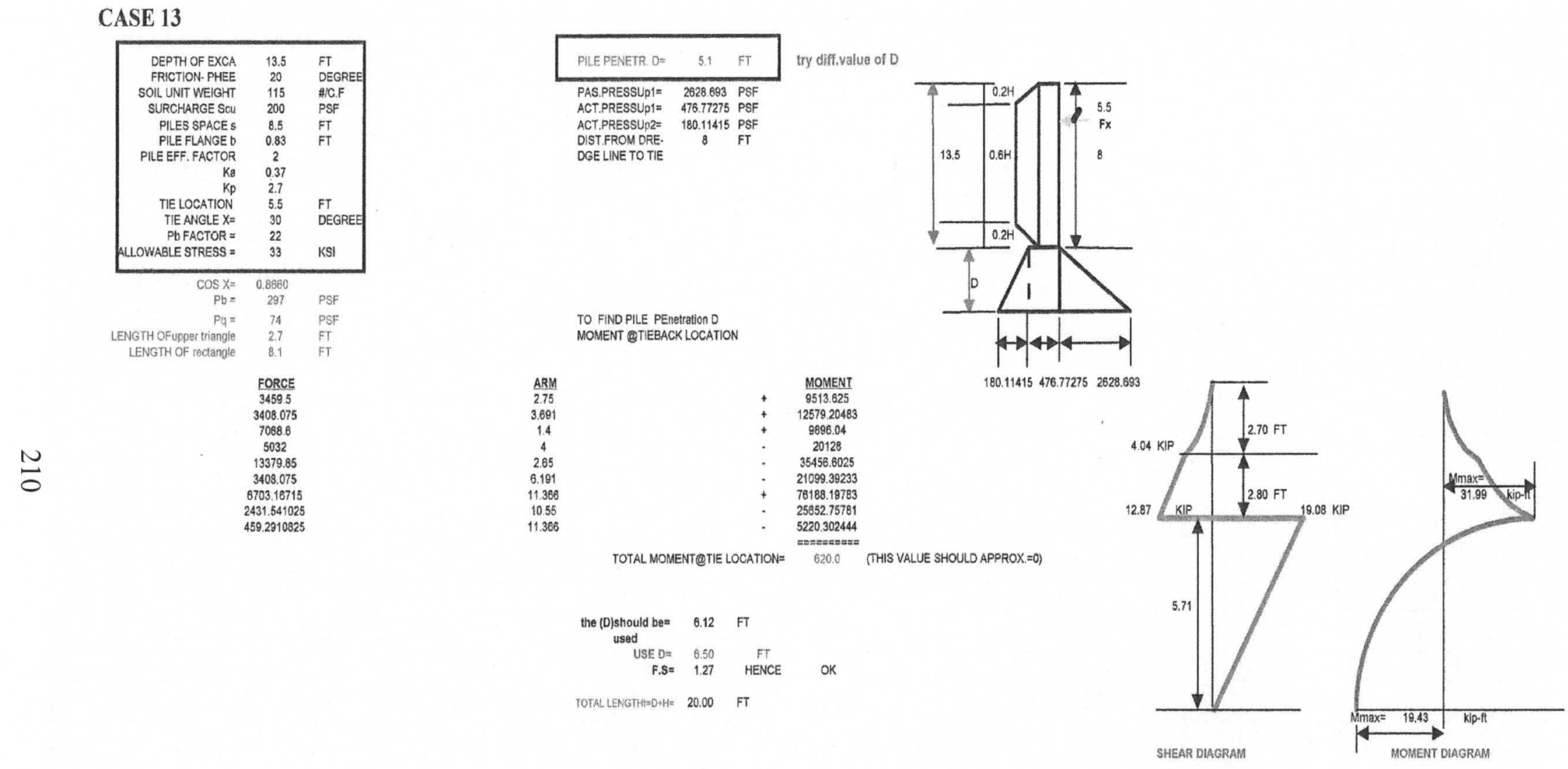


\section{CASE 13}

\begin{tabular}{|rcl|}
\hline DEPTH OF EXCA & 13.5 & FT \\
FRICTION-PHEE & 20 & DEGREE \\
SOIL UNIT WEIGHT & 115 & \#/C.F \\
SURCHARGE Scu & 200 & PSF \\
PILES SPACE S & 8.5 & FT \\
PILE FLANGE b & 0.83 & FT \\
PILE EFF. FACTOR & 2 & \\
Ka & 0.37 & \\
Kp & 2.7 & \\
TIE LOCATION & 5.5 & FT \\
TIE ANGLE X $=$ & 30 & DEGREE \\
Pb FACTOR = & 22 & \\
COS X $=$ & 0.8660 & \\
Pb $=$ & 297 & PSF \\
Pq $=$ & 74 & PSF \\
ALLOWABLE STRESS $=$ & 33 & KSI \\
\hline LENGTH OFupper triangle & 2.7 & FT \\
LENGTH OF rectangle & 8.1 & FT \\
& FORCE & \\
& 3459.5 & \\
& 3408.075 & \\
& 7068.6 & \\
& 5032 & \\
& 13379.85 & \\
& 3408.075 & \\
& 6703.16715 & \\
& 2431.541025 & \\
& 459.2910825 & \\
& & \\
& & \\
&
\end{tabular}

try diff.value of $D$

\begin{tabular}{|lcl|}
\multicolumn{3}{c}{ try diff.value of D } \\
\hline PILE PENETR. D $=$ & 5.1 & FT \\
\hline PAS.PRESSUP1 $=$ & 2628.693 & PSF \\
ACT.PRESSUP1 $=$ & 476.77275 & PSF \\
ACT.PRESSUp2 $=$ & 180.11415 & PSF \\
DIST.FROM DRE- & 8 & FT \\
DGE LINE TO TIE & & \\
\hline
\end{tabular}

TO FIND PILE PEnetration D

MOMENT @TIEBACK LOCATION

$\begin{array}{ccc}\frac{\text { ARM }}{2.75} & & \frac{\text { MOMENT }}{9513.625} \\ 3.691 & + & 12579.20483 \\ 1.4 & + & 9896.04 \\ 4 & - & 20128 \\ 2.65 & - & 35456.6025 \\ 6.191 & - & 21099.39233 \\ 11.366 & + & 76188.19783 \\ 10.55 & - & 25652.75781 \\ 11.366 & - & 5220.302444 \\ & \text { TOTAL MOMENT@TIE LOCATION= }=0=0=0 \\ & & 620.0\end{array}$

(THIS VALUE SHOULD APPROX. $=0$ )

the (D)should be= used

$\begin{array}{rlr}\text { USE D } & =6.50 & \text { FT } \\ \text { F.S } & =1.27 & \text { HENCE } \\ & & \\ \text { GTH }=D+H & =20.00 & \text { FT }\end{array}$

12/05/201010:12:38 PM1case 13.123। 


\begin{tabular}{|c|c|c|c|}
\hline & \multicolumn{2}{|c|}{$\begin{array}{l}\text { TO FIND TIEBACK FORCE } \\
\text { MAKE SUM. FOR Fx=0 }\end{array}$} & \\
\hline $\mathrm{FI}=$ & 8491.5 & + & \\
\hline $\mathrm{F} 2=$ & 6816.15 & + & \\
\hline $\mathrm{F} 3=$ & 20448.45 & + & \\
\hline $\mathrm{F} 4=$ & 2431.541025 & + & \\
\hline $\mathrm{F} 5=$ & 6703.16715 & - & \\
\hline $\mathrm{F} 6=$ & 459.2910825 & + & \\
\hline $\mathrm{F} X / \mathrm{ONE} \mathrm{BAY}=$ & 31.94 & KIP & \\
\hline $\mathrm{F} \times / \mathrm{ONE} \mathrm{FT}=$ & 3.76 & KIP/FT & \\
\hline $\mathrm{F} \times / \mathrm{BAY}=$ & 31.94 & KIP & 2 bays \\
\hline TIE FORCE $/ 1$ BAY $=$ & 36.89 & KIP & 73.77 \\
\hline PROOFTEST LOAD $=$ & 44.26 & KIP & 88.53 \\
\hline & FIND MAX. M & DMENT & \\
\hline
\end{tabular}

$1 @$ @IEBACK LOCATION =

\section{FORCE \\ 3459.5
3408.075}

3408.075
7068.6

$\stackrel{N}{N}$

2 @-DISTANGE FROM THE TOP OF THE PILE

FIND X WHEN SUM. OF FX $=0$

(ZERO SHEAR POINT)

$X=11.21035 \mathrm{FT}$

\section{$\frac{\text { ARM }}{2.75}$}

3.691

1.4
MOMENT

9513.63
12579.20

12579.20

MAX. MOMENT $=31.99 \quad$ KIP.FT

\section{MOMENT}

39523.83

182410.09
32040.51

91419.80

USE MAX. MOMENT MOD. SECTION =
ARM

5.7103504

9.4013504
4.2551752

$19.43 \quad$ KIP.FT

31.99 KIP.FT

11.63 CUB. IN (Gr-50) 
CASE 13

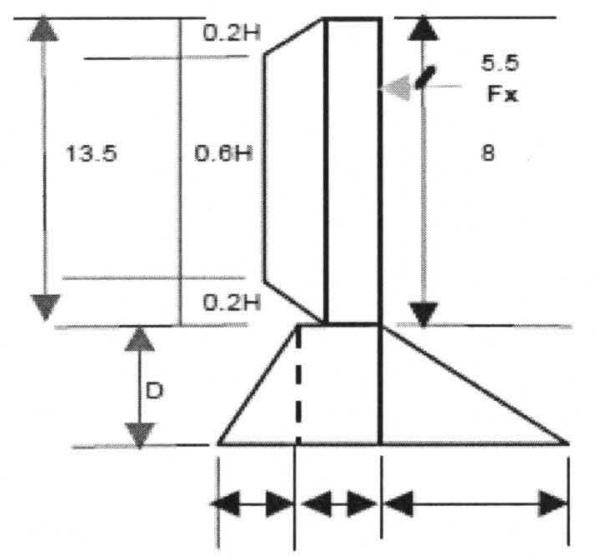

$180.11415 \quad 476.77275 \quad 2628.693$

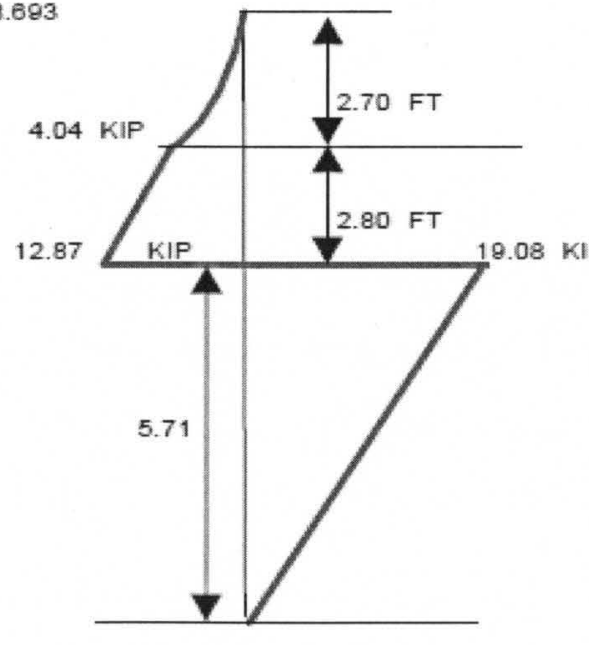

SHEAR DIAGRAM

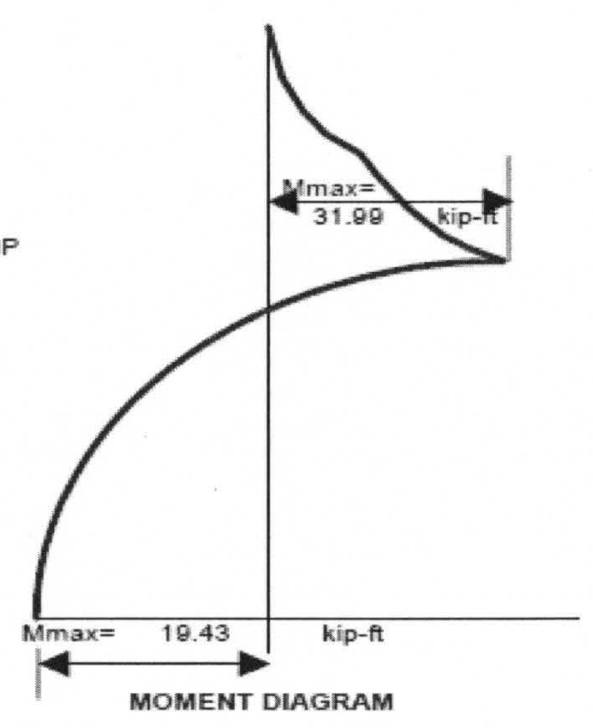



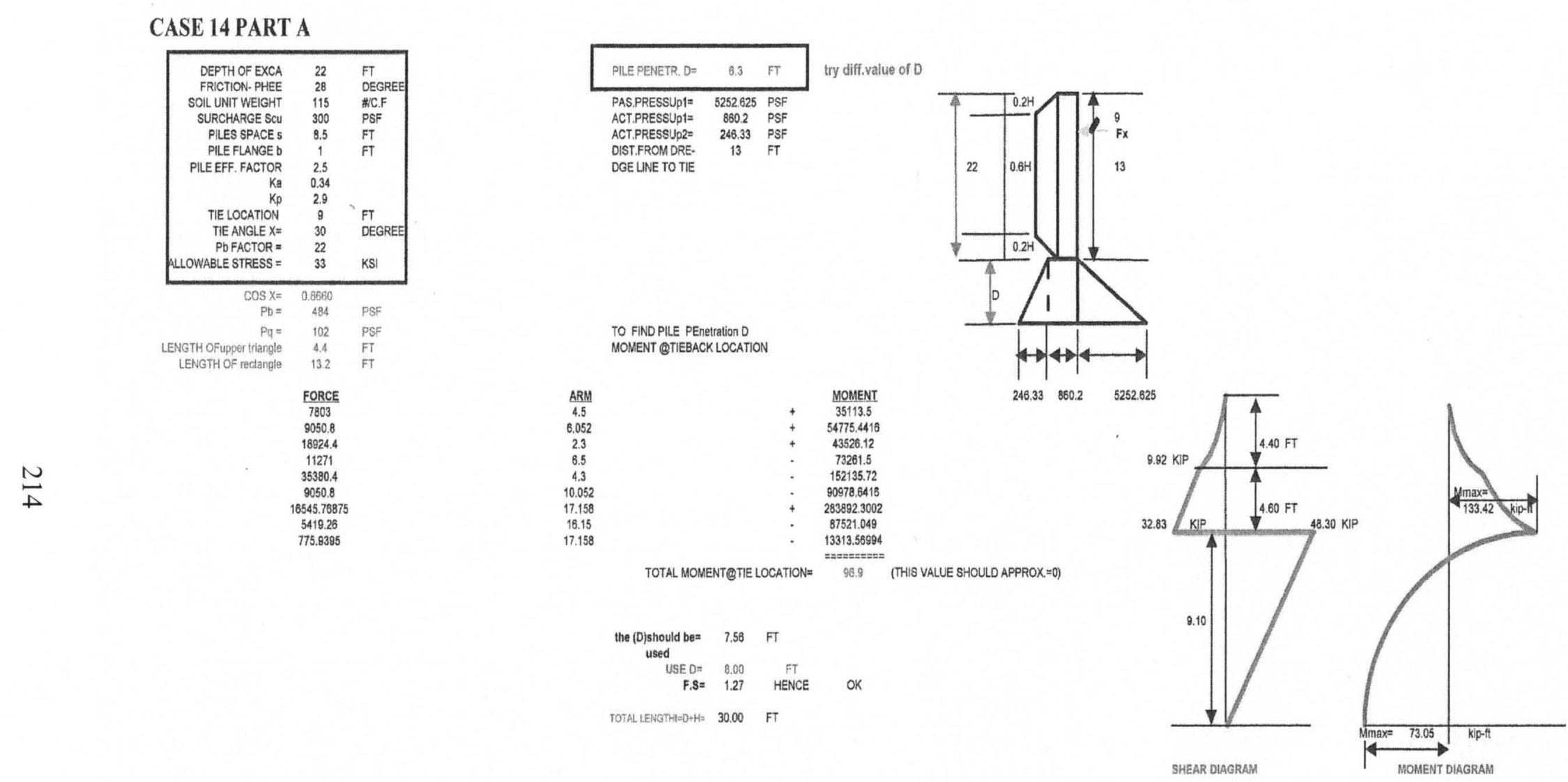


\section{CASE 14 PART A}

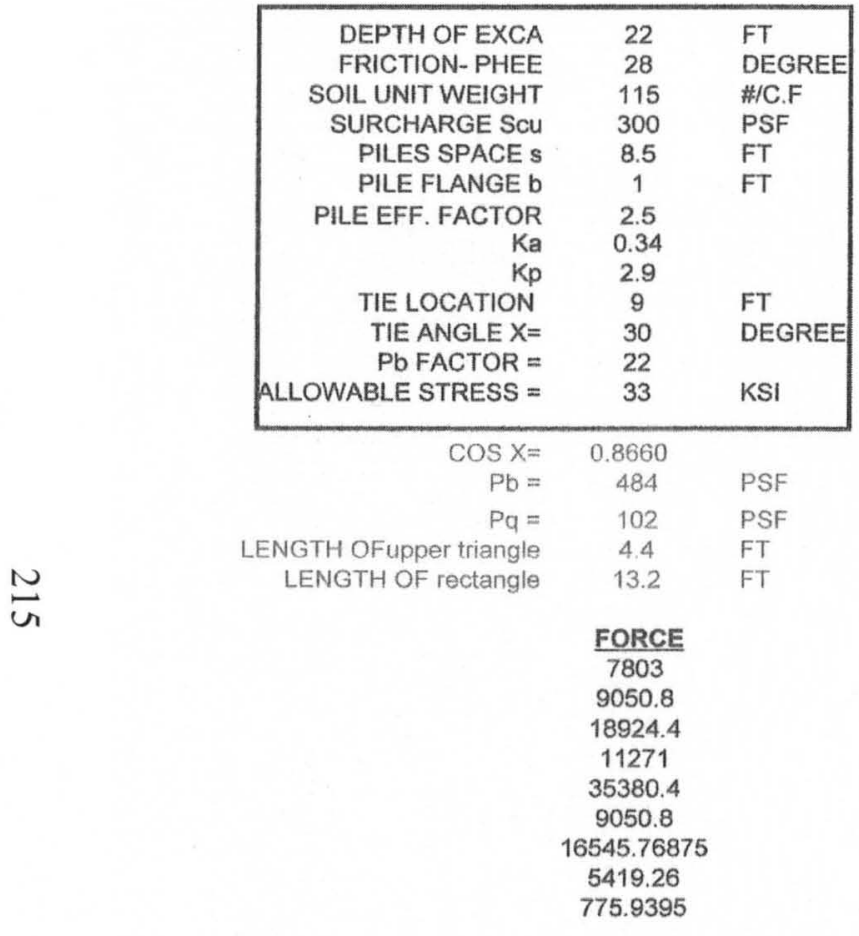

try diff.value of D

\begin{tabular}{|lcl|}
\hline PILE PENETR. D $=$ & 6.3 & FT \\
\hline PAS.PRESSUp1 $=$ & 5252.625 & PSF \\
ACT.PRESSUp1 $=$ & 860.2 & PSF \\
ACT.PRESSUP2 $=$ & 246.33 & PSF \\
DIST.FROM DRE- & 13 & $\mathrm{FT}$ \\
DGE LINE TO TIE & & \\
\hline
\end{tabular}

TO FIND PILE PEnetration D

MOMENT @TIEBACK LOCATION
TOTAL.MOMENT@TIE LOCATION=

\section{MOMENT \\ 35113.5 \\ 54775.4416
43526.12 \\ 43526.12
73261.5 \\ 73261.5 \\ 152135.72 \\ 90978.6416 \\ 283892.3002 \\ 87521.049
13313.56994 \\ $=======$}

(THIS VALUE SHOULD APPROX. $=0$ )

$\begin{array}{rrrr}\text { the (D)should be= } & 7.56 & \mathrm{FT} & \\ \text { used } \\ \text { USE D }= & 8.00 & \begin{array}{c}\mathrm{FT} \\ \text { HENCE }\end{array} & \text { OK } \\ \text { F.S } & = & 1.27 & \text { OK } \\ \text { TOTAL LENGTHt=D+H }= & 30.00 & \text { FT } & \end{array}$




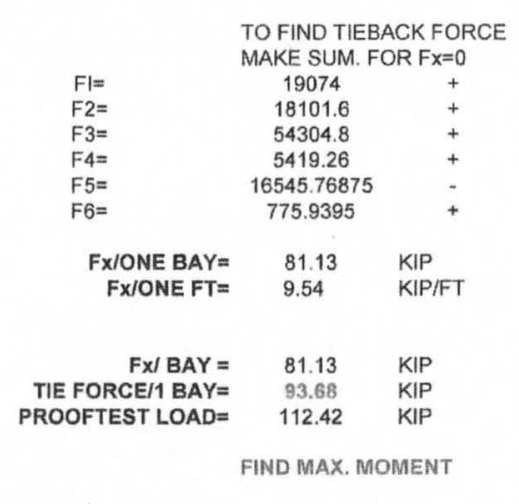

1 @TIEBACK LOCATION =

$$
\begin{gathered}
\text { FORCE } \\
\hline 7803 \\
9050.8 \\
18924.4
\end{gathered}
$$




\section{CASE 14 PART A}
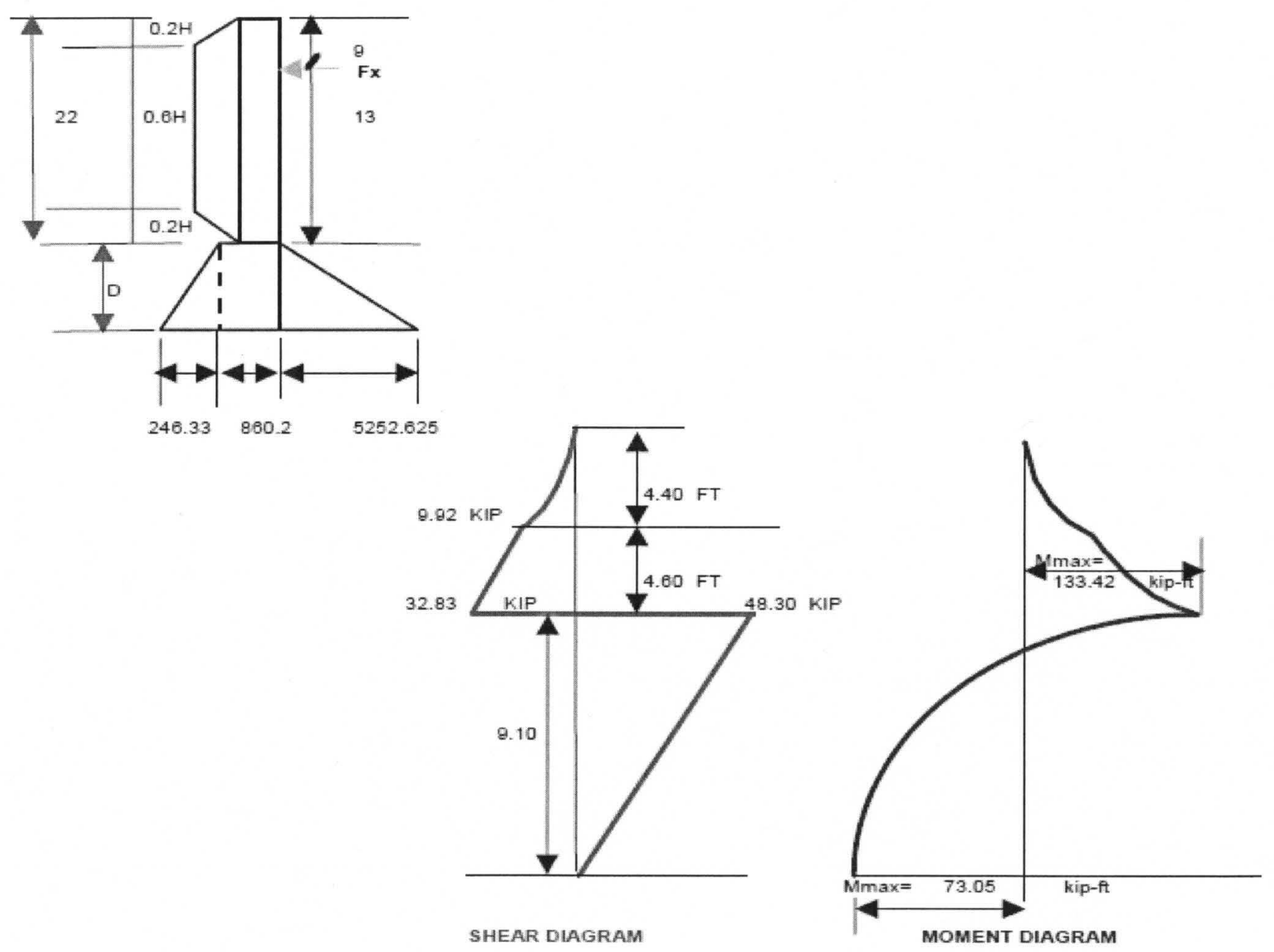

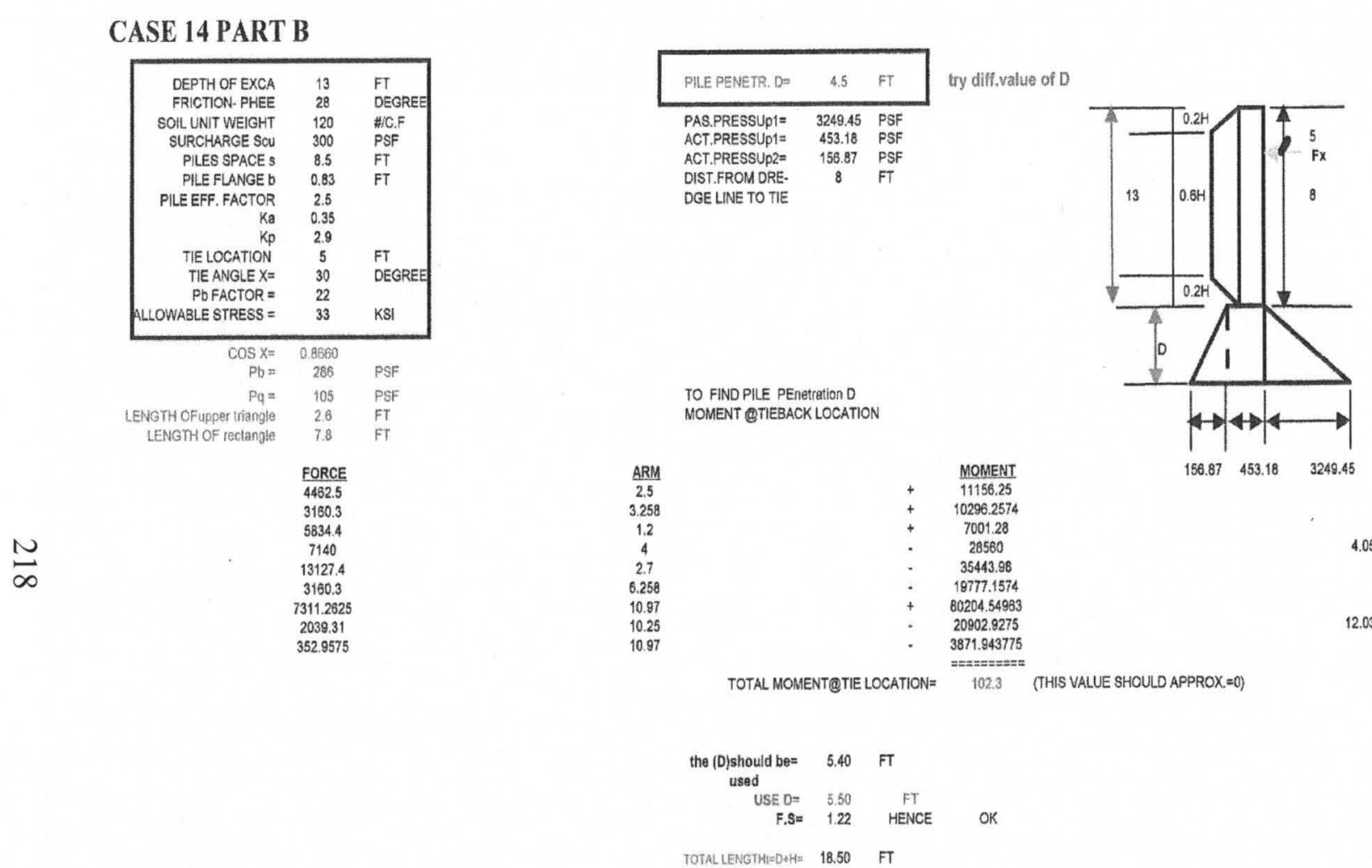

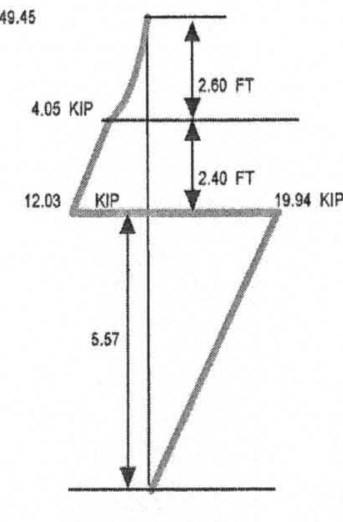

SHEAR DIAGRAM

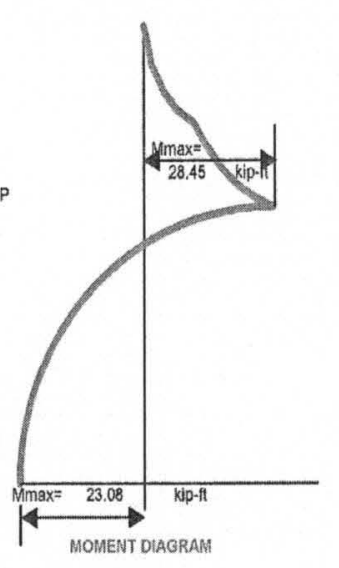




\section{CASE 14 PART B}

\begin{tabular}{|c|c|c|}
\hline DEPTH OF EXCA & 13 & FT \\
\hline FRICTION-PHEE & 28 & DEGREE \\
\hline SOIL UNIT WEIGHT & 120 & \#/C.F \\
\hline SURCHARGE SCU & 300 & PSF \\
\hline PILES SPACE $\mathbf{s}$ & 8.5 & FT \\
\hline PILE FLANGE $b$ & 0.83 & FT \\
\hline PILE EFF. FACTOR & 2.5 & \\
\hline & 0.35 & \\
\hline Kp & 2.9 & \\
\hline TIE LOCATION & 5 & FT \\
\hline TIE ANGLE $X=$ & 30 & DEGREE \\
\hline $\mathrm{Pb}$ FACTOR $=$ & 22 & \\
\hline ALLOWABLE STRESS = & 33 & kSI \\
\hline $\cos x=$ & 0.8660 & \\
\hline $\mathrm{Pb}=$ & 286 & PSF \\
\hline $\mathrm{Pq}=$ & 105 & PSF \\
\hline ENGTH OFupper triangle & 2.6 & FT \\
\hline LENGTH OF rectangle & 7.8 & FT \\
\hline
\end{tabular}

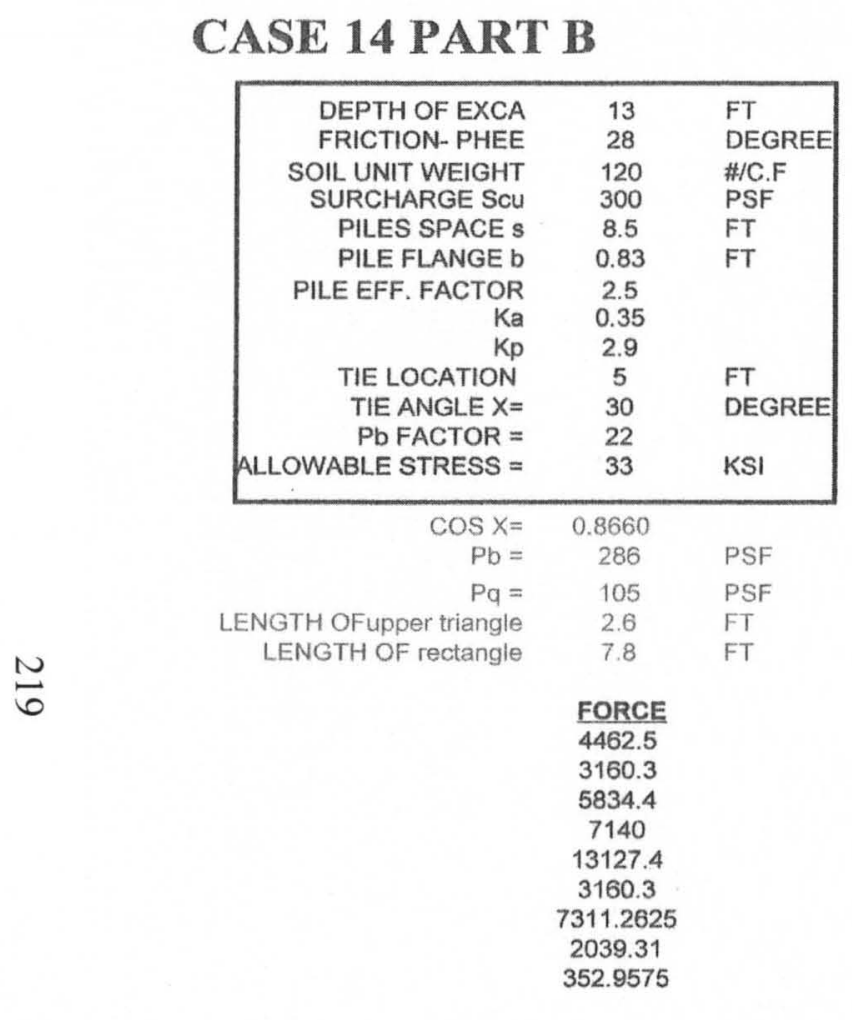

try diff.value of D

\begin{tabular}{|ccc|}
\multicolumn{3}{c}{ try diff.value of D } \\
\hline PILE PENETR. D $=$ & 4.5 & FT \\
\hline PAS.PRESSUp1 $=$ & 3249.45 & PSF \\
ACT.PRESSUp1 $=$ & 453.18 & PSF \\
ACT.PRESSUp2 $=$ & 156.87 & PSF \\
DIST.FROM DRE- & 8 & FT \\
DGE LINE TO TIE & & \\
\hline
\end{tabular}

TO FIND PILE PEnetration D

MOMENT @TIEBACK LOCATION

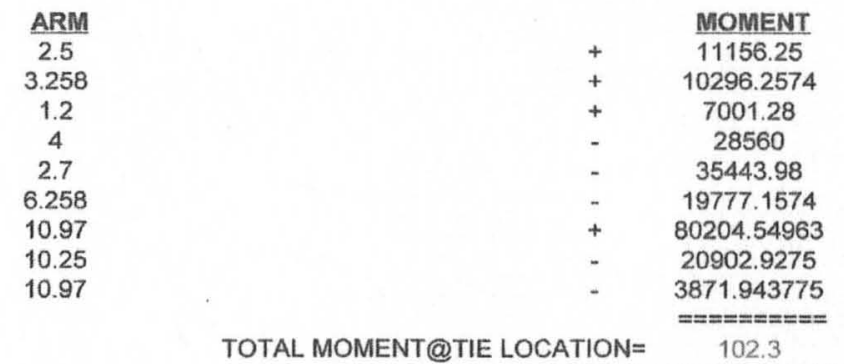

TOTAL MOMENT@TIE LOCATION=

(THIS VALUE SHOULD APPROX. $=0$ )

\begin{tabular}{|c|c|c|}
\hline $\begin{array}{c}\text { the (D)should be= } \\
\text { used }\end{array}$ & 5.40 & FT \\
\hline USE D $=$ & 5.50 & FT \\
\hline$F . S=$ & 1.22 & HENCE \\
\hline TOTAL LENGTHt=D+H= & 18.50 & FT \\
\hline
\end{tabular}

12f05/201010:15:20 PM1CASE14 PARTB.123। 


\begin{tabular}{|c|c|c|c|}
\hline & \multicolumn{2}{|c|}{ TO FIND TIEBACK FORCE } & \\
\hline $\mathrm{Fl}=$ & 11602.5 & + & \\
\hline$F_{2}=$ & 6320.6 & + & \\
\hline$F 3=$ & 18961.8 & + & \\
\hline $\mathrm{F} 4=$ & 2039.31 & + & \\
\hline$F 5=$ & 7311.2625 & - & \\
\hline$F 6=$ & 352.9575 & + & \\
\hline \multirow{3}{*}{$\begin{array}{r}\mathrm{Fx} / \mathrm{ONE} \mathrm{BAY}= \\
\mathrm{Fx} / \mathrm{ONE} \mathrm{FT}=\end{array}$} & 31.97 & KIP & \\
\hline & 3.76 & KIP/FT & \\
\hline & & & 2 BAYS \\
\hline $\mathrm{Fx} / \mathrm{BAY}=$ & 31.97 & KIP & 63.93 \\
\hline TIE FORCE/1 BAY= & 36.91 & KIP & 73.82 \\
\hline PROOFTEST LOAD= & 44.29 & KIP & 88.59 \\
\hline \multicolumn{4}{|c|}{$\mathrm{MEN}$} \\
\hline
\end{tabular}

1 @TIEBACK LOCATION =

\subsection{8 \\ 1.2}

MAX, MOMENT=

11156.25

10296.26

28.45

MOMENT

49848.18

27896.10

77191.06
MAX. MOMENT:

USE MAX. MOMENT: MOO. SECTION $=$

\section{ARM}

5.5690402

3.9845201

23.08 KIP.FT

28.45 KIP.FT
10.35 CUB. IN (Gr-50) 


\section{CASE 14 PART B}

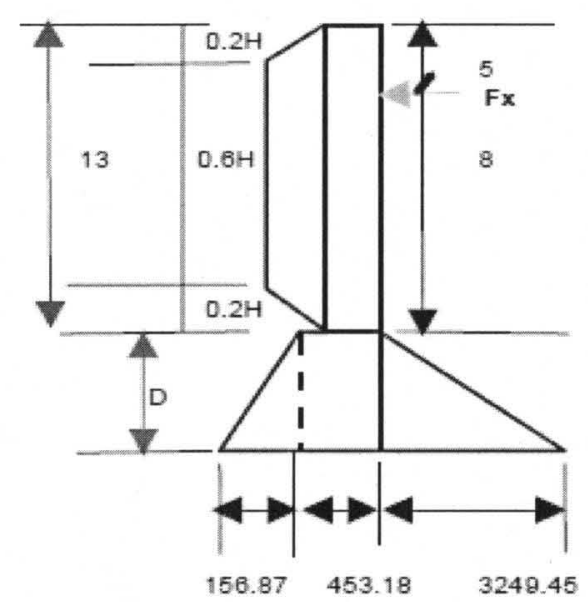

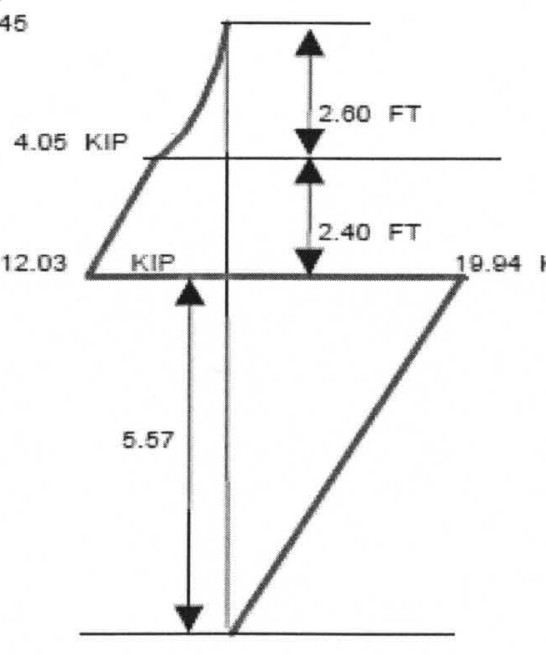

SHEAR DIAGRAM

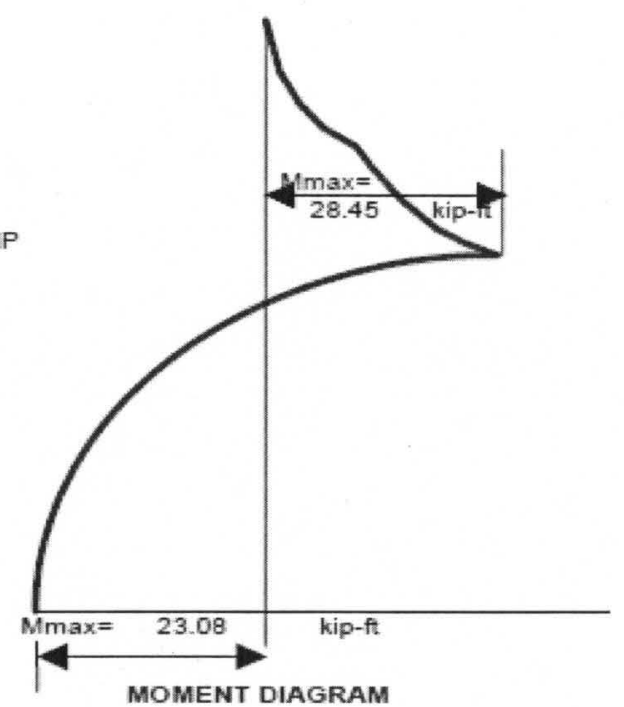




\section{CASE 15}

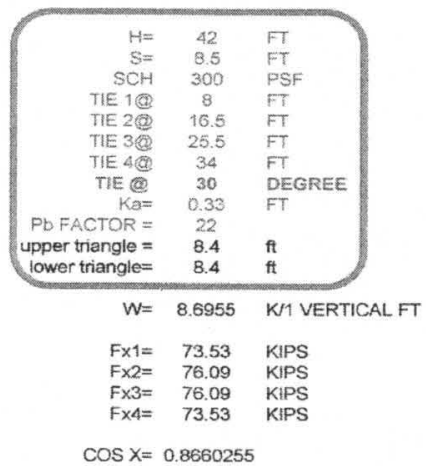

$\mathrm{DL} .1=85 \quad \mathrm{KPP}$

$\begin{array}{lll}\text { DL2 }= & 88 & \mathrm{KIP} \\ \mathrm{DL3}= & 88 & \mathrm{KIP} \\ \mathrm{DL4}= & 85 & \mathrm{KPP}\end{array}$

PROOF LOAD $1.2 \times D L$

PROOF TIE 1 $=102 \quad$ KIPS

PROOF TIE $2=105 \quad \mathrm{KIPS}$

$\begin{array}{lll}\text { PROOF TIE } 3= & 105 & \text { KIPS } \\ \text { PROOF TIE4 } & =102 & \text { KIPS }\end{array}$

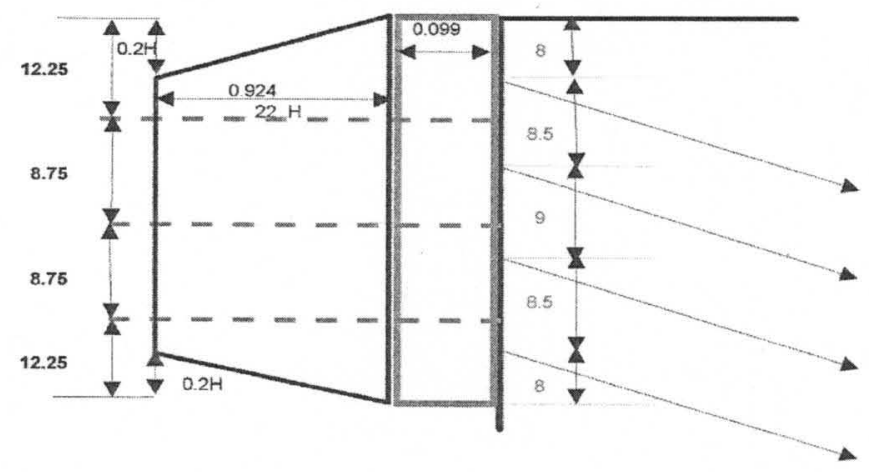

MAX MOMENT 1 O TEE 1 LOCATION

\section{$\frac{\text { FORCE }}{6.73}$ 6.73
29.92}

$X$ IS BELOW $0.2 H$

\section{FORCE \\ 7.07
32.99 \\ 32.99
33.48
73.53}

MAX MOMENT 2 @ TIE 2 LOCATION

MAX MOMENT 3 BETWEEN 2NO AND 3Rd TIE

$$
\begin{gathered}
\frac{\text { FORCE }}{7.07} \\
32.99 \\
70.43
\end{gathered}
$$

X2 IS BELOW $0.2 \mathrm{H}$

$$
x 2=12.60
$$

$$
\begin{gathered}
\frac{\text { FORCE }}{7.07} \\
32.99 \\
109.56 \\
73.53 \\
76.09
\end{gathered}
$$

MAX MOMENT 4 OTE 3 LOCATION

$$
\begin{gathered}
\frac{\text { FORCE }}{7.07} \\
32.99 \\
148.69 \\
73.53 \\
76.09
\end{gathered}
$$

MAX MOMENT 5 BETWEEN 3rd AND 4th TIE

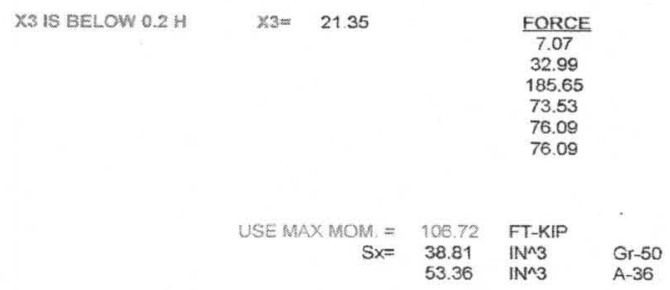

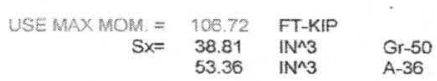

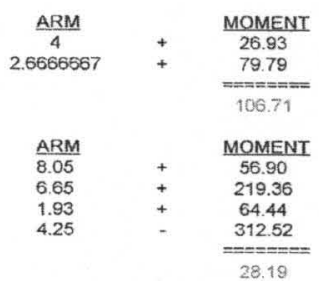

$\begin{array}{ccc}\text { ARM } & & \text { MOMENT } \\ 12.3 & + & 86.94 \\ 10.90 & + & 359.56 \\ 4.05 & + & 285.26 \\ 8.5 & - & 625.03 \\ & & =====-\end{array}$

106.72

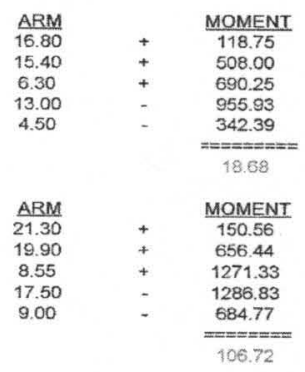

$\begin{array}{ccc}\text { ARM } & & \text { MOMENT } \\ 25.55 & + & 180.60 \\ 24.15 & + & 796.63 \\ 10.68 & + & 1981.80 \\ 21.75 & - & 1599.34 \\ 13.25 & - & 1008.13 \\ 4.25 & - & 323.36 \\ & & = \\ & & 28.19\end{array}$

\begin{tabular}{ll} 
FORCE \\
\hline 7.07 \\
32.99 \\
185.65 \\
73.53 \\
76.09 \\
76.09 \\
\\
\\
\\
FT-KIP \\
INN3 \\
IN & \\
IN 3 & Gr-50
\end{tabular}


Appendix C: Soil Nailing Design 


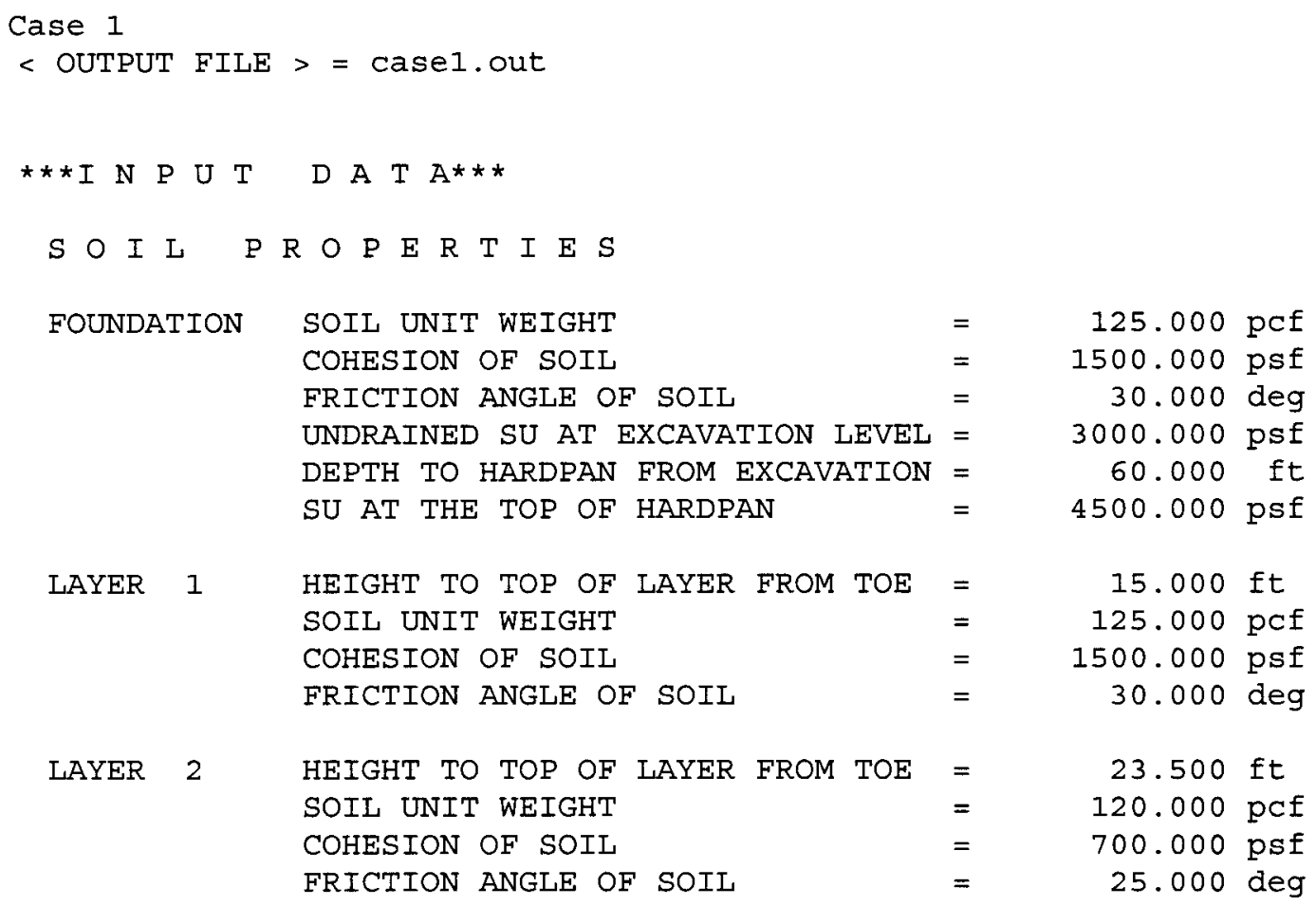

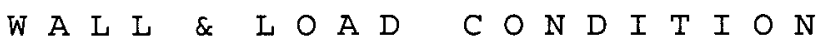

$\begin{array}{llr}\text { WAIL INCLINATION ANGLE } & = & 5.000 \mathrm{deg} \\ \text { SURCHARGE LOAD } & = & 300.000 \mathrm{psf} \\ \text { HOR. ACCELERATION COEFF. } & = & .000\end{array}$

N A I I P R O P E R T I E S

$\begin{array}{llr}\text { CROSS SECTIONAL AREA OF NAIL } & = & .790 \mathrm{si} \\ \text { GROUT DIAMETER } & = & 4.000 \mathrm{in} \\ \text { YIELD STRENGTH OF NAIL } & = & 60.000 \mathrm{ksi} \\ \text { NAIL INCLINATION ANGLE } & = & 20.000 \mathrm{deg} \\ \text { NAIL SKEW ANGLE AT SURFACE } & = & .000 \mathrm{deg} \\ \text { DEPTH TO UPPERMOST NAIL } & = & 2.000 \mathrm{ft} \\ \text { VER. SPACING OF NAIL } & = & 5.000 \mathrm{ft} \\ \text { HOR. SPACING OF NAIL } & = & 5.000 \mathrm{ft} \\ \text { TOTAL LENGTH OF UPPERMOST NAIL } & = & 20.000 \mathrm{ft} \\ \text { TOTAL LENGTH OF LOWERMOST NAIL } & = & 15.000 \mathrm{ft} \\ \text { TOTAL UNBONDED LENGTH OF NAIL } & = & 2.000 \mathrm{ft}\end{array}$

\begin{tabular}{|c|c|c|c|c|c|c|c|c|}
\hline$I=$ & 2 & $A=$ & .133 & F.S. $=$ & 7.077 & $\mathrm{~T}=$ & 5503.8660 & $1 b / f t$ \\
\hline$I=$ & 3 & $A=$ & .200 & F.S. $=$ & 4.378 & $\mathrm{~T}=$ & 8471.4570 & $1 b / f t$ \\
\hline$I=$ & 4 & $A=$ & .267 & F.S. $=$ & 3.459 & $\mathrm{~T}=$ & 10022.7700 & $1 \mathrm{~b} / \mathrm{ft}$ \\
\hline$I=$ & 5 & $A=$ & .333 & F.S. $=$ & 2.999 & $\mathrm{~T}=$ & 10816.7900 & $1 \mathrm{~b} / \mathrm{ft}$ \\
\hline$I=$ & 6 & $A=$ & .400 & F.S. = & 2.727 & $\mathrm{~T}=$ & 11132.3400 & $1 b / f t$ \\
\hline$I=$ & 7 & $A=$ & .467 & F.S. $=$ & 2.556 & $\mathrm{~T}=$ & 11135.6700 & $1 \mathrm{~b} / \mathrm{ft}$ \\
\hline$I=$ & 8 & $A=$ & .533 & F.S. $=$ & 2.444 & $\mathrm{~T}=$ & 10882.2900 & $1 \mathrm{~b} / \mathrm{ft}$ \\
\hline$I=$ & 9 & $A=$ & .600 & F.S. $=$ & 2.370 & $\mathrm{~T}=$ & 10488.4400 & $1 \mathrm{~b} / \mathrm{ft}$ \\
\hline$I=$ & 10 & $A=$ & .667 & F.S. $=$ & 2.324 & $\mathrm{~T}=$ & 9991.4200 & $1 \mathrm{~b} / \mathrm{ft}$ \\
\hline
\end{tabular}




\begin{tabular}{|c|c|c|c|c|c|c|c|c|}
\hline$I=$ & 11 & $A=$ & .733 & F.S. $=$ & 2.298 & $\mathrm{~T}=$ & 9426.2420 & $1 b / f t$ \\
\hline$I=$ & 12 & $A=$ & .800 & F.S. $=$ & 2.289 & $\mathrm{~T}=$ & 8819.0440 & $1 \mathrm{~b} / \mathrm{tt}$ \\
\hline$I=$ & 13 & $A=$ & .867 & F.S. = & 2.290 & $\mathrm{~T}=$ & 8195.4920 & $1 b / f t$ \\
\hline$I=$ & 14 & $A=$ & .933 & F.S. $=$ & 2.304 & $\mathrm{~T}=$ & 7555.6580 & $1 b / f t$ \\
\hline$I=$ & 15 & $A=$ & 1.000 & F.S. $=$ & 2.325 & $\mathrm{~T}=$ & 6919.8540 & $1 \mathrm{~b} / \mathrm{ft}$ \\
\hline$I=$ & 16 & $A=$ & 1.067 & F.S. $=$ & 2.352 & $\mathrm{~T}=$ & 6281.2810 & $1 b / f t$ \\
\hline$I=$ & 17 & $\mathrm{~A}=$ & 1.133 & F.S. $=$ & 2.388 & $\mathrm{~T}=$ & 5651.4060 & $1 \mathrm{~b} / \mathrm{ft}$ \\
\hline$I=$ & 18 & $A=$ & 1.200 & F.S. = & 2.441 & $\mathrm{~T}=$ & 5147.3830 & $1 b / f t$ \\
\hline$I=$ & 19 & $\mathrm{~A}=$ & 1.267 & F.S. $=$ & 2.494 & $\mathrm{~T}=$ & 4739.9440 & $1 \mathrm{~b} / \mathrm{Et}$ \\
\hline$I=$ & 20 & $A=$ & 1.333 & F.S. = & 2.550 & $\mathrm{~T}=$ & 4439.7350 & $1 \mathrm{~b} / \mathrm{ft}$ \\
\hline$I=$ & 21 & $A=$ & 1.400 & F.S. $=$ & 2.603 & $\mathrm{~T}=$ & 4161.5110 & $1 b / f t$ \\
\hline$I=$ & 22 & $A=$ & 1.467 & F.S. $=$ & 2.655 & $\mathrm{~T}=$ & 3902.4920 & $1 \mathrm{~b} / \mathrm{Et}$ \\
\hline$I=$ & 23 & $A=$ & 1.533 & F.S. $=$ & 2.708 & $\mathrm{~T}=$ & 3660.1650 & $1 b / \pm t$ \\
\hline$I=$ & 24 & $A=$ & 1.600 & F.S. $=$ & 2.763 & $\mathrm{~T}=$ & 3528.2610 & $1 b / \mathrm{ft}$ \\
\hline$I=$ & 25 & $A=$ & 1.667 & F.S. $=$ & 2.822 & $\mathrm{~T}=$ & 3400.6970 & $1 b / f t$ \\
\hline$I=$ & 26 & $A=$ & 1.733 & F.S. $=$ & 2.879 & $\mathrm{~T}=$ & 3282.1720 & $1 b / \mathrm{ft}$ \\
\hline$I=$ & 27 & $A=$ & 1.800 & F.S. $=$ & 2.937 & $\mathrm{~T}=$ & 3170.3480 & $1 \mathrm{~b} / \mathrm{ft}$ \\
\hline$I=$ & 28 & $A=$ & 1.867 & F.S. = & 2.995 & $\mathrm{~T}=$ & 3064.6080 & $1 b / f t$ \\
\hline$I=$ & 29 & $A=$ & 1.933 & F.S. $=$ & 3.053 & $\mathrm{~T}=$ & 2964.4420 & $1 b / f t$ \\
\hline$I=$ & 30 & $A=$ & 2.000 & F.S. $=$ & 3.113 & $\mathrm{~T}=$ & 2869.4180 & $1 \mathrm{~b} / \mathrm{ft}$ \\
\hline
\end{tabular}

$\mathrm{H} / \mathrm{LT}=1.175 \quad \mathrm{H} / \mathrm{LB}=1.567$

NO. OF NAILS (INCLUDING THE LOWERMOST) = 5

**F.S. AGAINST SLIDING THROUGH TOE $=2.29$

$\star \star F . S . ~ A G A I N S T$ DEEP SEATED ROTATION $=6.29$

1 TH NAIL FORCE =

2 TH NAIL FORCE =

3 TH NAIL FORCE =

$4 \mathrm{TH}$ NAIL FORCE =

$5 \mathrm{TH}$ NAIL FORCE $=$
$613.4692 \mathrm{lb} / \mathrm{ft}$

$1173.21601 \mathrm{~b} / \mathrm{ft}$

$1560.63001 \mathrm{~b} / \mathrm{et}$

$2163.4070 \mathrm{lb} / \mathrm{ft}$

$3308.3210 \mathrm{lb} / \mathrm{ft}$ 


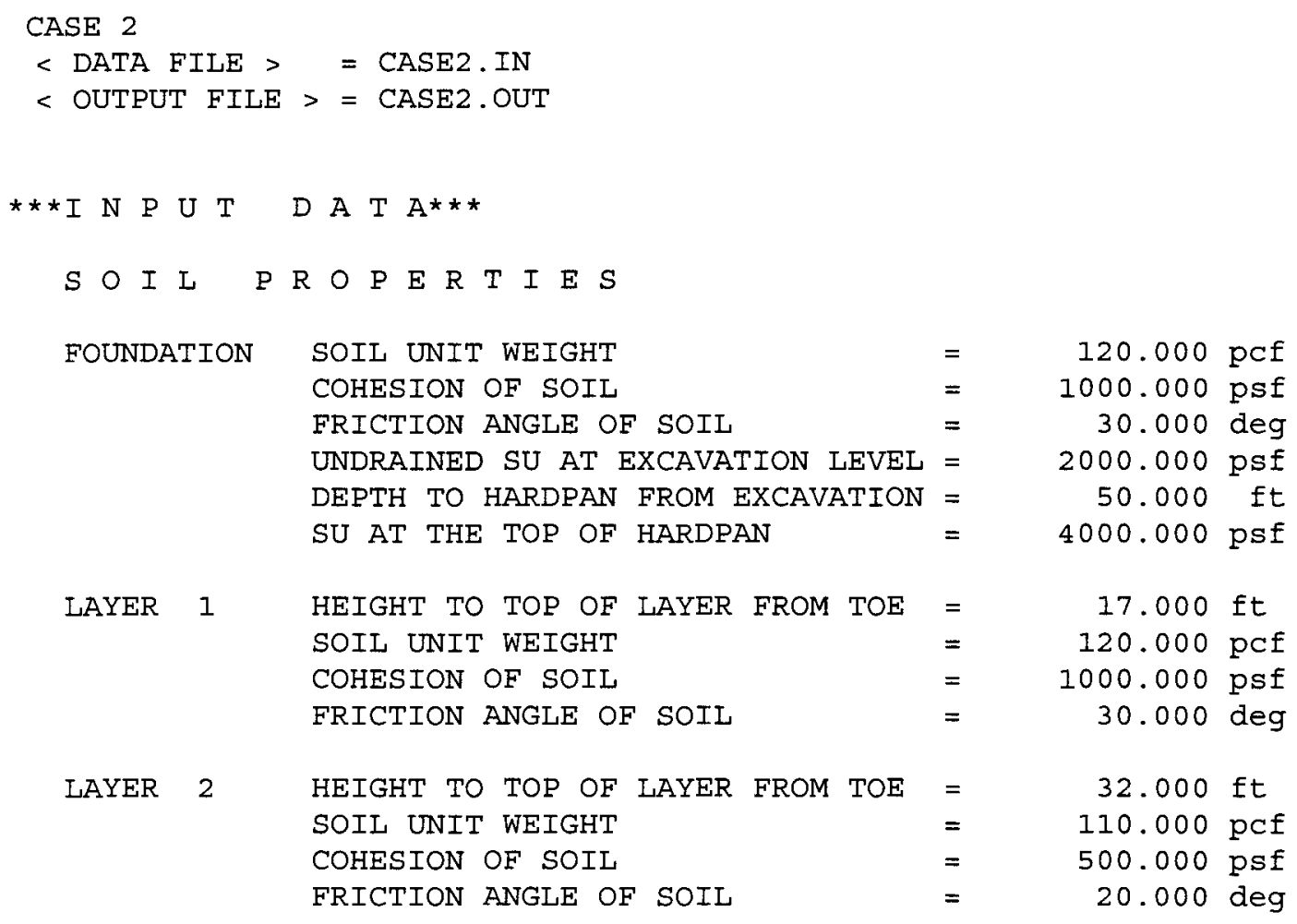

W A L L \& L O A D $\quad$ C O N D I T I O N

$\begin{array}{llr}\text { WALI INCLINATION ANGLE } & = & 5.000 \mathrm{deg} \\ \text { SURCHARGE LOAD } & = & 300.000 \mathrm{psf} \\ \text { HOR. ACCELERATION COEFF. } & = & .000\end{array}$

$N$ A I I P R O P E R T I E S

$\begin{array}{llr}\text { CROSS SECTIONAL AREA OF NAIL } & = & .790 \mathrm{si} \\ \text { GROUT DIAMETER } & = & 4.000 \mathrm{in} \\ \text { YIELD STRENGTH OF NAIL } & = & 60.000 \mathrm{ksi} \\ \text { NAIL INCLINATION ANGLE } & = & 20.000 \mathrm{deg} \\ \text { NAIL SKEW ANGLE AT SURFACE } & = & .000 \mathrm{deg} \\ \text { DEPTH TO UPPERMOST NAIL } & = & 2.000 \mathrm{ft} \\ \text { VER. SPACING OF NAIL } & = & 5.000 \mathrm{ft} \\ \text { HOR. SPACING OF NAIL } & = & 5.000 \mathrm{ft} \\ \text { TOTAL LENGTH OF UPPERMOST NAIL } & = & 28.000 \mathrm{ft} \\ \text { TOTAL LENGTH OF LOWERMOST NAIL } & = & 22.000 \mathrm{ft} \\ \text { TOTAL UNBONDED LENGTH OF NAIL } & = & 2.000 \mathrm{ft}\end{array}$

\begin{tabular}{|c|c|c|c|c|c|c|c|c|}
\hline$I=$ & 2 & $A=$ & .133 & F.S. $=$ & 3.622 & $T=$ & 15909.9900 & $1 \mathrm{~b} / \mathrm{ft}$ \\
\hline$I=$ & 3 & $A=$ & .200 & F.S. $=$ & 2.559 & $\mathrm{~T}=$ & 20901.1700 & $1 b / f t$ \\
\hline$I=$ & 4 & $A=$ & .267 & F.S. $=$ & 2.142 & $\mathrm{~T}=$ & 23113.2700 & $1 b / f t$ \\
\hline$I=$ & 5 & $A=$ & .333 & F.S. $=$ & 1.920 & $\mathrm{~T}=$ & 24033.1300 & $1 \mathrm{~b} / \mathrm{ft}$ \\
\hline$I=$ & 6 & $A=$ & .400 & F.S. $=$ & 1.783 & $\mathrm{~T}=$ & 24222.1900 & $\mathrm{Ib} / \mathrm{ft}$ \\
\hline$I=$ & 7 & $A=$ & .467 & F.S. = & 1.696 & $T=$ & 23813.9900 & $1 b / f t$ \\
\hline$I=$ & 8 & $A=$ & .533 & F.S. = & 1.639 & $\mathrm{~T}=$ & 23022.3000 & $1 b / f t$ \\
\hline$I=$ & 9 & $A=$ & .600 & F.S. $=$ & 1.604 & $\mathrm{~T}=$ & 21982.9300 & $1 b / f t$ \\
\hline
\end{tabular}




\begin{tabular}{|c|c|c|c|c|c|c|c|c|}
\hline$I=$ & 10 & $A=$ & .667 & F.S. $=$ & 1.582 & $\mathrm{~T}=$ & 20800.5700 & $1 b /$ ft \\
\hline$I=$ & 11 & $A=$ & .733 & F.S. $=$ & 1.573 & $T=$ & 19512.8600 & $1 b / \mathrm{ft}$ \\
\hline$I=$ & 12 & $A=$ & .800 & F.S. = & 1.573 & $\mathrm{~T}=$ & 18164.1300 & $1 \mathrm{~b} / \mathrm{ft}$ \\
\hline$I=$ & 13 & $A=$ & .867 & F.S. = & 1.580 & $\mathrm{~T}=$ & 16787.8700 & $1 b / f t$ \\
\hline$I=$ & 14 & $A=$ & .933 & F.S. $=$ & 1.593 & $\mathrm{~T}=$ & 15417.0900 & $1 \mathrm{~b} / \mathrm{ft}$ \\
\hline$I=$ & 15 & $A=$ & 1.000 & F.S. $=$ & 1.611 & $\mathrm{~T}=$ & 14050.8300 & $1 \mathrm{~b} / \mathrm{ft}$ \\
\hline$I=$ & 16 & $A=$ & 1.067 & F.S. $=$ & 1.633 & $\mathrm{~T}=$ & 12673.3600 & $1 b / f t$ \\
\hline$I=$ & 17 & $A=$ & 1.133 & F.S. $=$ & 1.658 & $\mathrm{~T}=$ & 11289.5100 & $1 b / f t$ \\
\hline$I=$ & 18 & $A=$ & 1.200 & F.S. $=$ & 1.708 & $\mathrm{~T}=$ & 10016.9300 & $I b / f t$ \\
\hline$I=$ & 19 & $A=$ & 1.267 & F.S. $=$ & 1.755 & $\mathrm{~T}=$ & 8997.1090 & $1 \mathrm{~b} / \mathrm{ft}$ \\
\hline$I=$ & 20 & $A=$ & 1.333 & F.S. $=$ & 1.796 & $\mathrm{~T}=$ & 8165.0090 & $1 b / f t$ \\
\hline$I=$ & 21 & $A=$ & 1.400 & F.S. $=$ & 1.836 & $\mathrm{~T}=$ & 7427.8940 & $1 b / f t$ \\
\hline$I=$ & 22 & $A=$ & 1.467 & F.S. $=$ & 1.881 & $\mathrm{~T}=$ & 6902.8730 & $1 b / \mathrm{et}$ \\
\hline$I=$ & 23 & $A=$ & 1.533 & F.S. = & 1.921 & $\mathrm{~T}=$ & 6424.9310 & $1 \mathrm{~b} / \mathrm{ft}$ \\
\hline$I=$ & 24 & $A=$ & 1.600 & F.S. $=$ & 1.960 & $\mathrm{~T}=$ & 5978.8790 & $1 b / \mathrm{ft}$ \\
\hline$I=$ & 25 & $A=$ & 1.667 & F.S. $=$ & 2.001 & $\mathrm{~T}=$ & 5556.2960 & $1 \mathrm{~b} / \mathrm{ft}$ \\
\hline$I=$ & 26 & $A=$ & 1.733 & F.S. $=$ & 2.041 & $\mathrm{~T}=$ & 5177.5890 & $1 b / f t$ \\
\hline$I=$ & 27 & $A=$ & 1.800 & F.S. $=$ & 2.085 & $\mathrm{~T}=$ & 4944.5800 & $1 \mathrm{~b} / \mathrm{ft}$ \\
\hline$I=$ & 28 & $A=$ & 1.867 & F.S. $=$ & 2.129 & $\mathrm{~T}=$ & 4726.2550 & $1 \mathrm{~b} / \mathrm{ft}$ \\
\hline$I=$ & 29 & $A=$ & 1.933 & F.S. $=$ & 2.173 & $\mathrm{~T}=$ & 4521.2840 & $1 \mathrm{~b} / \mathrm{ft}$ \\
\hline$I=$ & 30 & $A=$ & 2.000 & F.S. $=$ & 2.217 & $\mathrm{~T}=$ & 4328.5330 & $1 b / f t$ \\
\hline
\end{tabular}

$\mathrm{H} / \mathrm{LT}=1.143 \quad \mathrm{H} / \mathrm{LB}=1.455$

NO. OF NAILS (EXCLUDING THE LOWERMOST) = 6

**F.S. AGAINST SLIDING THROUGH TOE $=1.57$

$* *$ F.S. AGAINST DEEP SEATED ROTATION $=4.18$

1 TH NAIL FORCE =

2 TH NAIL FORCE =

3 TH NAIL FORCE =

4 TH NAIL FORCE =

5 TH NAIL FORCE =

$6 \mathrm{TH}$ NAIL FORCE =
$896.11401 \mathrm{~b} / \mathrm{ft}$

$1498.1950 \mathrm{lb} / \mathrm{ft}$

$2470.0860 \mathrm{lb} / \mathrm{ft}$

$3202.5090 \mathrm{lb} / \mathrm{ft}$

$4186.5750 \mathrm{lb} / \mathrm{ft}$

$5910.64601 \mathrm{~b} / \mathrm{ft}$ 


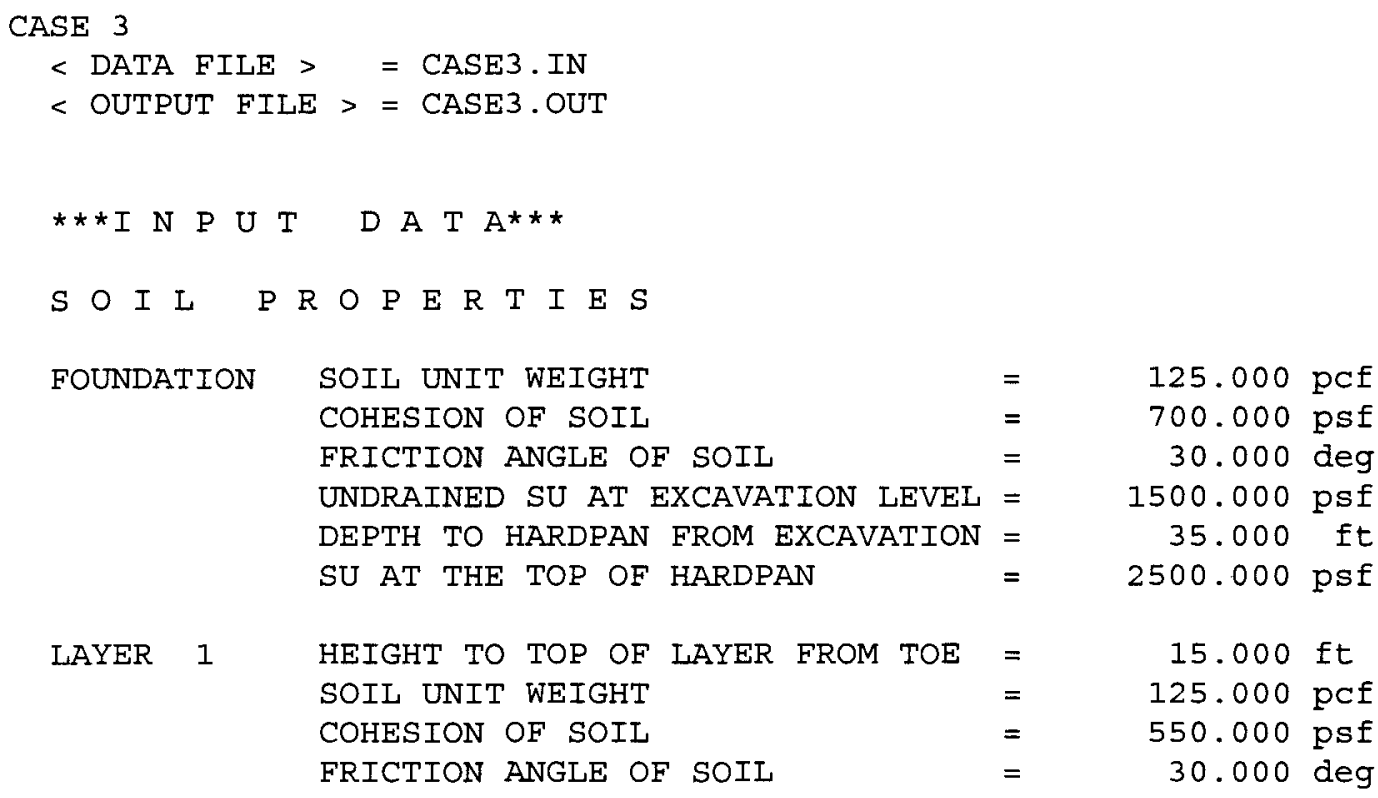

W A L I \& L O A D $\quad$ C O N D I T I O N

$\begin{array}{llr}\text { WALL INCLINATION ANGLE } & = & 5.000 \mathrm{deg} \\ \text { SURCHARGE LOAD } & = & 100.000 \mathrm{psf} \\ \text { HOR. ACCELERATION COEFF. } & = & .000\end{array}$

$N$ A I L P R O P E R T I E S

$\begin{array}{llr}\text { CROSS SECTIONAL AREA OF NAIL } & = & .440 \mathrm{si} \\ \text { GROUT DIAMETER } & = & 4.000 \mathrm{in} \\ \text { YIELD STRENGTH OF NAIL } & = & 60.000 \mathrm{ksi} \\ \text { NAIL INCLINATION ANGLE } & = & 20.000 \mathrm{deg} \\ \text { NAIL SKEW ANGLE AT SURFACE } & = & .000 \mathrm{deg} \\ \text { DEPTH TO UPPERMOST NAIL } & = & 2.000 \mathrm{ft} \\ \text { VER. SPACING OF NAIL } & = & 5.000 \mathrm{ft} \\ \text { HOR. SPACING OF NAIL } & = & 6.000 \mathrm{ft} \\ \text { TOTAL LENGTH OF UPPERMOST NAIL } & = & 12.000 \mathrm{ft} \\ \text { TOTAL LENGTH OF LOWERMOST NAIL } & = & 10.000 \mathrm{ft} \\ \text { TOTAL UNBONDED LENGTH OF NAIL } & = & 2.000 \mathrm{ft}\end{array}$

\begin{tabular}{|c|c|c|c|c|c|c|c|c|}
\hline$I=$ & 2 & $A=$ & .133 & F.S. = & 5.346 & $\mathrm{~T}=$ & 1018.3570 & $1 b / f t$ \\
\hline$I=$ & 3 & $A=$ & .200 & F.S. $=$ & 3.125 & $\mathrm{~T}=$ & 1644.8320 & $1 b / f t$ \\
\hline$I=$ & 4 & $A=$ & .267 & F.S. $=$ & 2.392 & $\mathrm{~T}=$ & 2019.7430 & $\mathrm{Ib} / \mathrm{ft}$ \\
\hline$I=$ & 5 & $A=$ & .333 & F.S. $=$ & 2.037 & $\mathrm{~T}=$ & 2199.8860 & $1 \mathrm{~b} / \mathrm{ft}$ \\
\hline$I=$ & 6 & $A=$ & .400 & F.S. $=$ & 1.833 & $\mathrm{~T}=$ & 2257.6530 & $1 \mathrm{~b} / \mathrm{ft}$ \\
\hline$I=$ & 7 & $A=$ & .467 & F.S. $=$ & 1.710 & $\mathrm{~T}=$ & 2224.8860 & $1 \mathrm{~b} / \mathrm{ft}$ \\
\hline$I=$ & 8 & $A=$ & .533 & F.S. $=$ & 1.635 & $\mathrm{~T}=$ & 2141.1770 & $1 \mathrm{~b} / \mathrm{ft}$ \\
\hline$I=$ & 9 & $A=$ & .600 & F.S. $=$ & 1.592 & $\mathrm{~T}=$ & 2023.4140 & $1 \mathrm{~b} / \mathrm{ft}$ \\
\hline$I=$ & 10 & $A=$ & .667 & F.S. $=$ & 1.571 & $T=$ & 1884.8360 & $1 b / f t$ \\
\hline$I=$ & 11 & $A=$ & .733 & F.S. $=$ & 1.567 & $\mathrm{~T}=$ & 1732.0180 & $I b / f t$ \\
\hline$I=$ & 12 & $A=$ & .800 & F.S. $=$ & 1.575 & $\mathrm{~T}=$ & 1573.0860 & $I b / f t$ \\
\hline$I=$ & 13 & $A=$ & .867 & F.S. $=$ & 1.593 & $\mathrm{~T}=$ & 1412.6720 & $\mathrm{Ib} / \mathrm{ft}$ \\
\hline$I=$ & 14 & $A=$ & .933 & F.S. $=$ & 1.617 & $\mathrm{~T}=$ & 1254.0750 & $1 \mathrm{~b} / \mathrm{ft}$ \\
\hline
\end{tabular}




\begin{tabular}{|c|c|c|c|c|c|c|c|c|}
\hline$I=$ & 15 & $A=$ & 1.000 & F.S. $=$ & 1.648 & $\mathrm{~T}=$ & 1099.5830 & $1 \mathrm{~b} / \mathrm{ft}$ \\
\hline$I=$ & 16 & $A=$ & 1.067 & F.S. $=$ & 1.684 & $T=$ & 950.7256 & $1 \mathrm{~b} / \mathrm{ft}$ \\
\hline$I=$ & 17 & $A=$ & 1.133 & F.S. $=$ & 1.736 & $T=$ & 850.3796 & $1 b / f t$ \\
\hline$I=$ & 18 & $A=$ & 1.200 & F.S. $=$ & 1.788 & $T=$ & 763.5302 & $\mathrm{lb} / \mathrm{ft}$ \\
\hline$I=$ & 19 & $A=$ & 1.267 & F.S. $=$ & 1.838 & $\mathrm{~T}=$ & 683.5601 & $1 \mathrm{~b} / \mathrm{ft}$ \\
\hline$I=$ & 20 & $A=$ & 1.333 & F.S. $=$ & 1.888 & $T=$ & 609.1956 & $1 \mathrm{~b} / \mathrm{ft}$ \\
\hline$I=$ & 21 & $A=$ & 1.400 & F.S. $=$ & 1.936 & $T=$ & 549.6973 & $\mathrm{lb} / \mathrm{ft}$ \\
\hline$I=$ & 22 & $A=$ & 1.467 & F.S. $=$ & 1.986 & $\mathrm{~T}=$ & 522.0972 & $1 \mathrm{~b} / \mathrm{ft}$ \\
\hline$I=$ & 23 & $A=$ & 1.533 & F.S. $=$ & 2.036 & $T=$ & 496.5759 & $1 \mathrm{~b} / \mathrm{ft}$ \\
\hline$I=$ & 24 & $\mathrm{~A}=$ & 1.600 & F.S. $=$ & 2.086 & $T=$ & 472.8983 & $1 b / f t$ \\
\hline$I=$ & 25 & $A=$ & 1.667 & F.S. $=$ & 2.136 & $T=$ & 450.8690 & $l b / f t$ \\
\hline$I=$ & 26 & $A=$ & 1.733 & F.S. $=$ & 2.186 & $T=$ & 430.3256 & $1 \mathrm{~b} / \mathrm{ft}$ \\
\hline$I=$ & 27 & $A=$ & 1.800 & F.S. $=$ & 2.236 & $T=$ & 411.1305 & $1 \mathrm{~b} / \mathrm{ft}$ \\
\hline$I=$ & 28 & $A=$ & 1.867 & F.S. $=$ & 2.286 & $T=$ & 393.1662 & $1 b / f t$ \\
\hline$I=$ & 29 & $A=$ & 1.933 & F.S. $=$ & 2.337 & $T=$ & 376.3316 & $1 \mathrm{~b} / \mathrm{ft}$ \\
\hline$I=$ & 30 & $A=$ & 2.000 & F.S. = & 2.388 & $\mathrm{~T}=$ & 360.5376 & $1 b / f$ \\
\hline
\end{tabular}

$\mathrm{H} / \mathrm{LT}=1.250 \quad \mathrm{H} / \mathrm{LB}=1.500$

NO. OF NAILS (INCLUDING THE LOWERMOST) = 3

**F.S. AGAINST SLIDING THROUGH TOE $=1.57$

**F.S. AGAINST DEEP SEATED ROTATION $=5.16$

1 TH NAIL FORCE =

2 TH NAIL FORCE =

3 TH NAIL FORCE =
$302.1914 \mathrm{lb} / \mathrm{ft}$

$510.61131 \mathrm{~b} / \mathrm{ft}$

$919.21531 \mathrm{~b} / \mathrm{ft}$ 


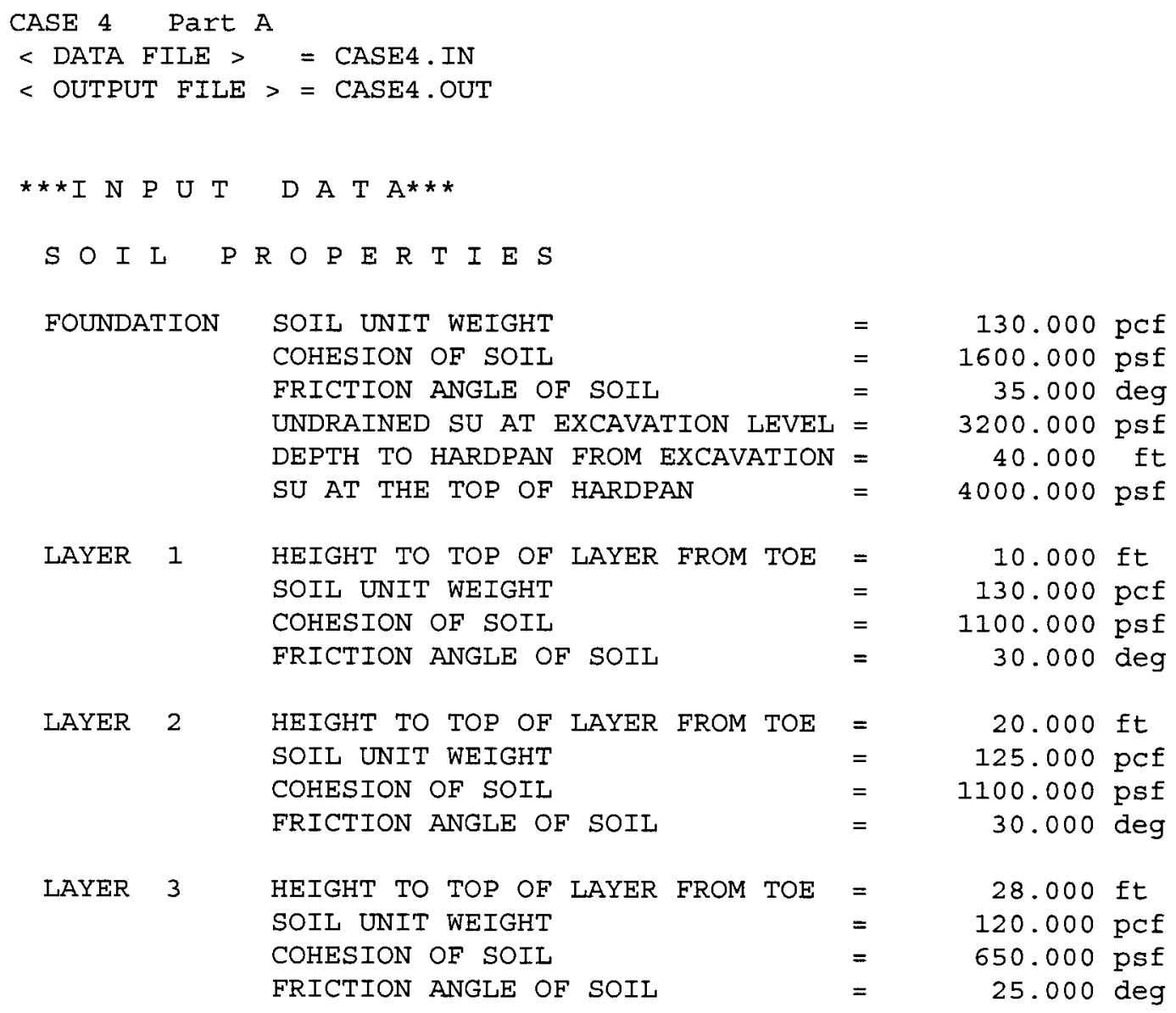

W A L L \& L O A D $\quad$ C O N D I T I O N

WAII INCLINATION ANGLE

SURCHARGE LOAD

HOR. ACCELERATION COEFF.
$=$

$=$

$=$

N A I L P R O P E R T I E S

CROSS SECTIONAL AREA OF NAIL = GROUT DIAMETER

YIELD STRENGTH OF NAIL

NAIL INCLINATION ANGLE

NAIL SKEW ANGLE AT SURFACE

DEPTH TO UPPERMOST NAIL

VER. SPACING OF NAIL

HOR. SPACING OF NAIL

TOTAL LENGTH OF UPPERMOST NAIL

TOTAL LENGTH OF LOWERMOST NAIL

TOTAL UNBONDED LENGTH OF NAIL

$$
\begin{array}{r}
5.000 \mathrm{deg} \\
250.000 \mathrm{psf} \\
.000
\end{array}
$$




\begin{tabular}{|c|c|c|c|c|c|c|c|c|}
\hline$I=$ & 2 & $A=$ & .133 & F.S. $=$ & 4.393 & $\mathrm{~T}=$ & 13252.5400 & $1 \mathrm{~b} / \mathrm{ft}$ \\
\hline$I=$ & 3 & $A=$ & .200 & F.S. = & 3.096 & $\mathrm{~T}=$ & 17732.9800 & $1 \mathrm{~b} / \mathrm{ft}$ \\
\hline$I=$ & 4 & $A=$ & .267 & F.S. $=$ & 2.595 & $\mathrm{~T}=$ & 19779.9400 & $1 \mathrm{~b} / \mathrm{ft}$ \\
\hline$I=$ & 5 & $A=$ & .333 & F.S. $=$ & 2.331 & $T=$ & 20723.3800 & $1 \mathrm{~b} / \mathrm{ft}$ \\
\hline$I=$ & 6 & $\mathrm{~A}=$ & .400 & F.S. $=$ & 2.169 & $T=$ & 21035.1600 & $1 \mathrm{~b} / \mathrm{ft}$ \\
\hline$I=$ & 7 & $A=$ & .467 & F.S. $=$ & 2.066 & $\mathrm{~T}=$ & 20918.5900 & $1 \mathrm{~b} / \mathrm{ft}$ \\
\hline$I=$ & 8 & $A=$ & .533 & F.S. $=$ & 2.001 & $\mathrm{~T}=$ & 20487.0400 & $1 \mathrm{~b} / \mathrm{ft}$ \\
\hline$I=$ & 9 & $A=$ & .600 & F.S. $=$ & 1.961 & $T=$ & 19850.1600 & $1 b / f t$ \\
\hline$I=$ & 10 & $A=$ & .667 & F.S. $=$ & 1.940 & $\mathrm{~T}=$ & 19060.2700 & $1 \mathrm{~b} / \mathrm{ft}$ \\
\hline$I=$ & 11 & $A=$ & .733 & F.S. $=$ & 1.930 & $\mathrm{~T}=$ & 18169.0500 & $1 \mathrm{~b} / \mathrm{ft}$ \\
\hline$I=$ & 12 & $A=$ & .800 & F.S. $=$ & 1.931 & $T=$ & 17212.1900 & $1 \mathrm{~b} / \mathrm{ft}$ \\
\hline$I=$ & 13 & $A=$ & .867 & F.S. $=$ & 1.936 & $T=$ & 16178.2300 & $1 \mathrm{~b} / \mathrm{ft}$ \\
\hline$I=$ & 14 & $A=$ & .933 & F.S. $=$ & 1.949 & $T=$ & 15131.6900 & $1 \mathrm{~b} / \mathrm{ft}$ \\
\hline$I=$ & 15 & $A=$ & 1.000 & F.S. $=$ & 1.965 & $\mathrm{~T}=$ & 14097.2600 & $1 \mathrm{~b} / \mathrm{ft}$ \\
\hline$I=$ & 16 & $A=$ & 1.067 & F.S. = & 1.989 & $\mathrm{~T}=$ & 13064.1500 & $1 \mathrm{~b} / \mathrm{ft}$ \\
\hline$I=$ & 17 & $A=$ & 1.133 & F.S. $=$ & 2.015 & $\mathrm{~T}=$ & 12049.2100 & $1 \mathrm{~b} / \mathrm{ft}$ \\
\hline$I=$ & 18 & $A=$ & 1.200 & F.S. $=$ & 2.058 & $T=$ & 11109.4800 & $1 \mathrm{~b} / \mathrm{ft}$ \\
\hline$I=$ & 19 & $A=$ & 1.267 & F.S. = & 2.110 & $\mathrm{~T}=$ & 10280.1500 & $1 \mathrm{~b} / \mathrm{ft}$ \\
\hline$I=$ & 20 & $A=$ & 1.333 & F.S. = & 2.162 & $\mathrm{~T}=$ & 9622.8340 & $1 \mathrm{~b} / \mathrm{ft}$ \\
\hline$I=$ & 21 & $A=$ & 1.400 & F.S. $=$ & 2.212 & $\mathrm{~T}=$ & 9068.8740 & $1 \mathrm{~b} / \mathrm{ft}$ \\
\hline$I=$ & 22 & $A=$ & 1.467 & F.S. $=$ & 2.260 & $\mathrm{~T}=$ & 8557.4080 & $1 b / f t$ \\
\hline$I=$ & 23 & $A=$ & 1.533 & F.S. $=$ & 2.306 & $\mathrm{~T}=$ & 8098.5090 & $1 b / f t$ \\
\hline$I=$ & 24 & $A=$ & 1.600 & F.S. $=$ & 2.355 & $\mathrm{~T}=$ & 7782.3040 & $1 \mathrm{~b} / \mathrm{ft}$ \\
\hline$I=$ & 25 & $A=$ & 1.667 & F.S. $=$ & 2.404 & $\mathrm{~T}=$ & 7485.4040 & $1 \mathrm{~b} / \mathrm{ft}$ \\
\hline$I=$ & 26 & $A=$ & 1.733 & F.S. $=$ & 2.452 & $T=$ & 7208.2800 & $1 \mathrm{~b} / \mathrm{ft}$ \\
\hline$I=$ & 27 & $A=$ & 1.800 & F.S. $=$ & 2.500 & $T=$ & 6947.5890 & $1 \mathrm{~b} / \mathrm{ft}$ \\
\hline$I=$ & 28 & $A=$ & 1.867 & F.S. $=$ & 2.547 & $T=$ & 6701.5480 & $1 \mathrm{~b} / \mathrm{ft}$ \\
\hline$I=$ & 29 & $A=$ & 1.933 & F.S. $=$ & 2.594 & $\mathrm{~T}=$ & 6468.7310 & $1 \mathrm{~b} / \mathrm{ft}$ \\
\hline$I=$ & 30 & $A=$ & 2.000 & F.S. $=$ & 2.642 & $\mathrm{~T}=$ & 6247.9790 & $1 \mathrm{~b} / \mathrm{ft}$ \\
\hline
\end{tabular}

$\mathrm{H} / \mathrm{LT}=1.120 \mathrm{H} / \mathrm{LB}=1.400$

NO. OF NAILS (INCLUDING THE LOWERMOST) = 6

**F.S. AGAINST SLIDING THROUGH TOE $=1.93$

**F.S. AGAINST DEEP SEATED ROTATION $=4.39$

$\begin{array}{lll}1 \mathrm{TH} \text { NAIL FORCE }= & 1324.2500 \mathrm{lb} / \mathrm{ft} \\ 2 \mathrm{TH} \text { NAIL FORCE }= & 1788.2400 \mathrm{lb} / \mathrm{ft} \\ 3 \mathrm{TH} \text { NAIL FORCE }= & 2329.6610 \mathrm{lb} / \mathrm{ft} \\ 4 \mathrm{TH} \text { NAIL FORCE }= & 3044.7810 \mathrm{lb} / \mathrm{ft} \\ 5 \mathrm{TH} \text { NAIL FORCE }= & 3997.90201 \mathrm{~b} / \mathrm{ft} \\ 6 \mathrm{TH} \text { NAIL FORCE }= & 5684.2140 \mathrm{lb} / \mathrm{ft}\end{array}$


CASE 4 PART B 35 FT WALL

$<$ OUTPUT FILE > = CASE4B. OUT

\begin{tabular}{|c|c|c|c|c|c|}
\hline $\mathrm{S} O \mathrm{I}$ & 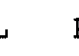 & $R O P \quad E R \quad T$ I E S & & & \\
\hline \multirow{6}{*}{\multicolumn{2}{|c|}{ FOUNDATION }} & SOIL UNIT WEIGHT & $=$ & 130.000 & pcf \\
\hline & & COHESION OF SOIL & $=$ & 1600.000 & psf \\
\hline & & FRICTION ANGLE OF SOIL & $=$ & 35.000 & deg \\
\hline & & UNDRAINED SU AT EXCAVATION LEVEL & $=$ & 3200.000 & psf \\
\hline & & DEPTH TO HARDPAN FROM EXCAVATION & $=$ & 33.000 & ft \\
\hline & & SU AT THE TOP OF HARDPAN & $=$ & 4000.000 & psf \\
\hline \multirow[t]{4}{*}{ LAYER } & 1 & HEIGHT TO TOP OF LAYER FROM TOE & $=$ & 17.000 & ft \\
\hline & & SOIL UNIT WEIGHT & $=$ & 130.000 & pcf \\
\hline & & COHESION OF SOIL & $=$ & 1100.000 & psf \\
\hline & & FRICTION ANGLE OF SOIL & $=$ & 30.000 & deg \\
\hline \multirow[t]{4}{*}{ LAYER } & 2 & HEIGHT TO TOP OF LAYER FROM TOE & $=$ & 27.000 & ft \\
\hline & & SOIL UNIT WEIGHT & $=$ & 125.000 & pef \\
\hline & & COHESION OF SOIL & $=$ & 1100.000 & psf \\
\hline & & FRICTION ANGLE OF SOIL & $=$ & 30.000 & deg \\
\hline \multirow[t]{4}{*}{ LAYER } & 3 & HEIGHT TO TOP OF LAYER FROM TOE & $=$ & 35.000 & ft \\
\hline & & SOIL UNIT WEIGHT & $=$ & 120.000 & $\operatorname{pcf}$ \\
\hline & & COHESION OF SOIL & $=$ & 650.000 & psf \\
\hline & & FRICTION ANGLE OF SOIL & $=$ & 25.000 & deg \\
\hline
\end{tabular}

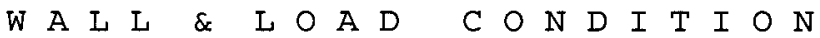

WALL INCLINATION ANGLE

SURCHARGE LOAD

HOR. ACCELERATION COEFF.
$=$

N A I L P R O P E R T I E S

CROSS SECTIONAL AREA OF NAIL= GROUT DIAMETER

YIELD STRENGTH OF NAIL

NAIL INCLINATION ANGLE

NAIL SKEW ANGLE AT SURFACE

DEPTH TO UPPERMOST NAIL

VER. SPACING OF NAIL

HOR. SPACING OF NAIL

TOTAL LENGTH OF UPPERMOST NAIL TOTAL LENGTH OF LOWERMOST NAIL TOTAL UNBONDED LENGTH OF NAIL

$.790 \mathrm{si}$
$4.000 \mathrm{in}$
$60.000 \mathrm{ksi}$
$20.000 \mathrm{deg}$
$.000 \mathrm{deg}$
$2.000 \mathrm{ft}$
$5.000 \mathrm{ft}$
$5.000 \mathrm{ft}$
$30.000 \mathrm{ft}$
$25.000 \mathrm{ft}$
$2.000 \mathrm{ft}$

\begin{tabular}{|c|c|c|c|c|c|c|c|}
\hline$I=$ & $2 \mathrm{~A}=$ & .133 & F.S. $=$ & 3.779 & $\mathrm{~T}=$ & 24687.3000 & $1 b / f t$ \\
\hline$I=$ & $3 \mathrm{~A}=$ & .200 & F.S. $=$ & 2.790 & $\mathrm{~T}=$ & 31042.4100 & $1 \mathrm{~b} / \mathrm{et}$ \\
\hline$I=$ & $4 A=$ & .267 & F.S. $=$ & 2.385 & $T=$ & 33798.9800 & $1 \mathrm{~b} / \mathrm{ft}$ \\
\hline$I=$ & $5 A=$ & .333 & F.S. $=$ & 2.157 & $\mathrm{~T}=$ & 34891.5900 & $1 \mathrm{~b} / \mathrm{ft}$ \\
\hline
\end{tabular}




\begin{tabular}{|c|c|c|c|c|c|c|c|c|}
\hline$I=$ & 6 & $A=$ & .400 & F.S. $=$ & 2.017 & $T=$ & 34958.5200 & $1 \mathrm{~b} / \mathrm{ft}$ \\
\hline$I=$ & 7 & $A=$ & .467 & F.S. $=$ & 1.922 & $\mathrm{~T}=$ & 34407.2600 & $1 \mathrm{~b} / \mathrm{ft}$ \\
\hline$I=$ & 8 & $A=$ & .533 & F.S. $=$ & 1.861 & $\mathrm{~T}=$ & 33370.4000 & $1 \mathrm{~b} / \mathrm{ft}$ \\
\hline$I=$ & 9 & $A=$ & .600 & F.S. $=$ & 1.823. & $\mathrm{~T}=$ & 32000.9800 & $1 \mathrm{~b} / \mathrm{ft}$ \\
\hline$I=$ & 10 & $A=$ & .667 & F.S. $=$ & 1.796 & $\mathrm{~T}=$ & 30422.1600 & $1 \mathrm{~b} / \mathrm{ft}$ \\
\hline$I=$ & 11 & $A=$ & .733 & F.S. $=$ & 1.779 & $\mathrm{~T}=$ & 28665.8600 & $1 \mathrm{~b} / \mathrm{ft}$ \\
\hline$I=$ & 12 & $A=$ & .800 & F.S. $=$ & 1.772 & $\mathrm{~T}=$ & 26810.5800 & $1 \mathrm{~b} / \mathrm{ft}$ \\
\hline$I=$ & 13 & $A=$ & .867 & F.S. $=$ & 1.771 & $T=$ & 24921.7400 & $1 \mathrm{~b} / \mathrm{ft}$ \\
\hline$I=$ & 14 & $A=$ & .933 & F.S. $=$ & 1.778 & $\mathrm{~T}=$ & 22987.8000 & $1 \mathrm{~b} / \mathrm{ft}$ \\
\hline$I=$ & 15 & $A=$ & 1.000 & F.S. $=$ & 1.791 & $\mathrm{~T}=$ & 21067.0200 & $\mathrm{lb} / \mathrm{ft}$ \\
\hline$I=$ & 16 & $A=$ & 1.067 & F.S. $=$ & 1.807 & $\mathrm{~T}=$ & 19176.4600 & $1 \mathrm{~b} / \mathrm{ft}$ \\
\hline$I=$ & 17 & $A=$ & 1.133 & F.S. $=$ & 1.840 & $\mathrm{~T}=$ & 17375.2100 & $1 \mathrm{~b} / \mathrm{ft}$ \\
\hline$I=$ & 18 & $A=$ & 1.200 & F.S. = & 1.884 & $\mathrm{~T}=$ & 15789.1100 & $1 \mathrm{~b} / \mathrm{ft}$ \\
\hline$I=$ & 19 & $A=$ & 1.267 & F.S. $=$ & 1.930 & $\mathrm{~T}=$ & 14535.2400 & $\mathrm{Ib} / \mathrm{ft}$ \\
\hline$I=$ & 20 & $A=$ & 1.333 & F.S. = & 1.972 & $\mathrm{~T}=$ & 13404.5900 & $I b / f t$ \\
\hline$I=$ & 21 & $A=$ & 1.400 & F.S. $=$ & 2.017 & $\mathrm{~T}=$ & 12569.0500 & $1 \mathrm{~b} / \mathrm{ft}$ \\
\hline$I=$ & 22 & $A=$ & 1.467 & F.S. $=$ & 2.059 & $T=$ & 11796.5000 & $1 \mathrm{~b} / \mathrm{ft}$ \\
\hline$I=$ & 23 & $A=$ & 1.533 & F.S. $=$ & 2.100 & $\mathrm{~T}=$ & 11078.0200 & $1 \mathrm{~b} / \mathrm{ft}$ \\
\hline$I=$ & 24 & $A=$ & 1.600 & F.S. $=$ & 2.142 & $\mathrm{~T}=$ & 10459.8200 & $1 \mathrm{~b} / \mathrm{ft}$ \\
\hline$I=$ & 25 & $A=$ & 1.667 & F.S. $=$ & 2.186 & $T=$ & 10008.5700 & $1 \mathrm{~b} / \mathrm{ft}$ \\
\hline$I=$ & 26 & $A=$ & 1.733 & F.S. $=$ & 2.230 & $\mathrm{~T}=$ & 9585.9750 & $1 \mathrm{~b} / \mathrm{ft}$ \\
\hline$I=$ & 27 & $A=$ & 1.800 & F.S. $=$ & 2.274 & $\mathrm{~T}=$ & 9188.9340 & $1 \mathrm{~b} / \mathrm{ft}$ \\
\hline$I=$ & 28 & $A=$ & 1.867 & F.S. $=$ & 2.317 & $\mathrm{~T}=$ & 8814.9540 & $1 b / f t$ \\
\hline$I=$ & 29 & $A=$ & 1.933 & F.S. $=$ & 2.361 & $\mathrm{~T}=$ & 8462.0050 & $1 \mathrm{~b} / \mathrm{ft}$ \\
\hline$I=$ & 30 & $\mathrm{~A}=$ & 2.000 & F.S. $=$ & 2.406 & $\mathrm{~T}=$ & 8128.3920 & $1 b / \mathrm{ft}$ \\
\hline
\end{tabular}

$\mathrm{H} / \mathrm{LT}=1.167 \mathrm{H} / \mathrm{LB}=1.400$

NO. OF NAILS (INCLUDING THE LOWERMOST) $=7$

**F.S. AGAINST SLIDING THROUGH TOE $=1.77$

**F.S. AGAINST DEEP SEATED ROTATION $=3.54$

$1 \mathrm{TH}$ NAIL FORCE $=1101.7300 \mathrm{lb} / \mathrm{ft}$

$2 \mathrm{TH}$ NAIL FORCE $=1552.0660 \mathrm{1b} / \mathrm{ft}$

$3 \mathrm{TH}$ NAIL FORCE $=2217.8890 \mathrm{Ib} / \mathrm{ft}$

$4 \mathrm{TH}$ NAIL FORCE $=3001.5250 \mathrm{Ib} / \mathrm{ft}$

$5 \mathrm{TH}$ NAIL FORCE $=4033.2320 \mathrm{lb} / \mathrm{ft}$

$6 \mathrm{TH}$ NAIL FORCE $=\quad 5443.0500 \mathrm{lb} / \mathrm{ft}$

$7 \mathrm{TH}$ NAIL FORCE $=7572.2500 \mathrm{lb} / \mathrm{ft}$ 


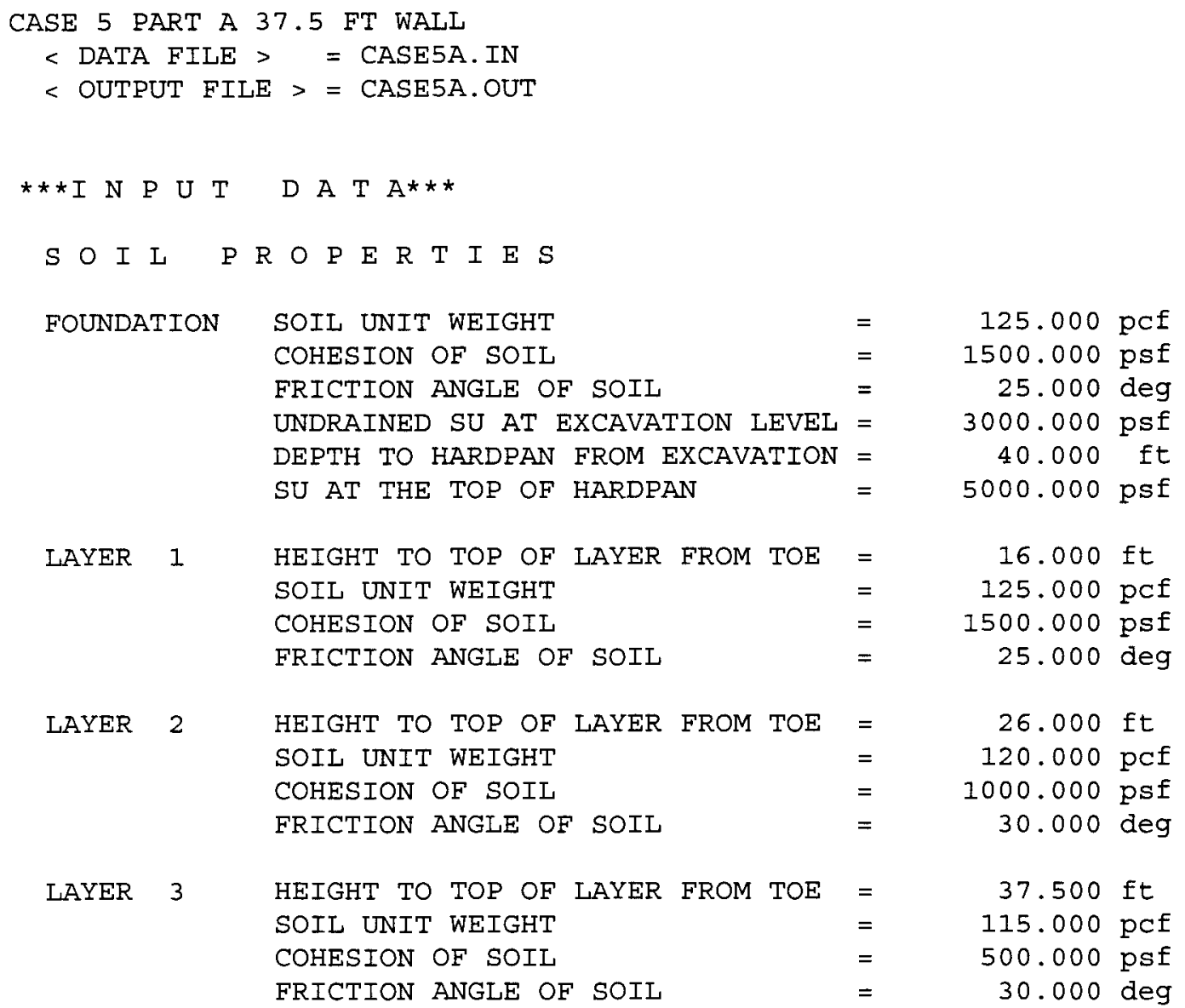

W A L L \& L O A D $\quad$ C O N D I T I O N

$\begin{array}{llr}\text { WALL INCLINATION ANGLE } & = & 5.000 \mathrm{deg} \\ \text { SURCHARGE LOAD } & = & 300.000 \mathrm{psf} \\ \text { HOR. ACCELERATION COEFF. } & = & .000\end{array}$

N A I L P R O P E R T I E S

$\begin{array}{llr}\text { CROSS SECTIONAL AREA OF NAIL } & = & .790 \mathrm{si} \\ \text { GROUT DIAMETER } & = & 4.000 \mathrm{in} \\ \text { YIELD STRENGTH OF NAIL } & = & 60.000 \mathrm{ksi} \\ \text { NAIL INCLINATION ANGLE } & = & 20.000 \mathrm{deg} \\ \text { NAIL SKEW ANGLE AT SURFACE } & = & .000 \mathrm{deg} \\ \text { DEPTH TO UPPERMOST NAIL } & = & 2.000 \mathrm{ft} \\ \text { VER. SPACING OF NAIL } & = & 5.500 \mathrm{ft} \\ \text { HOR. SPACING OF NAIL } & = & 5.000 \mathrm{ft} \\ \text { TOTAL LENGTH OF UPPERMOST NAIL } & = & 30.000 \mathrm{ft} \\ \text { TOTAL LENGTH OF LOWERMOST NAIL } & = & 25.000 \mathrm{ft} \\ \text { TOTAL UNBONDED LENGTH OF NAIL } & = & 2.000 \mathrm{ft}\end{array}$

\begin{tabular}{|c|c|c|c|c|c|c|c|}
\hline$I=$ & $2 A=$ & .133 & F.S. = & 4.102 & $\mathrm{~T}=$ & 22879.6900 & $1 \mathrm{~b} / \mathrm{ft}$ \\
\hline$I=$ & $3 A=$ & .200 & F.S. $=$ & 2.896 & $\mathrm{~T}=$ & 29925.6400 & $1 \mathrm{~b} / \mathrm{ft}$ \\
\hline$I=$ & $4 \mathrm{~A}=$ & .267 & F.S. $=$ & 2.421 & $\mathrm{~T}=$ & 33272.0000 & $1 b / f t$ \\
\hline
\end{tabular}




\begin{tabular}{|c|c|c|c|c|c|c|c|c|}
\hline$I=$ & 5 & $A=$ & .333 & F.S. $=$ & 2.166 & $\mathrm{~T}=$ & 34650.8500 & $1 \mathrm{~b} / \mathrm{ft}$ \\
\hline$I=$ & 6 & $A=$ & .400 & F.S. $=$ & 2.007 & $T=$ & 34955.6000 & $\mathrm{lb} / \mathrm{ft}$ \\
\hline$I=$ & 7 & $A=$ & .467 & F.S. $=$ & 1.903 & $T=$ & 34417.8600 & $l b / f t$ \\
\hline$I=$ & 8 & $A=$ & .533 & F.S. $=$ & 1.835 & $T=$ & 33306.4300 & $\mathrm{lb} / \mathrm{ft}$ \\
\hline$I=$ & 9 & $\mathrm{~A}=$ & .600 & F.S. $=$ & 1.787 & $T=$ & 31881.5700 & $1 \mathrm{~b} / \mathrm{ft}$ \\
\hline$I=$ & 10 & $A=$ & .667 & F.S. $=$ & 1.756 & $T=$ & 30204.3800 & $\mathrm{lb} / \mathrm{ft}$ \\
\hline$I=$ & 11 & $A=$ & .733 & F.S. $=$ & 1.738 & $\mathrm{~T}=$ & 28361.3900 & $l b / f t$ \\
\hline$I=$ & 12 & $A=$ & .800 & F.S. $=$ & 1.729 & $T=$ & 26433.6400 & $\mathrm{lb} / \mathrm{ft}$ \\
\hline$I=$ & 13 & $A=$ & .867 & F.S. $=$ & 1.729 & $T=$ & 24424.6300 & $l b / f t$ \\
\hline$I=$ & 14 & $A=$ & .933 & F.S. $=$ & 1.736 & $\mathrm{~T}=$ & 22403.3800 & $\mathrm{lb} / \mathrm{ft}$ \\
\hline$I=$ & 15 & $A=$ & 1.000 & F.S. $=$ & 1.746 & $\mathrm{~T}=$ & 20322.9200 & $1 \mathrm{~b} / \mathrm{ft}$ \\
\hline$I=$ & 16 & $A=$ & 1.067 & F.S. $=$ & 1.777 & $\mathrm{~T}=$ & 18370.5800 & $\mathrm{lb} / \mathrm{ft}$ \\
\hline$I=$ & 17 & $A=$ & 1.133 & F.S. $=$ & 1.815 & $\mathrm{~T}=$ & 16731.5800 & $\mathrm{lb} / \mathrm{ft}$ \\
\hline$I=$ & 18 & $A=$ & 1.200 & F.S. $=$ & 1.851 & $T=$ & 15343.4200 & $\mathrm{lb} / \mathrm{ft}$ \\
\hline$I=$ & 19 & $A=$ & 1.267 & F.S. = & 1.889 & $T=$ & 14258.7000 & $\mathrm{lb} / \mathrm{ft}$ \\
\hline$I=$ & 20 & $A=$ & 1.333 & F.S. $=$ & 1.929 & $T=$ & 13332.1200 & $\mathrm{lb} / \mathrm{ft}$ \\
\hline$I=$ & 21 & $A=$ & 1.400 & F.S. $=$ & 1.967 & $T=$ & 12469.8500 & $1 \mathrm{~b} / \mathrm{ft}$ \\
\hline$I=$ & 22 & $A=$ & 1.467 & F.S. $=$ & 2.007 & $\mathrm{~T}=$ & 11722.2600 & $\mathrm{lb} / \mathrm{ft}$ \\
\hline$I=$ & 23 & $A=$ & 1.533 & F.S. $=$ & 2.049 & $T=$ & 11189.4900 & $\mathrm{lb} / \mathrm{ft}$ \\
\hline$I=$ & 24 & $A=$ & 1.600 & F.S. $=$ & 2.092 & $T=$ & 10690.9700 & $1 \mathrm{~b} / \mathrm{ft}$ \\
\hline$I=$ & 25 & $A=$ & 1.667 & F.S. $=$ & 2.134 & $T=$ & 10223.0400 & $1 b / f t$ \\
\hline$I=$ & 26 & $A=$ & 1.733 & F.S. $=$ & 2.177 & $T=$ & 9782.7750 & $1 \mathrm{~b} / \mathrm{ft}$ \\
\hline$I=$ & 27 & $A=$ & 1.800 & F.S. $=$ & 2.220 & $T=$ & 9367.7940 & $\mathrm{lb} / \mathrm{ft}$ \\
\hline$I=$ & 28 & $A=$ & 1.867 & F.S. $=$ & 2.264 & $T=$ & 8976.1250 & $\mathrm{lb} / \mathrm{ft}$ \\
\hline & 29 & $A=$ & 1.933 & F.S. $=$ & 2.308 & $T=$ & 8606.0970 & $1 \mathrm{~b} / \mathrm{ft}$ \\
\hline & 30 & $A=$ & 2.000 & F.S. $=$ & 2.353 & $T=$ & 8256.2400 & $\mathrm{lb} / \mathrm{ft}$ \\
\hline
\end{tabular}

$\mathrm{H} / \mathrm{LT}=1.250 \quad \mathrm{H} / \mathrm{LB}=1.500$

NO. OF NAILS (INCLUDING THE LOWERMOST) = 7

**F.S. AGAINST SIIDING THROUGH TOE $=1.73$

**F.S. AGAINST DEEP SEATED ROTATION $=4.32$

1 TH NAIL FORCE =

2 TH NAIL FORCE =

3 TH NAIL FORCE =

4 TH NAIL FORCE =

$5 \mathrm{TH}$ NAIL FORCE =

6 TH NAIL FORCE =

7 TH NAIL FORCE = $\begin{array}{rl}958.8588 & 1 \mathrm{~b} / \mathrm{ft} \\ 1616.2710 & 1 \mathrm{~b} / \mathrm{ft} \\ 2323.0820 & 1 \mathrm{~b} / \mathrm{ft} \\ 3266.6650 & 1 \mathrm{~b} / \mathrm{ft} \\ 4331.3090 & 1 \mathrm{~b} / \mathrm{ft} \\ 5805.6800 & 1 \mathrm{~b} / \mathrm{ft} \\ 8131.7790 & 1 \mathrm{~b} / \mathrm{ft}\end{array}$ 
CASE 5 PART B 26 FT WALL

$<$ OUTPUT FILE > = CASE5B. OUT

\begin{tabular}{|c|c|c|c|c|c|}
\hline \multicolumn{6}{|c|}{$R O P E R$ T I E S } \\
\hline \multirow{6}{*}{\multicolumn{2}{|c|}{ FOUNDATION }} & SOIL UNIT WEIGHT & $=$ & 125.000 & pcf \\
\hline & & COHESION OF SOIL & $=$ & 1500.000 & psf \\
\hline & & FRICTION ANGLE OF SOIL & $=$ & 25.000 & deg \\
\hline & & UNDRAINED SU AT EXCAVATION LEVEL & $=$ & 3000.000 & psf \\
\hline & & DEPTH TO HARDPAN FROM EXCAVATION & $=$ & 51.000 & Et \\
\hline & & SU AT THE TOP OF HARDPAN & $=$ & 5000.000 & psf \\
\hline \multirow[t]{4}{*}{ LAYER } & 1 & HEIGHT TO TOP OF LAYER FROM TOE & $=$ & 4.500 & ft \\
\hline & & SOIL UNIT WEIGHT & $=$ & 125.000 & pcf \\
\hline & & COHESION OF SOIL & $=$ & 1500.000 & psf \\
\hline & & FRICTION ANGLE OF SOIL & $=$ & 25.000 & deg \\
\hline \multirow[t]{4}{*}{ LAYER } & 2 & HEIGHT TO TOP OF LAYER FROM TOE & $=$ & 14.500 & Et \\
\hline & & SOIL UNIT WEIGHT & $=$ & 120.000 & pcf \\
\hline & & COHESION OF SOIL & $=$ & 1000.000 & psf \\
\hline & & FRICTION ANGLE OF SOIL & $=$ & 30.000 & deg \\
\hline \multirow[t]{4}{*}{ LAYER } & 3 & HEIGHT TO TOP OF LAYER FROM TOE & $=$ & 26.000 & ft \\
\hline & & SOIL UNIT WEIGHT & $=$ & 115.000 & pcf \\
\hline & & COHESION OF SOIL & $=$ & 500.000 & psf \\
\hline & & FRICTION ANGLE OF SOIL & $=$ & 30.000 & deg \\
\hline
\end{tabular}

W A L L \& $\&$ L O A D $\quad$ C O N D I T I O N

WALI INCLINATION ANGLE

SURCHARGE LOAD

HOR. ACCELERATION COEFF.

$\begin{array}{lr}= & 5.000 \mathrm{deg} \\ = & 300.000 \mathrm{psf} \\ = & .000\end{array}$

$N$ A I L P R O P E R T I E S

$\begin{array}{llr}\text { CROSS SECTIONAL AREA OF NAIL } & = & .790 \mathrm{si} \\ \text { GROUT DIAMETER } & = & 4.000 \mathrm{in} \\ \text { YIELD STRENGTH OF NAIL } & = & 60.000 \mathrm{ksi} \\ \text { NAIL INCLINATION ANGLE } & = & 20.000 \mathrm{deg} \\ \text { NAIL SKEW ANGLE AT SURFACE } & = & .000 \mathrm{deg} \\ \text { DEPTH TO UPPERMOST NAIL } & = & 2.000 \mathrm{ft} \\ \text { VER. SPACING OF NAIL } & = & 5.000 \mathrm{ft} \\ \text { HOR. SPACING OF NAIL } & = & 5.000 \mathrm{ft} \\ \text { TOTAL LENGTH OF UPPERMOST NAIL } & = & 20.000 \mathrm{ft} \\ \text { TOTAL LENGTH OF LOWERMOST NAIL } & = & 15.000 \mathrm{ft} \\ \text { TOTAL UNBONDED IENGTH OF NAIL } & = & 2.000 \mathrm{ft}\end{array}$

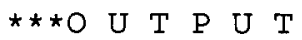
R E S U L T S***
$6058.9010 \mathrm{lb} / \mathrm{ft}$
$8946.1340 \mathrm{lb} / \mathrm{ft}$ $10276.8900 \mathrm{lb} / \mathrm{ft}$ $10806.8400 \mathrm{Ib} / \mathrm{ft}$ 


\begin{tabular}{|c|c|c|c|c|c|c|c|c|}
\hline$I=$ & 6 & $A=$ & .400 & F.S. $=$ & 2.026 & $\mathrm{~T}=$ & 10860.9100 & $1 \mathrm{~b} / \mathrm{ft}$ \\
\hline$I=$ & 7 & $A=$ & .467 & F.S. $=$ & 1.902 & $\mathrm{~T}=$ & 10596.5600 & $\mathrm{Ib} / \mathrm{ft}$ \\
\hline$I=$ & 8 & $A=$ & .533 & F.S. $=$ & 1.820 & $\mathrm{~T}=$ & 10129.9500 & $1 \mathrm{~b} / \mathrm{ft}$ \\
\hline$I=$ & 9 & $A=$ & .600 & F.S. $=$ & 1.769 & $\mathrm{~T}=$ & 9517.5800 & $1 b / f t$ \\
\hline$I=$ & 10 & $A=$ & .667 & F.S. $=$ & 1.739 & $T=$ & 8810.1890 & $1 b / f t$ \\
\hline$I=$ & 11 & $A=$ & .733 & F.S. $=$ & 1.724 & $\mathrm{~T}=$ & 8037.0160 & $1 b / f t$ \\
\hline$I=$ & 12 & $A=$ & .800 & F.S. $=$ & 1.719 & $T=$ & 7196.7130 & $1 \mathrm{~b} / \mathrm{ft}$ \\
\hline$I=$ & 13 & $A=$ & .867 & F.S. $=$ & 1.724 & $\mathrm{~T}=$ & 6341.6580 & $1 b / f t$ \\
\hline$I=$ & 14 & $A=$ & .933 & F.S. $=$ & 1.737 & $\mathrm{~T}=$ & 5493.4940 & $1 \mathrm{~b} / \mathrm{ft}$ \\
\hline$I=$ & 15 & $A=$ & 1.000 & F.S. $=$ & 1.760 & $\mathrm{~T}=$ & 4679.7290 & $1 b / f t$ \\
\hline$I=$ & 16 & $A=$ & 1.067 & F.S. $=$ & 1.801 & $\mathrm{~T}=$ & 3995.1290 & Ib/ft \\
\hline$I=$ & 17 & $A=$ & 1.133 & F.S. $=$ & 1.845 & $\mathrm{~T}=$ & 3538.9230 & $I b / f t$ \\
\hline$I=$ & 18 & $A=$ & 1.200 & F.S. $=$ & 1.888 & $T=$ & 3117.1950 & $I b / f t$ \\
\hline$I=$ & 19 & $A=$ & 1.267 & F.S. $=$ & 1.933 & $T=$ & 2812.2840 & $1 \mathrm{~b} / \mathrm{ft}$ \\
\hline$I=$ & 20 & $A=$ & 1.333 & F.S. $=$ & 1.979 & $T=$ & 2579.6100 & $1 \mathrm{~b} / \mathrm{ft}$ \\
\hline$I=$ & 21 & $A=$ & 1.400 & F.S. $=$ & 2.026 & $\mathrm{~T}=$ & 2362.6640 & $1 b / f t$ \\
\hline$I=$ & 22 & $A=$ & 1.467 & F.S. $=$ & 2.071 & $\mathrm{~T}=$ & 2164.3820 & $1 b / f t$ \\
\hline$I=$ & 23 & $A=$ & 1.533 & F.S. $=$ & 2.116 & $\mathrm{~T}=$ & 1980.0310 & $1 \mathrm{~b} / \mathrm{ft}$ \\
\hline$I=$ & 24 & $A=$ & 1.600 & F.S. $=$ & 2.161 & $\mathrm{~T}=$ & 1808.4740 & $\mathrm{Ib} / \mathrm{ft}$ \\
\hline$I=$ & 25 & $A=$ & 1.667 & F.S. $=$ & 2.207 & $\mathrm{~T}=$ & 1648.7360 & $1 b / f t$ \\
\hline$I=$ & 26 & $A=$ & 1.733 & F.S. $=$ & 2.256 & $\mathrm{~T}=$ & 1544.2970 & $\mathrm{Ib} / \mathrm{ft}$ \\
\hline$I=$ & 27 & $A=$ & 1.800 & F.S. $=$ & 2.308 & $\mathrm{~T}=$ & 1483.2490 & $1 b / f t$ \\
\hline$I=$ & 28 & $A=$ & 1.867 & F.S. $=$ & 2.360 & $T=$ & 1425.9990 & $1 b / f t$ \\
\hline$I=$ & 29 & $A=$ & 1.933 & F.S. $=$ & 2.412 & $T=$ & 1372.2310 & $1 b / f t$ \\
\hline$I=$ & 30 & $A=$ & 2.000 & F.S. $=$ & 2.469 & $\mathrm{~T}=$ & 1320.0930 & $1 b / f t$ \\
\hline
\end{tabular}

$\mathrm{H} / \mathrm{LT}=1.300 \mathrm{H} / \mathrm{LB}=1.733$

NO. OF NAILS (INCLUDING THE LOWERMOST) = 5

**F.S. AGAINST SLIDING THROUGH TOE $=1.72$

$\star \star$ F.S. AGAINST DEEP SEATED ROTATION $=6.16$

1 TH NAIL FORCE =

2 TH NAIL FORCE =

3 TH NAIL FORCE =

4 TH NAIL FORCE =

5 TH NAIL FORCE =

\author{
$437.92561 \mathrm{~b} / \mathrm{ft}$ \\ $847.64051 \mathrm{~b} / \mathrm{ft}$ \\ $1202.5260 \mathrm{lb} / \mathrm{ft}$ \\ $1827.5260 \mathrm{lb} / \mathrm{ft}$ \\ $2881.0940 \mathrm{lb} / \mathrm{ft}$
}


CASE 6 PART A 35.5 FT WALL

$<$ OUTPUT FILE > = CASE6A. OUT

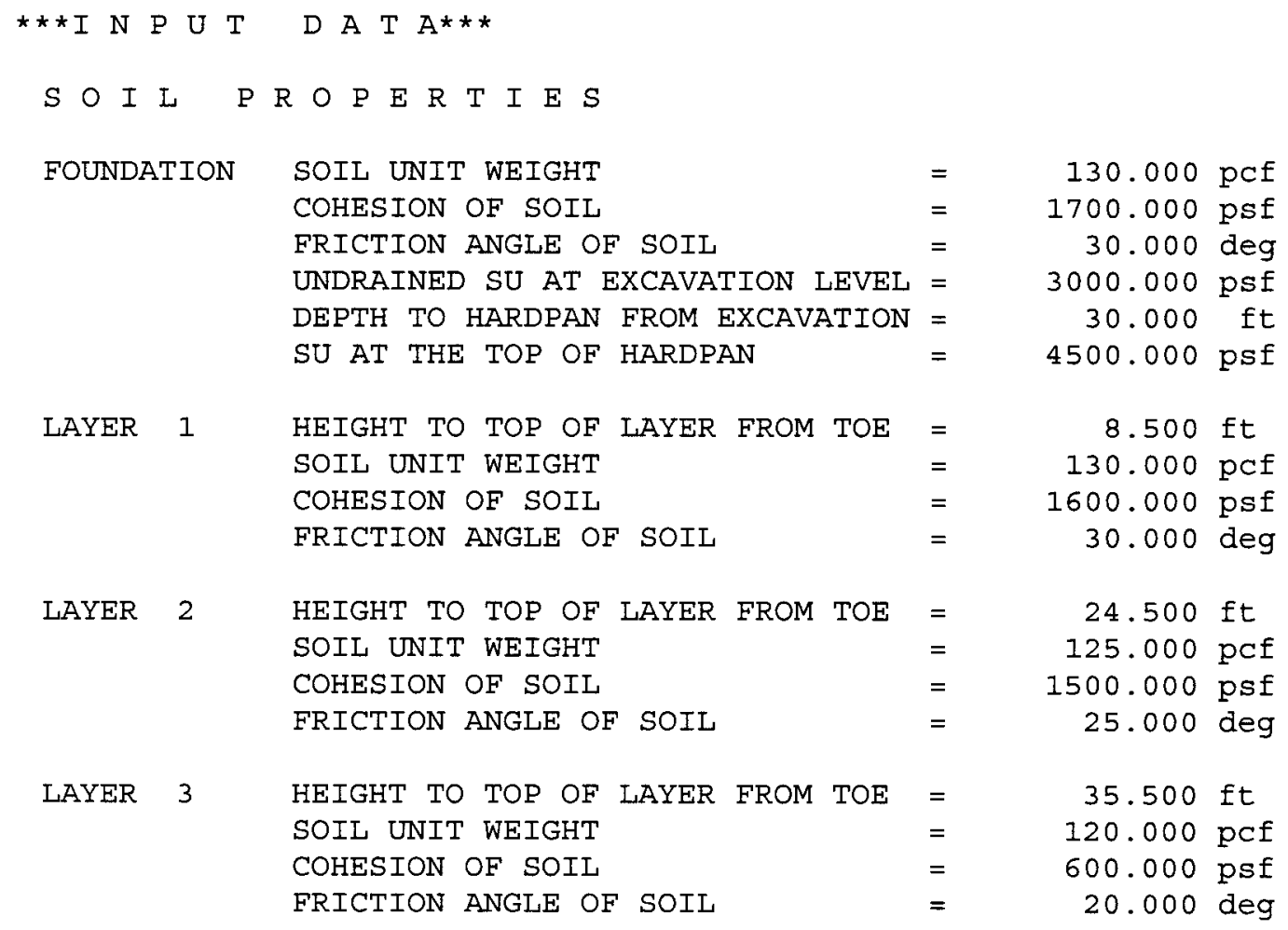

W A L L \& L $O A D$ D C O N D I T I O N

WALL INCLINATION ANGLE

SURCHARGE LOAD

HOR. ACCELERATION COEFF.

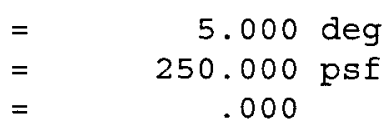

N A I L P R O P E R T I E S

CROSS SECTIONAL AREA OF NAIL = GROUT DIAMETER

YIELD STRENGTH OF NAIL

NAIL INCLINATION ANGLE

NAIL SKEW ANGLE AT SURFACE

DEPTH TO UPPERMOST NAIL

VER. SPACING OF NAIL

HOR. SPACING OF NAIL

TOTAL LENGTH OF UPPERMOST NAIL TOTAL LENGTH OF LOWERMOST NAIL

TOTAL UNBONDED LENGTH OF NAIL

$.790 \mathrm{si}$
$4.000 \mathrm{in}$
$60.000 \mathrm{ksi}$
$20.000 \mathrm{deg}$
$.000 \mathrm{deg}$
$2.000 \mathrm{ft}$
$5.000 \mathrm{ft}$
$5.000 \mathrm{ft}$
$30.000 \mathrm{ft}$
$25.000 \mathrm{ft}$
$2.000 \mathrm{ft}$

$.790 \mathrm{si}$

$=$

$=$

$=$

$=$

$=$

$=$

\begin{tabular}{|c|c|c|c|c|c|c|c|}
\hline$I=$ & $A=$ & .133 & F.S. $=$ & 4.441 & $\mathrm{~T}=$ & 22194.0400 & $1 \mathrm{~b} / \mathrm{ft}$ \\
\hline$I=$ & $3 A=$ & .200 & F.S. $=$ & 3.124 & $\mathrm{~T}=$ & 29345.1600 & $1 \mathrm{~b} / \mathrm{ft}$ \\
\hline$I=$ & $4 A=$ & .267 & F.S. $=$ & 2.622 & $\mathrm{~T}=$ & 32600.2200 & $1 \mathrm{~b} / \mathrm{ft}$ \\
\hline$I=$ & $5 A=$ & .333 & F.S. $=$ & 2.352 & $\mathrm{~T}=$ & 34013.5000 & $1 \mathrm{~b} / \mathrm{ft}$ \\
\hline
\end{tabular}




\begin{tabular}{|c|c|c|c|c|c|c|c|c|}
\hline$I=$ & 6 & $\mathrm{~A}=$ & .400 & F.S. $=$ & 2.185 & $\mathrm{~T}=$ & 34375.8100 & $1 b / f t$ \\
\hline$I=$ & 7 & $A=$ & .467 & F.S. = & 2.078 & $\mathrm{~T}=$ & 33967.5200 & $1 b / f t$ \\
\hline$I=$ & 8 & $\mathrm{~A}=$ & .533 & F.S. $=$ & 2.006 & $\mathrm{~T}=$ & 32925.8000 & $1 b / f t$ \\
\hline$I=$ & 9 & $\mathrm{~A}=$ & .600 & F.S. $=$ & 1.956 & $\mathrm{~T}=$ & 31588.1000 & $1 \mathrm{~b} / \mathrm{ft}$ \\
\hline$I=$ & 10 & $A=$ & .667 & F.S. $=$ & 1.924 & $\mathrm{~T}=$ & 30012.9500 & $1 b / f t$ \\
\hline$I=$ & 11 & $A=$ & .733 & F.S. $=$ & 1.906 & $\mathrm{~T}=$ & 28282.1600 & $1 b / f t$ \\
\hline$I=$ & 12 & $A=$ & .800 & F.S. $=$ & 1.899 & $\mathrm{~T}=$ & 26456.4300 & $1 b / f t$ \\
\hline$I=$ & 13 & $A=$ & .867 & F.S. $=$ & 1.899 & $\mathrm{~T}=$ & 24590.5600 & $1 b / f t$ \\
\hline$I=$ & 14 & $A=$ & .933 & F.S. $=$ & 1.907 & $\mathrm{~T}=$ & 22670.9700 & $I b / f t$ \\
\hline$I=$ & 15 & $A=$ & 1.000 & F.S. = & 1.916 & $\mathrm{~T}=$ & 20643.6200 & $1 b / f t$ \\
\hline$I=$ & 16 & $A=$ & 1.067 & F.S. = & 1.931 & $\mathrm{~T}=$ & 18628.8800 & $1 b / f t$ \\
\hline$I=$ & 17 & $A=$ & 1.133 & F.S. = & 1.968 & $\mathrm{~T}=$ & 16798.2700 & $1 b / \pm t$ \\
\hline$I=$ & 18 & $\mathrm{~A}=$ & 1.200 & F.S. $=$ & 2.012 & $\mathrm{~T}=$ & 15272.2500 & $1 b / f t$ \\
\hline$I=$ & 19 & $A=$ & 1.267 & F.S. $=$ & 2.055 & $\mathrm{~T}=$ & 13998.5600 & $I b / \pm t$ \\
\hline$I=$ & 20 & $A=$ & 1.333 & F.S. $=$ & 2.099 & $\mathrm{~T}=$ & 12960.3100 & $1 b / f t$ \\
\hline$I=$ & 21 & $\mathrm{~A}=$ & 1.400 & F.S. $=$ & 2.144 & $\mathrm{~T}=$ & 12101.6200 & $1 b /$ ft \\
\hline$I=$ & 22 & $A=$ & 1.467 & F.S. = & 2.186 & $\mathrm{~T}=$ & 11304.1000 & $1 b / \pm t$ \\
\hline$I=$ & 23 & $A=$ & 1.533 & F.S. $=$ & 2.228 & $\mathrm{~T}=$ & 10574.6700 & $1 b / E t$ \\
\hline$I=$ & 24 & $\mathrm{~A}=$ & 1.600 & F.S. = & 2.275 & $\mathrm{~T}=$ & 10064.6400 & $I b / f t$ \\
\hline$I=$ & 25 & $A=$ & 1.667 & F.S. $=$ & 2.321 & $\mathrm{~T}=$ & 9587.8830 & $1 \mathrm{~b} / \mathrm{ft}$ \\
\hline$I=$ & 26 & $\mathrm{~A}=$ & 1.733 & F.S. = & 2.366 & $\mathrm{~T}=$ & 9140.9280 & $1 b / f t$ \\
\hline$I=$ & 27 & $A=$ & 1.800 & E.S. = & 2.412 & $\mathrm{~T}=$ & 8721.6540 & $1 b / f t$ \\
\hline$I=$ & 28 & $A=$ & 1.867 & F.S. = & 2.456 & $\mathrm{~T}=$ & 8331.6190 & $1 b / f t$ \\
\hline$I=$ & 29 & $A=$ & 1.933 & F.S. $=$ & 2.500 & $T=$ & 7963.6640 & $I b / f t$ \\
\hline$I=$ & 30 & $A=$ & 2.000 & F.S. $=$ & 2.545 & $\mathrm{~T}=$ & 7616.1090 & $1 b / f t$ \\
\hline
\end{tabular}

$\mathrm{H} / \mathrm{LT}=1.183 \quad \mathrm{H} / \mathrm{LB}=1.420$

NO. OF NAILS (INCLUDING THE LOWERMOST) $=7$

${ }^{\star}$ F.S. AGAINST SLIDING THROUGH TOE $=1.90$

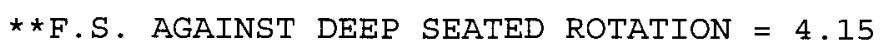

1 TH NAIL FORCE =

2 TH NAIL FORCE =

3 TH NAIL FORCE =

4 TH NAIL FORCE =

5 TH NAIL FORCE =

6 TH NAIL FORCE =

7 TH NAIL FORCE =
$978.6779 \mathrm{lb} / \mathrm{ft}$ $1589.4520 \mathrm{lb} / \mathrm{ft}$ $2125.5350 \mathrm{lb} / \mathrm{ft}$ $2814.07901 \mathrm{~b} / \mathrm{ft}$ $4077.0120 \mathrm{Ib} / \mathrm{ft}$ $5468.3210 \mathrm{Ib} / \mathrm{ft}$ $7537.4830 \mathrm{Ib} / \mathrm{ft}$ 
CASE 6 PART B FOR 26.5 AND 22 FT WALL

$<$ OUTPUT FILE > = CASE6B. OUT

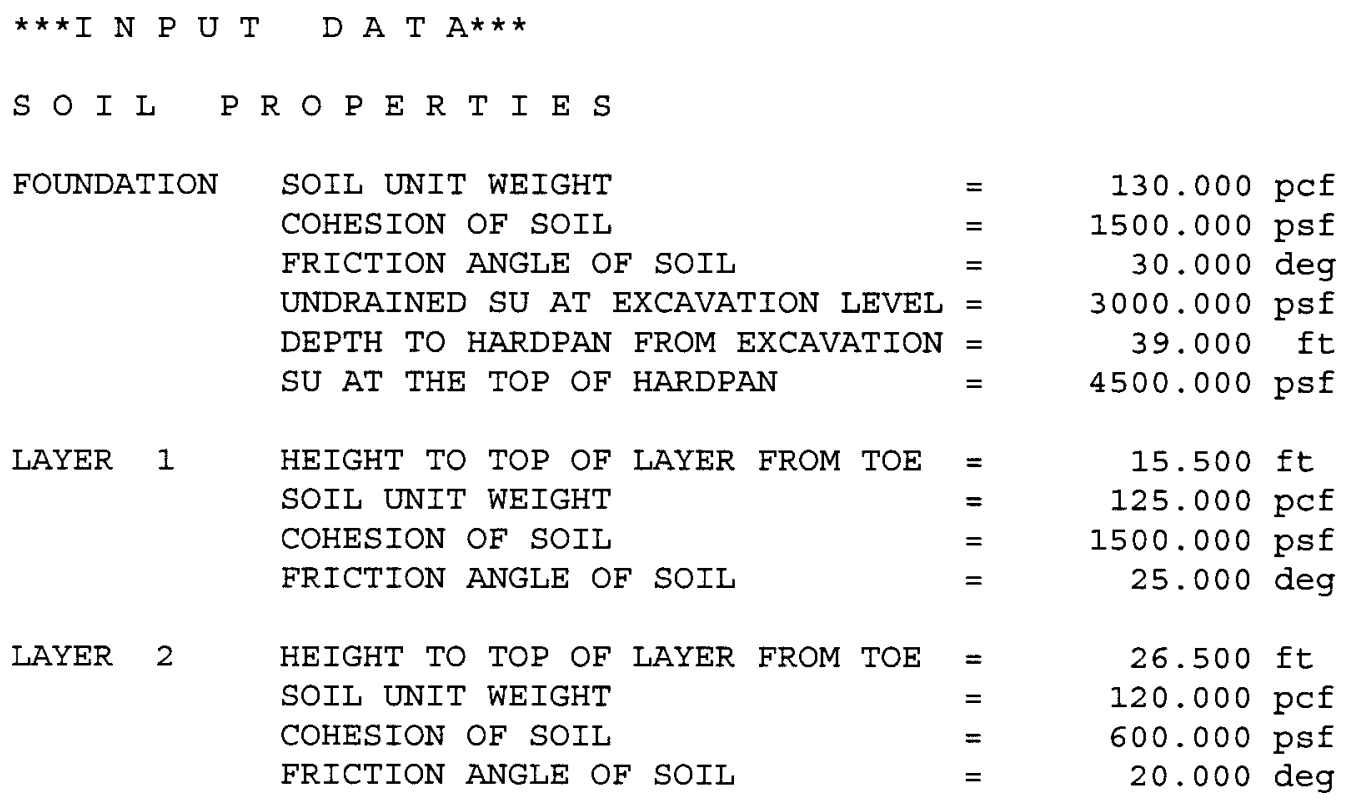

W A L L \& L O A D C O N D I T I O N

WALL INCLINATION ANGLE SURCHARGE LOAD

HOR. ACCELERATION COEFF.
$=$

$=$

$=$
$5.000 \mathrm{deg}$ 250.000 psf .000

$\mathrm{N} A$ I L P R O P E R T I E S

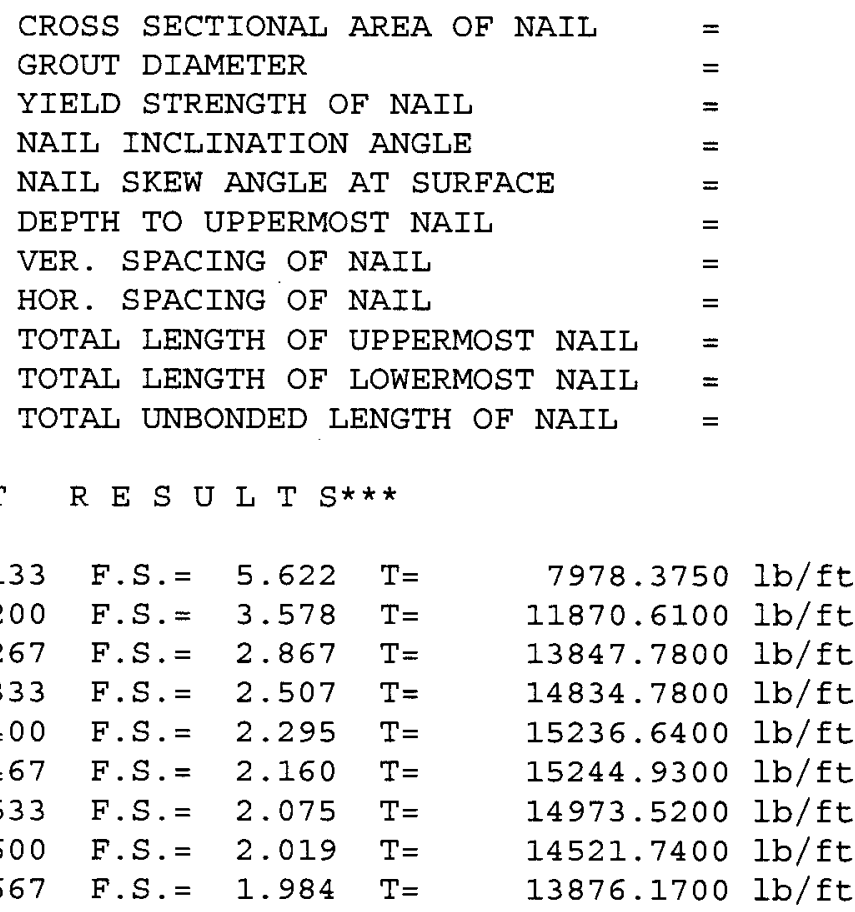




\begin{tabular}{|c|c|c|c|c|c|c|c|c|}
\hline$I=$ & 11 & $A=$ & .733 & F.S. $=$ & 1.963 & $\mathrm{~T}=$ & 13102.2000 & $1 \mathrm{~b} / \mathrm{ft}$ \\
\hline$I=$ & 12 & $A=$ & .800 & F.S. $=$ & 1.955 & $\mathrm{~T}=$ & 12273.3100 & $1 \mathrm{~b} / \mathrm{ft}$ \\
\hline$I=$ & 13 & $A=$ & .867 & F.S. = & 1.956 & $\mathrm{~T}=$ & 11421.9500 & $I b / f t$ \\
\hline$I=$ & 14 & $A=$ & .933 & F.S. $=$ & 1.966 & $\mathrm{~T}=$ & 10550.0800 & $1 \mathrm{~b} / \mathrm{ft}$ \\
\hline$I=$ & 15 & $A=$ & 1.000 & F.S. $=$ & 1.983 & $\mathrm{~T}=$ & 9583.0740 & $1 \mathrm{~b} / \mathrm{ft}$ \\
\hline$I=$ & 16 & $A=$ & 1.067 & F.S. $=$ & 2.005 & $\mathrm{~T}=$ & 8831.0580 & $1 \mathrm{~b} / \mathrm{ft}$ \\
\hline$I=$ & 17 & $A=$ & 1.133 & F.S. $=$ & 2.031 & $\mathrm{~T}=$ & 8001.4690 & $1 \mathrm{~b} / \mathrm{ft}$ \\
\hline$I=$ & 18 & $A=$ & 1.200 & F.S. $=$ & 2.062 & $\mathrm{~T}=$ & 7199.6000 & $1 b / f t$ \\
\hline$I=$ & 19 & $A=$ & 1.267 & F.S. = & 2.102 & $\mathrm{~T}=$ & 6445.7430 & $1 \mathrm{~b} / \mathrm{ft}$ \\
\hline$I=$ & 20 & $A=$ & 1.333 & F.S. $=$ & 2.148 & $\mathrm{~T}=$ & 5792.4090 & $1 b / f t$ \\
\hline$I=$ & 21 & $A=$ & 1.400 & F.S. $=$ & 2.193 & $T=$ & 5226.7410 & $1 b / f t$ \\
\hline$I=$ & 22 & $A=$ & 1.467 & F.S. $=$ & 2.243 & $\mathrm{~T}=$ & 4819.9720 & $I b / \pm t$ \\
\hline$I=$ & 23 & $A=$ & 1.533 & F.S. $=$ & 2.288 & $\mathrm{~T}=$ & 4448.7380 & $1 b / \mathrm{et}$ \\
\hline$I=$ & 24 & $A=$ & 1.600 & F.S. $=$ & 2.333 & $T=$ & 4101.7750 & $I b / f t$ \\
\hline$I=$ & 25 & $A=$ & 1.667 & F.S. $=$ & 2.380 & $\mathrm{~T}=$ & 3772.3880 & $1 b / \pm t$ \\
\hline$I=$ & 26 & $A=$ & 1.733 & F.S. $=$ & 2.430 & $T=$ & 3578.4970 & $I b / f t$ \\
\hline$I=$ & 27 & $A=$ & I. 800 & F.S. $=$ & 2.480 & $\mathrm{~T}=$ & 3401.2160 & $1 b / \mathrm{ft}$ \\
\hline$I=$ & 28 & $A=$ & 1.867 & F.S. $=$ & 2.530 & $T=$ & 3235.2220 & $1 b / f t$ \\
\hline$I=$ & 29 & $A=$ & 1.933 & F.S. $=$ & 2.580 & $\mathrm{~T}=$ & 3079.5230 & $1 \mathrm{~b} / \mathrm{ft}$ \\
\hline$I=$ & 30 & $A=$ & 2.000 & F.S. $=$ & 2.631 & $\mathrm{~T}=$ & 2933.2690 & $1 \mathrm{~b} / \mathrm{ft}$ \\
\hline
\end{tabular}

$\mathrm{H} / \mathrm{LT}=1.060 \mathrm{H} / \mathrm{LB}=1.325$

NO. OF NAILS (INCLUDING THE LOWERMOST) = 5

**F.S. AGAINST SLIDING THROUGH TOE $=1.96$

**.S. AGAINST DEEP SEATED ROTATION $=5.52$

1 TH NAIL FORCE =

2 TH NAIL FORCE =

3 TH NAIL FORCE =

$4 \mathrm{TH}$ NAIL FORCE =

$5 \mathrm{TH}$ NAIL FORCE $=$
$779.7014 \mathrm{lb} / \mathrm{ft}$

$1942.9830 \mathrm{lb} / \mathrm{ft}$

$2390.6170 \mathrm{Ib} / \mathrm{ft}$

$3011.1190 \mathrm{lb} / \mathrm{ft}$

$4148.8860 \mathrm{lb} / \mathrm{ft}$ 
CASE 722.5 FT WALL

$<$ OUTPUT FILE > = CASE7B. OUT

\begin{tabular}{|c|c|c|c|c|c|}
\hline \multicolumn{6}{|c|}{$S O I L$} \\
\hline \multirow{6}{*}{\multicolumn{2}{|c|}{ FOUNDATION }} & SOIL UNIT WEIGHT & $=$ & 125.000 & pcf \\
\hline & & COHESION OF SOIL & $=$ & 1100.000 & psf \\
\hline & & FRICTION ANGLE OF SOIL & $=$ & 30.000 & deg \\
\hline & & UNDRAINED SU AT EXCAVATION LEVEL & $=$ & 2200.000 & psf \\
\hline & & DEPTH TO HARDPAN FROM EXCAVATION & $=$ & 8.000 & ft \\
\hline & & SU AT THE TOP OF HARDPAN & $=$ & 3500.000 & psf \\
\hline \multirow[t]{4}{*}{ LAYER } & 1 & HEIGHT TO TOP OF LAYER FROM TOE & $=$ & 9.500 & ft \\
\hline & & SOIL UNIT WEIGHT & $=$ & 125.000 & pcf \\
\hline & & COHESION OF SOIL & $=$ & 1000.000 & psf \\
\hline & & FRICTION ANGLE OF SOIL & $=$ & 30.000 & $\operatorname{deg}$ \\
\hline \multirow[t]{4}{*}{ LAYER } & 2 & HEIGHT TO TOP OF LAYER FROM TOE & $=$ & 22.500 & ft \\
\hline & & SOIL UNIT WEIGHT & $=$ & 110.000 & pcf \\
\hline & & COHESION OF SOIL & $=$ & 750.000 & psf \\
\hline & & FRICTION ANGLE OF SOIL & $=$ & 20.000 & $\operatorname{deg}$ \\
\hline
\end{tabular}

W A L L \& L O A D C O N D I T I O N

WALL INCLINATION ANGLE

SURCHARGE LOAD

HOR. ACCELERATION COEFF.

$\begin{array}{lr}= & 5.000 \mathrm{deg} \\ = & 300.000 \mathrm{psf} \\ = & .000\end{array}$

N A I L P R O P E R T I E S

CROSS SECTIONAL AREA OF NAIL = GROUT DIAMETER

YIELD STRENGTH OF NAIL

NAIL INCLINATION ANGLE

NAIL SKEW ANGLE AT SURFACE

DEPTH TO UPPERMOST NAIL

VER. SPACING OF NAIL

HOR. SPACING OF NAIL

TOTAL LENGTH OF UPPERMOST NAIL TOTAL LENGTH OF LOWERMOST NAIL TOTAL UNBONDED LENGTH OF NAIL

$.790 \mathrm{si}$
$4.000 \mathrm{in}$
$60.000 \mathrm{ksi}$
$20.000 \mathrm{deg}$
$.000 \mathrm{deg}$
$2.000 \mathrm{ft}$
$5.500 \mathrm{ft}$
$6.000 \mathrm{ft}$
$20.000 \mathrm{ft}$
$15.000 \mathrm{ft}$
$2.000 \mathrm{ft}$

$.790 \mathrm{si}$

$=$

$=$

$=$

$=$

$=$

$=$

$=$

$=$

\begin{tabular}{|c|c|c|c|c|c|c|}
\hline$I=$ & 2 & $A=$ & .133 & F.S. $=$ & 5.845 & $\mathrm{~T}=$ \\
\hline$I=$ & 3 & $A=$ & .200 & F.S. $=$ & 3.443 & $\mathrm{~T}=$ \\
\hline$I=$ & 4 & $A=$ & .267 & F.S. $=$ & 2.646 & $T=$ \\
\hline$I=$ & 5 & $A=$ & .333 & F.S. $=$ & 2.251 & $\mathrm{~T}=$ \\
\hline$I=$ & 6 & $A=$ & .400 & F.S. $=$ & 2.024 & $\mathrm{~T}=$ \\
\hline$I=$ & 7 & $A=$ & .467 & F.S. $=$ & 1.883 & $\mathrm{~T}=$ \\
\hline$I=$ & 8 & $A=$ & .533 & F.S. $=$ & 1.794 & $\mathrm{~T}=$ \\
\hline$I=$ & 9 & $A=$ & .600 & F.S. $=$ & 1.739 & $\mathrm{~T}=$ \\
\hline$I=$ & 10 & $A=$ & .667 & F.S. $=$ & 1.708 & $\mathrm{~T}=$ \\
\hline
\end{tabular}

$\begin{array}{ll}3134.1630 & \mathrm{lb} / \mathrm{ft} \\ 5025.1370 & \mathrm{lb} / \mathrm{ft} \\ 6042.6960 & \mathrm{lb} / \mathrm{ft} \\ 6534.1570 & \mathrm{lb} / \mathrm{ft} \\ 6711.1930 & \mathrm{lb} / \mathrm{ft} \\ 6679.2290 & \mathrm{lb} / \mathrm{ft} \\ 6497.4730 & \mathrm{lb} / \mathrm{ft} \\ 6212.4800 & \mathrm{lb} / \mathrm{ft} \\ 5858.4100 & \mathrm{lb} / \mathrm{ft}\end{array}$ 


\begin{tabular}{|c|c|c|c|c|c|c|c|c|}
\hline$I=$ & 11 & $A=$ & .733 & F.S. $=$ & 1.694 & $\mathrm{~T}=$ & 5463.8070 & $1 \mathrm{~b} / \mathrm{ft}$ \\
\hline$I=$ & 12 & $A=$ & .800 & F.S. $=$ & 1.694 & $\mathrm{~T}=$ & 5040.0630 & $I \mathrm{~b} / \mathrm{ft}$ \\
\hline$I=$ & 13 & $A=$ & .867 & F.S. $=$ & 1.705 & $\mathrm{~T}=$ & 4606.2330 & $1 \mathrm{~b} / \mathrm{ft}$ \\
\hline$I=$ & 14 & $A=$ & .933 & F.S. $=$ & 1.724 & $\mathrm{~T}=$ & 4172.4250 & Ib/ft \\
\hline$I=$ & 15 & $A=$ & 1.000 & F.S. $=$ & 1.750 & $\mathrm{~T}=$ & 3746.1910 & $I \mathrm{~b} / \mathrm{ft}$ \\
\hline$I=$ & 16 & $A=$ & 1.067 & F.S. = & 1.781 & $T=$ & 3332.2150 & $1 \mathrm{~b} / \mathrm{ft}$ \\
\hline$I=$ & 17 & $A=$ & 1.133 & F.S. = & 1.817 & $\mathrm{~T}=$ & 2929.3270 & $1 \mathrm{~b} / \mathrm{ft}$ \\
\hline$I=$ & 18 & $A=$ & 1.200 & F.S. $=$ & 1.862 & $\mathrm{~T}=$ & 2550.4220 & $1 \mathrm{~b} / \mathrm{ft}$ \\
\hline$I=$ & 19 & $A=$ & 1.267 & F.S. $=$ & 1.917 & $\mathrm{~T}=$ & 2243.7440 & $1 \mathrm{~b} / \mathrm{ft}$ \\
\hline$I=$ & 20 & $A=$ & 1.333 & F.S. $=$ & 1.971 & $\mathrm{~T}=$ & 1976.4510 & $1 b / f t$ \\
\hline$I=$ & 21 & $A=$ & 1.400 & F.S. $=$ & 2.029 & $\mathrm{~T}=$ & 1813.7950 & $1 \mathrm{~b} / \mathrm{ft}$ \\
\hline$I=$ & 22 & $A=$ & 1.467 & F.S. $=$ & 2.084 & $\mathrm{~T}=$ & 1665.5530 & $1 \mathrm{~b} / \mathrm{ft}$ \\
\hline$I=$ & 23 & $A=$ & 1.533 & F.S. $=$ & 2.134 & $\mathrm{~T}=$ & 1530.4360 & $1 \mathrm{~b} / \mathrm{ft}$ \\
\hline$I=$ & 24 & $A=$ & 1.600 & F.S. $=$ & 2.183 & $\mathrm{~T}=$ & 1405.0670 & $1 \mathrm{~b} / \mathrm{ft}$ \\
\hline$I=$ & 25 & $A=$ & 1.667 & $F \cdot S \cdot=$ & 2.232 & $\mathrm{~T}=$ & 1288.4800 & $1 \mathrm{~b} / \mathrm{ft}$ \\
\hline$I=$ & 26 & $A=$ & 1.733 & F.S. $=$ & 2.281 & $\mathrm{~T}=$ & 1179.8700 & $1 \mathrm{~b} / \mathrm{ft}$ \\
\hline$I=$ & 27 & $A=$ & 1.800 & F.S. = & 2.331 & $T=$ & 1092.1270 & $1 \mathrm{~b} / \mathrm{ft}$ \\
\hline$I=$ & 28 & $A=$ & 1.867 & F.S. = & 2.383 & $\mathrm{~T}=$ & 1050.7940 & $1 b / f t$ \\
\hline$I=$ & 29 & $A=$ & 1.933 & F.S. = & 2.435 & $\mathrm{~T}=$ & 1012.0890 & $1 \mathrm{~b} / \mathrm{ft}$ \\
\hline$I=$ & 30 & $A=$ & 2.000 & $F \cdot S \cdot=$ & 2.490 & $T=$ & 974.9437 & $1 \mathrm{~b} / \mathrm{ft}$ \\
\hline
\end{tabular}

$\mathrm{H} / \mathrm{LT}=1.125 \mathrm{H} / \mathrm{LB}=1.500$

NO. OF NAILS (INCLUDING THE LOWERMOST) = 4

**F.S. AGAINST SLIDING THROUGH TOE $=1.69$

NO F.S. OF DEEP SEATED FAILURE IS CALCULATED

**DMAX IS TOO SMAIL

1 TH NAIL FORCE =

$2 \mathrm{TH}$ NAIL FORCE =

$3 \mathrm{TH}$ NAIL FORCE =

4 TH NAIL FORCE =
$731.8884 \mathrm{lb} / \mathrm{Et}$

$989.3829 \mathrm{lb} / \mathrm{Et}$

$1558.7860 \mathrm{lb} / \mathrm{ft}$

$2183.75001 \mathrm{~b} / \mathrm{ft}$ 
CASE 8 PART A 25 AND 28 FT WALL

$<$ OUTPUT FILE > = CASE8A. OUT

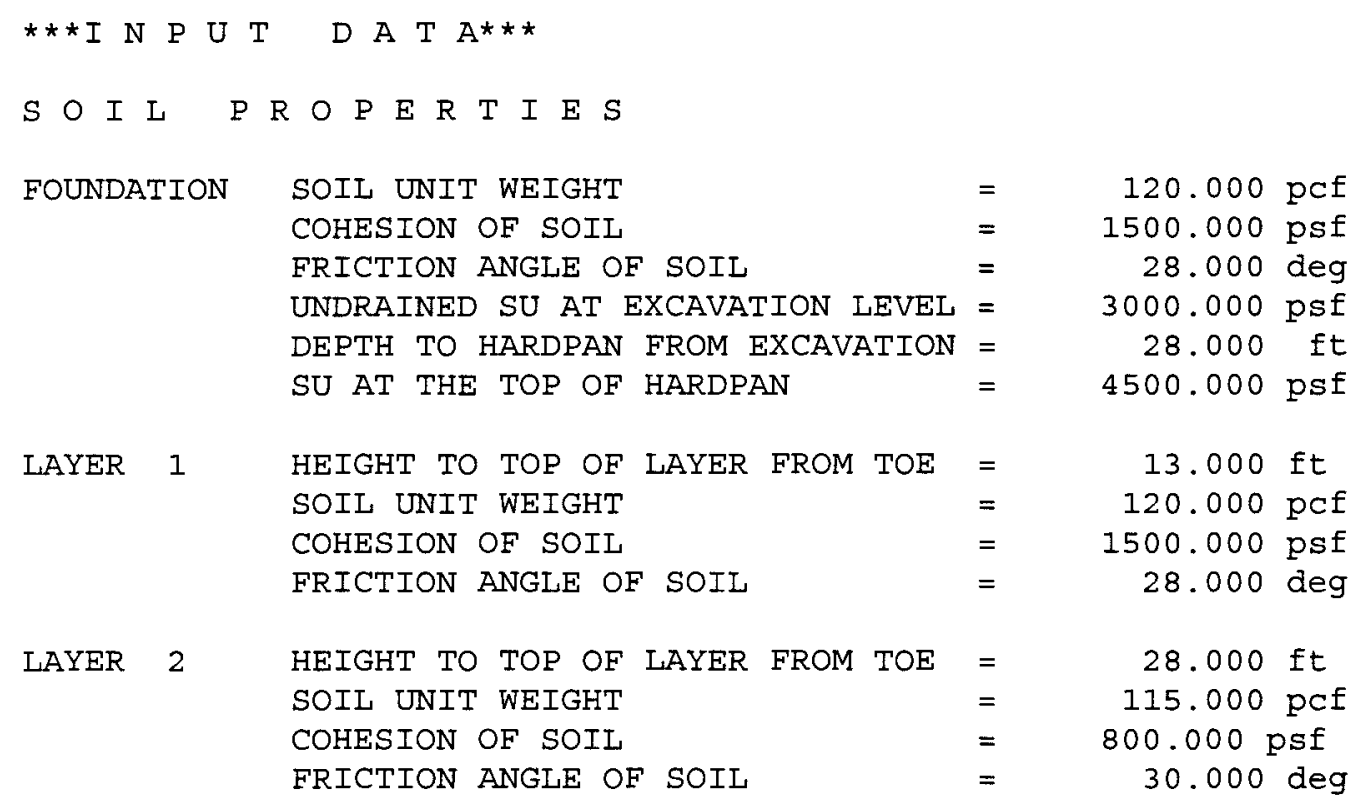

W A L L \& L

WALL INCLINATION ANGLE $=5.000 \mathrm{deg}$ SURCHARGE LOAD $\quad=200.000$ psE

HOR. ACCELERATION COEFF. $\quad .000$

$N$ A I L P R O P E R T I E S

$\begin{array}{llr}\text { CROSS SECTIONAL AREA OF NAIL } & = & .790 \mathrm{si} \\ \text { GROUT DIAMETER } & = & 4.000 \mathrm{in} \\ \text { YIELD STRENGTH OF NAIL } & = & 60.000 \mathrm{ksi} \\ \text { NAIL INCLINATION ANGLE } & = & 20.000 \mathrm{deg} \\ \text { NAIL SKEW ANGLE AT SURFACE } & = & .000 \mathrm{deg} \\ \text { DEPTH TO UPPERMOST NAIL } & = & 2.000 \mathrm{ft} \\ \text { VER. SPACING OF NAII } & = & 5.500 \mathrm{ft} \\ \text { HOR. SPACING OF NAIL } & = & 5.000 \mathrm{ft} \\ \text { TOTAL LENGTH OF UPPERMOST NAIL } & = & 25.000 \mathrm{ft} \\ \text { TOTAL LENGTH OF LOWERMOST NAIL } & = & 20.000 \mathrm{ft} \\ \text { TOTAL UNBONDED LENGTH OF NAIL } & = & 2.000 \mathrm{ft}\end{array}$

\begin{tabular}{|c|c|c|c|c|c|c|c|c|}
\hline$I=$ & 2 & $A=$ & .133 & F.S. = & 6.636 & $T=$ & 7602.4290 & $1 \mathrm{~b} / \mathrm{ft}$ \\
\hline$I=$ & 3 & $A=$ & .200 & F.S. $=$ & 4.189 & $\mathrm{~T}=$ & 11316.5800 & $1 b / f t$ \\
\hline$I=$ & 4 & $A=$ & .267 & F.S. $=$ & 3.335 & $\mathrm{~T}=$ & 13205.7900 & $1 b / f t$ \\
\hline$I=$ & 5 & $A=$ & .333 & F.S. $=$ & 2.896 & $\mathrm{~T}=$ & 14147.2300 & $1 \mathrm{~b} / \mathrm{ft}$ \\
\hline$I=$ & 6 & $\mathrm{~A}=$ & .400 & F.S. $=$ & 2.636 & $\mathrm{~T}=$ & 14478.7600 & $1 \mathrm{~b} / \mathrm{ft}$ \\
\hline$I=$ & 7 & $A=$ & .467 & F.S. $=$ & 2.469 & $\mathrm{~T}^{\prime}=$ & 14406.4500 & $I b / f t$ \\
\hline$I=$ & 8 & $A=$ & .533 & F.S. $=$ & 2.361 & $\mathrm{~T}=$ & 14052.1600 & $1 b / f t$ \\
\hline$I=$ & 9 & $A=$ & .600 & F.S. $=$ & 2.287 & $\mathrm{~T}=$ & 13516.9100 & $1 b / f t$ \\
\hline$I=$ & 10 & $A=$ & .667 & F.S. $=$ & 2.241 & $T=$ & 12847.0000 & $1 \mathrm{~b} / \mathrm{ft}$ \\
\hline
\end{tabular}




\begin{tabular}{|c|c|c|c|c|c|c|c|c|}
\hline$I=$ & 11 & $A=$ & .733 & F.S. $=$ & 2.214 & $\mathrm{~T}=$ & 12087.2600 & $1 \mathrm{~b} / \mathrm{ft}$ \\
\hline$I=$ & 12 & $A=$ & .800 & F.S. $=$ & 2.202 & $\mathrm{~T}=$ & 11271.2800 & $1 \mathrm{~b} / \mathrm{ft}$ \\
\hline$I=$ & 13 & $\mathrm{~A}=$ & .867 & F.S. $=$ & 2.199 & $T=$ & 10431.9400 & $1 \mathrm{~b} / \mathrm{ft}$ \\
\hline$I=$ & 14 & $A=$ & .933 & F.S. $=$ & 2.209 & $\mathrm{~T}=$ & 9570.1800 & $1 \mathrm{~b} / \mathrm{ft}$ \\
\hline$I=$ & 15 & $\mathrm{~A}=$ & 1.000 & F.S. $=$ & 2.226 & $\mathrm{~T}=$ & 8712.2710 & $1 \mathrm{~b} / \mathrm{ft}$ \\
\hline$I=$ & 16 & $A=$ & 1.067 & F.S. $=$ & 2.249 & $\mathrm{~T}=$ & 7868.3760 & $1 \mathrm{~b} / \mathrm{ft}$ \\
\hline$I=$ & 17 & $A=$ & 1.133 & F.S. $=$ & 2.278 & $\mathrm{~T}=$ & 7046.0410 & $1 \mathrm{~b} / \mathrm{ft}$ \\
\hline$I=$ & 18 & $A=$ & 1.200 & F.S. $=$ & 2.323 & $\mathrm{~T}=$ & 6298.4610 & $1 \mathrm{~b} / \mathrm{ft}$ \\
\hline$I=$ & 19 & $A=$ & 1.267 & F.S. $=$ & 2.377 & $\mathrm{~T}=$ & 5637.6350 & $1 \mathrm{~b} / \mathrm{ft}$ \\
\hline$I=$ & 20 & $A=$ & 1.333 & F.S. $=$ & 2.432 & $\mathrm{~T}=$ & 5123.6650 & $1 \mathrm{~b} / \mathrm{ft}$ \\
\hline$I=$ & 21 & $\mathrm{~A}=$ & 1.400 & F.S. $=$ & 2.488 & $\mathrm{~T}=$ & 4719.4480 & $1 \mathrm{~b} / \mathrm{ft}$ \\
\hline$I=$ & 22 & $A=$ & 1.467 & F.S. $=$ & 2.541 & $\mathrm{~T}=$ & 4345.1570 & $\mathrm{Ib} / \mathrm{ft}$ \\
\hline$I=$ & 23 & $A=$ & 1.533 & F.S. $=$ & 2.594 & $\mathrm{~T}=$ & 3995.0380 & $1 \mathrm{~b} / \mathrm{ft}$ \\
\hline$I=$ & 24 & $A=$ & 1.600 & F.S. $=$ & 2.646 & $\mathrm{~T}=$ & 3727.5750 & $1 \mathrm{~b} / \mathrm{ft}$ \\
\hline$I=$ & 25 & $A=$ & 1.667 & F.S. $=$ & 2.701 & $\mathrm{~T}=$ & 3543.3810 & $I b / f t$ \\
\hline$I=$ & 26 & $A=$ & 1.733 & F.S. = & 2.759 & $\mathrm{~T}=$ & 3368.0560 & $1 \mathrm{~b} / \mathrm{ft}$ \\
\hline$I=$ & 27 & $A=$ & 1.800 & F.S. $=$ & 2.816 & $\mathrm{~T}=$ & 3205.8140 & $1 \mathrm{~b} / \mathrm{ft}$ \\
\hline$I=$ & 28 & $A=$ & 1.867 & F.S. $=$ & 2.872 & $\mathrm{~T}=$ & 3053.7030 & $I b / f t$ \\
\hline$I=$ & 29 & $A=$ & 1.933 & F.S. $=$ & 2.929 & $T=$ & 2910.8550 & $1 b / \mathrm{et}$ \\
\hline$I=$ & 30 & $A=$ & 2.000 & F.S. $=$ & 2.986 & $T=$ & 2776.5290 & $1 \mathrm{~b} / \mathrm{ft}$ \\
\hline
\end{tabular}

$\mathrm{H} / \mathrm{LT}=1.120 \mathrm{H} / \mathrm{LB}=1.400$

NO. OF NAILS (INCLUDING THE LOWERMOST) = 5

**.S. AGAINST SLIDING THROUGH TOE $=2.20$

**F.S. AGAINST DEEP SEATED ROTATION $=5.58$

$1 \mathrm{TH}$ NAIL FORCE =

$2 \mathrm{TH}$ NAIL FORCE =

$3 \mathrm{TH}$ NAIL FORCE =

4 TH NAIL FORCE =

$5 \mathrm{TH}$ NAIL FORCE =

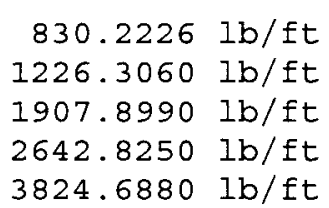

$830.2226 \mathrm{Ib} / \mathrm{ft}$

$1226.3060 \mathrm{lb} / \mathrm{et}$

$2642.8250 \mathrm{lb} / \mathrm{ft}$

$3824.6880 \mathrm{lb} / \mathrm{ft}$ 5 
CASE 8 PART C 15 FT WALL

$<$ OUTPUT FILE > = CASE8C.OUT

$\star \star \star I \quad N \quad P \quad U T \quad$ D A $T A * * *$

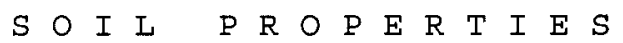

FOUNDATION SOIL UNIT WEIGHT $\quad=\quad 120.000$ pCf

COHESION OF SOIL $\quad=1500.000 \mathrm{psf}$

FRICTION ANGLE OF SOIL $\quad=\quad 28.000 \mathrm{deg}$

UNDRAINED SU AT EXCAVATION LEVEL $=3000.000$ psf

DEPTH TO HARDPAN FROM EXCAVATION $=41.000 \mathrm{ft}$

SU AT THE TOP OF HARDPAN $=4500.000$ psf

LAYER 1 HEIGHT TO TOP OF LAYER FROM TOE $=15.000 \mathrm{ft}$ SOIL UNIT WEIGHT $\quad=115.000$ pCf COHESION OF SOIL $\quad=800.000$ psf

FRICTION ANGLE OF SOIL = $30.000 \mathrm{deg}$

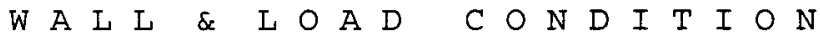

$\begin{array}{llr}\text { WALL INCLINATION ANGLE } & = & 5.000 \mathrm{deg} \\ \text { SURCHARGE LOAD } & = & 200.000 \mathrm{psf} \\ \text { HOR. ACCELERATION COEFF. } & = & .000\end{array}$

$N$ A I L P R O P E R T I E S

$\begin{array}{llr}\text { CROSS SECTIONAL AREA OF NAIL } & = & .790 \mathrm{si} \\ \text { GROUT DIAMETER } & = & 4.000 \mathrm{in} \\ \text { YIELD STRENGTH OF NAIL } & = & 60.000 \mathrm{ksi} \\ \text { NAIL INCLINATION ANGLE } & = & 20.000 \mathrm{deg} \\ \text { NAIL SKEW ANGLE AT SURFACE } & = & .000 \mathrm{deg} \\ \text { DEPTH TO UPPERMOST NAIL } & = & 2.000 \mathrm{ft} \\ \text { VER. SPACING OF NAIL } & = & 5.500 \mathrm{ft} \\ \text { HOR. SPACING OF NAIL } & = & 5.000 \mathrm{ft} \\ \text { TOTAL LENGTH OF UPPERMOST NAIL } & = & 12.000 \mathrm{ft} \\ \text { TOTAI LENGTH OF LOWERMOST NAIL } & = & 10.000 \mathrm{ft} \\ \text { TOTAL UNBONDED LENGTH OF NAIL } & = & 2.000 \mathrm{ft}\end{array}$

**

\begin{tabular}{|c|c|c|c|c|c|c|c|}
\hline$I=$ & $2 \mathrm{~A}=$ & .133 & F.S. $=$ & 10.486 & $\mathrm{~T}=$ & 955.5569 & $1 b / f t$ \\
\hline$I=$ & $3 \mathrm{~A}=$ & .200 & F.S. = & 5.853 & $\mathrm{~T}=$ & 1655.0820 & $1 b / f t$ \\
\hline$I=$ & $4 \mathrm{~A}=$ & .267 & F.S. $=$ & 4.361 & $T=$ & 2118.4950 & $1 b / f$ \\
\hline$I=$ & $5 \mathrm{~A}=$ & .333 & F.S. $=$ & 3.637 & $\mathrm{~T}=$ & 2372.9560 & $1 \mathrm{~b} / \mathrm{f}$ \\
\hline$I=$ & $6 A=$ & .400 & F.S. $=$ & 3.223 & $\mathrm{~T}=$ & 2509.2840 & $1 \mathrm{~b} / \mathrm{f}$ \\
\hline$I=$ & $7 \mathrm{~A}=$ & .467 & F.S. $=$ & 2.967 & $\mathrm{~T}=$ & 2557.8770 & $1 b / f$ \\
\hline$I=$ & $8 \mathrm{~A}=$ & .533 & F.S. $=$ & 2.799 & $\mathrm{~T}=$ & 2517.0350 & $1 \mathrm{~b} / \mathrm{f}$ \\
\hline$[=$ & $9 \mathrm{~A}=$ & .600 & F.S. $=$ & 2.690 & $\mathrm{~T}=$ & 2430.8000 & $1 b / f$ \\
\hline$I=$ & $10 \mathrm{~A}=$ & .667 & F.S. $=$ & 2.621 & $\mathrm{~T}=$ & 2312.9400 & $1 b / f$ \\
\hline & $11 \mathrm{~A}=$ & .733 & F.S. $=$ & 2.579 & $T=$ & 2175.2560 & $1 b / f$ \\
\hline$I=$ & $12 \mathrm{~A}=$ & .800 & F.S. $=$ & 2.562 & $\mathrm{~T}=$ & 2022.3720 & $1 \mathrm{~b} / \mathrm{t}$ \\
\hline$T=$ & $13 A=$ & .867 & F.S. $=$ & 2.561 & $\mathrm{~T}=$ & 1862.3860 & $1 \mathrm{~b} / \mathrm{t}$ \\
\hline$I=$ & $14 \mathrm{~A}=$ & .933 & F.S. $=$ & 2.573 & $\mathrm{~T}=$ & 1699.6880 & $\mathrm{Ib} /$ \\
\hline$T$ & $15 \mathrm{~A}=$ & 1.000 & F.S. $=$ & 2.596 & $\mathrm{~T}=$ & 1537.5160 & $\mathrm{Ib} /$ \\
\hline
\end{tabular}




\begin{tabular}{|c|c|c|c|c|c|c|c|c|}
\hline$I=$ & 16 & $A=$ & 1.067 & F.S. $=$ & 2.627 & $\mathrm{~T}=$ & 1378.2240 & Ib/ft \\
\hline$I=$ & 17 & $A=$ & 1.133 & F.S. $=$ & 2.681 & $\mathrm{~T}=$ & 1276.2540 & $1 \mathrm{~b} / \mathrm{Et}$ \\
\hline$I=$ & 18 & $A=$ & 1.200 & F.S. $=$ & 2.736 & $\mathrm{~T}=$ & 1187.9290 & $I b / f t$ \\
\hline$I=$ & 19 & $A=$ & 1.267 & F.S. = & 2.790 & $\mathrm{~T}=$ & 1105.5080 & $1 b / f t$ \\
\hline$I=$ & 20 & $A=$ & 1.333 & F.S. = & 2.844 & $\mathrm{~T}=$ & 1028.4000 & $1 \mathrm{~b} / \mathrm{ft}$ \\
\hline$I=$ & 21 & $A=$ & 1.400 & F.S. $=$ & 2.898 & $\mathrm{~T}=$ & 956.0954 & $I b / \pm t$ \\
\hline$I=$ & 22 & $A=$ & 1.467 & F.S. $=$ & 2.954 & $\mathrm{~T}=$ & 887.4468 & $1 b / f t$ \\
\hline$I=$ & 23 & $A=$ & 1.533 & F.S. $=$ & 3.014 & $T=$ & 860.8624 & $1 \mathrm{~b} / \mathrm{ft}$ \\
\hline$I=$ & 24 & $A=$ & 1.600 & F.S. $=$ & 3.074 & $\mathrm{~T}=$ & 836.4722 & $1 \mathrm{~b} / \mathrm{ft}$ \\
\hline$I=$ & 25 & $A=$ & 1.667 & F.S. = & 3.135 & $T=$ & 813.3091 & $1 b / f t$ \\
\hline$I=$ & 26 & $A=$ & 1.733 & F.S. $=$ & 3.198 & $\mathrm{~T}=$ & 791.2628 & $1 \mathrm{~b} / \mathrm{ft}$ \\
\hline$I=$ & 27 & $A=$ & 1.800 & F.S. $=$ & 3.265 & $\mathrm{~T}=$ & 769.4709 & $1 b / f t$ \\
\hline$I=$ & 28 & $A=$ & 1.867 & F.S. $=$ & 3.330 & $\mathrm{~T}=$ & 749.2644 & $1 b / \pm t$ \\
\hline$I=$ & 29 & $A=$ & 1.933 & F.S. $=$ & 3.396 & $\mathrm{~T}=$ & 729.9737 & $1 b / \pm t$ \\
\hline$I=$ & 30 & $A=$ & 2.000 & F.S. $=$ & 3.464 & $\mathrm{~T}=$ & 711.5373 & $1 b / E t$ \\
\hline
\end{tabular}

$\mathrm{H} / \mathrm{LT}=1.250 \mathrm{H} / \mathrm{LB}=1.500$

NO. OF NAILS (INCLUDING THE LOWERMOST) $=3$

**F.S. AGAINST SLIDING THROUGH TOE $=2.56$

$\star \star F . S . ~ A G A I N S T$ DEEP SEATED ROTATION $=10.23$

1 TH NAIL FORCE =

2 TH NAIL FORCE =

3 TH NAIL FORCE =
$224.6582 \mathrm{lb} / \mathrm{ft}$

$480.1544 \mathrm{lb} / \mathrm{ft}$

1157.5740 lb/ft 


\begin{tabular}{|c|c|c|c|c|}
\hline \multicolumn{5}{|c|}{$\begin{array}{l}\text { CASE } 933 \text { FT WALL } \\
<\text { OUTPUT FILE }>=\text { CASE9.OUT }\end{array}$} \\
\hline \multicolumn{5}{|c|}{ 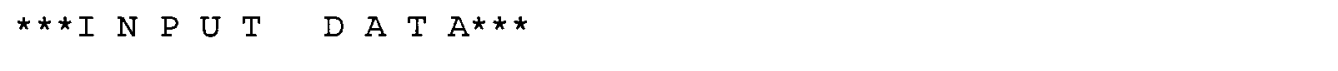 } \\
\hline \multicolumn{5}{|c|}{$S O I L \quad P R O P E R E I E S$} \\
\hline \multirow[t]{6}{*}{ FOUNDATION } & SOIL UNIT WEIGHT & $=$ & 130.000 & $\operatorname{pcf}$ \\
\hline & COHESION OF SOIL & $=$ & 1200.000 & psf \\
\hline & FRICTION ANGLE OF SOIL & $=$ & 33.000 & deg \\
\hline & UNDRAINED SU AT EXCAVATION LEVEL & $=$ & 2000.000 & psf \\
\hline & DEPTH TO HARDPAN FROM EXCAVATION & $=$ & 23.000 & ft \\
\hline & SU AT THE TOP OF HARDPAN & $=$ & 3500.000 & psf \\
\hline \multirow[t]{4}{*}{ LAYER } & HEIGHT TO TOP OF LAYER FROM TOE & $=$ & 16.000 & ft \\
\hline & SOIL UNIT WEIGHT & $=$ & 130.000 & $\operatorname{pcf}$ \\
\hline & COHESION OF SOIL & $=$ & 1100.000 & psf \\
\hline & FRICTION ANGLE OF SOIL & $=$ & 33.000 & deg \\
\hline \multirow[t]{4}{*}{ LAYER } & HEIGHT TO TOP OF LAYER FROM TOE & $=$ & 33.000 & ft \\
\hline & SOIL UNIT WEIGHT & $=$ & 115.000 & pcf \\
\hline & COHESION OF SOIL & $=$ & 550.000 & psf \\
\hline & FRICTION ANGLE OF SOIL & $=$ & 28.000 & deg \\
\hline
\end{tabular}

W A L L $\&$ L

WALL INCLINATION ANGLE $=5.000 \mathrm{deg}$ SURCHARGE LOAD $=100.000$ psf

HOR. ACCELERATION COEFF. $=000$

$N$ A I I P R O P E R T I E S

$\begin{array}{llr}\text { CROSS SECTIONAL AREA OF NAIL } & = & .790 \mathrm{si} \\ \text { GROUT DIAMETER } & = & 4.000 \mathrm{in} \\ \text { YIELD STRENGTH OF NAIL } & = & 60.000 \mathrm{ksi} \\ \text { NAIL INCLINATION ANGLE } & = & 20.000 \mathrm{deg} \\ \text { NAII SKEW ANGLE AT SURFACE } & = & .000 \mathrm{deg} \\ \text { DEPTH TO UPPERMOST NAIL } & = & 2.000 \mathrm{ft} \\ \text { VER. SPACING OF NAII } & = & 5.000 \mathrm{ft} \\ \text { HOR. SPACING OF NAIL } & = & 5.000 \mathrm{ft} \\ \text { TOTAL IENGTH OF UPPERMOST NAIL } & = & 28.000 \mathrm{ft} \\ \text { TOTAL LENGTH OF LOWERMOST NAIL } & = & 25.000 \mathrm{ft} \\ \text { TOTAL UNBONDED LENGTH OF NAIL } & = & 2.000 \mathrm{ft}\end{array}$

\begin{tabular}{|c|c|c|c|c|c|c|c|c|}
\hline$I=$ & 2 & $A=$ & .133 & F.S. $=$ & 3.564 & $\mathrm{~T}=$ & 23037.3800 & $1 \mathrm{~b} / \mathrm{ft}$ \\
\hline$I=$ & 3 & $A=$ & .200 & F.S. $=$ & 2.740 & $\mathrm{~T}=$ & 28099.2000 & $1 \mathrm{~b} / \mathrm{ft}$ \\
\hline$I=$ & 4 & $\mathrm{~A}=$ & .267 & F.S. $=$ & 2.389 & $\mathrm{~T}=$ & 30303.7000 & $1 \mathrm{~b} / \mathrm{ft}$ \\
\hline$I=$ & 5 & $A=$ & .333 & F.S. = & 2.193 & $\mathrm{~T}=$ & 31235.0200 & $I b / E t$ \\
\hline$I=$ & 6 & $A=$ & .400 & F.S. = & 2.075 & $\mathrm{~T}=$ & 31353.9000 & $I b / f t$ \\
\hline$I=$ & 7 & $A=$ & .467 & F.S. $=$ & 1.999 & $\mathrm{~T}=$ & 30990.5000 & $1 \mathrm{~b} / \mathrm{ft}$ \\
\hline$I=$ & 8 & $A=$ & .533 & F.S. $=$ & 1.951 & $\mathrm{~T}=$ & 30277.1000 & $I b / f t$ \\
\hline$I=$ & 9 & $A=$ & .600 & F.S. $=$ & 1.925 & $\mathrm{~T}=$ & 29302.0800 & $I b / f t$ \\
\hline$I=$ & 10 & $A=$ & .667 & F.S. $=$ & 1.914 & $\mathrm{~T}=$ & 28129.2800 & $1 \mathrm{~b} / \mathrm{ft}$ \\
\hline
\end{tabular}




\begin{tabular}{|c|c|c|c|c|c|c|c|c|}
\hline$I=$ & 11 & $A=$ & .733 & F.S. $=$ & 1.910 & $\mathrm{~T}=$ & 26816.0600 & $1 \mathrm{~b} / \mathrm{ft}$ \\
\hline$I=$ & 12 & $A=$ & .800 & F.S. $=$ & 1.915 & $\mathrm{~T}=$ & 25425.0700 & $1 b / f t$ \\
\hline$I=$ & 13 & $A=$ & .867 & F.S. $=$ & 1.926 & $\mathrm{~T}=$ & 24013.1500 & $I b / f t$ \\
\hline$I=$ & 14 & $A=$ & .933 & F.S. $=$ & 1.946 & $\mathrm{~T}=$ & 22569.2000 & $I b / f t$ \\
\hline$I=$ & 15 & $A=$ & 1.000 & F.S. $=$ & 1.970 & $T=$ & 21139.7700 & $I b / f t$ \\
\hline$I=$ & 16 & $A=$ & 1.067 & F.S. $=$ & 1.997 & $\mathrm{~T}=$ & 19736.7000 & $I b / f t$ \\
\hline$I=$ & 17 & $A=$ & 1.133 & F.S. $=$ & 2.053 & $\mathrm{~T}=$ & 18303.9300 & $1 \mathrm{~b} / \mathrm{ft}$ \\
\hline$I=$ & 18 & $A=$ & 1.200 & F.S. $=$ & 2.116 & $\mathrm{~T}=$ & 16965.4700 & $1 \mathrm{~b} / \mathrm{ft}$ \\
\hline$I=$ & 19 & $A=$ & 1.267 & F.S. $=$ & 2.183 & $\mathrm{~T}=$ & 15860.3600 & $1 b / f t$ \\
\hline$I=$ & 20 & $A=$ & 1.333 & F.S. $=$ & 2.238 & $T=$ & 14890.5800 & $1 \mathrm{~b} / \mathrm{ft}$ \\
\hline$I=$ & 21 & $A=$ & 1.400 & F.S. = & 2.293 & $\mathrm{~T}=$ & 14044.2500 & $I b / f t$ \\
\hline$I=$ & 22 & $A=$ & 1.467 & F.S. = & 2.351 & $\mathrm{~T}=$ & 13378.3800 & $1 b / f t$ \\
\hline$I=$ & 23 & $A=$ & 1.533 & F.S. $=$ & 2.409 & $\mathrm{~T}=$ & 12750.9000 & $1 \mathrm{~b} / \mathrm{ft}$ \\
\hline$I=$ & 24 & $A=$ & 1.600 & F.S. $=$ & 2.461 & $\mathrm{~T}=$ & 12182.4300 & $1 \mathrm{~b} / \mathrm{ft}$ \\
\hline$I=$ & 25 & $A=$ & 1.667 & F.S. $=$ & 2.511 & $\mathrm{~T}=$ & 11658.2000 & $1 \mathrm{~b} / \mathrm{ft}$ \\
\hline$I=$ & 26 & $A=$ & 1.733 & F.S. $=$ & 2.561 & $\mathrm{~T}=$ & 11165.1900 & $1 \mathrm{~b} / \mathrm{ft}$ \\
\hline$I=$ & 27 & $A=$ & 1.800 & F.S. $=$ & 2.612 & $\mathrm{~T}=$ & 10818.2600 & $1 \mathrm{~b} / \mathrm{ft}$ \\
\hline$I=$ & 28 & $A=$ & 1.867 & F.S. $=$ & 2.662 & $\mathrm{~T}=$ & 10507.9200 & $1 \mathrm{~b} / \mathrm{ft}$ \\
\hline$I=$ & 29 & $A=$ & 1.933 & F.S. $=$ & 2.707 & $\mathrm{~T}=$ & 10223.6800 & Ib/ft \\
\hline$I=$ & 30 & $A=$ & 2.000 & F.S. $=$ & 2.750 & $T=$ & 9964.0190 & $1 \mathrm{~b} / \mathrm{ft}$ \\
\hline
\end{tabular}

NO. OF NAILS (INCLUDING THE LOWERMOST) $=7$

**F.S. AGAINST SLIDING THROUGH TOE $=1.91$

**F.S. AGAINST DEEP SEATED ROTATION $=3.40$

$1 \mathrm{TH}$ NAIL FORCE =

2 TH NAIL FORCE =

3 TH NAIL FORCE =

$4 \mathrm{TH}$ NAIL FORCE $=$

5 TH NAIL FORCE =

$6 \mathrm{TH}$ NAIL FORCE =

$7 \mathrm{TH}$ NAIL FORCE =

\author{
$945.6563 \mathrm{lb} / \mathrm{ft}$ \\ $1336.6560 \mathrm{lb} / \mathrm{ft}$ \\ $2548.4430 \mathrm{Ib} / \mathrm{ft}$ \\ $3379.1010 \mathrm{Ib} / \mathrm{ft}$ \\ $4447.3010 \mathrm{lb} / \mathrm{ft}$ \\ $5898.13201 \mathrm{~b} / \mathrm{ft}$ \\ $8260.77301 \mathrm{~b} / \mathrm{ft}$
}




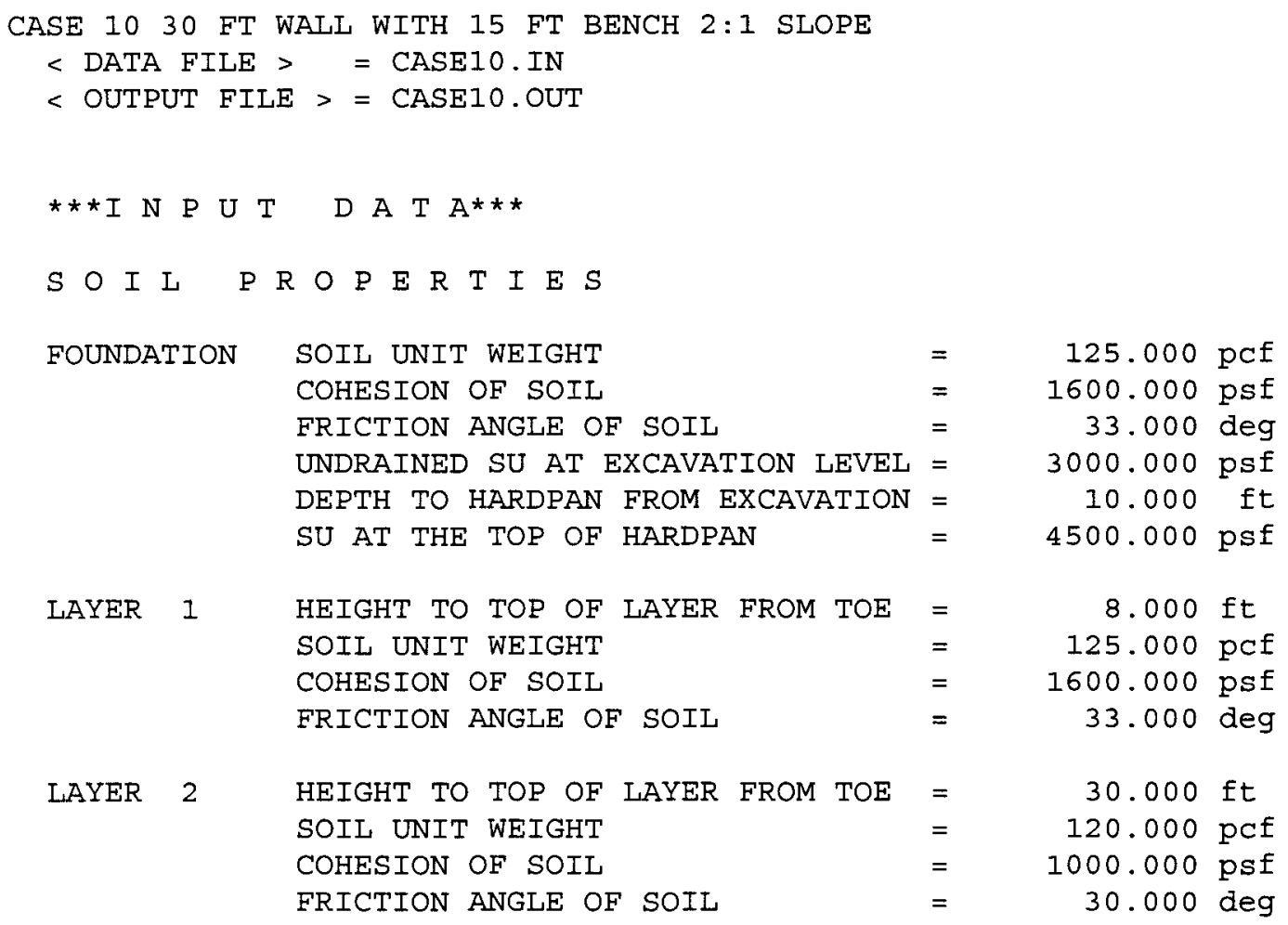

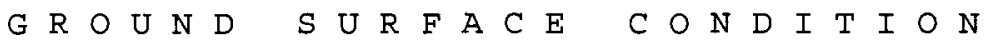

C O O R D I N A T E S O F L I N E S LINE NUMBER

$\mathrm{Y}-\mathrm{COORD} .(\mathrm{ft})$

1
2

10.000

30.000

45.000

$S O I L P R O P E R T I E S$ UNIT WEIGHT OF SOIL COHESION OF SOIL FRICTION ANGLE OF SOIL

$=\quad 110.000 \mathrm{pcf}$
$=\quad 500.000 \mathrm{psf}$
$=\quad 30.000 \mathrm{deg}$

W A L L \& L O A D C O N D I T I O N

WALI INCLINATION ANGLE

SURCHARGE LOAD

HOR. ACCELERATION COEFF. $=\quad 5.000 \mathrm{deg}$

$=\quad 100.000 \mathrm{psf}$

$=\quad .000$

N A I I P R O P E R T I E S

$\begin{array}{llr}\text { CROSS SECTIONAL AREA OF NAIL } & = & .790 \mathrm{si} \\ \text { GROUT DIAMETER } & = & 4.000 \mathrm{in} \\ \text { YIELD STRENGTH OF NAIL } & = & 60.000 \mathrm{ksi} \\ \text { NAIL INCLINATION ANGLE } & = & 20.000 \mathrm{deg} \\ \text { NAII SKEW ANGLE AT SURFACE } & = & .000 \mathrm{deg} \\ \text { DEPTH TO UPPERMOST NAIL } & = & 2.000 \mathrm{ft} \\ \text { VER. SPACING OF NAIL } & = & 5.000 \mathrm{ft} \\ \text { HOR. SPACING OF NAIL } & = & 5.000 \mathrm{ft} \\ \text { TOTAL LENGTH OF UPPERMOST NAIL } & = & 28.000 \mathrm{ft}\end{array}$



$\begin{array}{llr}\text { TOTAL LENGTH OF LOWERMOST NAIL } & = & 23.000 \mathrm{ft} \\ \text { TOTAL UNBONDED LENGTH OF NAIL } & = & 2.000 \mathrm{ft}\end{array}$

\begin{tabular}{|c|c|c|c|c|c|}
\hline$I=$ & 2 & $A=$ & .133 & F.S. $=$ & 4.725 \\
\hline$I=$ & 3 & $A=$ & .200 & F.S. $=$ & 3.504 \\
\hline$I=$ & 4 & $A=$ & .267 & F.S. $=$ & 3.007 \\
\hline$I=$ & 5 & $A=$ & .333 & F.S. $=$ & 2.742 \\
\hline$I=$ & 6 & $A=$ & .400 & F.S. $=$ & 2.566 \\
\hline$I=$ & 7 & $A=$ & .467 & F.S. $=$ & 2.439 \\
\hline$I=$ & 8 & $A=$ & .533 & F.S. $=$ & 2.345 \\
\hline$I=$ & 9 & $A=$ & .600 & F.S. $=$ & 2.269 \\
\hline$I=$ & 10 & $A=$ & .667 & F.S. $=$ & 2.208 \\
\hline$I=$ & 11 & $A=$ & .733 & F.S. $=$ & 2.157 \\
\hline$I=$ & 12 & $A=$ & .800 & F.S. $=$ & 2.111 \\
\hline$I=$ & 13 & $\mathrm{~A}=$ & .867 & F.S. $=$ & 2.070 \\
\hline$I=$ & 14 & $A=$ & .933 & F.S. $=$ & 2.031 \\
\hline$I=$ & 15 & $A=$ & 1.000 & F.S. $=$ & 2.008 \\
\hline$I=$ & 16 & $A=$ & 1.067 & F.S. $=$ & 2.019 \\
\hline$I=$ & 17 & $A=$ & 1.133 & F.S. $=$ & 2.039 \\
\hline$I=$ & 18 & $A=$ & 1.200 & F.S. $=$ & 2.066 \\
\hline$I=$ & 19 & $A=$ & 1.267 & F.S. $=$ & 2.099 \\
\hline$I=$ & 20 & $A=$ & 1.333 & F.S. $=$ & 2.137 \\
\hline$I=$ & 21 & $\mathrm{~A}=$ & 1.400 & F.S. $=$ & 2.182 \\
\hline$I=$ & 22 & $A=$ & 1.467 & F.S. $=$ & 2.226 \\
\hline $\mathrm{I}=$ & 23 & $A=$ & 1.533 & F.S. $=$ & 2.272 \\
\hline$I=$ & 24 & $A=$ & 1.600 & F.S. = & 2.316 \\
\hline$I=$ & 25 & $\mathrm{~A}=$ & 1.667 & $F \cdot S .=$ & 2.359 \\
\hline$I=$ & 26 & $A=$ & 1.733 & F.S. $=$ & 2.396 \\
\hline$I=$ & 27 & $A=$ & 1.800 & F.S. $=$ & 2.440 \\
\hline$I=$ & 28 & $A=$ & 1.867 & F.S. $=$ & 2.480 \\
\hline$I=$ & 29 & $\mathrm{~A}=$ & 1.933 & F.S. $=$ & 2.515 \\
\hline$I=$ & 30 & $A=$ & 2.000 & F.S. $=$ & 2.541 \\
\hline
\end{tabular}

$\begin{array}{rl}14812.8800 & \mathrm{lb} / \mathrm{ft} \\ 18412.1200 & \mathrm{lb} / \mathrm{ft} \\ 19865.9100 & \mathrm{lb} / \mathrm{ft} \\ 20329.8900 \mathrm{lb} / \mathrm{ft} \\ 20419.8500 \mathrm{lb} / \mathrm{ft} \\ 20249.1400 \mathrm{lb} / \mathrm{ft} \\ 19875.8100 \mathrm{lb} / \mathrm{ft} \\ 19369.0900 \mathrm{lb} / \mathrm{ft} \\ 18749.8600 \mathrm{lb} / \mathrm{ft} \\ 18045.3600 \mathrm{lb} / \mathrm{ft} \\ 17271.9400 \mathrm{lb} / \mathrm{ft} \\ 16398.6300 \mathrm{lb} / \mathrm{ft} \\ 15477.8500 \mathrm{lb} / \mathrm{ft} \\ 14397.1300 \mathrm{lb} / \mathrm{ft} \\ 13412.3200 \mathrm{lb} / \mathrm{ft} \\ 12530.3800 \mathrm{lb} / \mathrm{ft} \\ 11781.6500 \mathrm{lb} / \mathrm{ft} \\ 11036.9000 \mathrm{lb} / \mathrm{ft} \\ 10468.5300 \mathrm{lb} / \mathrm{ft} \\ 9966.4360 \mathrm{lb} / \mathrm{ft} \\ 9493.1150 \mathrm{lb} / \mathrm{ft} \\ 9036.6480 \mathrm{lb} / \mathrm{ft} \\ 8615.8000 \mathrm{lb} / \mathrm{ft} \\ 8218.3610 \mathrm{lb} / \mathrm{ft} \\ 7858.2590 \mathrm{lb} / \mathrm{ft} \\ 7638.1380 \mathrm{lb} / \mathrm{ft} \\ 7454.2070 \mathrm{lb} / \mathrm{ft} \\ 7293.0430 \mathrm{lb} / \mathrm{ft} \\ 7157.7830 \mathrm{lb} / \mathrm{ft}\end{array}$

$\mathrm{H} / \mathrm{LT}=1.071 \mathrm{H} / \mathrm{IB}=1.304$

NO. OF NAILS (INCLUDING THE LOWERMOST) $=6$

**F.S. AGAINST SLIDING THROUGH TOE $=2.01$

NO F.S. OF DEEP SEATED FAILURE IS CALCULATED

* DMAX IS TOO SMALL

1 TH NAIL FORCE = 2 TH NAIL FORCE = 3 TH NAIL FORCE = 4 TH NAIL FORCE = 5 TH NAIL FORCE = 6 TH NAIL FORCE =
$.0000 \mathrm{Ib} / \mathrm{ft}$ $442.7396 \mathrm{lb} / \mathrm{ft}$ $1082.9810 \mathrm{lb} / \mathrm{ft}$ $2427.87001 \mathrm{~b} / \mathrm{ft}$ $4006.42101 \mathrm{~b} / \mathrm{ft}$ $6437.1180 \mathrm{lb} / \mathrm{ft}$ 
CASE 11 PART A 16 FT WALL

$<$ OUTPUT FILE $>=$ CASEIIA.OUT

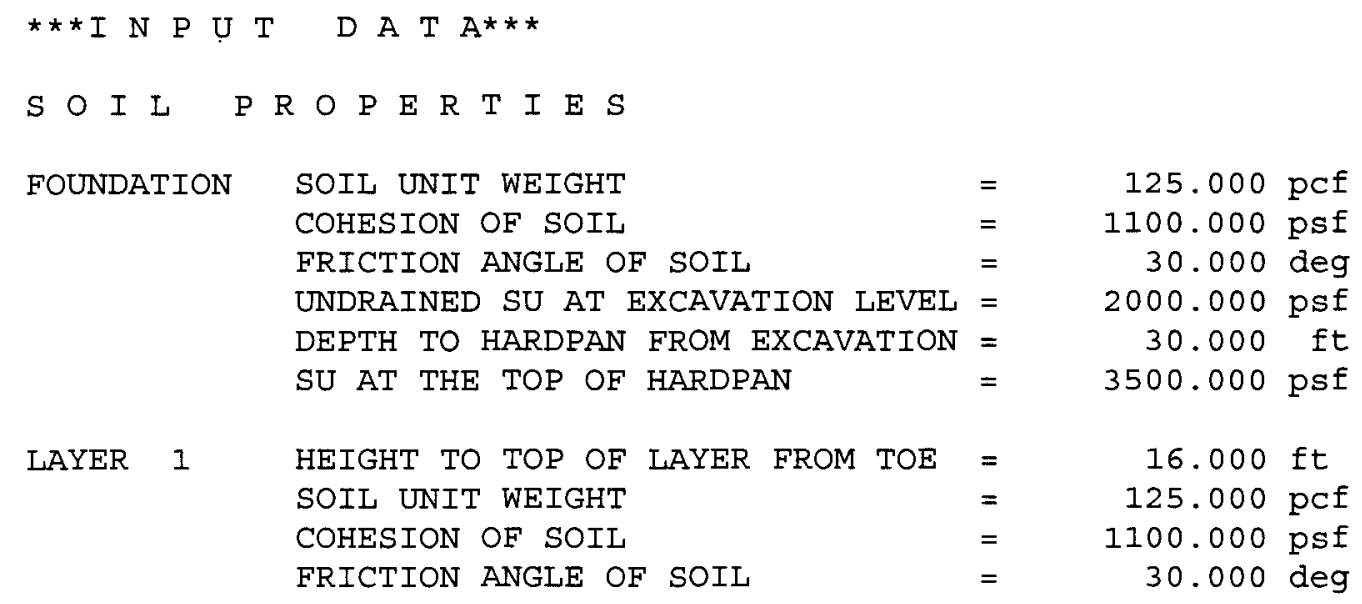

W A L L \& L O A D $\quad$ C O N D I T I O N

WALL INCLINATION ANGLE

SURCHARGE LOAD

HOR. ACCELERATION COEFF.

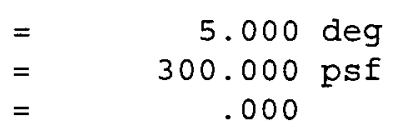

N A I L P R O P E R T I E S

CROSS SECTIONAL AREA OF NAIL
GROUT DIAMETER
YIELD STRENGTH OF NAIL
NAIL INCLINATION ANGLE
NAIL SKEW ANGLE AT SURFACE
DEPTH TO UPPERMOST NAIL
VER. SPACING OF NAIL
HOR. SPACING OF NAII
TOTAL LENGTH OF UPPERMOST NAIL
TOTAL LENGTH OF LOWERMOST NAIL
TOTAL UNBONDED LENGTH OF NAIL

$.790 \mathrm{si}$
$4.000 \mathrm{in}$
$60.000 \mathrm{ksi}$
$20.000 \mathrm{deg}$
$.000 \mathrm{deg}$
$2.000 \mathrm{ft}$
$6.000 \mathrm{ft}$
$5.000 \mathrm{ft}$
$15.000 \mathrm{ft}$
$12.000 \mathrm{ft}$
$2.000 \mathrm{ft}$

\begin{tabular}{|c|c|c|c|c|c|c|c|c|}
\hline$I=$ & 2 & $A=$ & .133 & F.S. $=$ & 8.666 & $\mathrm{~T}=$ & 1554.5450 & $\mathrm{Ib} / \mathrm{ft}$ \\
\hline$I=$ & 3 & $A=$ & .200 & F.S. $=$ & 4.945 & $T=$ & 2620.1590 & $1 \mathrm{~b} / \mathrm{ft}$ \\
\hline$I=$ & 4 & $A=$ & .267 & F.S. $=$ & 3.744 & $T=$ & 3280.5980 & $1 \mathrm{~b} / \mathrm{ft}$ \\
\hline$I=$ & 5 & $A=$ & .333 & F.S. $=$ & 3.160 & $T=$ & 3653.1700 & $1 b / f t$ \\
\hline$I=$ & 6 & $A=$ & .400 & F.S. = & 2.827 & $\mathrm{~T}=$ & 3853.6260 & $1 \mathrm{~b} / \mathrm{ft}$ \\
\hline$I=$ & 7 & $A=$ & .467 & F.S. $=$ & 2.619 & $\mathrm{~T}=$ & 3926.3700 & $1 \mathrm{~b} / \mathrm{ft}$ \\
\hline$I=$ & 8 & $A=$ & .533 & F.S. $=$ & 2.484 & $\mathrm{~T}=$ & 3886.6280 & $1 \mathrm{~b} / \mathrm{ft}$ \\
\hline$I=$ & 9 & $A=$ & .600 & F.S. = & 2.397 & $T=$ & 3784.2450 & $1 \mathrm{~b} / \mathrm{ft}$ \\
\hline$I=$ & 10 & $A=$ & .667 & F.S. $=$ & 2.345 & $\mathrm{~T}=$ & 3638.0920 & $1 \mathrm{~b} / \mathrm{ft}$ \\
\hline$I=$ & 11 & $A=$ & .733 & F.S. $=$ & 2.316 & $\mathrm{~T}=$ & 3462.3070 & $1 \mathrm{~b} / \mathrm{ft}$ \\
\hline$I=$ & 12 & $A=$ & .800 & F.S. $=$ & 2.305 & $\mathrm{~T}=$ & 3269.5390 & $1 \mathrm{~b} / \mathrm{ft}$ \\
\hline$I=$ & 13 & $A=$ & .867 & F.S. = & 2.309 & $\mathrm{~T}=$ & 3063.0140 & $1 b / f t$ \\
\hline$I=$ & 14 & $A=$ & .933 & F.S. $=$ & 2.324 & $\mathrm{~T}=$ & 2851.7980 & $1 \mathrm{~b} / \mathrm{ft}$ \\
\hline$I=$ & 15 & $A=$ & 1.000 & F.S. $=$ & 2.348 & $\mathrm{~T}=$ & 2640.2120 & $1 \mathrm{~b} / \mathrm{ft}$ \\
\hline
\end{tabular}




\begin{tabular}{|c|c|c|c|c|c|c|c|c|}
\hline$I=$ & 16 & $A=$ & 1.067 & F.S. $=$ & 2.379 & $\mathrm{~T}=$ & 2431.4120 & $1 b / f t$ \\
\hline$I=$ & 17 & $A=$ & 1.133 & F.S. $=$ & 2.416 & $\mathrm{~T}=$ & 2227.6570 & $1 b / f t$ \\
\hline$I=$ & 18 & $A=$ & 1.200 & F.S. $=$ & 2.458 & $\mathrm{~T}=$ & 2030.5170 & $1 \mathrm{~b} / \mathrm{ft}$ \\
\hline$I=$ & 19 & $A=$ & 1.267 & F.S. $=$ & 2.505 & $\mathrm{~T}=$ & 1841.0300 & $1 \mathrm{~b} / \mathrm{ft}$ \\
\hline$I=$ & 20 & $A=$ & 1.333 & F.S. $=$ & 2.565 & $\mathrm{~T}=$ & 1708.3350 & $1 \mathrm{~b} / \mathrm{ft}$ \\
\hline$I=$ & 21 & $A=$ & 1.400 & F.S. $=$ & 2.627 & $\mathrm{~T}=$ & 1604.1140 & $1 b / f t$ \\
\hline$I=$ & 22 & $A=$ & 1.467 & F.S. $=$ & 2.688 & $\mathrm{~T}=$ & 1507.5620 & $1 \mathrm{~b} / \mathrm{ft}$ \\
\hline$I=$ & 23 & $A=$ & 1.533 & F.S. $=$ & 2.750 & $\mathrm{~T}=$ & 1416.6720 & $1 b / f t$ \\
\hline$I=$ & 24 & $\mathrm{~A}=$ & 1.600 & F.S. $=$ & 2.807 & $\mathrm{~T}=$ & 1333.7210 & $1 \mathrm{~b} / \mathrm{ft}$ \\
\hline$I=$ & 25 & $A=$ & 1.667 & F.S. $=$ & 2.863 & $T=$ & 1255.8850 & lb/ft \\
\hline$I=$ & 26 & $A=$ & 1.733 & F.S. $=$ & 2.920 & $\mathrm{~T}=$ & 1182.7090 & $1 \mathrm{~b} / \mathrm{ft}$ \\
\hline$I=$ & 27 & $A=$ & 1.800 & F.S. $=$ & 2.980 & $\mathrm{~T}=$ & 1112.7150 & $1 b / f t$ \\
\hline$I=$ & 28 & $A=$ & 1.867 & F.S. $=$ & 3.042 & $\mathrm{~T}=$ & 1073.6880 & $1 b / f t$ \\
\hline$I=$ & 29 & $A=$ & 1.933 & F.S. $=$ & 3.106 & $\mathrm{~T}=$ & 1047.2190 & $1 b / f t$ \\
\hline$I=$ & 30 & $A=$ & 2.000 & F.S. = & 3.170 & $\mathrm{~T}=$ & 1022.0380 & $1 b / f t$ \\
\hline
\end{tabular}

$\mathrm{H} / \mathrm{LT}=1.067 \mathrm{H} / \mathrm{LB}=1.333$

NO. OF NAILS (INCLUDING THE LOWERMOST) $=3$

**F.S. AGAINST SLIDING THROUGH TOE $=2.30$

**F.S. AGAINST DEEP SEATED ROTATION $=6.91$

1 TH NAIL FORCE =

$2 \mathrm{TH}$ NAIL FORCE =

$3 \mathrm{TH}$ NAIL FORCE =
$650.2002 \mathrm{lb} / \mathrm{ft}$

$973.7742 \mathrm{lb} / \mathrm{ft}$

1645.5640 lb/ft 


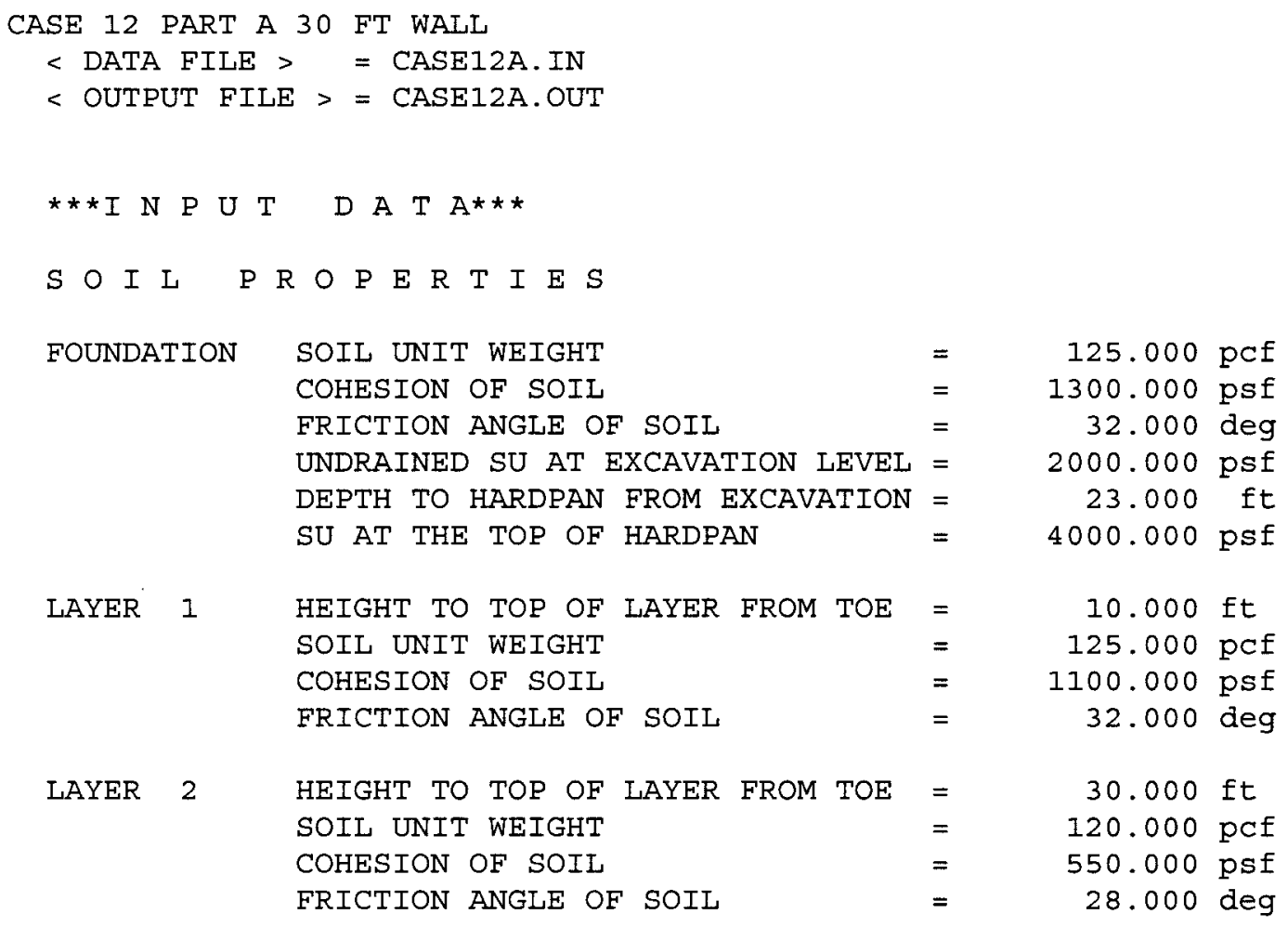

W A I L \& I O A D $\quad$ C O N D I T I O N

$\begin{array}{llr}\text { WALL INCLINATION ANGLE } & = & 5.000 \mathrm{deg} \\ \text { SURCHARGE LOAD } & = & 300.000 \mathrm{psf} \\ \text { HOR. ACCELERATION COEFF. } & = & .000\end{array}$

N A I L P R O P E R T I E S

$\begin{array}{llr}\text { CROSS SECTIONAL AREA OF NAIL } & = & .790 \mathrm{si} \\ \text { GROUT DIAMETER } & = & 4.000 \mathrm{in} \\ \text { YIELD STRENGTH OF NAIL } & = & 60.000 \mathrm{ksi} \\ \text { NAIL INCLINATION ANGLE } & = & 20.000 \mathrm{deg} \\ \text { NAIL SKEW ANGLE AT SURFACE } & = & .000 \mathrm{deg} \\ \text { DEPTH TO UPPERMOST NAIL } & = & 2.000 \mathrm{ft} \\ \text { VER. SPACING OF NAIL } & = & 5.000 \mathrm{ft} \\ \text { HOR. SPACING OF NAIL } & = & 5.000 \mathrm{ft} \\ \text { TOTAL LENGTH OF UPPERMOST NAIL } & = & 25.000 \mathrm{ft} \\ \text { TOTAL LENGTH OF LOWERMOST NAIL } & = & 20.000 \mathrm{ft} \\ \text { TOTAL UNBONDED LENGTH OF NAIL } & = & 2.000 \mathrm{ft}\end{array}$

\begin{tabular}{|c|c|c|c|c|c|c|c|c|}
\hline$I=$ & 2 & $\mathrm{~A}=$ & .133 & F.S. = & 3.445 & $\mathrm{~T}=$ & 14818.0600 & $1 b / f t$ \\
\hline$I=$ & 3 & $A=$ & .200 & F.S. $=$ & 2.471 & $\mathrm{~T}=$ & 19169.1700 & $1 b / f t$ \\
\hline$I=$ & 4 & $A=$ & .267 & F.S. $=$ & 2.083 & $\mathrm{~T}=$ & 21087.7200 & $1 b / f t$ \\
\hline$I=$ & 5 & $A=$ & .333 & F.S. $=$ & 1.874 & $\mathrm{~T}=$ & 21774.4200 & $1 \mathrm{~b} / \mathrm{ft}$ \\
\hline$I=$ & 6 & $A=$ & .400 & F.S. $=$ & 1.745 & $T=$ & 21819.6800 & $1 b / f t$ \\
\hline$I=$ & 7 & $A=$ & .467 & F.S. $=$ & 1.663 & $\mathrm{~T}=$ & 21422.8400 & $1 \mathrm{~b} / \mathrm{ft}$ \\
\hline$I=$ & 8 & $A=$ & .533 & F.S. $=$ & 1.612 & $\mathrm{~T}=$ & 20707.2100 & $1 \mathrm{~b} / \mathrm{ft}$ \\
\hline$I=$ & 9 & $A=$ & .600 & F.S. $=$ & 1.581 & $\mathrm{~T}=$ & 19727.0200 & $1 \mathrm{~b} / \mathrm{ft}$ \\
\hline
\end{tabular}




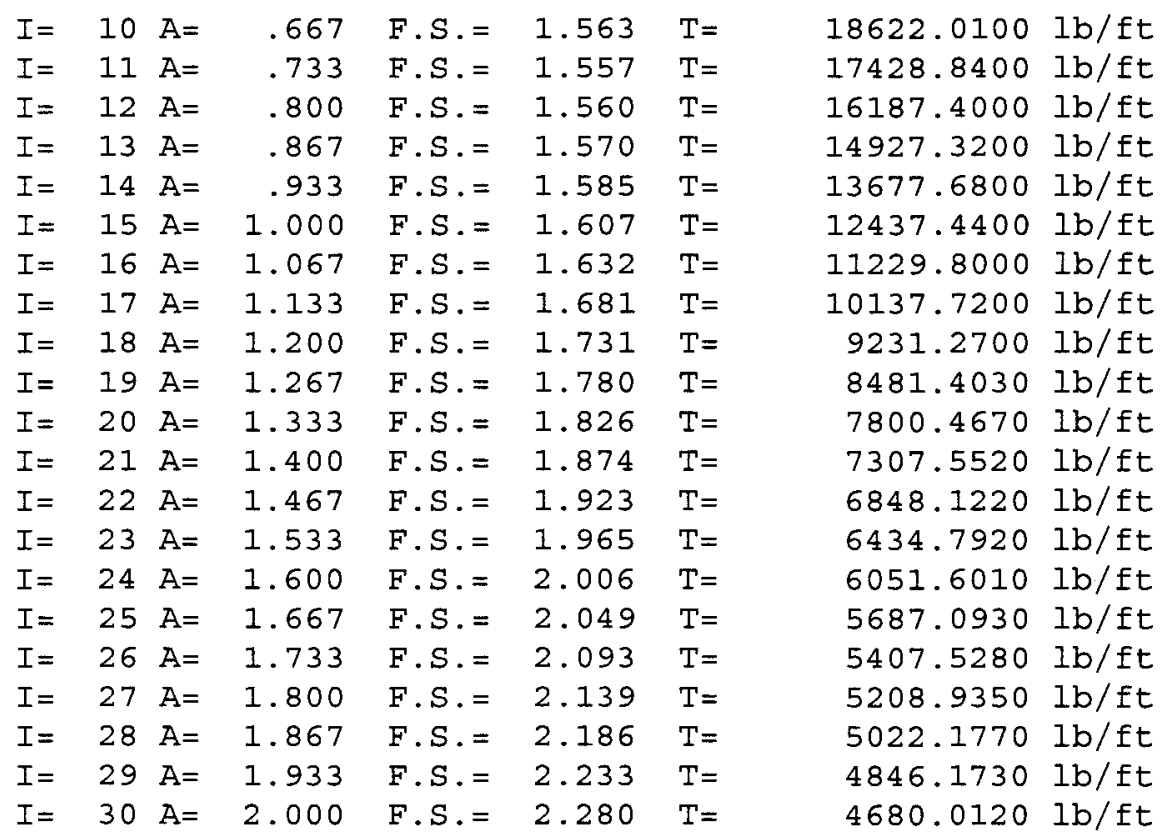

$\mathrm{H} / \mathrm{LT}=1.200 \quad \mathrm{H} / \mathrm{LB}=1.500$

NO. OF NAILS (INCLUDING THE LOWERMOST) = 6

**F.S. AGAINST SLIDING THROUGH TOE $=1.56$

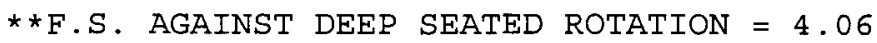

$\begin{array}{lll}1 \mathrm{TH} \text { NAIL FORCE }= & 1028.6790 \mathrm{lb} / \mathrm{ft} \\ 2 \mathrm{TH} \text { NAIL FORCE }= & 1386.0530 \mathrm{lb} / \mathrm{ft} \\ 3 \mathrm{TH} \text { NAIL FORCE }= & 1832.5430 \mathrm{lb} / \mathrm{ft} \\ 4 \mathrm{TH} \text { NAIL FORCE }= & 3189.0050 \mathrm{lb} / \mathrm{ft} \\ 5 \mathrm{TH} \text { NAIL FORCE }= & 4200.8570 \mathrm{lb} / \mathrm{ft} \\ 6 \mathrm{TH} \text { NAIL FORCE }= & 5791.7080 \mathrm{lb} / \mathrm{ft}\end{array}$




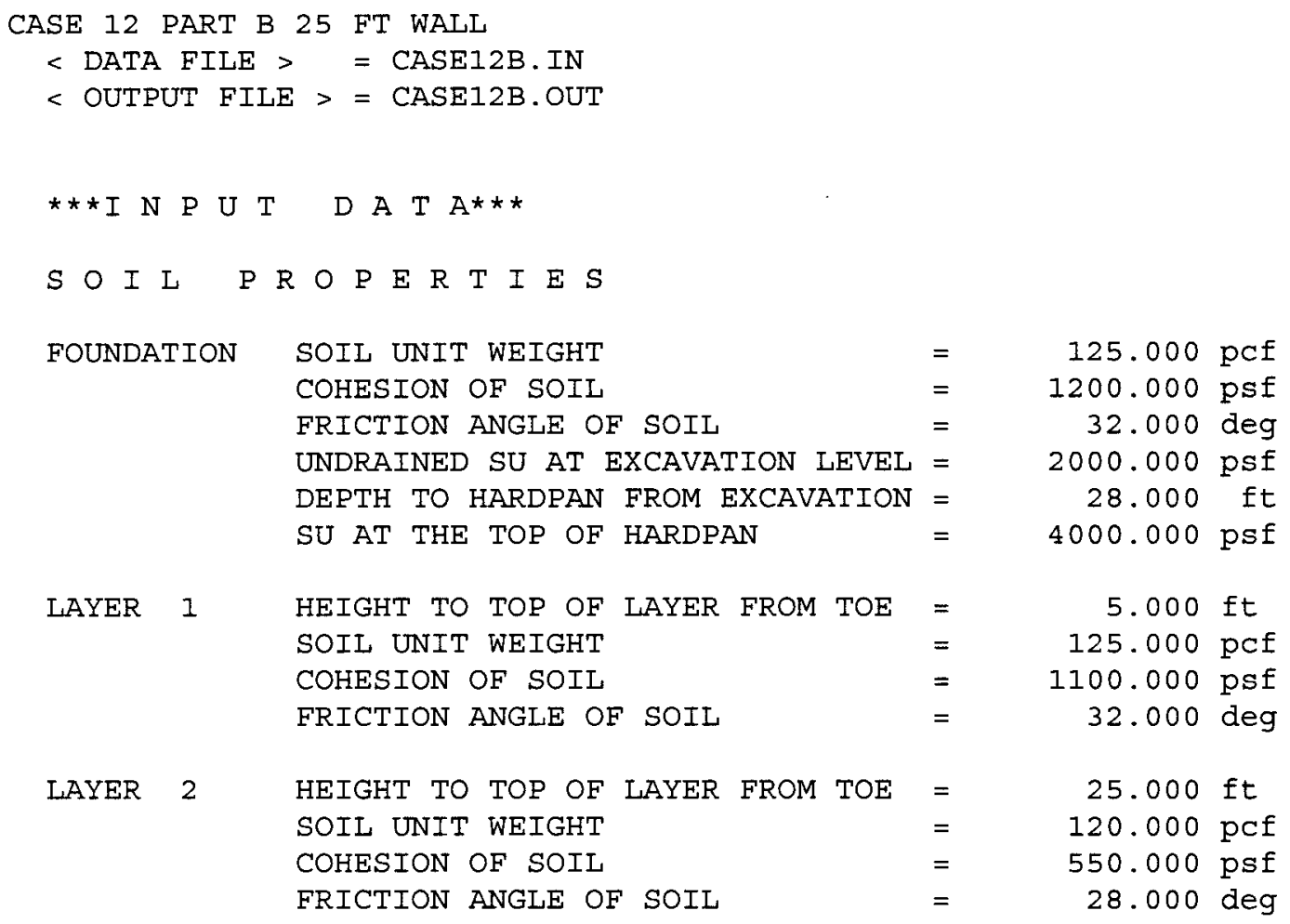

W A L L \& L O A D $\quad$ C O N D I T I O N

$\begin{array}{llr}\text { WALL INCLINATION ANGLE } & = & 5.000 \mathrm{deg} \\ \text { SURCHARGE LOAD } & = & 300.000 \mathrm{psf} \\ \text { HOR. ACCELERATION COEFF. } & = & .000\end{array}$

N A I L P R O P E R T I E S

$\begin{array}{llr}\text { CROSS SECTIONAL AREA OF NAIL } & = & .790 \mathrm{si} \\ \text { GROUT DIAMETER } & = & 4.000 \mathrm{in} \\ \text { YIELD STRENGTH OF NAIL } & = & 60.000 \mathrm{ksi} \\ \text { NAIL INCLINATION ANGLE } & = & 20.000 \mathrm{deg} \\ \text { NAIL SKEW ANGLE AT SURFACE } & = & .000 \mathrm{deg} \\ \text { DEPTH TO UPPERMOST NAIL } & = & 2.000 \mathrm{ft} \\ \text { VER. SPACING OF NAIL } & = & 5.000 \mathrm{ft} \\ \text { HOR. SPACING OF NAIL } & = & 5.000 \mathrm{ft} \\ \text { TOTAL LENGTH OF UPPERMOST NAIL } & = & 20.000 \mathrm{ft} \\ \text { TOTAL LENGTH OF LOWERMOST NAIL } & = & 18.000 \mathrm{ft} \\ \text { TOTAL UNBONDED LENGTH OF NAIL } & = & 2.000 \mathrm{ft}\end{array}$

\begin{tabular}{|c|c|c|c|c|c|c|c|c|}
\hline$I=$ & 2 & $A=$ & .133 & F.S. $=$ & 3.666 & $\mathrm{~T}=$ & 8465.2760 & $1 \mathrm{~b} / \mathrm{ft}$ \\
\hline$I=$ & 3 & $A=$ & .200 & F.S. $=$ & 2.517 & $\mathrm{~T}=$ & 11523.5400 & $1 \mathrm{~b} / \mathrm{ft}$ \\
\hline$I=$ & 4 & $A=$ & .267 & F.S. $=$ & 2.084 & $\mathrm{~T}=$ & 12923.1200 & $1 b / f t$ \\
\hline$I=$ & 5 & $A=$ & .333 & F.S. $=$ & 1.858 & $\mathrm{~T}=$ & 13487.9000 & $1 \mathrm{~b} / \mathrm{ft}$ \\
\hline$I=$ & 6 & $A=$ & .400 & F.S. $=$ & 1.721 & $\mathrm{~T}=$ & 13586.9800 & $1 \mathrm{~b} / \mathrm{ft}$ \\
\hline$I=$ & 7 & $A=$ & .467 & F.S. $=$ & 1.637 & $\mathrm{~T}=$ & 13367.7500 & $1 \mathrm{~b} / \mathrm{ft}$ \\
\hline$I=$ & 8 & $A=$ & .533 & F.S. = & 1.587 & $\mathrm{~T}=$ & 12935.2000 & $1 \mathrm{~b} / \mathrm{ft}$ \\
\hline$I=$ & 9 & $A=$ & .600 & F.S. $=$ & 1.556 & $\mathrm{~T}=$ & 12379.0600 & $1 \mathrm{~b} / \mathrm{ft}$ \\
\hline
\end{tabular}




\begin{tabular}{|c|c|c|c|c|c|c|c|}
\hline$I=$ & $A=$ & .667 & F.S. $=$ & 1.542 & $T=$ & 11728.8600 & $1 b / f t$ \\
\hline$I=$ & $A=$ & .733 & F.S. $=$ & 1.540 & $\mathrm{~T}=$ & 11020.6300 & $1 b / f t$ \\
\hline$I=$ & $A=$ & .800 & F.S. $=$ & 1.547 & $\mathrm{~T}=$ & 10280.7100 & $1 \mathrm{~b} / \mathrm{ft}$ \\
\hline$I=$ & $A=$ & .867 & F.S. $=$ & 1.559 & $T=$ & 9499.9340 & $1 b / f t$ \\
\hline$I=$ & $A=$ & .933 & F.S. $=$ & 1.578 & $\mathrm{~T}=$ & 8714.3180 & $1 b /$ ft \\
\hline$I=$ & $A=$ & 1.000 & F.S. $=$ & 1.603 & $\mathrm{~T}=$ & 7943.5140 & $1 \mathrm{~b} / \mathrm{ft}$ \\
\hline$I=$ & $A=$ & 1.067 & F.S. $=$ & 1.642 & $\mathrm{~T}=$ & 7228.9170 & $1 b / f t$ \\
\hline$I=$ & $A=$ & 1.133 & F.S. $=$ & 1.691 & $\mathrm{~T}=$ & 6603.8290 & $1 b / \pm t$ \\
\hline$I=$ & $A=$ & 1.200 & F.S. $=$ & 1.737 & $\mathrm{~T}=$ & 6063.8700 & $1 \mathrm{~b} / \mathrm{Et}$ \\
\hline$I=$ & $A=$ & 1.267 & F.S. $=$ & 1.785 & $T=$ & 5655.7730 & $1 b / f t$ \\
\hline$I=$ & $A=$ & 1.333 & F.S. $=$ & 1.830 & $\mathrm{~T}=$ & 5280.3920 & $1 b / f t$ \\
\hline$I=$ & $-A=$ & 1.400 & F.S. $=$ & 1.876 & $\mathrm{~T}=$ & 4929.3220 & $1 \mathrm{~b} / \mathrm{ft}$ \\
\hline$I=$ & $A=$ & 1.467 & F.S. $=$ & 1.917 & $\mathrm{~T}=$ & 4609.9880 & $1 b / \pm t$ \\
\hline$I=$ & $A=$ & 1.533 & F.S. = & 1.961 & $\mathrm{~T}=$ & 4370.7580 & $1 b / f t$ \\
\hline$I=$ & $A=$ & 1.600 & F.S. $=$ & 2.008 & $\mathrm{~T}=$ & 4173.4990 & $1 \mathrm{~b} / \mathrm{ft}$ \\
\hline$I=$ & $A=$ & 1.667 & F.S. $=$ & 2.054 & $\mathrm{~T}=$ & 3991.0590 & $1 \mathrm{~b} / \mathrm{ft}$ \\
\hline$I=$ & $A=$ & 1.733 & F.S. $=$ & 2.100 & $\mathrm{~T}=$ & 3820.0300 & $1 \mathrm{~b} / \mathrm{ft}$ \\
\hline$I=$ & $A=$ & 1.800 & F.S. $=$ & 2.147 & $\mathrm{~T}=$ & 3659.3500 & $1 b /$ ft \\
\hline$I=$ & $3 A=$ & 1.867 & F.S. $=$ & 2.193 & $\mathrm{~T}=$ & 3508.2790 & $1 b / \mathrm{ft}$ \\
\hline$I=$ & (7) & 1.933 & F.S. $=$ & 2.239 & $\mathrm{~T}=$ & 3367.2820 & $1 b / f t$ \\
\hline$I=$ & $A=$ & 2.000 & F.S. = & 2.285 & $\mathrm{~T}=$ & 3234.1200 & $1 b / f t$ \\
\hline \multicolumn{8}{|c|}{$\mathrm{H} / \mathrm{LT}=1.250 \quad \mathrm{H} / \mathrm{LB}=1.389$} \\
\hline No. & NAIL & SS I INC & LUDING & THE LOW & ERMOST) & $=$ & \\
\hline$\star \star F . S$. & - AGAI & INST SI & IDING T & HROUGH & $\mathrm{TOE}=$ & 1.54 & \\
\hline$* * F . S$. & - AGAI & INST DF & EP SEAT & IED ROTA & TION = & 4.82 & \\
\hline $1 \mathrm{TH} \mathrm{I}$ & NAIL & FORCE & $=$ & 709.64 & $15 \mathrm{lb} / \mathrm{ft}$ & & \\
\hline $2 \mathrm{TH} \mathrm{I}$ & NAIL & FORCE & $=$ & 1088.86 & $30 \mathrm{lb} / \mathrm{ft}$ & & \\
\hline $3 \mathrm{TH} \mathrm{I}$ & NAIL & FORCE & $=$ & 1607.40 & $201 \mathrm{~b} / \mathrm{ft}$ & & \\
\hline $4 \mathrm{TH} 1$ & NAIL & FORCE & $=$ & 3057.38 & $001 \mathrm{~b} / \mathrm{ft}$ & & \\
\hline $5 \mathrm{TH} 1$ & NAIL & FORCE & $=$ & 4557.34 & $101 \mathrm{~b} / \mathrm{ft}$ & & \\
\hline
\end{tabular}




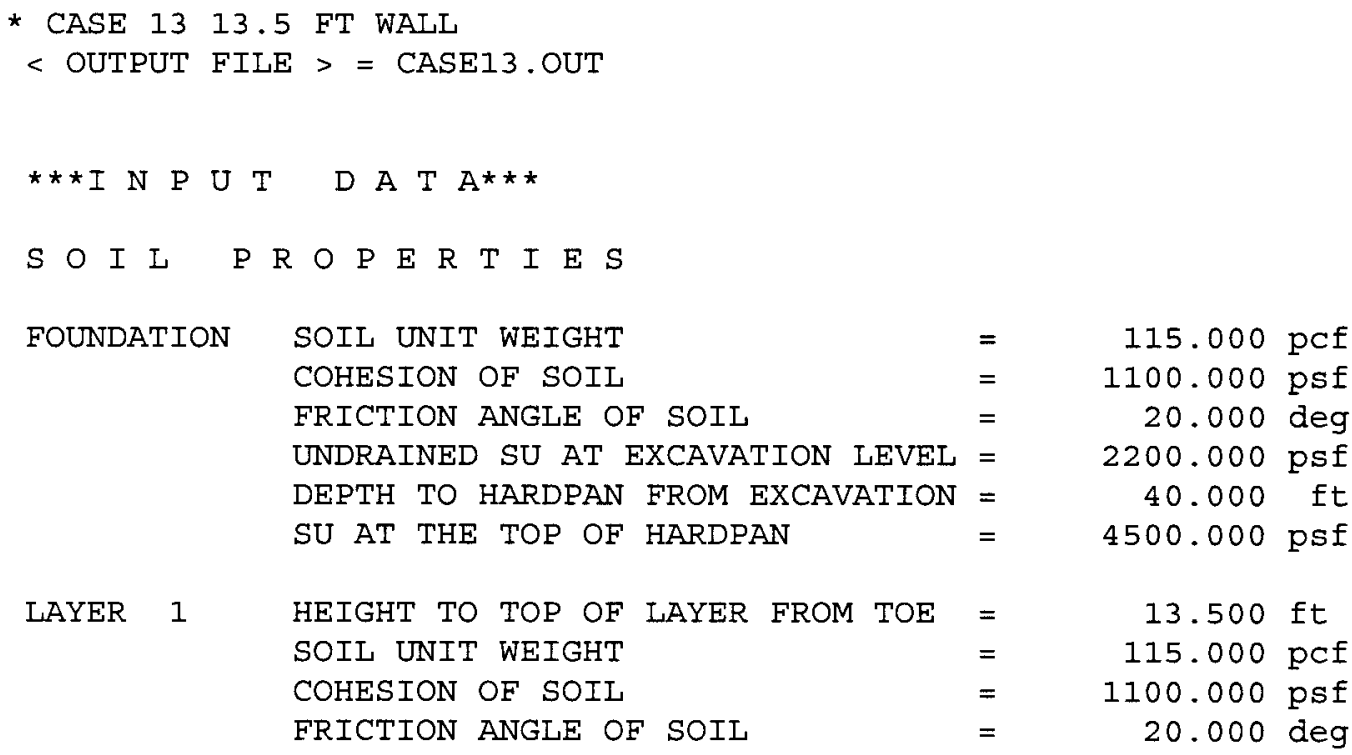

W A L L \& L O A D C O N D I T I O N

$\begin{array}{llr}\text { WALL INCLINATION ANGLE } & = & 5.000 \text { deg } \\ \text { SURCHARGE LOAD } & = & 200.000 \text { psf } \\ \text { HOR. ACCELERATION COEFF. } & = & .000\end{array}$

N A I L P R O P E R T I E S

$\begin{array}{llr}\text { CROSS SECTIONAI AREA OF NAIL } & = & .440 \mathrm{si} \\ \text { GROUT DIAMETER } & = & 4.000 \mathrm{in} \\ \text { YIELD STRENGTH OF NAIL } & = & 60.000 \mathrm{ksi} \\ \text { NAIL INCLINATION ANGLE } & = & 20.000 \mathrm{deg} \\ \text { NAIL SKEW ANGLE AT SURFACE } & = & .000 \mathrm{deg} \\ \text { DEPTH TO UPPERMOST NAIL } & = & 2.000 \mathrm{ft} \\ \text { VER. SPACING OF NAIL } & = & 4.000 \mathrm{ft} \\ \text { HOR. SPACING OF NAIL } & = & 6.000 \mathrm{ft} \\ \text { TOTAL LENGTH OF UPPERMOST NAIL } & = & 12.000 \mathrm{ft} \\ \text { TOTAL LENGTH OF LOWERMOST NAIL } & = & 10.000 \mathrm{ft} \\ \text { TOTAL UNBONDED LENGTH OF NAIL } & = & 2.000 \mathrm{ft}\end{array}$

\begin{tabular}{|c|c|c|c|c|c|c|c|c|}
\hline$I=$ & 2 & $A=$ & .133 & F.S. $=$ & 11.544 & $\mathrm{~T}=$ & 567.2046 & $1 \mathrm{~b} / \mathrm{ft}$ \\
\hline$I=$ & 3 & $A=$ & .200 & F.S. $=$ & 6.214 & $\mathrm{~T}=$ & 1030.8820 & $1 b / f t$ \\
\hline$I=$ & 4 & $A=$ & .267 & F.S. $=$ & 4.511 & $\mathrm{~T}=$ & 1379.7120 & $1 \mathrm{~b} / \mathrm{ft}$ \\
\hline$I=$ & 5 & $A=$ & .333 & F.S. $=$ & 3.691 & $\mathrm{~T}=$ & 1582.9620 & $1 b / f$ \\
\hline$I=$ & 6 & $A=$ & .400 & F.S. $=$ & 3.220 & $\mathrm{~T}=$ & 1686.3220 & $1 \mathrm{~b} / \mathrm{f}$ \\
\hline$I=$ & 7 & $A=$ & .467 & F.S. $=$ & 2.924 & $\mathrm{~T}=$ & 1716.3920 & $1 b / f$ \\
\hline$I=$ & 8 & $A=$ & .533 & F.S. = & 2.726 & $\mathrm{~T}=$ & 1698.9190 & $1 b / f$ \\
\hline$I=$ & 9 & $A=$ & .600 & F.S. $=$ & 2.596 & $\mathrm{~T}=$ & 1643.8350 & $1 \mathrm{~b} / \mathrm{f}$ \\
\hline$I=$ & 10 & $A=$ & .667 & F.S. $=$ & 2.510 & $\mathrm{~T}=$ & 1563.0680 & $1 \mathrm{~b} / \mathrm{f}$ \\
\hline$I=$ & 11 & $A=$ & .733 & F.S. $=$ & 2.454 & $\mathrm{~T}=$ & 1464.4730 & $1 b / f$ \\
\hline$I=$ & 12 & $A=$ & .800 & F.S. $=$ & 2.421 & $\mathrm{~T}=$ & 1354.1770 & $1 \mathrm{~b} / \mathrm{f}$ \\
\hline$I=$ & 13 & $A=$ & .867 & F.S. = & 2.406 & $\mathrm{~T}=$ & 1236.9160 & $1 b / f$ \\
\hline$I=$ & 14 & $A=$ & .933 & F.S. $=$ & 2.404 & $T=$ & 1116.3190 & $1 \mathrm{~b} / \mathrm{f}$ \\
\hline$I=$ & 15 & $A=$ & 1.000 & F.S. $=$ & 2.413 & $\mathrm{~T}=$ & 995.1240 & $1 b / f$ \\
\hline
\end{tabular}




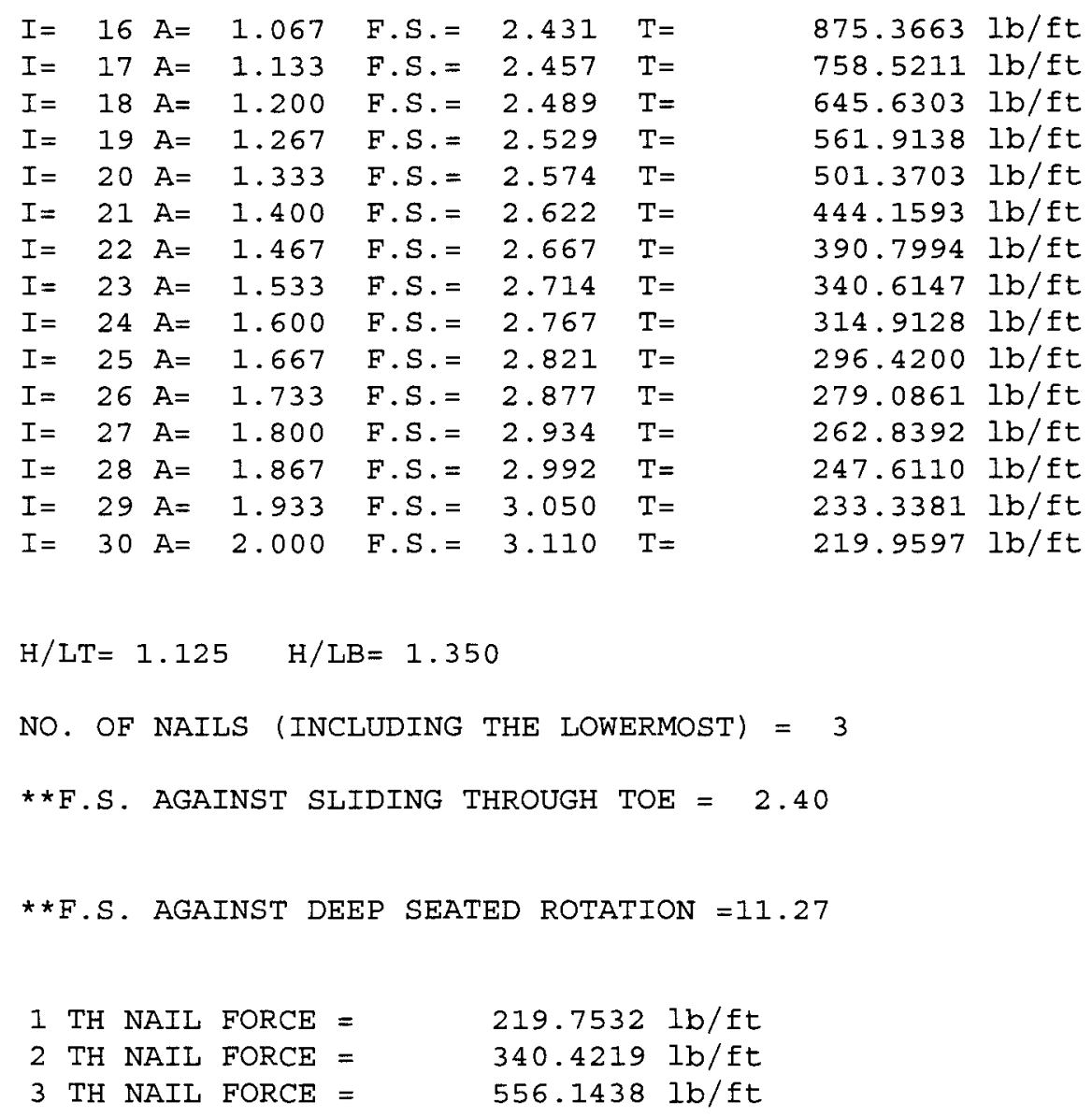


CASE 14 PART A 22 FT WALL

$<$ OUTPUT FILE > = CASE14A. OUT

\begin{tabular}{|c|c|c|c|c|c|}
\hline \multicolumn{6}{|c|}{$S O I L$} \\
\hline \multirow{6}{*}{\multicolumn{2}{|c|}{ FOUNDATION }} & SOIL UNIT WEIGHT & $=$ & 120.000 & pcf \\
\hline & & COHESION OF SOIL & $=$ & 1100.000 & psf \\
\hline & & FRICTION ANGLE OF SOIL & $=$ & 30.000 & deg \\
\hline & & UNDRAINED SU AT EXCAVATION LEVEL & $=$ & 2000.000 & psf \\
\hline & & DEPTH TO HARDPAN FROM EXCAVATION & $=$ & 25.000 & ft \\
\hline & & SU AT THE TOP OF HARDPAN & $=$ & 4500.000 & $\operatorname{psf}$ \\
\hline \multirow[t]{4}{*}{ LAYER } & 1 & HEIGHT TO TOP OF LAYER FROM TOE & $=$ & 9.000 & ft \\
\hline & & SOIL UNIT WEIGHT & $=$ & 120.000 & pof \\
\hline & & COHESION OF SOIL & $=$ & 1100.000 & psf \\
\hline & & FRICTION ANGLE OF SOIL & $=$ & 30.000 & $\operatorname{deg}$ \\
\hline \multirow[t]{4}{*}{ LAYER } & 2 & HEIGHT TO TOP OF LAYER FROM TOE & $=$ & 22.000 & ft \\
\hline & & SOIL UNIT WEIGHT & $=$ & 110.000 & pcf \\
\hline & & COHESION OF SOIL & $=$ & 500.000 & psf \\
\hline & & FRICTION ANGLE OF SOIL & $=$ & 28.000 & deg \\
\hline
\end{tabular}

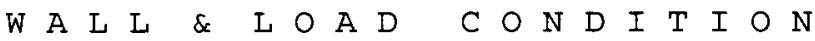

WALL INCLINATION ANGLE =

SURCHARGE LOAD

HOR. ACCELERATION COEFF.
$=$
$5.000 \mathrm{deg}$

300.000 psf

.000

N A I L P R O P E R T I E S

CROSS SECTIONAL AREA OF NAIL =

GROUT DIAMETER

YIELD STRENGTH OF NAIL

NAIL INCLINATION ANGLE

NAIL SKEW ANGLE AT SURFACE

DEPTH TO UPPERMOST NAIL

VER. SPACING OF NAIL

HOR. SPACING OF NAIL

TOTAL LENGTH OF UPPERMOST NAIL=

TOTAL LENGTH OF LOWERMOST NAIL =

TOTAL UNBONDED LENGTH OF NAIL =

(1)

$.790 \mathrm{si}$
$4.000 \mathrm{in}$
$60.000 \mathrm{ksi}$
$20.000 \mathrm{deg}$
$.000 \mathrm{deg}$
$2.000 \mathrm{ft}$
$4.500 \mathrm{ft}$
$6.000 \mathrm{ft}$
$18.000 \mathrm{ft}$
$15.000 \mathrm{ft}$
$2.000 \mathrm{ft}$

$4341.9030 \mathrm{Ib} / \mathrm{ft}$ $6495.7700 \mathrm{lb} / \mathrm{ft}$ $7572.0930 \mathrm{Ib} / \mathrm{ft}$ $8118.3150 \mathrm{lb} / \mathrm{ft}$ $8319.2480 \mathrm{lb} / \mathrm{ft}$ $8264.1870 \mathrm{lb} / \mathrm{ft}$ $8028.0540 \mathrm{lb} / \mathrm{ft}$ $7694.2030 \mathrm{lb} / \mathrm{ft}$ $7291.1250 \mathrm{lb} / \mathrm{ft}$ 


\begin{tabular}{|c|c|c|c|c|c|c|c|c|}
\hline$I=$ & 11 & $A=$ & .733 & F.S. $=$ & 1.737 & $\mathrm{~T}=$ & 6844.6630 & $1 b / f t$ \\
\hline$I=$ & 12 & $A=$ & .800 & F.S. $=$ & 1.739 & $T=$ & 6378.7210 & $1 b / f t$ \\
\hline$I=$ & 13 & $A=$ & .867 & F.S. $=$ & 1.752 & $\mathrm{~T}=$ & 5895.6130 & $1 \mathrm{~b} / \mathrm{ft}$ \\
\hline$I=$ & 14 & $A=$ & .933 & F.S. $=$ & 1.773 & $\mathrm{~T}=$ & 5413.2820 & $1 b / f t$ \\
\hline$I=$ & 15 & $A=$ & 1.000 & F.S. $=$ & 1.800 & $\mathrm{~T}=$ & 4938.8370 & $I b / f t$ \\
\hline$I=$ & 16 & $A=$ & 1.067 & F.S. $=$ & 1.831 & $\mathrm{~T}=$ & 4477.3240 & $1 b / f t$ \\
\hline$I=$ & 17 & $A=$ & 1.133 & F.S. $=$ & 1.884 & $T=$ & 4086.9140 & $1 \mathrm{~b} / \mathrm{ft}$ \\
\hline$I=$ & 18 & $A=$ & 1.200 & F.S. $=$ & 1.934 & $\mathrm{~T}=$ & 3730.3320 & $1 b / f t$ \\
\hline$I=$ & 19 & $A=$ & 1.267 & F.S. $=$ & 1.986 & $\mathrm{~T}=$ & 3464.5930 & $\mathrm{lb} / \mathrm{ft}$ \\
\hline$I=$ & 20 & $A=$ & 1.333 & F.S. $=$ & 2.037 & $\mathrm{~T}=$ & 3229.0440 & $1 b / f t$ \\
\hline$I=$ & 21 & $A=$ & 1.400 & F.S. $=$ & 2.084 & $\mathrm{~T}=$ & 3012.9620 & $1 b / f t$ \\
\hline$I=$ & 22 & $A=$ & 1.467 & F.S. $=$ & 2.132 & $\mathrm{~T}=$ & 2810.4290 & $1 \mathrm{~b} / \mathrm{ft}$ \\
\hline$I=$ & 23 & $A=$ & 1.533 & F.S. $=$ & 2.177 & $\mathrm{~T}=$ & 2641.7670 & $1 \mathrm{~b} / \mathrm{ft}$ \\
\hline$I=$ & 24 & $A=$ & 1.600 & F.S. = & 2.226 & $\mathrm{~T}=$ & 2535.5150 & $1 b / f t$ \\
\hline$I=$ & 25 & $A=$ & 1.667 & F.S. $=$ & 2.278 & $\mathrm{~T}=$ & 2433.6170 & $1 \mathrm{~b} / \mathrm{ft}$ \\
\hline$I=$ & 26 & $A=$ & 1.733 & F.S. $=$ & 2.328 & $\mathrm{~T}=$ & 2339.2010 & $\mathrm{lb} / \mathrm{ft}$ \\
\hline$I=$ & 27 & $A=$ & 1.800 & F.S. $=$ & 2.379 & $T=$ & 2250.3590 & $\mathrm{Ib} / \mathrm{ft}$ \\
\hline$I=$ & 28 & $A=$ & 1.867 & F.S. $=$ & 2.430 & $T=$ & 2166.6070 & $\mathrm{lb} / \mathrm{ft}$ \\
\hline$I=$ & 29 & $A=$ & 1.933 & F.S. = & 2.481 & $\mathrm{~T}=$ & 2087.5350 & $1 \mathrm{~b} / \mathrm{ft}$ \\
\hline$I=$ & 30 & $A=$ & 2.000 & F.S. = & 2.533 & $\mathrm{~T}=$ & 2012.7900 & $1 \mathrm{~b} / \mathrm{ft}$ \\
\hline
\end{tabular}

$\mathrm{H} / \mathrm{L} \mathrm{T}=1.222 \quad \mathrm{H} / \mathrm{LB}=1.467$

NO. OF NAILS (INCLUDING THE LOWERMOST) = 5

**F.S. AGAINST SLIDING THROUGH TOE $=1.74$

$\star \star F . S$. AGAINST DEEP SEATED ROTATION $=6.34$

1 TH NAIL FORCE =

2 TH NAIL FORCE =

3 TH NAIL FORCE =

4 TH NAIL FORCE =

5 TH NAIL FORCE $=$
$482.6588 \mathrm{lb} / \mathrm{ft}$

$681.4896 \mathrm{lb} / \mathrm{ft}$

$1287.9620 \mathrm{lb} / \mathrm{ft}$

$1781.7990 \mathrm{lb} / \mathrm{ft}$

$2610.7540 \mathrm{lb} / \mathrm{ft}$ 
CASE 14 B 13 FT WALL

$<$ OUTPUT FILE $>=$ CASE14B. OUT

\begin{tabular}{|c|c|c|c|c|}
\hline$S O I L$ & $\mathrm{R} O \mathrm{P} E \mathrm{E}$ T I E $\mathrm{S}$ & & & \\
\hline \multirow[t]{6}{*}{ FOUNDATION } & SOIL UNIT WEIGHT & $=$ & 120.000 & pef \\
\hline & COHESION OF SOIL & $=$ & 1100.000 & psf \\
\hline & FRICTION ANGLE OF SOIL & $=$ & 30.000 & deg \\
\hline & UNDRAINED SU AT EXCAVATION LEVEL & $=$ & 2000.000 & psf \\
\hline & DEPTH TO HARDPAN FROM EXCAVATION & $=$ & 33.000 & ft \\
\hline & SU AT THE TOP OF HARDPAN & $=$ & 4000.000 & psf \\
\hline \multirow[t]{4}{*}{ LAYER } & HEIGHT TO TOP OF LAYER FROM TOE & $=$ & 13.000 & ft \\
\hline & SOIL UNIT WEIGHT & $=$ & 110.000 & pef \\
\hline & COHESION OF SOIL & $=$ & 500.000 & psf \\
\hline & FRICTION ANGLE OF SOIL & $=$ & 28.000 & deg \\
\hline
\end{tabular}

W A L I \& I O A D C O N D I T I O N

WALL INCLINATION ANGLE SURCHARGE LOAD

HOR. ACCELERATION COEFF.

$\begin{array}{lr}= & 5.000 \mathrm{deg} \\ = & 300.000 \mathrm{psf} \\ = & .000\end{array}$

$N$ A I I $P R O P E R T I E S$

CROSS SECTIONAL AREA OF NAIL = GROUT DIAMETER YIELD STRENGTH OF NAIL NAIL INCLINATION ANGLE NAIL SKEW ANGLE AT SURFACE DEPTH TO UPPERMOST NAIL VER. SPACING OF NAIL HOR. SPACING OF NAIL TOTAL LENGTH OF UPPERMOST NATI TOTAL LENGTH OF LOWERMOST NAIL = TOTAL UNBONDED LENGTH OF NAIL=

$$
\begin{array}{rl}
.790 & \mathrm{si} \\
4.000 \mathrm{in} \\
60.000 \mathrm{ksi} \\
20.000 \mathrm{deg} \\
.000 \mathrm{deg} \\
2.000 \mathrm{ft} \\
4.500 \mathrm{ft} \\
6.000 \mathrm{ft} \\
11.000 \mathrm{ft} \\
9.000 \mathrm{ft} \\
2.000 \mathrm{ft}
\end{array}
$$

\begin{tabular}{|c|c|c|c|c|c|c|c|c|}
\hline$I=$ & 2 & $A=$ & .133 & F.S. $=$ & 5.851 & $\mathrm{~T}=$ & 838.3091 & $1 b / f t$ \\
\hline$I=$ & 3 & $A=$ & .200 & F.S. $=$ & 3.329 & $\mathrm{~T}=$ & 1397.3720 & $1 \mathrm{~b} / \mathrm{ft}$ \\
\hline$I=$ & 4 & $A=$ & .267 & F.S. $=$ & 2.524 & $\mathrm{~T}=$ & 1762.8160 & $1 \mathrm{~b} / \mathrm{ft}$ \\
\hline$I=$ & 5 & $A=$ & .333 & F.S. $=$ & 2.136 & $\mathrm{~T}=$ & 1949.2420 & $1 \mathrm{~b} / \mathrm{ft}$ \\
\hline$I=$ & 6 & $A=$ & .400 & F.S. $=$ & 1.915 & $\mathrm{~T}=$ & 2037.6140 & $1 \mathrm{~b} / \mathrm{ft}$ \\
\hline$I=$ & 7 & $A=$ & .467 & F.S. $=$ & 1.781 & $\mathrm{~T}=$ & 2061.4430 & $1 \mathrm{~b} / \mathrm{ft}$ \\
\hline$I=$ & 8 & $A=$ & .533 & F.S. $=$ & 1.698 & $\mathrm{~T}=$ & 2027.2590 & $1 \mathrm{~b} / \mathrm{ft}$ \\
\hline$I=$ & 9 & $A=$ & .600 & F.S. $=$ & 1.647 & $\mathrm{~T}=$ & 1951.0920 & $1 \mathrm{~b} / \mathrm{ft}$ \\
\hline$I=$ & 10 & $A=$ & .667 & F.S. $=$ & 1.618 & $\mathrm{~T}=$ & 1854.8580 & $1 \mathrm{~b} / \mathrm{ft}$ \\
\hline$I=$ & 11 & $A=$ & .733 & F.S. $=$ & 1.607 & $\mathrm{~T}=$ & 1743.3730 & $1 \mathrm{~b} / \mathrm{ft}$ \\
\hline$I=$ & 12 & $A=$ & .800 & F.S. $=$ & 1.609 & $\mathrm{~T}=$ & 1624.3700 & $1 \mathrm{~b} / \mathrm{ft}$ \\
\hline$I=$ & 13 & $A=$ & .867 & F.S. $=$ & 1.620 & $\mathrm{~T}=$ & 1501.8930 & $1 b / f t$ \\
\hline$I=$ & 14 & $A=$ & .933 & F.S. = & 1.639 & $\mathrm{~T}=$ & 1378.9450 & $1 b / f t$ \\
\hline$I=$ & 15 & $A=$ & 1.000 & F.S. = & 1.664 & $\mathrm{~T}=$ & 1257.6740 & $1 \mathrm{~b} / \mathrm{ft}$ \\
\hline
\end{tabular}




\begin{tabular}{|c|c|c|c|c|c|c|c|}
\hline$I=$ & $A=$ & 1.067 & F.S. $=$ & 1.694 & $\mathrm{~T}=$ & 1139.5780 & $1 b / f t$ \\
\hline$I=$ & $17 \mathrm{~A}=$ & 1.133 & F.S. $=$ & 1.728 & $\mathrm{~T}=$ & 1025.6660 & $1 b / f t$ \\
\hline$I=$ & $A=$ & 1.200 & E.S. = & 1.769 & $\mathrm{~T}=$ & 937.7746 & $I b / f t$ \\
\hline$I=$ & $19 \mathrm{~A}=$ & 1.267 & F.S. $=$ & 1.815 & $\mathrm{~T}=$ & 873.8356 & $1 \mathrm{~b} / \mathrm{ft}$ \\
\hline$I=$ & $20 \mathrm{~A}=$ & 1.333 & F.S. $=$ & 1.859 & $\mathrm{~T}=$ & 814.3790 & $1 \mathrm{~b} / \mathrm{ft}$ \\
\hline$I=$ & $21 \mathrm{~A}=$ & 1.400 & F.S. $=$ & 1.904 & $\mathrm{~T}=$ & 758.5441 & $1 \mathrm{~b} / \mathrm{ft}$ \\
\hline$I=$ & $22 A=$ & 1.467 & F.S. = & 1.947 & $\mathrm{~T}=$ & 707.0550 & $I b / f t$ \\
\hline$I=$ & $23 \mathrm{~A}=$ & 1.533 & F.S. $=$ & 1.991 & $\mathrm{~T}=$ & 658.7742 & $1 b / \pm t$ \\
\hline$I=$ & $24 A=$ & 1.600 & F.S. $=$ & 2.036 & $T=$ & 622.6808 & $1 \mathrm{~b} / \mathrm{ft}$ \\
\hline$I=$ & $A=$ & 1.667 & F.S. $=$ & 2.083 & $\mathrm{~T}=$ & 603.6078 & $I b / f t$ \\
\hline$I=$ & $A=$ & 1.733 & F.S. $=$ & 2.134 & $\mathrm{~T}=$ & 585.0589 & $I b / f t$ \\
\hline$I=$ & $A=$ & 1.800 & F.S. $=$ & 2.183 & $\mathrm{~T}=$ & 567.9261 & $I b / f t$ \\
\hline$I=$ & $A=$ & 1.867 & F.S. $=$ & 2.233 & $\mathrm{~T}=$ & 551.6949 & $I b / f t$ \\
\hline$I=$ & $A=$ & 1.933 & F.S. $=$ & 2.283 & $\mathrm{~T}=$ & 536.2932 & $1 \mathrm{~b} / \mathrm{ft}$ \\
\hline$I=$ & $30 A=$ & 2.000 & F.S. = & 2.333 & $\mathrm{~T}=$ & 521.6588 & $1 \mathrm{~b} / \mathrm{ft}$ \\
\hline
\end{tabular}

$\mathrm{H} / \mathrm{LT}=1.182 \mathrm{H} / \mathrm{LB}=1.444$

NO. OF NAILS (INCLUDING THE LOWERMOST) = 3

**F.S. AGAINST SLIDING THROUGH TOE $=1.61$

**F.S. AGAINST DEEP SEATED ROTATION $=9.81$

1 TH NAIL FORCE =

2 TH NAIL FORCE =

3 TH NAIL FORCE =
$320.4303 \mathrm{lb} / \mathrm{ft}$

$480.8821 \mathrm{lb} / \mathrm{ft}$

$942.0610 \mathrm{lb} / \mathrm{ft}$ 


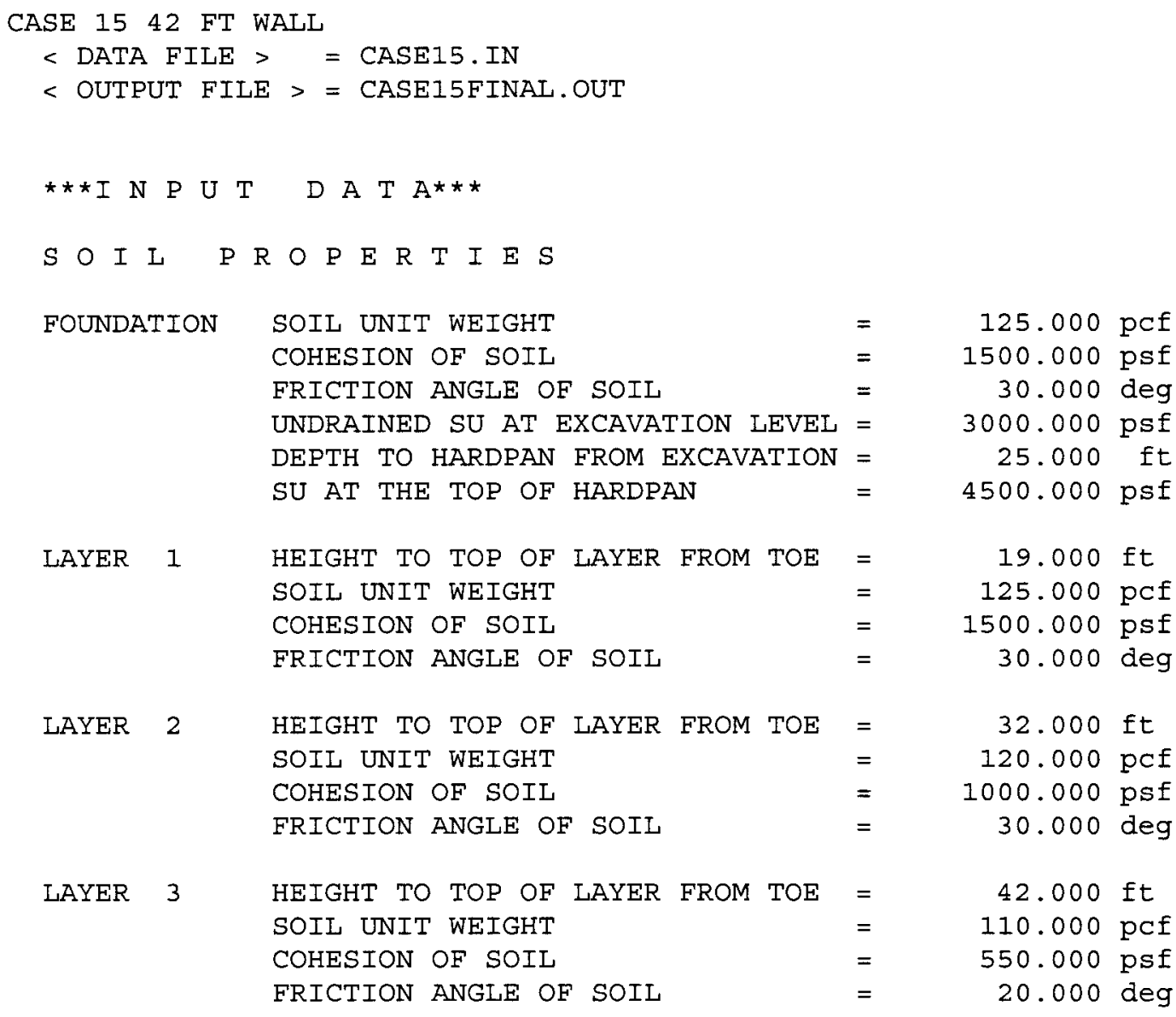

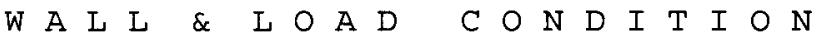

WALL INCLINATION ANGLE = SURCHARGE LOAD

HOR. ACCELERATION COEFF.
$5.000 \mathrm{deg}$ 300.000 psE .000

N A I L P R O P E R T I E S

CROSS SECTIONAL AREA OF NAIL= GROUT DIAMETER

YIELD STRENGTH OF NAIL

NAIL INCLINATION ANGLE

NAIL SKEW ANGLE AT SURFACE

DEPTH TO UPPERMOST NAIL

VER. SPACING OF NAIL

HOR. SPACING OF NAIL

TOTAL LENGTH OF UPPERMOST NAIL

TOTAL LENGTH OF LOWERMOST NAIL

TOTAL UNBONDED LENGTH OF NAIL

$$
\begin{aligned}
1.000 \mathrm{si} \\
4.000 \mathrm{in} \\
60.000 \mathrm{ksi} \\
20.000 \mathrm{deg} \\
.000 \mathrm{deg} \\
2.000 \mathrm{ft} \\
4.500 \mathrm{ft} \\
6.000 \mathrm{ft} \\
35.000 \mathrm{ft} \\
30.000 \mathrm{ft} \\
2.000 \mathrm{ft}
\end{aligned}
$$

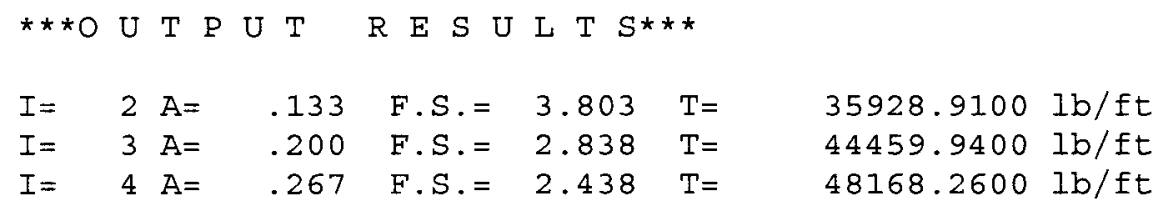




\begin{tabular}{|c|c|c|c|c|c|c|c|c|}
\hline$I=$ & 5 & $A=$ & .333 & F.S. $=$ & 2.214 & $\mathrm{~T}=$ & 49646.9800 & $1 b / f t$ \\
\hline$I=$ & 6 & $A=$ & .400 & F.S. $=$ & 2.075 & $\mathrm{~T}=$ & 49596.8400 & $1 \mathrm{~b} / \mathrm{ft}$ \\
\hline$I=$ & 7 & $\mathrm{~A}=$ & .467 & F.S. $=$ & 1.981 & $\mathrm{~T}=$ & 48649.5800 & $1 b / f t$ \\
\hline$I=$ & 8 & $A=$ & .533 & F.S. $=$ & 1.920 & $\mathrm{~T}=$ & 47039.8400 & $I b / f t$ \\
\hline$I=$ & 9 & $A=$ & .600 & F.S. $=$ & 1.881 & $\mathrm{~T}=$ & 44978.7200 & $1 \mathrm{~b} / \mathrm{ft}$ \\
\hline$I=$ & 10 & $A=$ & .667 & F.S. = & 1.855 & $\mathrm{~T}=$ & 42670.7300 & $1 b / f t$ \\
\hline$I=$ & 11 & $A=$ & .733 & F.S. $=$ & 1.839 & $\mathrm{~T}=$ & 40129.9800 & $1 \mathrm{~b} / \mathrm{ft}$ \\
\hline$I=$ & 12 & $A=$ & .800 & F.S. $=$ & 1.831 & $\mathrm{~T}=$ & 37441.2000 & $1 b / f t$ \\
\hline$I=$ & 13 & $A=$ & .867 & F.S. $=$ & 1.829 & $\mathrm{~T}=$ & 34669.3300 & $1 b / f t$ \\
\hline$I=$ & 14 & $A=$ & .933 & F.S. $=$ & 1.834 & $\mathrm{~T}=$ & 31837.8400 & $1 \mathrm{~b} / \mathrm{ft}$ \\
\hline$I=$ & 15 & $A=$ & 1.000 & F.S. $=$ & 1.845 & $\mathrm{~T}=$ & 29025.7900 & $1 b / f t$ \\
\hline$I=$ & 16 & $A=$ & 1.067 & F.S. $=$ & 1.863 & $\mathrm{~T}=$ & 26256.1000 & $I b / f t$ \\
\hline$I=$ & 17 & $A=$ & 1.133 & F.S. $=$ & 1.907 & $\mathrm{~T}=$ & 23667.3700 & $1 b / f t$ \\
\hline$I=$ & 18 & $\mathrm{~A}=$ & 1.200 & F.S. $=$ & 1.950 & $\mathrm{~T}=$ & 21504.7000 & $1 b / f t$ \\
\hline$I=$ & 19 & $A=$ & 1.267 & F.S. $=$ & 1.993 & $\mathrm{~T}=$ & 19752.2600 & $1 b / f t$ \\
\hline$I=$ & 20 & $A=$ & 1.333 & F.S. = & 2.032 & $\mathrm{~T}=$ & 18188.5800 & $1 b / f t$ \\
\hline$I=$ & 21 & $A=$ & 1.400 & F.S. $=$ & 2.074 & $\mathrm{~T}=$ & 16978.8400 & $1 \mathrm{~b} / \mathrm{ft}$ \\
\hline$I=$ & 22 & $A=$ & 1.467 & F.S. $=$ & 2.114 & $\mathrm{~T}=$ & 15855.3600 & $1 \mathrm{~b} / \mathrm{ft}$ \\
\hline$I=$ & 23 & $A=$ & 1.533 & F.S. $=$ & 2.153 & $\mathrm{~T}=$ & 14858.2500 & $1 b / f t$ \\
\hline$I=$ & 24 & $A=$ & 1.600 & F.S. $=$ & 2.195 & $\mathrm{~T}=$ & 14099.5700 & $1 \mathrm{~b} / \mathrm{ft}$ \\
\hline$I=$ & 25 & $\mathrm{~A}=$ & 1.667 & F.S. = & 2.237 & $\mathrm{~T}=$ & 13389.5000 & $1 b / f t$ \\
\hline$I=$ & 26 & $A=$ & 1.733 & F.S. $=$ & 2.279 & $\mathrm{~T}=$ & 12722.8800 & $1 b / f t$ \\
\hline$I=$ & 27 & $A=$ & 1.800 & F.S. $=$ & 2.321 & $T=$ & 12095.5700 & $1 b / f t$ \\
\hline$I=$ & 28 & $\mathrm{~A}=$ & 1.867 & F.S. $=$ & 2.363 & $\mathrm{~T}=$ & 11504.2500 & $1 \mathrm{~b} / \mathrm{ft}$ \\
\hline$I=$ & 29 & $\mathrm{~A}=$ & 1.933 & F.S. $=$ & 2.408 & $\mathrm{~T}=$ & 11040.9100 & $1 b / f t$ \\
\hline$I=$ & 30 & $A=$ & 2.000 & F.S. = & 2.455 & $T=$ & 10656.6700 & $1 \mathrm{~b} / \mathrm{ft}$ \\
\hline
\end{tabular}

$\mathrm{H} / \mathrm{LT}=1.200 \mathrm{H} / \mathrm{LB}=1.400$

NO. OF NAILS (INCLUDING THE LOWERMOST) = 9

**F.S. AGAINST SLIDING THROUGH TOE $=1.83$

**F.S. AGAINST DEEP SEATED ROTATION $=3.65$

1 TH NAIL FORCE =

2 TH NAIL FORCE =

3 TH NAIL FORCE =

4 TH NAIL FORCE =

5 TH NAIL FORCE =

$6 \mathrm{TH}$ NAIL FORCE =

$7 \mathrm{TH}$ NAIL FORCE =

$8 \mathrm{TH}$ NAIL FORCE =

$9 \mathrm{TH}$ NAIL FORCE =

$\begin{array}{rl}938.5042 & 1 \mathrm{~b} / \mathrm{ft} \\ 1283.4570 & \mathrm{lb} / \mathrm{ft} \\ 1708.7710 & \mathrm{lb} / \mathrm{ft} \\ 2606.9420 & \mathrm{lb} / \mathrm{ft} \\ 3320.7850 & 1 \mathrm{~b} / \mathrm{ft} \\ 4197.1860 & \mathrm{lb} / \mathrm{ft} \\ 5289.5090 & \mathrm{lb} / \mathrm{ft} \\ 6693.6060 & \mathrm{lb} / \mathrm{ft} \\ 8630.5700 & 1 \mathrm{~b} / \mathrm{ft}\end{array}$


Appendix D: Materials Take offs 


\section{CASE 1}

\begin{tabular}{|c|c|c|c|c|c|c|c|c|c|}
\hline & & & & & & & & & \\
\hline \multicolumn{2}{|c|}{ CONVENTIONAL } & & & & & & & \\
\hline & & & & & & & & & \\
\hline & AREA $=$ & 12,560 & Sq ft & & & FT & Each & Total, FT & Total steel \# \\
\hline & & & & $\begin{array}{c}\text { HP } \\
12 \times 53\end{array}$ & 32.5 & 63 & 2047.5 & \\
\hline $\begin{array}{c}\text { TIE } \\
\text { BACK }\end{array}$ & 63 & Each & $\begin{array}{c}1.25 ~ " \\
\text { rebar }\end{array}$ & $\begin{array}{c}\text { HP } \\
12 \times 53\end{array}$ & 15 & 1 & 15 & \\
\hline & WALES & 30 & Each & $10 \mathrm{ft}$ & $\begin{array}{c}\mathrm{HP} \\
12 \times 53\end{array}$ & 22 & 1 & 22 & \\
\hline & WALES & 1 & Each & $20 \mathrm{ft}$ & pound & & & $=====$ & \\
\hline & & & & 53 & & & $2,084.50$ & $110,478.50$ \\
\hline & & & & & & & & & \\
\hline
\end{tabular}

\begin{tabular}{|c|c|c|c|c|}
\hline \multicolumn{5}{|l|}{ SOILNAILING } \\
\hline & & Each & Length & Total Length \\
\hline \multirow[t]{7}{*}{ \#8 rebar } & $1 \mathrm{st}$ & 111 & 20.00 & 2,220 \\
\hline & 2 nd & 109 & 19.00 & 2,071 \\
\hline & $3 \mathrm{rd}$ & 107 & 17.50 & 1,873 \\
\hline & 4 th & 105 & 16.50 & 1,733 \\
\hline & 5 th & 103 & 15.00 & 1,545 \\
\hline & & $=======$ & & $=======$ \\
\hline & & 535 & & 9,441 \\
\hline \#4 wales & 10,700 & $\mathrm{Ft}$ & & \\
\hline $6 \times 6$ wire mesh & 12,560 & Sqft & & \\
\hline 22 " gunnite & 12,560 & Sqft & 153.51 & Cy \\
\hline no. of nails & 535 & & & \\
\hline
\end{tabular}

\begin{tabular}{|r|c|l|l|l|}
\hline SOIL NAILING & & & & \\
\hline total linear $\mathrm{ft}$ of nails drill & 9,441 & $\mathrm{ft}$ & & \\
\hline \# 8 total linear $\mathrm{ft}$ of nails steel & 9,441 & $\mathrm{ft}$ & & \\
\hline no. of soil nails & 535 & each & & \\
\hline no. of soil nails plates \& nuts & 535 & each & & \\
\hline \#4 wales & 10,700 & Ift & & \\
\hline 6x6 wire mesh & 12,560 & sqft & & \\
\hline shotcrete or gunnite 2 2" & 12,560 & sqft & & \\
\hline OTA & & ls & & \\
\hline & & & & \\
\hline & & & & \\
\hline
\end{tabular}


CASE 2

\begin{tabular}{|c|c|c|c|c|c|c|c|c|c|}
\hline \multicolumn{2}{|c|}{ CONVENTIONAL } & & & & & & & \\
\hline & & & & & & & & & \\
\hline AREA $=$ & 22,400 & Sqft & & & & FT & Each & Total, FT & $\begin{array}{c}\text { Total } \\
\text { steel \# }\end{array}$ \\
\hline & & & & & $\begin{array}{c}\text { HP } \\
12 \times 53\end{array}$ & 34 & 84 & 2,856 & \\
\hline $\begin{array}{c}\text { TIE } \\
\text { BACK }\end{array}$ & 164 & Each & $\begin{array}{c}1.25 \\
\text { rebar }\end{array}$ & & & & & & \\
\hline WALES & 80 & Each & $10 \mathrm{FT}$ & & & & & & \\
\hline WALES & 2 & Each & 20 ' FT & & pound & & & $======$ & \\
\hline & & & & & 53 & & & 2856 & 151368 \\
\hline
\end{tabular}

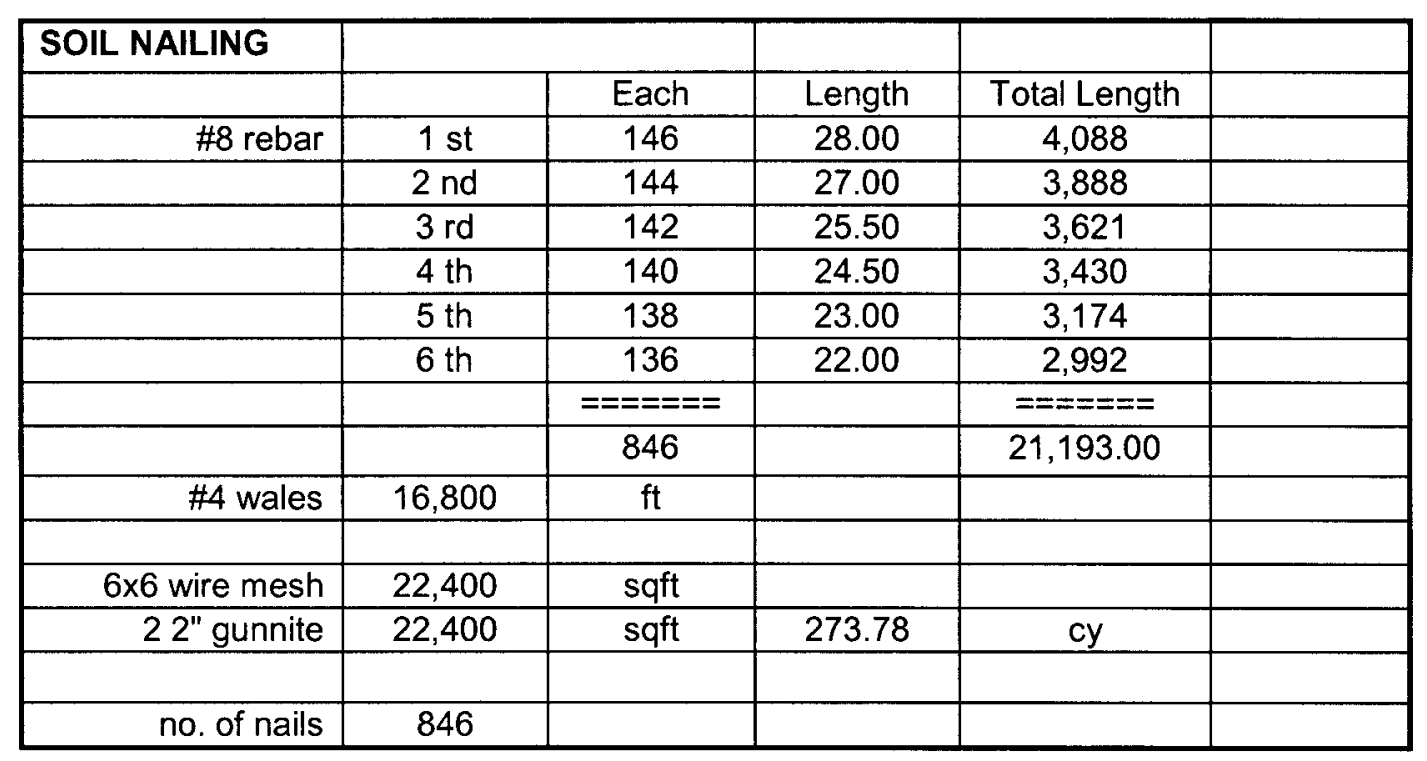

\begin{tabular}{|c|c|c|c|c|}
\hline SOIL NAILING & & & & \\
\hline total linear $\mathrm{ft}$ of nails drill & 21,193 & $\mathrm{ft}$ & & \\
\hline $\begin{array}{r}\text { \# } 8 \text { total linear } \mathrm{ft} \text { of nails } \\
\text { steel }\end{array}$ & 21,193 & $\mathrm{ft}$ & & \\
\hline no. of soil nails & 846 & each & & \\
\hline no. of soil nails plates \& nuts & 846 & each & & \\
\hline \#4 wales & 16,800 & Ift & & \\
\hline $6 \times 6$ wire mesh & 22400 & sqft & & \\
\hline shotcrete or gunnite 2 2" & 22400 & sqft & & \\
\hline layout & 40 & man/day & & \\
\hline
\end{tabular}




\section{CASE 3}

\begin{tabular}{|c|c|c|c|c|c|c|c|c|}
\hline \multicolumn{2}{|c|}{ CONVENTIONAL } & & & & & & \\
\hline & & & & & & & & \\
\hline AREA $=$ & 1,875 & Sq ft & & & FT & Each & Total, FT & Total steel \# \\
\hline & & & & $\begin{array}{c}\text { HP } \\
10 X 42\end{array}$ & 21 & 14 & 294 & \\
\hline $\begin{array}{c}\text { TIE } \\
\text { BACK }\end{array}$ & 7 & Each & $\begin{array}{c}1 " \\
\text { rebar }\end{array}$ & $\begin{array}{c}\text { HP } \\
10 \times 42\end{array}$ & 15 & 2 & 30 & \\
\hline WALES & 7 & Each & $10 \mathrm{FT}$ & & & & & \\
\hline & & & & pound & & & $=======$ & \\
\hline & & & & 42 & & & 324 & $13,608.00$ \\
\hline
\end{tabular}

\begin{tabular}{|r|c|c|c|c|}
\hline SOIL NAILING & \multicolumn{2}{|c|}{} & & \\
\hline & & Each & Length & Total length \\
\hline$\# 8$ rebar & 1 st & 23 & 12.00 & 276 \\
\hline & 2 nd & 21 & 11.00 & 231 \\
\hline & $3 \mathrm{rd}$ & 20 & 10.00 & 200 \\
\hline & & $======$ & & $======$ \\
\hline & & 64 & & 707.00 \\
\hline \#4 wales & 1,440 & $\mathrm{ft}$ & & \\
\hline & & & & \\
\hline 6x6 wire mesh & 1,875 & sqft & & \\
\hline 2 2" gunnite & 1,875 & sqft & 22.92 & cy \\
\hline & & & & \\
\hline $\begin{array}{r}\text { no. of nail plate } \\
\text { plates }\end{array}$ & 64 & & & \\
\hline
\end{tabular}

\begin{tabular}{|r|c|l|l|l|}
\hline SOIL NAILING & & & & \\
\hline total linear ft of nails drill & 707 & $\mathrm{ft}$ & & \\
\hline \# 8 total linear ft of nails steel & 707 & $\mathrm{ft}$ & & \\
\hline no. of soil nails & 64 & each & & \\
\hline no. of soil nails plates \& nuts & 64 & each & & \\
\hline \#4 wales & 1,440 & $\mathrm{fft}$ & & \\
\hline $6 \times 6$ wire mesh & $1,875.00$ & sqft & & \\
\hline shotcrete or gunnite 2 2" & $1,875.00$ & sqft & & \\
\hline layout & 40 & man/day & & \\
\hline
\end{tabular}




\section{Case 4}

\begin{tabular}{|c|c|c|c|c|c|c|c|c|c|c|}
\hline \multicolumn{2}{|c|}{ CONVENTIONAL } & & & & & & & & \\
\hline & AREA $=$ & 8,940 & Sq ft & & & FT & Each & Total, Ft & Total steel \# \\
\hline & & & & $\begin{array}{c}\text { HP } \\
10 \times 42\end{array}$ & 30 & 24 & 720 & \\
\hline $\begin{array}{c}\text { TIE } \\
\text { BACK }\end{array}$ & 7 & Each & $\begin{array}{c}1 " \\
\text { rebar }\end{array}$ & $\begin{array}{c}\text { HP } \\
10 \times 42\end{array}$ & 25 & 1 & 25 & \\
\hline $\begin{array}{c}\text { TIE } \\
\text { BACK }\end{array}$ & 46 & Each & $\begin{array}{c}1.25 " \\
\text { rebar }\end{array}$ & $\begin{array}{c}\text { HP } \\
10 \times 42\end{array}$ & 37 & 10 & 370 & \\
\hline & & & $\begin{array}{c}\text { HP } \\
10 \times 42\end{array}$ & 27 & 2 & 54 & \\
\hline & WALES & 2 & Each & 10 FT & pound & & $=====$ & $=====$ & \\
\hline & WALES & 25 & Each & 20 FT & 42 & & 37 & $1,169.00$ & $49,098.00$ \\
\hline
\end{tabular}

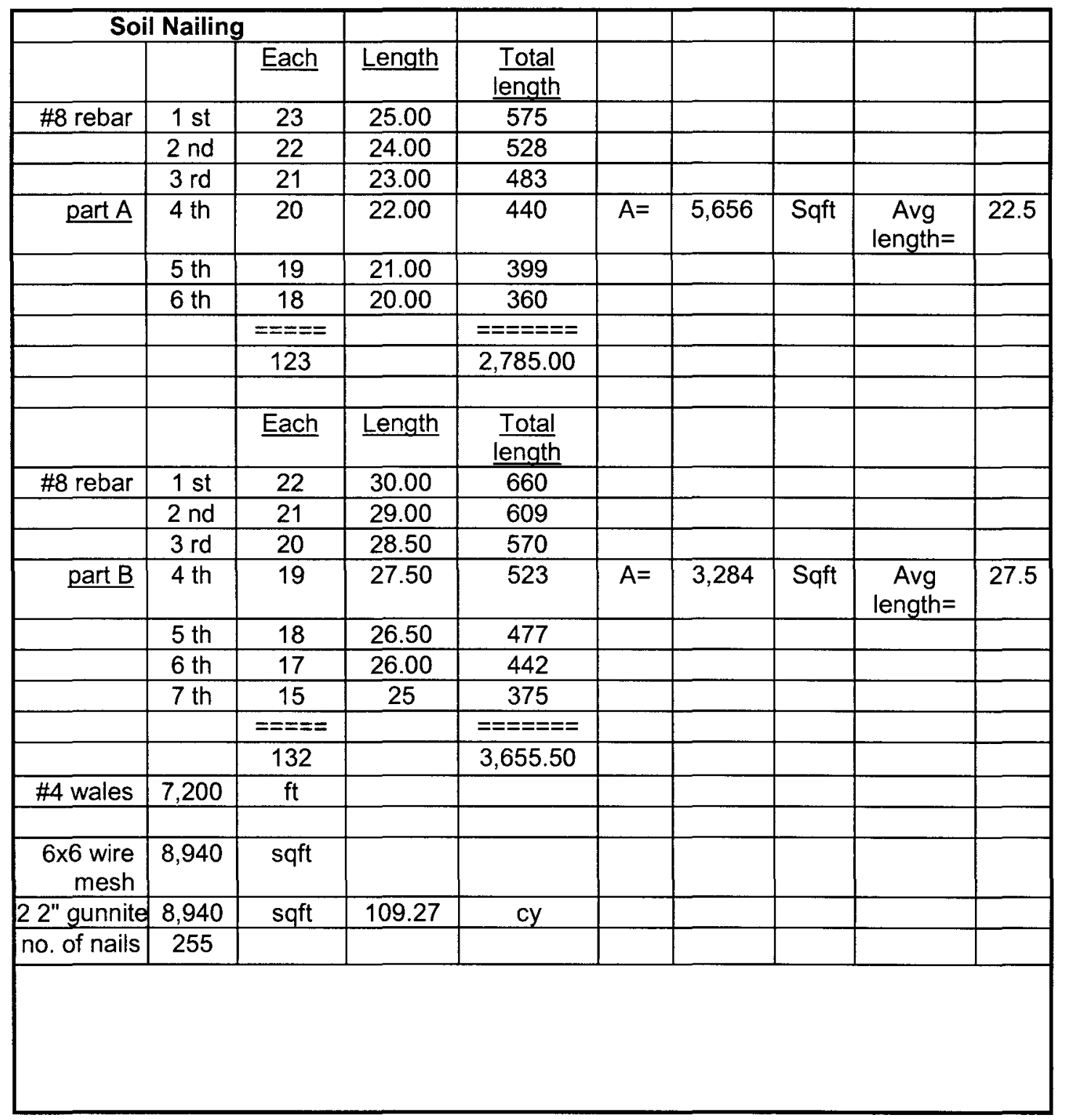




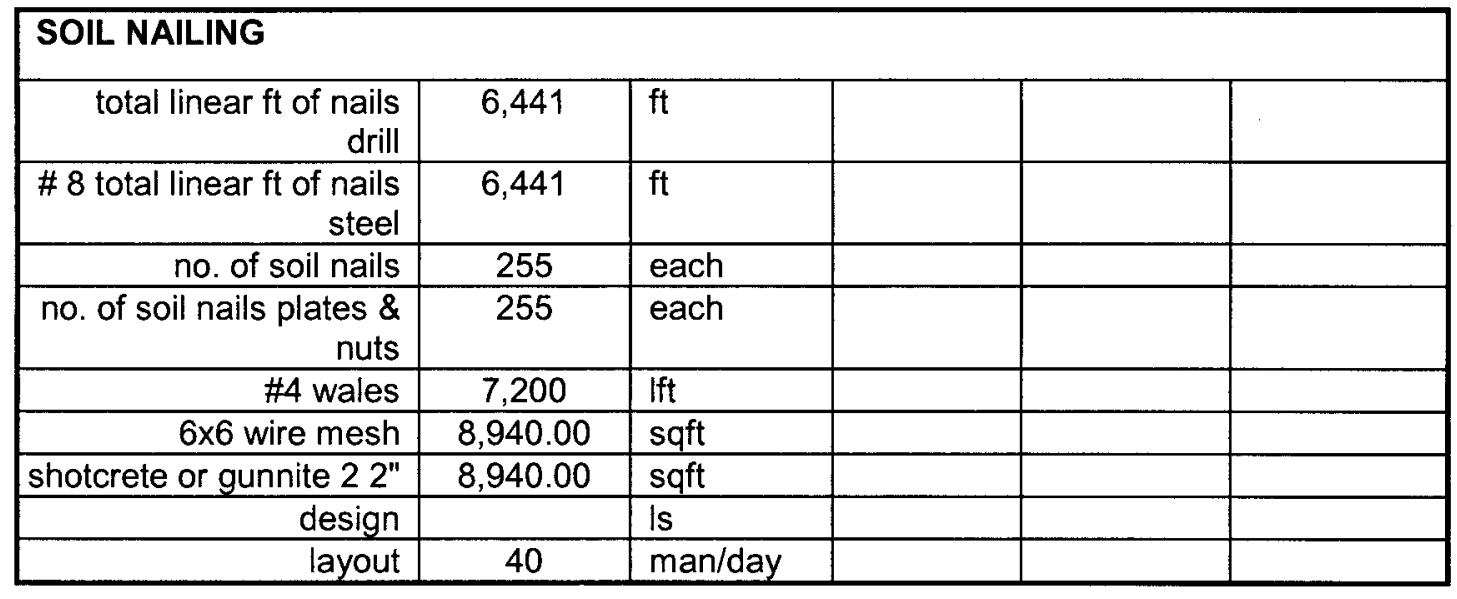




\section{CASE 5}

\begin{tabular}{|c|c|c|c|c|c|c|c|c|}
\hline \multicolumn{9}{|c|}{ CONVENTIONAL } \\
\hline \multirow[t]{2}{*}{ AREA= } & 24,318 & $\mathrm{Sqft}$ & & & $\mathrm{FT}$ & Each & Total $\mathrm{ft}$ & Total steel \# \\
\hline & & & & $\begin{array}{c}\mathrm{HP} \\
12 \times 53\end{array}$ & 30 & 42 & $1,260.0$ & \\
\hline \multirow[t]{3}{*}{$\begin{array}{c}\text { TIE } \\
\text { BACK }\end{array}$} & 190 & Each & $\begin{array}{l}1.25 " \\
\text { rebar }\end{array}$ & & & & & \\
\hline & & & & & & & & \\
\hline & & & & pound & & $===$ & $=====$ & $=======$ \\
\hline WALES & 3 & Each & $10 \mathrm{ft}$ & 53 & & 42 & $1,260.0$ & $66,780.0$ \\
\hline \multirow[t]{2}{*}{ WALES } & 30 & Each & $20 \mathrm{ft}$ & & & & & \\
\hline & & & & & & & & \\
\hline \multirow[t]{10}{*}{$\begin{array}{c}12 \times 53 \\
\text { Beam } \\
\text { Penetration } \\
\end{array}$} & 130 & Each & & $\begin{array}{c}\mathrm{HP} \\
10 \times 42\end{array}$ & 10 & 1 & 10 & \\
\hline & & & & $\begin{array}{c}\mathrm{HP} \\
10 \times 42\end{array}$ & 25 & 2 & 50 & \\
\hline & & & & $\begin{array}{c}\mathrm{HP} \\
10 \times 42\end{array}$ & 33 & 1 & 33 & \\
\hline & & & & $\begin{array}{c}\mathrm{HP} \\
10 \times 42\end{array}$ & 28 & 46 & 1288 & \\
\hline & & & & $\begin{array}{c}\mathrm{HP} \\
10 \times 42\end{array}$ & 20 & 1 & 20 & \\
\hline & & & & $\begin{array}{c}\mathrm{HP} \\
10 \times 42\end{array}$ & 6.5 & 1 & 6.5 & \\
\hline & & & & pound & & $====$ & $=====$ & \\
\hline & & & & 42 & & 52.00 & $1,407.5$ & $59,115.0$ \\
\hline & & & & & & & & $=======$ \\
\hline & & & & & & & & $125,895.00$ \\
\hline
\end{tabular}




\section{CASE 5}

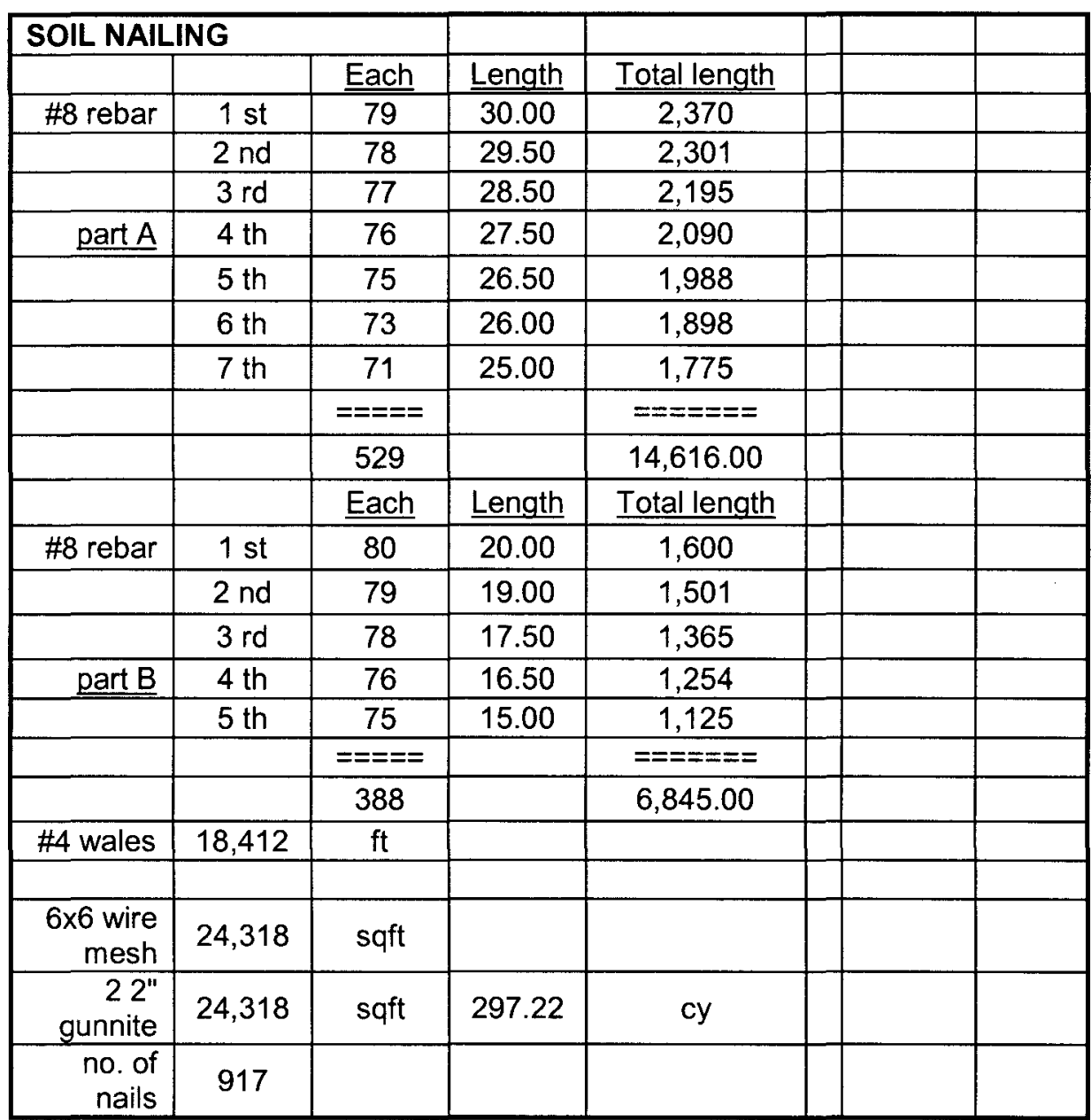

\begin{tabular}{|r|c|l|l|l|l|}
\hline SOIL NAILING & & & & & \\
\hline $\begin{array}{r}\text { total linear ft of nails } \\
\text { drill }\end{array}$ & 21,461 & $\mathrm{ft}$ & & & \\
\hline $\begin{array}{r}\text { \# 8 total linear ft of } \\
\text { nails steel }\end{array}$ & 21,461 & $\mathrm{ft}$ & & & \\
\hline no. of soil nails & 917 & each & & & \\
\hline $\begin{array}{r}\text { no. of soil nails plates \& } \\
\text { nuts }\end{array}$ & 917 & each & & & \\
\hline \#ales & 18,412 & Ift & & & \\
\hline 6x6 wire mesh & $24,318.00$ & sqft & & & \\
\hline shotcrete or gunnite 2 2" & $24,318.00$ & sqft & & & \\
\hline layout & 40 & man/day & & & \\
\hline mob/demob & & Is & & & \\
\hline
\end{tabular}




\section{CASE 6}

\begin{tabular}{|c|c|c|c|c|c|c|c|c|}
\hline \multicolumn{9}{|c|}{ CONVENTIONAL } \\
\hline $\mathrm{AREA}=$ & 24,933 & $\mathrm{Sq} \mathrm{ft}$ & & & FT & Each & Total, ft & Total steel \# \\
\hline & & & & $\begin{array}{c}\mathrm{HP} \\
12 \times 53 \\
\end{array}$ & 25 & 1 & 25.00 & \\
\hline TIE BACK & 148 & Each & $\begin{array}{c}1 " \\
\text { rebar }\end{array}$ & & 37.5 & 37 & $1,387.50$ & \\
\hline \multirow[t]{2}{*}{ TIE BACK } & 40 & Each & $\begin{array}{l}1.25^{\prime \prime} \\
\text { rebar }\end{array}$ & & 30 & 68 & $2,040.00$ & \\
\hline & & & & & 15 & 1 & 15.00 & \\
\hline \multirow[t]{2}{*}{$\begin{array}{r}\text { Beam } \\
\text { Penetration }\end{array}$} & 148 & Each & & pound & & $====$ & $======$ & $=======8$ \\
\hline & & & & 53 & & 107 & $3,467.50$ & $183,777.50$ \\
\hline WALES & 20 & Each & $20 \mathrm{ft}$ & & & & & \\
\hline
\end{tabular}

\begin{tabular}{|r|c|l|l|l|l|}
\hline SOIL NAILING & & & & & \\
\hline total linear ft of nails drill & 23,886 & $\mathrm{ft}$ & & & \\
\hline $\begin{array}{r}\text { \# 8 total linear ft of nails } \\
\text { steel }\end{array}$ & 23,886 & $\mathrm{ft}$ & & & \\
\hline no. of soil nails & 951 & each & & & \\
\hline $\begin{array}{r}\text { no. of soil nails plates \& } \\
\text { nuts }\end{array}$ & 951 & each & & & \\
\hline \#4 wales & 19,080 & lft & & & \\
\hline 6x6 wire mesh & $24,933.00$ & sqft & & & \\
\hline shotcrete or gunnite 2 2" & $24,933.00$ & sqft & & & \\
\hline & & & & & \\
\hline design & & Is & & & \\
\hline layout & 40 & man/day & & & \\
\hline
\end{tabular}




\section{CASE 6}

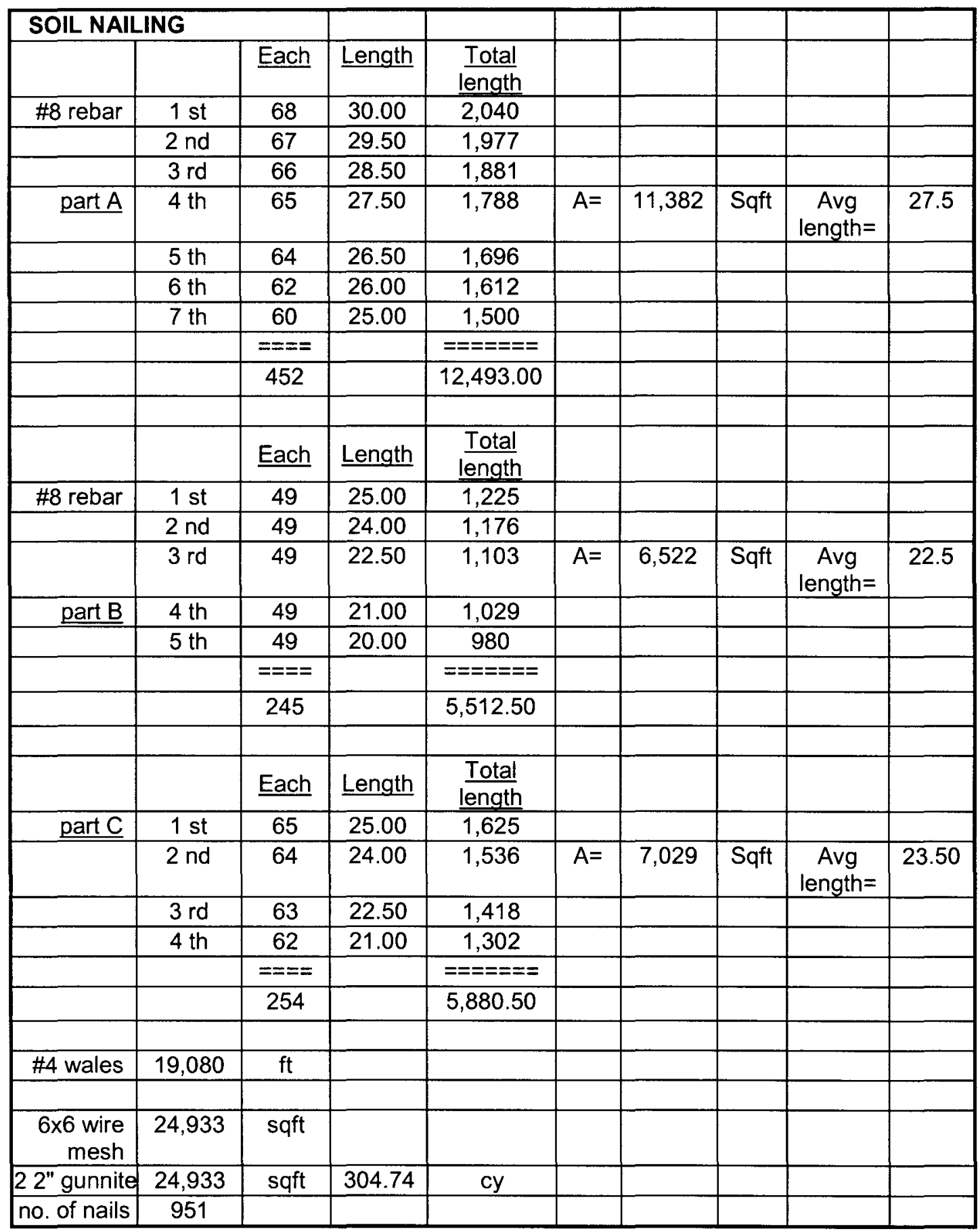




\section{CASE 7}

\section{CONVENTIONAL}

\begin{tabular}{|r|c|c|c|c|c|c|c|c|}
\hline AREA $=$ & 3,020 & $\mathrm{Sq} \mathrm{ft}$ & & & $\mathrm{FT}$ & EACH & LFT & Total steel \# \\
\hline & & & & $\begin{array}{c}\mathrm{HP} \\
10 \mathrm{X} 42\end{array}$ & 22 & 10 & 220.00 & \\
\hline TIE BACK & 0 & Each & $\begin{array}{c}1 " \\
\text { rebar }\end{array}$ & $\begin{array}{c}\mathrm{HP} \\
10 \times 42\end{array}$ & 31.5 & 10 & 315.00 & \\
\hline TIE BACK & 14 & Each & $\begin{array}{c}1.25 " \\
\text { rebar }\end{array}$ & & & & & \\
\hline & & & & & & & & \\
\hline $\begin{array}{r}\text { Beam } \\
\text { penetration }\end{array}$ & 10 & Each & & pound & & $=====$ & $=====$ & $======$ \\
\hline & & & & 42 & & 20.00 & 535.00 & $22,470.00$ \\
\hline & & & & & & & & \\
\hline WALES & 4 & Each & $10 \mathrm{FT}$ & & & & & \\
\hline
\end{tabular}

\begin{tabular}{|c|c|c|c|c|c|c|c|c|}
\hline \multicolumn{9}{|c|}{ SOIL NAILING } \\
\hline & & Each & Length & $\frac{\text { Total }}{\text { length }}$ & & & & \\
\hline \multirow[t]{2}{*}{$\begin{array}{r}\# 8 \\
\text { rebar } \\
\end{array}$} & $1 \mathrm{st}$ & 12 & 12.00 & 144 & & & & Avg length $=$ \\
\hline & $2 \mathrm{nd}$ & 11 & 11.00 & 121 & $A=$ & 1,005 & Sqft & 11 \\
\hline \multirow[t]{6}{*}{ part A } & $3 \mathrm{rd}$ & 10 & 10.00 & 100 & & & & \\
\hline & & $======$ & & $======$ & & & & \\
\hline & & 33 & & 365.00 & & & & \\
\hline & & & & & & & & \\
\hline & & Each & Length & $\frac{\text { Total }}{\text { length }}$ & & & & \\
\hline & $1 \mathrm{st}$ & 17 & 20.00 & 340 & & & & Avg length= \\
\hline \multirow[t]{5}{*}{ part B } & $2 \mathrm{nd}$ & 16 & 18.50 & 296 & $A=$ & 2,015 & Sqft & 17 \\
\hline & $3 \mathrm{rd}$ & 15 & 16.50 & 248 & & & & \\
\hline & 4 th & 13 & 15.00 & 195 & & & & \\
\hline & & $======$ & & $=======$ & & & & \\
\hline & & 61 & & $1,078.50$ & & & & \\
\hline & & & & & & & & \\
\hline $\begin{array}{r}\# 4 \\
\text { wales }\end{array}$ & 2,272 & $\mathrm{ft}$ & & & & & & \\
\hline & & & & & & & & \\
\hline $\begin{array}{r}6 \times 6 \\
\text { wire } \\
\text { mesh }\end{array}$ & 3,020 & sqft & & & & & & \\
\hline $\begin{array}{r}22 " \\
\text { gunnite }\end{array}$ & 3,020 & sqft & 36.91 & cy & & & & \\
\hline $\begin{array}{r}\text { no. of } \\
\text { nails }\end{array}$ & 94 & & & & & & & \\
\hline
\end{tabular}


CASE 7

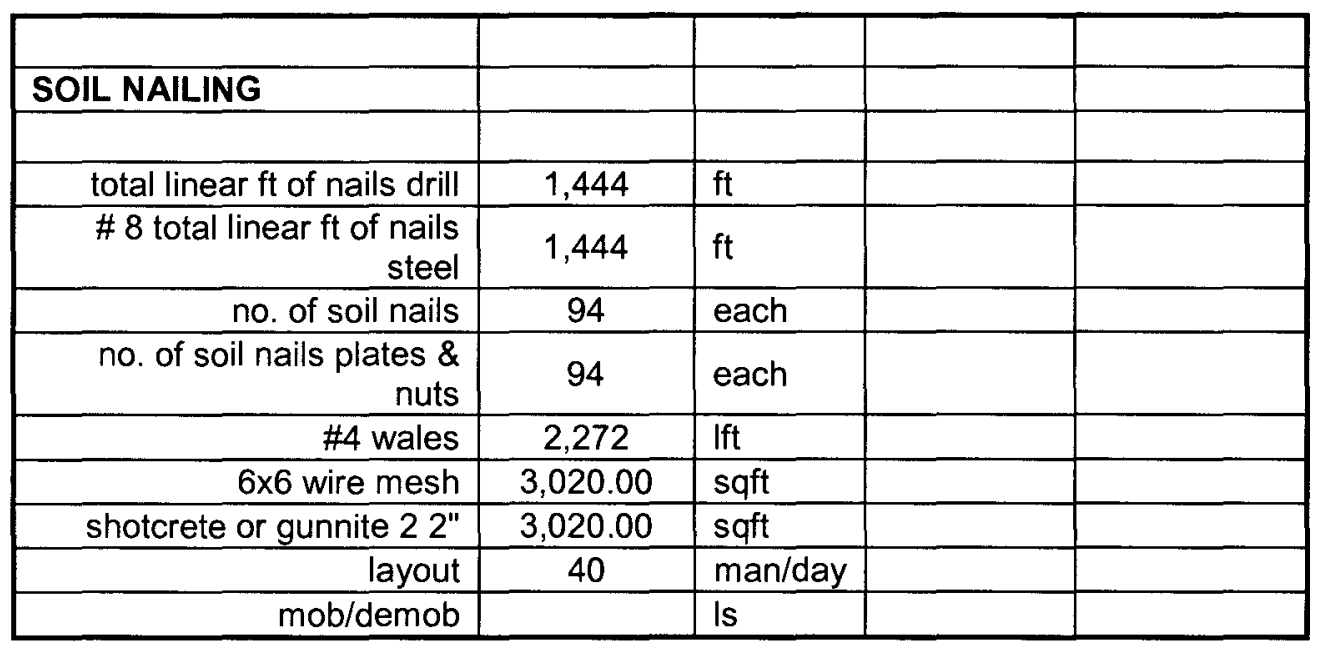




\section{CASE 8}

\begin{tabular}{|c|c|c|c|c|c|c|c|c|}
\hline \multicolumn{9}{|c|}{ CONVENTIONAL } \\
\hline & & & & & & & & \\
\hline & & & & & & & & \\
\hline \multirow[t]{2}{*}{ AREA= } & 13,234 & $\mathrm{Sq} \mathrm{ft}$ & & & FT & Each & LFT & Total steel \# \\
\hline & & & & $\begin{array}{c}\mathrm{HP} \\
10 \times 42\end{array}$ & 11 & 1 & 11.00 & \\
\hline \multirow[t]{6}{*}{$\begin{array}{c}\text { TIE } \\
\text { BACK }\end{array}$} & 86 & Each & $\begin{array}{c}1 " \\
\text { rebar }\end{array}$ & $\begin{array}{c}\mathrm{HP} \\
10 \times 42\end{array}$ & 20 & 1 & 20.00 & \\
\hline & & & & $\begin{array}{c}\mathrm{HP} \\
10 \times 42\end{array}$ & 30 & 10 & 300.00 & \\
\hline & & & & $\begin{array}{c}\mathrm{HP} \\
10 \times 42\end{array}$ & 28 & 39 & $1,092.0$ & \\
\hline & & & & $\begin{array}{c}\mathrm{HP} \\
10 \times 42\end{array}$ & 21 & 11 & 231.00 & \\
\hline & & & & pound & & $=======$ & $======$ & $=======$ \\
\hline & & & & 42 & & 62.00 & $1,654.0$ & $69,468.00$ \\
\hline WALES & 20 & Each & $10 \mathrm{ft}$ & & & & & \\
\hline WALES & 26 & Each & $20 \mathrm{ft}$ & & & & & \\
\hline
\end{tabular}

\begin{tabular}{|r|r|l|l|l|}
\hline SOIL NAILING & & & & \\
\hline total linear ft of nails drill & 10,931 & $\mathrm{ft}$ & & \\
\hline $\begin{array}{r}\text { \# 8 total linear ft of nails } \\
\text { steel }\end{array}$ & 10,931 & $\mathrm{ft}$ & & \\
\hline no. of soil nails & 514 & each & & \\
\hline $\begin{array}{r}\text { no. of soil nails plates \& } \\
\text { nuts }\end{array}$ & 514 & each & & \\
\hline \#4 wales & 10,264 & Ift & & \\
\hline 6x6 wire mesh & $13,234.0$ & sqft & & \\
\hline shotcrete or gunnite 2 2" & $13,234.0$ & sqft & & \\
\hline design & & Is & & \\
\hline layout & 40 & man/day & & \\
\hline
\end{tabular}


CASE 8

\begin{tabular}{|c|c|c|c|c|}
\hline \multicolumn{2}{|c|}{ SOIL NAILING } & \multirow[b]{2}{*}{ Each } & \multirow[b]{2}{*}{ Length } & \multirow[b]{2}{*}{ Total length } \\
\hline & & & & \\
\hline \multirow[t]{3}{*}{ \#8 rebar } & $1 \mathrm{st}$ & 31 & 25.00 & 775 \\
\hline & 2 nd & 30 & 24.00 & 720 \\
\hline & $3 \mathrm{rd}$ & 29 & 22.50 & 653 \\
\hline \multirow[t]{6}{*}{ part A } & 4 th & 28 & 21.00 & 588 \\
\hline & 5 th & 27 & 20.00 & 540 \\
\hline & & $=======$ & & $=======$ \\
\hline & & 145 & & $3,275.50$ \\
\hline & & & & \\
\hline & & Each & Length & Total length \\
\hline \multirow[t]{3}{*}{ \#8 rebar } & $1 \mathrm{st}$ & 63 & 25.00 & 1,575 \\
\hline & 2 nd & 63 & 24.00 & 1,512 \\
\hline & $3 \mathrm{rd}$ & 63 & 22.50 & 1,418 \\
\hline \multirow[t]{6}{*}{ part B } & 4 th & 62 & 21.00 & 1,302 \\
\hline & 5 th & 61 & 20.00 & 1,220 \\
\hline & & $==== \pm==$ & & $======$ \\
\hline & & 312 & & $7,026.50$ \\
\hline & & & & \\
\hline & & Each & Length & Total length \\
\hline \multirow[t]{5}{*}{ part C } & $1 \mathrm{st}$ & 20 & 12.00 & 240 \\
\hline & 2 nd & 19 & 11.00 & 209 \\
\hline & $3 \mathrm{rd}$ & 18 & 10.00 & 180 \\
\hline & & $== \pm====$ & & $=======$ \\
\hline & & 57 & & 629.00 \\
\hline \#4 wales & 10,264 & $\mathrm{ft}$ & & \\
\hline & & & & \\
\hline $\begin{array}{r}6 \times 6 \text { wire } \\
\text { mesh }\end{array}$ & 13,234 & sqft & & \\
\hline 22 "gunnite & 13,234 & sqft & 161.75 & cy \\
\hline no. of nails & 514 & & & \\
\hline
\end{tabular}




\section{CASE 9}

\begin{tabular}{|c|c|c|c|c|c|c|c|c|}
\hline \\
\hline \multicolumn{9}{|c|}{\begin{tabular}{c|c}
\multicolumn{2}{c}{ CONVENTIONAL } \\
AREA $=$ & 8,514
\end{tabular}} \\
\hline & & & & $\begin{array}{c}\mathrm{HP} \\
12 \times 53\end{array}$ & 35 & 28 & 980.00 & \\
\hline & & & & $\begin{array}{c}\mathrm{HP} \\
12 \times 53\end{array}$ & 30 & 2 & 60.00 & \\
\hline TIE BACK & 57 & Each & $\begin{array}{l}1.25^{\prime \prime} \\
\text { rebar }\end{array}$ & & & & & \\
\hline & & & & & & & & \\
\hline $\begin{array}{r}\text { beam } \\
\text { penetration }=\end{array}$ & 57 & Each & & & & & & \\
\hline & & & & pound & & $====$ & $======$ & $=======$ \\
\hline & & & & 53 & & 30.00 & $1,040.0$ & $55,120.00$ \\
\hline
\end{tabular}

\begin{tabular}{|c|c|c|c|c|c|c|c|c|c|}
\hline \multicolumn{3}{|c|}{ SOIL NAILING } & \multirow[b]{2}{*}{ Length } & \multirow[b]{2}{*}{$\begin{array}{l}\text { Total } \\
\text { length }\end{array}$} & & & & & \\
\hline & & Each & & & & & & & \\
\hline $\begin{array}{r}\# 8 \\
\text { rebar }\end{array}$ & $1 \mathrm{st}$ & 51 & 28.00 & 1,428 & & & & & \\
\hline & 2 nd & 50 & 27.50 & 1,375 & & & & & \\
\hline & $3 \mathrm{rd}$ & 49 & 27.00 & 1,323 & $A=$ & 8,514 & Sqft & $\begin{array}{c}\text { Avg } \\
\text { length= }\end{array}$ & 26.50 \\
\hline & 4 th & 48 & 26.00 & 1,248 & & & & & \\
\hline & 5 th & 47 & 25.50 & 1,199 & & & & & \\
\hline & 6 th & 46 & 25.00 & 1,150 & & & & & \\
\hline & & $=======$ & & $=======$ & & & & & \\
\hline & & 291.00 & & $7,722.50$ & & & & & \\
\hline & & & & & & & & & \\
\hline & & & & & & & & & \\
\hline $\begin{array}{r}\# 4 \\
\text { walers }\end{array}$ & 5,808 & $\mathrm{ft}$ & & & & & & & \\
\hline & & & & & & & & & \\
\hline $\begin{array}{r}6 \times 6 \\
\text { wire } \\
\text { mesh }\end{array}$ & 8,514 & sqft & & & & & & & \\
\hline $\begin{array}{r}22^{\prime \prime} \\
\text { gunnite }\end{array}$ & 8,514 & sqft & 104.06 & cy & & & & & \\
\hline $\begin{array}{r}\text { no. of } \\
\text { nails }\end{array}$ & 291.00 & & & & & & & & \\
\hline
\end{tabular}




\section{CASE 9}

\begin{tabular}{|r|c|l|l|l|}
\hline SOIL NAILING & & & & \\
\hline total linear ft of nails drill & 7,723 & $\mathrm{ft}$ & & \\
\hline \# 8 total linear $\mathrm{ft}$ of nails steel & 7,723 & $\mathrm{ft}$ & & \\
\hline no. of soil nails & 291.00 & each & & \\
\hline no. of soil nails plates \& nuts & 291 & each & & \\
\hline \#4 wales & 5,808 & lft & & \\
\hline $6 \times 6$ wire mesh & $8,514.00$ & sqft & & \\
\hline shotcrete or gunnite 2 2" & $8,514.00$ & sqft & & \\
\hline layout & 40 & man/day & & \\
\hline mob/demob & & ls & & \\
\hline OTA & & ls & & \\
\hline
\end{tabular}


CASE 10

\begin{tabular}{|c|c|c|c|c|c|c|c|c|}
\hline \multicolumn{9}{|c|}{ CONVENTIONAL } \\
\hline & & & & & & & & \\
\hline \multirow[t]{3}{*}{ AREA $=$} & 11,940 & $\mathrm{Sq} \mathrm{ft}$ & & & FT & Each & LFT & Total steel \# \\
\hline & & & & $\begin{array}{c}\mathrm{HP} \\
12 \times 53\end{array}$ & 15 & 1 & 15.00 & \\
\hline & & & & & 20 & 1 & 20.00 & \\
\hline \multirow[t]{5}{*}{$\begin{array}{c}\text { TIE } \\
\text { BACK }\end{array}$} & 46 & Each & $\begin{array}{l}1.25 " \\
\text { rebar }\end{array}$ & & 25 & 2 & 50.00 & \\
\hline & & & & & 32 & 46 & $1,472.0$ & \\
\hline & & & & & & & & \\
\hline & & & & pound & & $====$ & $=====$ & $=== \pm====$ \\
\hline & & & & 53 & & 50.0 & $1,557.0$ & $82,521.00$ \\
\hline WALES & 46 & Each & $10 \mathrm{FT}$ & & & & & \\
\hline & & & & & & & & \\
\hline
\end{tabular}

\begin{tabular}{|c|c|c|c|c|c|c|c|c|c|}
\hline \multicolumn{10}{|c|}{ SOIL NAILING } \\
\hline & & Each & Length & $\begin{array}{l}\text { Total } \\
\text { length }\end{array}$ & & & & & \\
\hline \multirow[t]{8}{*}{$\begin{array}{r}\# 8 \\
\text { rebar }\end{array}$} & $1 \mathrm{st}$ & 84 & 28.00 & 2,352 & & & & & \\
\hline & 2 nd & 82 & 27.50 & 2,255 & & & & & \\
\hline & $3 \mathrm{rd}$ & 80 & 27.00 & 2,160 & $A=$ & 11,940 & Sqft & $\begin{array}{c}\text { Avg } \\
\text { length= }\end{array}$ & 26.50 \\
\hline & 4 th & 78 & 26.00 & 2,028 & & & & & \\
\hline & 5 th & 76 & 25.50 & 1,938 & & & & & \\
\hline & 6 th & 74 & 25.00 & 1,850 & & & & & \\
\hline & & $= \pm== \pm==$ & & $=======$ & & & & & \\
\hline & & 474.00 & & $12,583.00$ & & & & & \\
\hline & & & & & & & & & \\
\hline & & & & & & & & & \\
\hline $\begin{array}{r}\# 4 \\
\text { walers }\end{array}$ & 9,552 & $\overline{\mathrm{ft}}$ & & & & & & & \\
\hline & & & & & & & & & \\
\hline $\begin{array}{r}6 \times 6 \\
\text { wire } \\
\text { mesh }\end{array}$ & 11,940 & sqft & & & & & & & \\
\hline $\begin{array}{r}2,2 " \\
\text { gunnite }\end{array}$ & 11,940 & sqft & 145.93 & cy & & & & & \\
\hline $\begin{array}{r}\text { no. of } \\
\text { nails }\end{array}$ & 474.00 & & & & & & & & \\
\hline
\end{tabular}




\section{CASE 10}

\begin{tabular}{|c|c|c|}
\hline \multicolumn{3}{|l|}{ SOIL NAILING } \\
\hline total linear $\mathrm{ft}$ of nails drill & 12,583 & $\mathrm{ft}$ \\
\hline $\begin{array}{r}\text { \# } 8 \text { total linear } \mathrm{ft} \text { of nails } \\
\text { steel }\end{array}$ & 12,583 & $\mathrm{ft}$ \\
\hline no. of soil nails & 474.00 & each \\
\hline $\begin{array}{r}\text { no. of soil nails plates \& } \\
\text { nuts }\end{array}$ & 474 & each \\
\hline \#4 wales & 9,552 & Ift \\
\hline $6 \times 6$ wire mesh & $11,940.00$ & sqft \\
\hline shotcrete or gunnite $22^{\prime \prime}$ & $11,940.00$ & sqft \\
\hline design & & Is \\
\hline layout & 40 & man/day \\
\hline mob/demob & & Is \\
\hline OTA & & Is \\
\hline
\end{tabular}




\section{CASE 11}

\begin{tabular}{|c|c|c|c|c|c|c|c|c|}
\hline \multicolumn{9}{|c|}{ CONVENTIONAL } \\
\hline AREA $=$ & 6,218 & $\mathrm{Sq} \mathrm{ft}$ & & & FT & Each & LFT & total steel \# \\
\hline & & & & $\begin{array}{c}\mathrm{HP} \\
10 \times 42\end{array}$ & 24 & 21 & 504.00 & \\
\hline \multirow[t]{2}{*}{$\begin{array}{c}\text { TIE } \\
\text { BACK }\end{array}$} & 35 & Each & $\begin{array}{l}1 " \\
\text { rebar }\end{array}$ & $\begin{array}{c}\mathrm{HP} \\
10 \times 42\end{array}$ & 19.5 & 16 & 312.00 & \\
\hline & & & & $\begin{array}{c}\mathrm{HP} \\
10 \times 42\end{array}$ & 16 & 12 & 192.00 & \\
\hline \multirow[t]{5}{*}{ WALES } & 25 & Each & $\begin{array}{l}10 \\
\text { FT }\end{array}$ & & & & & \\
\hline & & & & & & & & \\
\hline & & & & pound & & $===$ & $====$ & $========$ \\
\hline & & & & 42 & & 49.00 & $1,008.0$ & $42,336.00$ \\
\hline & & & & & & & & \\
\hline
\end{tabular}

\begin{tabular}{|c|c|c|c|c|c|c|c|c|c|}
\hline \multicolumn{2}{|c|}{ SOIL NAILING } & Each & $\underline{\text { Length }}$ & $\begin{array}{c}\text { Total } \\
\text { length }\end{array}$ & & & & & \\
\hline \#8 rebar & $1 \mathrm{st}$ & 74 & 15.00 & 1,110 & & & & & \\
\hline & $2 \mathrm{nd}$ & 72 & 14.00 & 1,008 & $\mathrm{~A}=$ & 6,218 & Sqft & $\begin{array}{c}\text { Avg } \\
\text { length }\end{array}$ & 13.50 \\
\hline & $3 \mathrm{rd}$ & 71 & 13.00 & 923 & & & & & \\
\hline & $4 \mathrm{th}$ & 33 & 12.00 & 396 & & & & & \\
\hline & & $======$ & & $======$ & & & & & \\
\hline & & 250.00 & & $3,437.00$ & & & & & \\
\hline & & & & & & & & & \\
\hline & & & & & & & & & \\
\hline \#4 wales & 3,368 & $\mathrm{ft}$ & & & & & & & \\
\hline $\begin{array}{c}6 \times 6 \text { wire } \\
\text { mesh }\end{array}$ & 6,218 & sqft & & & & & & & \\
\hline $\begin{array}{c}2,2 " \\
\text { gunnite }\end{array}$ & 6,218 & sqft & 76.00 & cy & & & & & \\
\hline & & & & & & & & & \\
\hline $\begin{array}{c}\text { no. of } \\
\text { nails }\end{array}$ & 250.00 & & & & & & & & \\
\hline
\end{tabular}




\section{CASE 11}

\begin{tabular}{|r|c|l|l|}
\hline \multicolumn{4}{|l|}{ SOIL NAILING } \\
\hline total linear ft of nails drill & 3,437 & $\mathrm{ft}$ & \\
\hline \# total linear ft of nails steel & 3,437 & $\mathrm{ft}$ & \\
\hline no. of soil nails & 250.00 & each & \\
\hline no. of soil nails plates \& nuts & 250 & each & \\
\hline \#4 wales & 3,368 & Ift & \\
\hline sx6 wire mesh & $6,218.00$ & sqft & \\
\hline design & & ls & \\
\hline layout & 40 & man/day & \\
\hline mob/demob & & Is & \\
\hline OTA & & ls & \\
\hline
\end{tabular}


CASE 12

\begin{tabular}{|c|c|c|c|c|c|c|c|c|c|}
\hline \multicolumn{10}{|c|}{ CONVENTIONAL } \\
\hline & & & & & & & & & \\
\hline & & & & & & & & & \\
\hline \multirow[t]{2}{*}{ AREA= } & 14,710 & $\mathrm{Sq} \mathrm{ft}$ & & & & FT & Each & Total ft & Total steel \# \\
\hline & & & & $\begin{array}{c}\mathrm{HP} \\
10 \times 42\end{array}$ & 42 & 15 & 1 & 15.00 & 630.00 \\
\hline $\begin{array}{c}\text { TIE } \\
\text { BACK }\end{array}$ & 24 & Each & $\begin{array}{c}1 " \\
\text { rebar }\end{array}$ & $\begin{array}{c}\mathrm{HP} \\
10 \times 42\end{array}$ & 42 & 20 & 2 & 40.00 & $1,680.00$ \\
\hline $\begin{array}{c}\text { TIE } \\
\text { BACK }\end{array}$ & 42 & Each & $\begin{array}{l}1.25 " \\
\text { rebar }\end{array}$ & $\begin{array}{c}\mathrm{HP} \\
12 \times 53\end{array}$ & 53 & 32 & 21 & 672.00 & $35,616.00$ \\
\hline \multirow[t]{3}{*}{$\begin{array}{c}\text { TIE } \\
\text { BACK }\end{array}$} & 24 & Each & $\begin{array}{l}1.25 " \\
\text { rebar }\end{array}$ & $\begin{array}{c}\mathrm{HP} \\
12 \times 53\end{array}$ & 53 & 34 & 25 & 850.00 & $45,050.00$ \\
\hline & & & & $\begin{array}{c}\mathrm{HP} \\
12 \times 53\end{array}$ & 53 & 28.5 & 23 & 655.50 & $34,741.50$ \\
\hline & & & & & & & $====$ & $=====$ & $========$ \\
\hline WALES & 45 & Each & $10 \mathrm{FT}$ & & & & 72.00 & $2,232.5$ & $117,717.50$ \\
\hline & & & & & & & & & \\
\hline & & & & & & & & & \\
\hline
\end{tabular}

\begin{tabular}{|r|c|l|l|l|}
\hline SOIL NAILING & & & & \\
\hline total linear ft of nails drill & 12,389 & $\mathrm{ft}$ & & \\
\hline \# 8 total linear ft of nails steel & 12,389 & $\mathrm{ft}$ & & \\
\hline no. of soil nails & 579.0 & each & & \\
\hline no. of soil nails plates \& nuts & 579 & each & & \\
\hline$\# 4$ wales & 11,592 & lft & & \\
\hline 6x6 wire mesh & $14,710.00$ & sqft & & \\
\hline shotcrete or gunnite 2 2" & $14,710.00$ & sqft & & \\
\hline design & & is & & \\
\hline layout & 40 & man/day & & \\
\hline mob/demob & & is & & \\
\hline OTA & & is & & \\
\hline
\end{tabular}


CASE 12

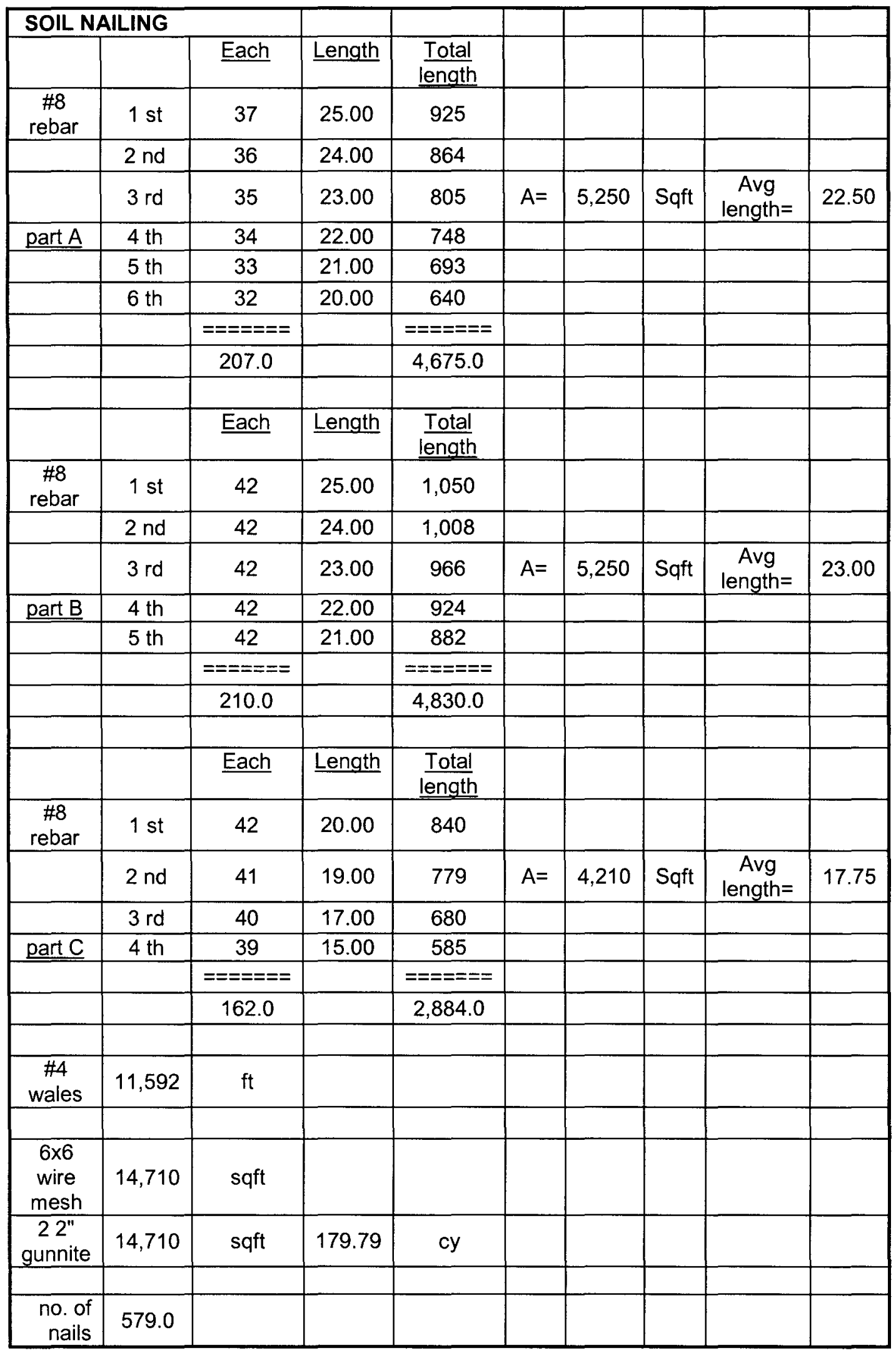


CASE 13

CONVENTIONAL

\begin{tabular}{|c|c|c|c|c|c|c|c|c|c|c|}
\hline & & & & & & & & & & \\
\hline AREA $=$ & 2,765 & Sq ft & & & & & FT & Each & Total, ft & Total steel \# \\
\hline & & & & & $\begin{array}{c}\text { HP } \\
10 \times 42\end{array}$ & 42 & 20 & 25 & 500.00 & $21,000.00$ \\
\hline $\begin{array}{c}\text { TIE } \\
\text { BACK }\end{array}$ & 12 & Each & $\begin{array}{c}1^{\prime \prime} \\
\text { rebar }\end{array}$ & & & & & & \\
\hline & & & & & & & & & & \\
\hline & & & & & & & & & & \\
\hline & & & & & & & & & & \\
\hline & & & & & & & & 25.00 & 500.00 & $21,000.00$ \\
\hline WALES & 12 & Each & $10 \mathrm{FT}$ & & & & & & & \\
\hline & & & & & & & & & & \\
\hline
\end{tabular}

\begin{tabular}{|c|c|c|c|c|c|}
\hline \multicolumn{6}{|l|}{ SOIL NAILING } \\
\hline & & each & length & total length & \\
\hline \multirow[t]{5}{*}{ \#8 rebar } & $1 \mathrm{st}$ & 35 & 12.00 & 420 & \\
\hline & $2 \mathrm{nd}$ & 35 & 11.00 & 385 & \\
\hline & 3 rd & 34 & 10.00 & 340 & \\
\hline & & $=======$ & & $=======$ & \\
\hline & & 104 & & 1145 & \\
\hline \#4 wales & 2160 & $f t$ & & & \\
\hline \#4 wales & 2,460 & II & & & \\
\hline $6 \times 6$ wire mesh & 2,765 & sqft & & & \\
\hline $22^{\prime \prime}$ gunnite & 2,765 & sqft & 33.79 & cy & \\
\hline no. of nails & 104 & & & & \\
\hline & & & & & \\
\hline
\end{tabular}




\section{CASE 13}

\begin{tabular}{|r|c|l|l|}
\hline \multicolumn{2}{|l|}{ SOIL NAILING } \\
\hline total linear ft of nails drill & 1,145 & $\mathrm{ft}$ & \\
\hline \# 8 total linear $\mathrm{ft}$ of nails steel & 1,145 & $\mathrm{ft}$ & \\
\hline no. of soil nails & 104 & each & \\
\hline no. of soil nails plates \& nuts & 104 & each & \\
\hline \#4 wales & 2,460 & Ift & \\
\hline 6x6 wire mesh & $\begin{array}{c}2,765.0 \\
0\end{array}$ & sqft & \\
\hline shotcrete or gunnite 2 2" & $2,765.0$ & sqft & \\
& 0 & & \\
\hline design & & Is & \\
\hline layout & 40 & man/day & \\
\hline mob/demob & & Is & \\
\hline OTA & & is & \\
\hline & & & \\
\hline
\end{tabular}




\section{CASE 14}

\begin{tabular}{|c|c|c|c|c|c|c|c|c|c|}
\hline \multicolumn{10}{|c|}{ CONVENTIONAL } \\
\hline \multirow{3}{*}{ AREA $=$} & & Soff & & & & & & & \\
\hline & 4,100 & $\mathrm{Sq} \mathrm{tt}$ & & & & FT & Each & Total ft & TTotal steel \# \\
\hline & & & & $\begin{array}{c}\mathrm{HP} \\
10 \times 42\end{array}$ & 42 & 15 & 1 & 15.00 & 630.00 \\
\hline $\begin{array}{c}\text { TIE } \\
\text { BACK }\end{array}$ & 5 & Each & $\begin{array}{c}1 " \\
\text { rebar }\end{array}$ & $\begin{array}{c}\mathrm{HP} \\
10 \times 42\end{array}$ & 42 & 20 & 2 & 40.00 & $1,680.00$ \\
\hline $\begin{array}{c}\text { TIE } \\
\text { BACK }\end{array}$ & 16 & Each & $\begin{array}{l}1.25 " \\
\text { rebar }\end{array}$ & $\begin{array}{c}\mathrm{HP} \\
10 \times 42\end{array}$ & 42 & 30 & 16 & 480.00 & $20,160.00$ \\
\hline \multirow[t]{4}{*}{$\begin{array}{c}\text { TIE } \\
\text { BACK } \\
\end{array}$} & 0 & Each & $\begin{array}{l}1.25 " \\
\text { rebar }\end{array}$ & $\begin{array}{c}\mathrm{HP} \\
10 \times 42\end{array}$ & 42 & 25 & 1 & 25.00 & $1,050.00$ \\
\hline & & & & $\begin{array}{c}\mathrm{HP} \\
10 \times 42\end{array}$ & 42 & 18.5 & 9 & 166.50 & $6,993.00$ \\
\hline & & & & & & & $======$ & $======$ & $======$ \\
\hline & & & & & & & 29.00 & 726.50 & $30,513.00$ \\
\hline WALES & 13 & $\mathrm{EACH}$ & $10 \mathrm{FT}$ & & & & & & \\
\hline & & & & & & & & & \\
\hline
\end{tabular}

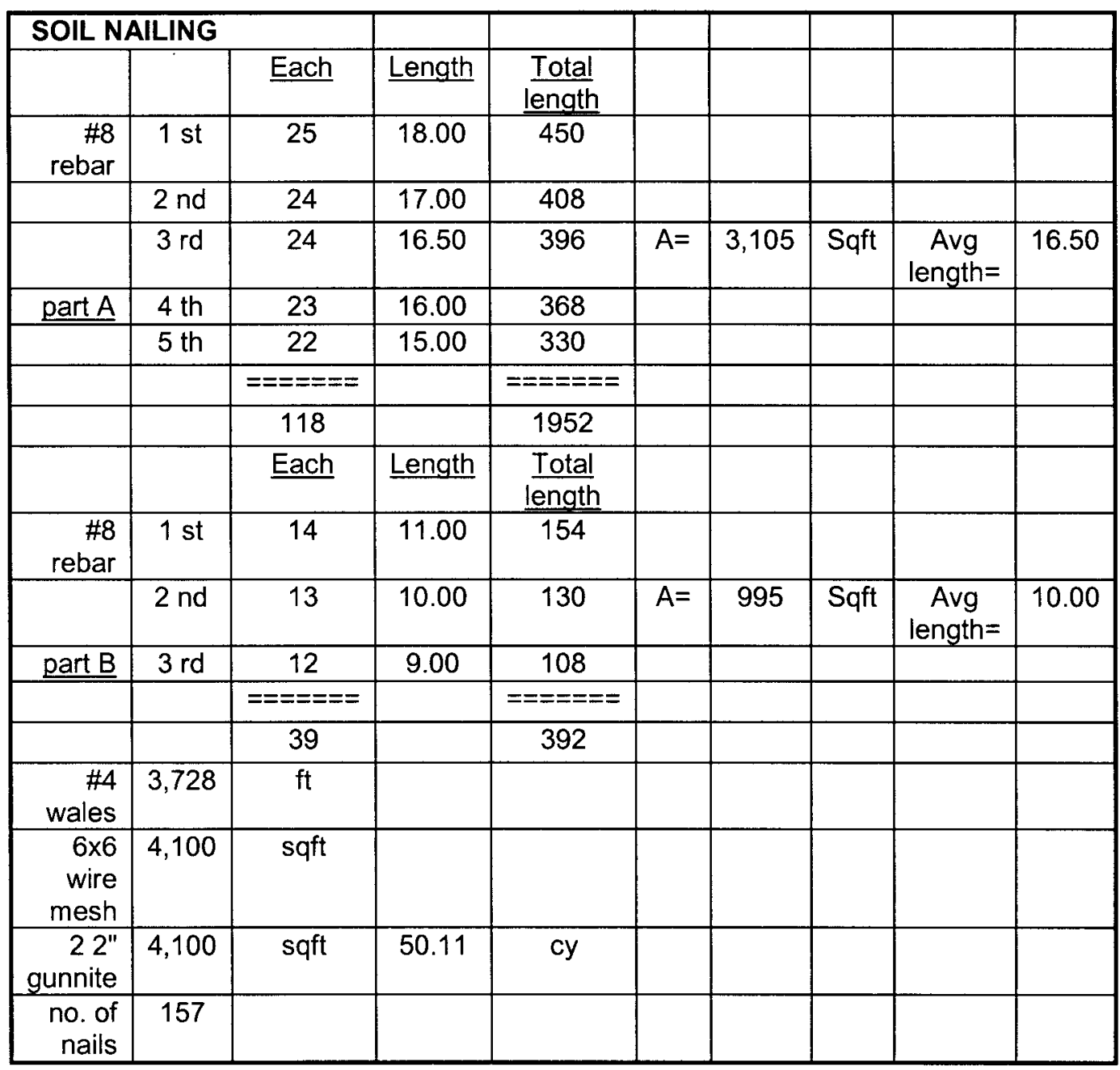




\section{CASE 14}

\begin{tabular}{|r|c|l|l|l|}
\hline & & & & \\
\hline SOIL NAILING & & & & \\
\hline & & & & \\
\hline total linear ft of nails drill & 2,344 & $\mathrm{ft}$ & & \\
\hline $\begin{array}{r}\text { \# } 8 \text { total linear ft of nails } \\
\text { steel }\end{array}$ & 2,344 & $\mathrm{ft}$ & & \\
\hline no. of soil nails & 157 & each & & \\
\hline $\begin{array}{r}\text { no. of soil nails plates \& } \\
\text { nuts }\end{array}$ & 157 & each & & \\
\hline \#4 wales & 3,728 & lft & & \\
\hline 6x6 wire mesh & $4,100.00$ & sqft & & \\
\hline shotcrete or gunnite 2 2" & $4,100.00$ & sqft & & \\
\hline design & & Is & & \\
\hline layout & 40 & man/day & & \\
\hline mob/demob & & ls & & \\
\hline OTA & & Is & & \\
\hline
\end{tabular}




\section{CASE 15}

\section{CONVENTIONAL}

\begin{tabular}{|r|c|c|c|c|c|c|c|c|c|c|}
\hline & & & & & & & & & & \\
\hline AREA $=$ & 71,820 & Sq ft & & & & & FT & Each & Total ft & $\begin{array}{c}\text { Total steel } \\
\#\end{array}$ \\
\hline & & & & $\begin{array}{c}\text { HP } \\
12 \times 53\end{array}$ & 53 & 44 & 202 & $8,888.00$ & $471,064.00$ \\
\hline TIE BACK & 808 & Each & $\begin{array}{c}1 " \\
\text { rebar }\end{array}$ & & & & & & & \\
\hline $\begin{array}{r}\text { beam } \\
\text { penetration }\end{array}$ & 808 & Each & & & & & & & & \\
\hline
\end{tabular}

\begin{tabular}{|c|c|c|c|c|c|c|c|c|c|}
\hline \multicolumn{3}{|c|}{ SOIL NAILING } & \multirow[b]{2}{*}{ Length } & \multirow[b]{2}{*}{$\begin{array}{l}\text { Total } \\
\text { length }\end{array}$} & & & & & \\
\hline & & Each & & & & & & & \\
\hline $\begin{array}{r}\# 8 \\
\text { rebar }\end{array}$ & $1 \mathrm{st}$ & 286 & 35.00 & 10,010 & & & & & \\
\hline & $2 n d$ & 286 & 34.50 & 9,867 & & & & & \\
\hline & $3 \mathrm{rd}$ & 286 & 34.00 & 9,724 & & & & & \\
\hline & 4 th & 286 & 33.00 & 9,438 & $A=$ & 71,820 & Sqft & $\begin{array}{c}\text { Avg } \\
\text { length }=\end{array}$ & 32.50 \\
\hline & 5 th & 286 & 32.50 & 9,295 & & & & & \\
\hline & 6 th & 286 & 32.00 & 9,152 & & & & & \\
\hline & 7 th & 286 & 31.50 & 9,009 & & & & & \\
\hline & 8 th & 286 & 30.50 & 8,723 & & & & & \\
\hline & 9 th & 286 & 30.00 & 8,580 & & & & & \\
\hline & & $===== \pm=$ & & $=======$ & & & & & \\
\hline & & $1,716.0$ & & $57,486.0$ & & & & & \\
\hline & & & & & & & & & \\
\hline $\begin{array}{r}\# 4 \\
\text { wales } \\
\end{array}$ & 61,596 & $\mathrm{ft}$ & & & & & & & \\
\hline & & & & & & & & & \\
\hline $\begin{array}{r}6 \times 6 \\
\text { wire } \\
\text { mesh } \\
\end{array}$ & 71,820 & sqft & & & & & & & \\
\hline $\begin{array}{r}22^{\prime \prime} \\
\text { gunnite }\end{array}$ & 71,820 & sqft & 877.80 & cy & & & & & \\
\hline $\begin{array}{r}\text { no. of } \\
\text { nails }\end{array}$ & $1,716.0$ & & & & & & & & \\
\hline
\end{tabular}




\section{CASE 15}

\begin{tabular}{|c|c|c|}
\hline SOIL NAILING & & \\
\hline total linear $\mathrm{ft}$ of nails drill & 57,486 & $\mathrm{ft}$ \\
\hline $\begin{array}{r}\# 8 \text { total linear } \mathrm{ft} \text { of nails } \\
\text { steel }\end{array}$ & 57,486 & $\mathrm{ft}$ \\
\hline no. of soil nails & $1,716.0$ & each \\
\hline $\begin{array}{r}\text { no. of soil nails plates \& } \\
\text { nuts }\end{array}$ & 1716 & each \\
\hline \#4 wales & 61,596 & $\mathrm{Ift}$ \\
\hline $6 \times 6$ wire mesh & $71,820.00$ & sqft \\
\hline shotcrete or qunnite 2 2" & $71,820.00$ & sqft \\
\hline pins to hold mesh & & \\
\hline design & & Is \\
\hline layout & 40 & man/day \\
\hline $\mathrm{mob} / \mathrm{demob}$ & & Is \\
\hline OTA & & Is \\
\hline
\end{tabular}


Appendix E: Cost for Conventional Systems 


\section{FOR TIEBACK Anchor}

\section{CASE 1}

use proof load @ 120\% of DL

1 inch

$11 / 4$ inch

3.1

$13 / 8$ inch

5.7

bonded zone

$25 \mathrm{ft}$ FOR 1 " BAR

$30 \mathrm{ft}$ FOR 1.25" BAR

8 bag

10 bag

\begin{tabular}{|c|c|c|c|}
\hline $\begin{array}{r}11 / 4 \text { inch bar= } \\
\text { nut + plate = }\end{array}$ & $(3.85+.14) \times 1.06=$ & $\begin{array}{l}4.23 \\
34.8\end{array}$ & $\begin{array}{l}\text { \$/ft } \\
\$ / \text { each }\end{array}$ \\
\hline \multicolumn{4}{|l|}{$40^{\prime}$ long } \\
\hline \multirow{2}{*}{$\begin{array}{r}\text { tieback labor } 6 \mathrm{mh} / \text { tie }= \\
\text { cement }=\end{array}$} & $1.5 \times 192.5=$ & 288.75 & \\
\hline & 10 bags $\times 10=$ & 100 & \\
\hline for tieback length of & 43 & \multirow{2}{*}{\multicolumn{2}{|c|}{21.66}} \\
\hline labor for this length vs $40^{\prime}=$ & 0.075 & & \\
\hline \multirow{3}{*}{$\begin{array}{r}\text { bar length for tieback }= \\
\text { tail }=\end{array}$} & 43 & \\
\hline & 3 & \multicolumn{2}{|l|}{ ft } \\
\hline & 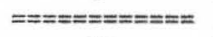 & & \\
\hline total tie length $=$ & 46 & \multicolumn{2}{|l|}{$\mathrm{ft}$} \\
\hline for $1^{\text {t }}$ bar= & & \multirow{2}{*}{$\begin{array}{r}0.00 \\
194.55\end{array}$} & \multirow{2}{*}{$\begin{array}{l}\text { pick one of them } \\
\text { pick one of them }\end{array}$} \\
\hline for $11 / 4^{\prime \prime}$ bar= & & & \\
\hline Nut and Plate+tax $=$ & \multirow{2}{*}{\multicolumn{2}{|c|}{$\begin{array}{r}36.89 \\
100.00\end{array}$}} & \multirow{2}{*}{ \$/each } \\
\hline test $/$ stress load $=$ & & & \\
\hline Tieback Equip. and $F O G=$ & \multicolumn{2}{|r|}{225.00} & $\$$ /each \\
\hline \multirow[t]{2}{*}{ Grout Equip. and Air comp.= } & \multicolumn{3}{|c|}{$===== \pm== \pm==$} \\
\hline & tieback cost $=$ & $1,027.00$ & \$leach \\
\hline
\end{tabular}

Beam at $8.5^{\circ} \mathrm{c}-\mathrm{C}$

driving cost=

$\mathrm{H}$ bearn length $=$

$\mathrm{H}$ beam $=$

for 53 beam =

for 42 beam=

o. of tie backs=

\section{Install lagging \\ top $8^{\prime}=$ \\ below $8^{\prime}=$ \\ Production rate $=$ Job sft= \\ How many days= OTA $=6 \times 100 \times$ days $=$}

Waler $10^{\circ}$

Waler $20^{\circ}$

bearn penetration $10^{\prime \prime}$ beam= or $12^{\prime \prime}$ beam=

$\begin{array}{cl}10 & \$ / f t \\ 32.5 & \mathrm{ft} \\ 0.52 & \text { Lftpound } \\ 895.70 & \text { pick one of them } \\ 709.80 & \text { pick one of them }\end{array}$

$4.1 \quad \$ /$ sft

$6.76 \$ /$ sft

$1,200.00$ sft/day

$12,560.00$ sft

11.00 day

$6,600.00 \$ / j o b$

550 \$/each or beam penetration

650 \$leach or beam penetration

100.00 pick one of them , or use Waler

125.00 pick one of them or use Waler

\footnotetext{
3,500 \$ more than soilnailig out of town

1,000 \$ more than soilnailig in town
} 
CASE 1

SHEETING COST

능

driving in earth
steel cost beam
wale $10^{\prime}$ long
wale $20^{\prime}$ long
wale $10^{\prime}$ uninstall
wale $20^{\prime}$ uninstall
tieback cost
pent. throu. $10^{\prime \prime}$ beam
pent. throu. $12^{\prime \prime}$ beam
wood lagging down to 1 st tie
wood lagging below
mob/demob + shop dwg
OTA
set pile in hole

$\frac{\text { rate } \$}{10.00}$
0.52
450.00
550.00
200.00
250.00
$1,027.00$
100.00
125.00
4.10
6.76
1.00
100.00
5.00

per
$\mathrm{ft}$
$\mathrm{lb}$
ea.
ea.
ea.
ea.
ea.
ea.
ea.
sft
sft
ea.
M / DAY
\$/ft

unit
$2,084.50$
$110,478.5$
30
1
30
1
63
0
0
$5,365.00$
$7,195.00$
$10,000.00$
0
$2,084.50$

rate $x$ unit

$20,845.00$

$\$ /$ sft

$0,478.5 \quad 57,448.82$

$13,500.00 \quad 1.07$

$550.00 \quad 0.04$

$6,000.00 \quad 0.48$

$250.00 \quad 0.02$

$64,701.00 \quad 5.15$

$0.00 \quad 0.00$

$0.00 ; \quad 0.00$

$21,996.50 \quad 1.75$

$48,638.20 \quad 3.87$

$10,000.00$

$0.00 \quad 0.00$

$10,422.50 \quad 0.83$

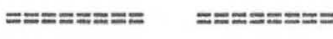

$254,352.02 \quad 20.25$

total sheeted area $=12,560.00 \mathrm{sft}$

$\cos t=\quad 20.25 \quad \$ / \mathrm{sft}$


CASE 2

SHEETING COST

driving in earth

steel cost beam

wale $10^{\prime}$ long

wale $20^{\prime}$ long

wale $10^{\prime}$ uninstall

wale $20^{\prime}$ uninstall

tieback cost

pent. throu. 10" beam

pent. throu. 12" beam

wood lagging down to 1 st tie

wood lagging below

mob/demob + shop dwg

OTA

set pile in hole

\begin{tabular}{c} 
rate $\$$ \\
\hline 10.00 \\
0.52 \\
450.00 \\
550.00 \\
200.00 \\
250.00 \\
$1,200.00$ \\
100.00 \\
125.00 \\
4.10 \\
6.76 \\
1.00 \\
100.00 \\
5.00
\end{tabular}

per
$\mathrm{ft}$
$\mathrm{lb}$
ea.
ea.
ea.
ea.
ea.
ea.
ea.
sft
sft
ea.
M DAY
\$/ft

unit
$2,856.00$
$151,368.0$
80
2
80
2
164
0
0
$5,224.0$
$17,176.0$
$10,000.00$
0
$2,856.00$

$\cos t=$

$\begin{array}{cc}\text { rate } x \text { unit } & \text { \$/sft } \\ 28,560.00 & 1.28 \\ 78,711.36 & 3.51 \\ 36,000.00 & 1.61 \\ 1,100.00 & 0.05 \\ 16,000.00 & 0.71 \\ 500.00 & 0.02 \\ 196,800.00 & 8.79 \\ 0.00 & 0.00 \\ 0.00 & 0.00 \\ 21,418.40 & 0.96 \\ 116,109.76 & 5.18 \\ 10,000.00 & 0.45 \\ 0.00 & 0.00 \\ 14,280.00 & 0.64 \\ ======== & ======== \\ 519,479.52 & 23.19\end{array}$

23.19 
CASE 3

SHEETING COST

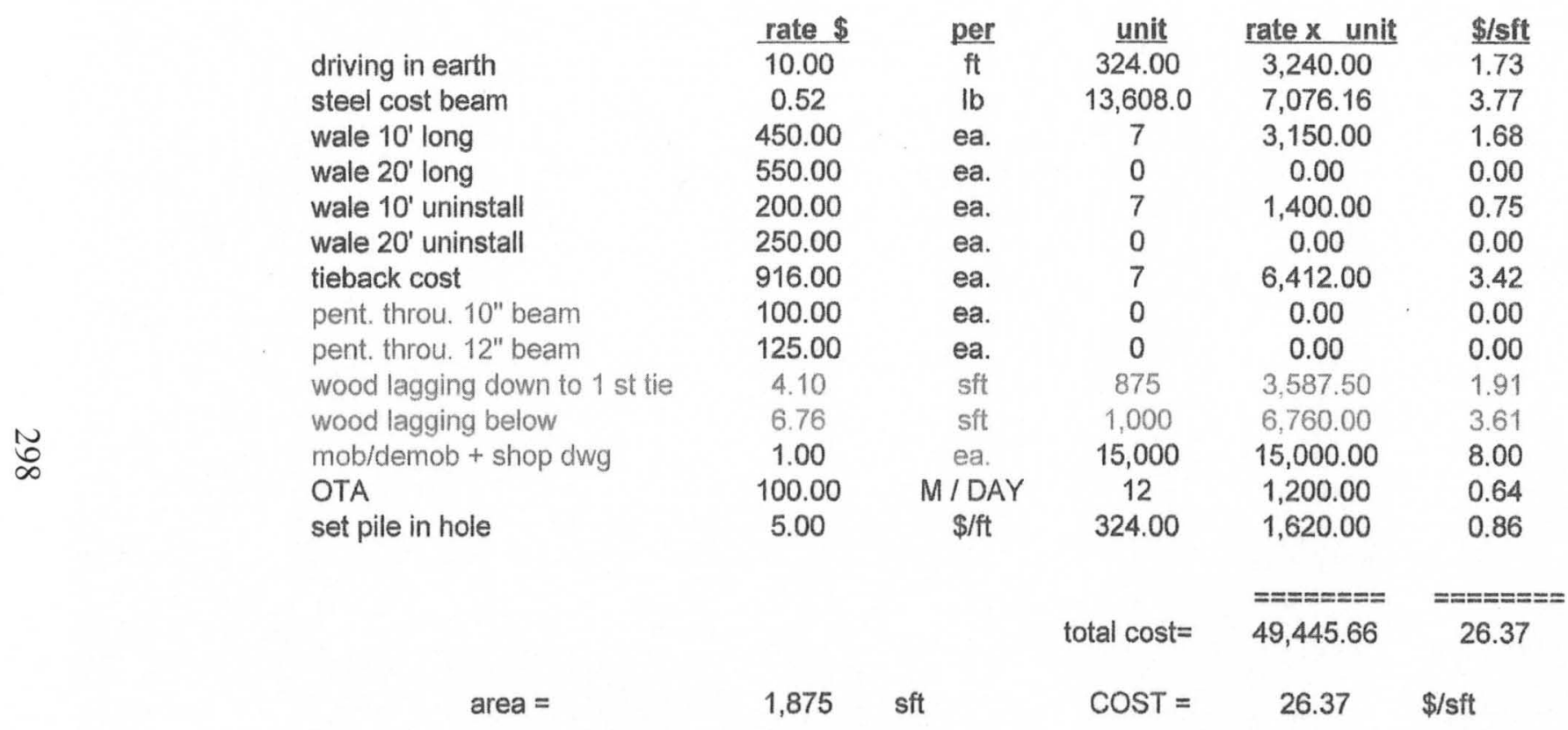


CASE 4

SHEETING COST

\begin{tabular}{c} 
rate $\$$ \\
\hline 10.00 \\
0.52 \\
450.00 \\
550.00 \\
200.00 \\
250.00 \\
$1,140.00$ \\
100.00 \\
125.00 \\
4.10 \\
6.76 \\
1.00 \\
100.00 \\
5.00
\end{tabular}

8,940

per
$\mathrm{ft}$
$\mathrm{lb}$
ea.
ea.
ea.
ea.
ea.
ea.
ea.
sft
sft
ea.
M / DAY
\$/ft

u,169.0
49,098
2
25
2
53
2,6
6,3
10,000
1,16

$1,169.00$

.

2

25

2

25

53

0

$2,640.0$

$6,300.0$

$10,000.00$

0

set pile in hole
$\$ / f t$ rate $x$ unit

$11,690.00$

$25,530.96$

900.00

$13,750.00$

400.00

$6,250.00$

$60,420.00$

0.00

0.00

$10,824.00$

$42,588.00$

$10,000.00$

0.00

$5,845.00$

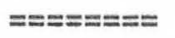

$188,197.96$

21.05
$\$ /$ sft

1.31

2.86

0.10

1.54

0.04

6.76

0.00

0.00

1.21

4.76

1.12

0.00

0.65

=x==x==е

21.05

area $=$

sft

$\cos t=$

$\$ /$ sft 
CASE 5

SHEETING COST

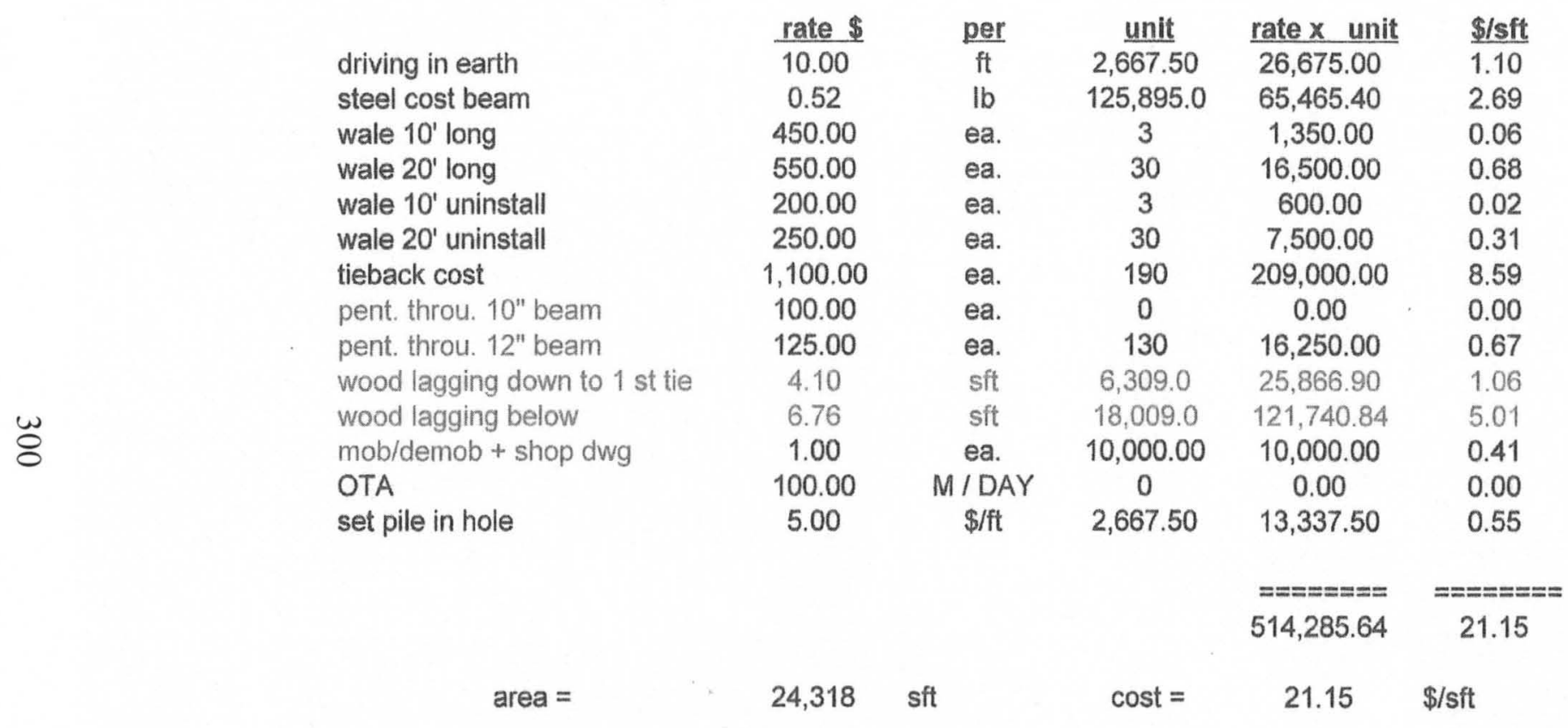


CASE 6

SHEETING COST

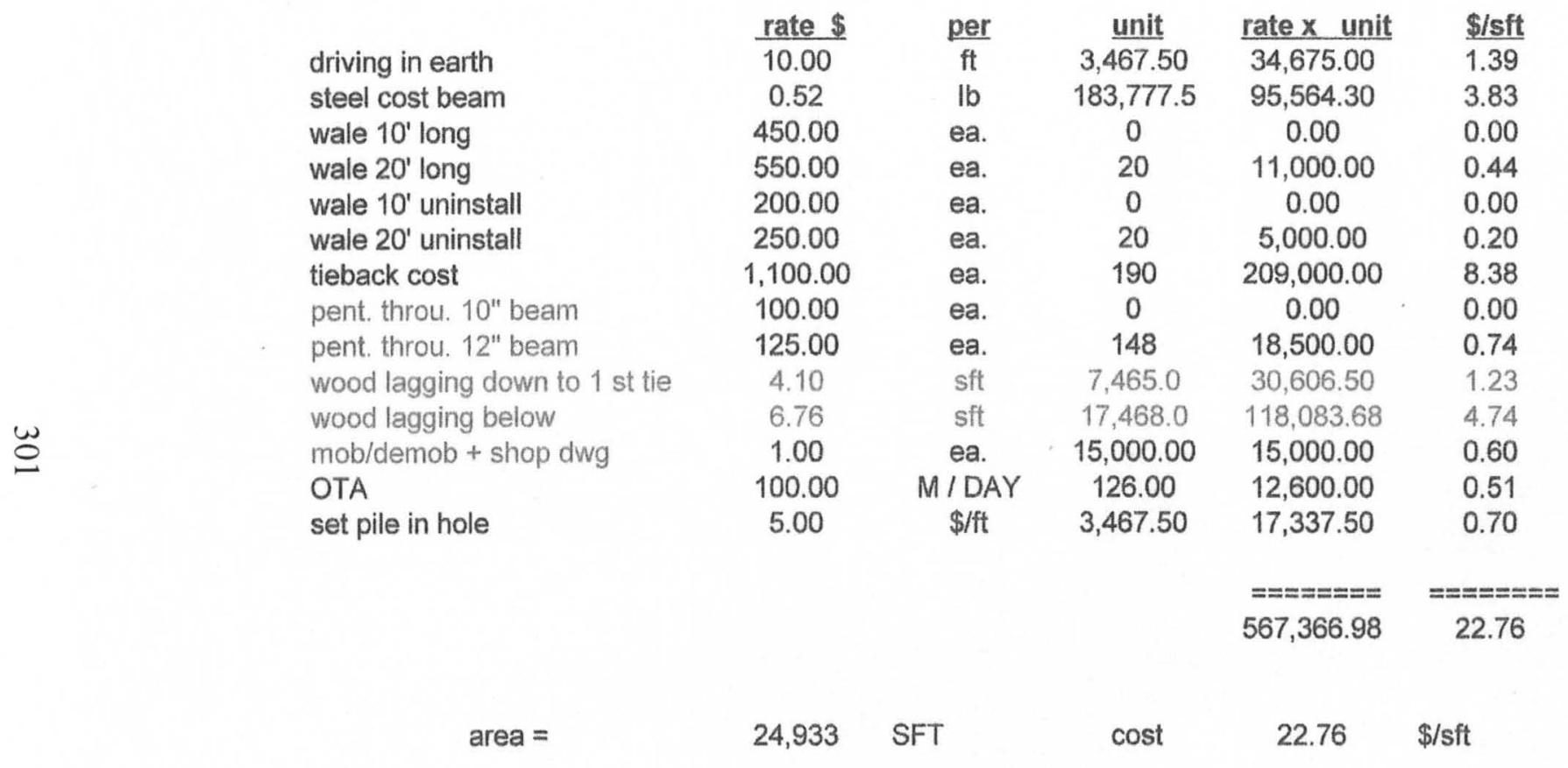


CASE 7

SHEETING COST

\begin{tabular}{|c|c|c|c|c|c|}
\hline & rate $\$$ & per & $\underline{\text { unit }}$ & rate $x$ unit & $\$ /$ sft \\
\hline driving in earth & 10.00 & $\mathrm{ft}$ & 535.00 & $5,350.00$ & 1.77 \\
\hline steel cost beam & 0.52 & Ib & $22,470.0$ & $11,684.40$ & 3.87 \\
\hline wale $10^{\prime}$ long & 450.00 & ea. & 4 & $1,800.00$ & 0.60 \\
\hline wale $20^{\prime}$ long & 550.00 & ea. & 0 & 0.00 & 0.00 \\
\hline wale 10 uninstall & 200.00 & ea. & 4 & 800.00 & 0.26 \\
\hline wale $20^{\prime}$ uninstall & 250.00 & ea. & 0 & 0.00 & 0.00 \\
\hline tieback cost & $1,027.00$ & ea. & 14 & $14,378.00$ & 4.76 \\
\hline pent. throu. $10^{\prime \prime}$ beam & 100.00 & ea. & 10 & $1,000.00$ & 0.33 \\
\hline pent. throu. $12 "$ beam & 125.00 & ea. & 0 & 0.00 & 0.00 \\
\hline wood lagging down to 1 st tie & 4.10 & sft & $1,329.0$ & $5,448.90$ & 1.80 \\
\hline wood lagging below & 6.76 & sit & $1,691.0$ & $11,431.16$ & 3.79 \\
\hline mob/demob + shop dwg & 1.00 & ea. & $15,000.00$ & $15,000.00$ & 4.97 \\
\hline OTA & 100.00 & $M / D A Y$ & 0 & 0.00 & 0.00 \\
\hline set pile in hole & 5.00 & $\$ / f t$ & 535.00 & $\begin{array}{c}2,675.00 \\
======\end{array}$ & $\begin{array}{c}0.89 \\
=======\end{array}$ \\
\hline & & & & $69,567.46$ & 23.04 \\
\hline area $=$ & 3,020 & SFT & cost $=$ & 23.04 & $\$ / s f t$ \\
\hline
\end{tabular}


CASE 8

SHEETING COST

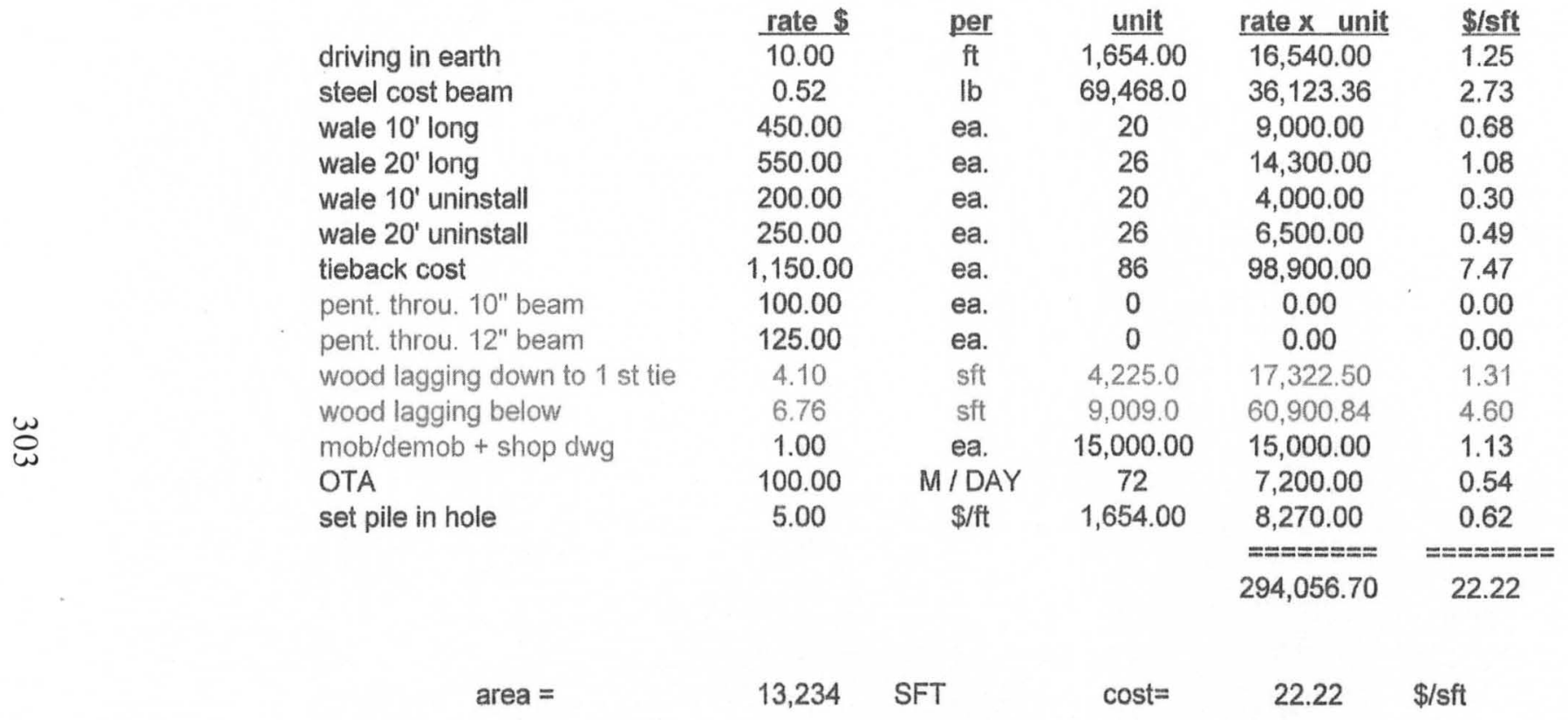


CASE 9

SHEETING COST

\begin{tabular}{|c|c|c|c|c|c|}
\hline & rate $\$$ & per & unit & rate $x$ unit & $\$$ /sft \\
\hline driving in earth & 10.00 & $\mathrm{ft}$ & $1,040.00$ & $10,400.00$ & 1.22 \\
\hline steel cost beam & 0.52 & Ib & $55,120.0$ & $28,662.40$ & 3.37 \\
\hline wale $10^{\prime}$ long & 450.00 & ea. & 0 & 0.00 & 0.00 \\
\hline wale $20^{\prime}$ long & 550.00 & ea. & 0 & 0.00 & 0.00 \\
\hline wale $10^{\prime}$ uninstall & 200.00 & ea. & 0 & 0.00 & 0.00 \\
\hline wale $20^{\prime}$ uninstall & 250.00 & ea. & 0 & 0.00 & 0.00 \\
\hline tieback cost & $1,150.00$ & ea. & 57 & $65,550.00$ & 7.70 \\
\hline pent. throu. 10" beam & 100.00 & ea. & 57 & $5,700.00$ & 0.67 \\
\hline pent. throu. $12 "$ beam & 125.00 & ea. & 0 & 0.00 & 0.00 \\
\hline wood lagging down to $1 \mathrm{st}$ tie & 4.10 & sft & $3,267.0$ & $13,394.70$ & 1.57 \\
\hline wood lagging below & 6.76 & sft & $5,247.0$ & $35,469.72$ & 4.17 \\
\hline mob/demob + shop dwg & 1.00 & ea. & $15,000.00$ & $15,000.00$ & 1.76 \\
\hline OTA & 100.00 & M/DAY & 0 & 0.00 & 0.00 \\
\hline set pile in hole & 5.00 & $\$ / f t$ & $1,040.00$ & $\begin{array}{l}5,200.00 \\
== \pm====\end{array}$ & $\begin{array}{c}0.61 \\
=======\end{array}$ \\
\hline & & & & $179,376.82$ & 21.07 \\
\hline area $=$ & 8,514 & SFT & $\cos t=$ & 21.07 & $\$ / \mathrm{sft}$ \\
\hline
\end{tabular}


CASE 10

SHEETING COST

driving in earth

steel cost beam

wale $10^{\prime}$ long

wale $20^{\prime}$ long

wale $10^{\prime}$ uninstall

wale $20^{\prime}$ uninstall

tieback cost

pent. throu. 10" beam

pent. throu. 12" beam

wood lagging down to 1 st tie

wood lagging below

mob/demob + shop dwg

OTA

set pile in hole

\begin{tabular}{ccccc} 
rate $\$$ & per & unit & rate $x$ unit & $\underline{\$ / \text { sft }}$ \\
\hline 10.00 & ft & $1,557.00$ & $15,570.00$ & 1.30 \\
0.52 & lb & $82,521.0$ & $42,910.92$ & 3.59 \\
450.00 & ea. & 46 & $20,700.00$ & 1.73 \\
550.00 & ea. & 0 & 0.00 & 0.00 \\
200.00 & ea. & 46 & $9,200.00$ & 0.77 \\
250.00 & ea. & 0 & 0.00 & 0.00 \\
$1,150.00$ & ea. & 46 & $52,900.00$ & 4.43 \\
100.00 & ea. & 0 & 0.00 & 0.00 \\
125.00 & ea. & 0 & 0.00 & 0.00 \\
4.10 & sft & $3,578.0$ & $14,669.80$ & 1.23 \\
6.76 & sft & $8,362.0$ & $56,527.12$ & 4.73 \\
1.00 & ea. & $15,000.00$ & $15,000.00$ & 1.26 \\
100.00 & M / DAY & 0 & 0.00 & 0.00 \\
5.00 & \$/ft & $1,557.00$ & $7,785.00$ & 0.65 \\
& & & $========$ & $=======$ \\
& & & $235,262.84$ & 19.70
\end{tabular}

$11,940 \quad$ SFT cost

19.70 \$/sit 
CASE 11

SHEETING COST

driving in earth

steel cost beam

wale $10^{\prime}$ long

wale $20^{\prime}$ long

wale $10^{\prime}$ uninstall

wale $20^{\prime}$ uninstall

tieback cost

pent. throu. 10" beam

pent. throu. 12" beam

wood lagging down to 1 st tie

wood lagging below

mob/demob + shop dwg

OTA

set pile in hole

area $=$

\begin{tabular}{c} 
rate $\$$ \\
\hline 10.00 \\
0.52 \\
450.00 \\
550.00 \\
200.00 \\
250.00 \\
$1,000.00$ \\
100.00 \\
125.00 \\
4.10 \\
6.76 \\
1.00 \\
100.00 \\
5.00
\end{tabular}

per
$\mathrm{ft}$
$\mathrm{lb}$
ea.
ea.
ea.
ea.
ea.
ea.
ea.
sft
sft
ea.
M I DAY
\$/ft

unit

$1,008.00$

$42,336.0$

rate $x$ unit

$10,080.00$

$22,014.72$

25

$11,250.00$

0.00

$5,000.00$

0.00

$35,000.00$

0.00

0.00

$11,238.10$

$23,504.52$

$3,477.0$

$15,000.00$

0

$15,000.00$

0.00

$1,008.00$

$5,040.00$

$138,127.34$

$\$$ /sft

1.62

3.54

1.81

0.00

0.80

0.00

5.63

0.00

0.00

1.81

3.78

2.41

0.00

$== \pm===$

cost $=\quad 22.21 \quad \$ / s f t$ 
CASE 12

SHEETING COST

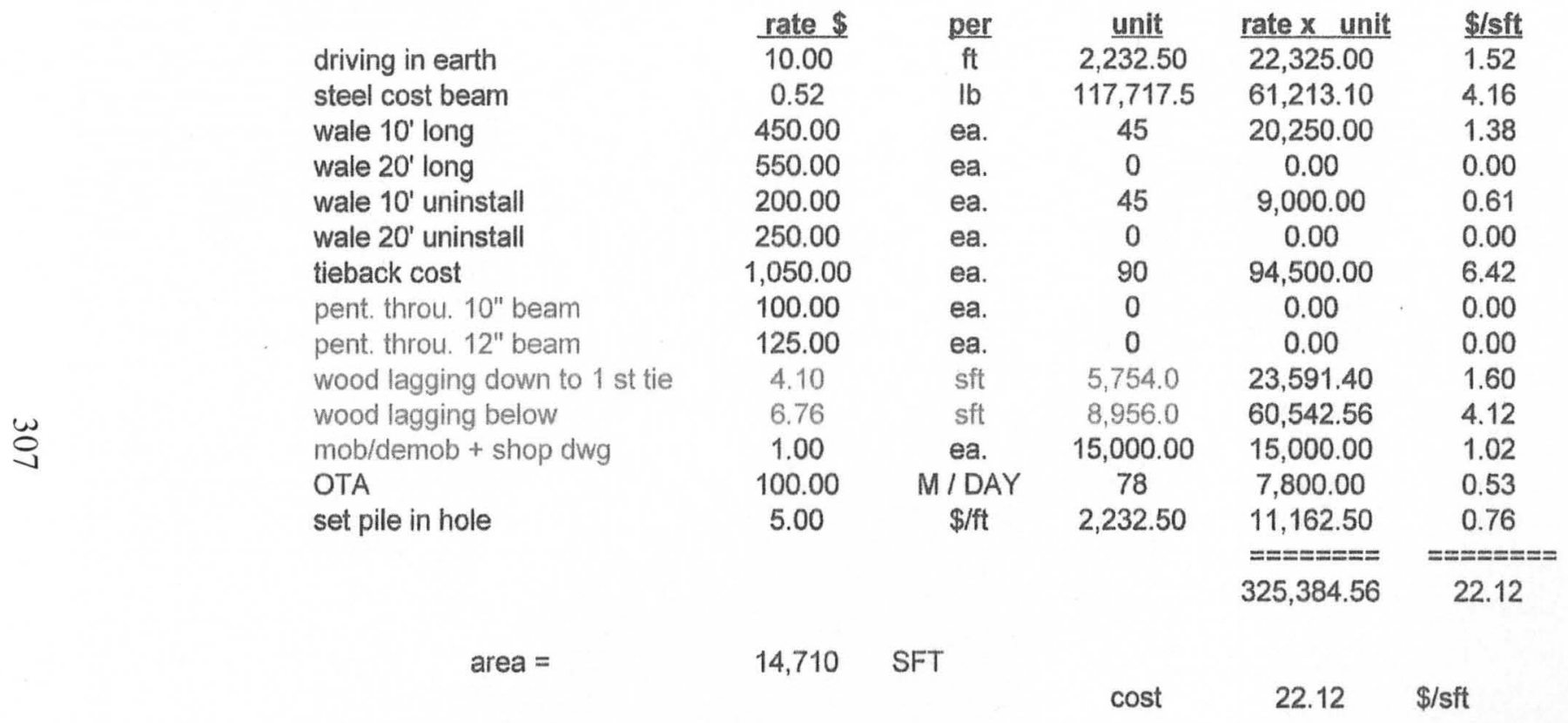


CASE 13

SHEETING COST

driving in earth
steel cost beam
wale $10^{\prime}$ long
wale $20^{\prime}$ long
wale $10^{\prime}$ uninstall
wale $20^{\prime}$ uninstall
tieback cost
pent. throu. $10^{\prime \prime}$ beam
pent. throu. $12^{\prime \prime}$ beam
wood lagging down to 1 st tie
wood lagging below
mob/demob + shop dwg
OTA
set pile in hole

area $=$

\begin{tabular}{ccccc} 
rate $\$$ & per & unit & rate $\times$ unit & $\$$ /sft \\
\hline 10.00 & ft & 500.00 & $5,000.00$ & 1.81 \\
0.52 & lb & $21,000.0$ & $10,920.00$ & 3.95 \\
450.00 & ea. & 12 & $5,400.00$ & 1.95 \\
550.00 & ea. & 0 & 0.00 & 0.00 \\
200.00 & ea. & 12 & $2,400.00$ & 0.87 \\
250.00 & ea. & 0 & 0.00 & 0.00 \\
$1,000.00$ & ea. & 12 & $12,000.00$ & 4.34 \\
100.00 & ea. & 0 & 0.00 & 0.00 \\
125.00 & ea. & 0 & 0.00 & 0.00 \\
4.10 & sft & $1,258.0$ & $5,157.80$ & 1.87 \\
6.76 & sft & $1,507.0$ & $10,187.32$ & 3.68 \\
1.00 & ea. & $15,000.00$ & $15,000.00$ & 5.42 \\
100.00 & M DAY & 0 & 0.00 & 0.00 \\
5.00 & \$/ft & 500.00 & $2,500.00$ & 0.90 \\
& & & $=======$ & $======$ \\
& & & $68,565.12$ & 24.80
\end{tabular}

cost $=\quad 24.80 \quad \$ / \mathrm{sft}$ 
CASE 14

SHEETING COST

\author{
driving in earth \\ steel cost beam \\ wale $10^{\prime}$ long \\ wale $20^{\prime}$ long \\ wale $10^{\prime}$ uninstall \\ wale $20^{\prime}$ uninstall \\ tieback cost \\ pent. throu. 10" beam \\ pent. throu. 12" beam \\ wood lagging down to $1 \mathrm{st}$ tie \\ wood lagging below \\ mob/demob + shop dwg \\ OTA \\ set pile in hole
}

\begin{tabular}{c} 
rate $\$$ \\
\hline 10.00 \\
0.52 \\
450.00 \\
550.00 \\
200.00 \\
250.00 \\
$1,050.00$ \\
100.00 \\
125.00 \\
4.10 \\
6.76 \\
1.00 \\
100.00 \\
5.00
\end{tabular}

per
$\mathrm{ft}$
$\mathrm{lb}$
ea.
ea.
ea.
ea.
ea.
ea.
ea.
sft
sft
ea.
/ DAY
\$/ft

unit

$30,513.0$

$\frac{\text { rate } x \text { unit }}{7,265.00}$

$$
1.77
$$

$15,866.76 \quad 3.87$

$5,850.00 \quad 1.43$

$0.00 \quad 0.00$

$2,600.00 \quad 0.63$

$0.00 \quad 0.00$

$22,050.00 \quad 5.38$

$0.00 \quad 0.00$

$0.00 \quad 0.00$

$\begin{array}{lll}1,742.0 & 7,142.20 & 1.74\end{array}$

$\begin{array}{lll}2,358.0 & 15,940.08 & 3.89\end{array}$

$\begin{array}{lll}15,000.00 & 15,000.00 & 3.66\end{array}$

$\begin{array}{lll}0 & 0.00 & 0.00\end{array}$

$\begin{array}{lll}726.50 & 3,632.50 & 0.89\end{array}$

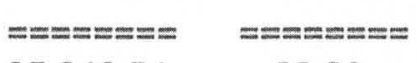

$95,346.54 \quad 23.26$

cost $=\quad 23.26 \quad \$ / s f t$ 


\author{
driving in earth \\ steel cost beam \\ wale $10^{\prime}$ long \\ wale $20^{\prime}$ long \\ wale $10^{\prime}$ uninstall \\ wale $20^{\prime}$ uninstall \\ tieback cost \\ pent. throu. 10" beam \\ pent. throu. 12" beam \\ wood lagging down to 1 st tie \\ wood lagging below \\ mob/demob + shop dwg \\ OTA \\ set pile in hole
}

\begin{tabular}{c} 
rate $\$$ \\
\hline 10.00 \\
0.52 \\
450.00 \\
550.00 \\
200.00 \\
250.00 \\
$1,100.00$ \\
100.00 \\
125.00 \\
4.10 \\
6.76 \\
1.00 \\
100.00 \\
5.00
\end{tabular}

71,820

per
$\mathrm{ft}$
$\mathrm{lb}$
ea.
ea.
ea.
ea.
ea.
ea.
ea.
sft
sft
ea.
M DAY
\$/ft

SFT

\begin{tabular}{|c|c|c|}
\hline unit & rate $x$ unit & $\$ /$ sft \\
\hline $8,888.00$ & $88,880.00$ & 1.24 \\
\hline $471,064.0$ & $244,953.28$ & 3.41 \\
\hline 0 & 0.00 & 0.00 \\
\hline 0 & 0.00 & 0.00 \\
\hline 0 & 0.00 & 0.00 \\
\hline 0 & 0.00 & 0.00 \\
\hline 808 & $888,800.00$ & 12.38 \\
\hline 0 & 0.00 & 0.00 \\
\hline 808 & $101,000.00$ & 1.41 \\
\hline $13,000.0$ & $53,300.00$ & 0.74 \\
\hline $58,820.0$ & $397,623.20$ & 5.54 \\
\hline $15,000.00$ & $15,000.00$ & 0.21 \\
\hline 0 & 0.00 & 0.00 \\
\hline \multirow[t]{3}{*}{$8,888.00$} & $44,440.00$ & 0.62 \\
\hline & $==\approx=== \pm=$ & $========$ \\
\hline & $1,833,996.48$ & 25.54 \\
\hline cost $=$ & 25.54 & $\$ /$ sft \\
\hline
\end{tabular}


Appendix F: Cost for Soil Nailing System 


\section{$\underline{\text { Case } 1 \text { Soil Nailing Cost }}$}

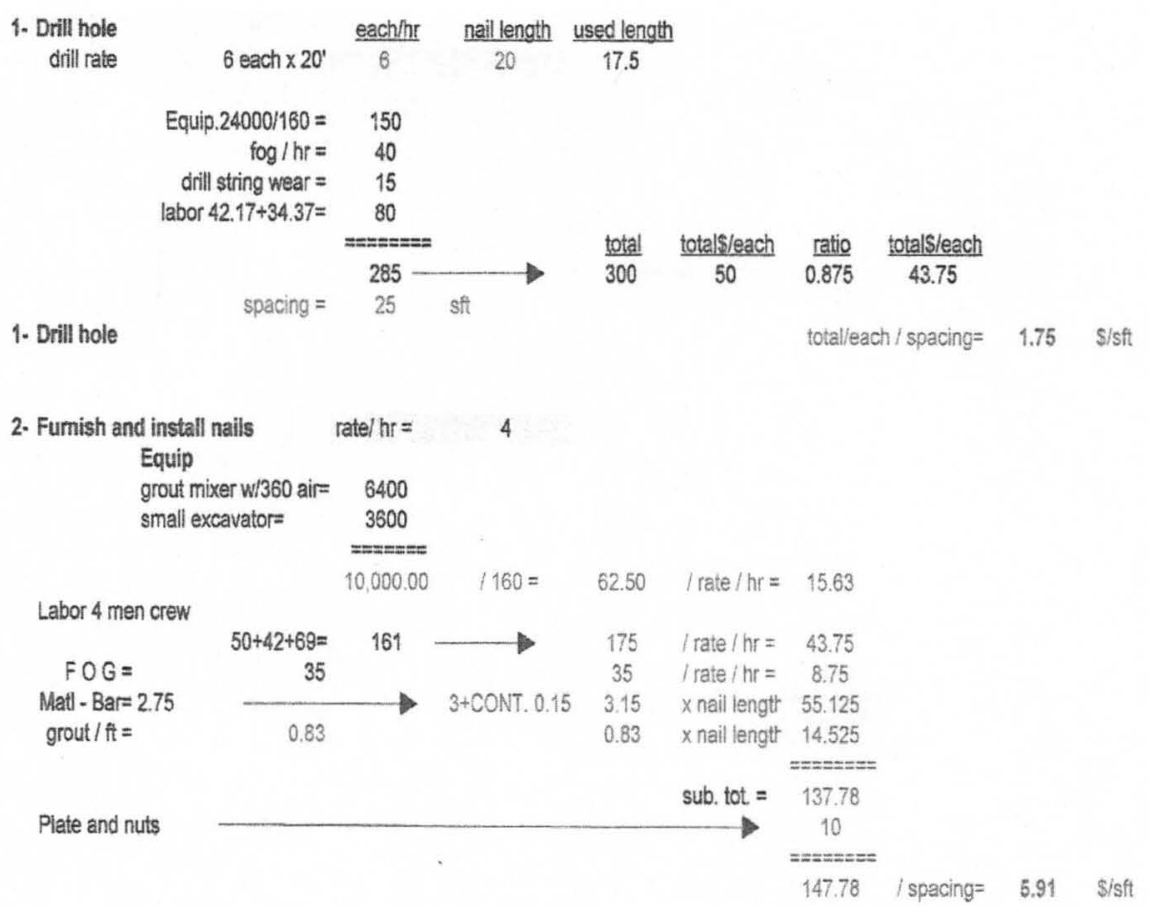

3- Place $6 \times 6$ mesh w/ miradrain

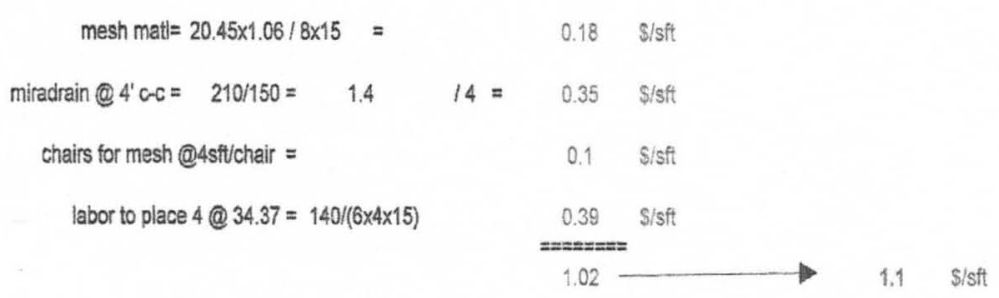

contin. walers (2) dbl \#4 and $4^{\prime}$
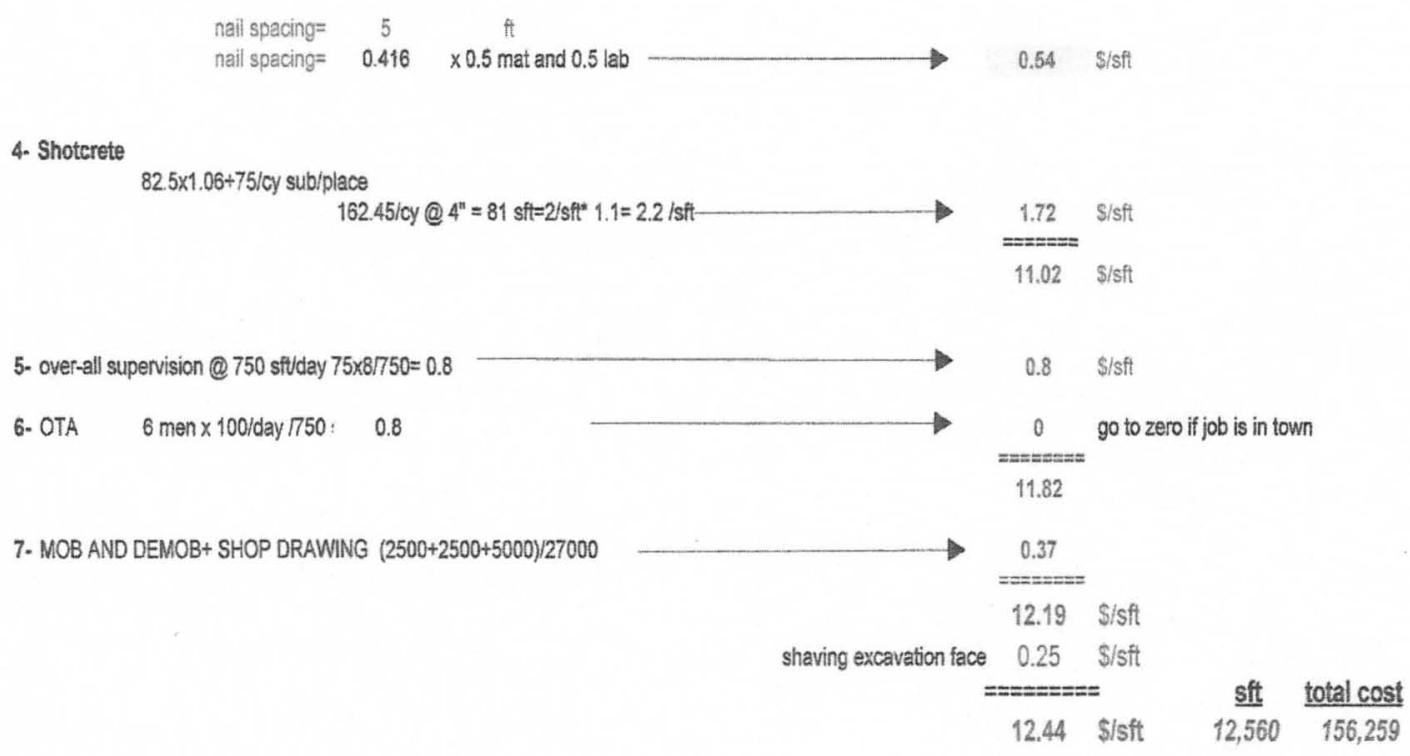


\section{$\underline{\text { Case } 2 \text { Soil Nailing Cost }}$}

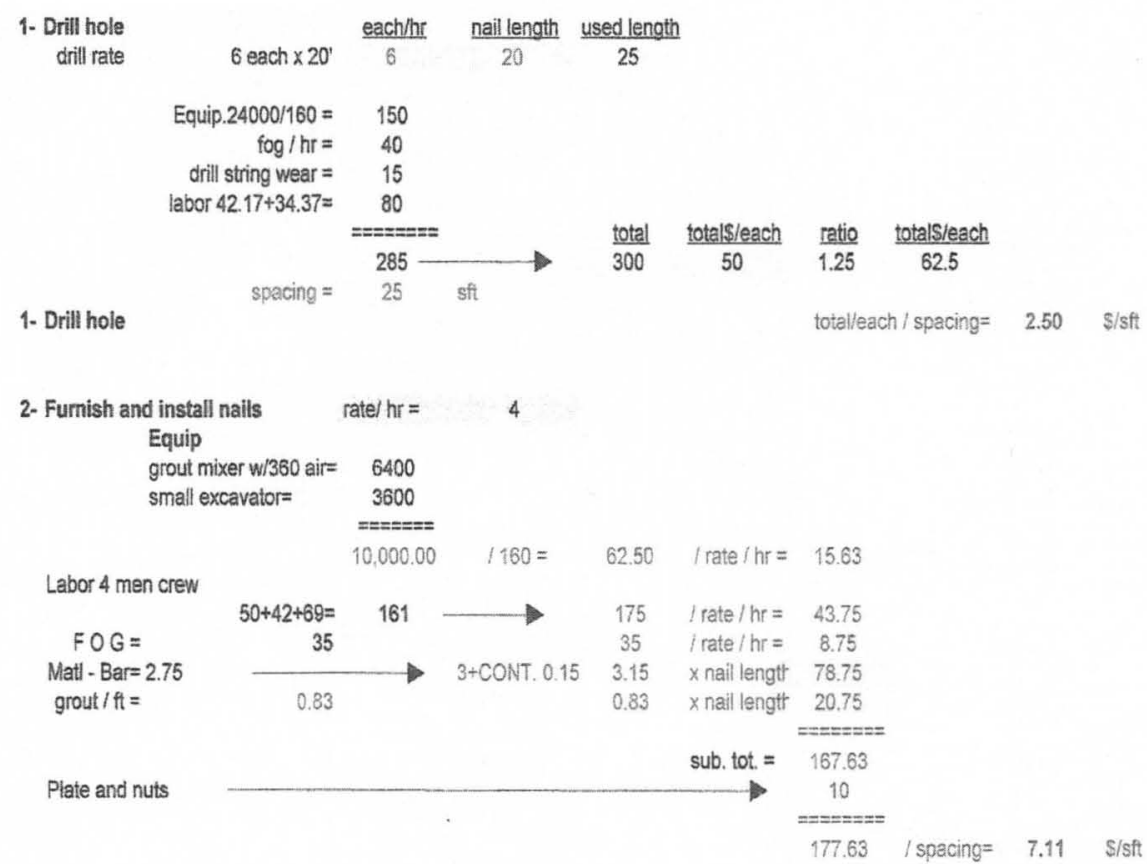

3- Place $6 \times 6$ mesh w/ miradrain

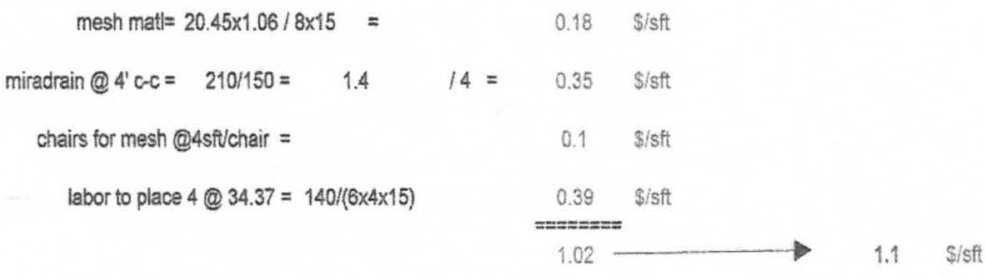

contin. walers @ dbl \#4 and $4^{\prime}$

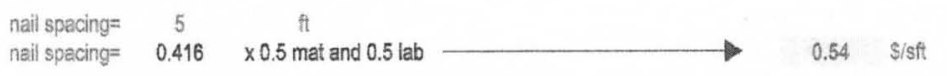

4- Shotcrete

$82.5 \times 1.06+75 /$ cy sub/place

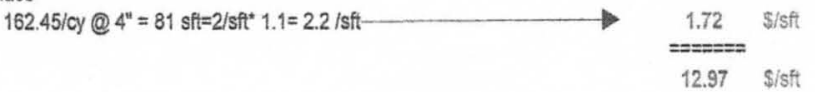

5- over-all supervision @ 750 sftiday $75 \times 8 / 750=0.8 \longrightarrow 0.8 \quad \$ / 5 \mathrm{ft}$

6. OTA 6 men $\times 100 /$ day $7750: 0.8 \longrightarrow \frac{0}{13.77}$ go to zero if job is in town

7. MOB AND DEMOB+ SHOP DRAWING $(2500+2500+5000) / 27000$

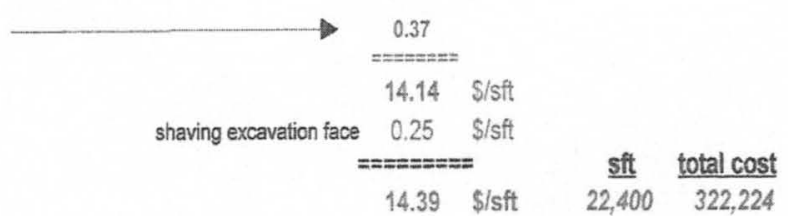


Case 3 Soil Nailing Cost

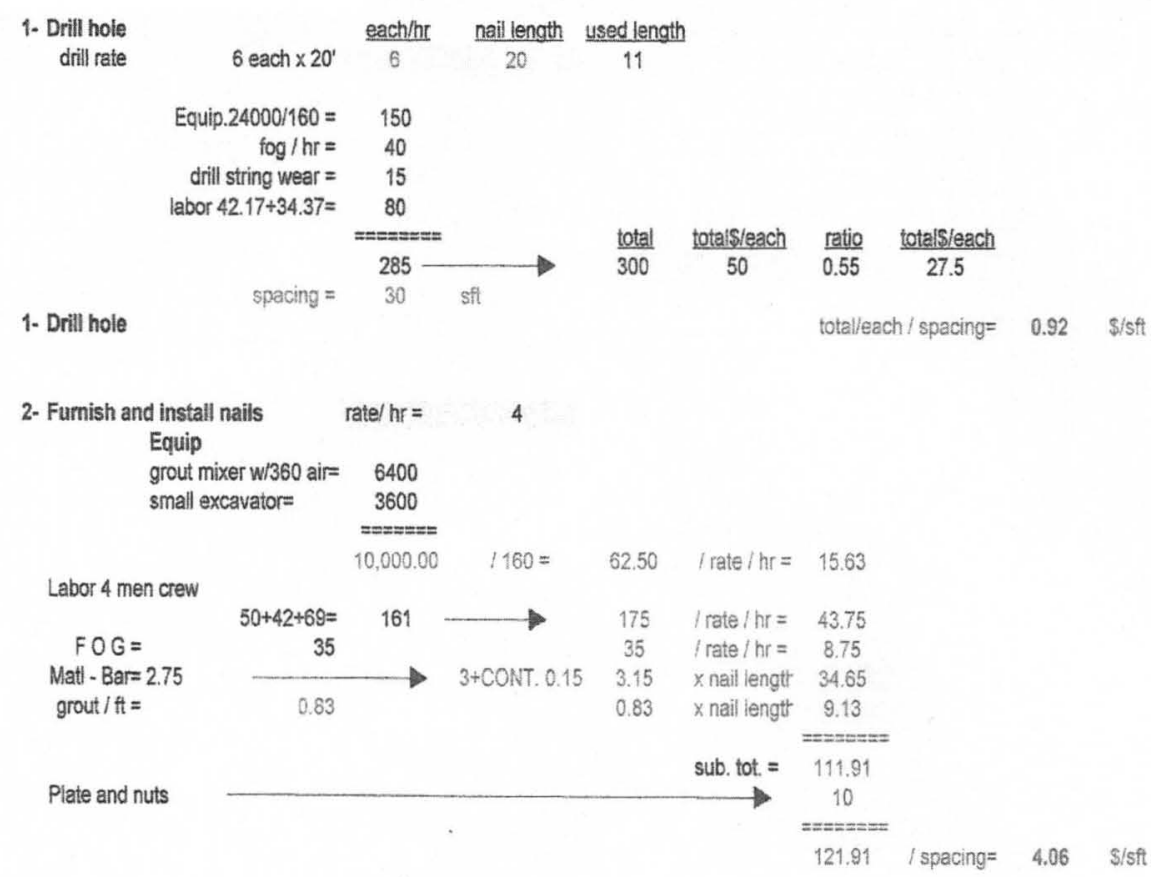

3- Place $6 \times 6$ mesh wi miradrain

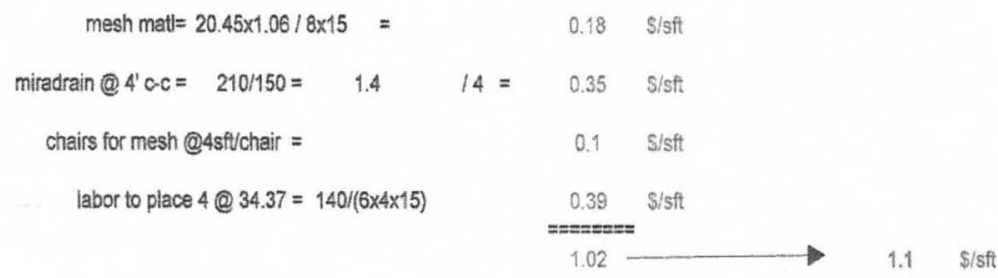

contin. walers @ dbi \#4 and 4'

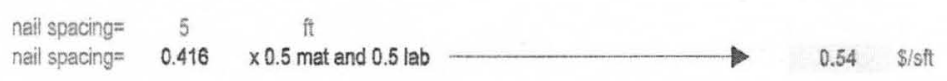

4- Shotcrete

$82.5 \times 1.06+75 / c y$ sub/place
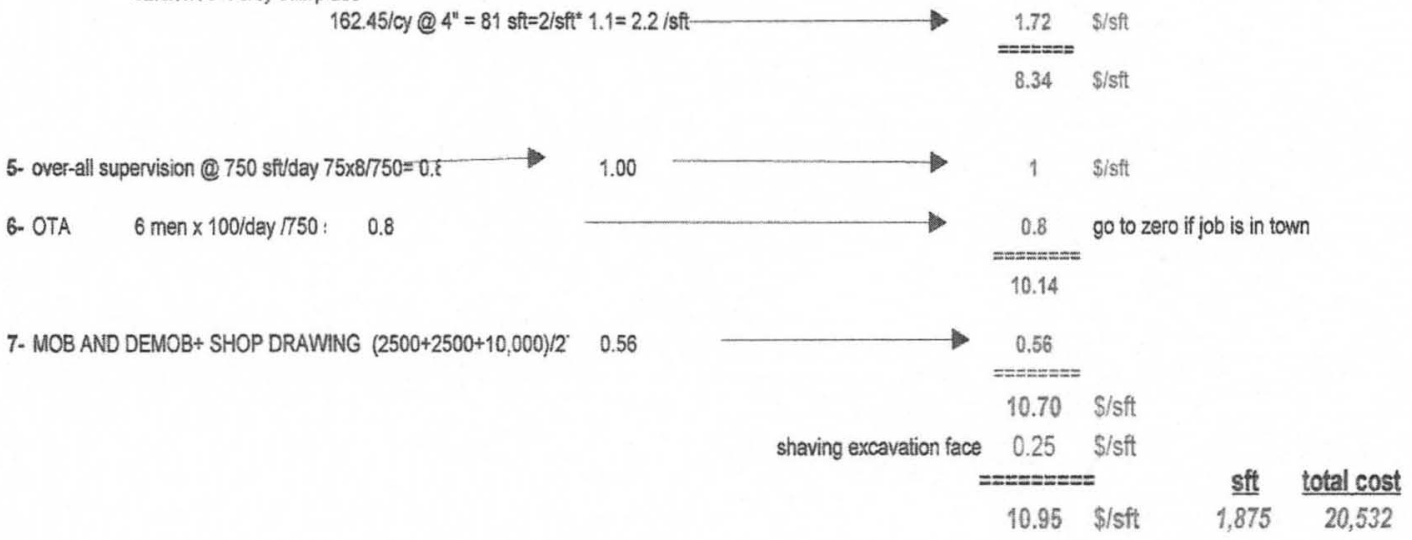


\section{Case 4 Part A Soil Nailing Cost}

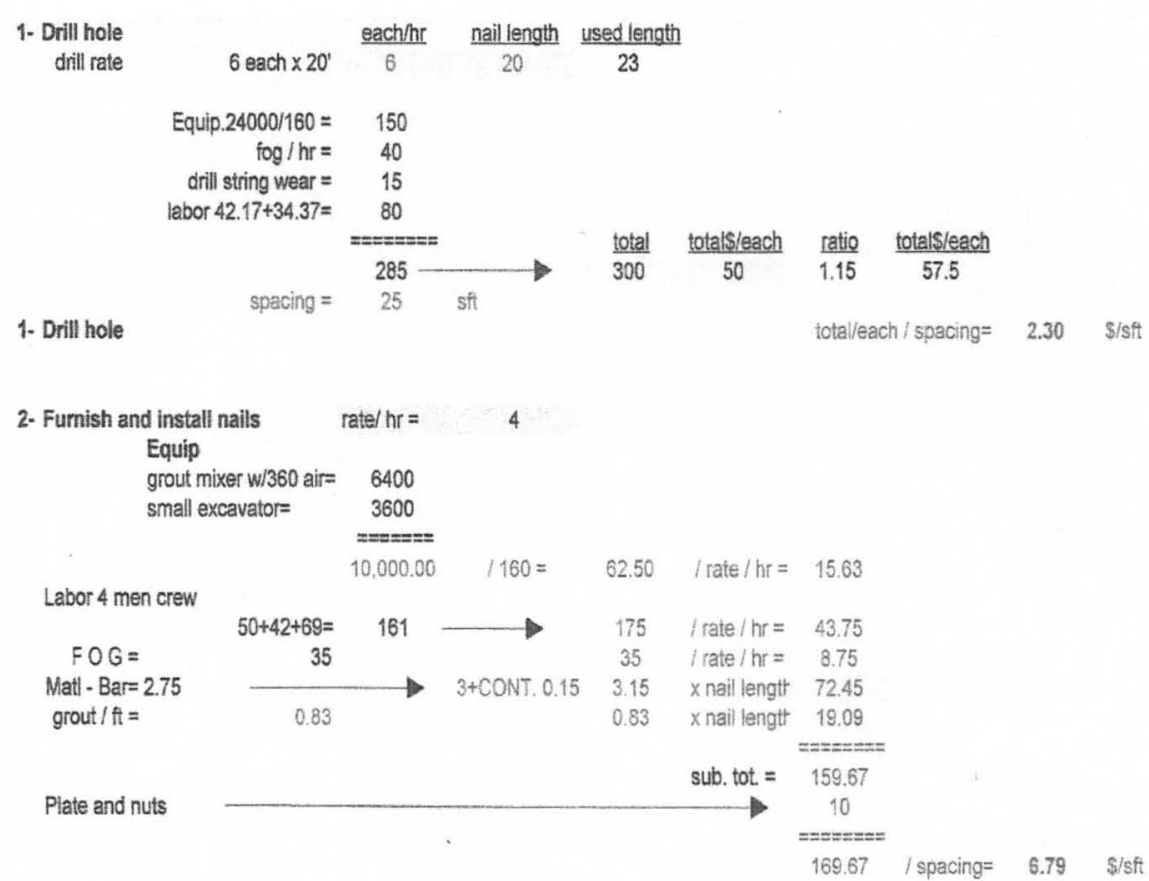

3- Place $6 \times 6$ mesh wi miradrain

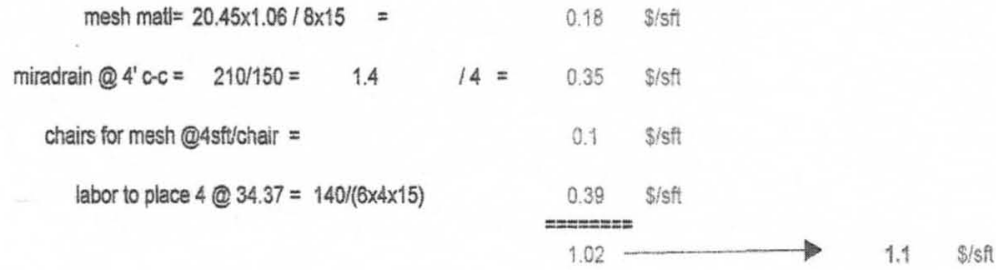

contin. walers @ dbi \#4 and 4'

nail spacing=

nail spacing=

5

At

$0.416 \times 0.5$ mat and $0.5 \mathrm{lab} \longrightarrow 0.54 \mathrm{~S} / \mathrm{sfl}$

4. Shotcrete

$82.5 \times 1.06+75 /$ cy sub/place

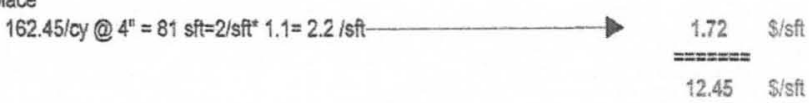

5. over-all supervision @ 750 sft/day $75 \times 8 / 750=0.8$

$0.8 \quad \$ / s f t$

6- OTA 6 men $\times 100 /$ day $7750: \quad 0,8$

$==2$ go to zero if job is in town

7. MOB AND DEMOB+ SHOP DRAWING $(2500+2500 \div 5000) / 27000$

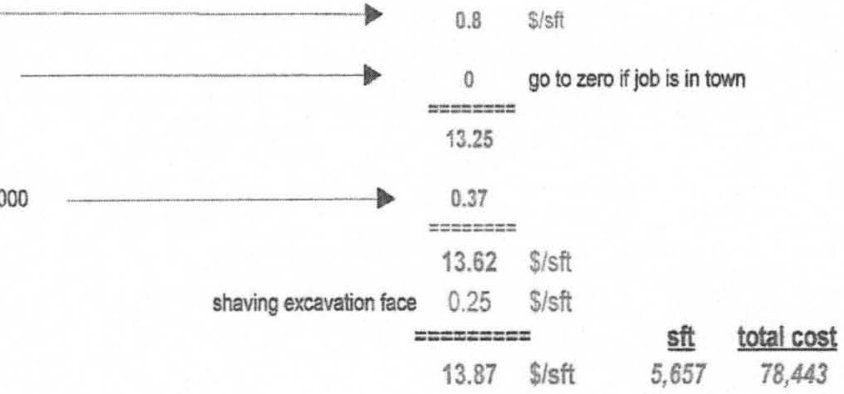




\section{Case 4 Part B Soil Nailing Cost}

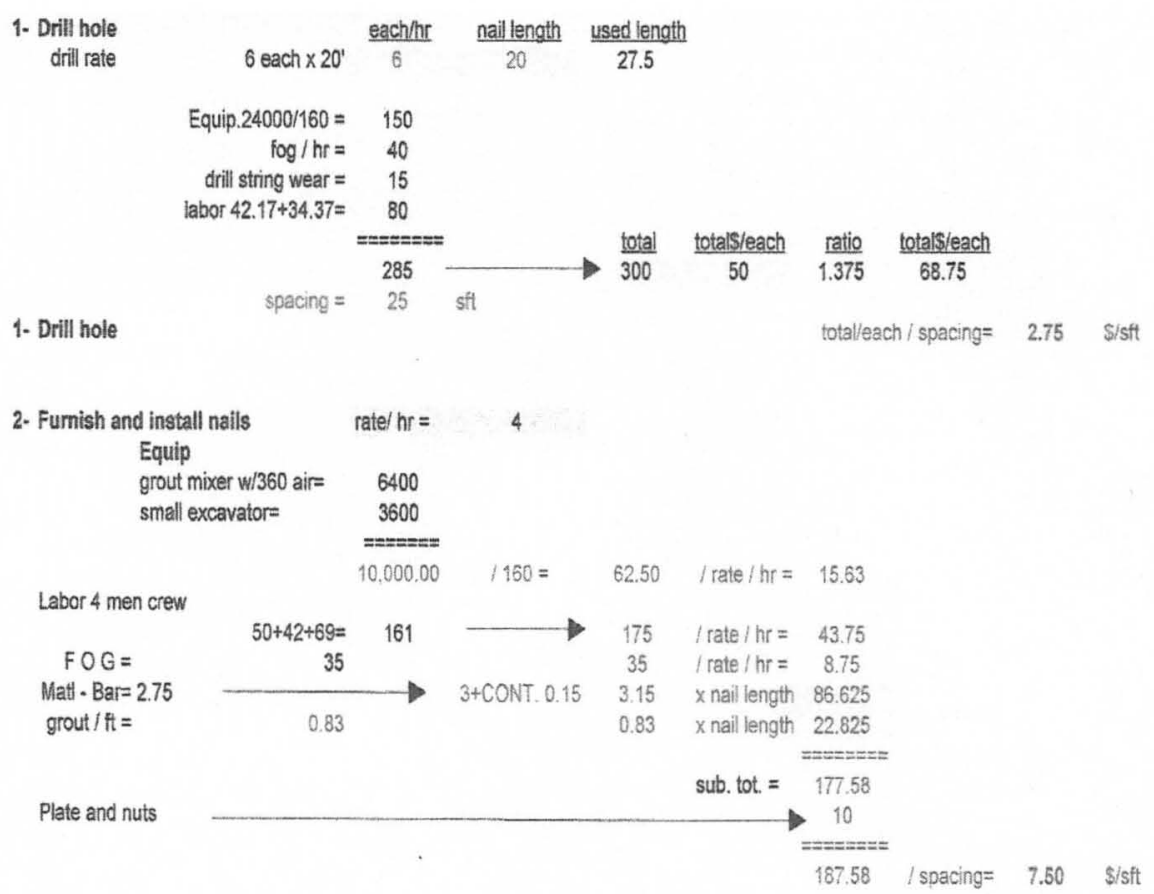

3- Place $6 \times 6$ mesh w/ miradrain

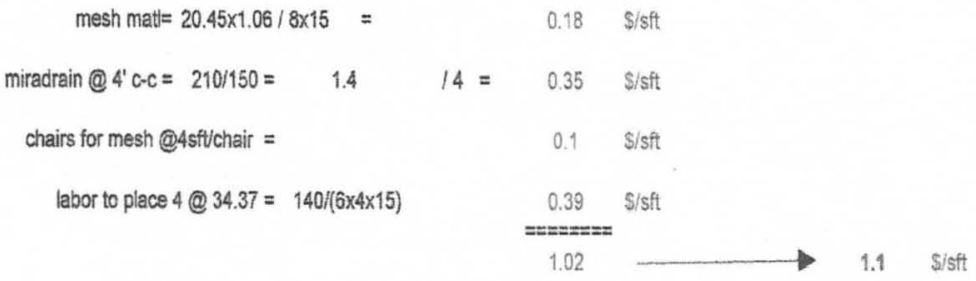

contin. walers @ dbl "th and 4'
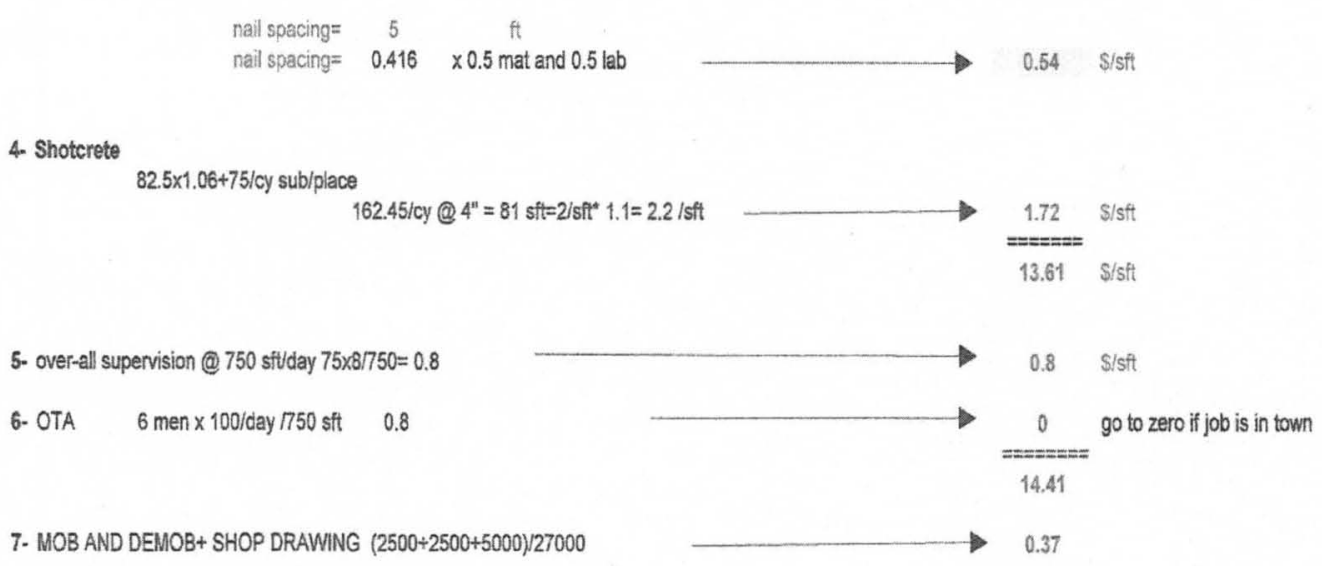


\section{$\underline{\text { Case } 5 \text { Part A Soil Nailing Cost }}$}

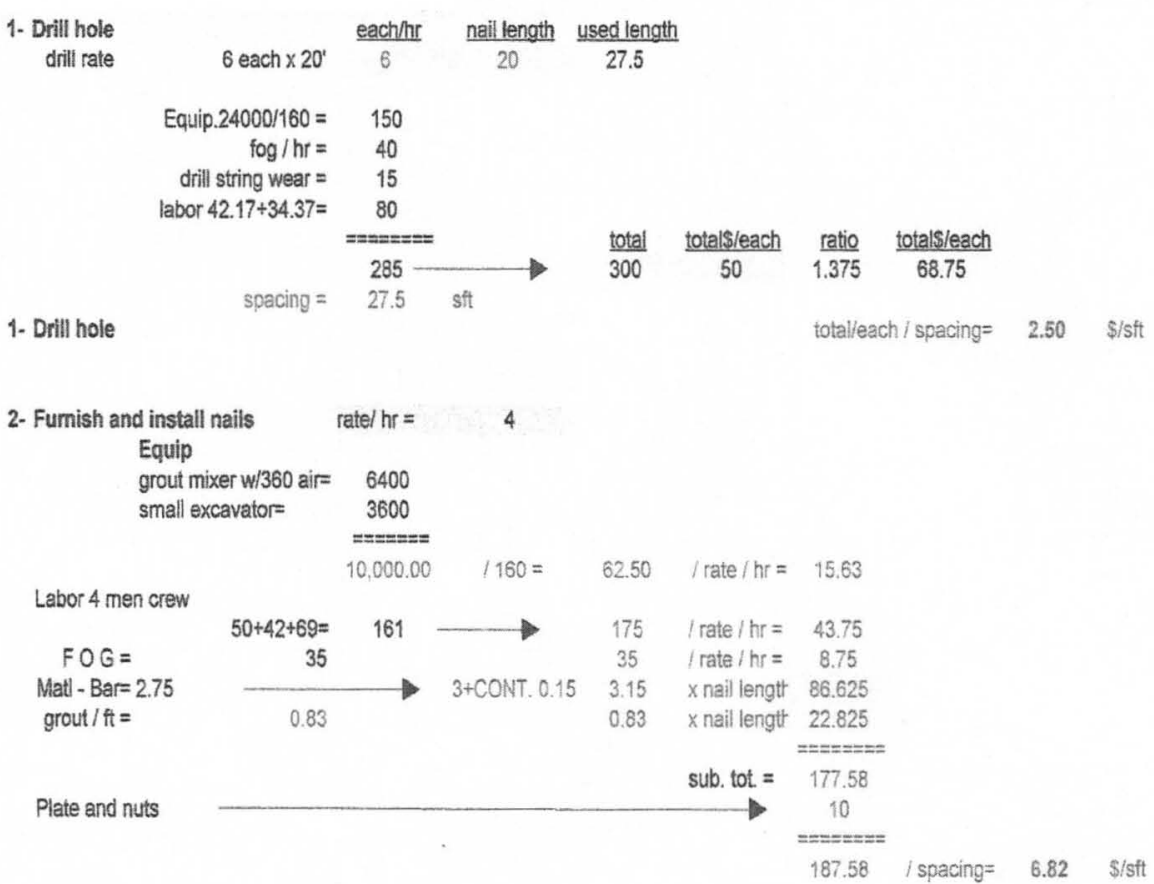

3- Place $6 \times 6$ mesh w/ miradrain

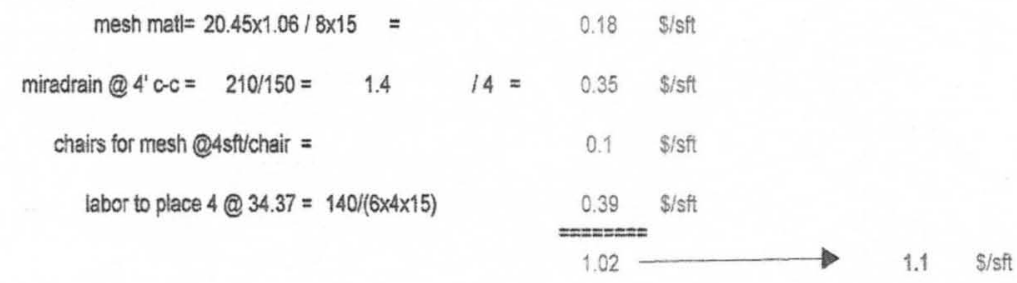

contin. walers @ dbl \#4 and 4'

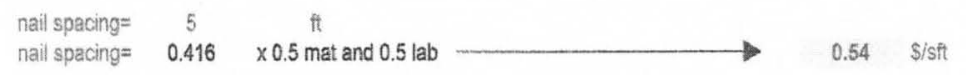

4. Shotcrete

\section{$82.5 \times 1.06+75 /$ cy sub/place}
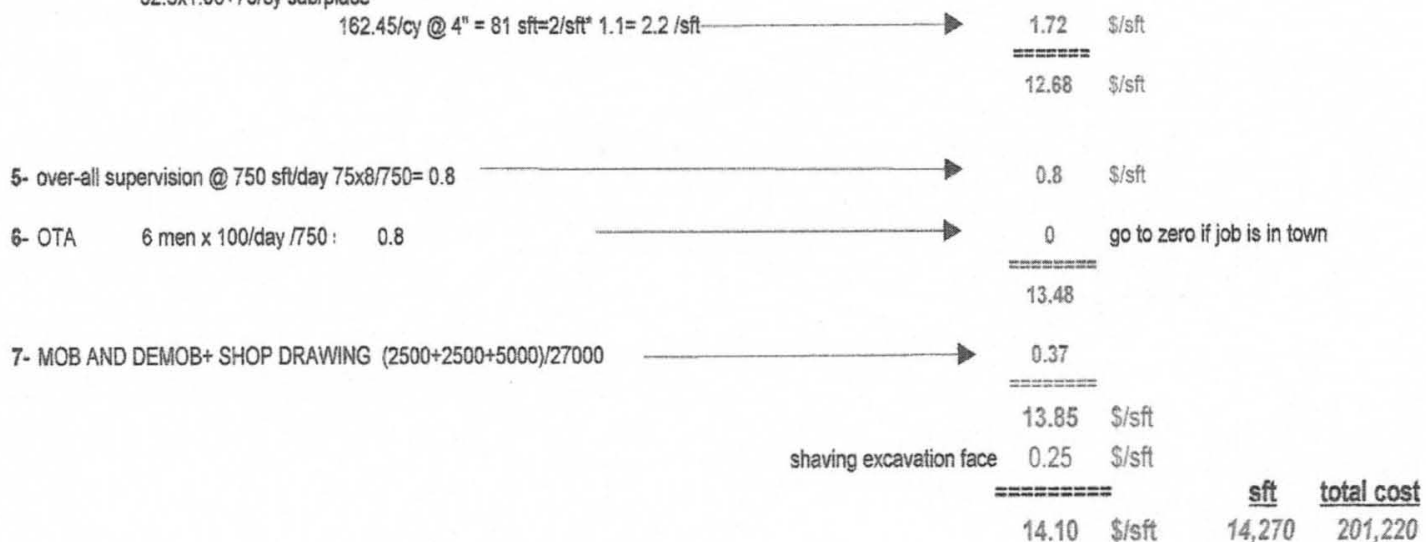
$\underline{\text { Case } 5 \text { Part B Soil Nailing Cost }}$

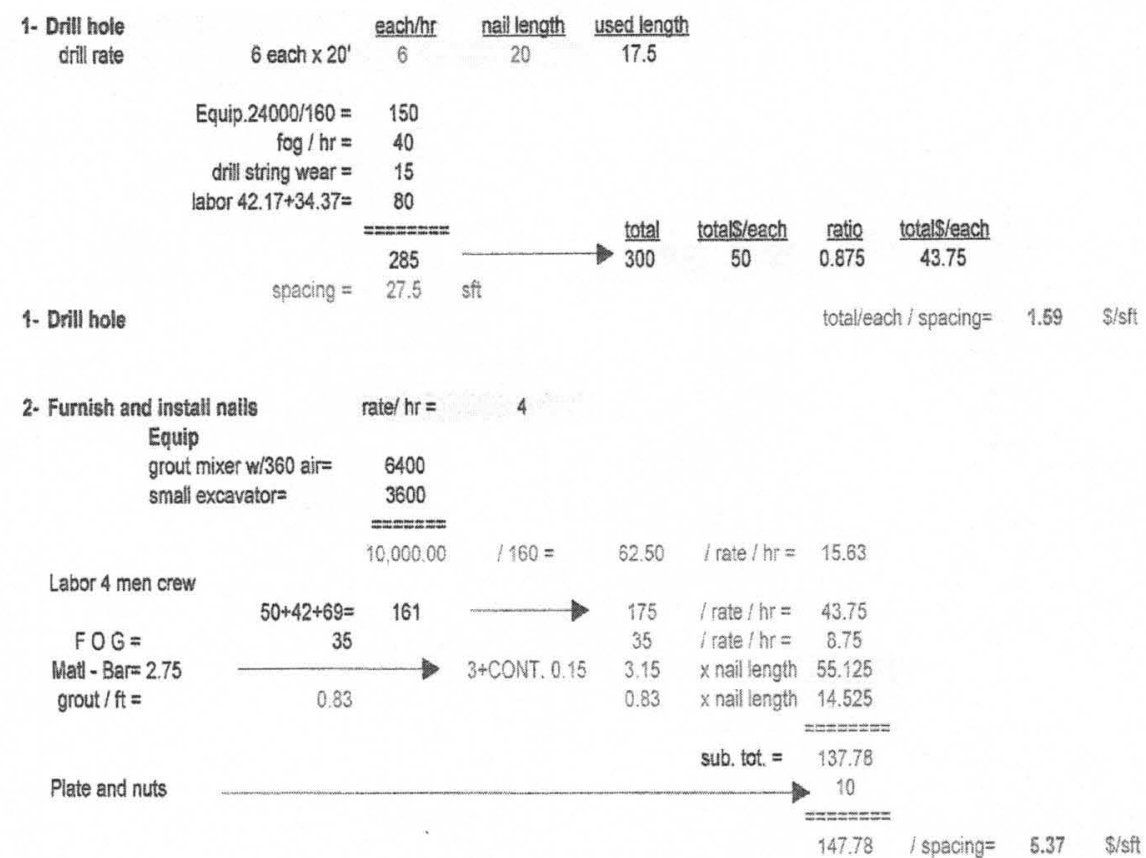

3. Place $6 \times 6$ mesh w/ miradrain

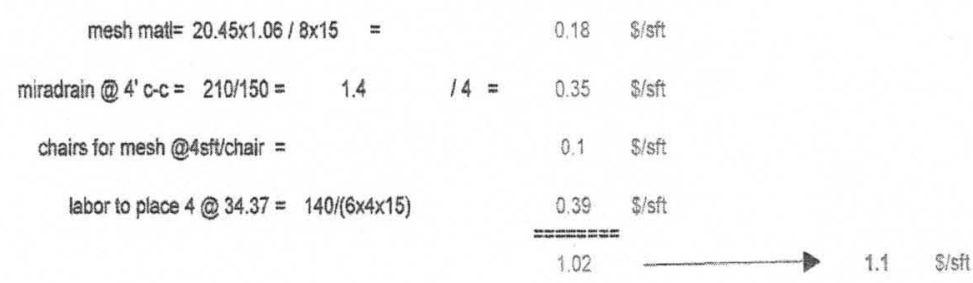

contin. waiers @ dbi $\# 4$ and $4^{\prime}$

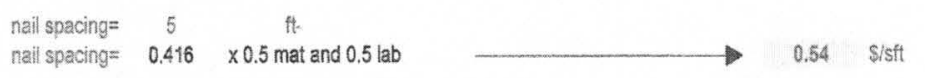

4. Shotcrete

$82.5 \times 1.06+75 /$ cy sub/place

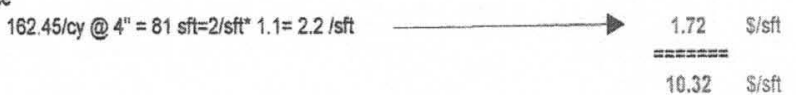

5. over-all supervision @ 750 sftdday $75 \times 8 / 750=0.8$

6- OTA

6 men $\times 100 /$ day $750 \mathrm{sit} \quad 0.8$

7- MOB AND DEMOB+ SHOP DRAWING $(2500+2500+5000) / 27000$

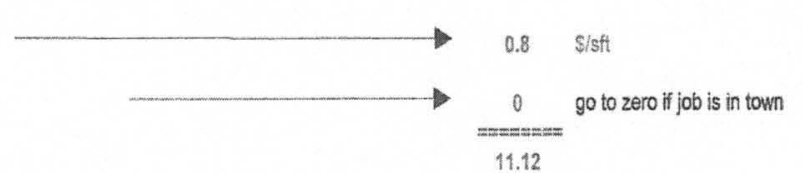

11.12

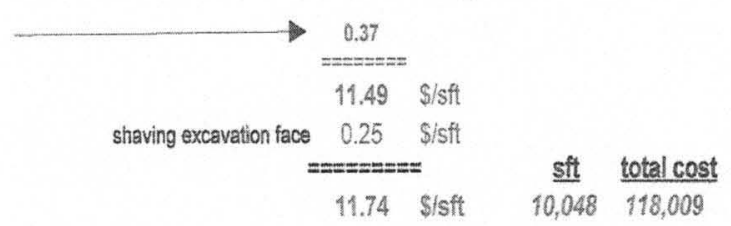




\section{Case 6 Part A Soil Nailing Cost}

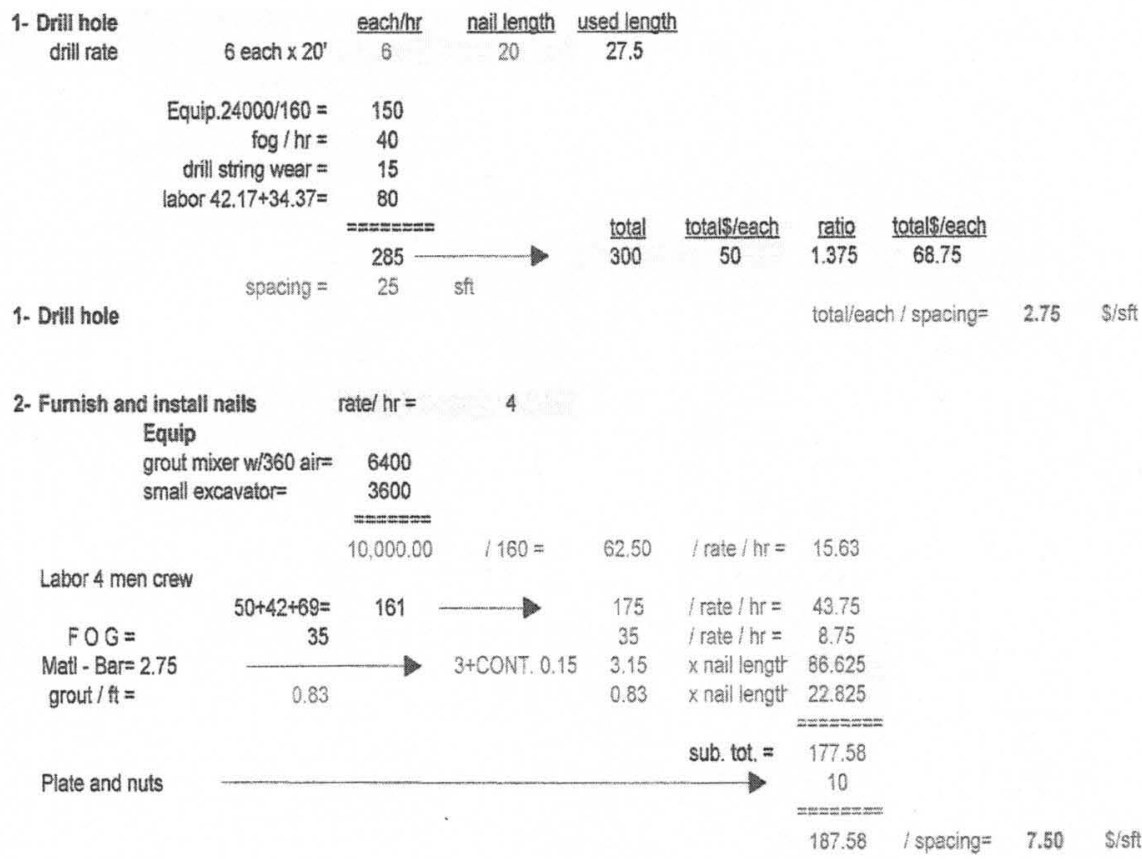

3. Place $6 \times 6$ mesh w/ miradrain

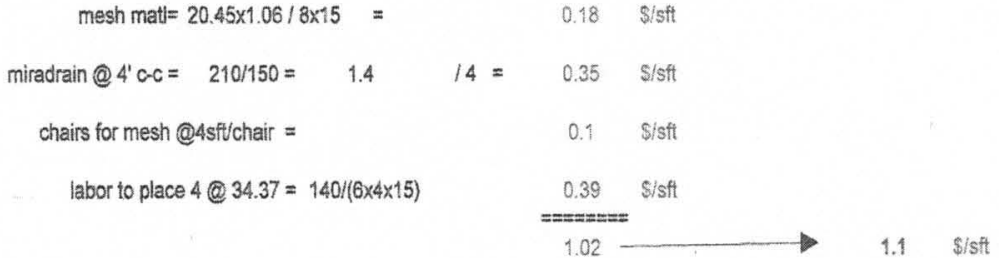




\section{Case 6 Part C Soil Nailing Cost}

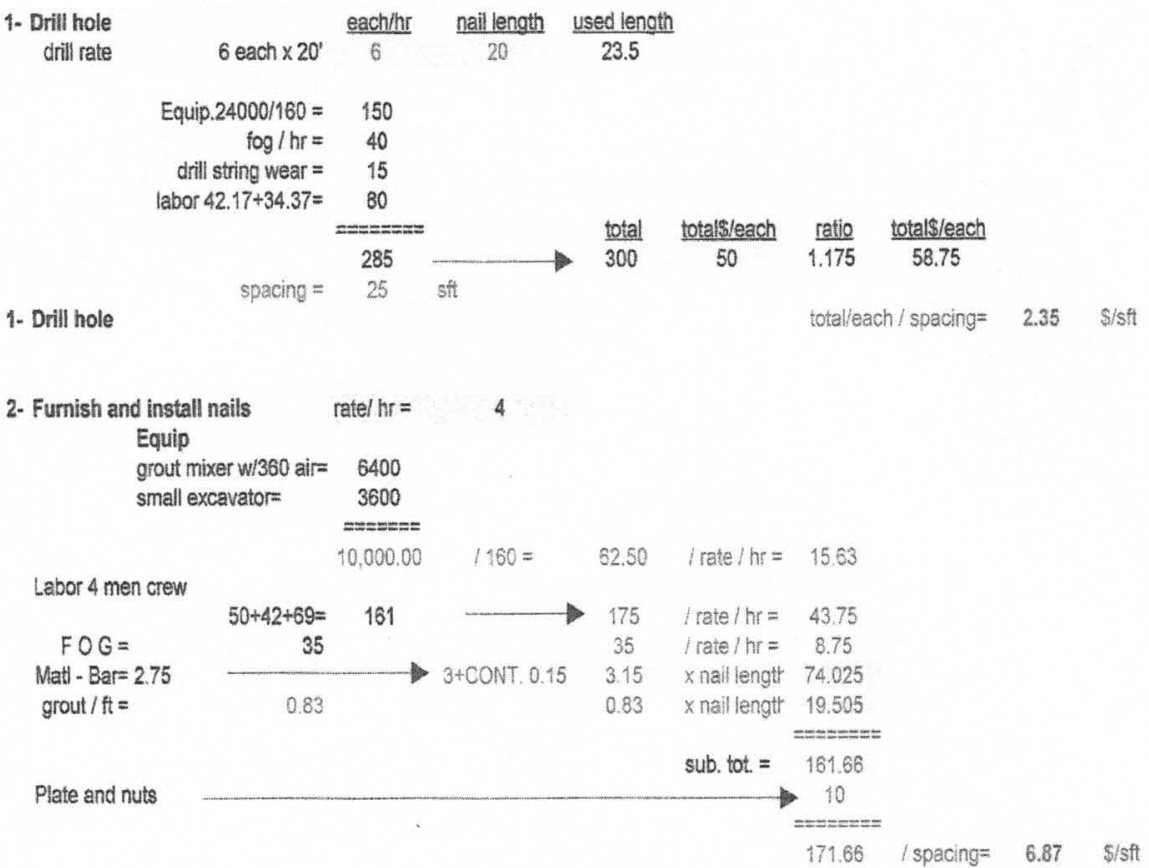

3- Place $6 \times 6$ mesh wi miradrain

mesh matl $=20.45 \times 1.06 / 8 \times 15=$

miradrain@ $4^{\prime} c-c=210 / 150=1.4$

$14=0.35 \quad$ Sisft

chairs for mesh @4sit/chair =

0.1 Sisft

labor to place $4 @ 34.37=140 /(6 \times 4 \times 15)$

$0.39 \quad \$ 1 / \mathrm{stt}$

$1.02 \longrightarrow 1.1$ \$isft

contin. walers @o dbl \#4 and 4'

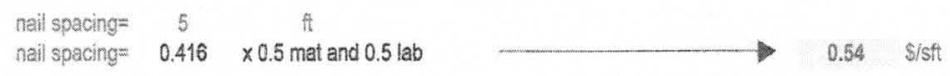

4. Shotcrete

\section{$82.5 \times 1.06+75 /$ cy sub/place}

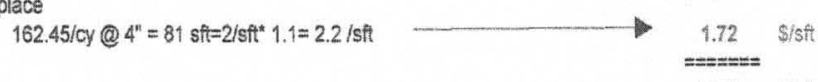

5. over-all supervision @ 750 sftday $75 \times 8 / 750=0.8$

6. OTA 6 men $\times 100 /$ day $7750: 0.8$

7- MOB AND DEMOB+SHOP DRAWING $(2500+2500+10,000) / 27000$
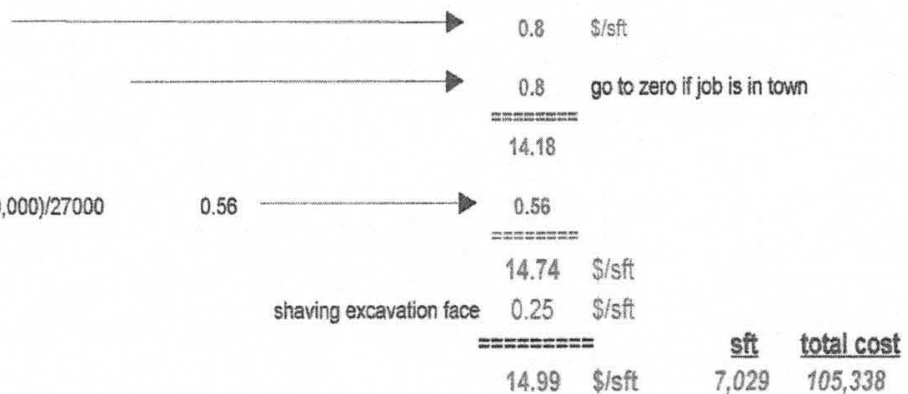


\section{Case 7 Part A Soil Nailing Cost}

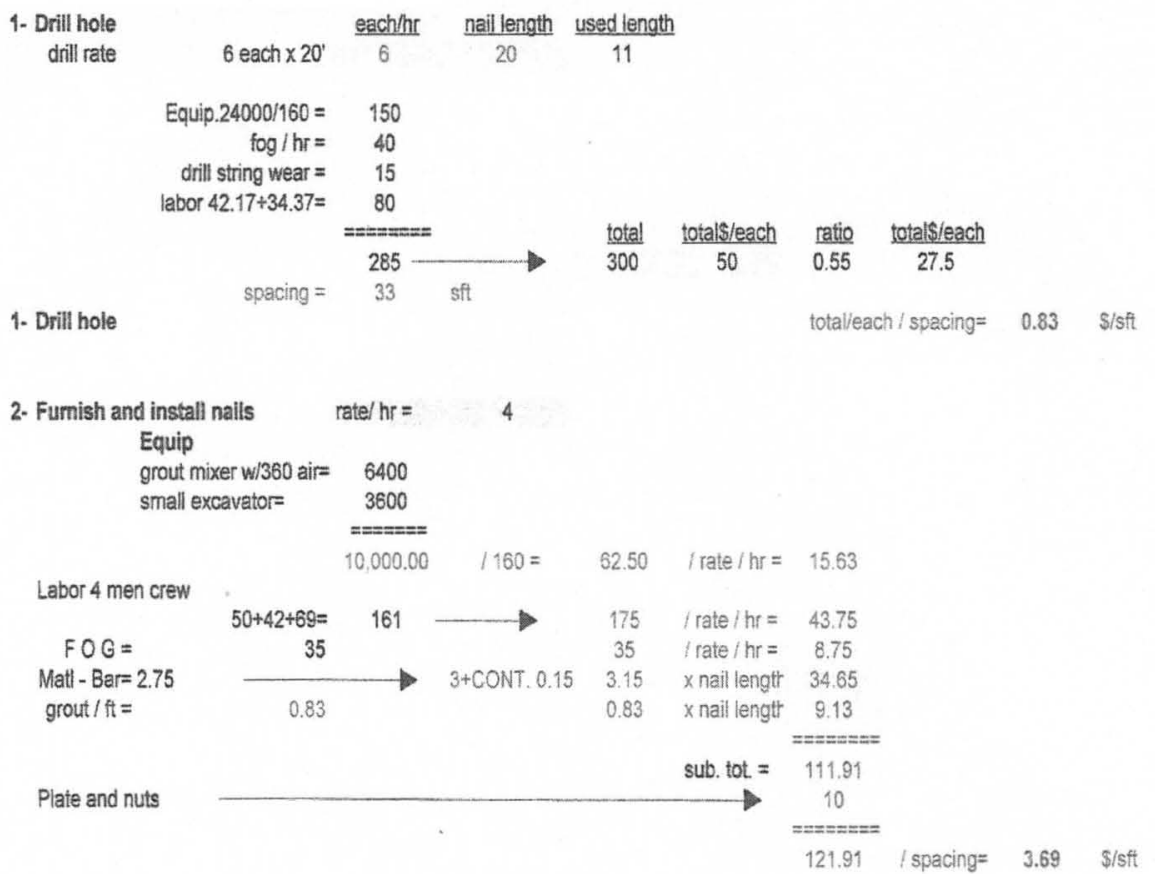

3. Place $6 \times 6$ mesh wi miradrain

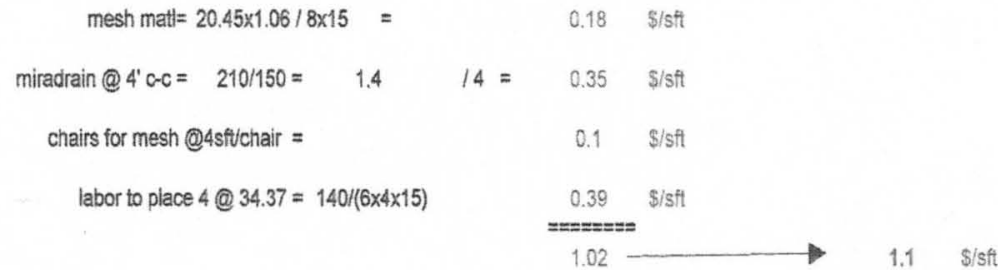

contin. walers @ dbl \#4 and 4'
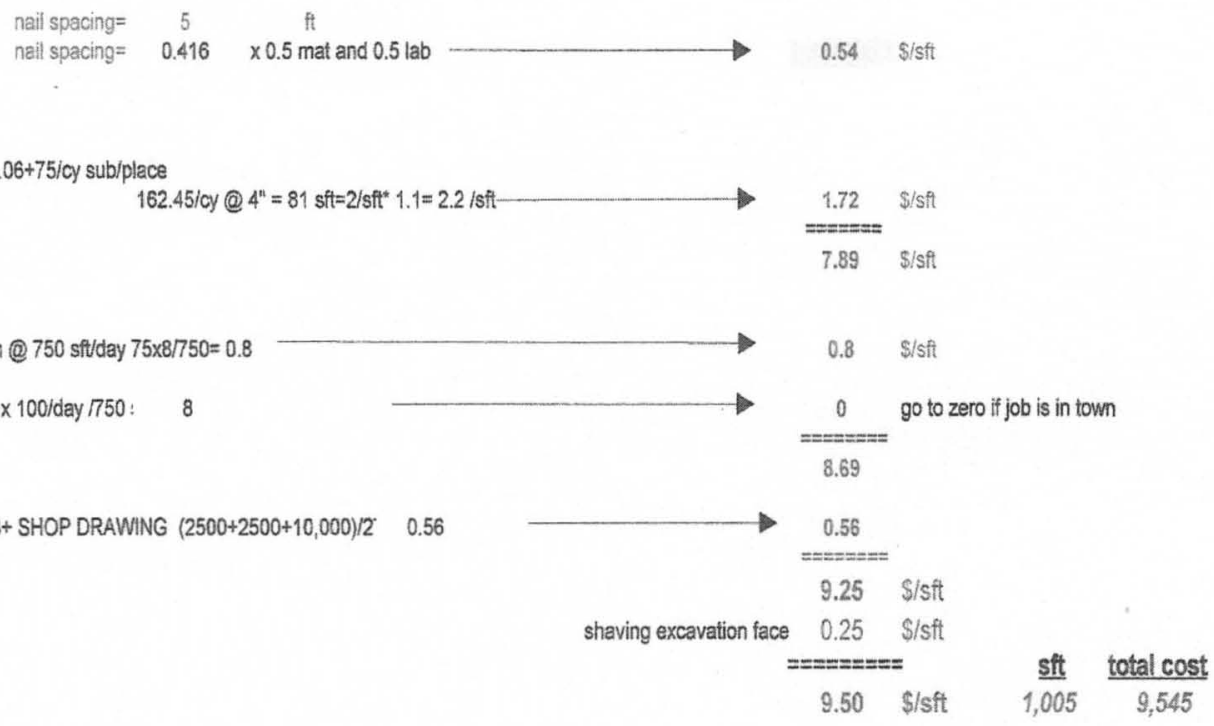


\section{Case 7 Part B Soil Nailing Cost}

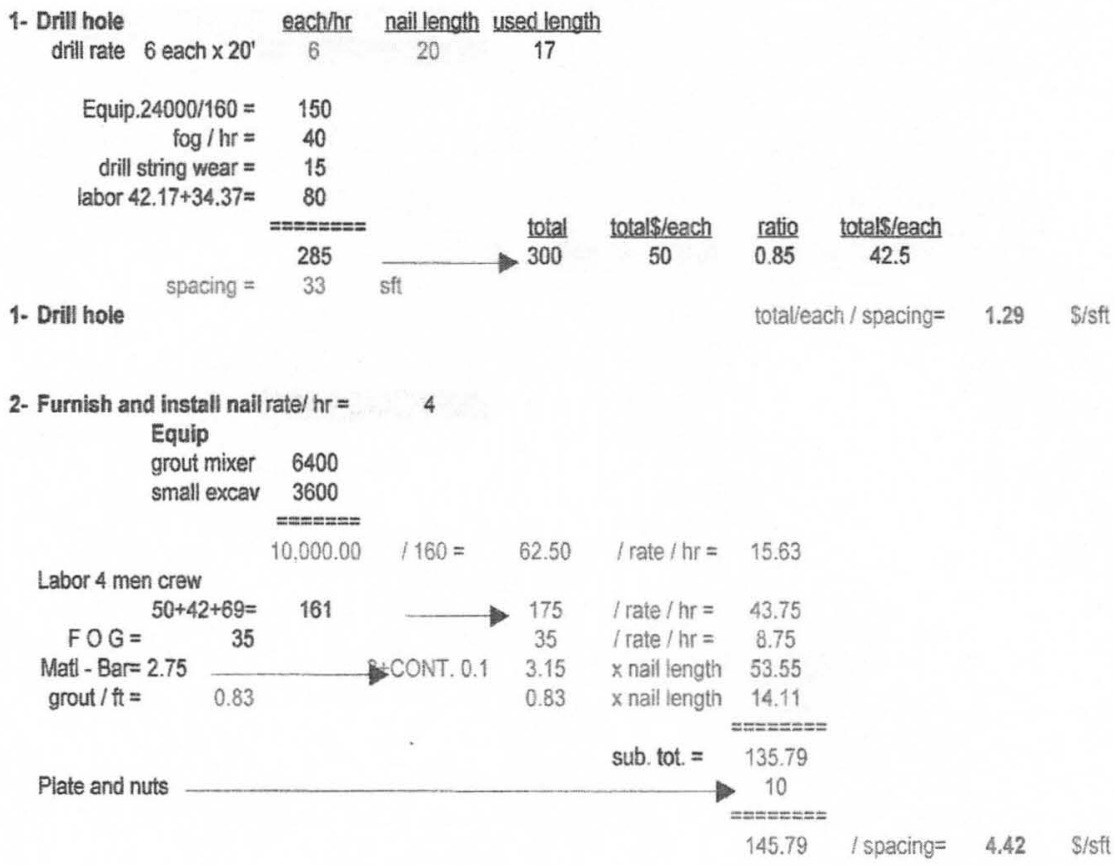

3- Place $6 \times 6$ mesh w/ miradrain

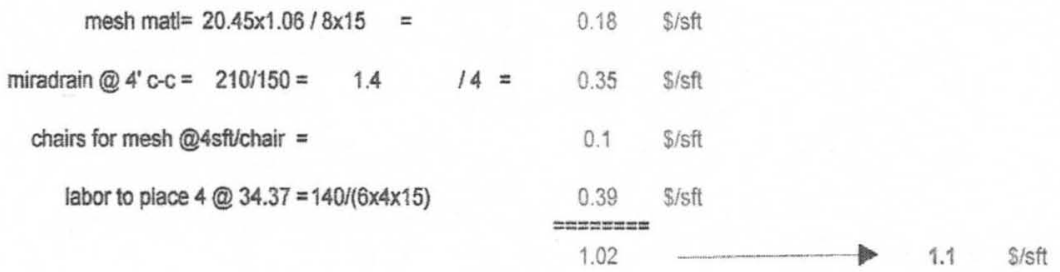

contin. walers @ dbl \#4 and 4'
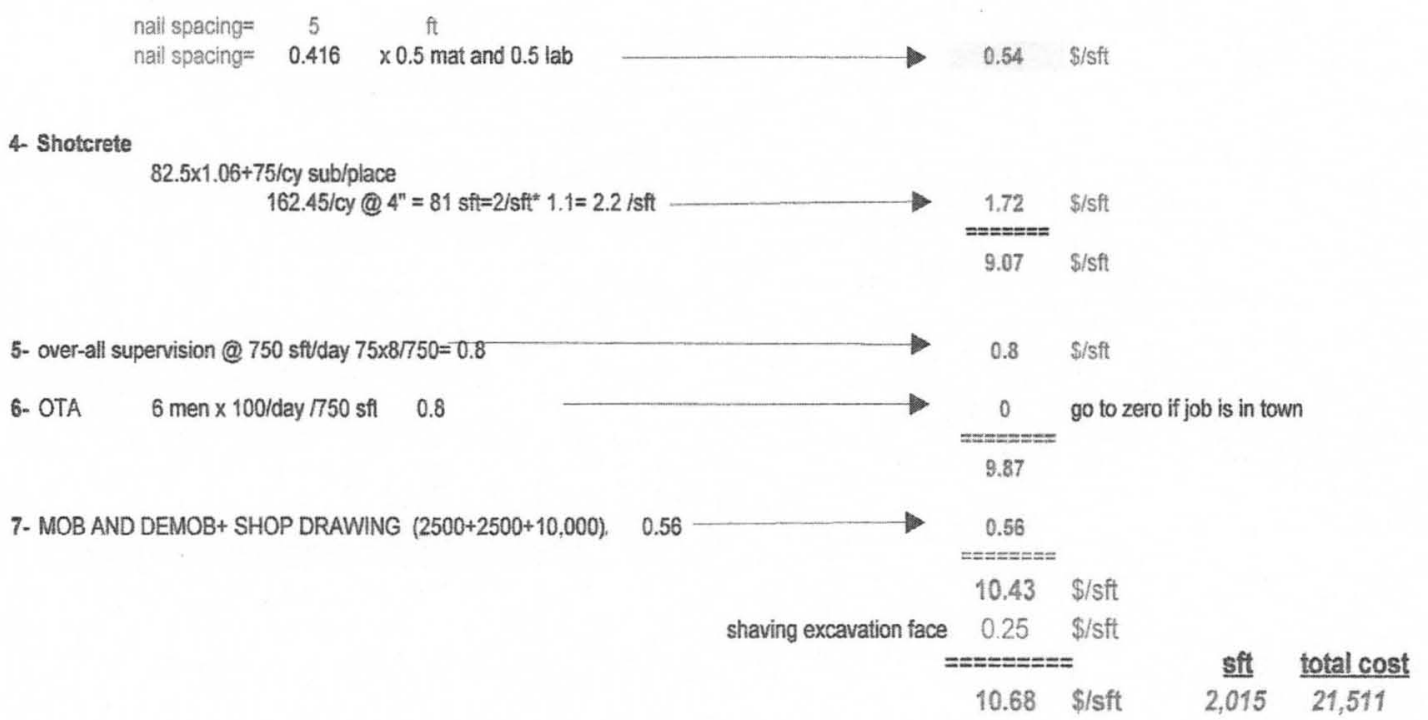
$\underline{\text { Case } 8 \text { Part A Soil Nailing Cost }}$

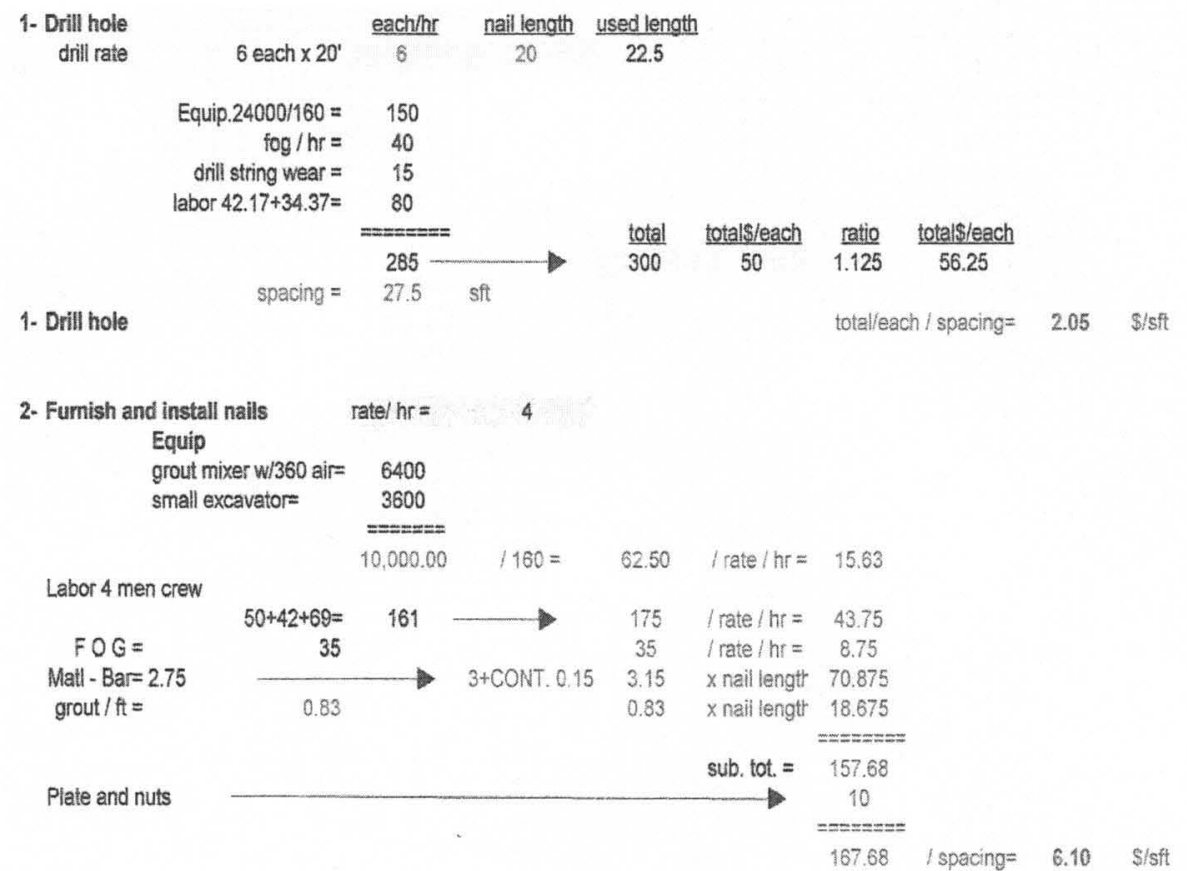

3. Place $6 \times 6$ mesh w/ miradrain

mesh matl $=20.45 \times 1.06 / 8 \times 15=0.18 \mathrm{~S} / \mathrm{sft}$

miradrain @ $4^{\prime} c-c=210 / 150=1.4 \quad / 4=0.35 \quad$ Sisft

chairs for mesh @4sftichair = 0.1 \$/sft

labor to place $4 @ 34.37=140 /(6 \times 4 \times 15) \quad 0.39$ \$ist

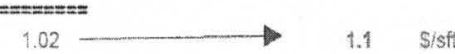

contin. walers @ dbl H4 and 4'

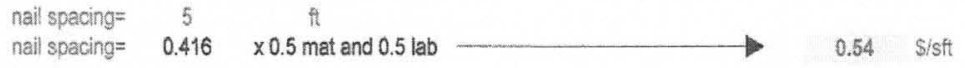

4. Shotcrete

$82.5 \times 1.06+75 /$ cy sub/place

$162.45 / \mathrm{cy} @ 4^{\mathrm{n}}=81 \mathrm{sft}=2 / \mathrm{st}^{*} 1.1=2.2 / \mathrm{sft} \longrightarrow 1.72 \$ \mathrm{~S} / \mathrm{sft}$

11.50 \$ist

5- over-all supervision @ 750 sftday $75 \times 8 / 750=0.8$

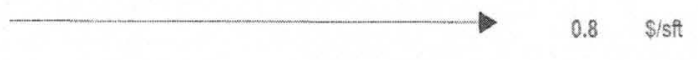

6- OTA $\quad 6$ men $\times 100 /$ day $\pi 50: \quad 0.8$

$=\underset{13.10}{0.8}$ go to zero if job is in town

7. MOB AND DEMOB+ SHOP DRAWING $(2500+2500 \div 10,000) / 2 \quad 0.56$

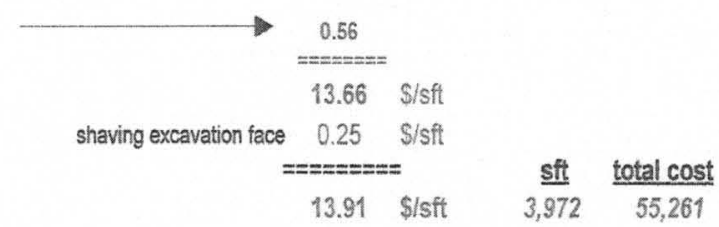




\section{Case 8 Part B Soil Nailing Cost}

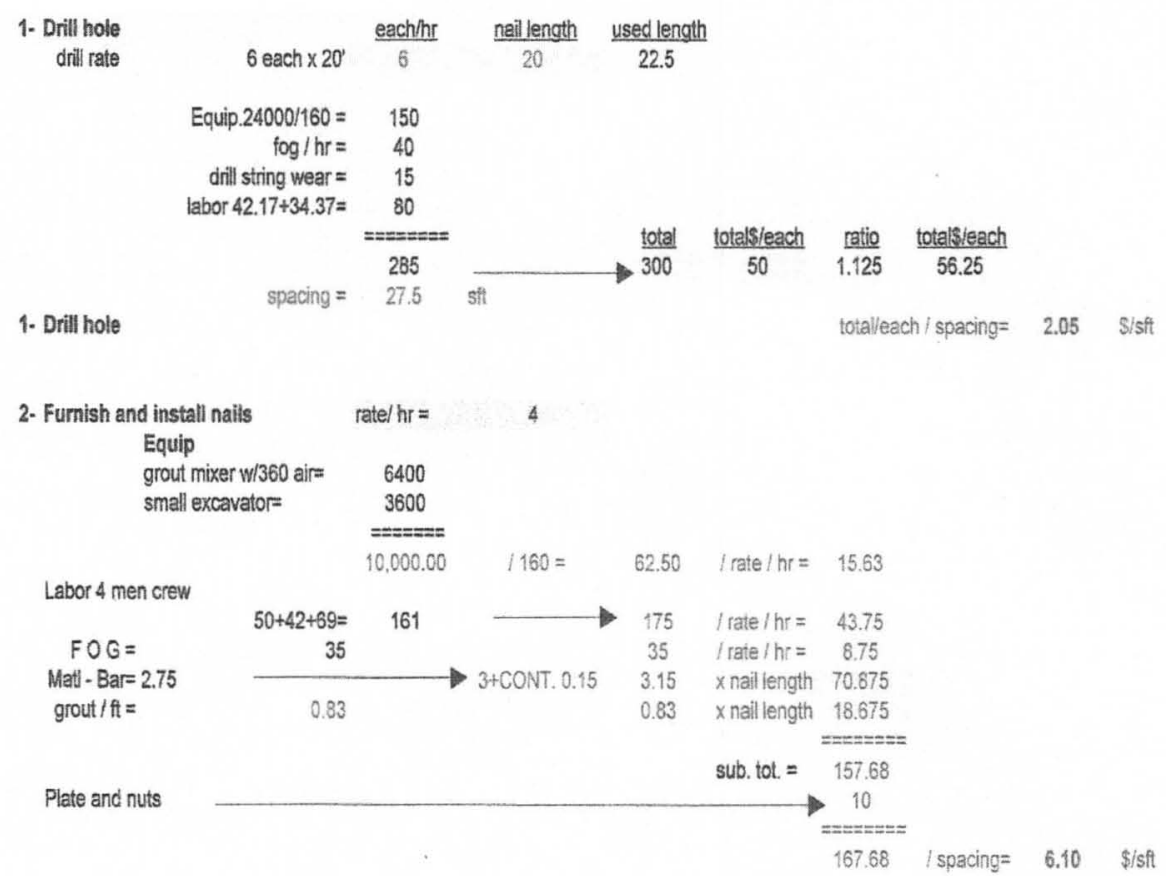

3. Place $6 \times 6$ mesh wi miradrain

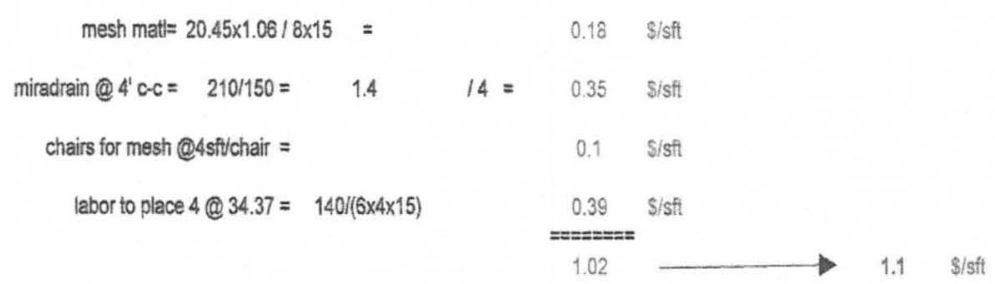

contin. walers @ dbl \#4 and $4^{\prime}$

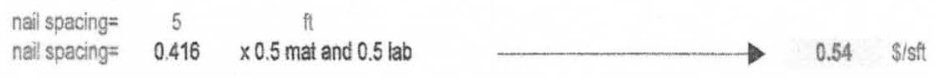

4. Shotcrete

$82.5 \times 1.06+75 / c y$ sub/place

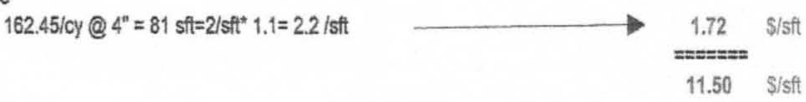

5- over-all supervision @ 750 sftday $75 \times 87750=0.8$

6. OTR 6 men $\times 100 /$ day $7750 \mathrm{stt} \quad 0.8$

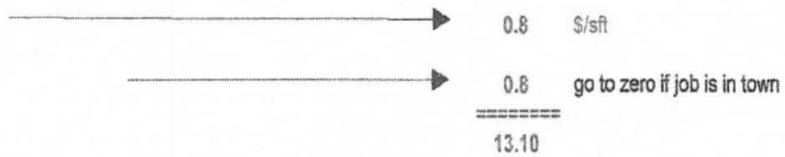

7. MOB AND DEMOB+SHOP DRAWING $(2500+2500+10,000) / 27000$

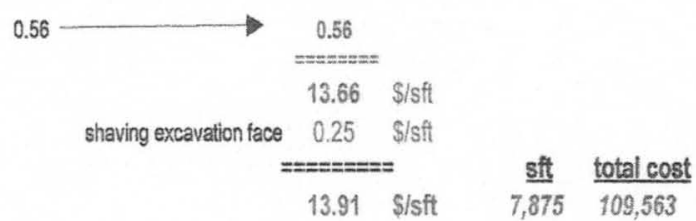




\section{Case 8 Part C Soil Nailing Cost}

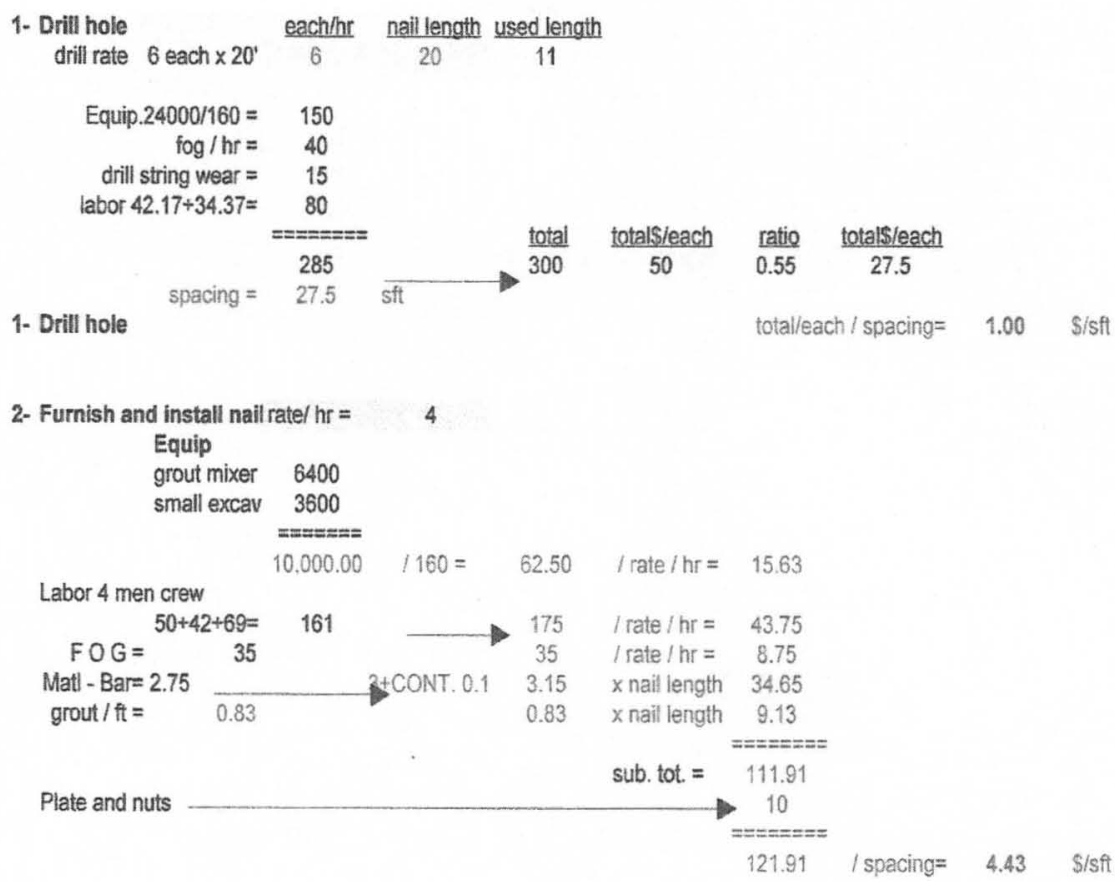

3- Place $6 \times 6$ mesh w/ miradrain

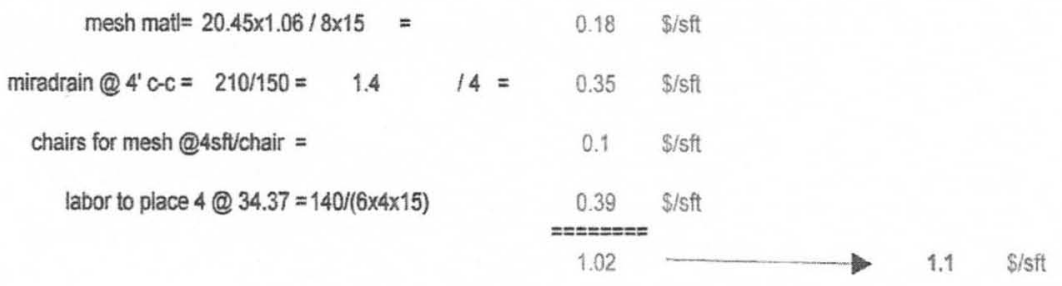

contin. walers@ dbl \#4 and 4'
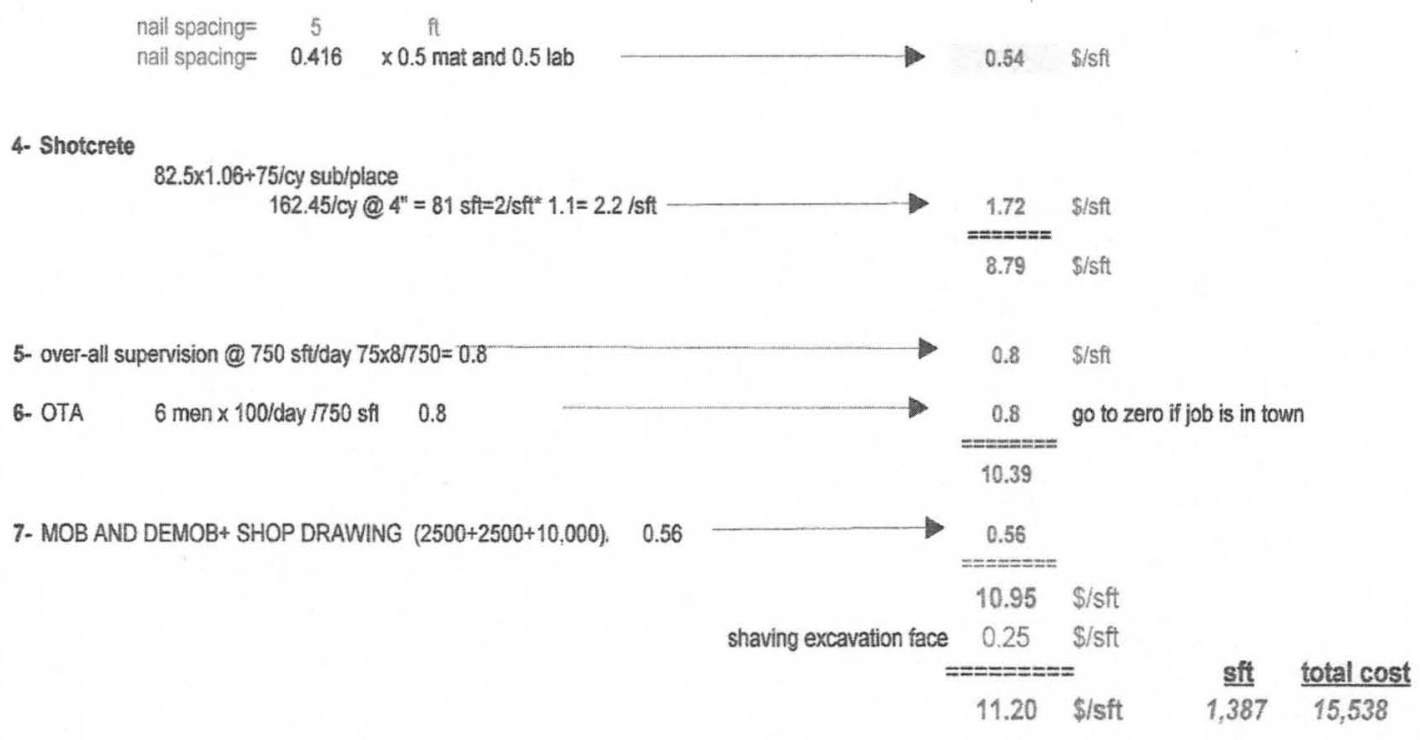


\section{$\underline{\text { Case } 9 \text { Soil Nailing Cost }}$}

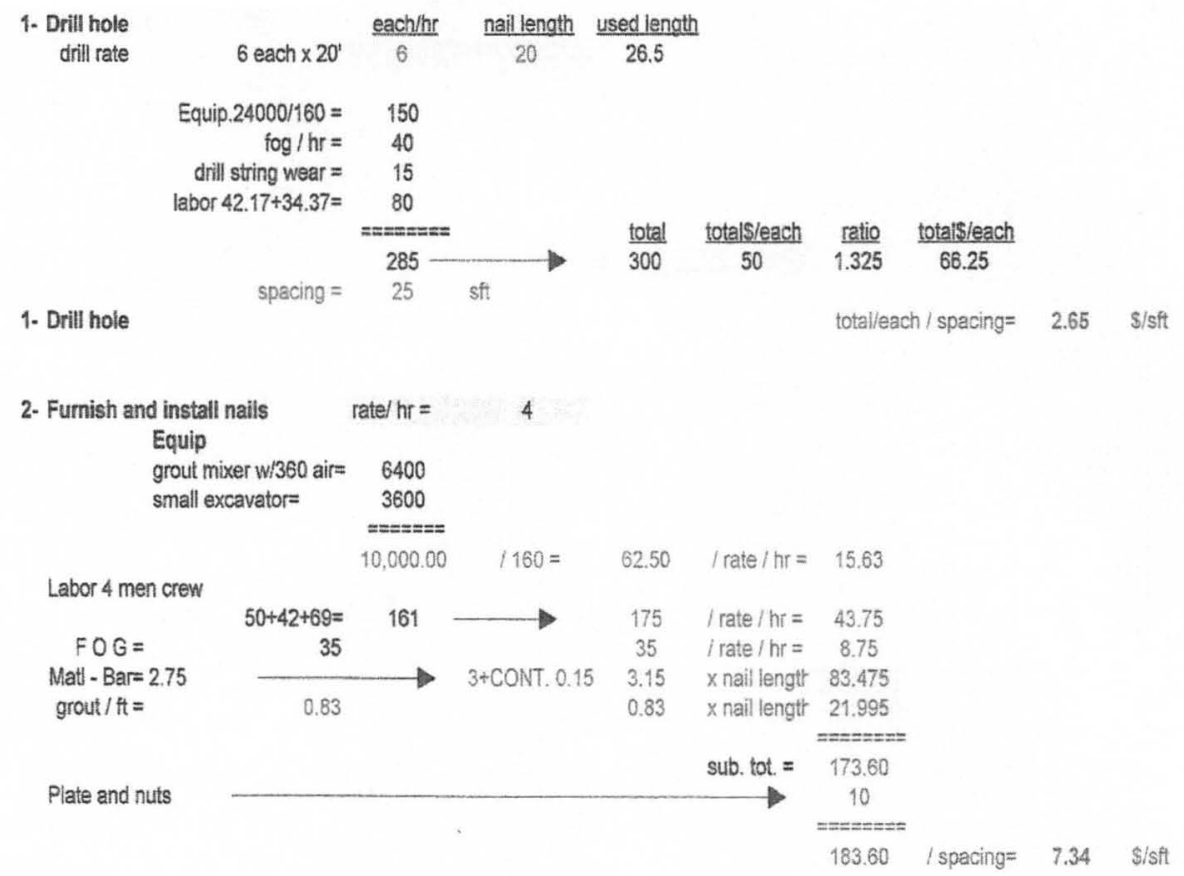

3- Place $6 \times 6$ mesh w/ miradrain

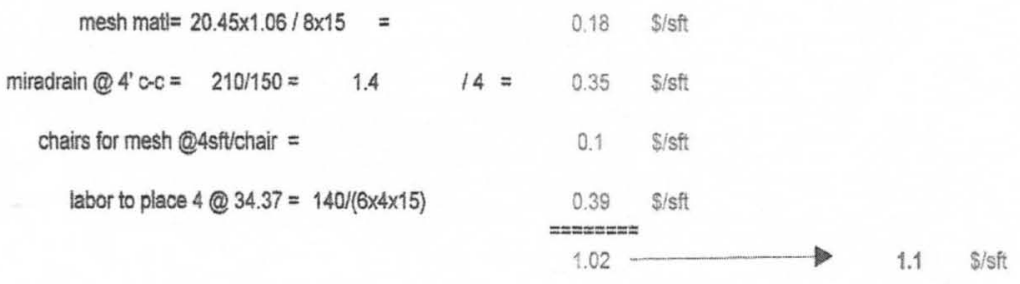

contin. walers @ dbl \#4 and $4^{\prime}$

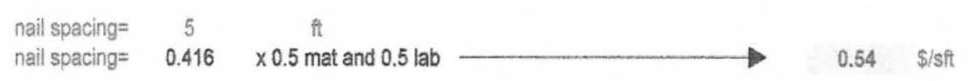

4. Shotcrete

$82.5 \times 1.06+75 /$ cy sub/place

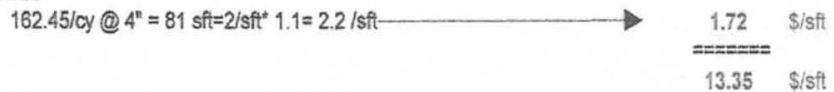

5. over-all supervision @ 750 sfiday $75 \times 8 / 750=0.8$

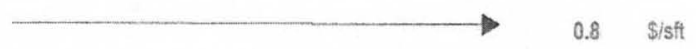

6. OTA 6 men $\times 100 /$ day $7750: \quad 0.8$

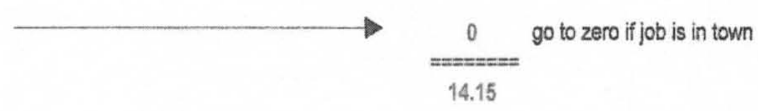

7. MOB AND DEMOB+ SHOP DRAWING $(2500+2500+10,000) / 2 \quad 0.56$

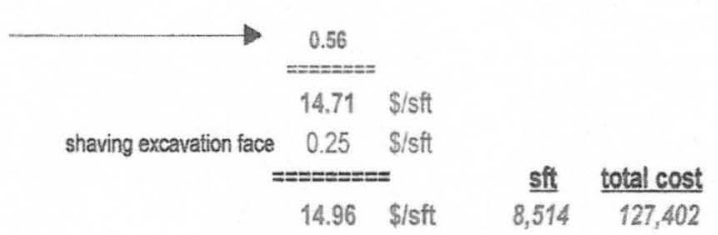




\section{Case 10 Soil Nailing Cost}

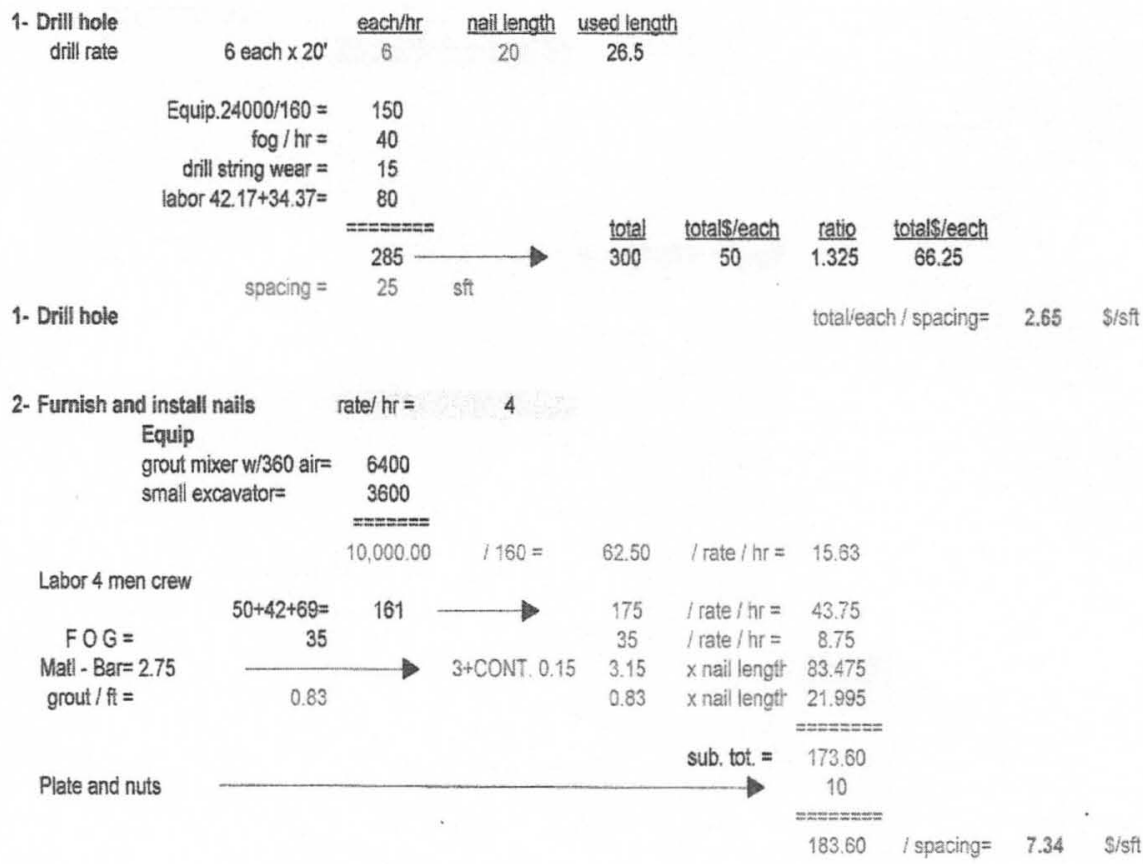

3- Place $6 \times 6$ mesh w/ miradrain

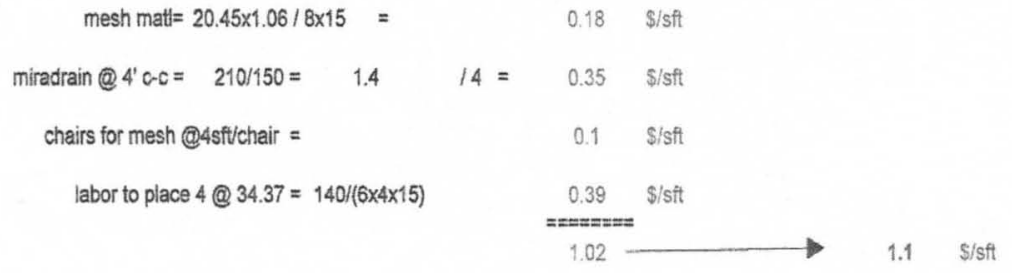

contin. walers @ dbl \#4 and 4'

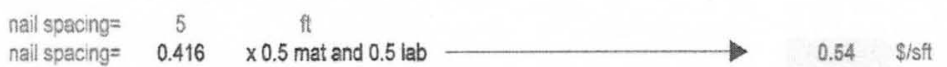

4. Shotcrete

$82.5 \times 1.06+75 /$ cy sub/place

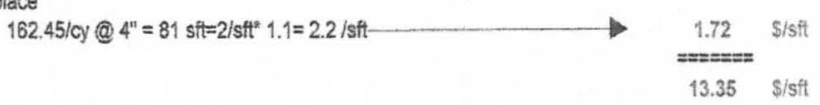

5- over-all supervision @ 750 sftday $75 \times 8 / 750=0.8$

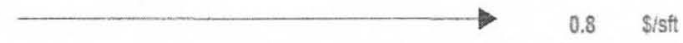

6. OTA 6 men $\times 100 /$ day $/ 750: \quad 0.8$

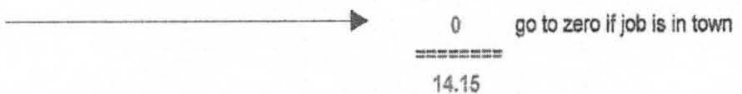

7. MOB AND DEMOB+ SHOP DRAWING $(2500+2500+5,000) / 271 \quad 0.37$

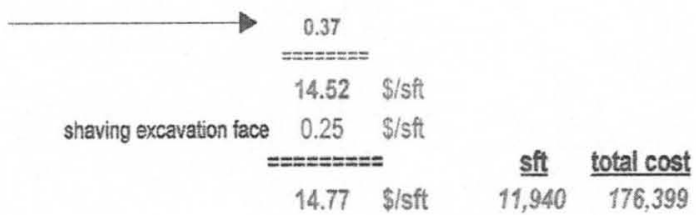




\section{Case 11 Soil Nailing Cost}

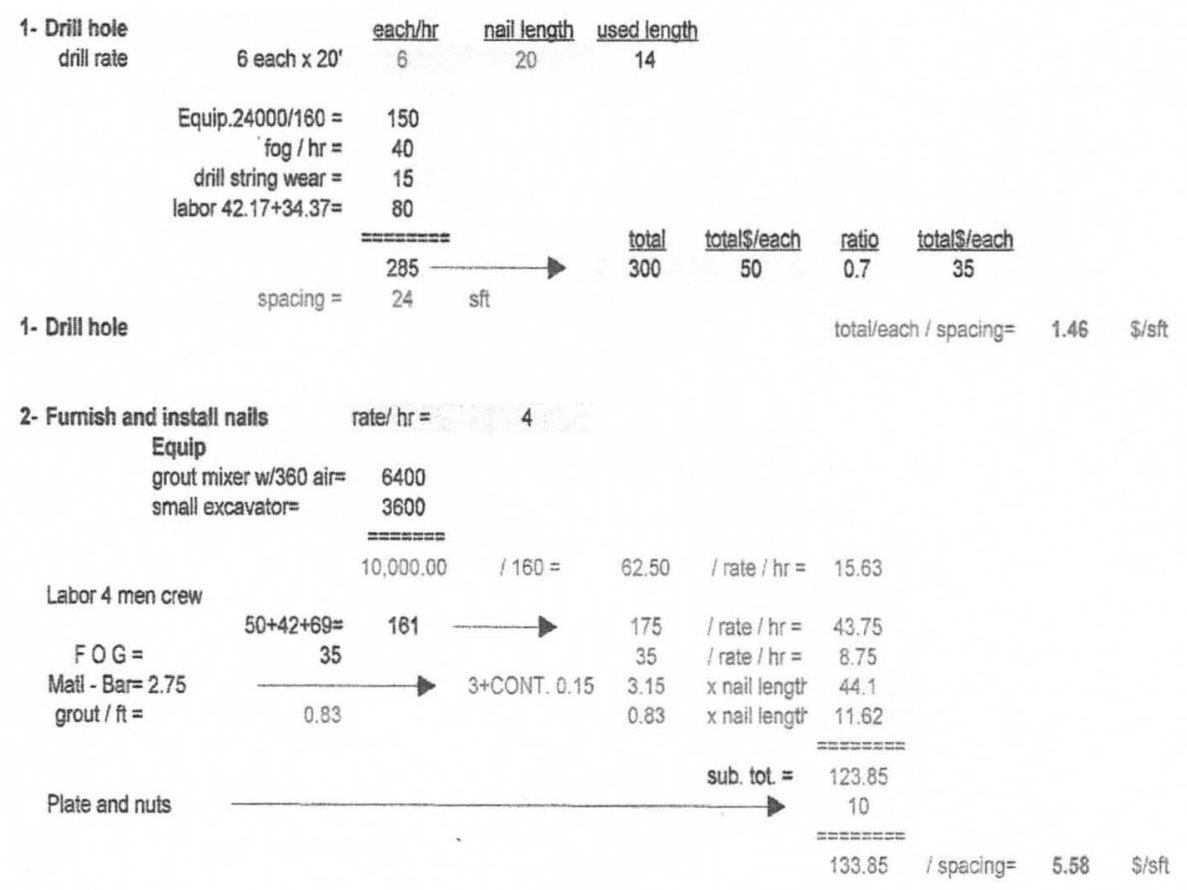

3. Place $6 \times 6$ mesh w/ miradrain

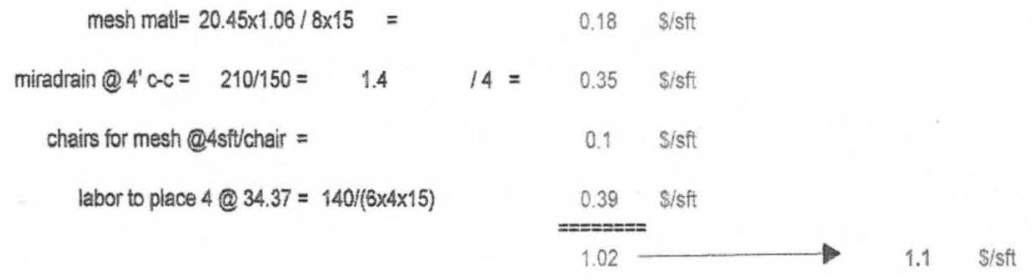

contin. walers @ dbl \#4 and 4'
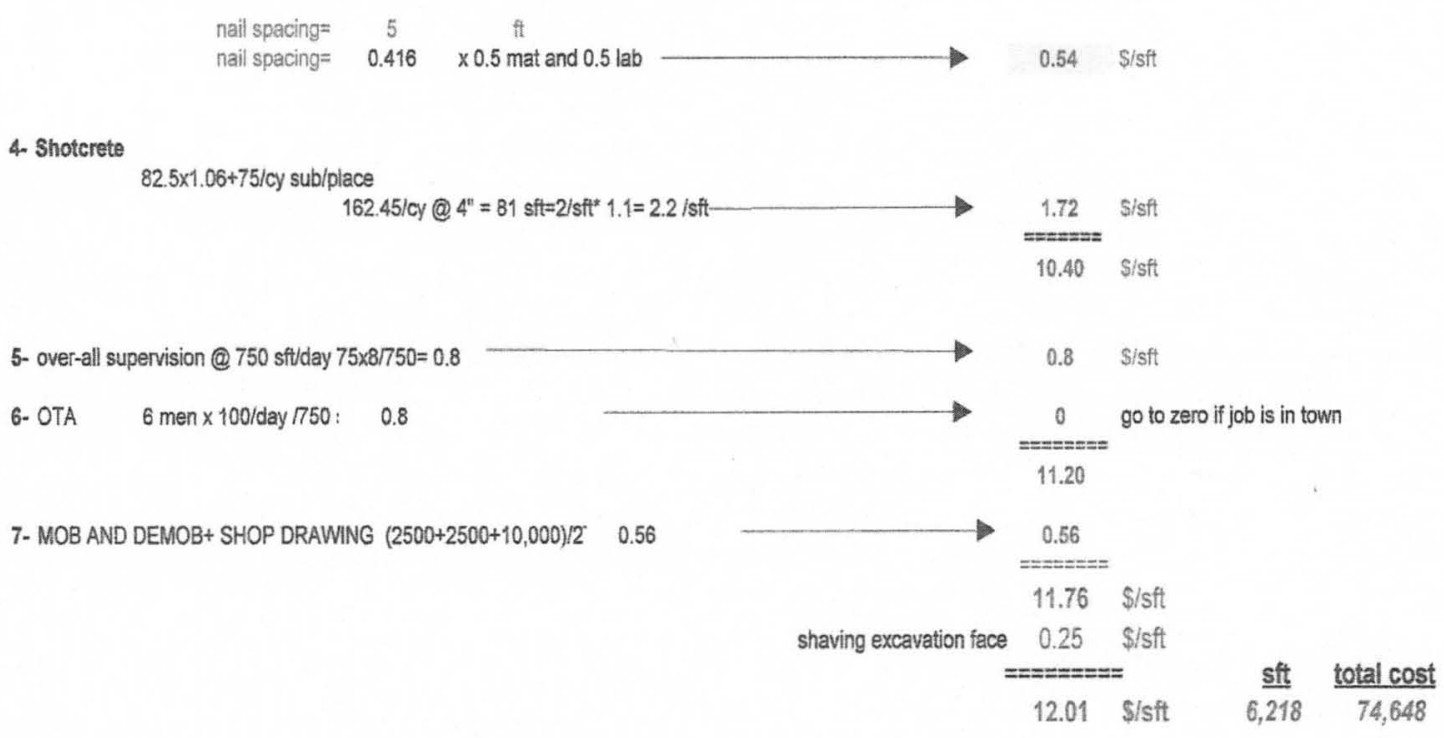


\section{Case 12 Part A Soil Nailing Cost}

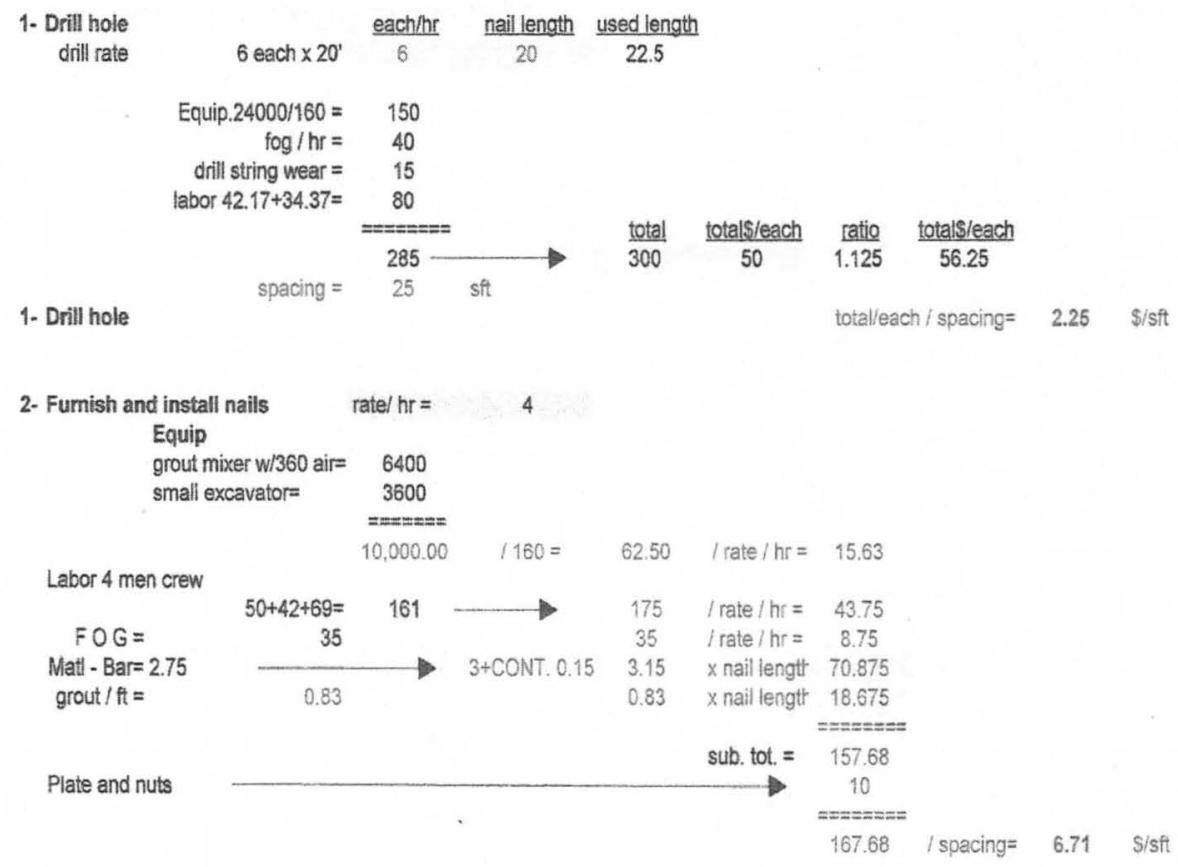

3. Place $6 \times 6$ mesh w/ miradrain

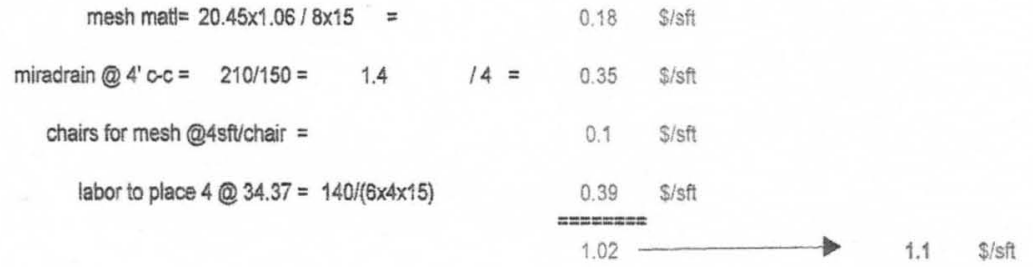

contin. walers @ dbl \#4 and 4'

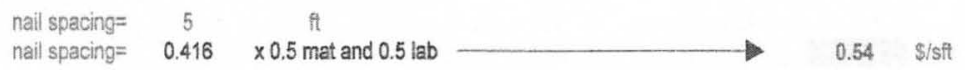

4. Shotcrete

$82.5 \times 1.06+75 /$ cy sub/place

$162.45 / \mathrm{cy}$ @ $4^{\prime \prime}=81 \mathrm{sft}=2 / \mathrm{sft}^{*} 1.1=2.2 / \mathrm{sft} \longrightarrow 1.72 \mathrm{~S} / \mathrm{sft}$

12.32 Sist

5- over-all supervision @ 750 sft/day $75 \times 8 / 750=0.8$

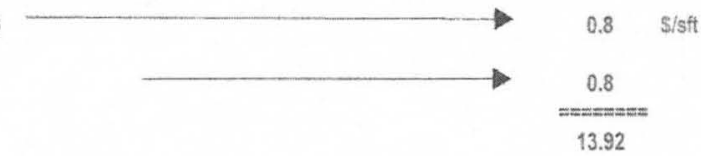

6- OTA 6 men $\times 100 /$ day 7750

0.8

7- MOB AND DEMOB+ SHOP DRAWING $(2500 \div 2500 \div 10,000) / 2 \quad 0.56$

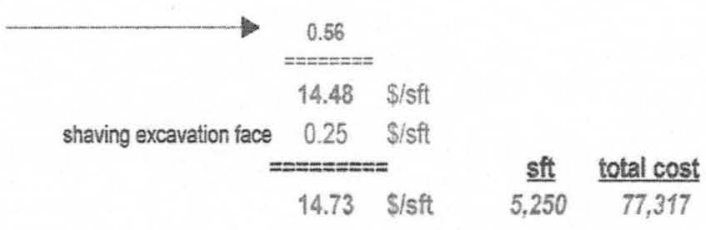




\section{Case 12 Part B Soil Nailing Cost}

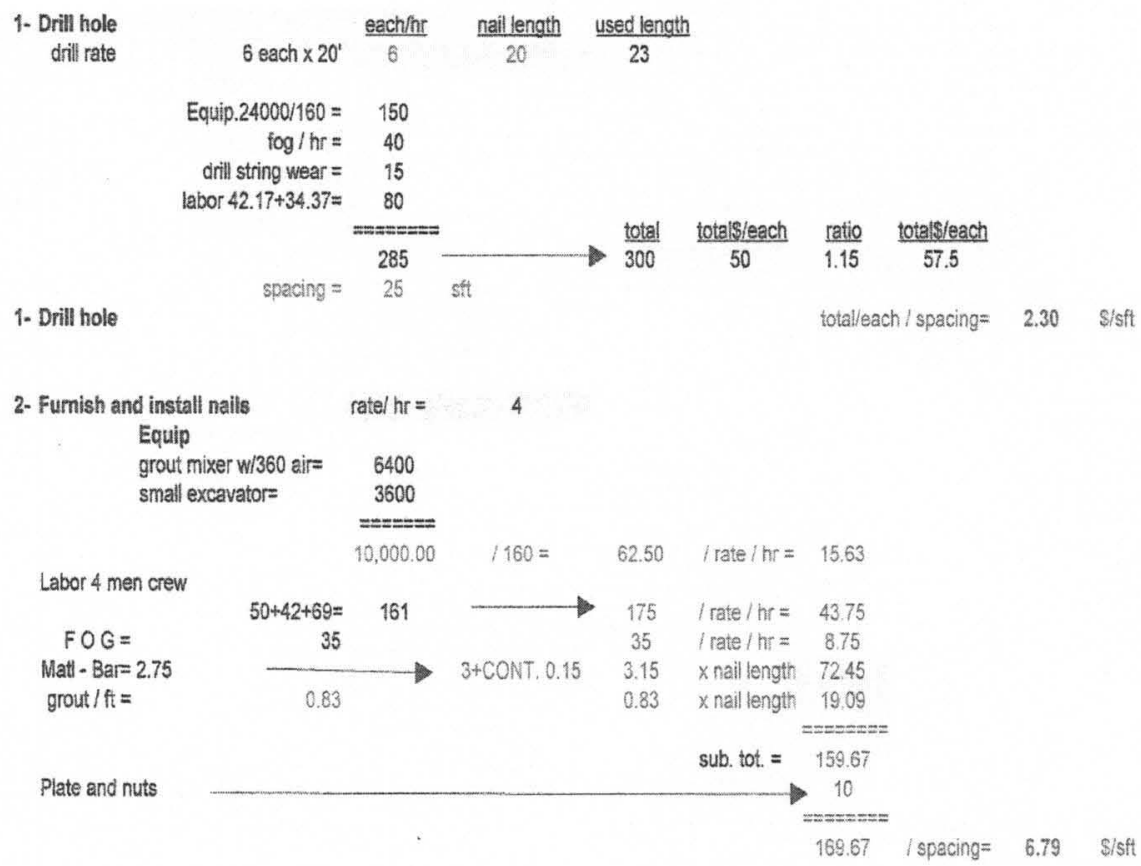

3- Place $6 \times 6$ mesh wi miradrain

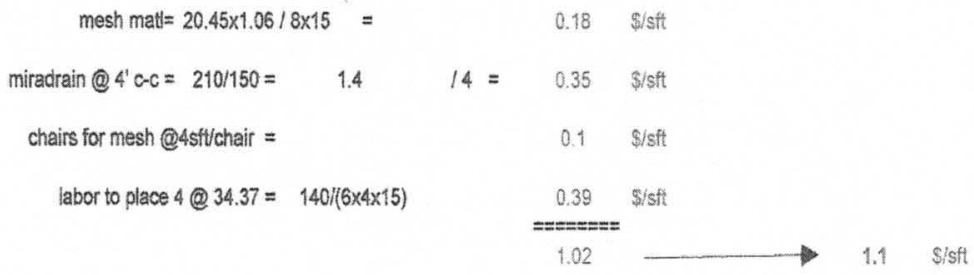

contin. walers @ dbl ath and $4^{\prime}$

$\begin{array}{lcc}\text { nail spacing }= & 5 & \text { ft } \\ \text { nail spacing }= & 0.416 & \times 0.5 \text { mat and } 0.5 \text { lab }\end{array}$

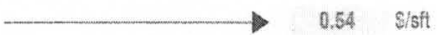

4. Shotcrete

$82.5 \times 1.06+75 / \mathrm{cy}$ sub/place

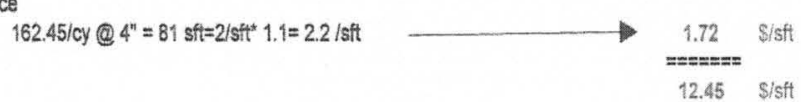

5- over-all supervision @ 750 sftiday $75 \times 8 / 750=0.8$

6. OTA 6 men $\times 100 /$ day $7750 \mathrm{sft} \quad 0.8$

7. MOB AND DEMOB+ SHOP DRAWING $(2500+2500+10,000) / 27000$

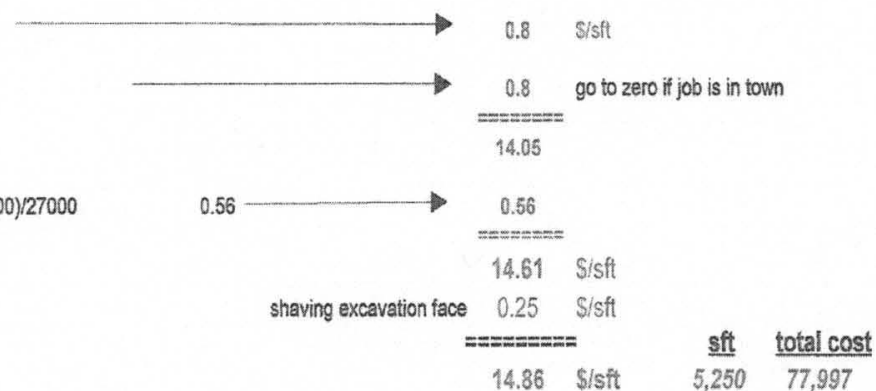




\section{Case 12 Part C Soil Nailing Cost}

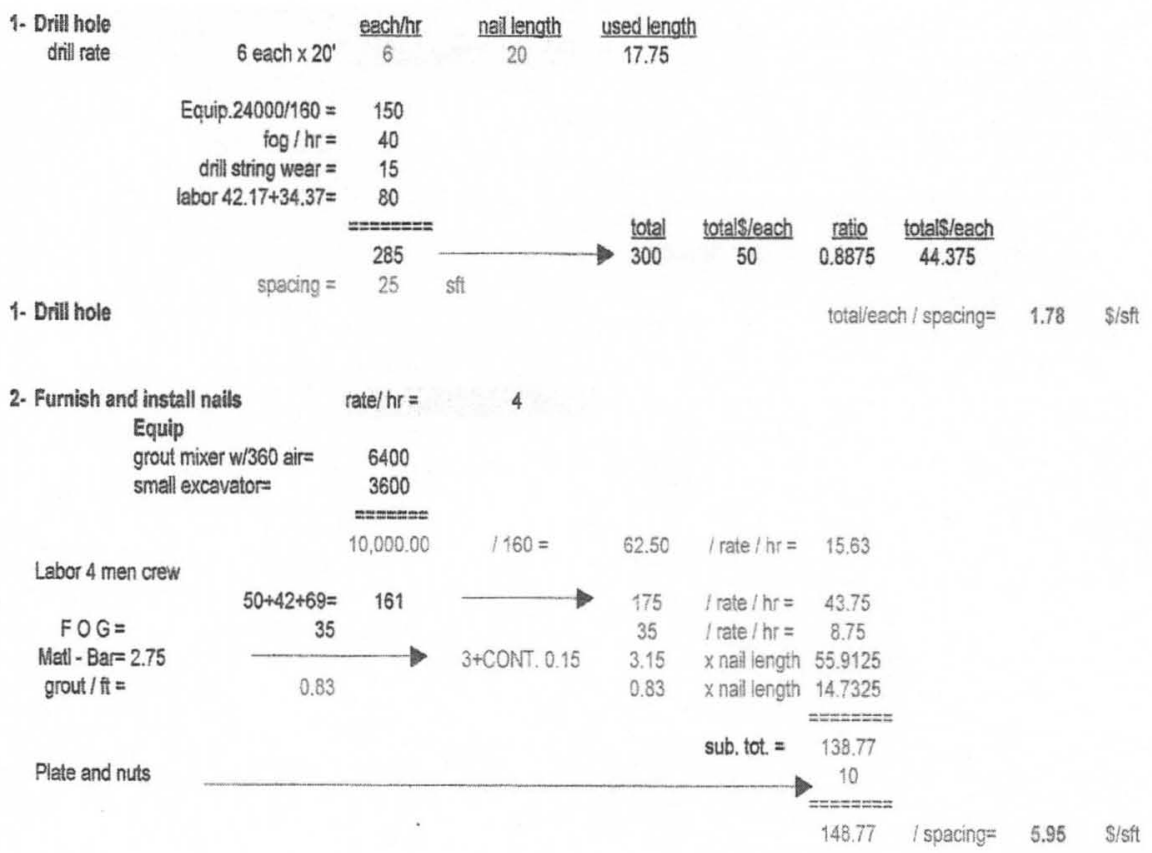

3. Place $6 \times 6$ mesh w/ miradrain

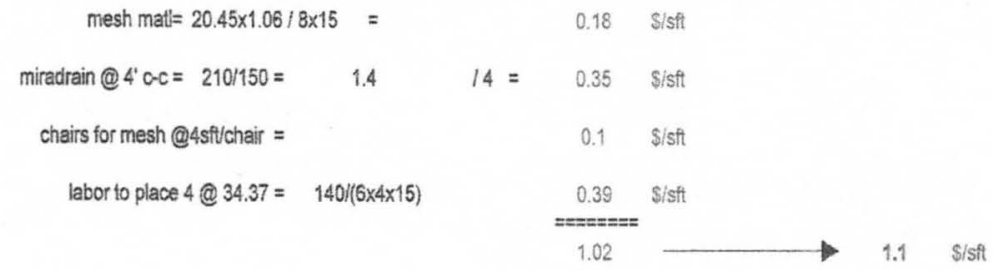

contin. walers @ dbi \#4 and 4'
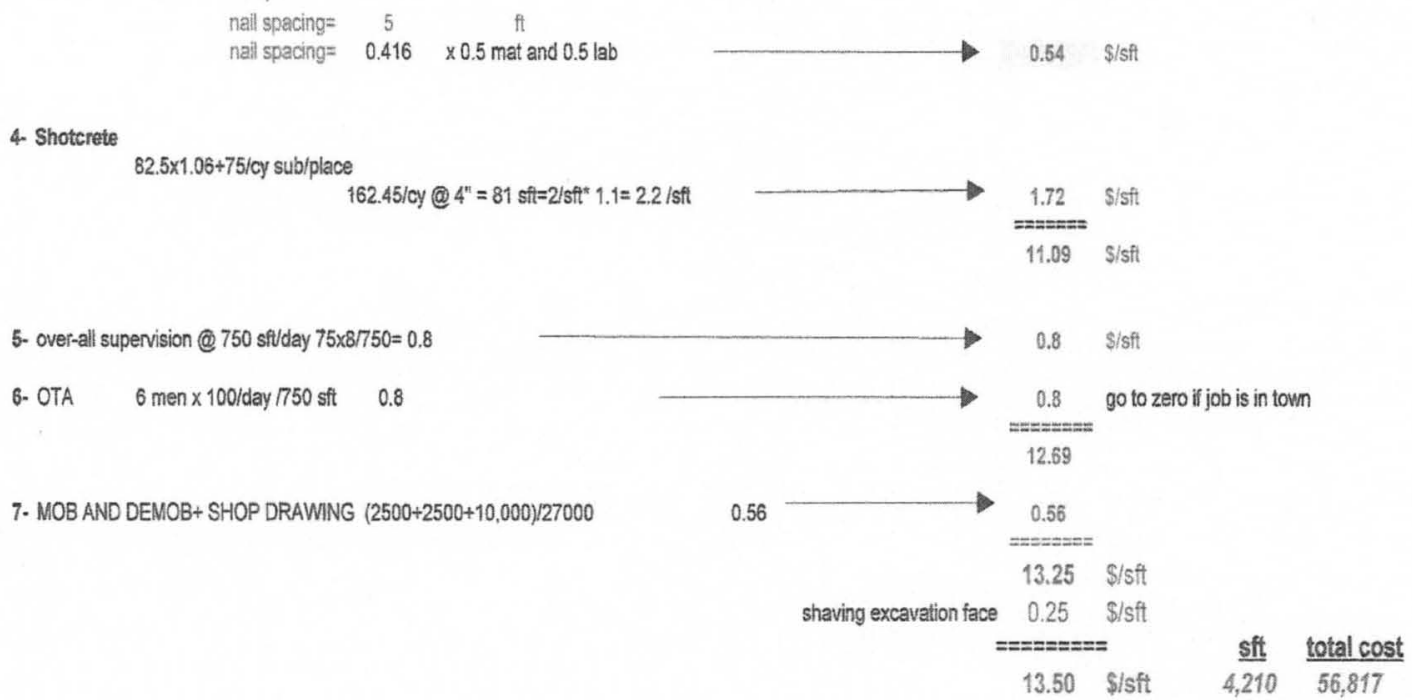


\section{Case 13 Soil Nailing Cost}

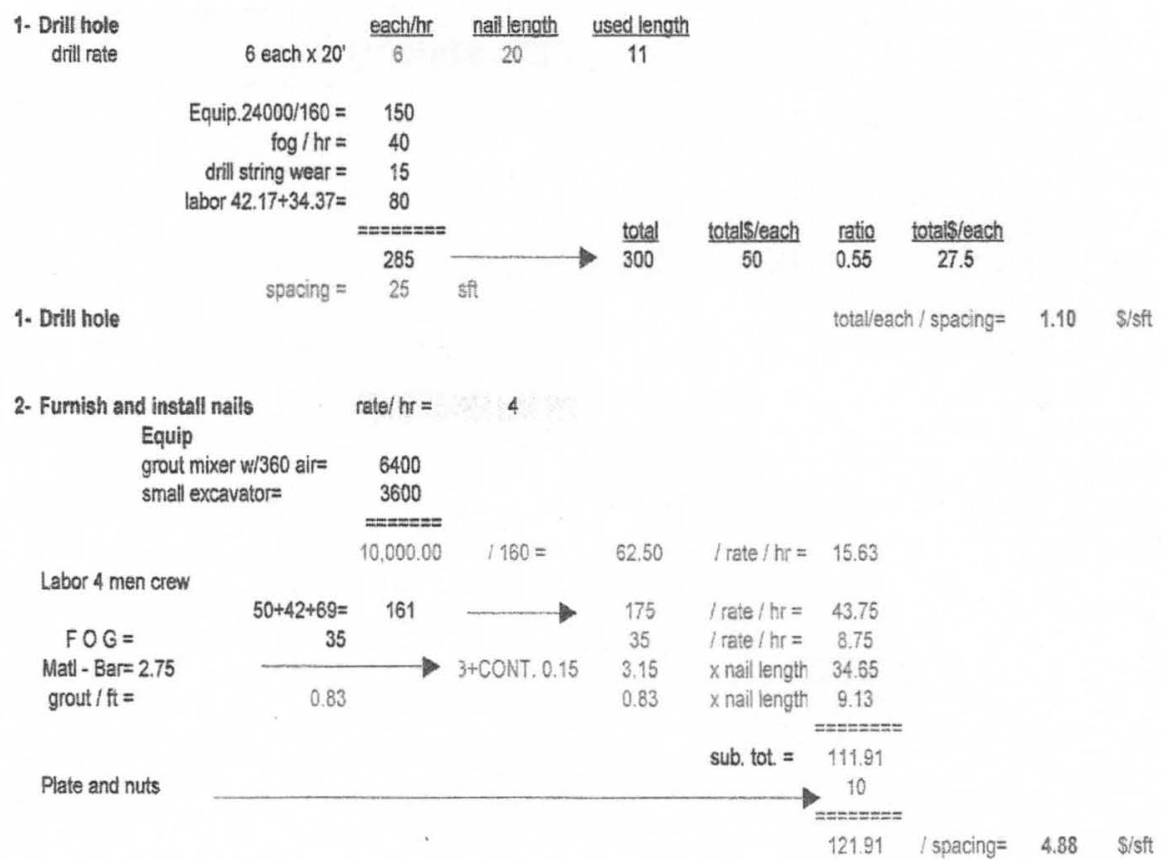

3. Place $6 \times 6$ mesh wi miradrain

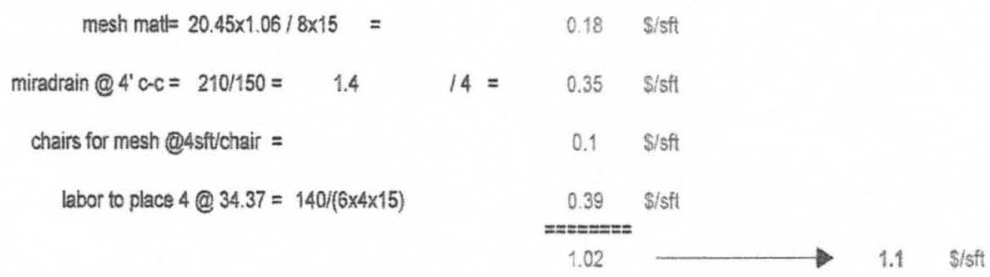

contin. walers @ $\mathrm{dbl} \# 4$ and 4 '

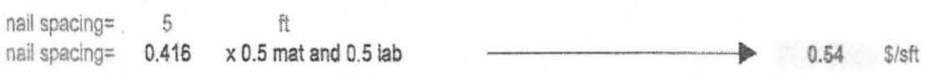

4- Shoterete

$82.5 \times 1.06+75 /$ cy sub/place

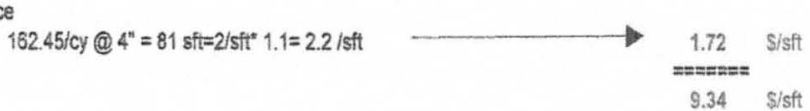

5- over-all supervision @ $750 \mathrm{stt} /$ day $75 \times 8 / 750=0.8$

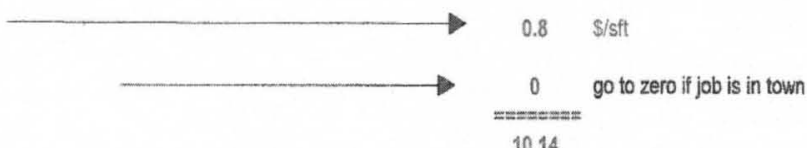

6- OTA 6 men $\times 100 /$ day $/ 750$ sft $\quad 0.8$

7. MOB AND DEMOB+ SHOP DRAWING $(2500 \div 2500+10,000) / 27000$

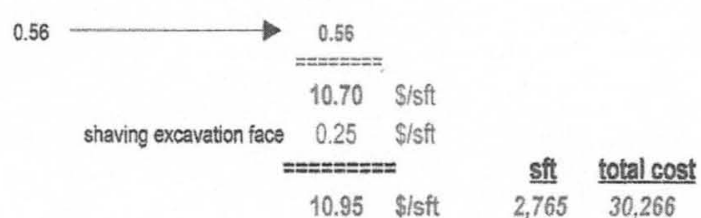




\section{$\underline{\text { Case } 14 \text { Part A Soil Nailing Cost }}$}

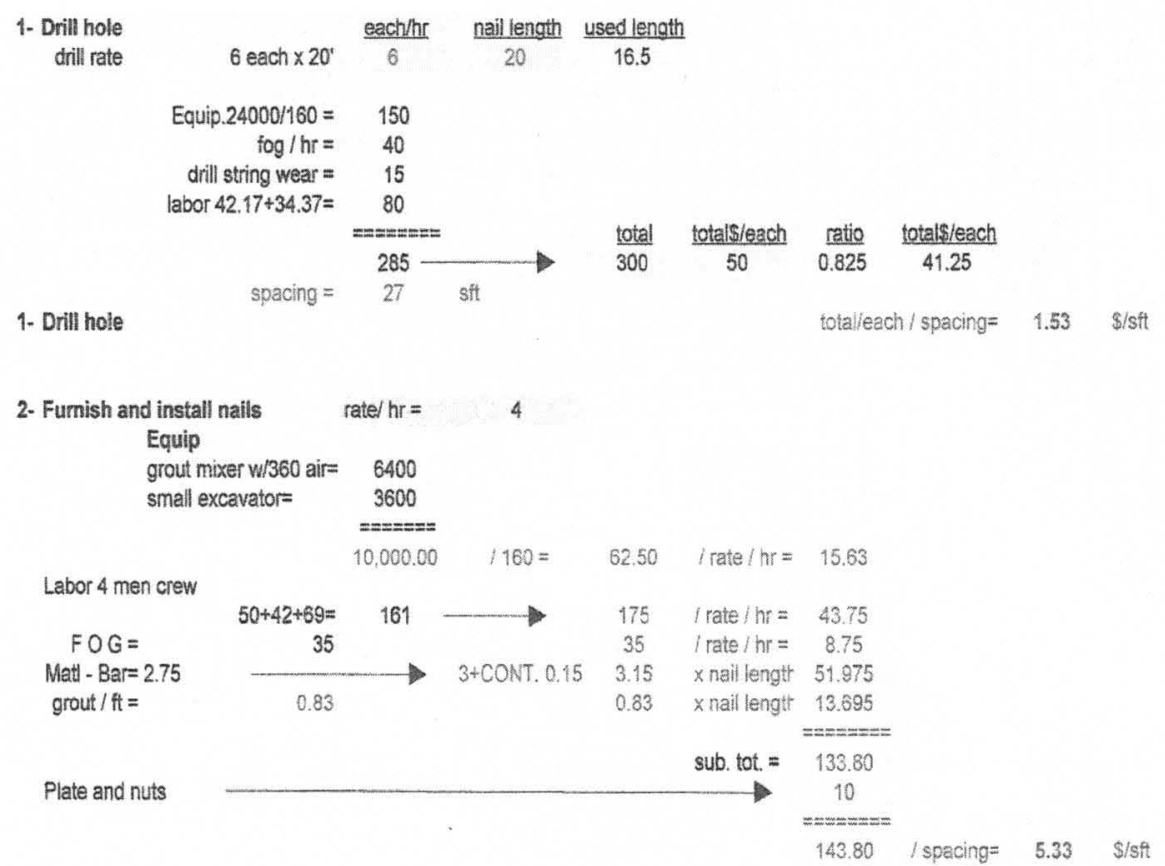

3. Place $6 \times 6$ mesh wi miradrain

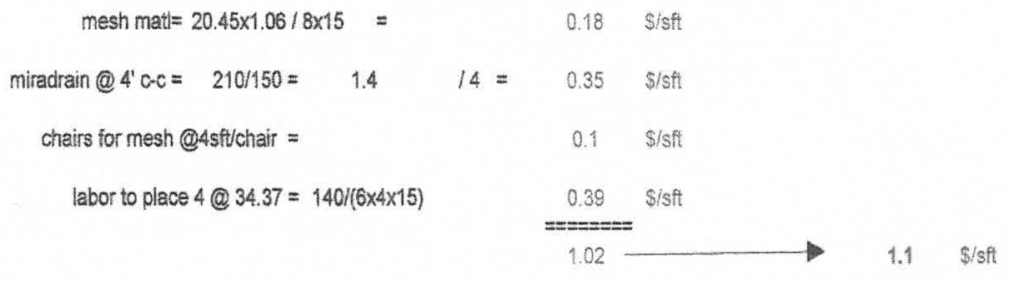

contin. walers @ dbl \#4 and 4'

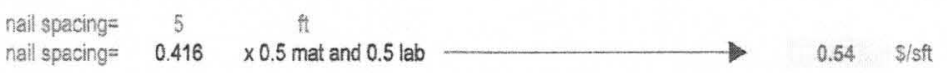

4. Shotcrete

$82.5 \times 1.06+75 /$ cy sub/place

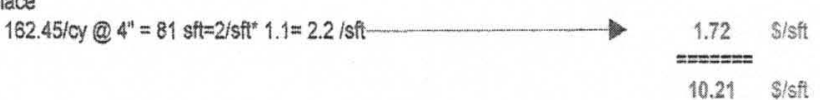

5- over-all supervision @ 750 sftdday $75 \times 8 / 750=0.8 \longrightarrow 0.8$ Sisft

6. OTA 6 men $\times 100 /$ day $750: \quad 0.8$

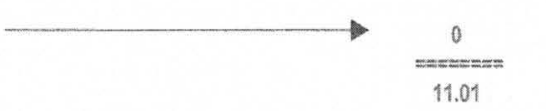

7. MOB AND DEMOB+ SHOP DRAWING $(2500+2500+10,000) / 2 \quad 0.56$

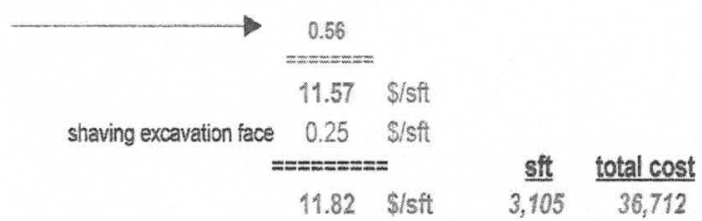




\section{Case 14 Part B Soil Nailing Cost}

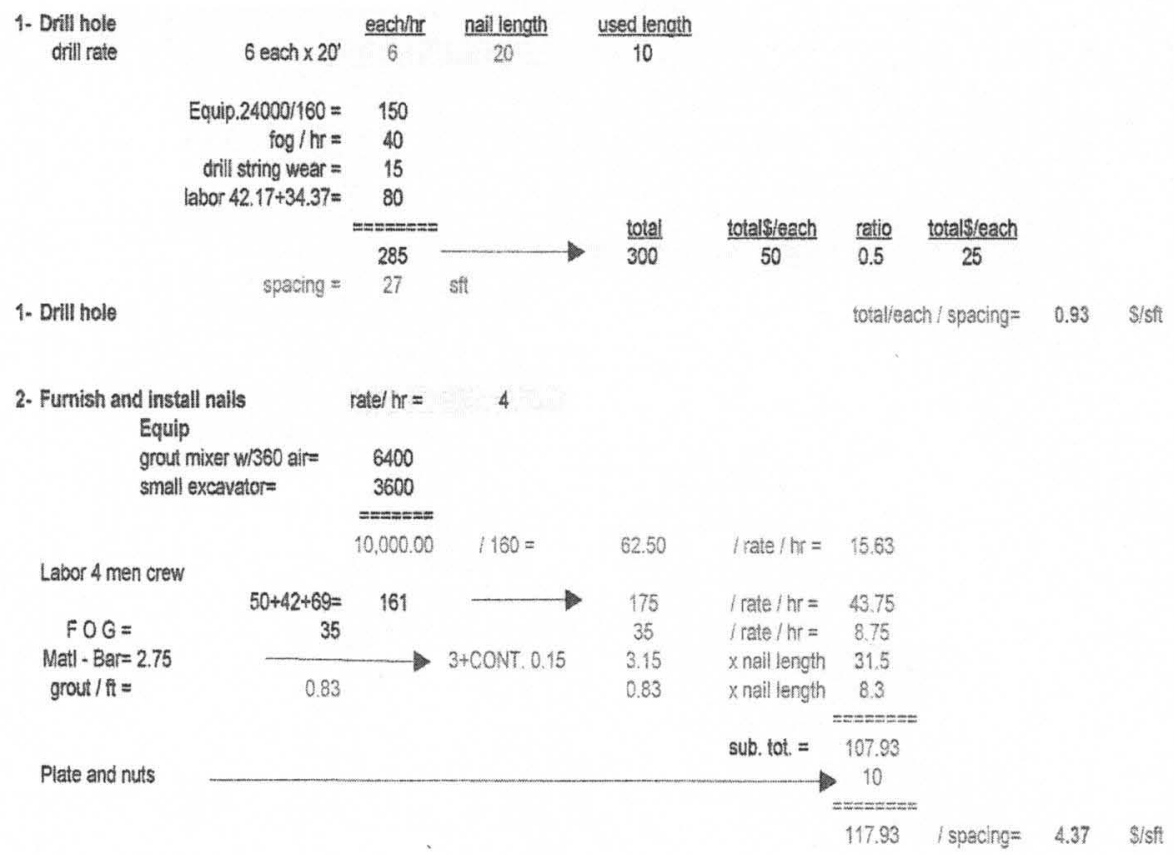

3. Place $6 \times 6$ mesh wi miradrain

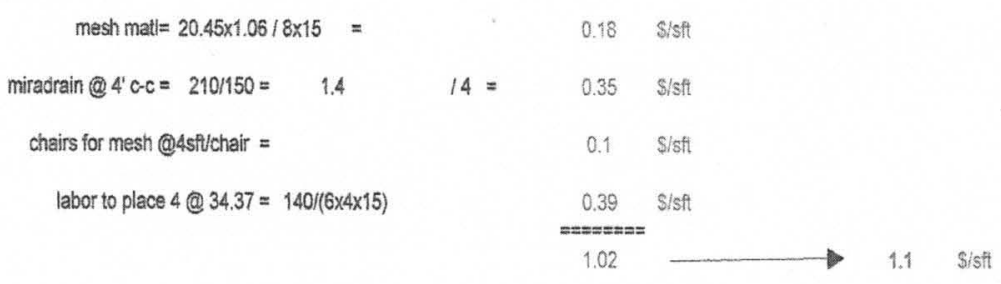

contin. walers @ dbl w4 and 4'

$$
\begin{array}{lcc}
\text { nail spacing }= & 5 & \text { ft } \\
\text { nail spacing }= & 0.416 \quad \times 0.5 \text { mat and } 0.5 \mathrm{lab}
\end{array}
$$

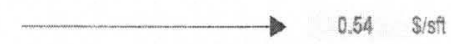

4. Shotcrete

$$
82.5 \times 1.06+75 / \text { cy sub/place }
$$

$$
162.45 / \mathrm{cy} \text { ( ) } 4^{\prime \prime}=81 \mathrm{sft}=2 / \mathrm{sft}^{*} 1.1=2.2 / \mathrm{sft}
$$

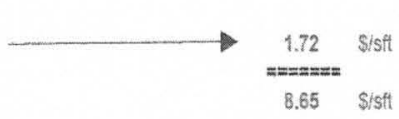

5. over-all supervision @ 750 sftday $75 \times 8 / 750=0.8$

6. OTA 6 men $\times 100 /$ day $/ 750$ sft $\quad 0.8$

7. MOB AND DEMOB+ SHOP DRAWING $(2500+2500+10,000) / 27000$

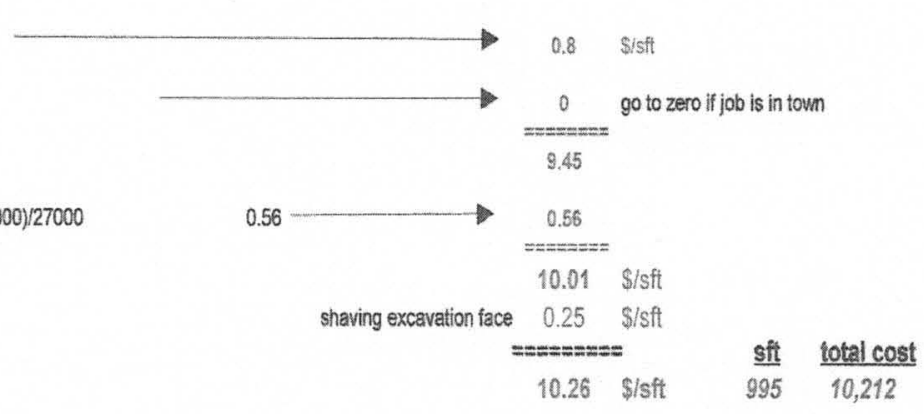




\section{Case 15 Soil Nailing Cost}

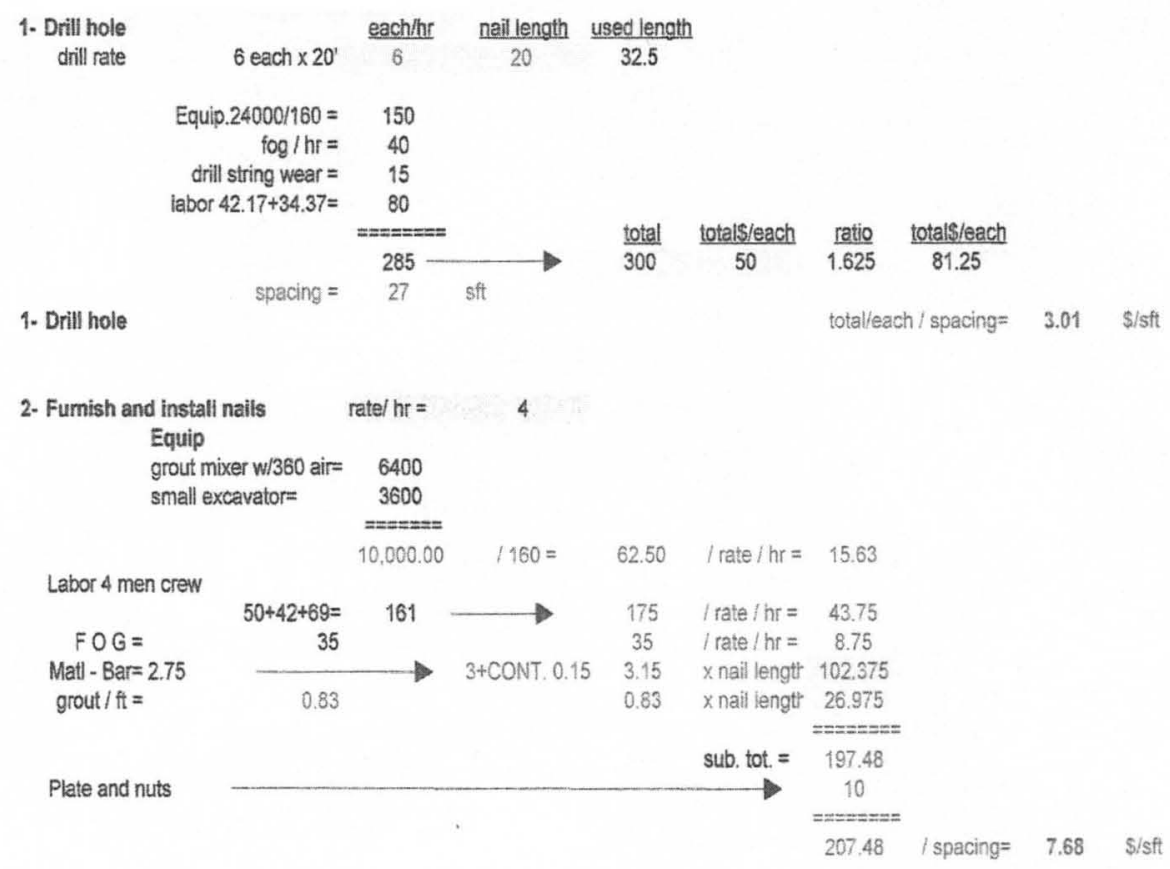

3- Place $6 \times 6$ mesh w/ miradrain

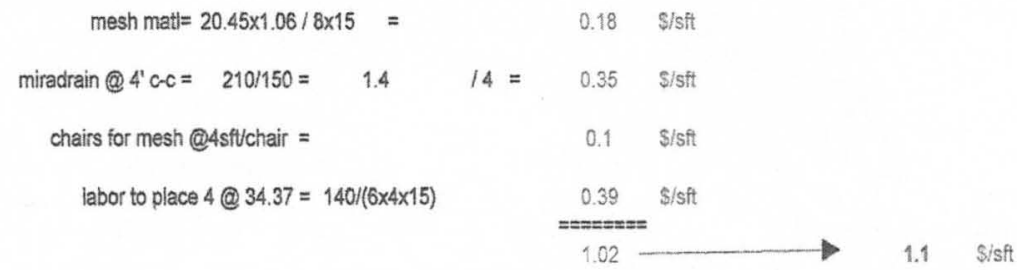

contin. walers @ dbl \#4 and $4^{\prime}$

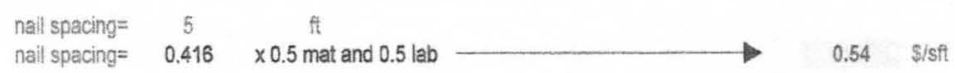

4. Shotcrete

$82.5 \times 1.06+75 /$ cy sublpiace

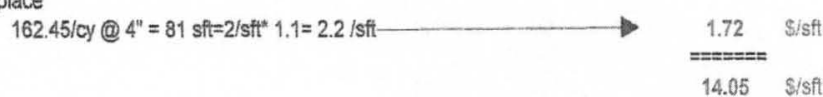

5- over-all supervision @ 750 sttday $75 \times 8 / 750=0.8$

6. OTA 6 men $\times 100 /$ day $7750: \quad 0.8$

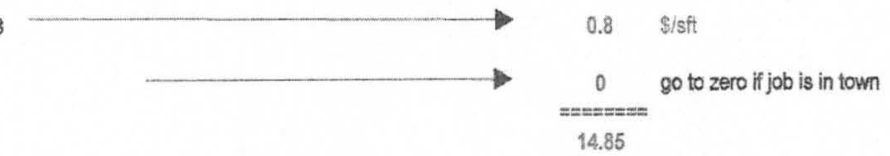

7. MOB AND DEMOB+ SHOP DRAWING $(2500+2500+10,000) / 2 \quad 0.56$

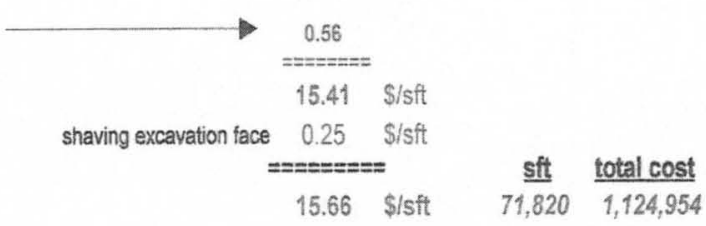




\section{CURRICULUM VITA}

NAME: $\quad$ Abdul Amir Al-Helu

ADDRESS: 9304 Minute Men Ct

Louisville, KY 40214

DOB: $\quad$ July, $1^{\text {st }} 1966$

EDUCATION

\& TRAINING: B.S. Building and Construction Engineering

Technology University, Baghdad, Iraq

1983-1987

M.Eng., Civil Engineering

University of Louisville, Louisville, Kentucky

1995-1997

Ph.D., Civil Engineering

University of Louisville, Louisville, Kentucky

2004-2011

PROFESSIONAL SOCIETIES:

The author is a member of the Chi Epsilon honor society and the American Society of Civil Engineers. 